\title{
Glass Science Tutorial: Lecture Number 7, Waste Glass \\ Technology for Hanford
}

Prepared for the U.S. Department of Energy Office of Environmental Restoration and

Waste Management

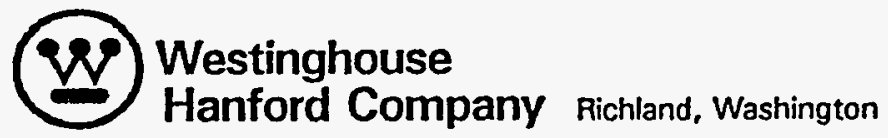

Management and Operations Contractor for the

U.S. Depertment of Energy under Contract DE-AC06-87RL10930

Approved for Public Release

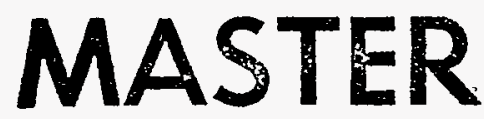
DISTRIBUTION OF THIS DOCUMENT IS UNLIMITED 


\section{DISCLAIMER}

Portions of this document may be illegible in electronic image products. Images are produced from the best available original document. 


\title{
Glass Science Tutorial: Lecture Number 7; Waste Glass Technology for Hanford
}

\author{
A. A. Kruger \\ Westinghouse Hanford Company \\ P. Harma, Lecturer \\ Date Published \\ July 1995
}

Prepared for the U.S. Department of Energy Office of Environmental Restoration and Waste Management

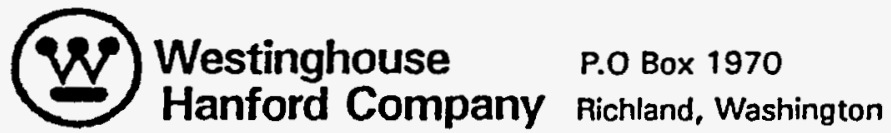

Management and Operations Contractor for the

U.S. Department of Energy under Contract DE-ACO6-87RL10930 


\section{LEGAL DISCLAMMER}

This report was prepared as an account of work sponsored by an agency of the United States Government. Neither the United States Government nor any agency thereof, nor any of their employees, nor any of their contractors, subcontractors or their employees, makes any warranty, express or implied, or assumes any legal liability or responsibility for the. accuracy, completeness, or any third party's use or the results of such use of any information, apparatus, product, or process disclosed, or represents that its use would not infringe privately owned rights. Reference herein to any specific commercial product, process, or service by trade name, tredemark, menufacturer, or otherwise, does not necesserily constitute or imply its ondorsement, recommendation, or fevoring by the United States Government or any agency thereof or its contractors or subcontractors. The views and opinions of authors expressed herein do not necessarily state or reflect those of the United States Government or any egency thereof.

This report has been reproduced from the best available copy. Available in paper copy and microfiche.

Available to the U.S. Department of Energy and its contractors from

Office of Scientific and Technical Information

P.O. Box 62

Ook Ridge, TN 37831

(615) 576-8401

Aveilable to the public from the U.S. Department of Commerce National Technicel information Service 5285 Port Royal Rosd

Springfield, VA 22161

(703) 487-4650

Printed in the Unitad Stater of Americe

DISCLM-1.CHP (1-91) 


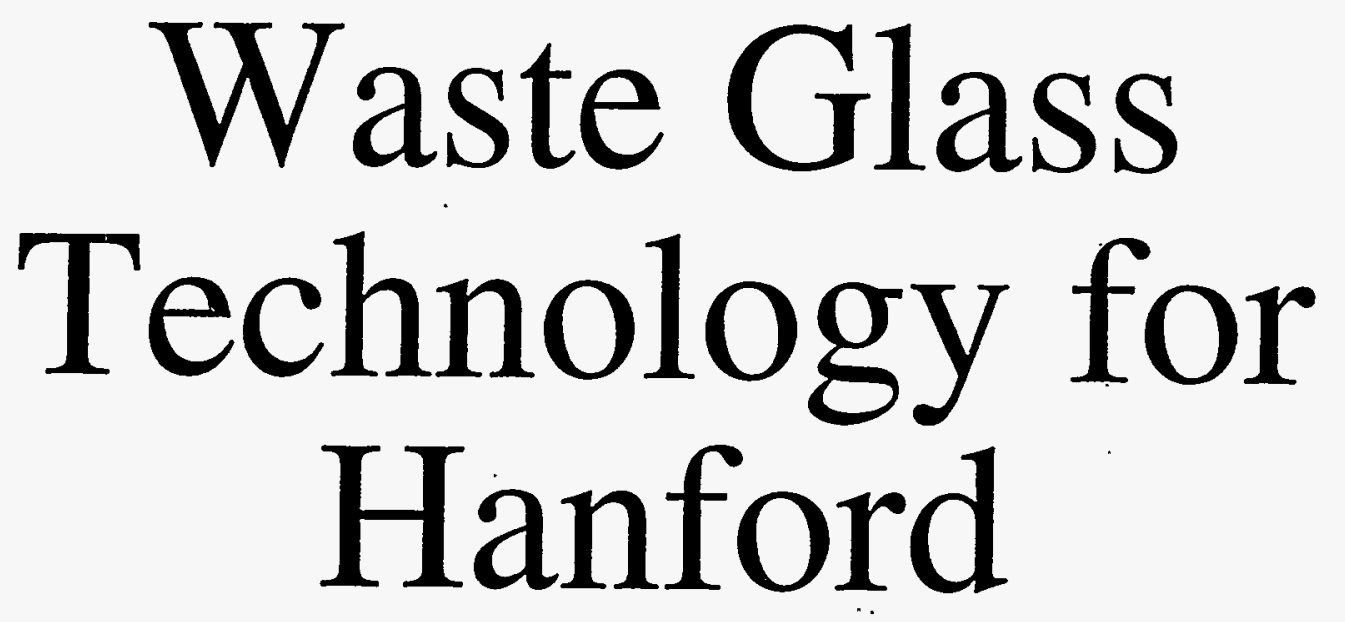

P. Hrma, M. Schweiger, G. Piepel, P. Smith, K. Sundaram, X. Feng,

J. Darab, T. Redgate,

J. Vienna, D. Peeler, Hong Li

27 \& 28 June 1995 
Tuesday Morning, June 27

Introduction (Pavel Hrma)

Glass properties and their measurement (Michael Schweiger)

Statistical approach to glass development (Greg Piepel)

Feed melting reactions: laboratory investigation of foaming)

(Peter Smith)

Processing properties of nuclear waste glasses (Pavel Hrma)

Tuesday Afternoon, June 27

Understanding glass composition effects on glass durability (Xiangdong Feng)

LLW glass structure (John Darab)

Prediction of nuclear waste glass dissolution as a function of composition (Pavel Hrma)

Model comparisons: free energy of hydration (Trish Redgate) 
Wednesday Morning, June 28

Introduction (Pavel Hrma)

Glass crystallization (John Vienna)

Effect of crystallization on the chemical durability of nuclear waste glasses (David Peeler)

Amorphous phase separation: theory, prediction, and application (David Peeler)

Corrosion of refractories and electrodes in waste glass melters (Kamakshi Sundaram)

Wednesday Afternoon, June 28

Minor components in nuclear waste glasses (Hong Li)

Effects of experimental parameters on glass durability (Xiangdong Feng)

Glass formulation for maximum waste loading (Pavel Hrma)

Concluding remarks (P. Hrma) 


\section{Laboratory Investigations of Foaming}

reboil pressure

indirect observation of melt ring heigh

direct observation of foaming

Pocific Northwest Laboratory 


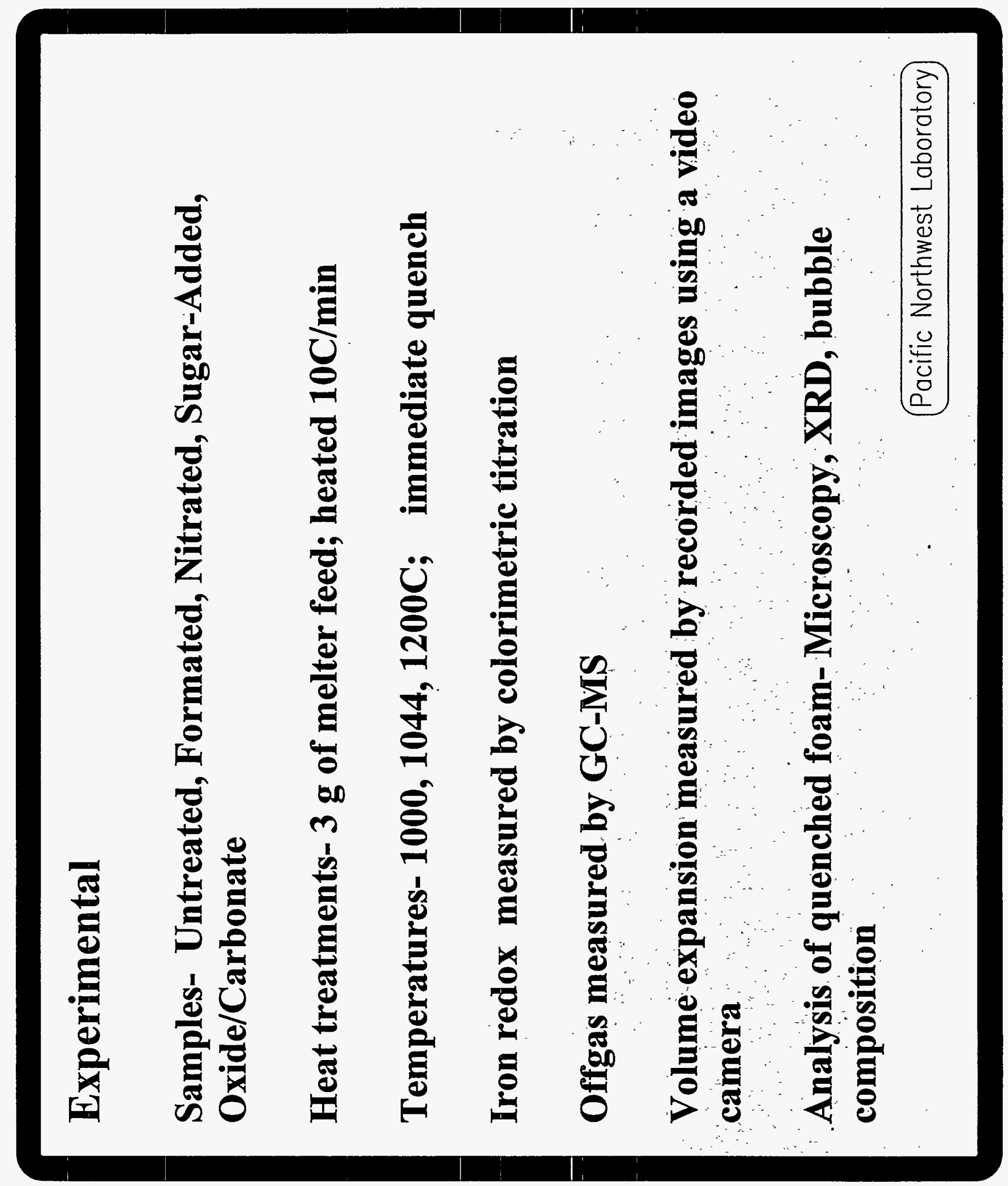


Sodium Nitrite/Nitrate Decomposition

$\mathrm{NaNO}_{3} \rightarrow \mathrm{NaNO}_{2}+(1 / 2) \mathrm{O}_{2}$

$2 \mathrm{NaNO}_{2} \rightarrow \mathrm{Na}_{2} \mathrm{O}+2 \mathrm{NO}+(1 / 2) \mathrm{O}_{2}$

$2 \mathrm{NaNO}_{2} \rightarrow \mathrm{Na}_{2} \mathrm{O}+\mathrm{N}_{2}+(3 / 2) \mathrm{O}_{2}$

Abe et al (1983) reacted sodium nitrite with silica $T<500 C$, NO observed $T>600 \mathrm{C}$, NO and $Q$ observed 


\section{Outline \\ Introduction}

Foaming and Iron Redox

Temperature Effects

Experimental

Results and Discussion

Offgas Results from Untreated, Formated, Nit Oxides/Carbonates and Sugar-added

Volume Expansion Measurements and Analys

Iron Redox

Summary 


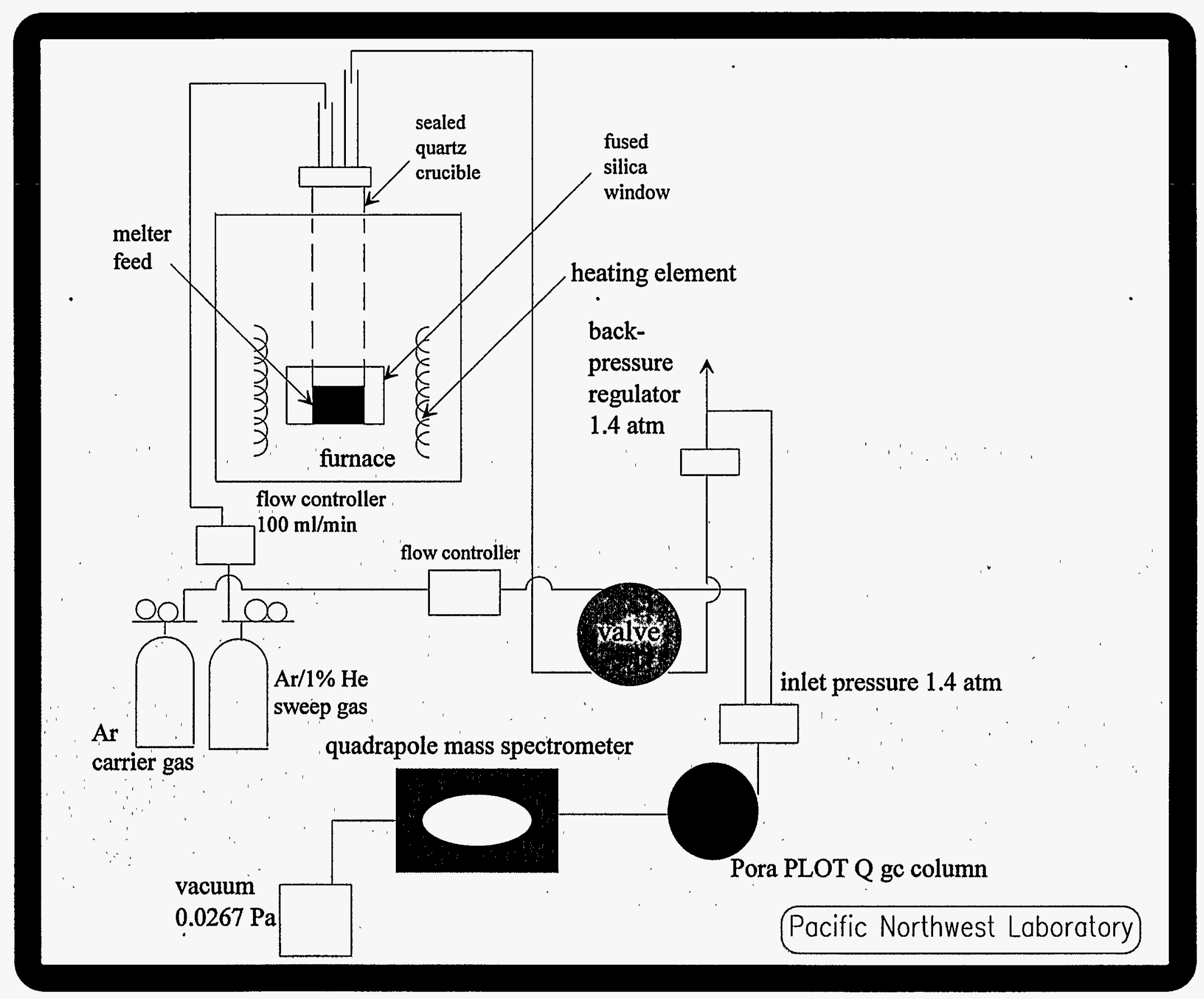




\section{Cold Cap Process}

Cold cap- region of unreacted feed floating on the melt in a continuous melter

Melting reactions have largest effect in this region

4 zones of gas

unrestrained-gas escape feed expansion

bubbly layer

glass melt

Crucible experiments show max $T$ of decomposition gas free escape

Gas retention affects heat transfer Feed expansion zone and bubbly layer have low $k$

Batches prone to expansion- correlated w/ low melting rate? 
Differences in nuclear waste vitrification and conventional glass

Raw Materials and their Introduction to the Melter Conv.- raw material choice, carbonate batches, . refining agents matched; powder/pellet NW- batch contains nitrates and multivalent oxides, redox control via additives; slurry

Frit-

Conv.- cullet and batch are nearly identical in composition NW- vitrification chemicals are premelted into frit 
Foaming and Iron Redox in Simulated Nuclear Waste G

2 categories of foaming

1) feed expansion (from batch reactions)

2) molten glass foam

$\mathrm{Fe}^{2+}+(1 / 4)_{2} \mathrm{O}+(3 / 2) \stackrel{2}{\longleftrightarrow} \quad i_{2}^{-} \mathrm{FeO}$

Typically, reducing agents are used to mitigate foam 


\section{Summary}

For samples (except sugar) prepared under inert atmosphere, the iron redox was not a function of the batch chemistry.

As expected, temperature strongly affected iron redox.

Differences in volume expansion were attributed to reaction paths which resulted from the batch chemistry.

The use of a reductant for foam mitigation may be unneccessary. 


\section{Compositional Analysis of Bubbles}

(wt\% of each component)

Sample

Formated

Untreated

Ox/Carbon

Nitrated
$\mathrm{Y}$

17.6

6.1

25.5

21.2 $\mathbf{q}$

66.0

74.3

6.9

$62.0 \quad 2.8$
ÇO

1.7

14.6

65.5

12.7
NO

12.9

3.5

NA

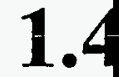


Stages of Melting

First Stage- Drying, Removing Chemically Bound Water, Hydrothermal Reactions, Crystalline Inversions and Solid State Reactions

Second Stage- Vigorous Reactions, Presence of Molten Salts, Melt Develops, Formation of Intermediate Compounds

Redox/Gas Generating Reactions

Third Stage- Dissolution of Solid Residues, Bubble Removal 


\section{Stages of Melting}

First Stage- Drying, Removing Chemically Bound Water, Hydrothermal Reactions, Crystalline Inversions and Solid State Reactions

Second Stage- Vigorous Reactions, Presence of Molten Salts, Melt Develops, Formation of Intermediate Compounds

Redox/Gas Generating Reactions

Third Stage- Dissolution of Solid Residues, Bubble Removal 
Differences in nuclear waste vitrification and conventional glass

Raw Materials and their Introduction to the Melter Conv.- raw material choice, carbonate batches, refining agents matched; powder/pellet NW- batch contains nitrates and multivalent oxides, redox control via additives; slurry

\section{Frit-}

Conv.- cullet and batch are nearly identical in composition NW- vitrification chemicals are premelted into frit 


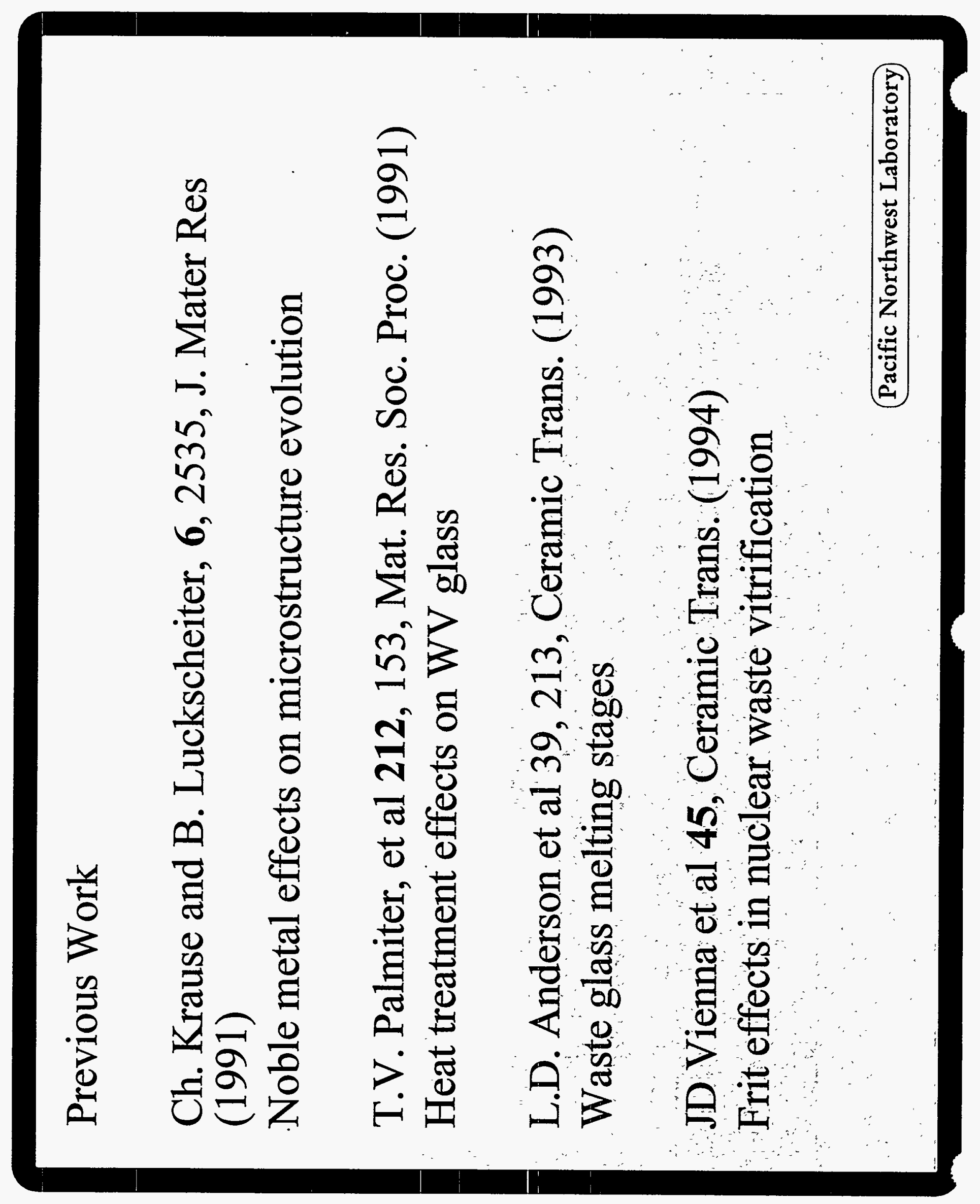




\section{Laboratory Investigations of Foaming}

reboil pressure indirect observation of melt ring height direct observation of foaming 


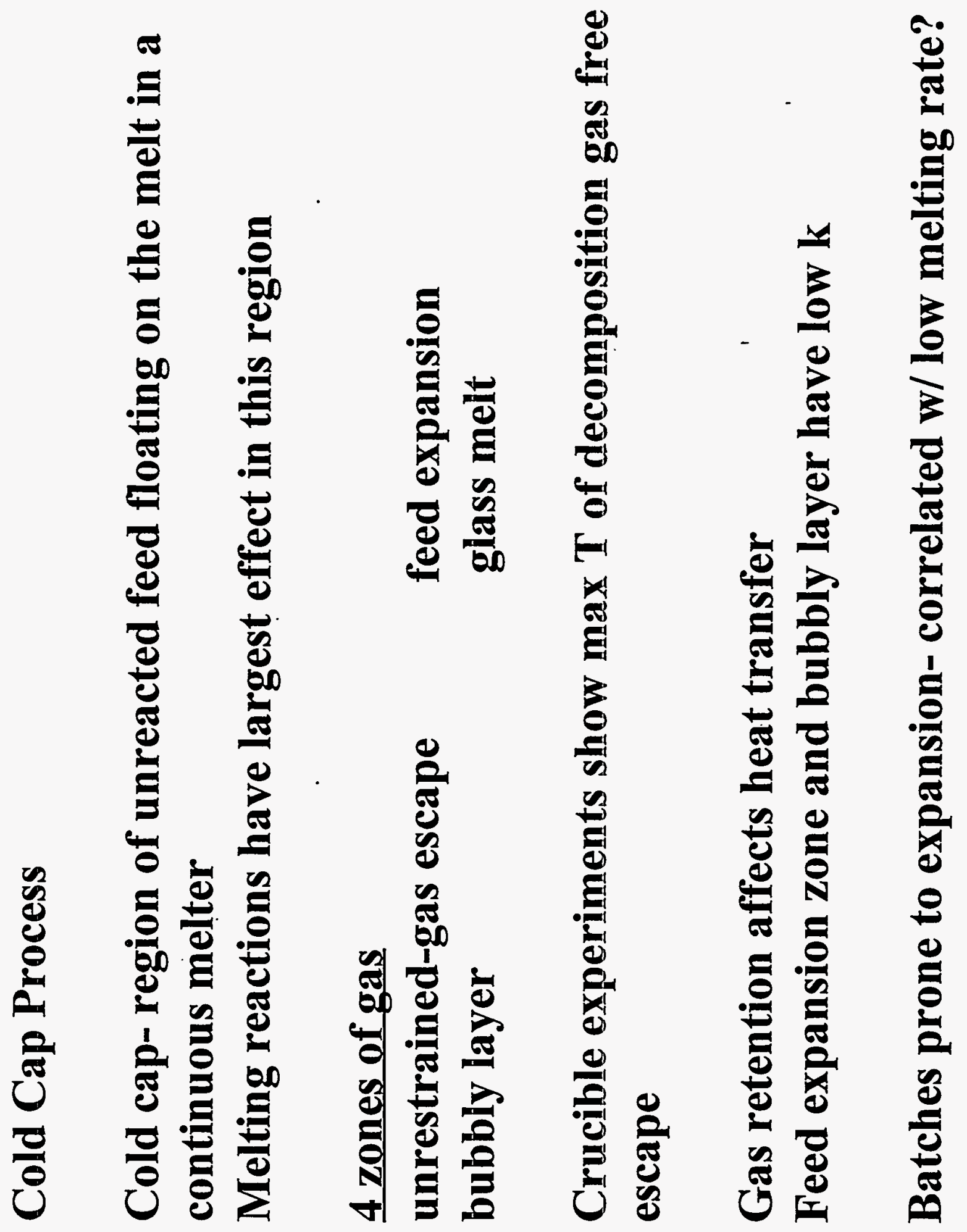




\section{Summary}

For samples (except sugar) prepared under inert atmosphere, the iron redox was not a function of the batch chemistry.

As expected, temperature strongly affected iron redox.

Differences in volume expansion were attributed to reaction paths which resulted from the batch chemistry.

The use of a reductant for foam mitigation may be unneccessary. 
Table 5.8. Volume Expansion Summary

\begin{tabular}{|c|c|c|c|c|c|c|c|c|c|}
\hline & \multirow[b]{2}{*}{ Sample } & \multicolumn{5}{|c|}{ Expansion Temperalures $\left({ }^{\circ} \mathrm{C}\right)$} & \multicolumn{3}{|c|}{ Detected Gasess ${ }^{(a)}$} \\
\hline & & Range(b) & $\begin{array}{c}\text { Begin } \\
\text { Shrinkage }\end{array}$ & $\begin{array}{l}\text { Maximum } \\
\text { Shrinkage }\end{array}$ & $\begin{array}{c}\text { Return lu } \\
\text { Original Volume }\end{array}$ & $\begin{array}{l}\text { Maximuun } \\
\text { Expansion }\end{array}$ & Species & $\begin{array}{l}\text { Amount } \\
\text { (mmol) }\end{array}$ & $\begin{array}{l}\text { Temperature } \\
\text { Range }\left({ }^{\circ} \mathrm{C}\right)\end{array}$ \\
\hline & Formated $\not H 1$ & $700-853$ & NA & NA & NA & 816 & $\mathrm{O}_{2}$ & 0.215 & $448-708$ \\
\hline & Formated $/ 2$ & $710-873$ & 710 & 735 & 750 & 783 & & 0.048 & $718-838$ \\
\hline & & & & & & & $\mathrm{CO}_{2}$ & 0.176 & $691-1200$ \\
\hline & & & & & & & & 0.009 & $700-873$ \\
\hline & & & & & & & $\mathrm{N}_{2}$ & 0.252 & $228-778$ \\
\hline & & & & & & & & 0.012 & $700-778$ \\
\hline & & & & & & & No & 1.9 & $488-708$ \\
\hline & & & & & & & & 0.361 & $718-878$ \\
\hline & & & & & & & & 0.399 & $700-873$ \\
\hline & Nitric $H I$ & $740-890$ & 740 & 785 & 820 & 865 & $\mathrm{O}_{2}$ & 0.150 & $605-805$ \\
\hline & Nitric $\not 2$ & $720-885$ & 720 & 755 & 802 & 845 & & 0.002 & 720.805 \\
\hline & Nitric $\not 33$ & $720-858$ & 720 & 755 & 805 & 858 & $\mathrm{CO}_{2}$ & 4.34 & $559-819$ \\
\hline & & & & & & & & 0.695 & $720-819$ \\
\hline & & & & & & & No & 0.980 & 025.765 \\
\hline & & & & & & & & 0.085 & $720-765$ \\
\hline 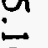 & Unformated \#1 & $720-852$ & 720 & 737 & 757 & 830 & $\mathrm{O}_{2}$ & 0.314 & 538.808 \\
\hline$a$ & Unformated $\# 2$ & $730-865$ & 730 & 740 & 745 & 854 & & 0.011 & $818-908$ \\
\hline & & & & & & & & 0.069 & $720-865$ \\
\hline & & & & & & & $\mathrm{CO}_{2}$ & 5.93 & $461-761$ \\
\hline & & & & & & & & 0.016 & $720-761$ \\
\hline & & & & & & & No & 0.222 & $598-888$ \\
\hline & & & & & & & & 0.523 & 720.865 \\
\hline & Nitric acid $4 X$ weight & $160-763$ & NA & NA & NA & 280 & $\mathrm{O}_{2}$ & 0.34 & $446-746$ \\
\hline & & & & & & & & 0.023 & $700-746$ \\
\hline & (2 ranges) & $763-852$ & NA & NA & NA & 850 & $\mathrm{CO}_{2}$ & 18.5 & $449-719$ \\
\hline & & & & & & & & 0.080 & $700-719$ \\
\hline & & & & & & & No & 2.67 & $576-776$ \\
\hline & & & & & & & & 0.066 & $700-776$ \\
\hline & Oxide/Carbonate & $743-894$ & NA & NA & NA & 893 & $\mathrm{CO}_{2}$ & 0.004 & $743-785$ \\
\hline
\end{tabular}

(a) Only one measurement of the gas products was obtained.

(b) Expansion temperature range corresponds to recorded deviation of normalized voluıne from $1 \mathrm{com}^{3}$. 
ID: COMPARISON PLOT

File: 940811A1.MDI Scan: 5-75/.04/30/\$1751, Anode: CU

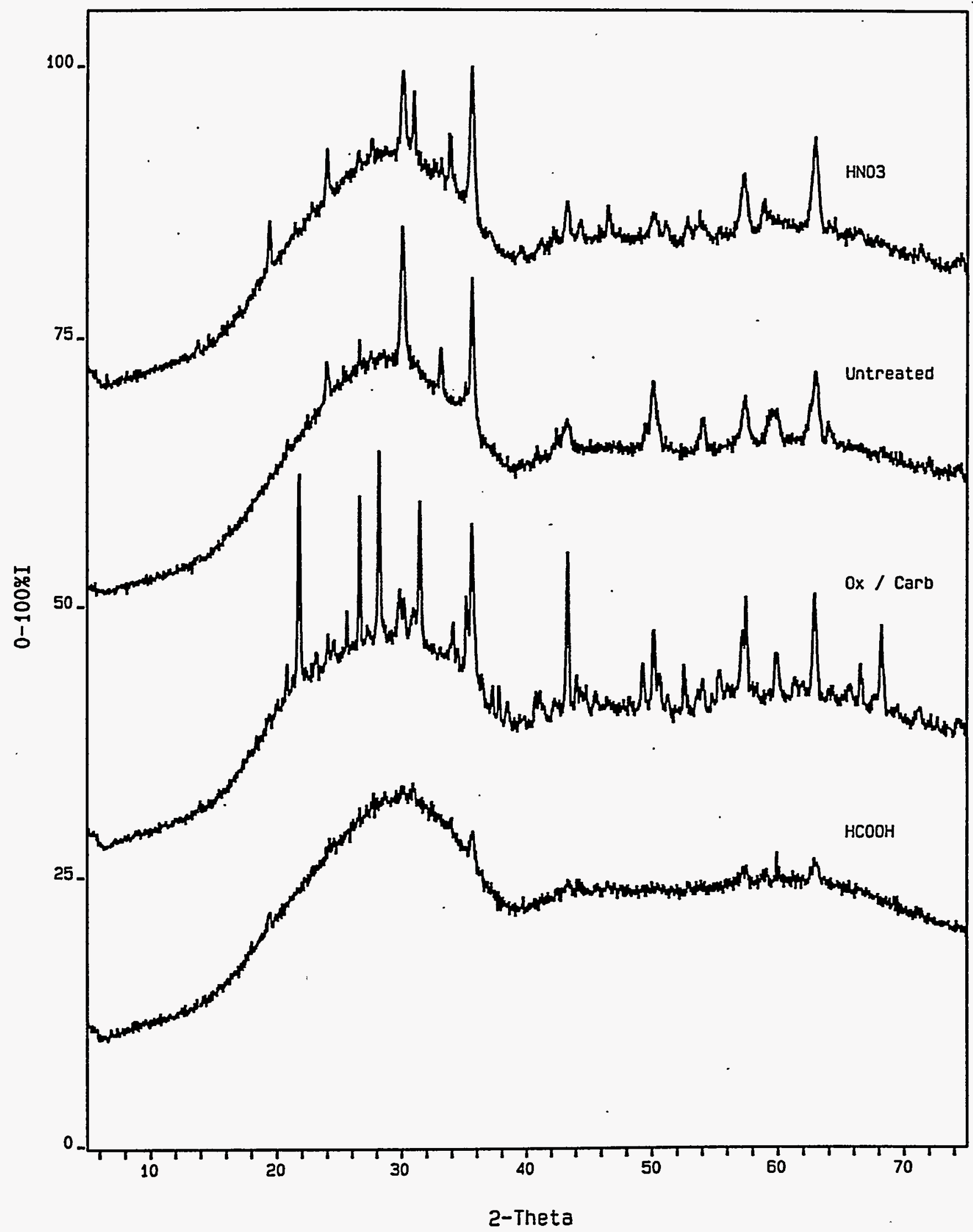

$F_{i j, 11}$ 


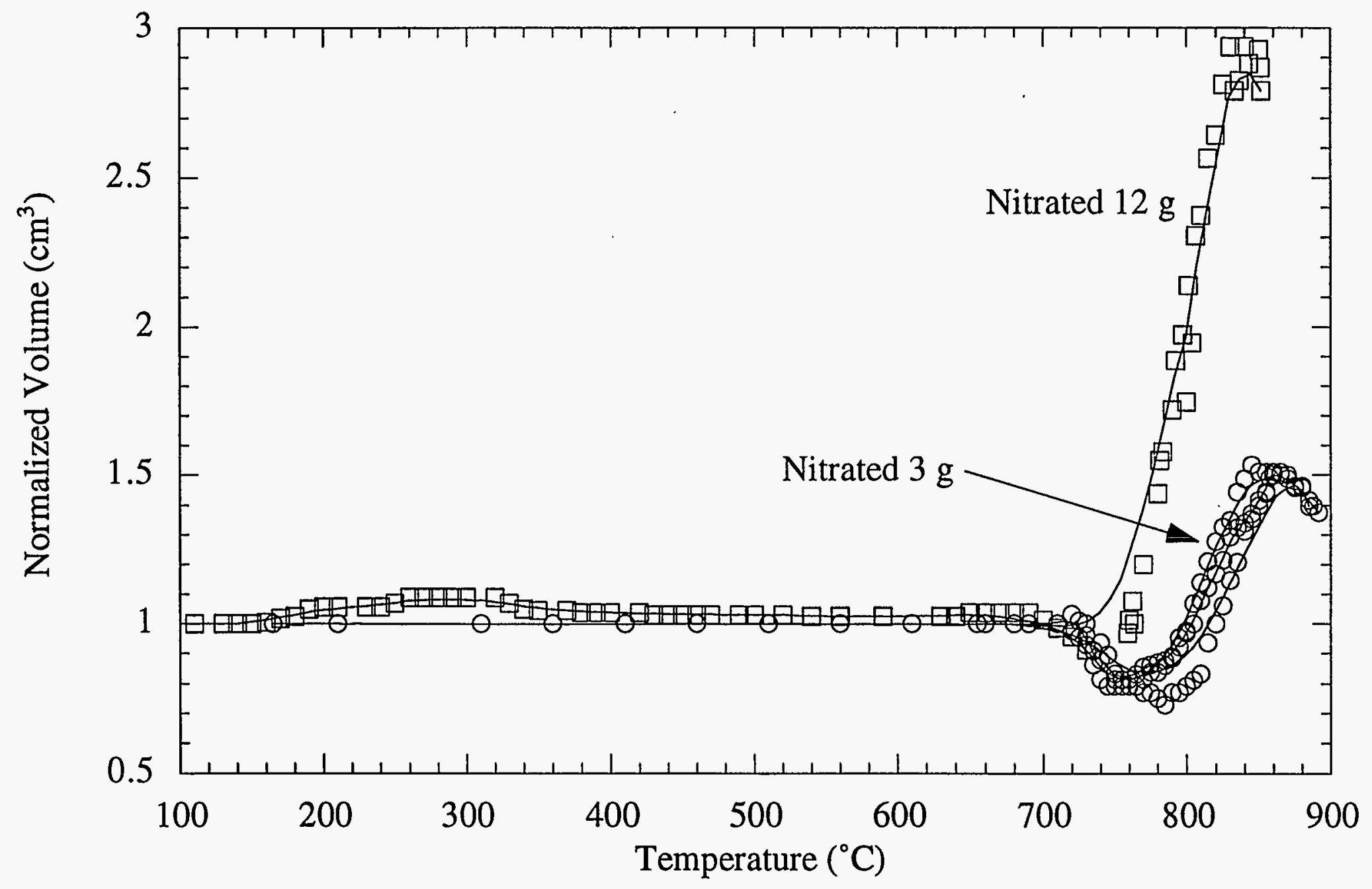




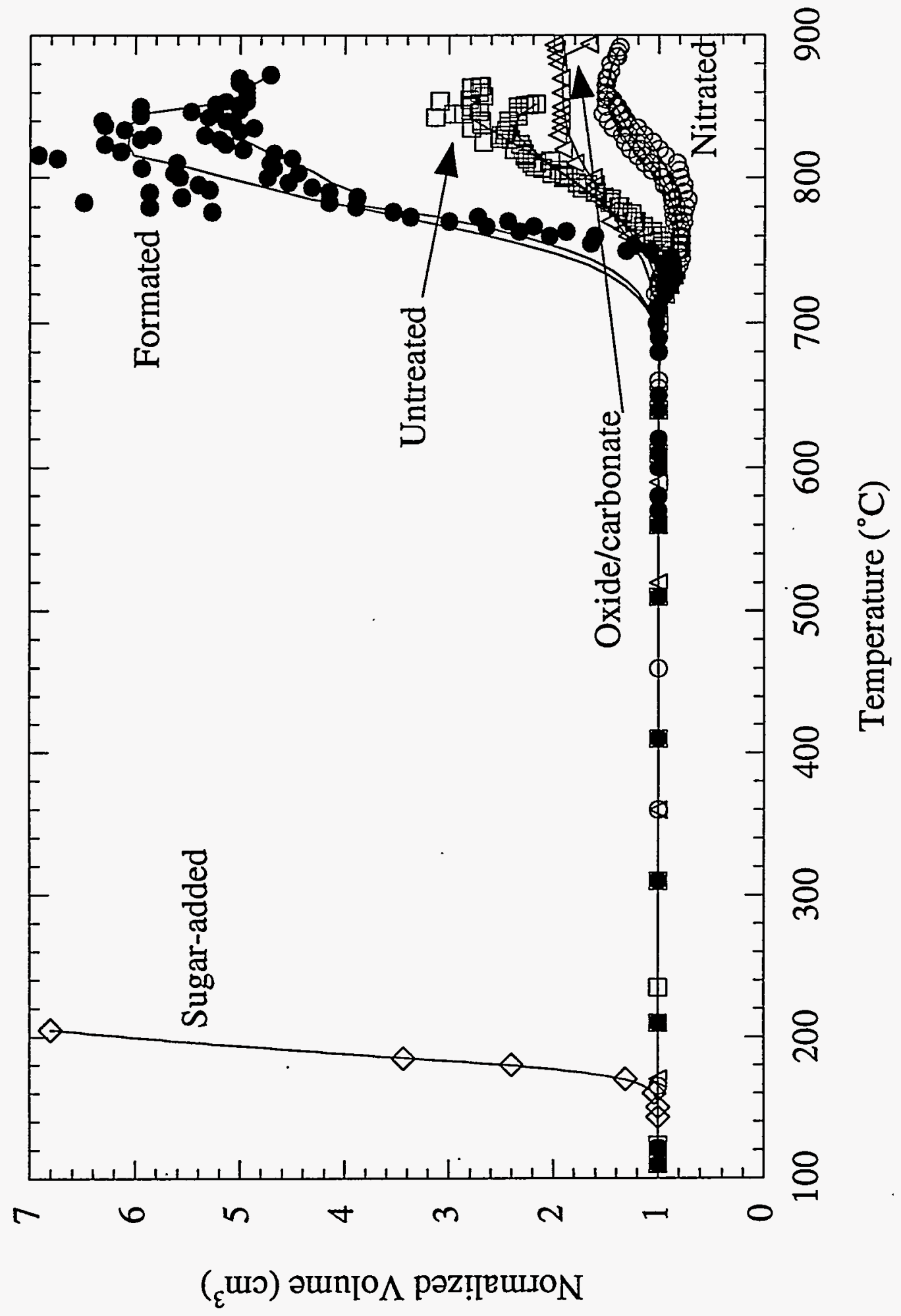




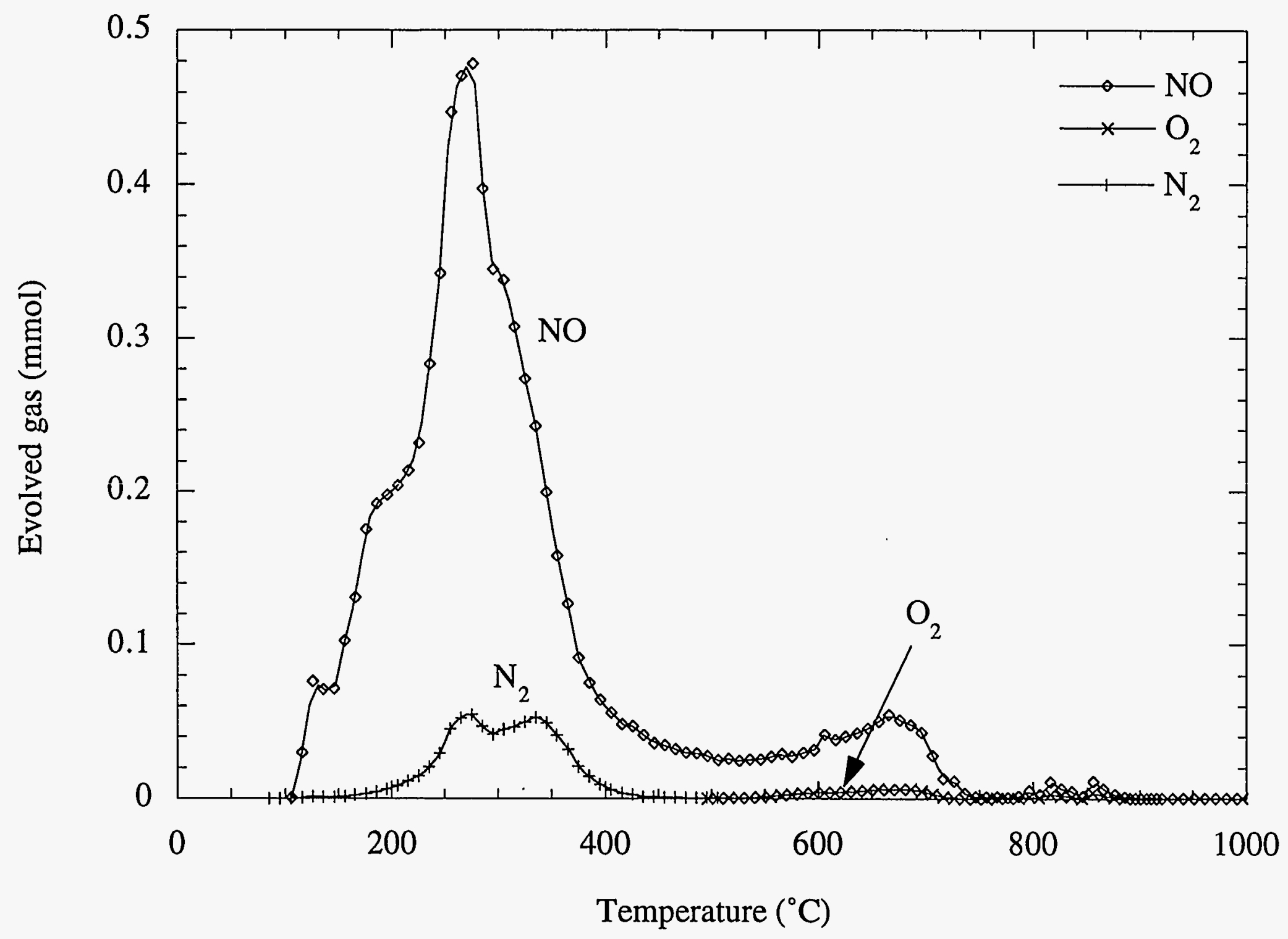


LLW thermal analysis observations

158-292 C

$\mathrm{Na}_{4}$ EDTA melts

$\mathrm{Na}_{4} \mathrm{EDTA}+\mathrm{NaNOx}$ (s)

292-363 C

$\mathrm{NaNO}_{2}, \mathrm{NaNO}_{3}$ melt

$\mathrm{Na}_{4}$ EDTA + NaNOx (1)

$\mathrm{NOx}$

$\mathrm{CH}_{4}$

$\mathrm{H}_{2}$

$\mathrm{CO}_{2}$

327-567 EDTA decomposes

$\mathrm{CO}_{2}$

514-804 NaNOx்(1) $+\mathrm{SiO}_{2}$

$\mathrm{NOx}, \mathrm{O}_{2} \mathrm{CH}_{4}$ 
Sodium Nitrite/Nitrate Decomposition

$\mathrm{NaNO}_{3} \rightarrow \mathrm{NaNO}_{2}+(1 / 2) \mathrm{O}_{2}$

$2 \mathrm{NaNO}_{2} \rightarrow \mathrm{Na}_{2} \mathrm{O}+2 \mathrm{NO}+(1 / 2) \mathrm{O}_{2}$

$2 \mathrm{NaNO}_{2} \rightarrow \mathrm{Na}_{2} \mathrm{O}+\mathrm{N}_{2}+(3 / 2) \mathrm{O}_{2}$

Abe et al (1983) reacted sodium nitrite with silica $T<500 \mathrm{C}$, NO observed $T>600 C$, NO and $Q$ observed 


\section{Experimental}

Samples- Untreated, Formated, Nitrated, Sugar-Added, Oxide/Carbonate

Heat treatments- 3 g. of melter feed; heated $10 \mathrm{C} / \mathrm{min}$

Temperatures- 1000, 1044, 1200C; immediate quench

Iron redox measured by colorimetric titration

Offgas measured by GC-MS

Volume expansion measured by recorded images using a video camera

Analysis of quenched foam- Microscopy, XRD, bubble composition 


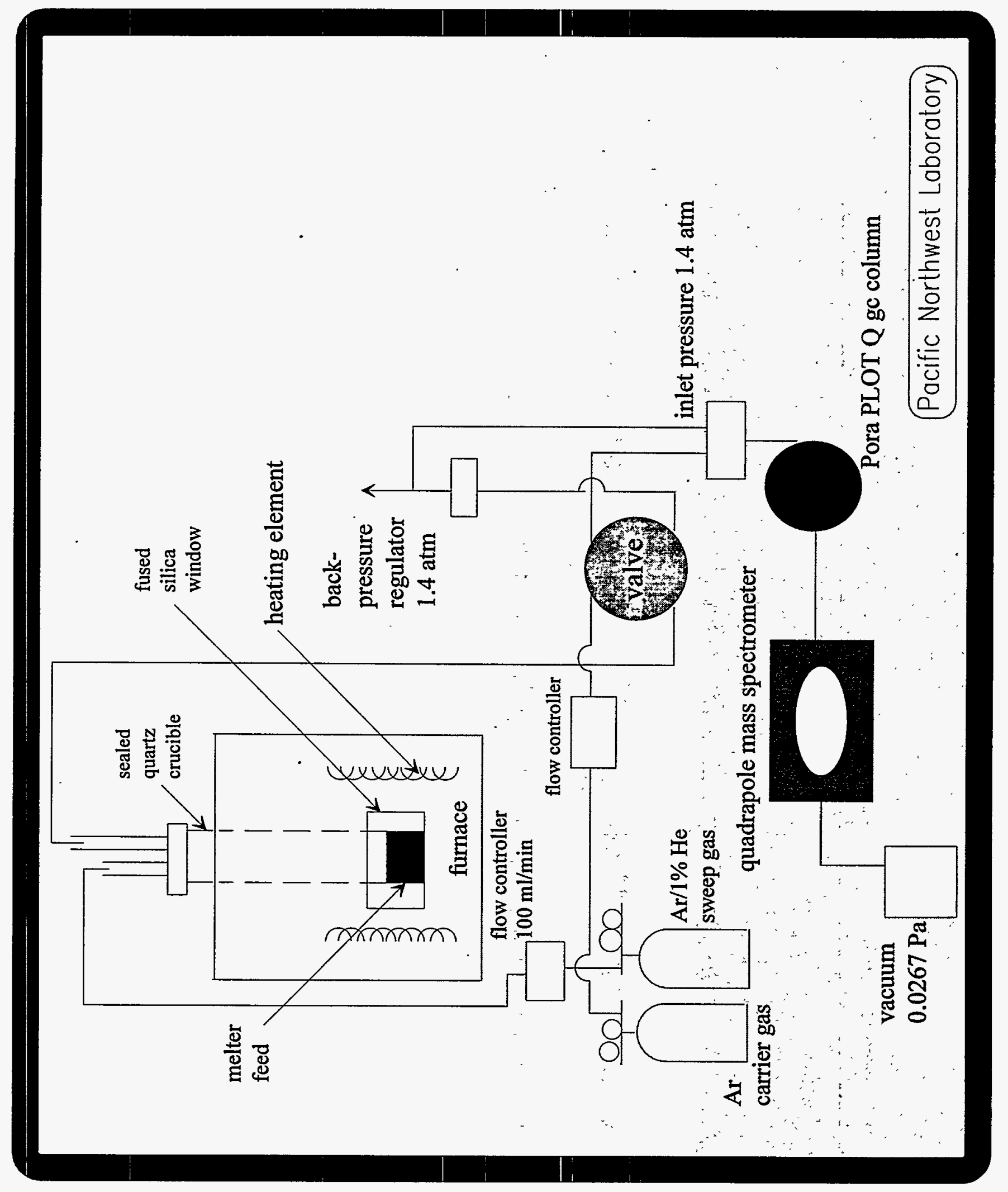


Compositional Analysis of Bubbles (wt\% of each component)

Sample

Formated

Untreated

Ox/Carbon

Nitrated
$\mathrm{Y}$

17.6

6.1

25.5

21.2
Q

$66.0 \quad 1.8$

$74.3 \quad 1.5$

$6.9 \quad 2.1$

$62.0 \quad 2.8$
ÇO

1.7

14.6

65.5

12.7
NO

12.9

3.5

NA

1.4 


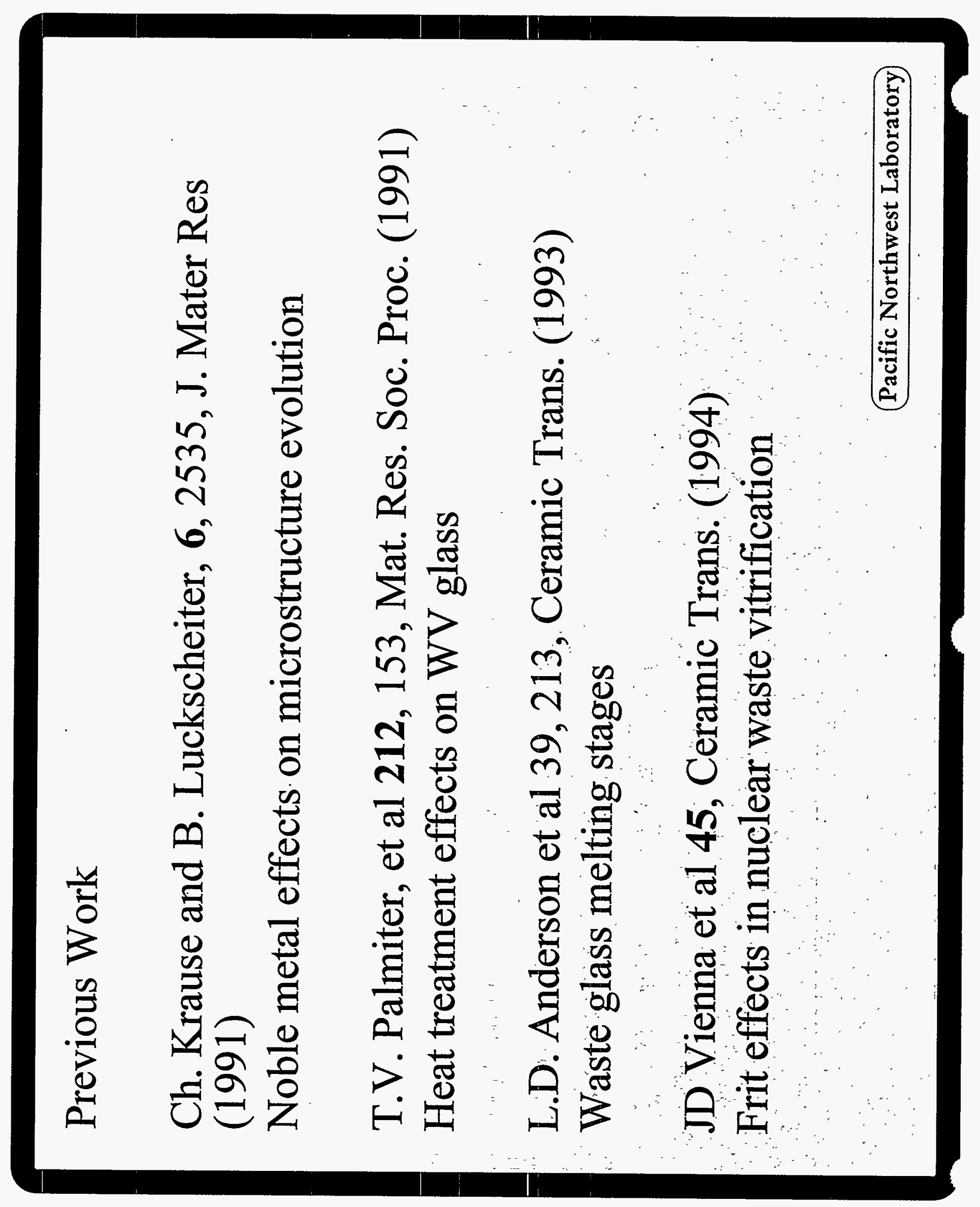


Motivations for Studying Batch Melting

Slow steady state melting rate- currently

Conventional borosilicate glass production $80-240 \mathrm{~kg} / \mathrm{h} / \mathrm{m} 2$ (Trier 1987)

Best liquid-fed ceramic melter run $56 \mathrm{~kg} / \mathrm{h} / \mathrm{m} 2$ [Compendium of 44 melter runs at PNL, SRL and WV (Elliot et al 1989)]

Avoid oscillatory operation/ batch pile up 
LLW thermal analysis observations

158-292 C

$\mathrm{Na}_{4}$ EDTA melts

$\mathrm{Na}_{4}$ EDTA + NaNOx (s)

292-363 C

$\mathrm{NaNO}_{2}, \mathrm{NaNO}_{3}$ melt

$\mathrm{Na}_{4}$ EDTA + NaNOx (1)

327-567 EDTA decomposes

514-804 $\mathrm{NaNOx}(1)+\mathrm{SiO}_{2}$
NOx

$\mathrm{CH}_{4}$

$\mathrm{H}_{2}$

$\mathrm{CO}_{2}$

$\mathrm{CO}_{2}$

$\mathrm{NOx}, \mathrm{O}_{2} \mathrm{CH}_{4}$ 
Why study the conversion of nuclear waste to glass?

Large-scale runs are expensive

Safety issues can be identified in small scale

Enhancement of melting rate

Conventional glass has been experimenting for a long time

Lack of experience in radioactive vitrification- Only French melters are in operation 


\section{The Technetium Problem}

Expected in $\mathrm{LLW}-\mathrm{HTcO}_{4}, \mathrm{TcO}_{4}^{-}, \mathrm{TcO}^{+}, \mathrm{TcO}(\mathrm{OH})^{+}$ $\mathbf{T c O}(\mathbf{O H})_{2}^{0}$

When Tc is oxidized- high vapor pressure, volatile

LLW contains nitrates which oxidize Te

LLW contains chlorides and fluorides; the stability of Tc halides is uncertain in LLW, However, decomposition of Te halides produces Te metal which is non-volatile.

Oxide/Carbonate Batches of LLW $>\mathbf{8 0} \%$ Tc volatilization

Nitrate/ EDTA batches- Reduction in Volatilization 
Reductant Reactions

Formic acid

$\mathrm{HCOOH} \longrightarrow \mathrm{H}_{2}+\mathrm{CO}$

$\mathrm{HCOOH} \longrightarrow \mathrm{H}_{2} \mathrm{O}+\mathrm{CO}_{2}$

Sugar

$\mathrm{C}_{12} \mathrm{H}_{22} \mathrm{O}_{11}+8 \mathrm{NaNO}_{3} \rightarrow 4 \mathrm{Na}_{2} \mathrm{O}+4 \mathrm{~N}_{2}+8 \mathrm{CO}_{2}+4 \mathrm{CO}+11 \mathrm{H}_{2} \mathrm{O}$ $\mathrm{C}_{12} \mathrm{H}_{22} \mathrm{O}_{11}+12 \mathrm{NaNO}_{2} \rightarrow 6 \mathrm{Na}_{2} \mathrm{O}+6 \mathrm{~N}_{2}+6 \mathrm{CO}_{2}+6 \mathrm{CO}+11 \mathrm{H}_{2} \mathrm{O}$

Elemental Carbon

$$
\begin{aligned}
& 3 \mathrm{C}+2 \mathrm{NaNO}_{3} \longrightarrow \mathrm{Na}_{2} \mathrm{O}+\mathrm{N}_{2}+2 \mathrm{CO}_{2}+\mathrm{CO} \\
& 2 \mathrm{C}+2 \mathrm{NaNO}_{2} \longrightarrow \mathrm{Na}_{2} \mathrm{O}+\mathrm{N}_{2}+\mathrm{CO}_{2}+\mathrm{CO}
\end{aligned}
$$




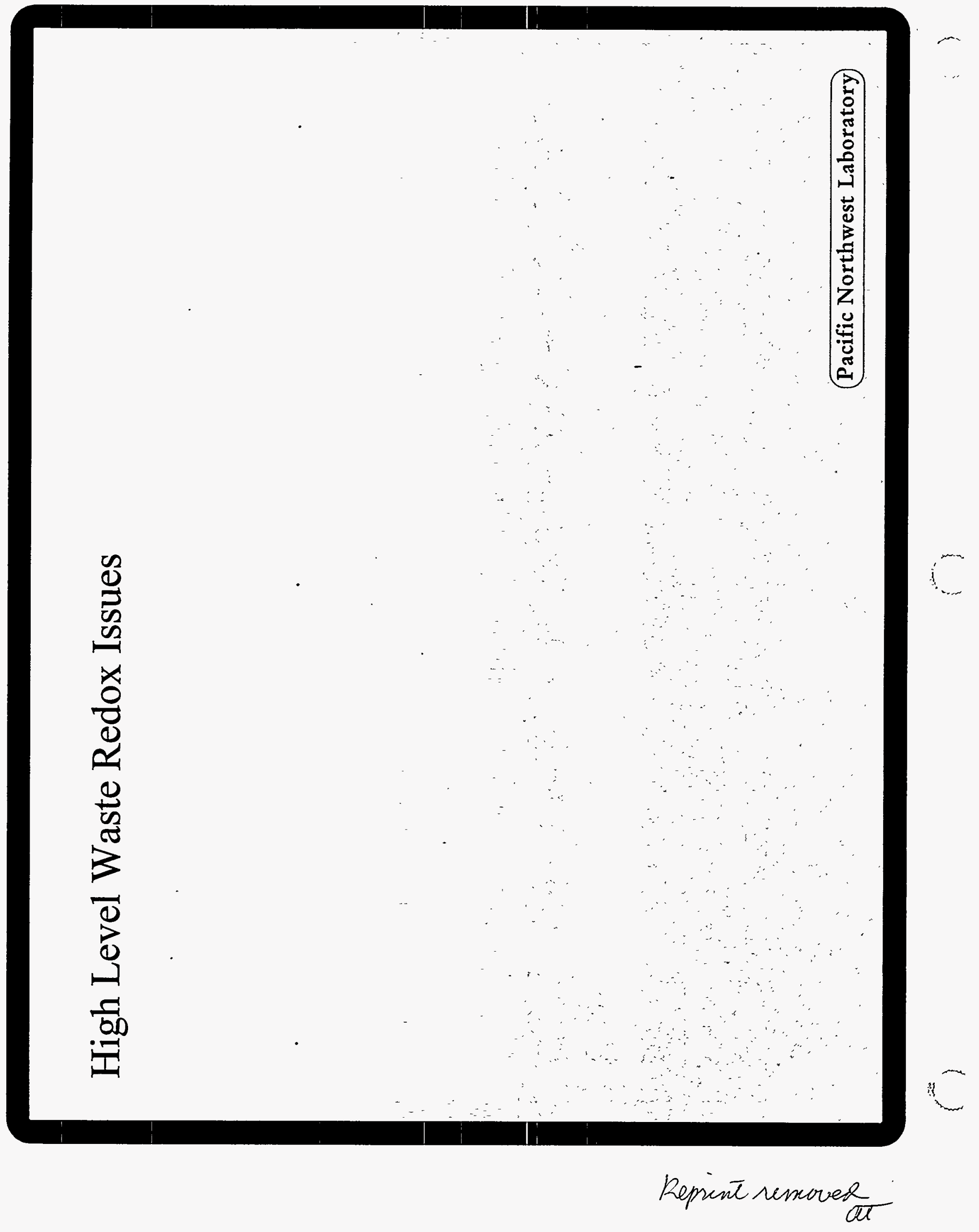




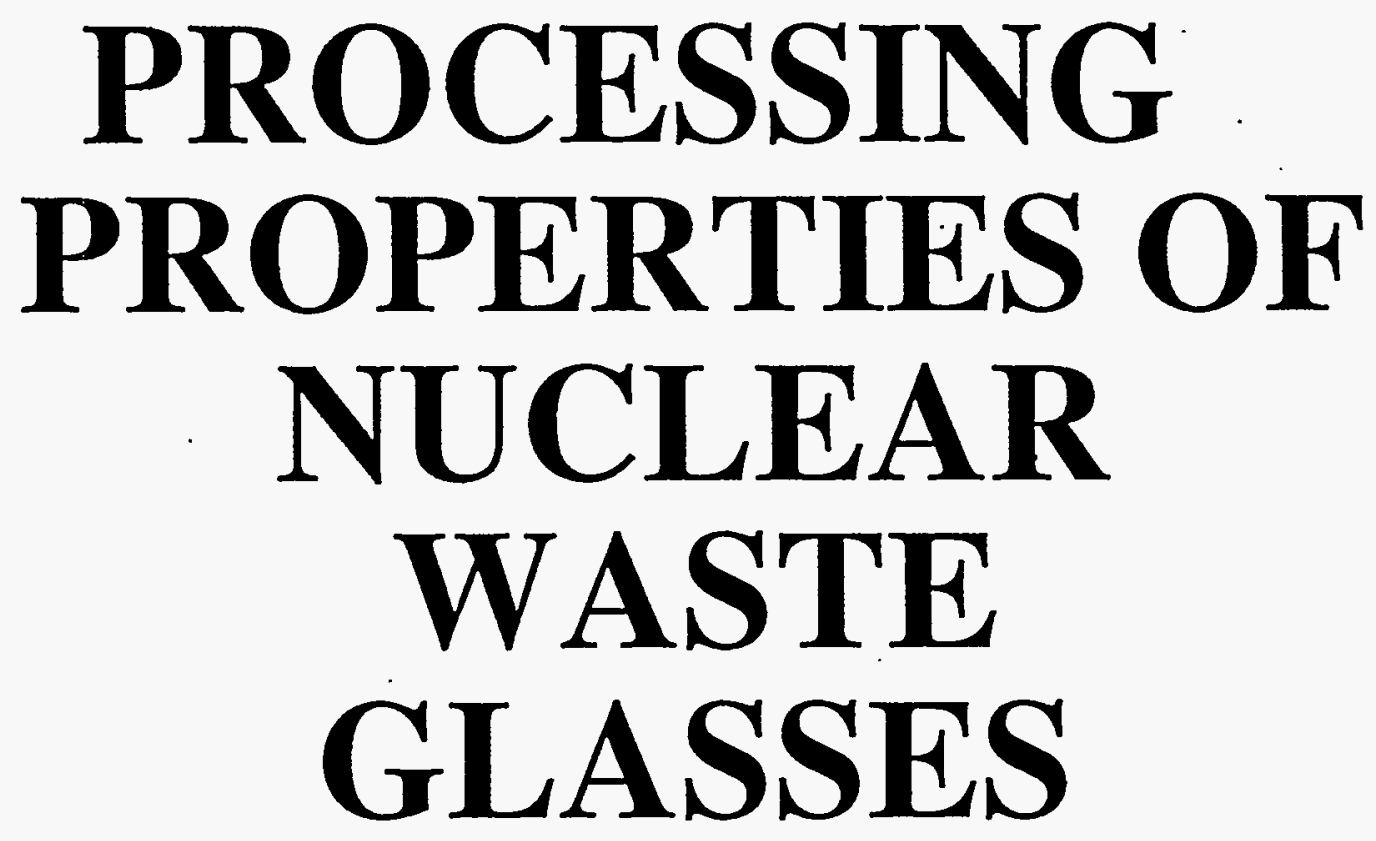




\section{PROPERTY VS. PRIMARY VARIABLES}

- glass can be viewed as a mixture of components

- a mixture property $(\xi)$ depends on primary thermodynamic variables $(T, P, \mathbf{g})$ :

$$
\xi=f(T, P, \mathbf{g})
$$

$T$ temperature ,

$P$ pressure

$\mathbf{g}=\left(g_{1}, g_{2}, \cdots, g_{n-1}\right)$ composition vector

$g_{i}$ i-th component mass or mole fraction

$n$ number of components

- glass melting operation: $P=$ const.

$$
\xi=f(T, \mathbf{g})
$$


PROPERTIES RELEVANT FOR

GLASS MELTING PROCESS:

$$
\xi \equiv \eta, \varepsilon, T_{g}
$$

$\eta$ viscosity

$\varepsilon$ electrical conductivity

$T_{g}$ glass transition temperature

- we need to determine

$$
\eta=\hat{\eta}(T, \mathbf{g}), \varepsilon=\hat{\varepsilon}(T, \mathbf{g}), \text { and } T_{g}=\hat{T}_{g}(\mathbf{g})
$$

PROPERTY VS. COMPOSITION FUNCTIONS experimental design:

- selection of compositions to cover the composition region and property ranges of interest

- manageable data generation: statistical theory of mixtures

data evaluation:

- plausible assumptions regarding the form of the property function $\xi=f(T, \mathbf{g})$ 


\section{EMPIRICAL MODELS}

- provide the most accurate practically achievable information regarding the effects of composition on compositiondependent variables

- minimize the amount of laboratory testing by restricting the compositional region

- employ statistical experimental design to optimize the coverage of this region by data points

- assume simple functional forms for the dependence of properties on composition 


\section{HANFORD SITE WASTE GLASS COMPOSITION REGION (wt\%)}

$\mathrm{SiO}_{2} \quad 40-60$

$\mathrm{B}_{2} \mathrm{O}_{3} \leq 15$

$\mathrm{Na}_{2} \mathrm{O} \quad 5-25$

$\mathrm{Li}_{2} \mathrm{O} \leq 7$.

$\mathrm{CaO} \leq 3$

$\mathrm{MgO} \leq 1$

$\mathrm{Fe}_{2} \mathrm{O}_{3} \leq 15$

$\mathrm{Al}_{2} \mathrm{O}_{3} \leq 17$

$\mathrm{Zr}_{2} \mathrm{O} \leq 14$

$\mathrm{CeO}_{2} \leq 2$

$\mathrm{Bi}_{2} \mathrm{O}_{3} \leq 2$

$\mathrm{P}_{2} \mathrm{O}_{5} \leq 3(?)$

$\mathrm{UO}_{3} \leq 17$

$\mathrm{TiO}_{2} \leq 9$

$\mathrm{NiO} \leq 2$

$\mathrm{Cr}_{2} \mathrm{O}_{3} \leq 2$

$\mathrm{MnO} \leq 5$

$\mathrm{SO}_{3} \leq 1$

$\mathrm{F} \quad \leq 2$

- these ranges reflect waste components inventory or solubility limits or both

- these ranges are estimated for statistical test matrices and should not be used as acceptable ranges for engineering calculations 


\section{PROPERTY CONSTRAINTS}

- the selected composition region is further restricted by imposing property constraints:

$$
\begin{aligned}
& T_{L}<T_{M}-100^{\circ} \mathrm{C} \\
& 2 \mathrm{~Pa} \cdot \mathrm{s}<\eta\left(T_{M}\right)<10 \mathrm{~Pa} \cdot \mathrm{s}
\end{aligned}
$$

$T_{L} \quad$ liquidus temperature

$T_{M}$ melting (melter.operating) temperature

- low-temperature melter:

$$
T_{M}=1050-1200^{\circ} \mathrm{C}
$$

- high-temperature melter:

$$
T_{M}=1200-1500^{\circ} \mathrm{C}
$$




\section{TEMPERATURE-DEPENDENT}

\section{PROPERTIES}

viscosity

- Vogel-Fulcher-Tammann (VFT)

equation is generally used for viscosity as a function of temperature:

$$
\eta=\exp \left[A(\mathbf{g})+\frac{B(\mathbf{g})}{T-T_{0}(\mathbf{g})}\right]
$$

- Arrhenius equation (for a narrow temperature interval, i.e., $950-1250^{\circ} \mathrm{C}$ ):

$$
\varepsilon=\exp \left[C(\mathbf{g})+\frac{D(\mathbf{g})}{T}\right]
$$

A, B, C, D temperature-independent coefficients

electrical conductivity

- both equations (VFT and Arrhenius) can be used 


\section{TEMPERATURE INDEPENDENT \\ PROPERTIES VS. COMPOSITION}

$$
\Phi \equiv\left(\eta_{T}, \varepsilon_{T}, T_{g}, A, B, T_{o}\right)
$$

$\eta_{T}$ and $\varepsilon_{T}$ viscosity and electrical conductivity at a given (constant) temperature

Scheffé forms:

first-order mixture models:

$$
\Phi=\sum_{i=1}^{n} b_{i} g_{i}
$$

second-order mixture models:

$$
\Phi=\sum_{i=1}^{n} b_{i} g_{i}+\sum_{i<j} b_{i j} g_{i} g_{j}
$$

$b_{i}$ and $b_{i j}$ are first- and second-order coefficients 


\section{PHYSICAL MEANING OF FIRST- ORDER COEFFICIENTS}

1) replacement of $i$-th component by a k-th component

$$
\partial \Phi / \partial g_{i}=b_{i}-b_{k}
$$

2) i-th component addition to the mixture (component effect)

$$
\partial \Phi /\left.\partial g_{i}^{\prime}\right|_{a d d}=\frac{b_{i}-\Phi}{1-g_{i}}
$$



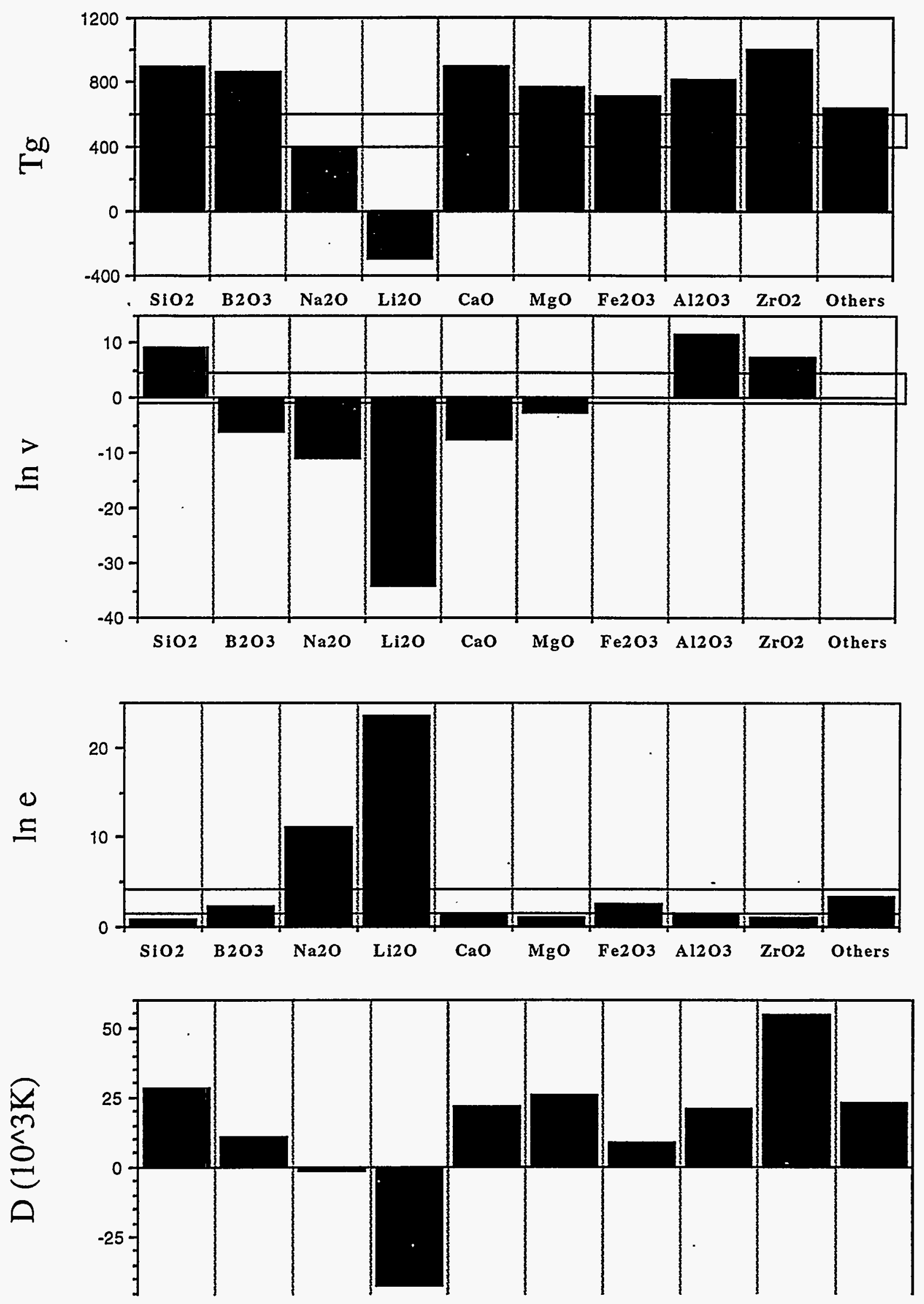

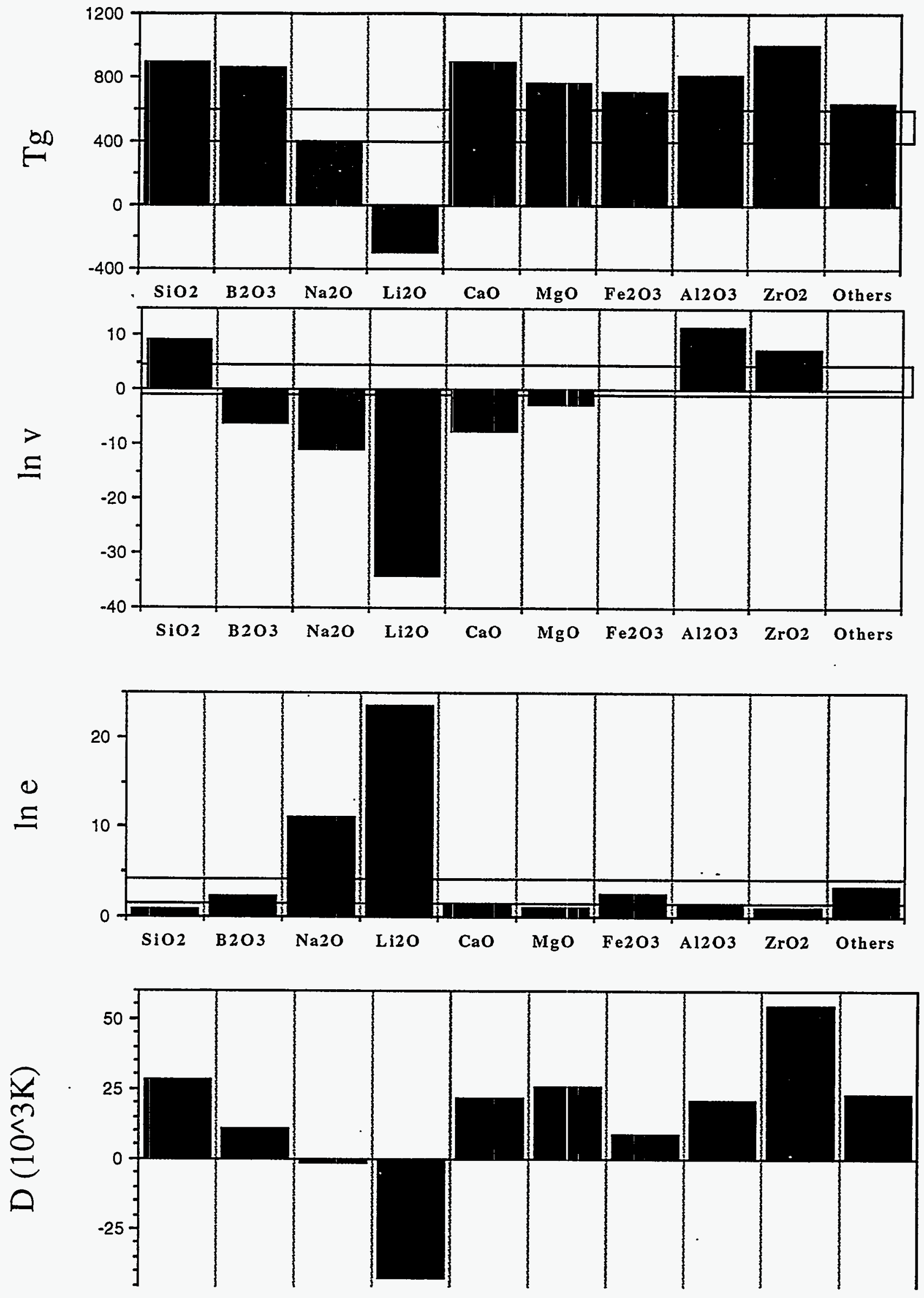

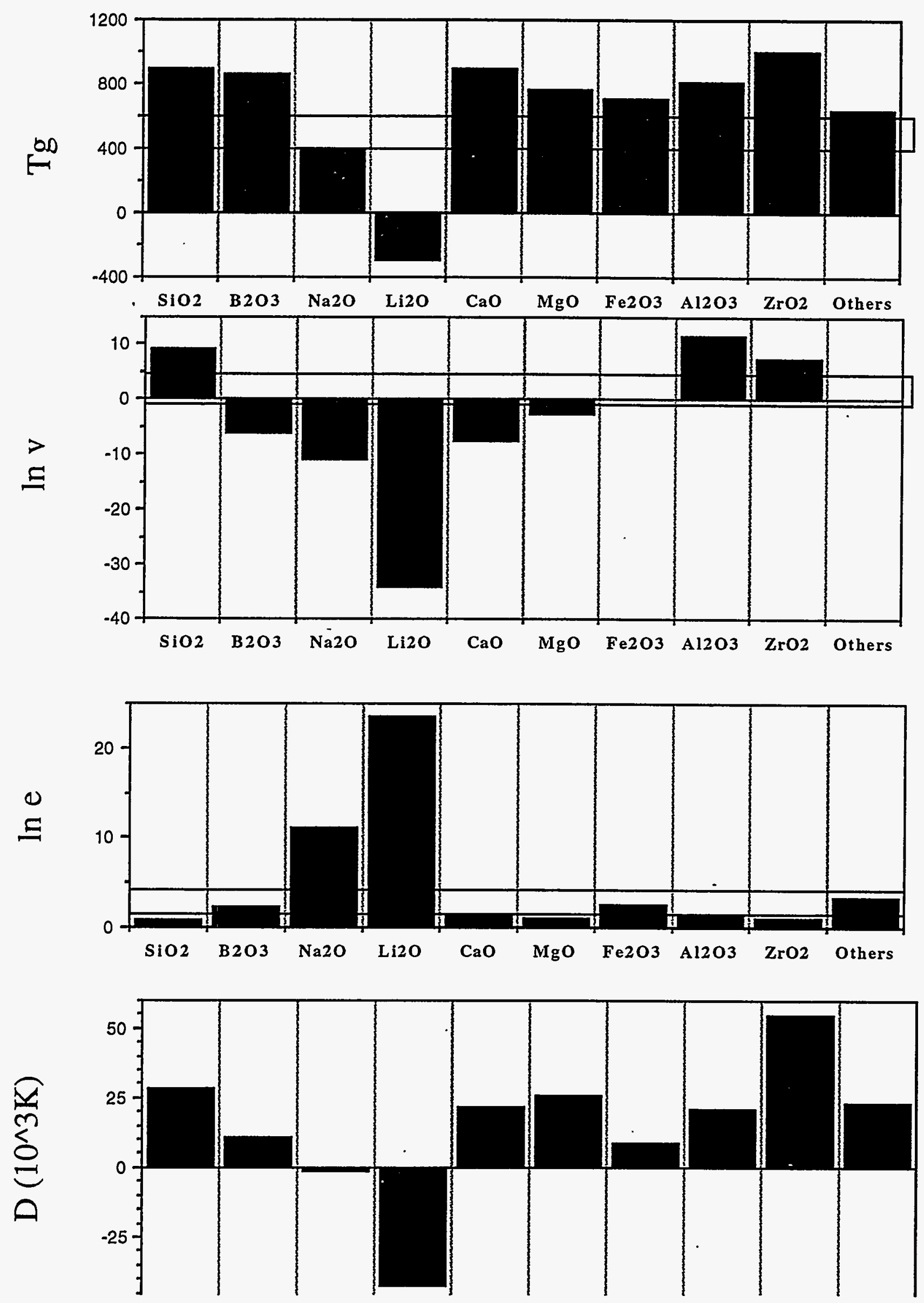


\section{GLASS TRANSITION TEMPERATURE (HLW GLASSES FOR LOW-TEMPERATURE MELTER)}

$T_{g}$ first-order coefficients, $T_{g i}\left({ }^{\circ} C\right)$

\begin{tabular}{|l|rrrrrrrrrrr|c|}
\hline comp. & $\mathrm{SiO}_{2}$ & $\mathrm{~B}_{2} \mathrm{O}_{3}$ & $\mathrm{Na}_{2} \mathrm{O}$ & $\mathrm{Li}_{2} \mathrm{O}$ & $\mathrm{CaO}$ & $\mathrm{MgO}_{2} \mathrm{Fe}_{2} \mathrm{O}_{3}$ & $\mathrm{Al}_{2} \mathrm{O}_{3}$ & $\mathrm{ZrO}_{2}$ & $\mathrm{Other}$ & $\mathrm{R}^{2}$ \\
\hline mass & 623 & 585 & 129 & -571 & 622 & 494 & 427 & 544 & 730 & 364 & 0.89 \\
mole & 615 & 589 & 138 & -6 & 606 & 490 & 331 & 579 & 953 & 162 & 0.88 \\
\hline
\end{tabular}

$T_{g} \uparrow$ if $T_{g i}>600^{\circ} \mathrm{C}: \quad \mathrm{ZrO}_{2}>\mathrm{SiO}_{2}>\mathrm{CaO}$

$T_{g} \downarrow$ if $T_{g i}<400^{\circ} C: \quad \quad \mathrm{Li}_{2} \mathrm{O}<<\mathrm{Na}_{2} \mathrm{O}<$ Others

$T_{g} \uparrow$ if $400^{\circ} \mathrm{C}<T_{g i}<600^{\circ} \mathrm{C}$ :

$$
\mathrm{B}_{2} \mathrm{O}_{3} \approx \mathrm{Al}_{2} \mathrm{O}_{3}>\mathrm{MgO}>\mathrm{Fe}_{2} \mathrm{O}_{3}
$$




\section{VISCOSITY AT $1150^{\circ} \mathrm{C}$ (HLW GLASSES FOR LOW-TEMPERATURE MELTER)}

$\eta\left(1150^{\circ} \mathrm{C}\right)$ first-order coefficients, $\ln \eta_{i}(P a \cdot s)$

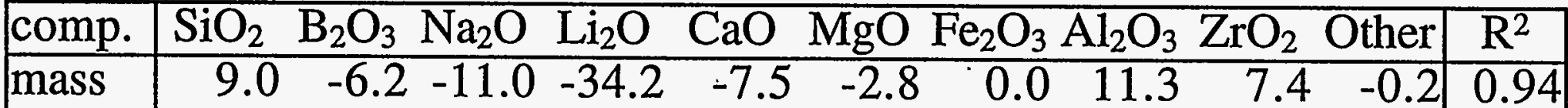

$$
\begin{aligned}
& \begin{array}{l|lllllllllll|}
\text { mole } & 8.5 & -6.8 & -10.7 & -15.0 & -6.3 & -1.2 & -2.5 & 17.1 & 12.8 & -3.6 & 0.95 \\
\hline
\end{array} \\
& \eta \uparrow \text { if } \ln \eta_{i}>4.5 \\
& \mathrm{Al}_{2} \mathrm{O}_{3}>\mathrm{ZrO}_{2}>\mathrm{SiO}_{2} \\
& \eta \downarrow \text { if } \ln \eta_{i}<-1 \quad \mathrm{Li}_{2} \mathrm{O}<\mathrm{Na}_{2} \mathrm{O}<\mathrm{CaO} \approx \mathrm{B}_{2} \mathrm{O}_{3}<\mathrm{MgO} \\
& \eta \uparrow \text { if }-1<\ln \eta_{i}<4.5 \quad \text { Others } \approx \mathrm{Fe}_{2} \mathrm{O}_{3}
\end{aligned}
$$




\section{ELECTRICAL CONDUCTIVITY AT $1150^{\circ} \mathrm{C}$ (HLW GLASSES FOR LTM)}

$\varepsilon\left(1150^{\circ} \mathrm{C}\right)$ first-order coefficients, $\ln \varepsilon_{i}(S / m)$

\begin{tabular}{|c|c|c|c|c|c|c|c|c|c|c|c|}
\hline omp. & $\mathrm{SiO}_{2}$ & $\mathrm{~B}_{2} \mathrm{O}_{3}$ & $\mathrm{Na}_{2} \mathrm{O}$ & $\mathrm{Li}_{2} \mathrm{O}$ & $\mathrm{CaO}$ & $\mathrm{MgO}$ & $\mathrm{Fe}_{2} \mathrm{O}_{3}$ & $\mathrm{Al}_{2} \mathrm{O}_{3}$ & $\mathrm{ZrO}_{2}$ & Other & $\mathrm{R}^{2}$ \\
\hline & 0.9 & 2.3 & 11.0 & 23.5 & 1.4 & 1.1 & 2.6 & 1.3 & 1.1 & 3.5 & 0.93 \\
\hline nole & 1.0 & 2.2 & 10.8 & 12.7 & 1.6 & 3.0 & 1.8 & 0.2 & -0.9 & 3.9 & 0.94 \\
\hline
\end{tabular}

$\varepsilon \uparrow$ if $\ln \varepsilon_{i}>4.6 \quad \mathrm{Li}_{2} \mathrm{O}>\mathrm{Na}_{2} \mathrm{O}$

$\varepsilon \downarrow$ if $\ln \varepsilon_{i}<1.8 \quad$ all non-alkali components except $\mathrm{B}_{2} \mathrm{O}_{3}, \mathrm{Fe}_{2} \mathrm{O}_{3}$, and Others

- electricity in molten glass is conducted by alkali ions

- relation $\eta \varepsilon=$ const. is not valid as glass composition varies 


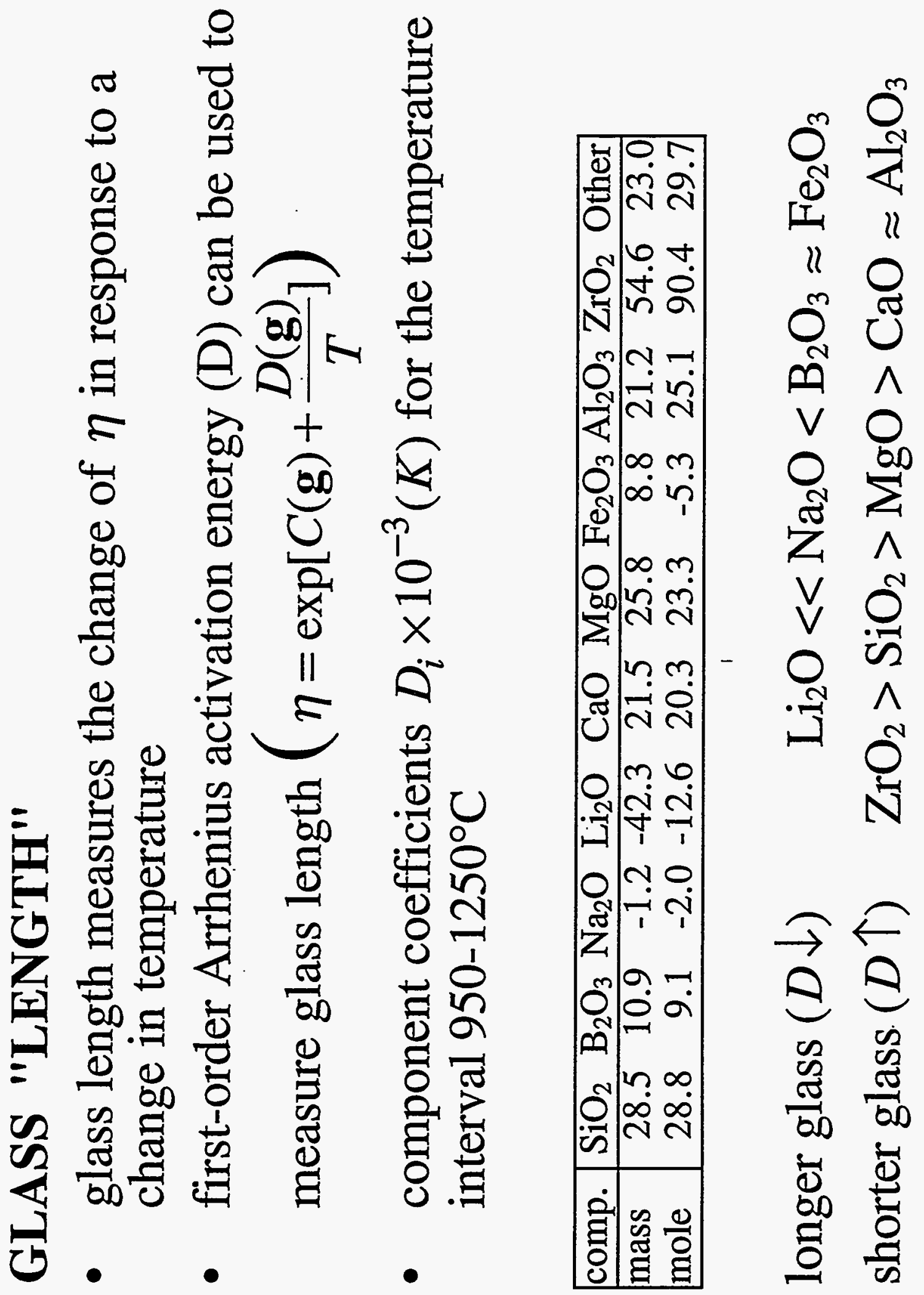



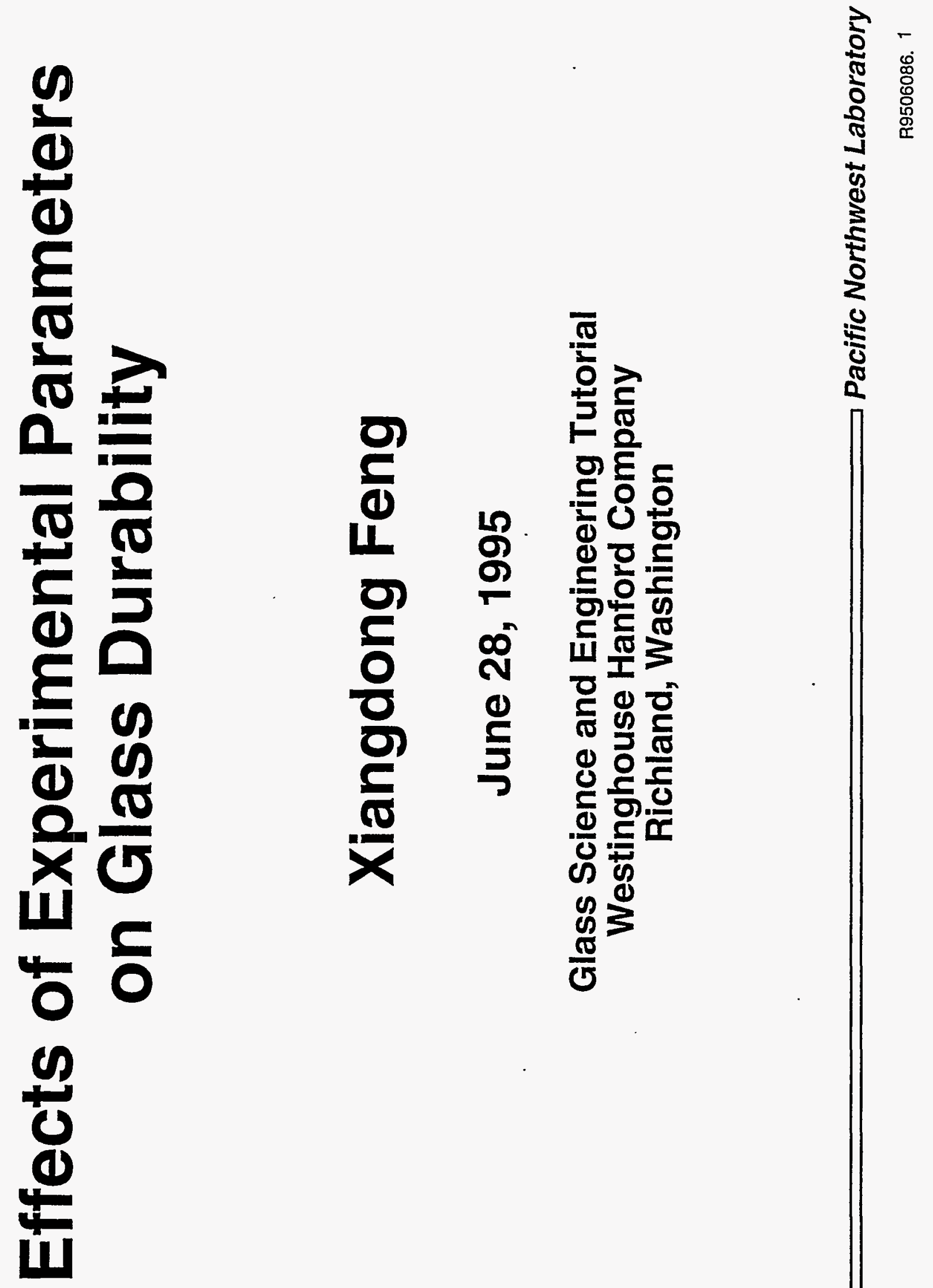


\section{Topics in Experimental Parameters}

- Test methods

- PCT (Product Consistency Test)

- Single-Pass Flow-Through Test (SPFT)

- Vapor Hydration Test (VHT)

- S/V (ratio of glass surface area to solution volume)

- Leachant composition

- lonic strength

- Inorganic/organic

- Individual cations

- pH

- Presence of metals

- Simulated glasses/fully radioactive glasses 


\section{Chemical Description of Glass Reaction}

- Water diffusion

- Ion exchange

- Hydrolysis

- Secondary phase formation 


\section{lon Exchange}

$\equiv \mathrm{SiO}-\mathrm{M}+\mathrm{H}_{2} \mathrm{O} \longrightarrow \mathrm{SiO}-\mathrm{H}+\mathrm{M}^{+}+\mathrm{OH}^{-}$

$$
\begin{gathered}
\mathrm{K}_{\mathrm{M}}=\frac{[\equiv \mathrm{SiO}-\mathrm{H}]\left[\mathrm{M}^{+}\right]\left[\mathrm{OH}^{-}\right]}{[\equiv \mathrm{SiO}-\mathrm{H}]\left[\mathrm{H}_{2} \mathrm{O}\right]} \\
\frac{d}{d t}\left[\mathrm{M}^{+}\right]=\frac{\mathrm{SA}}{\mathrm{V}} \mathrm{k}_{\mathrm{M}}\left[\mathrm{H}_{2} \mathrm{O}\right]\left(1-\frac{\left[\mathrm{M}^{+}\right][\mathrm{OH}]}{\mathrm{K}_{\mathrm{M}}}\right)
\end{gathered}
$$



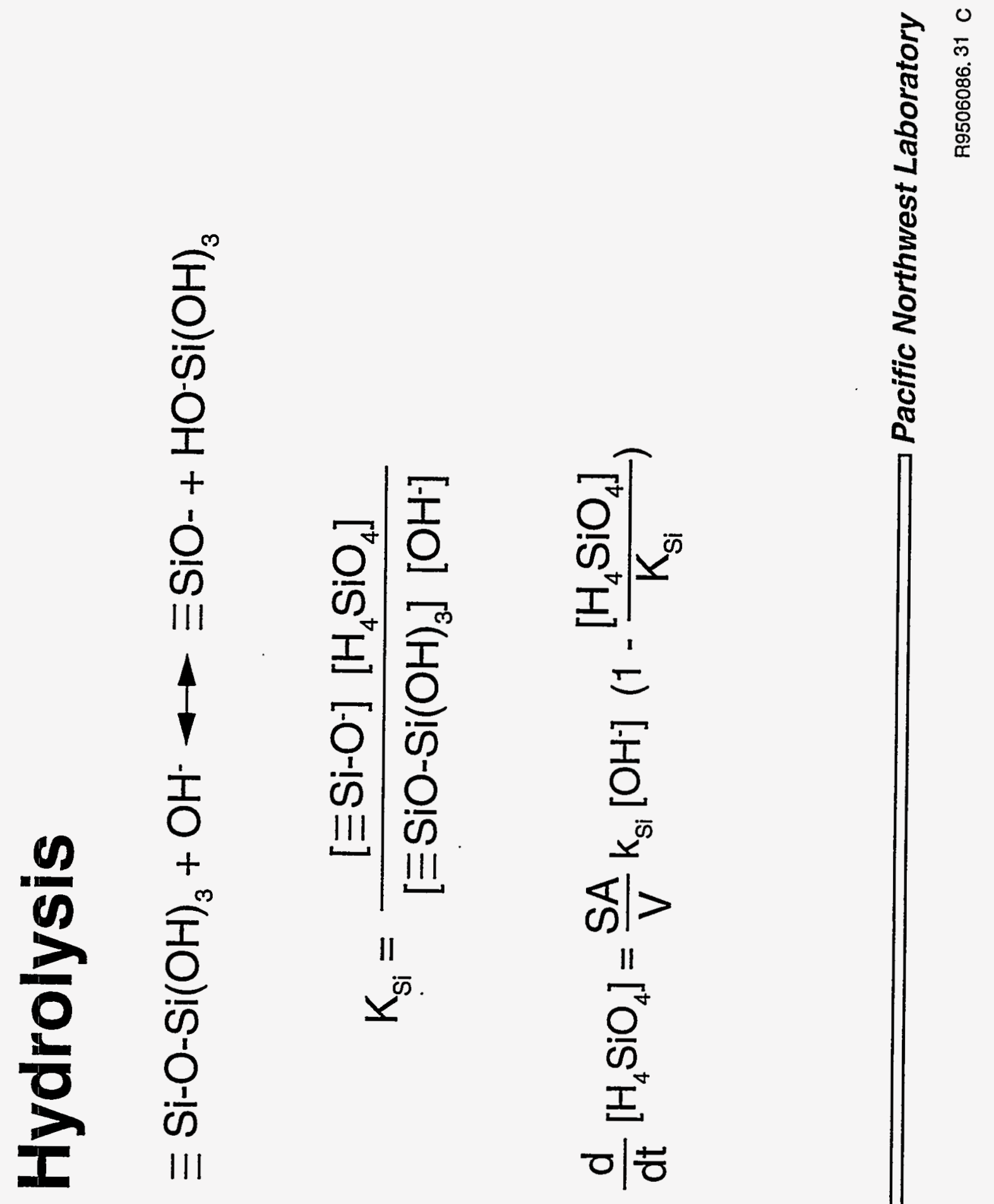
- Description of glass reaction must account for influence of all processes

- Test conditions may be used to promote or quench specific processes of water diffusion, ion exchange, hydrolysis, or secondary phase formation 


\section{S/V Effects on Glass Corrosion}

- S/V has been used as a reaction acceleration parameter to speed up glass reaction progress, i.e., equal leachate concentration can be obtained as long as:

$$
\left(\frac{s}{v}\right)_{1} \cdot t_{1}=\left(\frac{s}{v}\right)_{2} \cdot t_{2}
$$

- Waste glasses may experience different S/V conditions under disposal conditions due to:

- Glass cracking

- Change in groundwater flow through the disposal site 

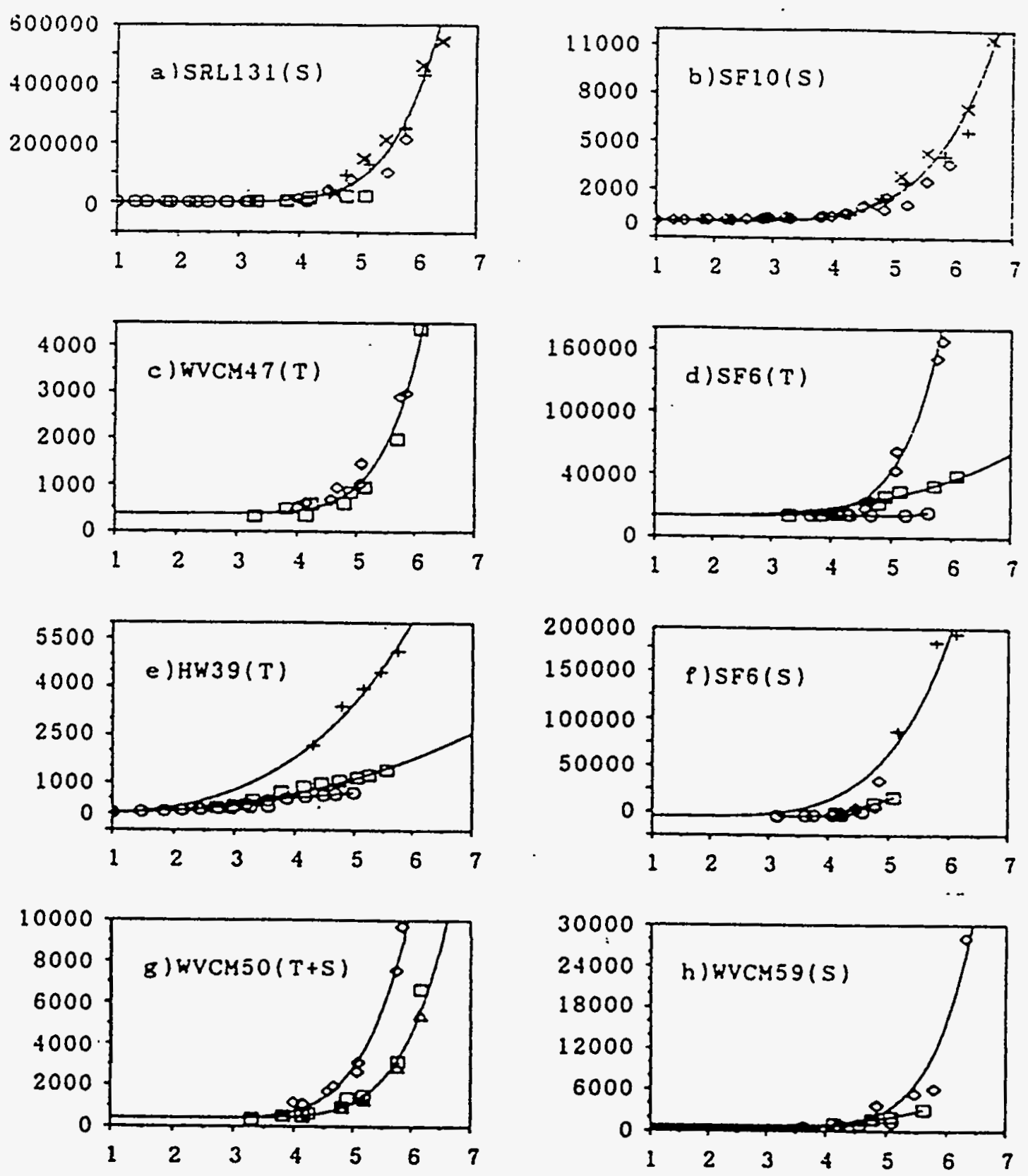

Normalized Boron Concentration (PPH) vs $\log ((S / V) \cdot t)\left(\right.$ day $\left.\cdot m^{-1}\right)$
$O S / V \leq 600 \mathrm{M}^{-1}$
$\square S / V=2000 \mathrm{M}^{-1}(T)$
$\Delta S / V=2000 H^{-1}(S)$
$0 S / V=10000 \mathrm{M}^{-1}$
$\nabla S / V=14000 \mathrm{M}^{-1}$
$+S / V=20000 \mathrm{M}^{-1}$
$\times S / V=40000 \mathrm{M}^{-1}$

Feng et al., MRS Proc. (1990) 

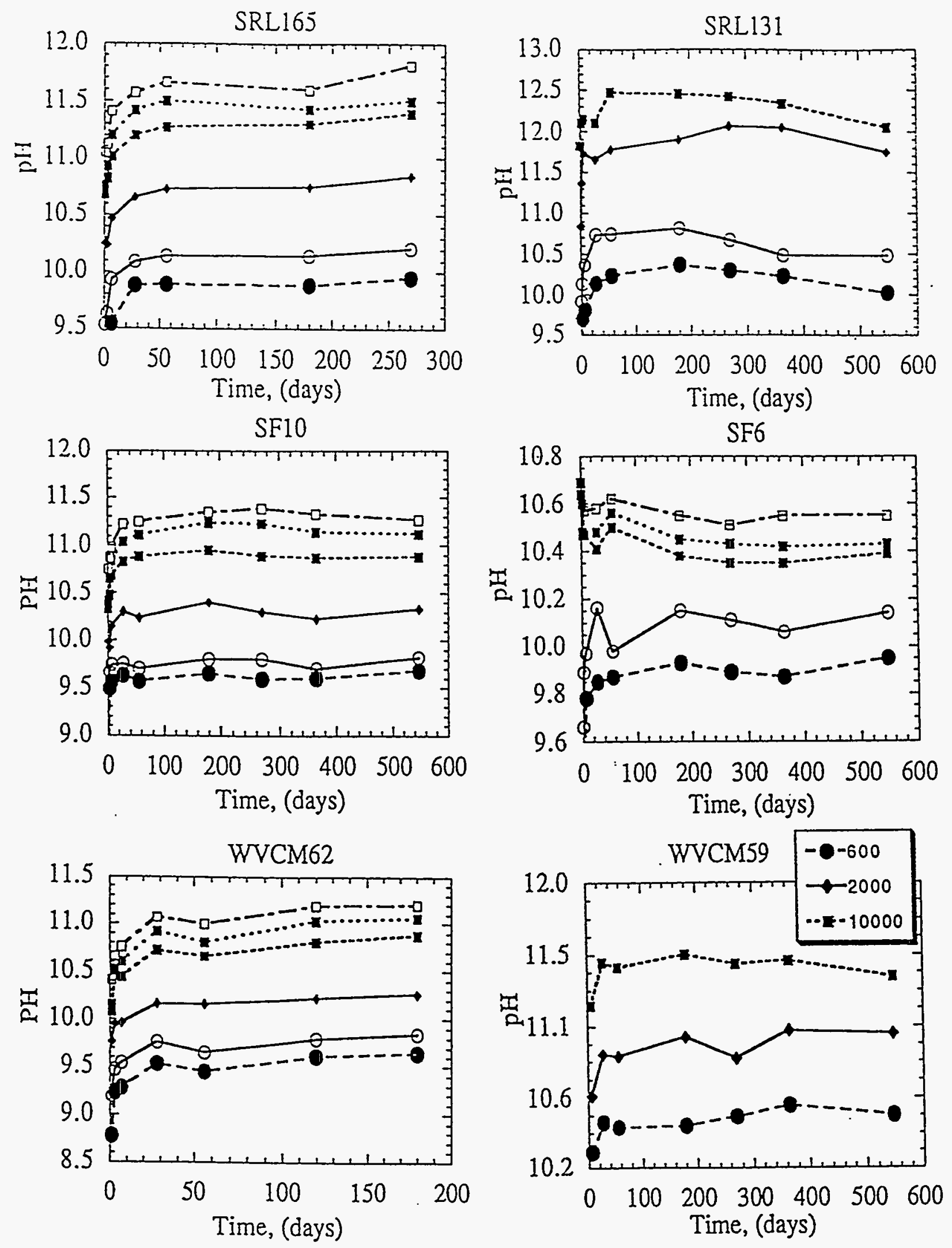

\begin{tabular}{lll|}
$-0-20$ & $\rightarrow-2000$ & $\cdots \cdot 20000$ \\
$-0-200$ & $\cdots \cdot 10000$ & $-\square-40000$ \\
\hline
\end{tabular}

Feng et al. J. Non-Cryst. Solids, (1994) 


\section{Ion Exchange}

\section{$\equiv \mathrm{SiO}-\mathrm{M}+\mathrm{H}_{2} \mathrm{O} \leftrightarrow \mathrm{SiO}-\mathrm{H}+\mathrm{M}^{+}+\mathrm{OH}^{-}$}

$$
\begin{gathered}
\mathrm{K}_{\mathrm{M}}=\frac{[\equiv \mathrm{SiO}-\mathrm{H}]\left[\mathrm{M}^{+}\right]\left[\mathrm{OH}^{-}\right]}{[\equiv \mathrm{SiO}-\mathrm{H}]\left[\mathrm{H}_{2} \mathrm{O}\right]} \\
\frac{\mathrm{d}}{\mathrm{dt}}\left[\mathrm{OH}^{-}\right]=\frac{\mathrm{SA}}{\mathrm{V}} \mathrm{K}_{\mathrm{M}}\left[\mathrm{H}_{2} \mathrm{O}\right]\left(1-\frac{\left[\mathrm{M}^{+}\right]\left[\mathrm{OH}^{-}\right]}{\mathrm{K}_{\mathrm{M}}}\right)
\end{gathered}
$$




\section{Isotope Effects Summary $\left(\mathrm{H}_{2} \mathrm{O} / \mathrm{D}_{2} \mathrm{O}\right)$}

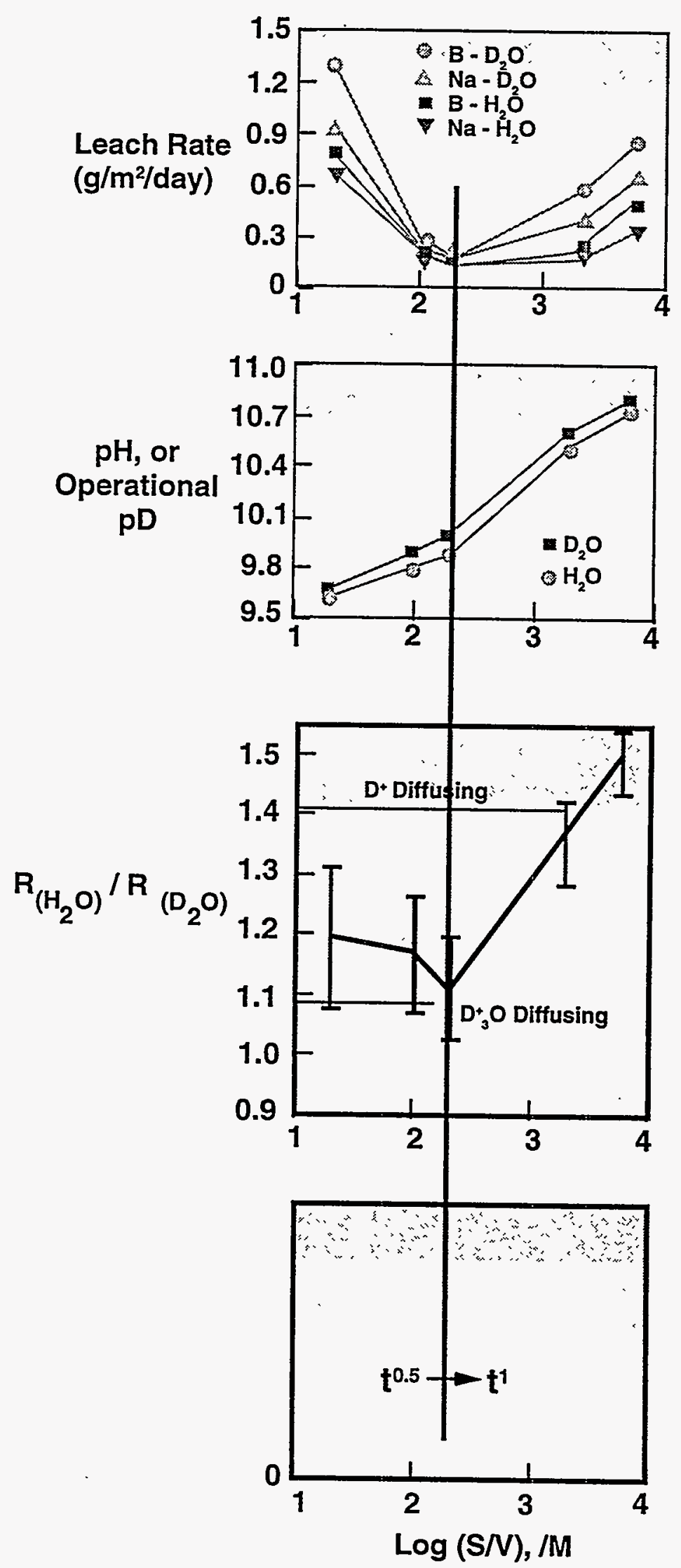

When SA/V Changes:

Rate

Changes

$\mathrm{pH}$

Changes

Isotope

Effect

Changes

Solution

Kinetics

Changes

Mechanism Transition: $t^{0.5} \rightarrow t^{1}$

Feng et al., MRS Proc. 1991 


\section{Mechanistic Investigation pH Effects on Mechanisms}

- In $\mathrm{pH}=\mathbf{8 . 5}$ buffers

- Solution kinetics

$\mathrm{S} / \mathrm{V}=200 / \mathrm{m} \rightarrow \mathrm{t}^{0.5}$

$\mathrm{S} / \mathrm{V}=2000 / \mathrm{m} \rightarrow \mathrm{t}^{0.5}$

- Isotope effects, support diffusion

$\mathrm{S} / \mathrm{V}=200 / \mathrm{m} \rightarrow 1.1^{*}$

$\mathrm{S} / \mathrm{V}=2000 / \mathrm{m} \rightarrow 1.1^{*}$

- In $\mathrm{pH}=10.0$ buffers

- Solution kinetics

$$
\begin{aligned}
& S / V=200 / m \rightarrow t^{1} \\
& S / V=2000 / m \rightarrow t^{1}
\end{aligned}
$$

- Isotope effects, matrix dissolution

$\mathrm{S} / \mathrm{V}=200 / \mathrm{m}>>1.1^{*}$

$\mathrm{S} / \mathrm{V}=2000 / \mathrm{m}>>1.1^{*}$

Feng et al., Nucl. Waste Mgmt. (1991) 


\section{Isotope Effects Summary $\left(\mathrm{H}_{2} \mathrm{O} / \mathrm{D}_{2} \mathrm{O}\right)$}

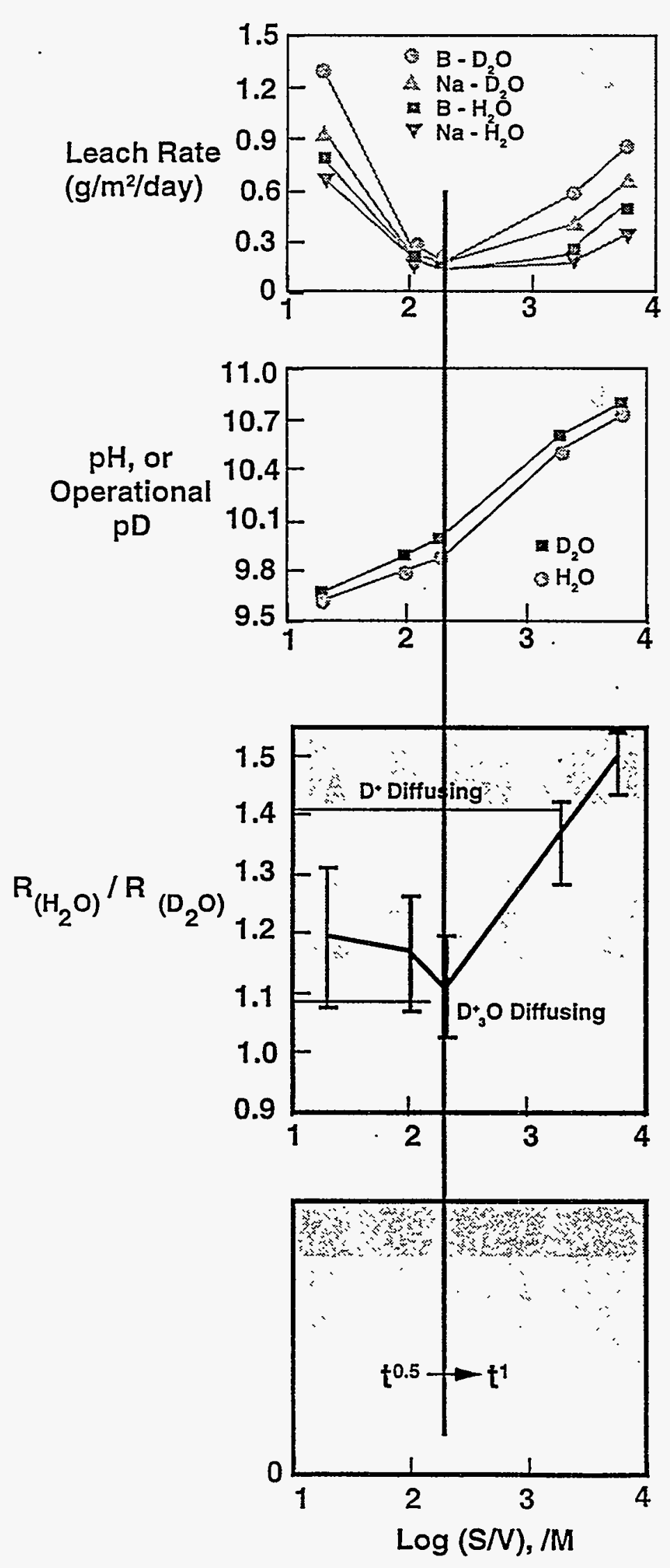

When SAIV Changes:

Rate

Changes

$\mathrm{pH}$

Changes

Isotope

Effect

Changes

Solution

Kinetics

Changes

Mechanism Transition: $t^{0.5} \rightarrow \mathrm{t}^{1}$

Feng et al., MRS Proc. 1991 


\section{The Nature of S/V Effect}

- It is the combination of $\mathrm{pH}$ and concentration effect

- $\mathrm{pH}$

- Determines controlling glass RXN mechanism

- Dominates glass RXN rates

- Influences identities of alteration phases

- Dominates thickness of alteration layers

- Concentration

- Contributes to glass $\mathrm{RXN}$ rates

- Determines when secondary phases form (if nucleation is not hindered)

- Controls amount of secondary phases formed

- Affects thickness of alteration layer

- $\mathrm{pH}$ is a more dominant factor in glass RXN 


\section{Summary of S/V Effects}

- $\mathrm{S} / \mathrm{V}$ is a very important parameter in glass reaction

- Understanding S/V effect is the key to proper modeling

- The S/V induces pH change and mechanism change need to be incorporated into the existing modeling effects

Feng et al. Acers Meeting (1992) 


\section{Leachant Composition Effects on Glass Durability}

- lonic strength

- Feng et al., Phys. Chem. Glasses, (1994)

- Inorganic/organic

- Feng et al., MRS Proc. (1986)

- Individual cations

- Feng et al., Proc. Intern. SEE (1992)

- Feng, UMI (1988)

- $\mathrm{pH}$

- Feng et al., Nucl. Waste Mgmt. (1991)

- Presence of metals

- Feng, Waste Mgmt. (1994) 


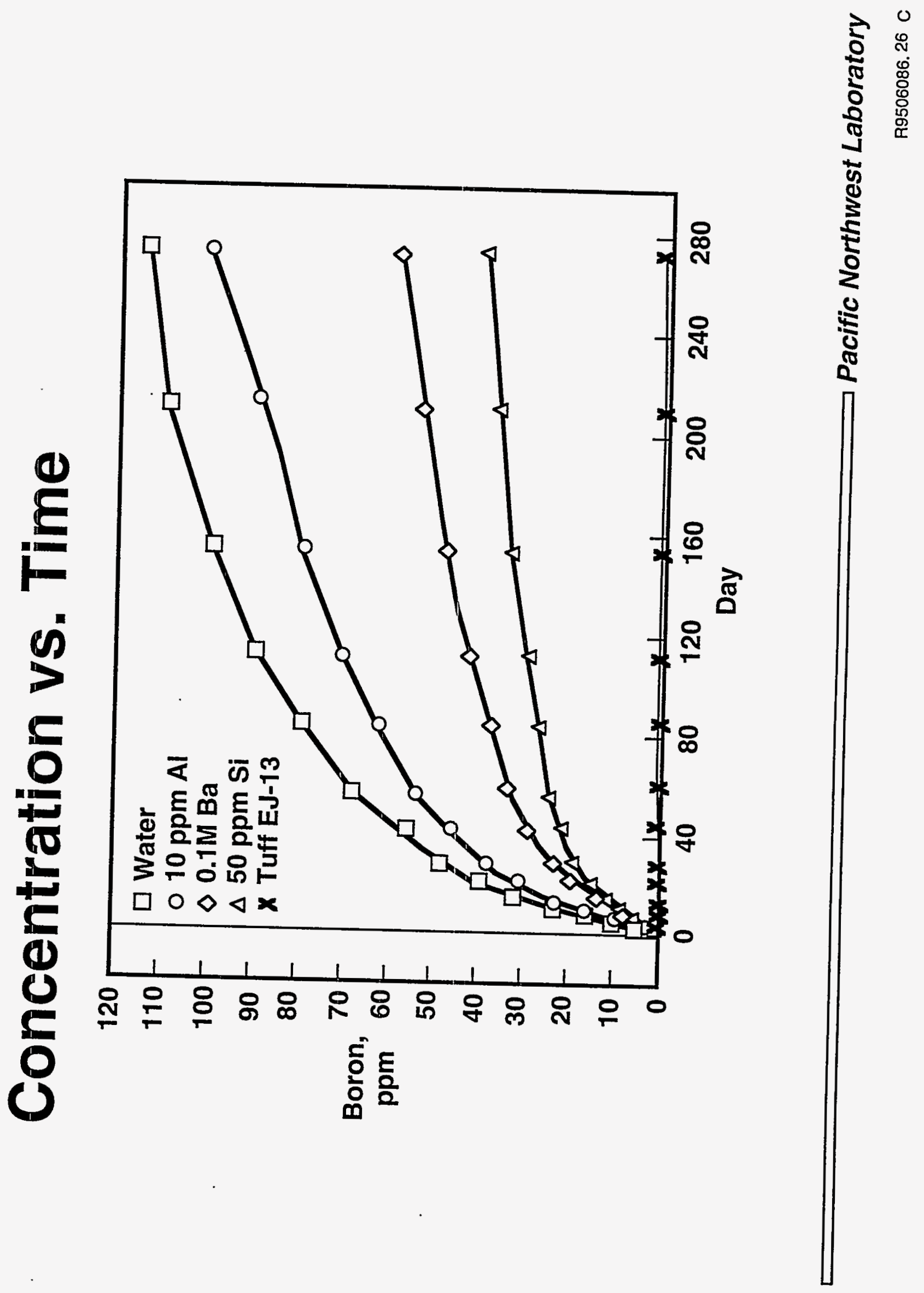




\section{Ion Exchange}

(A) Destructive exchange:

(B) Non-destructive exchange:"

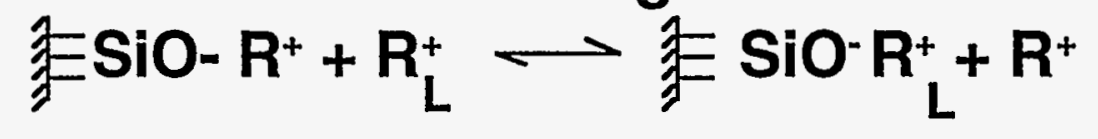

- Salt suppresses Case A

- Facilitates competing reaction in Case B

- $\longrightarrow$ Reduces glass leaching

- Lower pH

- Expect:

- Small effect for non-exchangeable $R_{L}^{+}$

- Dependence on mobility of $R_{L}^{+}$ 


\section{Cation Effects}

Relative Mobility of Cations

\begin{tabular}{lcccc} 
& $\mathrm{Li}$ & $\mathrm{Na}$ & $\mathrm{K}$ & $\mathrm{Cs}$ \\
\cline { 2 - 5 } $\begin{array}{l}\text { Crystal Radii }(\AA) \\
0.86\end{array}$ & 1.12 & 1.44 & 1.84 \\
\cline { 2 - 5 } $\begin{array}{l}\text { Hydrated Radii }(\AA) \\
\begin{array}{l}\text { Relative Mobility } \\
\text { in Water }\end{array}\end{array}$ & 33.5 & 43.5 & 64.6 & 68.0 \\
\cline { 2 - 5 }
\end{tabular}




\section{Summary of Solution Composition Effects}

- lonic strength (salt effects)

- Salt reduces corrosion rate

- Due to kinetic ion exchange

- Not thermodynamic ionic strength effects

Feng et al., Phys. Chem. Glasses (1994)

- Inorganic/organic buffers at the same pH

- L.R. in inorganic > that in organic due to hydrophobic coating on and complexing with glass surfaces

Feng et al., MRS Proc. 1986 


\section{Summary of Solution Composition Effects (cont.)}

- Individual cations

- Corrosiveness of solutions:

$-\mathrm{Li}^{+}>\mathrm{Na}^{+}>\mathrm{K}^{+}>\mathrm{Cs}^{+}$

- Due to differences in mobility and size, which affect ion exchange reactions

Feng et al., Proc. Intern. SEE 1992

- Silicate or aluminate water

- Reduce corrosion by reducing reaction affinity

Feng Waste Mgmt. 1994

- $\mathrm{pH}$

- Affect corrosion mechanism and secondary phase formation

Feng et al., Nucl. Waste Mgmt. 1991 


\section{Summary of Solution Composition Effects (cont.)}

- EJ-13 groundwater

- Lowest leach rate under dynamic test condition

- Due to compounding effects of salt, alumina and silica, and buffering capability

Feng et al., MRS Proc. 1986

- Presence of metals

- Fe enhances corrosion

- Due to formation of Fe(II)-silicates in solution, that affects reaction affinity

Feng, UMI 1988

Feng, Waste Mgmt. 1994 

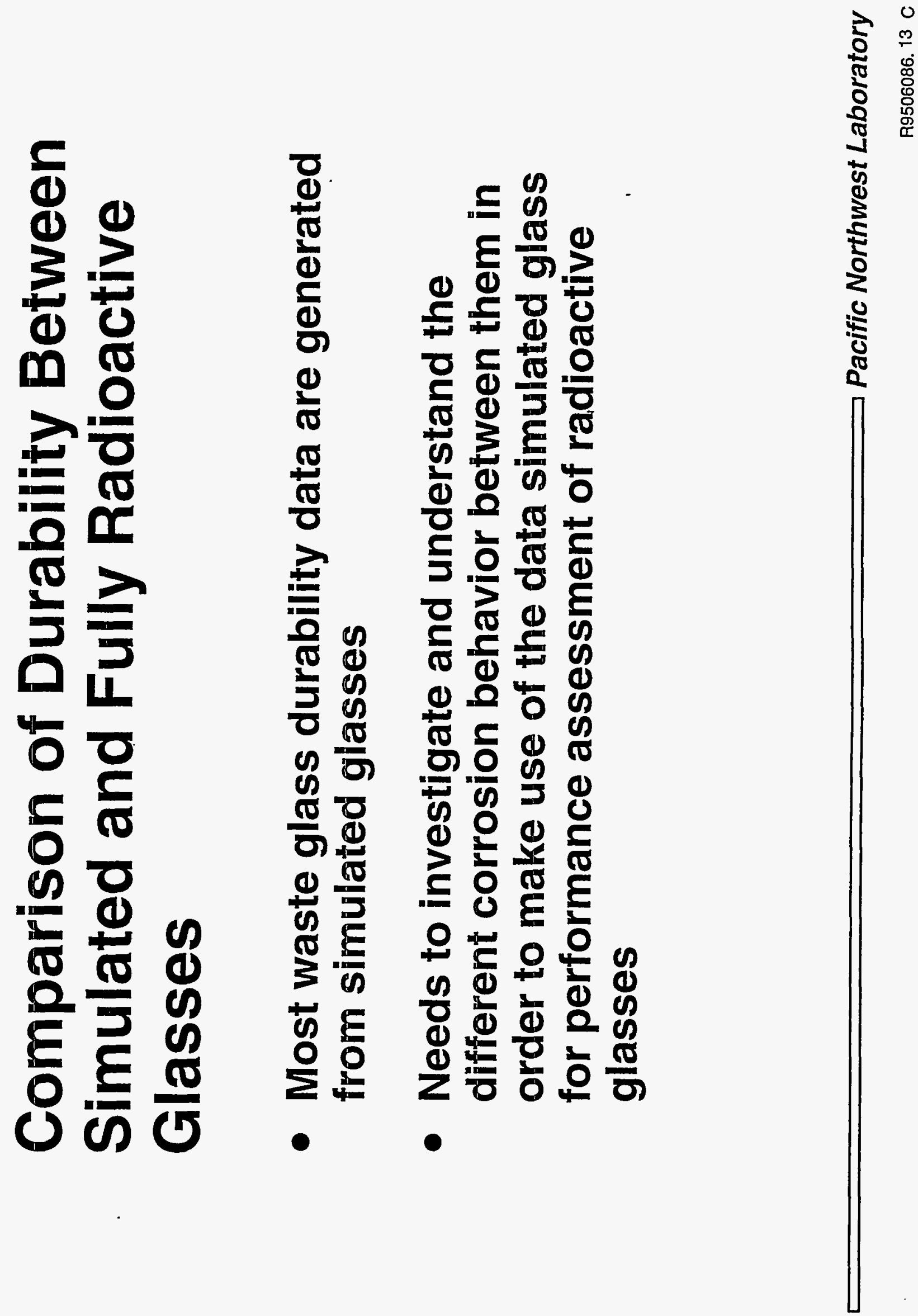
SRL 165/42 glasses were tested at $2000 \mathrm{~m}^{-1}$. R- and S-glasses show similar corrosion behavior
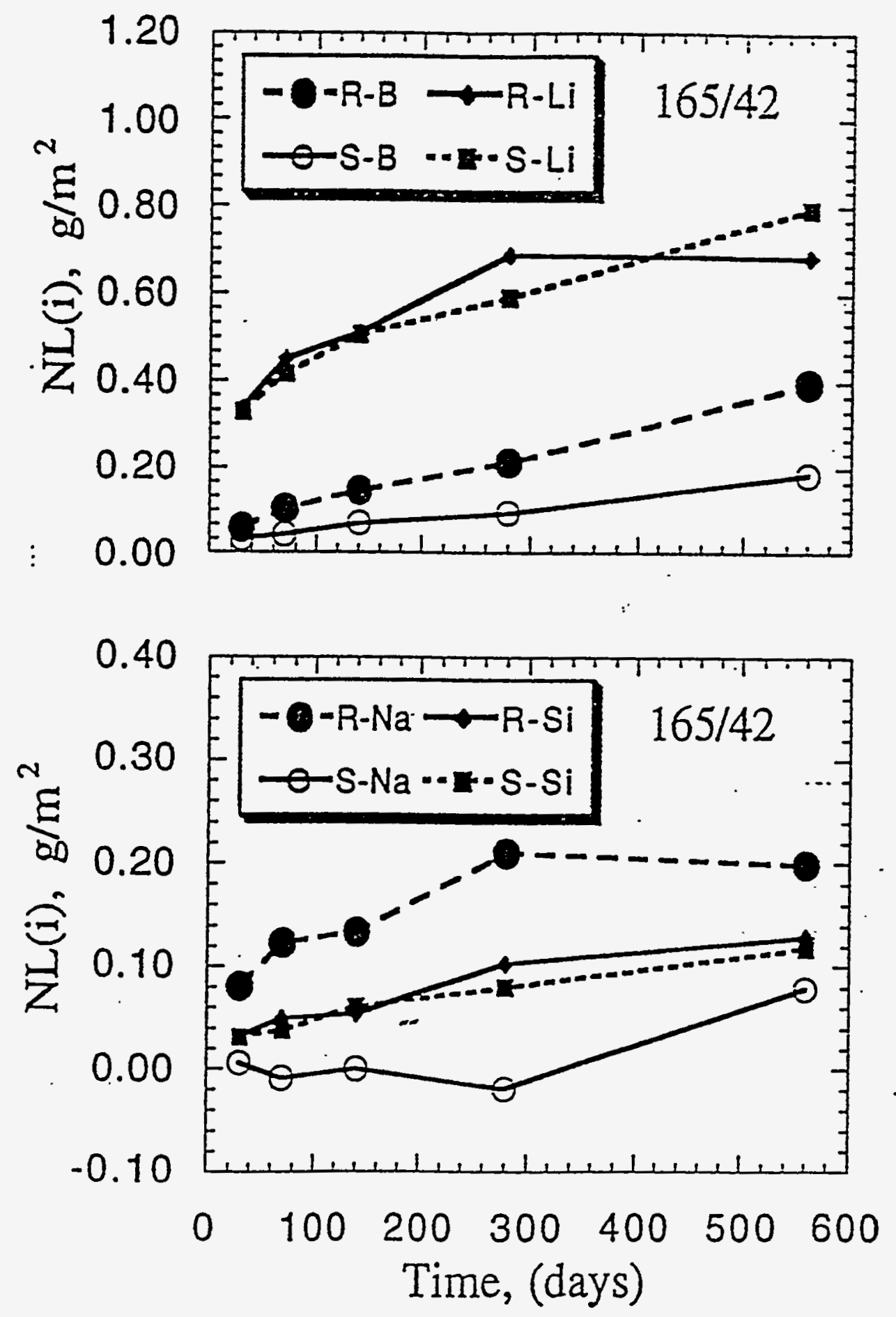
SRL 200 glasses were tested at $2000 \mathrm{~m}^{-1}$ and similar corrosion behavior was observed
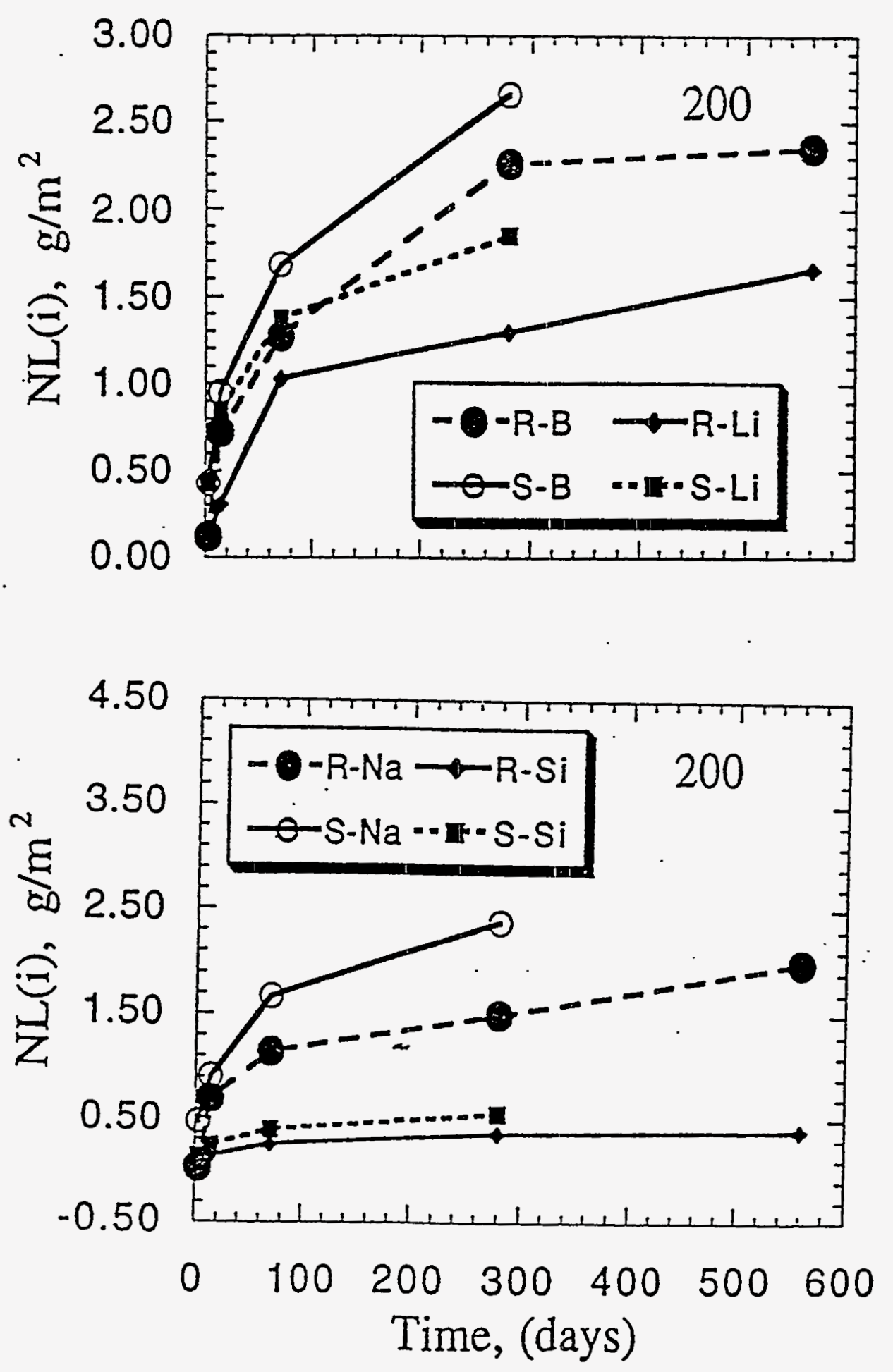
A large difference in corrosion behavior was observed for SRL 200R and SRL 200S glasses when these glasses were tested at $20,000 \mathrm{~m}^{-1}$ for one year or longer
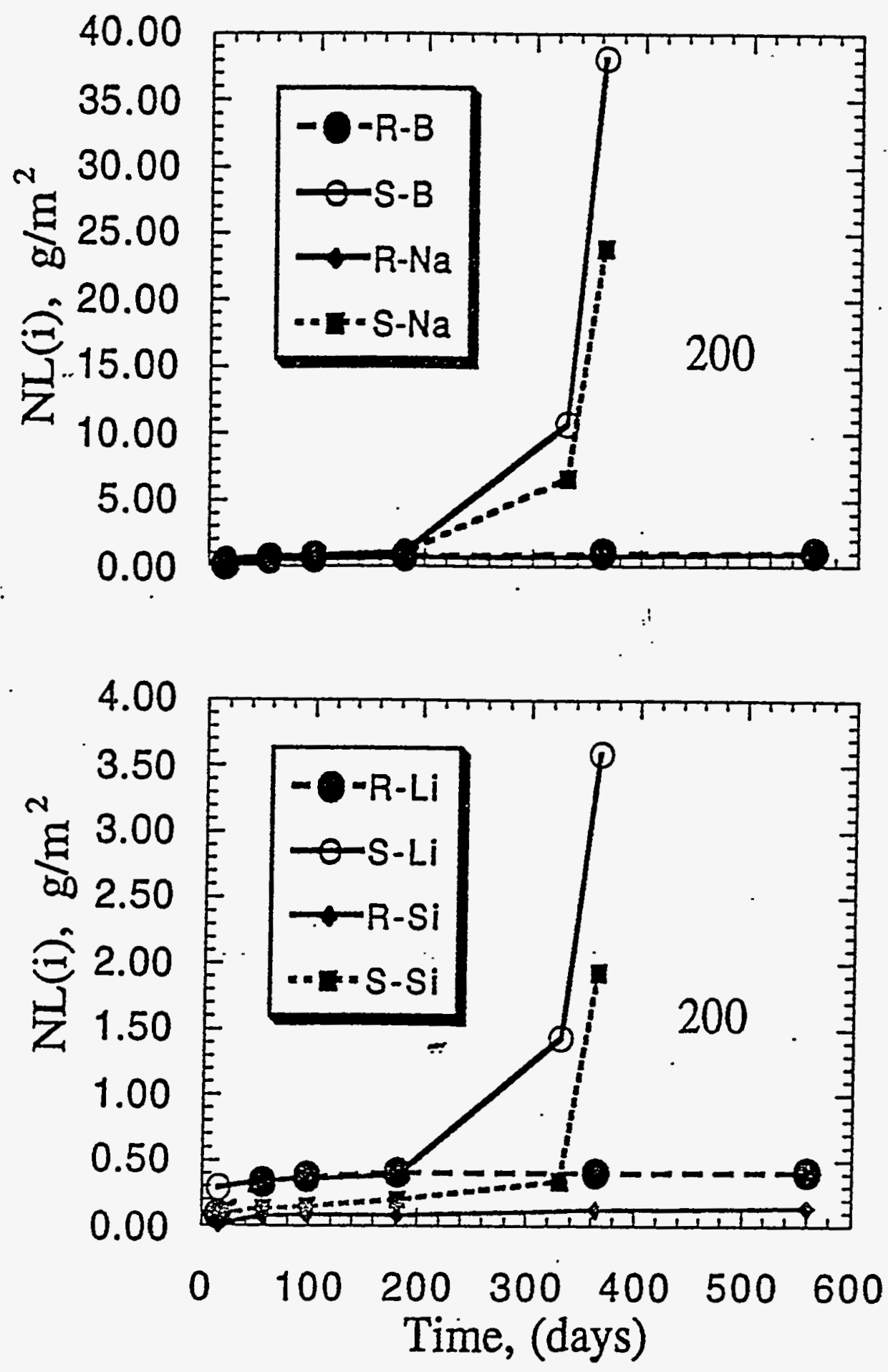


\section{0 at $20,000 \mathrm{~m}^{-1}$}

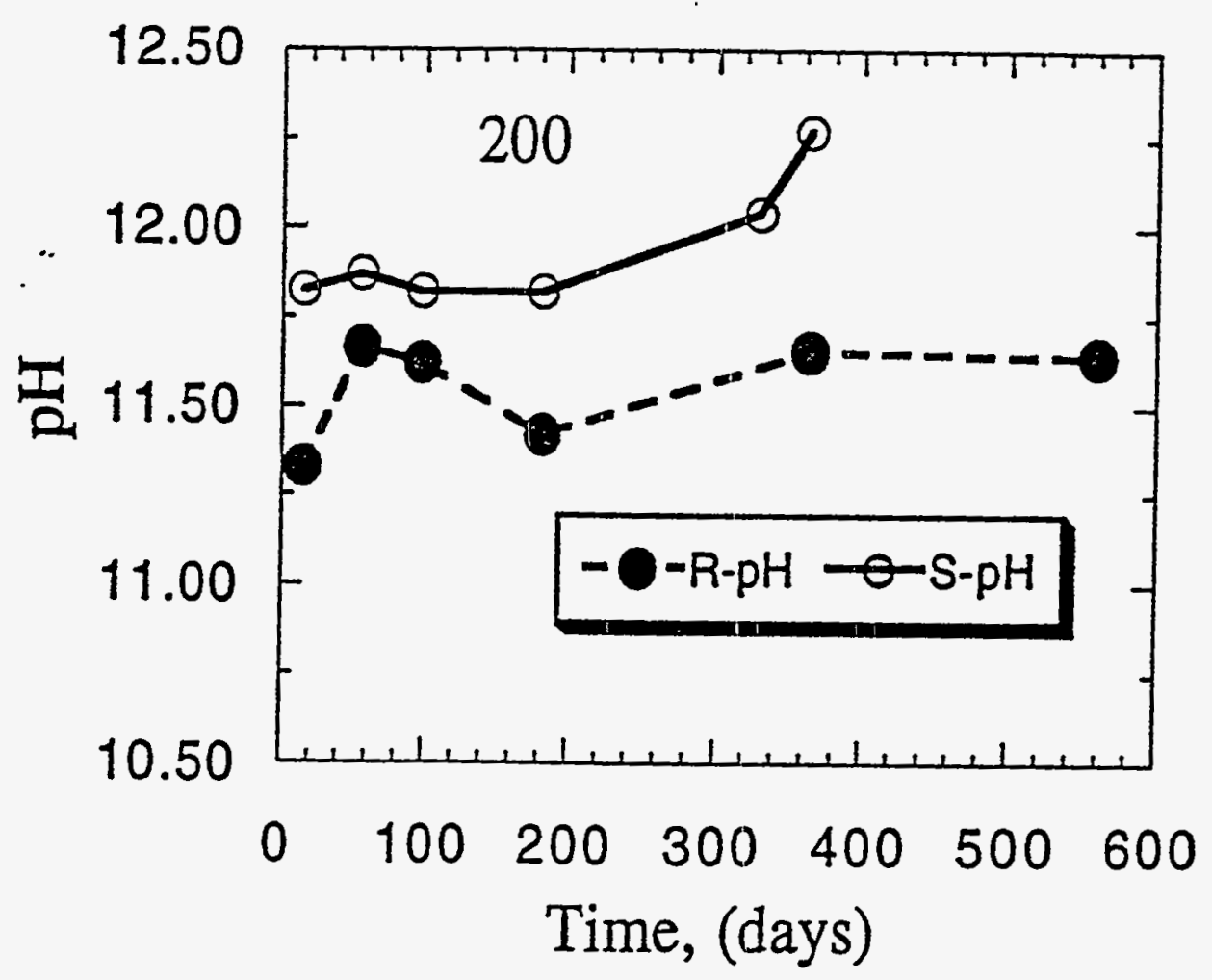




\section{SURFACE LAYER THICKNESS (200S at $20,000 \mathrm{~m}^{-1}$ )}

98 day

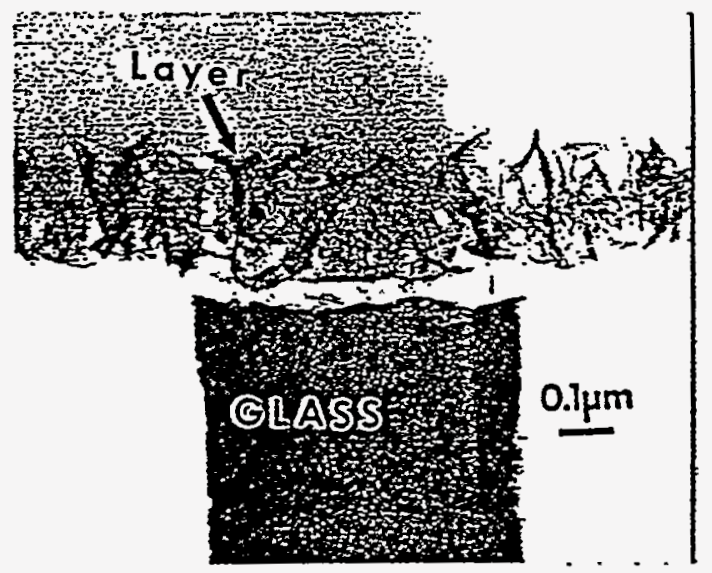

182 day

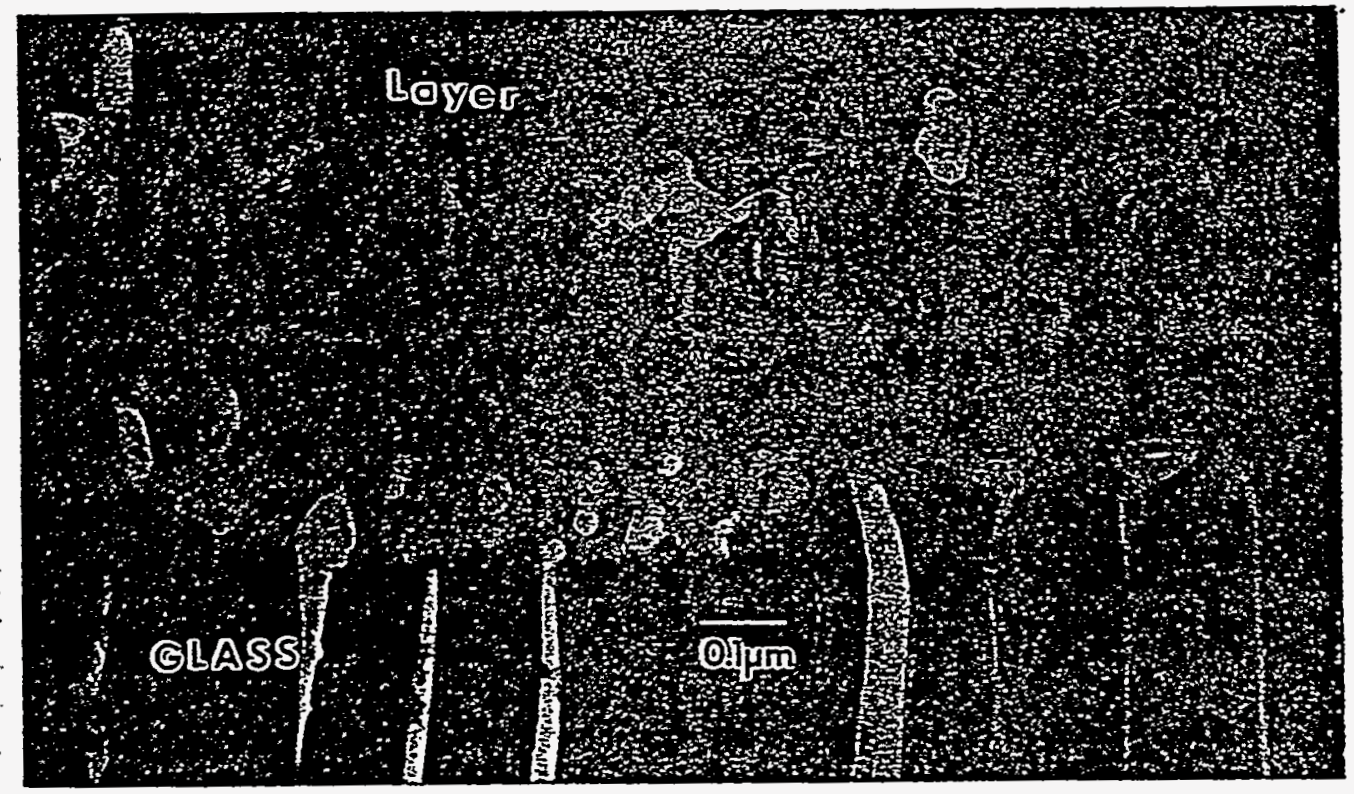




\section{SURFACE LAYER THICKNESS (200s at $20,000 \mathrm{~m}^{-1}$ )}

364 DAYS

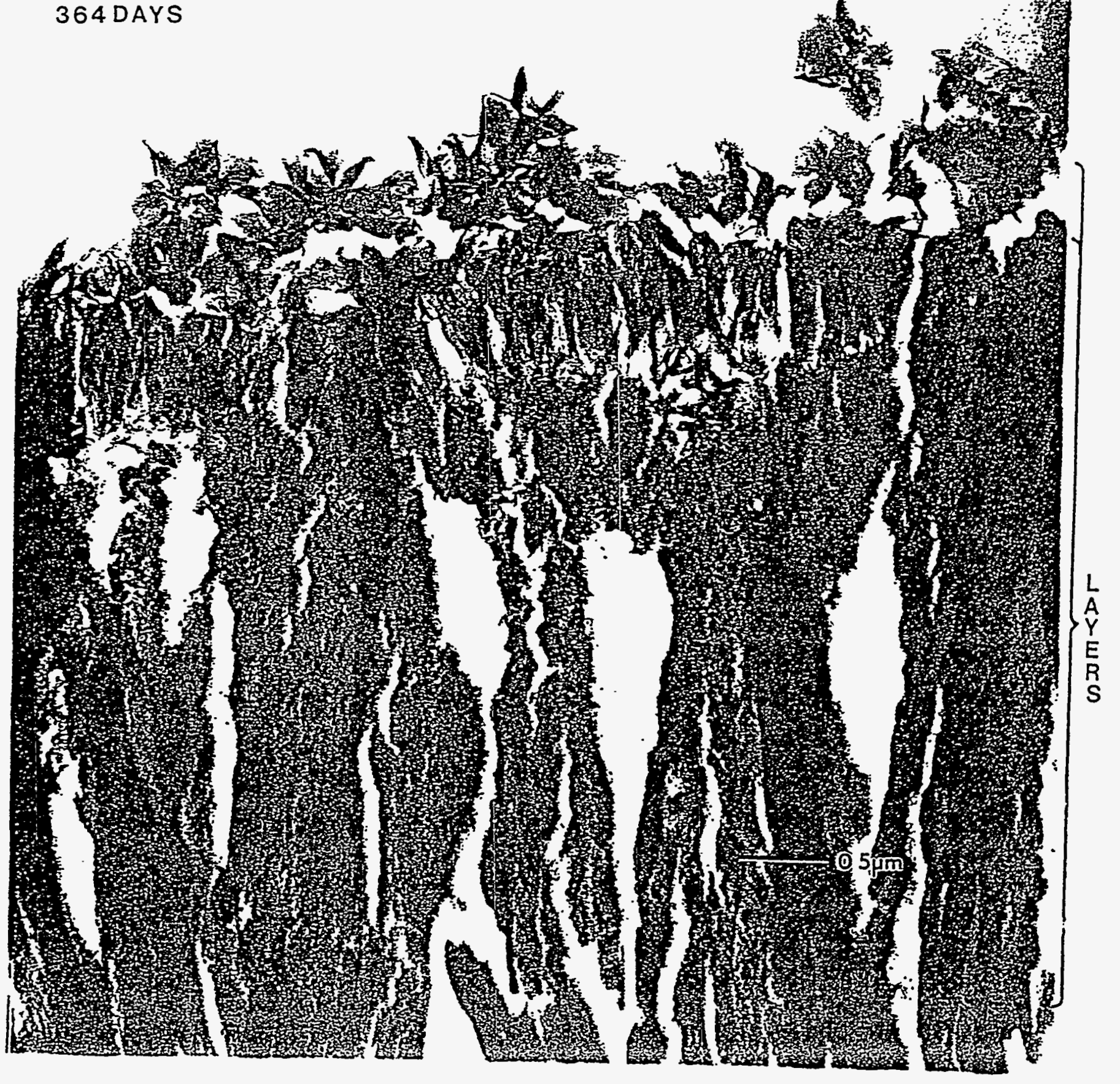




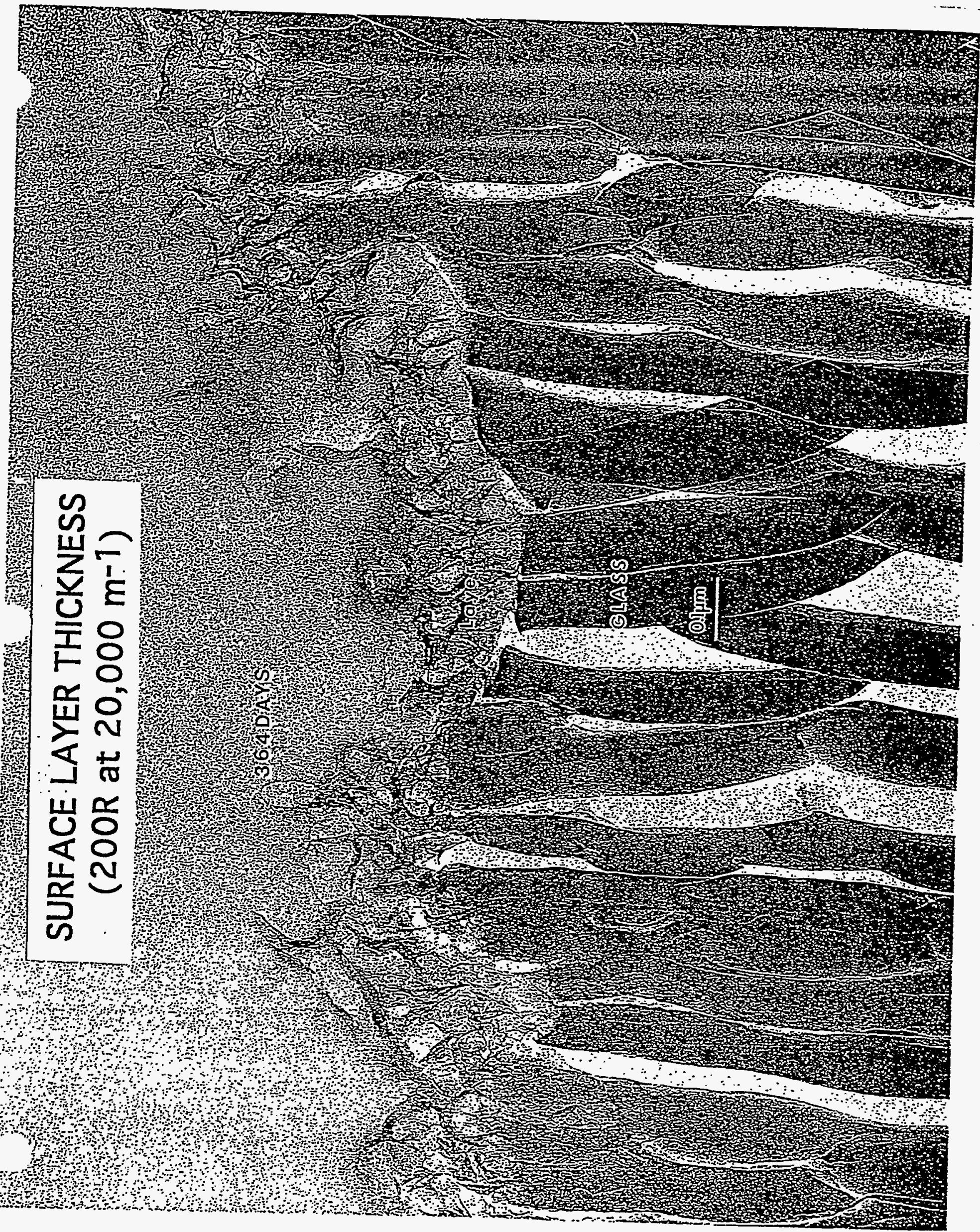




\section{SECONDARY PHASE FORMATION (200S at $20,000 \mathrm{~m}^{-1}$ )}

98 day

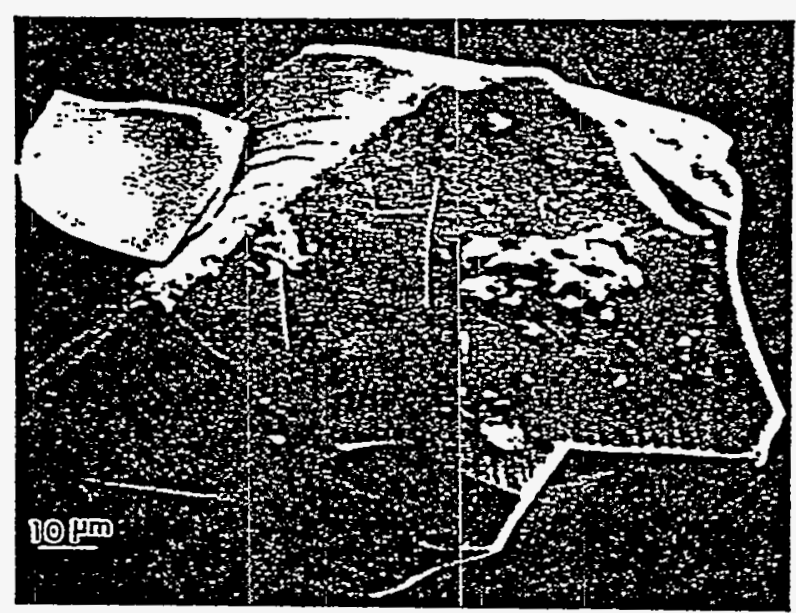

182 day

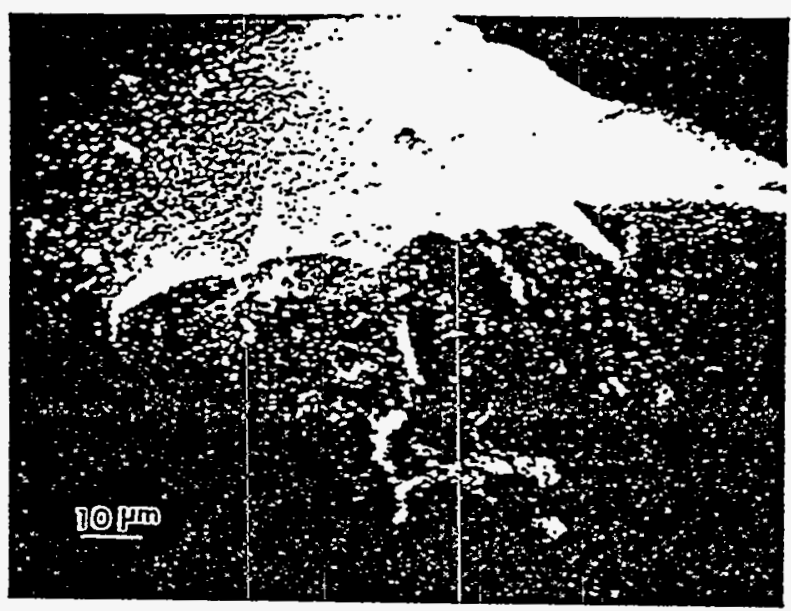

364 day

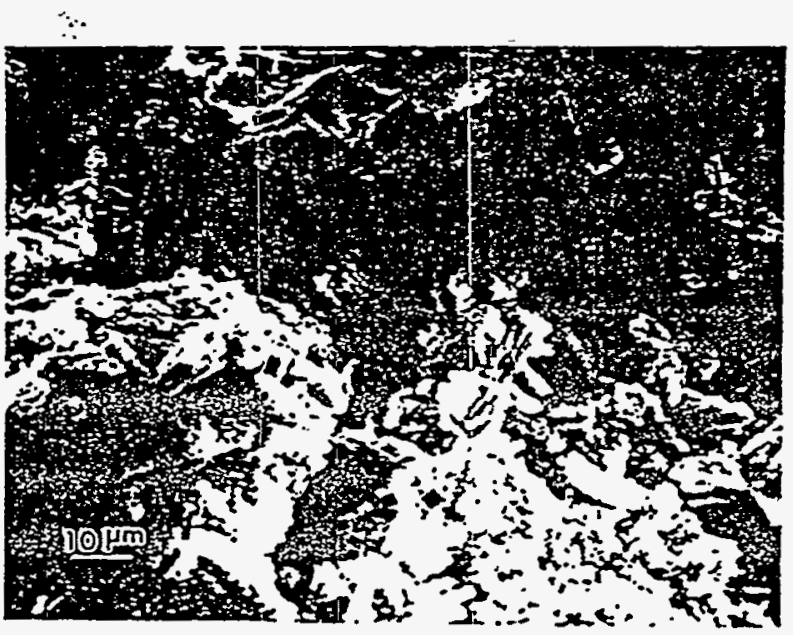



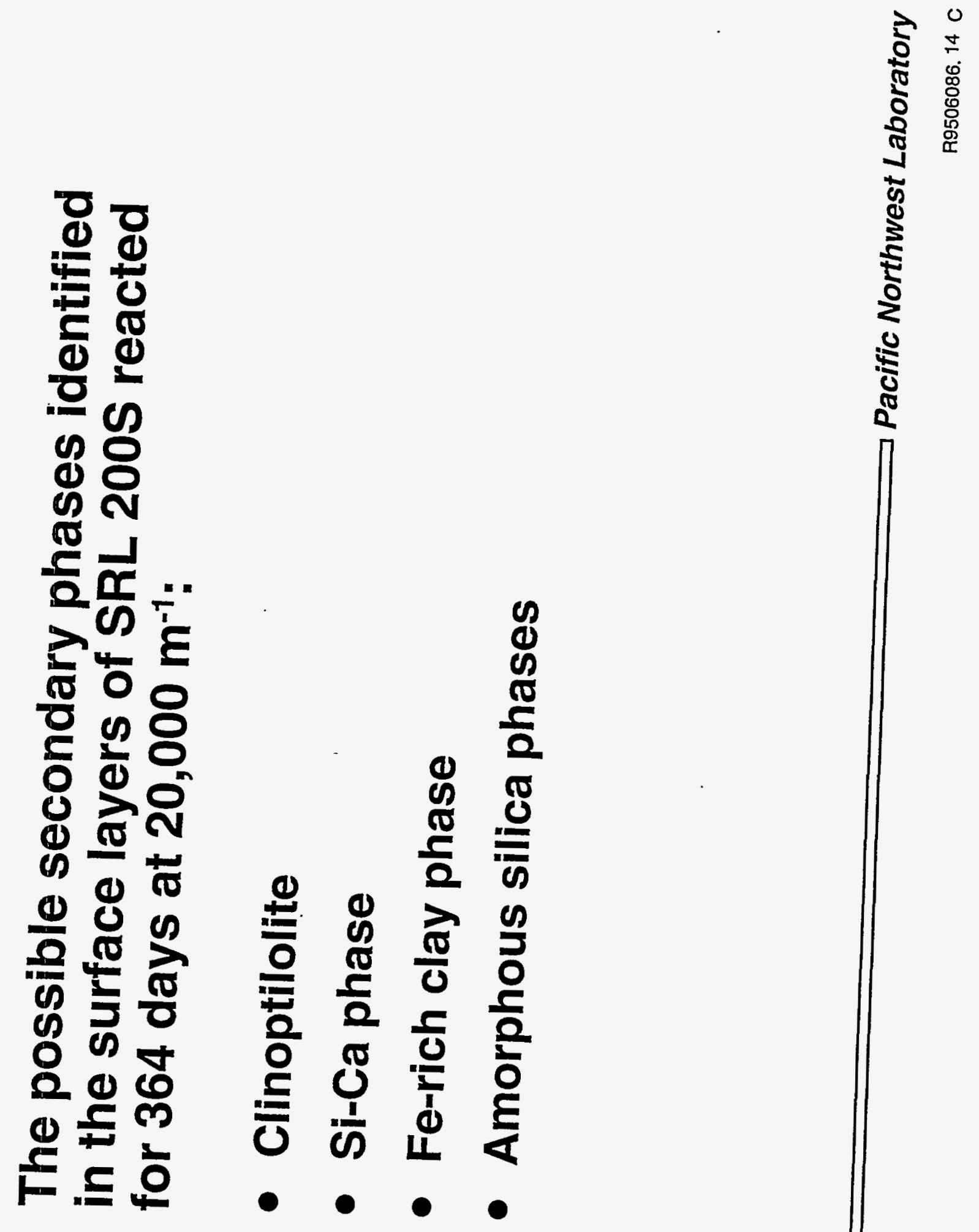


\section{Possible Explanations}

- Radiation-induced lowering of pH of R-glass leachate prevents accelerated glass reaction in R-glass

- Extensive secondary phase formation in tests with S-glass increased the reaction affinity and resulted in increased glass reaction rate 


\section{Implications}

- Utilization of S-glass corrosion data for modeling fully radioactive waste glasses requires caution

- Radiation effects (such as the effects on leachate $\mathrm{pH}$ ) have to be incorporated in the long-term modeling

- A meaningful comparison study between R- and S-glasses should include tests at both high- and lowSA/V's and for long-term

- Long-term testing of fully radioactive glasses is a MUST for performance assessment of nuclear waste glasses 


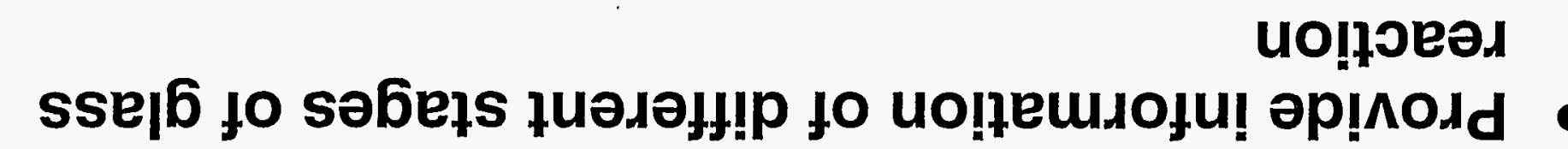
uolfe.np łsoł de|!u!̣ 6u!nnp

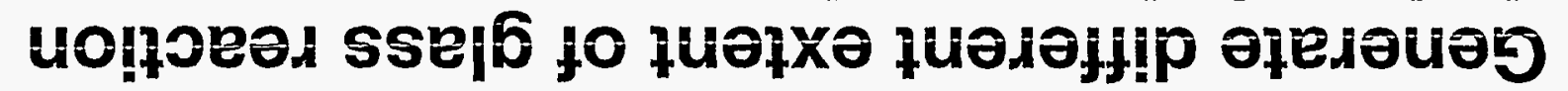

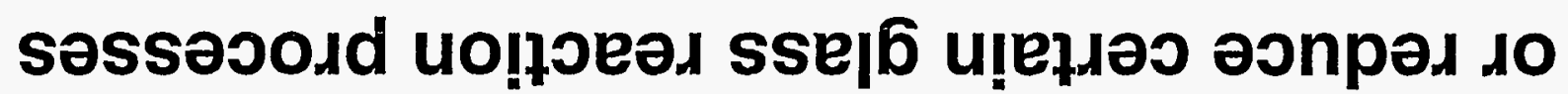

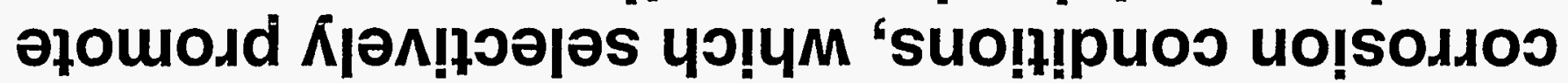

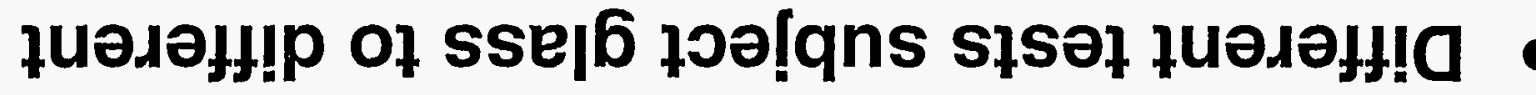

\author{
Kł!I!qe.dng ssejפ \\ to UO!ןen|en
}




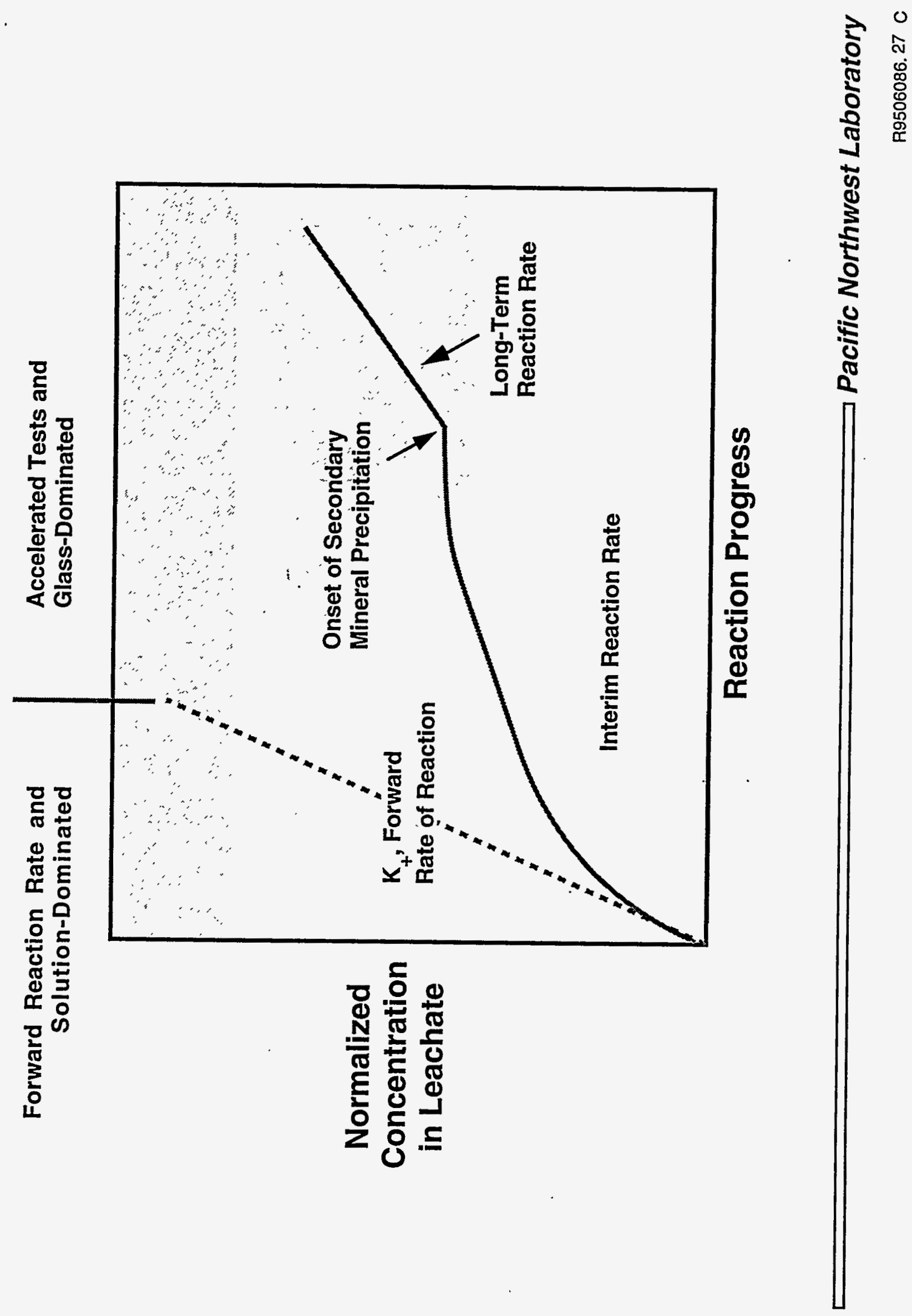




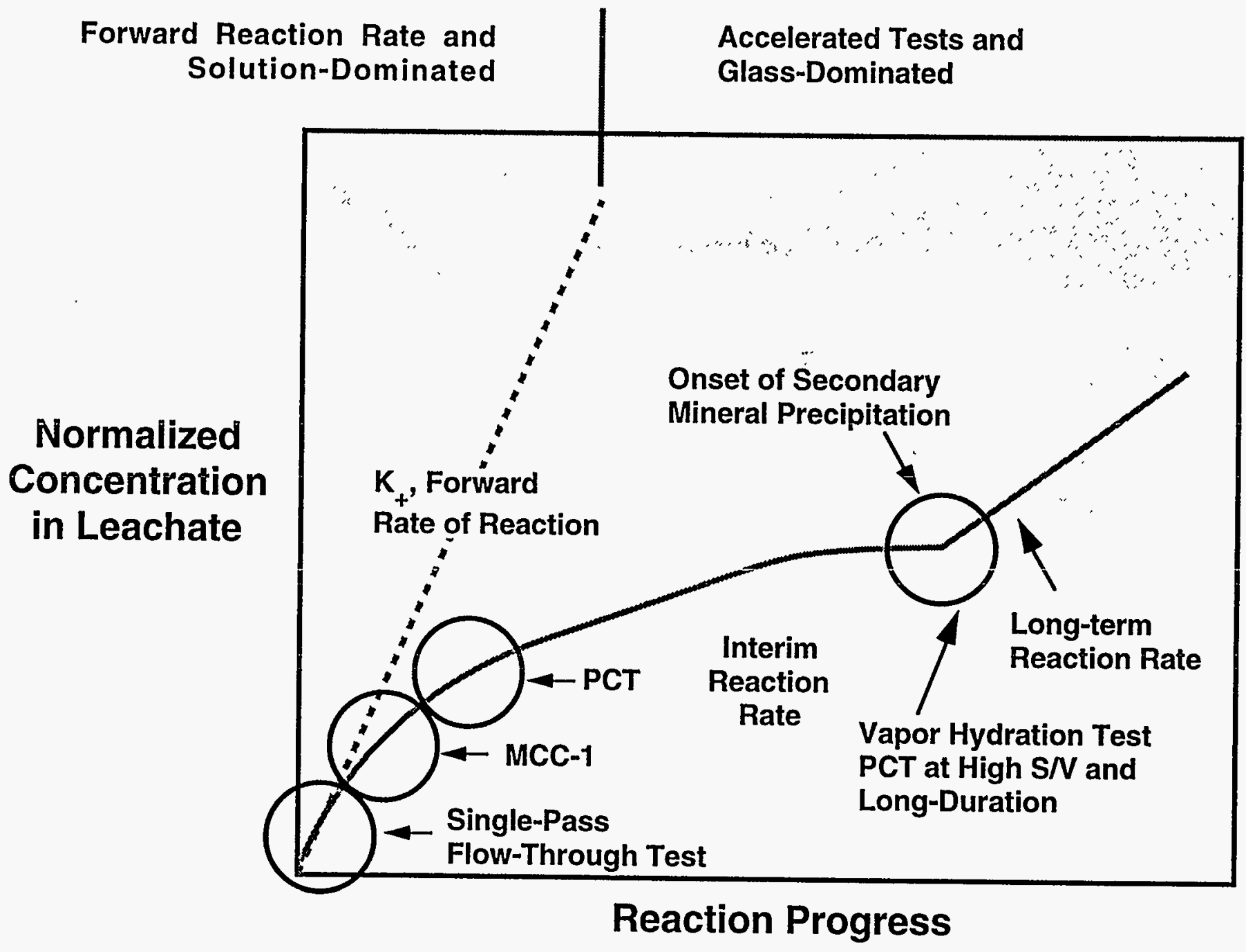

Pacific Northwest Laboratory 


\section{Single-Pass Flow-Through Test (SPFT) Product Consistency Test (PCT) Vapor Hydration Test (VHT)}

\begin{tabular}{|c|c|c|c|c|c|}
\hline Temp. ${ }^{\circ} \mathrm{C}$ & Leachant & $\mathrm{S} / \mathrm{V}$ & Glass Samples & Flow Rate & pH \\
\hline SPFT $20-90^{\circ} \mathrm{C}$ & variable & variable & $\begin{array}{l}\text { monolith } \\
\text { or powders }\end{array}$ & variable & constant \\
\hline РCT 20-200 & $\begin{array}{l}\text { deionized } \\
\text { water }\end{array}$ & variable & powders & static & changing \\
\hline VHT up to 300 & $\begin{array}{l}\text { adsorbed } \\
\text { water vapor }\end{array}$ & $\begin{array}{l}\text { much higher } \\
\text { than } 2000 / m\end{array}$ & $\begin{array}{l}\text { monolith } \\
\text { usually }\end{array}$ & static & changing \\
\hline
\end{tabular}


Cpmparison of Durability Using PCT (90C) VS. Single-Pass Flow Through Test (SPFT) (at 90C and $\mathrm{pH}=12.0$ )
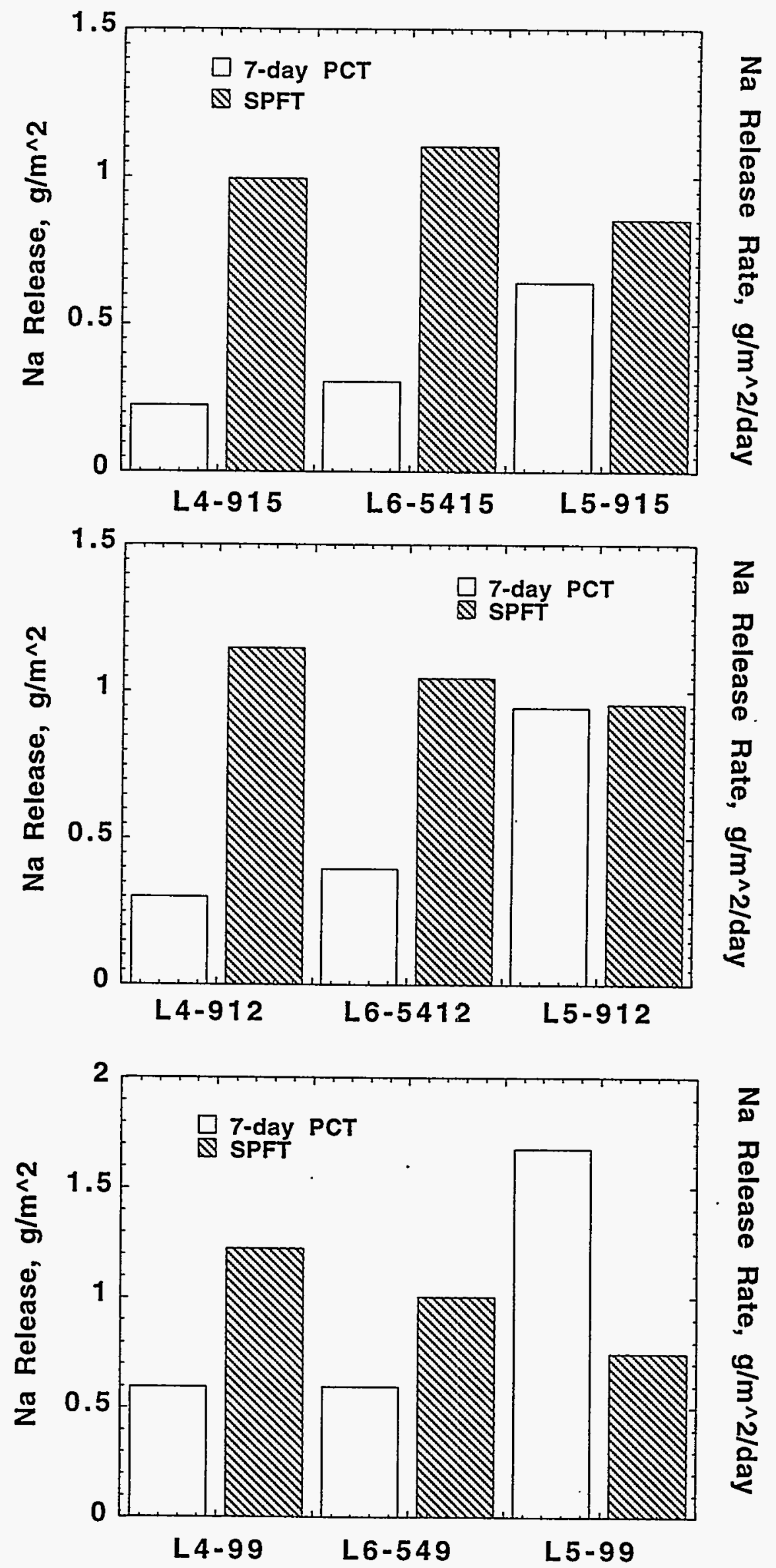
Cpmparison of Durability Using PCT (90C) VS. Single-Pass Flow Through Test (SPFT) (at 90C and $\mathrm{pH}=12.0$ )
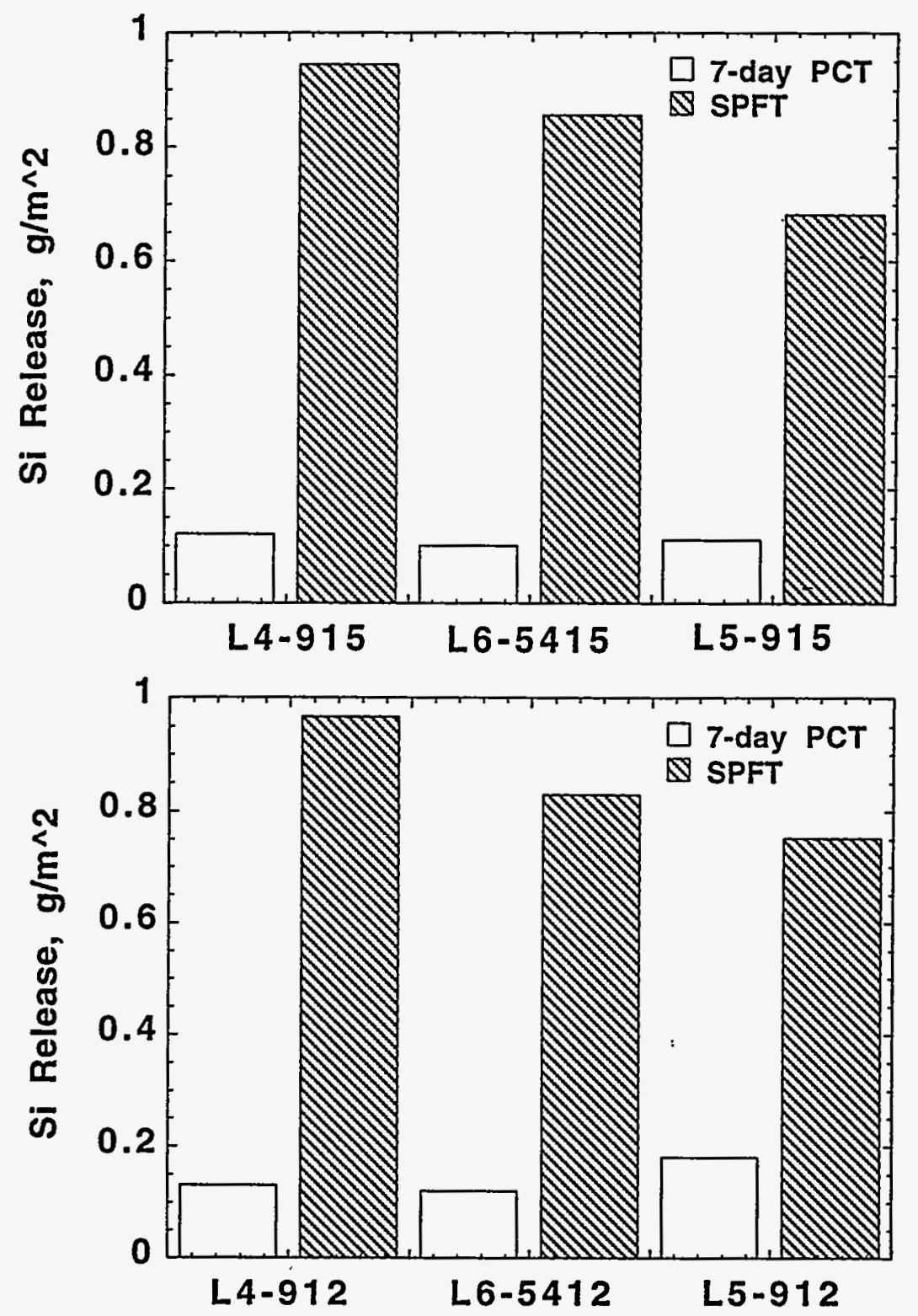

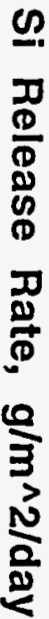

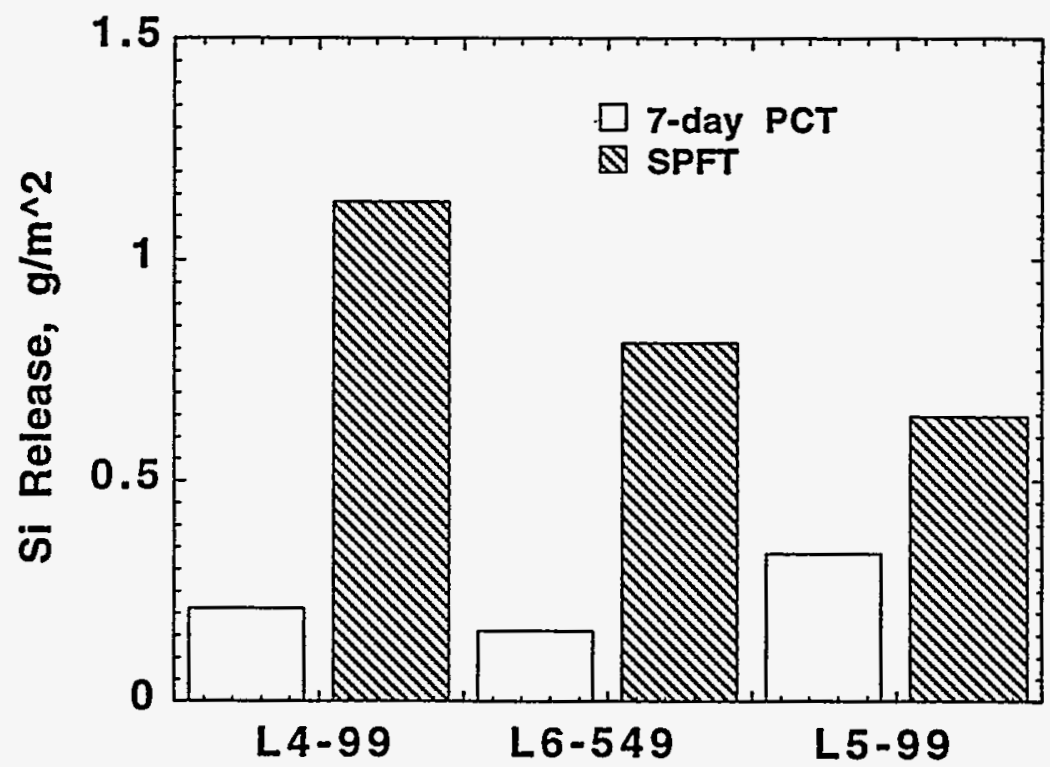

$\omega$

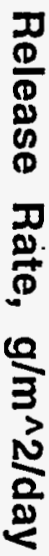




\section{Durability Order Measured with PCT and SPFT:}

- On Glass Systems

- L4 - Boron only glasses

- L5 - Calcium only glasses

- L6 - Mixture of boron and calcium

- In PCT $\left(90^{\circ} \mathrm{C}\right)$

- L4 > L6 > L5

- In SPFT $\left(90^{\circ} \mathrm{C}, \mathrm{pH}=12\right)$

- L5 > L6 > L4 


\section{PCT Durability Order: \\ B-Glass > $(\mathrm{B}+\mathrm{Ca})$ - Glass $>$ Ca-Glass}

- Understandable based on glass structure

- $\mathrm{B}_{2} \mathrm{O}_{3}$ replaces $\mathrm{NBO}$ bonds with $\mathrm{BO}$

- CaO replaces NBO with hybrid of $\mathrm{BO}+\mathrm{NBO}$

- More durability improvement is expected for $\mathrm{B}_{2} \mathrm{O}_{3}$ than for $\mathrm{CaO}$

- Boron containing glasses releases boron that buffers leachate $\mathrm{pH}$ in static test. Lower $\mathrm{pH}$ results in lower glass corrosion rate.

- Observation: Boron-only glasses have pH's lower by 1-2 $\mathrm{pH}$ units than the corresponding Ca-only glasses. 


\section{SPFT (at pH12) Durability Order: Ca-Glass $>(\mathrm{B}+\mathrm{Ca})$-Glass $>$ Ca-Glass}

- Difficult to understand based on glass structure

- Understandable based on solution chemistry:

- Ca-compound, such as $\mathrm{Ca}(\mathrm{OH})_{2}$ have low solubilities at pH 12 while boron compound are easily dissolved at $\mathrm{pH} 12$

- Observation: (1) Ca release is very low compared with any other glass components. (2) Possible Ca phases on glass surfaces.

- The boron buffering effects can not be realized in a buffered and flow-through test system 


\section{Vapor Hydration Results}

Durability is measured by the thickness of the alteration layers formed on corroded glasses

\begin{tabular}{|c|c|c|c|c|c|c|}
\hline \multirow[b]{2}{*}{ Glass } & \multicolumn{3}{|c|}{$\begin{array}{l}\text { Alteration Layer } \\
\text { Thickness }(\mu \mathrm{m})\end{array}$} & \multicolumn{3}{|c|}{$\begin{array}{c}\text { Glass Composition } \\
\text { (wt } \%)\end{array}$} \\
\hline & 7 day & 14 day & 28 day & $\mathrm{B}_{2} \mathrm{O}_{3}$ & $\mathrm{CaO}$ & $\mathrm{Al}_{2} \mathrm{O}_{3}$ \\
\hline L4-96 & 0 & 300 & 0 & 9 & 0 & 6 \\
\hline L4-99 & 0 & 0 & 0 & 9 & 0 & 9 \\
\hline L4-612 & 0 & 0 & 300 & 6 & 0 & 12 \\
\hline L4-912 & 0 & 0 & 0 & 9 & 0 & 12 \\
\hline$L 4-1212$ & 0 & 0 & 0 & 12 & 0 & 12 \\
\hline L5-96 & 30 & 100 & 300 & 0 & 9 & 6 \\
\hline L5-912 & 40 & 50 & $>$ & 0 & 9 & 12 \\
\hline L6-546 & 50 & $>$ & $>$ & 5 & 4 & 6 \\
\hline L6-549 & 300 & $>$ & $>$ & 5 & 4 & 9 \\
\hline L6-5412 & 0 & 400 & $>$ & 5 & 4 & 12 \\
\hline L6-5412 & 0 & 200 & $>$ & 5 & 4 & 12 \\
\hline
\end{tabular}

$>$ Completely altered

Durability order: $\mathrm{L} 4>\mathrm{L} 5 \approx \mathrm{L} 6$ i.e., Boron Only $>\mathrm{Ca}$-only $\approx(\mathrm{Ca}+\mathrm{B})$

This order is similar to PCT results and can be understood based on glass structure and pH effect of boron. 


\section{Summary of Effects of Test Methods}

- PCT and VHT results are easy to understand based on glass structure

- SPFT (at pH 12) results are understandable based on solution chemistry

- PCT results are similar to VHT results, which is relevant to long-term glass corrosions AND PCT results are more relevant to glass composition effects. THEREFORE, PCT may be a viable test for the glass optimization program that requires testing on every glass within short time and optimizes glass to have good long-term durability 


\section{Conclusions}

- Testing parameters affect glass corrosion process

- These effects can be understood in terms of solution chemistry

- Description of glass reaction must account for influence on all processes

- A good understanding of experimental parameter effects can help the proper selection of a combination of tests to achieve glass optimization and to develop test methods that are more relevant to long-term glass durability 
List of References in X. Feng's Talk on June 28, 1995

1. X. Feng and A. Barkatt, "Effects of Aqueous Phase Composition on the Leach Behavior of Nuclear Waste Glasses," Scientific Basis for Nuclear Waste Management X, Eds., J. K. Bates and W. B. Seefeldt, Vol.8 4, 519-531 (1987).

2. X. Feng, "Composition Effects on Chemical Durability and Viscosity of Nuclear Waste Glasses - Systematic Studies and Structural Thermodynamic Models," Ph.D. Thesis, The Catholic University of America (1988), published by UMI (1988), $300 \mathrm{~N}$. Zeeb Rd., Ann Arbor, Michigan 48106, U.S.A., Order No. 8820009.

3. X. Feng, I. L. Pegg, Aa. Barkatt, and P. B. Macedo, "Effects of Surface-Area-ToSolution Volume on the Chemical Durability of Nuclear Waste Glasses," Scientific Basis for Nuclear Waste Management XIII, Eds., V. M. Oversby and P. W. Brown, Vol. 176, 383-402 (1990).

4. X. Feng, L. Fu; T. K. Choudhury, I. L. Pegg, and P. B. Macedo, "Mechanistic Effects of Deuteration on the Aqueous Corrosion of Nuclear Waste Glasses," Scientific Basis for Nuclear Waste Management XIV, Eds., T. A. Abrajano, Jr. and L. H. Johnson, Vol. 212, 49-56 (1991).

5. X. Feng, I. L. Pegg, Q. Yan, X. Mao, and P. B. Macedo, "Effect of pH on the Leaching Mechanism of Nuclear Waste Glasses," Nuclear Waste Management IV, Ceramic Transactions, Vol. 23, Eds., G. G. Wicks, D. F. Bickford, and L. R. Bunnell, 95-104 (1991).

6. X. Feng and J. K. Bates, "Initial Comparison of Leach Behavior Between Fully . Radioactive and Simulated Nuclear Waste Glasses through Long-term Testing. Part 1. Solution Analysis," Proceeding of 1992 international High-Level Radioactive Waste Management Conference, Las Vegas, Nevada, April 12-16, 1992, 925-933.

7. X. Feng and I. L. Pegg, "Kinetic Ion Exchange Salt Effects on Waste Glass Leaching," Proceedings of International Symposium on Energy, Environment, and Information Management, Chicago, Illinois, September 15-18, 1992, 7.9-7.16 (1992).

8. X. Feng, J. K. Bates, C. R. Bradley, and E. C. Buck, "Does Fully Radioactive Glass Behave Differently Than Simulated Waste Glass?" Scientific Basis for Nuclear Waste Management XVI, Eds., C. G. Interrante and R. T. Pabalan, Vol. 294, 207-214 (1993).

9. J. C. Cunnane, J. K. Bates, W. L. Ebert, X. Feng, J. J. Mazer, D. J. Wronkiewicz, J. Sproull, W. L. Bourcier, and P. McGrail, "High-Level Nuclear Waste Borosilicate Glass: A Compendium of Characteristics," Scientific Basis for Nuclear Waste Management XVI, Eds., C. G. Interrante and R. T. Pabalan, Vol. 294, 577-582 (1993).

10. W. L. Bourcier, W. L. Ebert, and X. Feng, "Modeling Surface Area to Volume Effects on Borosilicate Glass Dissolution," Scientific Basis for Nuclear Waste Management 
XVI, Eds., C. G. Interrante and R. T. Pabalan, Vol. 294, 225-232 (1993).

11. X. Feng and J. K. Bates, "Factors Influencing Chemical Durability of Nuclear Waste Glasses," Proceedings of the Ninth International Conference on Advanced Science and Technology, March 27, 1993, Schaumburg, Illinois, 128-135 (1993).

12. X. Feng, J. K. Bates, E. C. Buck, C. R. Bradley, and M. Gong, "Long-Term Comparison of Dissolution Behavior Between Fully Radioactive and Simulated Nuclear Waste Glasses," Nuclear Technology 104, 193-206 (1993).

13. X. Feng and I. L. Pegg, "Kinetic Ion Exchange Salt Effects on Glass/Water Reactions," Phys. Chem. Glasses, 35(2), 98-103 (1994).

14. X. Feng and I. L. Pegg, "A Glass Dissolution Model for the Effects of S/V on Leachate pH," Journal of Non-Crystalline Solids, 175, 281-293 (1994).

15. X. Feng, J. K. Bates, E. C. Buck, C. Mertz, J. C. Cunnane, and D. J. Chaiko, "Characteristics of the Colloids Generated from Interaction of Nuclear Waste Glasses with Groundwater," Roadiochimica Acta 66/67, 197-205 (1994).

16. X. Feng, "Surface Layer Effects on Glass Corrosion," Mat. Res. Soc. Symp. Proc., 333, 55-68 (1994). 
$n$

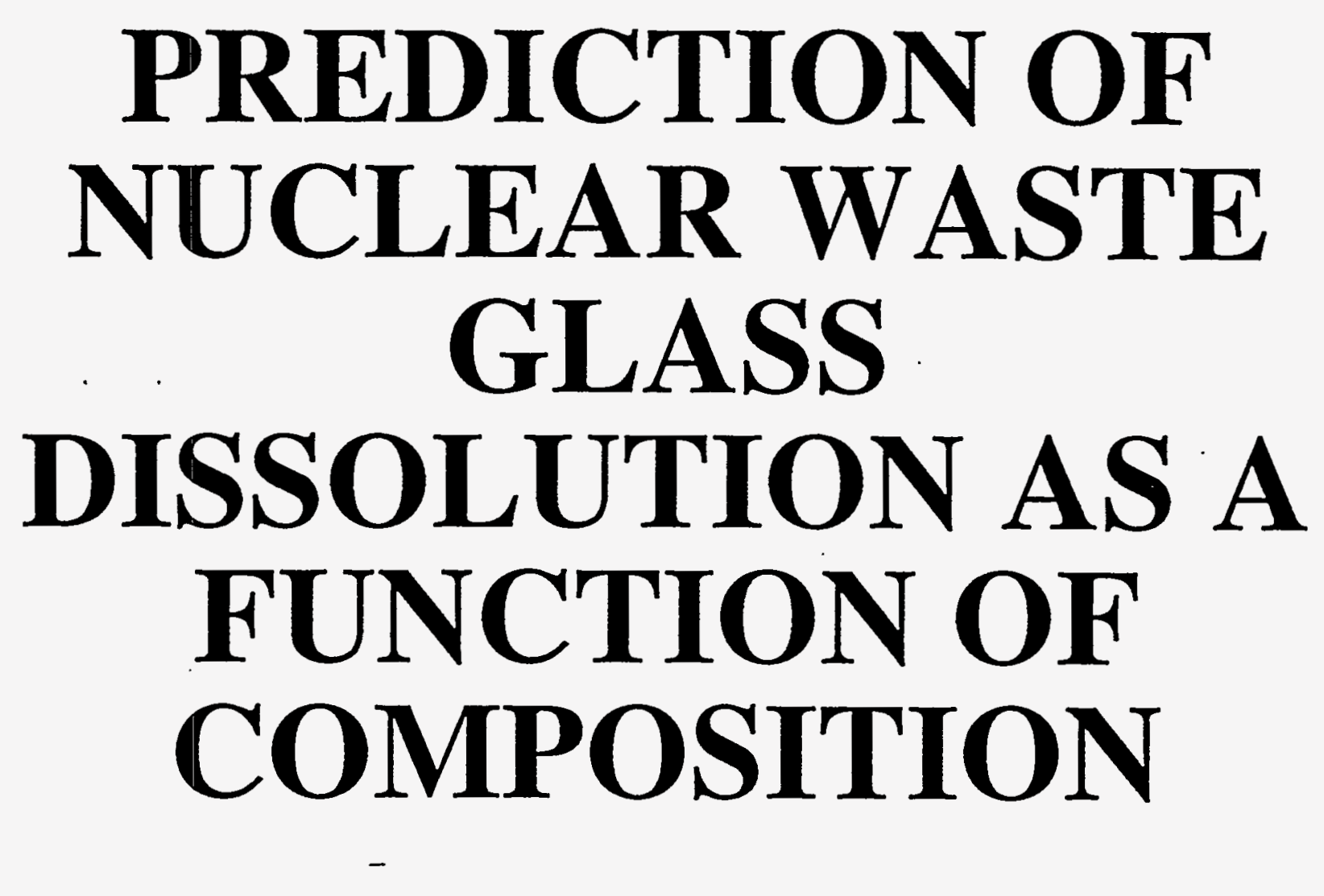




\section{GLASS DURABILITY}

- glass durability $=$ the resistance of glass against environmental corrosive effects

- dissolution of glass is a complex process of interaction between glass and water (or a humid environment)

- it involves

- glass matrix hydration

- formation of gel layer on the glass surface

- nucleation and growth of secondary

phases

- glass durability has not yet been fully resolved into well-defined easy-to-measure thermo-chemical properties, for which component and temperature coefficients could be determined 


\section{GLASS DURABILITY}

\section{MEASUREMENT TECHNIQUES}

- various techniques have been used by commercial and waste glass industries to measure the extent of glass dissolution under a constant temperature and fixed hydrodynamic conditions:

- static tests

- flow-through tests

- component and temperature coefficients can be determined from the test results

- these coefficients do not represent thermochemical properties of the glass-water system

- they can be used, with caution, for glass formulation and prediction of glass dissolution as a function of composition. 


\section{STATIC TESTS FOR WASTE GLASS DURABILITY}

- Product Consistency Test (PCT)

- Materials Characterization Center MCC-1 test

\section{test conditions}

- deionized water

- $90^{\circ} \mathrm{C}$

- glass surface area to solution volume ratio

- PCT - $2000 \mathrm{~m}^{-1}$

- MCC-1 $10 \mathrm{~m}^{-1}$

- standard duration

- PCT 7 days

- MCC-1 28 days

test data

- concentrations of elements in the solution (determined by ICP and AA) 


\section{$\alpha$-TH ELEMENT NORMALIZED \\ RELEASE}

$$
R_{\alpha}=c_{\alpha} /\left(\sigma g_{\alpha}\right)
$$

$c_{\alpha} \alpha$-th element concentration in the solution $\sigma$ glass surface area to solution volume ratio $g_{\alpha} \alpha$-th element mass fraction in the glass

congruent dissolution assumption

- normalized B release $=$ glass loss per unit glass surface area

- normalized releases of other elements indicate secondary effects associated with glass dissolution 


\section{FIRST- AND SECONID-ORDER MIXTURE MODELS}

$$
\begin{gathered}
L_{\alpha}=\sum_{i=1}^{n} b_{\alpha i} g_{i} \\
L_{\alpha}=\sum_{i=1}^{n} b_{\alpha i} g_{i}+\sum_{i \leq j} b_{\alpha i j} g_{i} g_{j}
\end{gathered}
$$

$L_{\alpha}=\ln R_{\alpha}$

$b_{\alpha i} \mathrm{i}$-th component first-order coefficient for $\alpha$-th element

$b_{\alpha i j} \mathrm{i}$-th and $\mathrm{j}$-th components second-order coefficient for $\alpha$-th element 


\section{FIRST-ORDER MODELS}

- first-order coefficients provide information about the effect of individual components on glass dissolution

- effect of replacing an k-th component by an equivalent of an i-th component while keeping the fractions of all other components constant:

$$
\partial L_{\alpha} / \partial g_{i}=b_{\alpha i}-b_{\alpha k}
$$

- effect of adding $\mathrm{i}$-th component to the mixture (component effect)

$$
\partial L_{\alpha}(\mathbf{g}) /\left.\partial g_{i}\right|_{\alpha d d}=\frac{b_{\alpha i}-L_{\alpha}(\mathbf{g})}{1-g_{i}}
$$




\section{TYPICAL VALUES AND DATA}

\section{RANGES}

- 7-day PCT normalized B release

$$
\begin{aligned}
& R_{B}=0.3 \mathrm{~g} / \mathrm{m}^{2}\left(0.1 \text { to } 30 \mathrm{~g} / \mathrm{m}^{2}\right) \\
& L_{B} \approx-1(-3 \text { to } 4)
\end{aligned}
$$

- 28-day MCC-1 normalized B release

$$
\begin{aligned}
& R_{\mathrm{B}}=15 \mathrm{~g} / \mathrm{m}^{2}\left(3 \text { to } 100 \mathrm{~g} / \mathrm{m}^{2}\right) \\
& L_{B} \approx 2.5(1 \text { to } 5)
\end{aligned}
$$

- there is no direct or simple correlation between the results of the MCC-1 tests and the PCT

- in other words, the component coefficients for these two tests (their vectors in the composition space) are not collinear 


\section{RELEASES OF OTHER ELEMENTS}

alkalis

- initial ion exchange

- participation in secondary phases

- normalized releases of $\mathrm{Na}, \mathrm{Li}$, and $\mathrm{B}$ have similar values

silica

- solubility of silica in water is limited:

$$
R_{S i} / R_{B} \leq 1
$$

- there is no direct or simple correlation between the releases of different elements from a glass treated in a given test if these elements participate in gel layer formation and secondary reactions 


\section{PCT NORMALIZED B RELEASE (HLW GLASSES FOR LOW-TEMPERATURE MELTER)}

first-order coefficients (based on mass fractions)

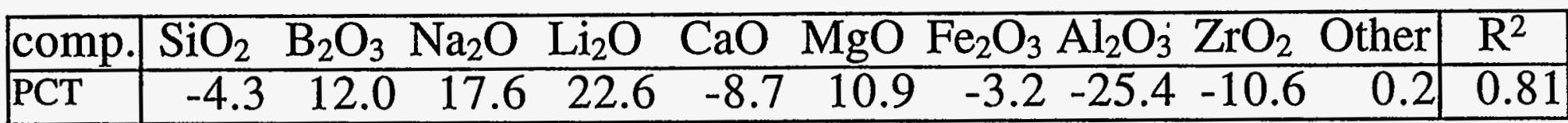

$R_{\mathrm{B}} \uparrow$ if $L_{B i}>4:$

$\mathrm{Li}_{2} \mathrm{O}>\mathrm{Na}_{2} \mathrm{O}>\mathrm{B}_{2} \mathrm{O}_{3}>\mathrm{MgO}$

$R_{B} \downarrow$ if $L_{B i}<-3$ :

$\mathrm{Al}_{2} \mathrm{O}_{3}<\mathrm{ZrO}_{2}<\mathrm{CaO}<\mathrm{SiO}_{2}<\mathrm{Fe}_{2} \mathrm{O}_{3}$

$R_{B} \uparrow$ if $-3<L_{B i}<4$ :

Others

$\underline{\mathrm{MgO}}$ enhances dissolution

- by precipitation of magnesium silicate secondary phases

- not recommended for frits 


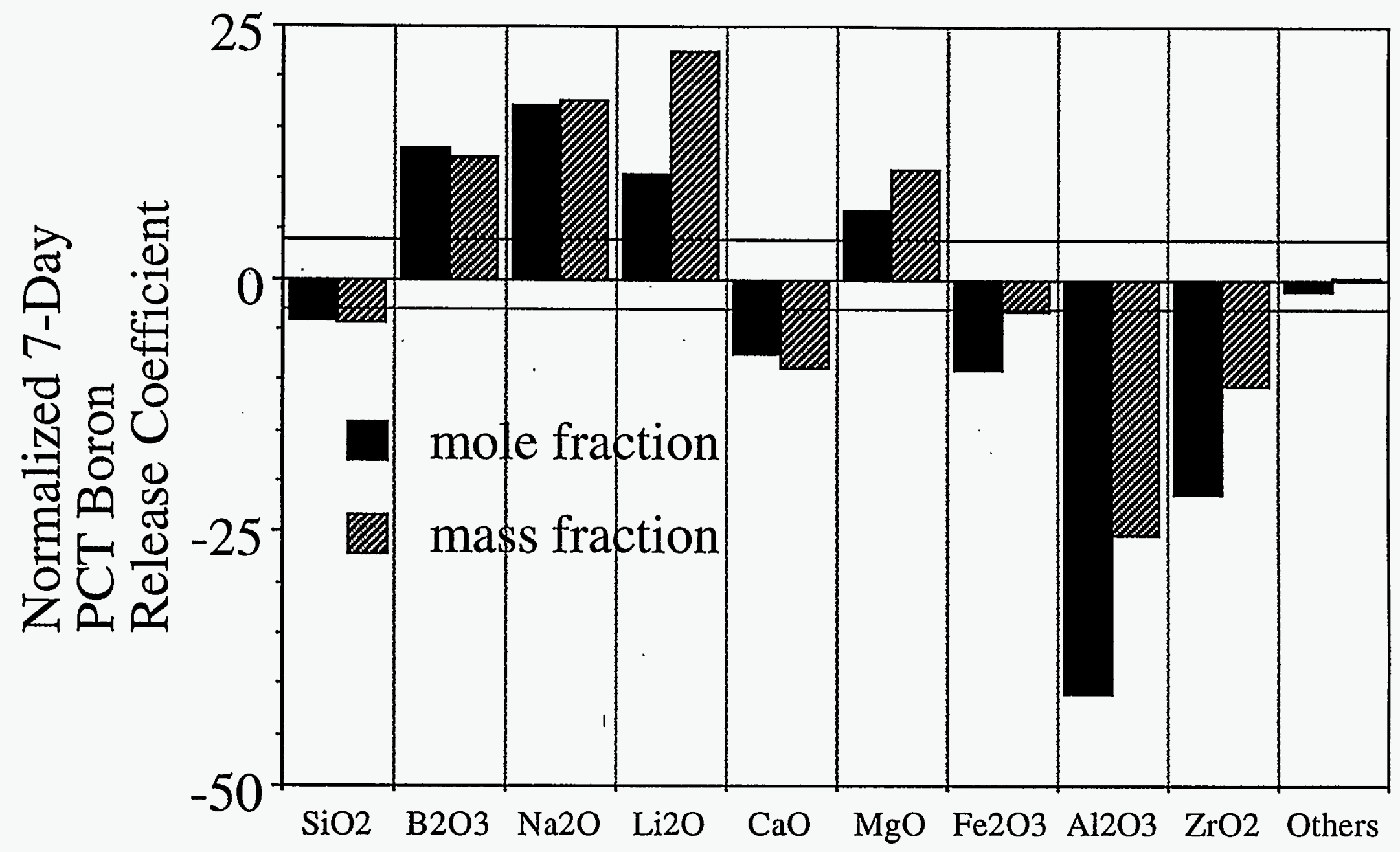




\section{MCC-1 NORMALIZED B RELEASE (HLW GLASSES FOR LOW-TEMPERATURE MELTER)}

first-order coefficients (based on mass fractions)

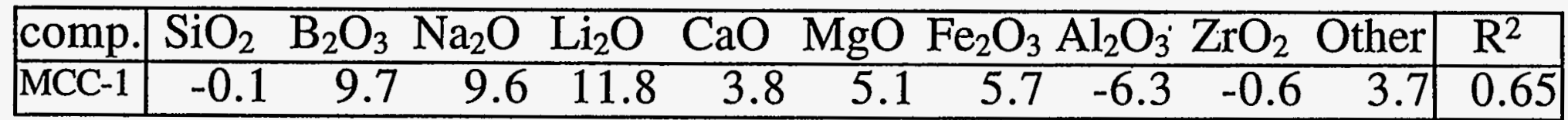

$$
\begin{array}{ll}
R_{\mathrm{B}} \uparrow \text { if } L_{B i}>5: & \mathrm{Li}_{2} \mathrm{O}>\mathrm{B}_{2} \mathrm{O}_{3}>\mathrm{Na}_{2} \mathrm{O}>\mathrm{Fe}_{2} \mathrm{O}_{3}>\mathrm{MgO} \\
R_{B} \downarrow \text { if } L_{B i}<1: & \mathrm{Al}_{2} \mathrm{O}_{3}<\mathrm{ZrO}_{2}<\mathrm{SiO}_{2} \\
R_{B} \uparrow \text { if } 1<L_{B i}<5: & \text { Others }>\mathrm{CaO}
\end{array}
$$




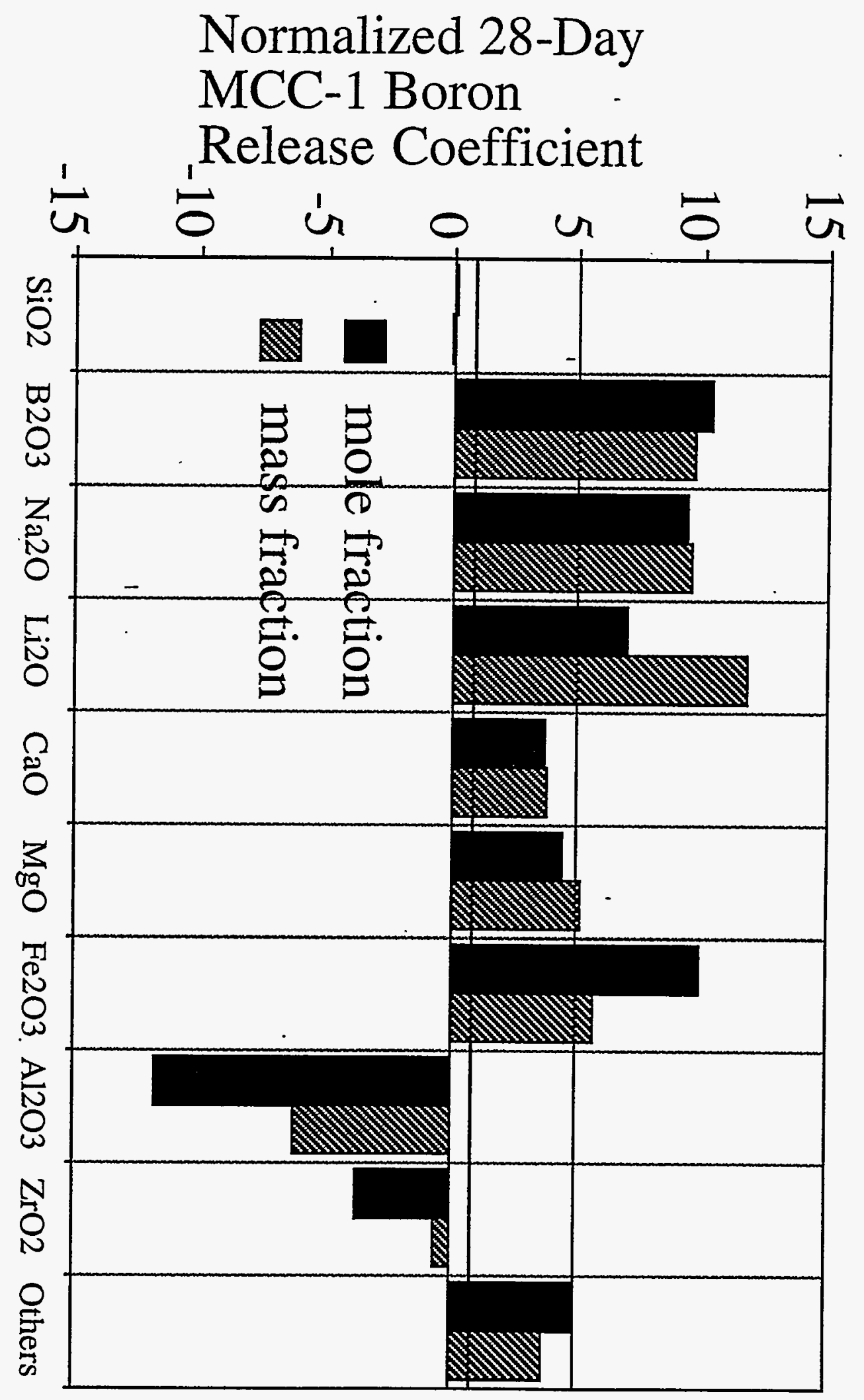




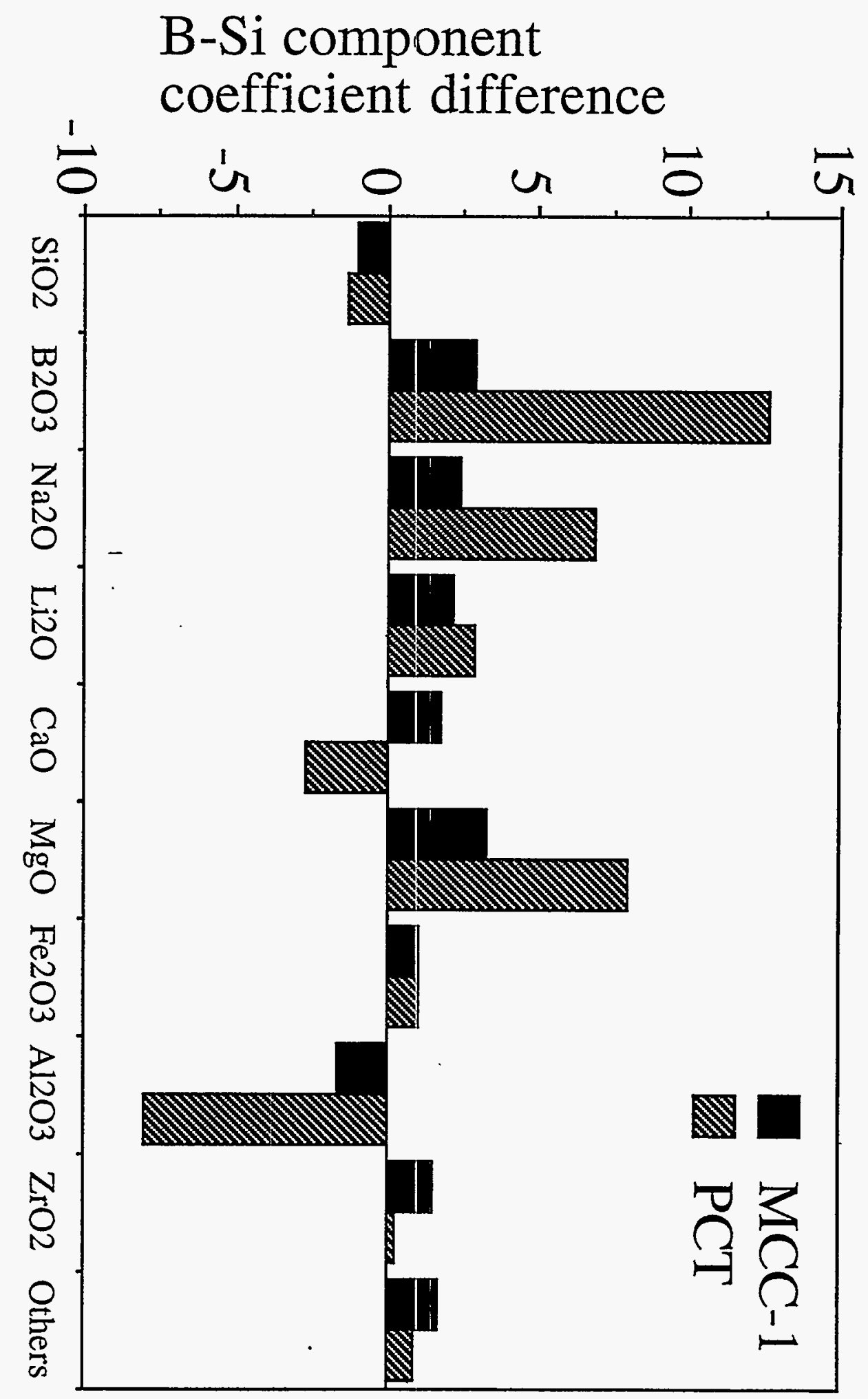




\section{pH VALUES (HLW GLASSES FOR LOW- TEMPERATURE MELTER)}

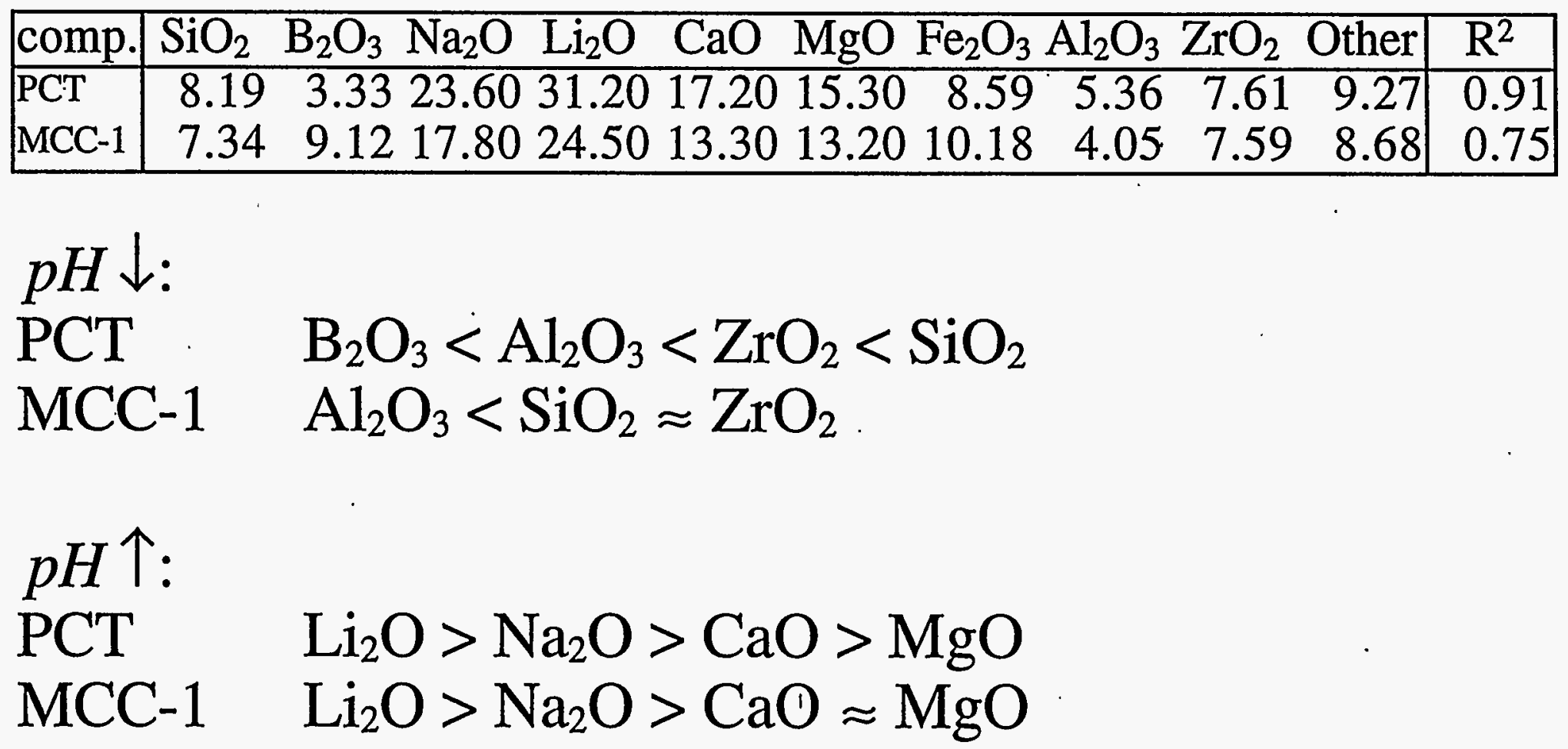




\section{SECOND-ORDER TERMS (HLW GLASSES FOR LOW-TEMPERATURE MELTER)}

$\underline{\mathrm{PCT}}$

$\mathrm{Al}_{2} \mathrm{O}_{3} \times \mathrm{Al}_{2} \mathrm{O}_{3}, \mathrm{~B}_{2} \mathrm{O}_{3} \times \mathrm{B}_{2} \mathrm{O}_{3}, \mathrm{SiO}_{2} \times \mathrm{MgO}$,

$\mathrm{Na}_{2} \mathrm{O} \times \mathrm{CaO}, \mathrm{B}_{2} \mathrm{O}_{3} \times \mathrm{CaO}, \mathrm{MgO} \times \mathrm{ZrO}_{2} \mathrm{R}^{2}=0.90$

$\underline{\mathrm{MCC}-1}$

$\mathrm{Al}_{2} \mathrm{O}_{3} \times \mathrm{Al}_{2} \mathrm{O}_{3}, \mathrm{Al}_{2} \mathrm{O}_{3} \times \mathrm{B}_{2} \mathrm{O}_{3}, \mathrm{CaO} \times \mathrm{SiO}_{2} \mathrm{R}^{2}=0.88$

expected terms:

squared terms: $\mathrm{Al}_{2} \mathrm{O}_{3}, \mathrm{~B}_{2} \mathrm{O}_{3}$

crossproduct terms:

- $\mathrm{Al}_{2} \mathrm{O}_{3} \times \mathrm{Na}_{2} \mathrm{O}$ (electric charge balance)

- $\mathrm{Na}_{2} \mathrm{O} \times \mathrm{Li}_{2} \mathrm{O}$ (mixed alkali effect)

- $\mathrm{SiO}_{2} \times \mathrm{MgO}$ (reaction in the solution) 


\section{HYDRATION ENERGY APPROACH}

- estimates the hydration energy of glass as a weighted sum of hydration energies of silicates and oxides

- linearly correlates these estimates with logarithmic normalized elemental releases obtained by the MCC-1 test or the PCT

- is identical in form with the first-order model except that the component coefficients are not derived from data

- $\quad$ works whenever a binary variation dominates and the $R_{\alpha}$ versus $\Delta \mathrm{G}$ plot is close to linear

- $\quad R_{\alpha}$ versus $\Delta \mathrm{G}$ correlation is poor for glasses tested in this work 

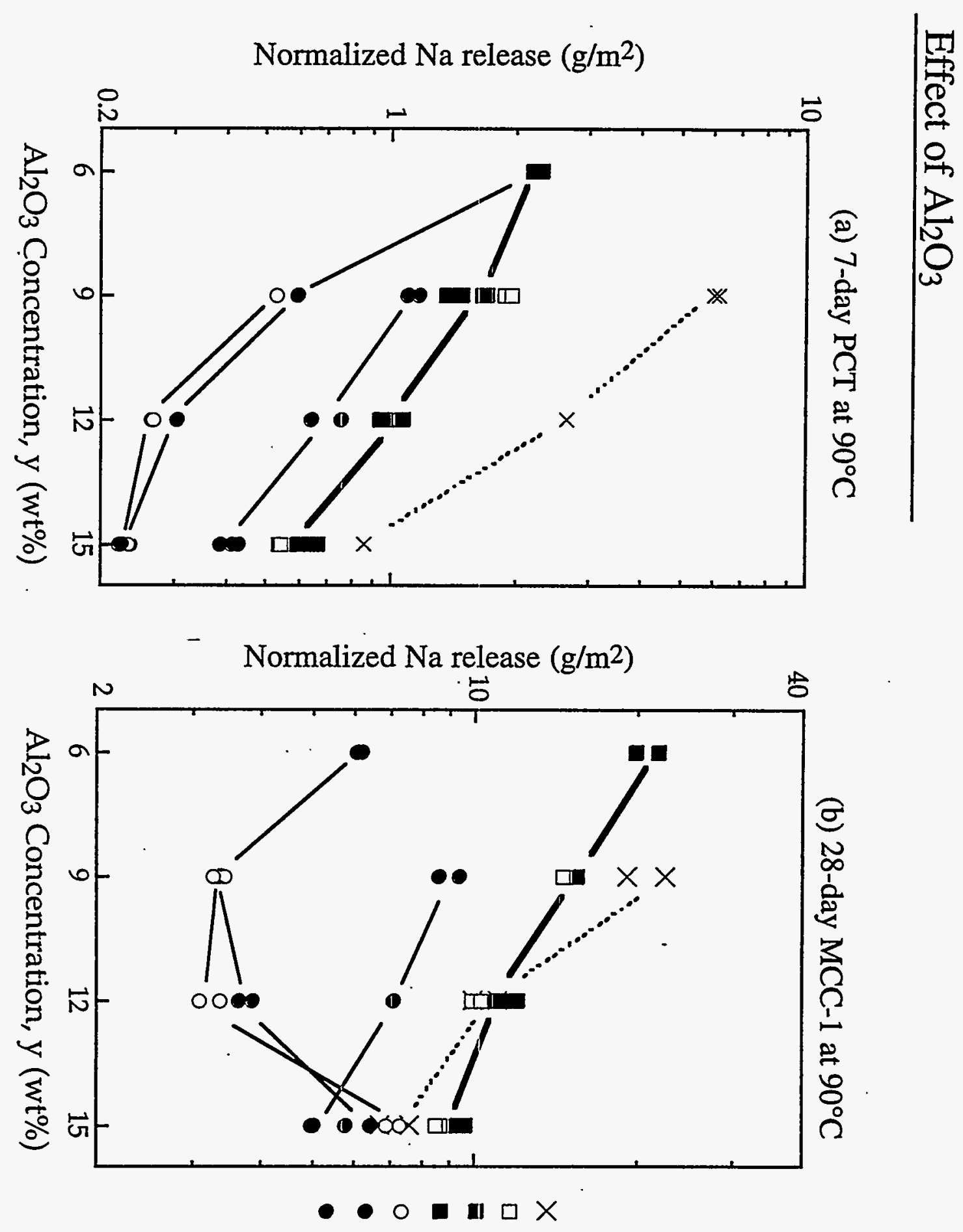

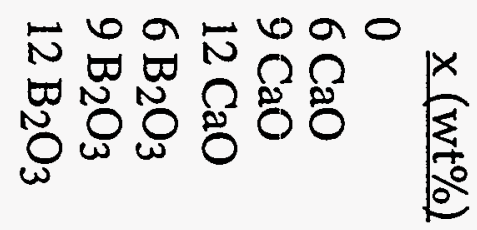




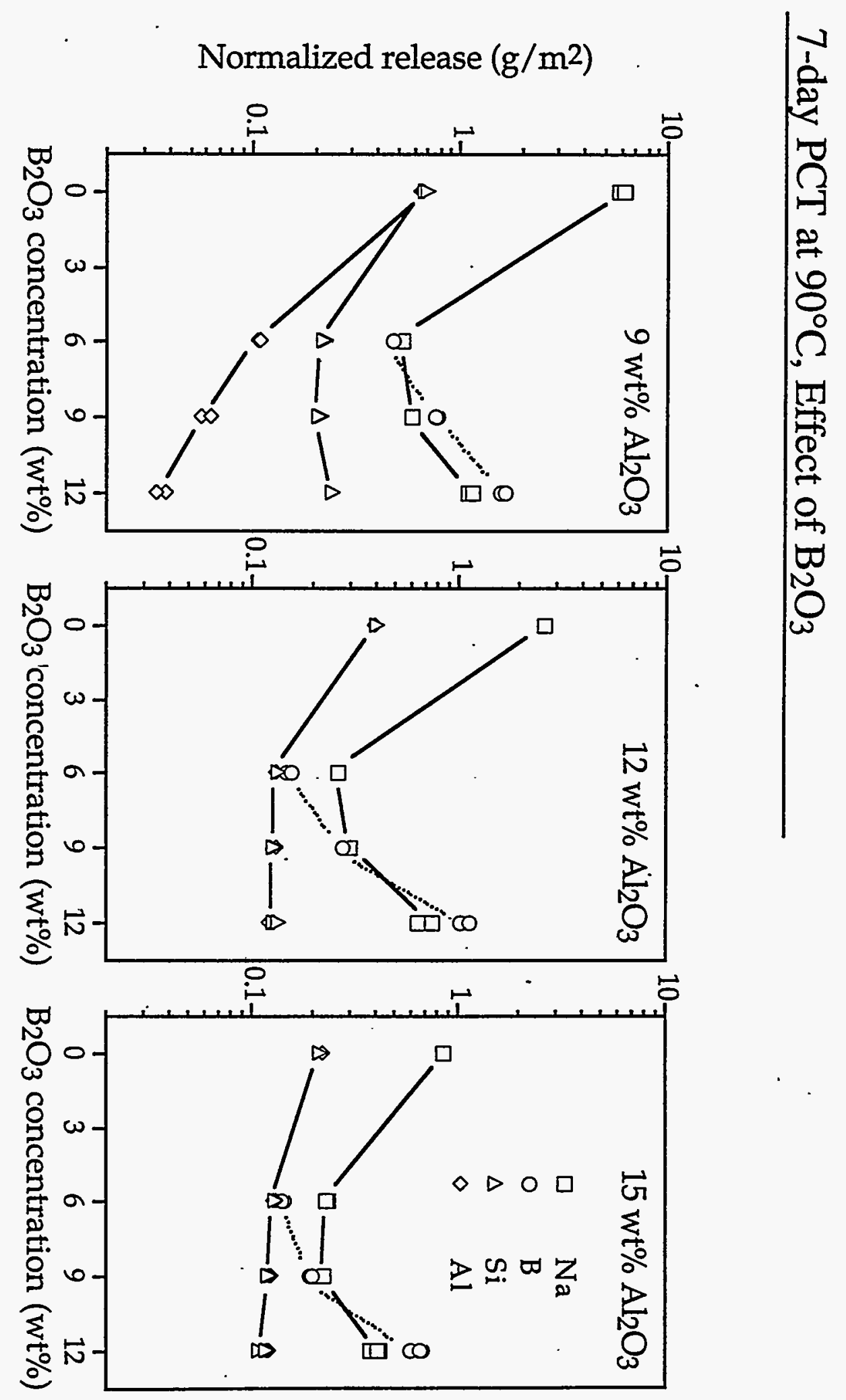




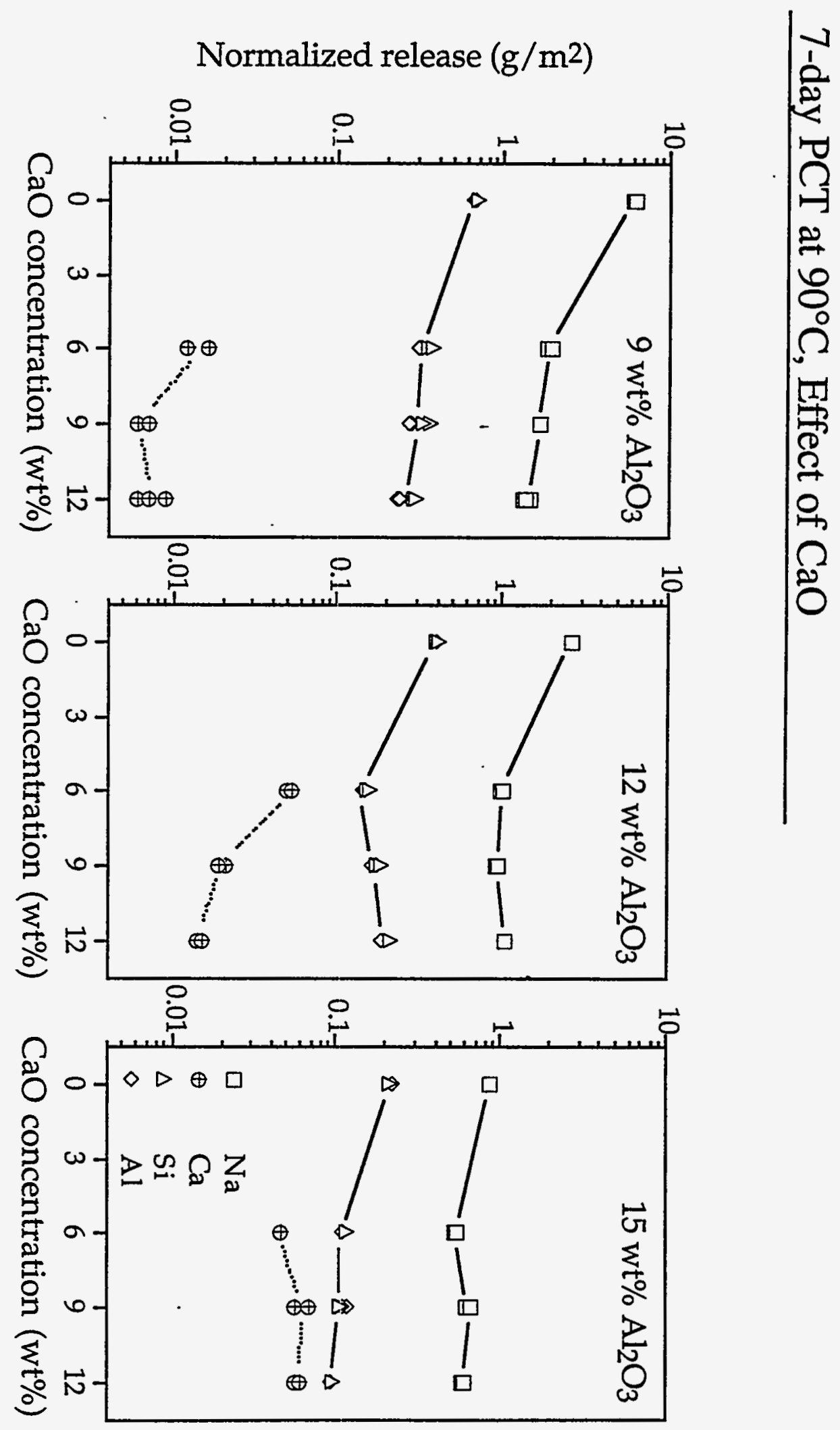



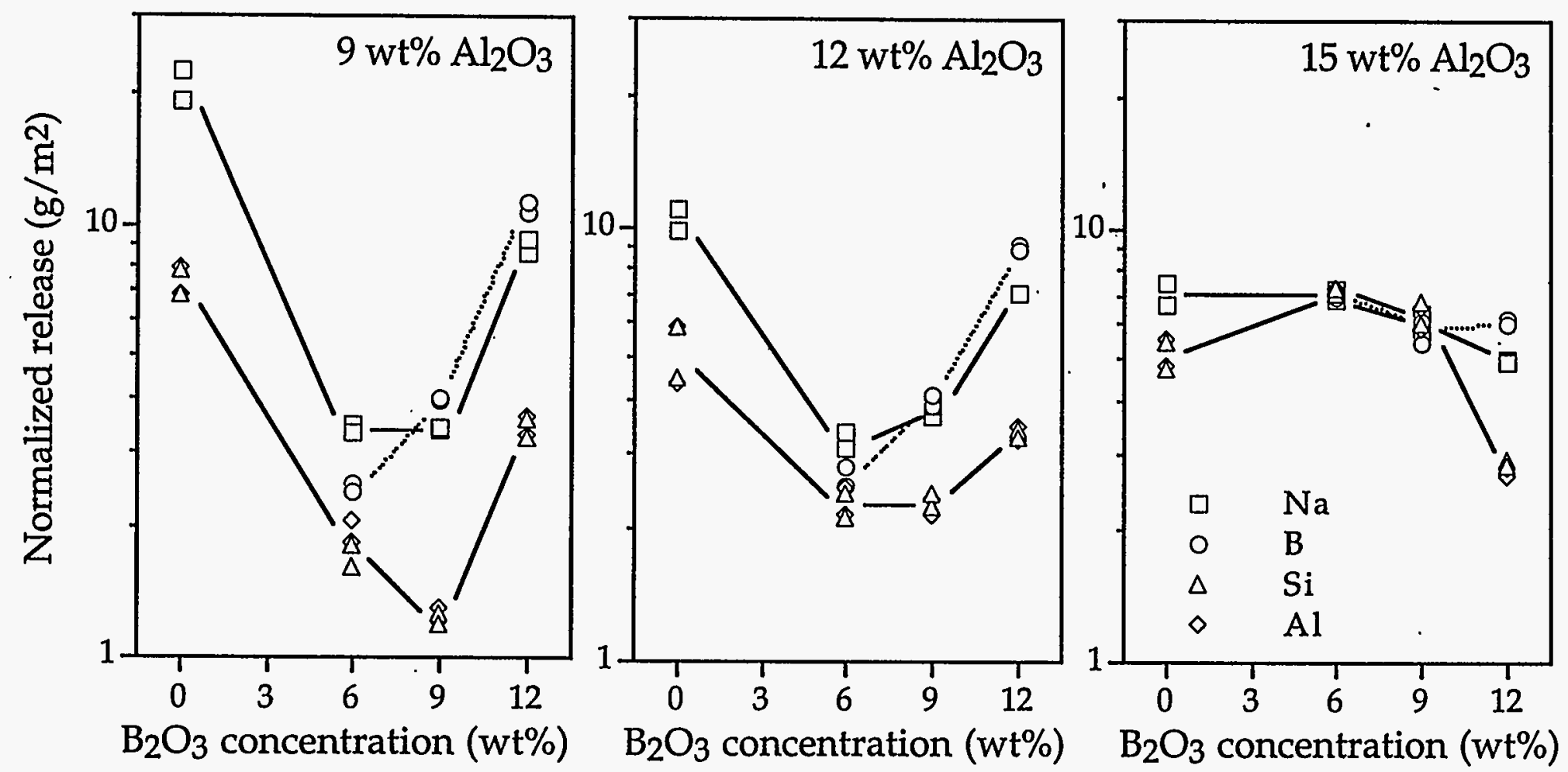


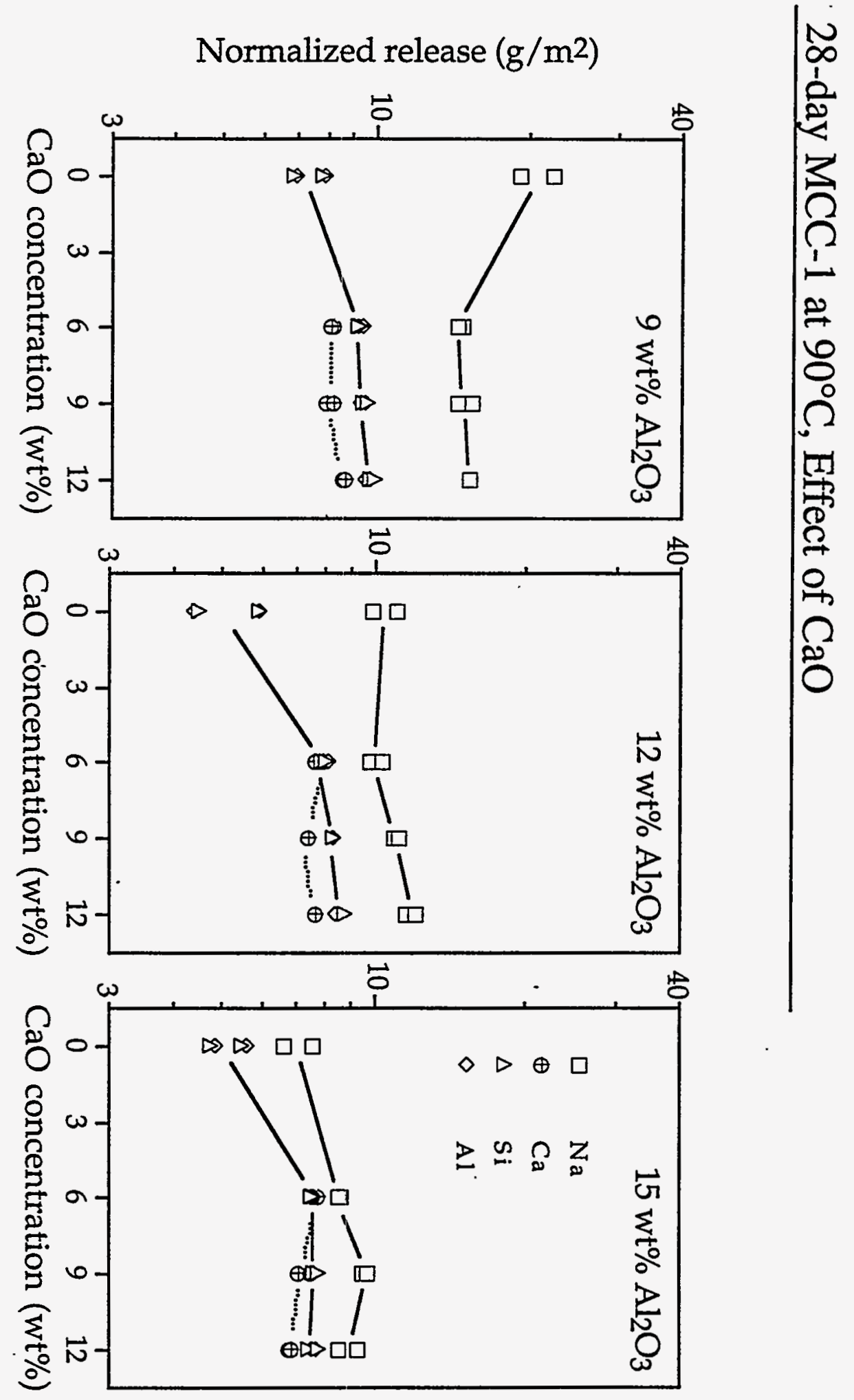




\section{Effect of Crystallization on the Chemical Durability of Simulated Nuclear Waste Glasses}




\section{Chemical Durability}

- Chemical durability is a key property in meeting radioactive waste glass acceptability

- Extent of reaction in an aqueous medium is used as a relative measure of durability

- Aqueous dissolution depends on factors both internal and external to the glass 


\section{External Factors}

- Nature of aqueous medium

- Static versus dynamic dissolution conditions

- Surface area to volume ratio

- Repository conditions

- Radiation environment

- Soil chemistry

- Ambient soil temperature

- Pressure 


\section{Internal Glass Factors}

- Primary internal factors

- Composition

- Thermal history

- Microstructural characteristics

- Crystallization

- Amorphous phase separation

- Structural integrity 


\section{Thermal History}

- Influences the kinetics of crystallization

- Rapid cooling (quenching) kinetically limits crystallization

- Slower cooling favors crystallization, if thermodynamically favorable

- HLW glasses will have a complex thermal history canistered

- Quenched vs canistered centerline cooled (CCC)

- CCC represents the slowest cooling rate of canistered glass

- Highest potential for crystallization 


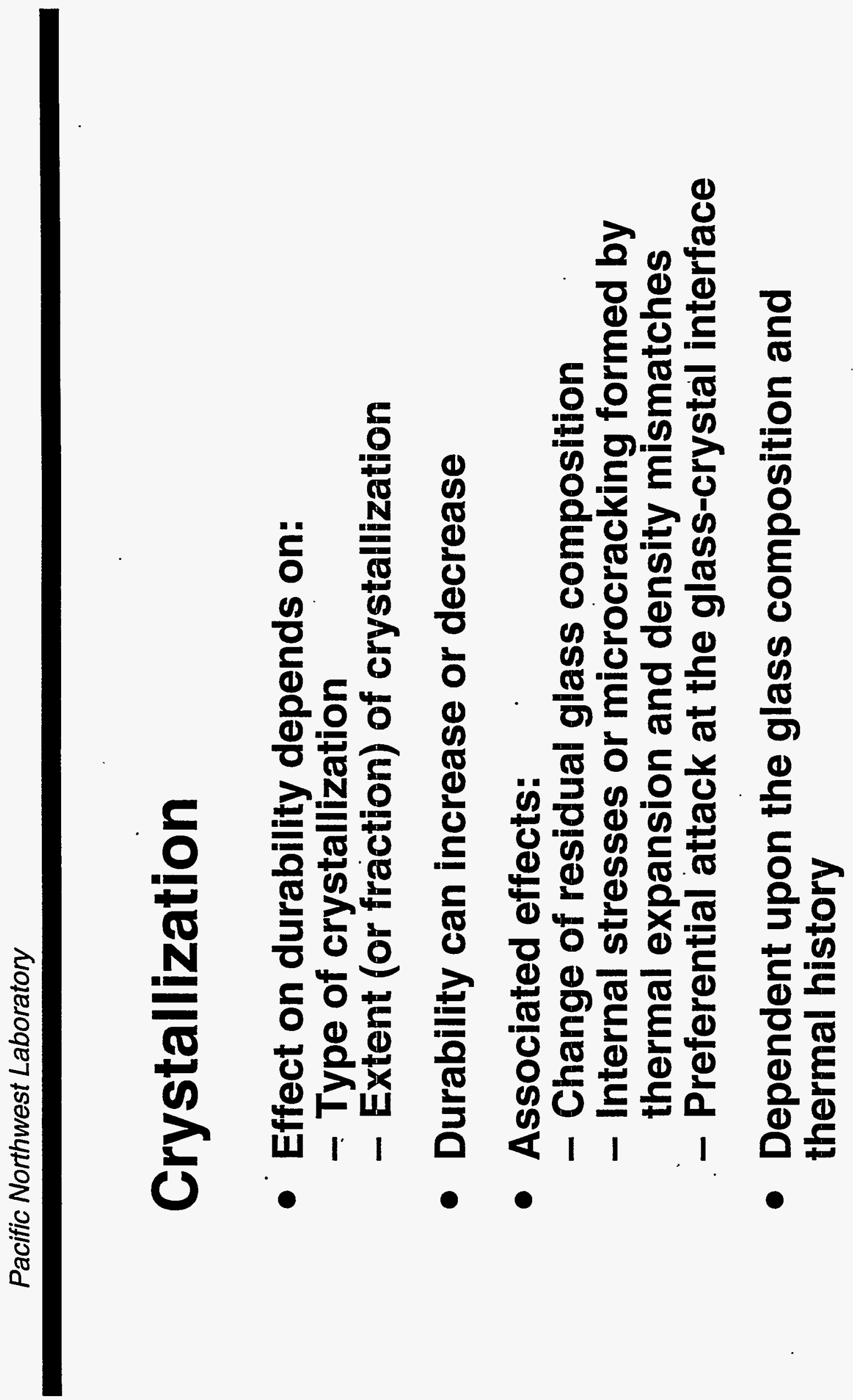




\section{Objective}

- Determine the effect of crystallization on the chemical durability of simulated HLW nuclear waste glasses

- Identify the type and extent of crystallization for 121 CVS (Compositional Variation Study) glasses

- Bound "extreme" thermal history profiles (quenched versus CCC)

- Correlate predicted durability (PCT B release) with calculated residual phase composition 


\section{Experimental}

- 121 CVS simulated HLW glasses

- Thermal history

- Quenched or as-melted

- CCC simulated time-temperature schedule

- SEM/EDS, XRD, optical microscopy

- Semi-quantitative volume fractions of various phases

- Qualitative identification of crystalline phases

- Chemical durability

- 7-day PCT $\left(90^{\circ} \mathrm{C}\right)$

- Both quenched and CCC glasses

- Normalized boron release 


\section{Composition Region of CVS Glasses}

\begin{tabular}{|ll|}
\hline Oxide & Range (wt\%) \\
\hline $\mathrm{SiO}_{2}$ & $42-57$ \\
$\mathrm{~B}_{2} \mathrm{O}_{3}$ & $5-20$ \\
$\mathrm{Na}_{2} \mathrm{O}$ & $5-20$ \\
$\mathrm{Li}_{2} \mathrm{O}$ & $1-7$ \\
$\mathrm{CaO}$ & $0-10$ \\
$\mathrm{MgO}$ & $0-8$ \\
$\mathrm{Fe}_{2} \mathrm{O}_{3}$ & $0.5-15$ \\
$\mathrm{Al}_{2} \mathrm{O}_{3}$ & $0-17$ \\
$\mathrm{ZrO}_{2}$ & $0-13$ \\
"Others" & $1-10$ \\
\hline
\end{tabular}

- "Others" component was composed of $\mathrm{BaO}, \mathrm{CdO}, \mathrm{CeO}_{2}, \mathrm{Cr}_{2} \mathrm{O}_{3}$, $\mathrm{Cs}_{2} \mathrm{O}, \mathrm{CuO}, \mathrm{F}, \mathrm{La}_{2} \mathrm{O}_{3}, \mathrm{MnO}_{2}, \mathrm{MoO}_{3}, \mathrm{Nd}_{2} \mathrm{O}_{3}, \mathrm{NiO}, \mathrm{P}_{2} \mathrm{O}_{5}, \mathrm{PdO}, \mathrm{Pr}_{6} \mathrm{O}_{11}$, $\mathrm{Rb}_{2} \mathrm{O}, \mathrm{Rh}_{2} \mathrm{O}_{3}, \mathrm{RuO}_{2}, \mathrm{SO}_{3}, \mathrm{Sm}_{2} \mathrm{O}_{3}, \mathrm{SrO}$, and $\mathrm{Y}_{2} \mathrm{O}_{3}$. 


\section{Crystallization of Quenched Glasses}

- Quenched or as-melted glasses virtually crystal-free

- 31 of the $121 \mathrm{CVS}$ glasses checked by SEM/EDS and optical microscopy

- $<1$ vol\% undissolved $\mathrm{ZrO}_{2}$ in two glasses

- Al-containing crystals in one glass

- CCC treatment of these three glasses produced $\geq 14 \mathrm{vol} \%$ crystallization 


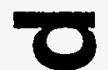

a

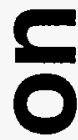

(a)

(1) 1

() 18

(1) 6

D

$c_{10} 40$

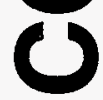

(1) 10

(1) 10

(1) क

స్ำ

(a)

4 ac

$\begin{array}{llllll}10 & 0 & 0 & 0 & 0 \\ 0 & 0 & 0 & 0 & 0 \\ 0 & 0 & 0\end{array}$

2

(1) 0

(4) क 15

ป⿻ 000

ర్ల 


\section{Crystallinity of CCC Glasses: Classifications}

- Glasses with no crystallization

- Glasses with $<7$ volume $\%$

- Glasses with $\geq 7$ volume $\%$

*Volume \% based on XRD data of primary crystalline phase 


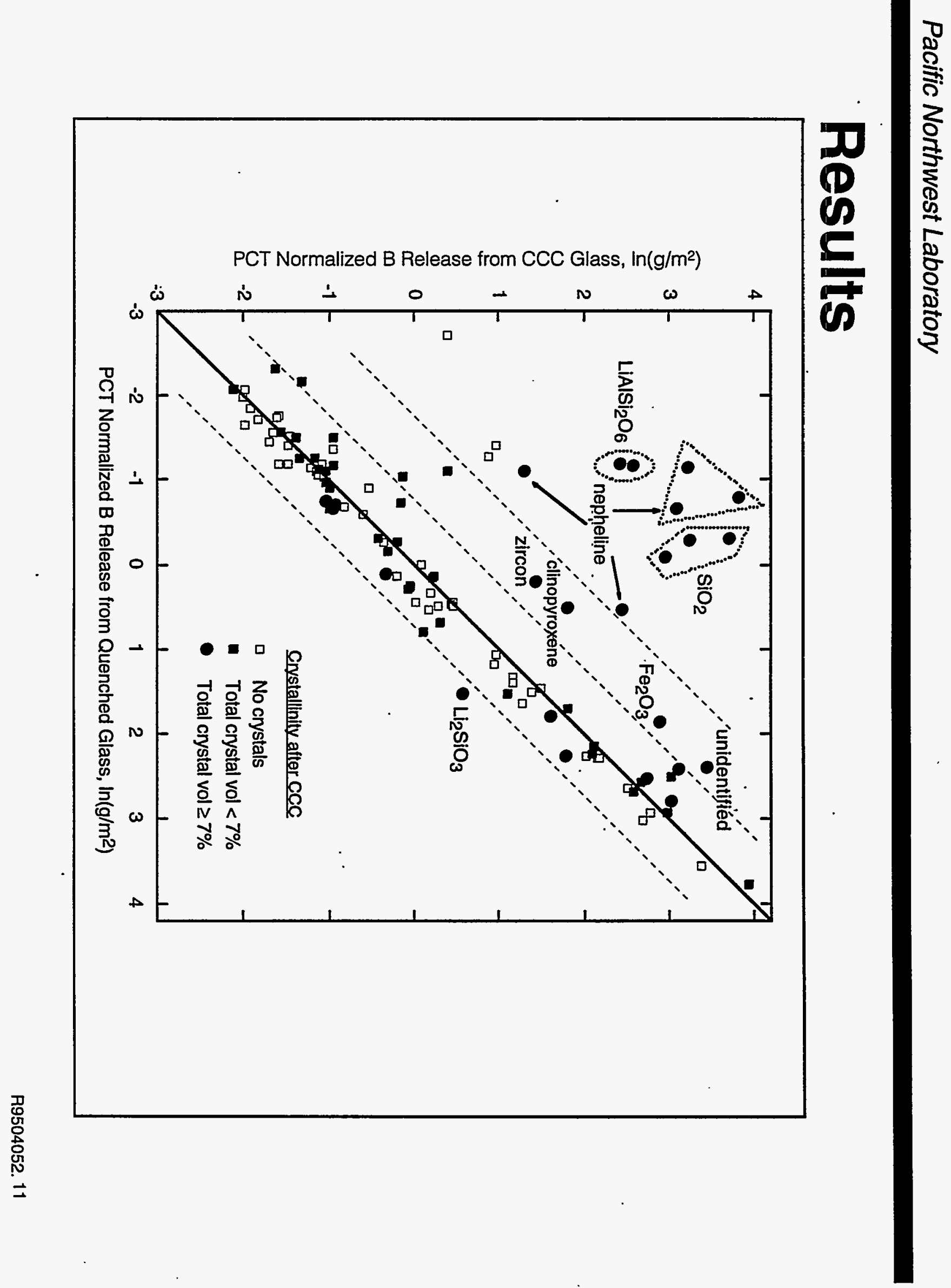




\section{Normalized Boron Release Versus Crystallinity on CCC Glasses}

\begin{tabular}{lcccc}
\hline & No Crystals & $\begin{array}{c}\text { Low Crystal } \\
(<7 \text { vol\%) }\end{array}$ & $\begin{array}{c}\text { High Crystal } \\
(\geq 7 \text { vol\%) }\end{array}$ & Total \\
\hline No Change & 49 & 31 & 9 & 89 \\
Moderate Increase & 0 & 3 & 4 & 7 \\
Strong Increase & 3 & 0 & 10 & 13 \\
Moderate Decrease & 0 & 0 & 1 & 1 \\
\hline Total & 52 & 34 & 24 & $110^{\star}$ \\
\hline
\end{tabular}

*11 replicates 


\section{Glasses with No Crystallinity}

- Effect on Normalized Boron Release

No Change

Moderate Increase

Strong Increase

Moderate Decrease

Total
49

0

3

0

52

- Majority show no change in durability upon CCC

- Three glasses have a "strong increase" in B release after CCC (decrease in durability)

- Not an effect of crystallization

- Amorphous phase separation

- Compositionally not prone

- SEM/TEM failed to detect 


\section{Glasses with Low Crystallization} (<7 vol\%)

- Effect on Normalized Boron Release

No Change

Moderate Increase

Strong Increase

Moderate Decrease

Total
31

3

0

- Majority show no change in durability

- Three glasses show a moderate increase in boron release (decrease in durability)

- Spinel or nepheline ( $\mathrm{NaAlSiO}_{4}$ )

- Although classified as "moderate increase", both quenched and $\mathrm{CCC}$ well below the EA glass limit $\left(r_{B}=8.35 \mathrm{~g} / \mathrm{m}^{2} / 7\right.$-day $)$ 


\section{Glasses with High Crystallinity} ( $\geq 7 \mathrm{vol} \%$ )

- Effect on Normalized Boron Release No Change 9 Moderate Increase Strong Increase Moderate Decrease Total $\frac{1}{24}$

- 10 glasses show a "strong increase" in boron release (decrease durability)

- Nepheline (NaAlSiO $)_{4}$, LiAlSi ${ }_{2} \mathrm{O}_{6}$, or crystalline $\mathrm{SiO}_{2}$ as primary phase

- Effects of residual glass composition 


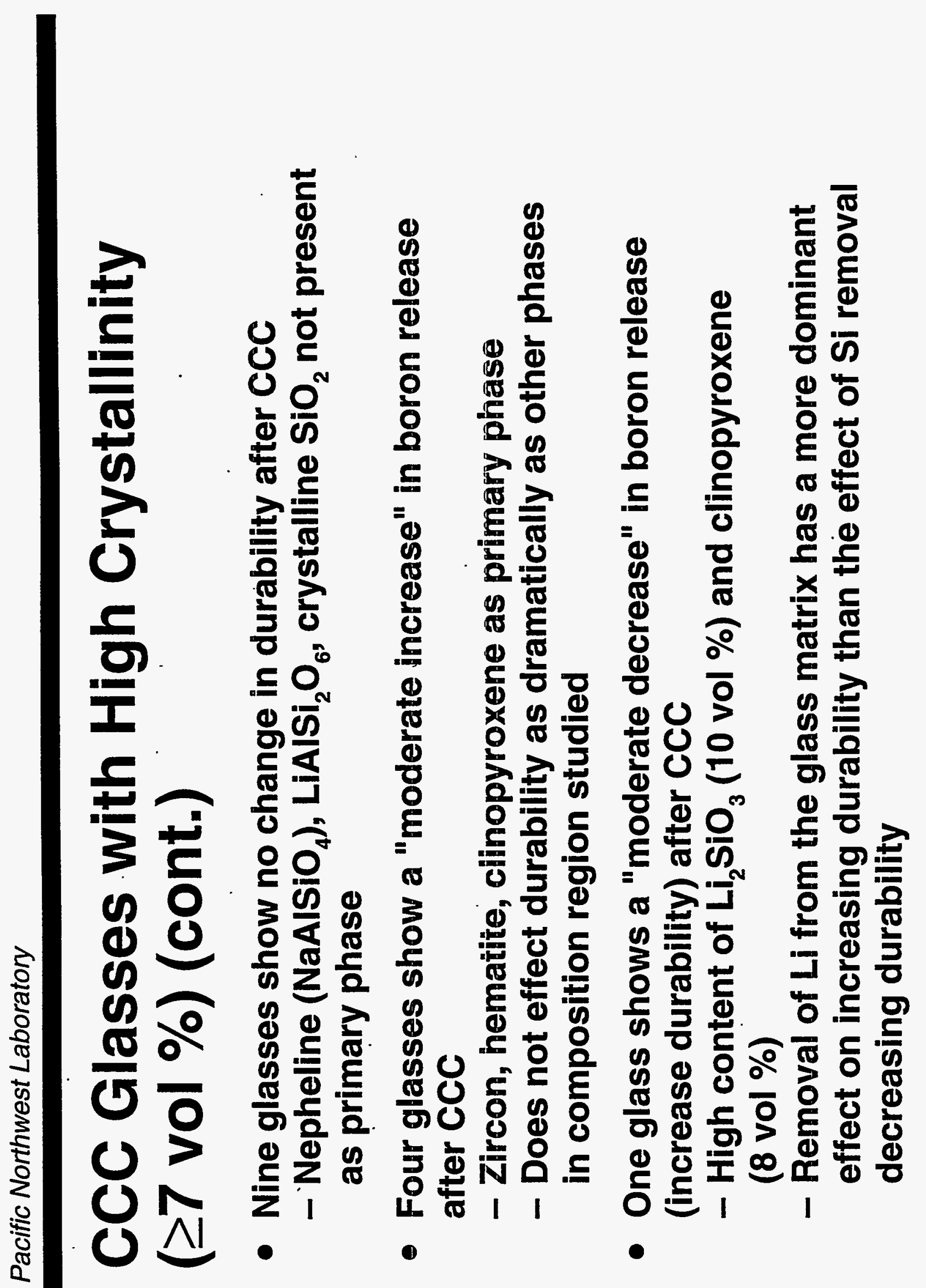




\section{Residual Glass Composition}

- Crystalline phase formation extracts specific elements from the glass matrix

- Chemical durability of the residual glass may be affected

- Component mass balance equation for crystallization:

$$
g_{i}=\sum_{j=1}^{n} c_{i j} f_{j}+r_{i}\left(1-\sum_{j=1}^{n} f_{j}\right)
$$

$g_{i}$ : mass fraction of the $i$-th component in glass before crystallization

$r_{i}$ : mass fraction of the $i$-th component after crystallization

$c_{i j}$ : mass fraction of the $i-t h$ component in the j-th crystal

$f_{j}$ : mass fraction of the j-th crystal in the partially crystallized glass

$n$ : number of different crystal types 


\section{Component Mass Balance Equation}

-Assume only one type of crystal forms $(n=1)$

$$
g_{i}=c_{i} f+r_{i}(1-f)
$$

- Rearranging, we obtain the residual glass composition as a function of crystal mass fraction (f)

$$
r_{i}=\frac{g_{i}-c_{i} f}{1-f}
$$

- $i$-th component concentration in the residual glass (after crystallization) increases if its fraction in the crystalline phase is smaller than in the original glass $\left(g_{i}>c_{i}\right)$ 


\section{Composition of CVS1-1 Glass}

\begin{tabular}{|lc|}
\hline Oxide & (wt\%) \\
\hline $\mathrm{SiO}_{2}$ & 48.0 \\
$\mathrm{~B}_{2} \mathrm{O}_{3}$ & 11.4 \\
$\mathrm{Na}_{2} \mathrm{O}$ & 10.0 \\
$\mathrm{Li}_{2} \mathrm{O}$ & 3.8 \\
$\mathrm{CaO}$ & 2.8 \\
$\mathrm{MgO}$ & 3.6 \\
$\mathrm{Fe}_{2} \mathrm{O}_{3}$ & 5.7 \\
$\mathrm{Al}_{2} \mathrm{O}_{3}$ & 6.4 \\
$\mathrm{ZrO}_{2}$ & 4.3 \\
"Others" & 4.1 \\
\hline
\end{tabular}

- "Others" component was composed of $\mathrm{BaO}, \mathrm{CdO}, \mathrm{CeO}_{2}, \mathrm{Cr}_{2} \mathrm{O}_{3}$, $\mathrm{Cs}_{2} \mathrm{O}, \mathrm{CuO}, \mathrm{F}, \mathrm{La}_{2} \mathrm{O}_{3}, \mathrm{MnO}_{2}, \mathrm{MoO}_{3}, \mathrm{Nd}_{2} \mathrm{O}_{3}, \mathrm{NiO}, \mathrm{P}_{2} \mathrm{O}_{5}, \mathrm{PdO}, \mathrm{Pr}_{6} \mathrm{O}_{11}$, $\mathrm{Rb}_{2} \mathrm{O}, \mathrm{Rh}_{2} \mathrm{O}_{3}, \mathrm{RuO}_{2}, \mathrm{SO}_{3}, \mathrm{Sm}_{2} \mathrm{O}_{3}, \mathrm{SrO}$, and $\mathrm{Y}_{2} \mathrm{O}_{3}$. 


\section{Predicted Normalized Boron Release from CVS1-1 Glass as a Function of Primary Crystalline Phases}

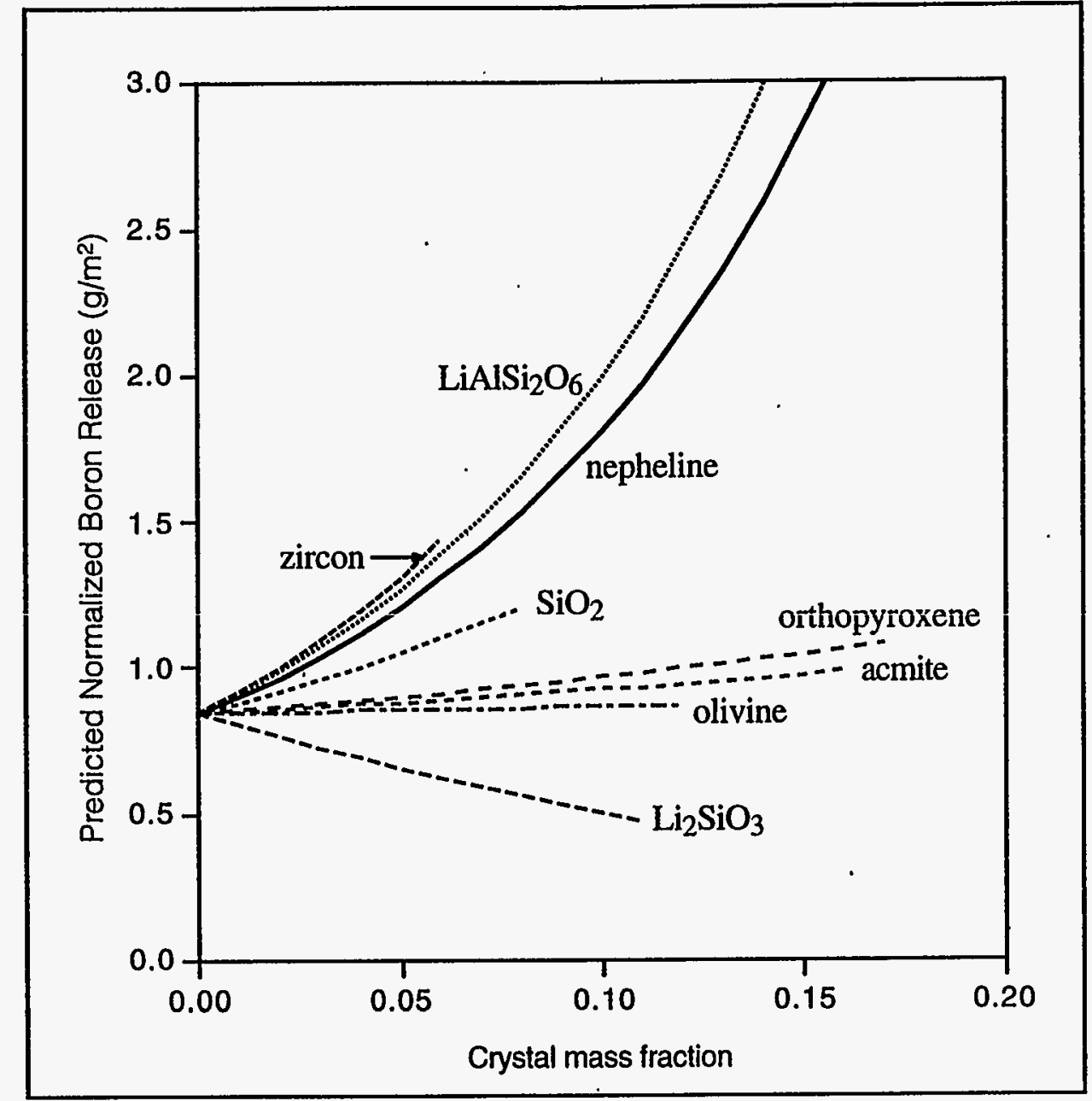

*Predicted normalized release calculated using the CVS first-order model 


\section{Predicted Effects of Residual Glass Composition}

- No or negligible effect with crystallization of orthopyroxene, acmite, or olivine

- Formation of $\mathrm{Li}_{2} \mathrm{SiO}_{3}$ causes a decrease in predicted boron release

- Agrees with experimental observations

- Effect not observed in a glass with higher crystallization of $\mathrm{Li}_{2} \mathrm{SiO}_{3}$ and $\mathrm{Li}_{2} \mathrm{MgSiO}_{4}$

- Crystallization of nepheline $\left(\mathrm{NaAISiO}_{4}\right.$ ), $\mathrm{LiAlSi}_{2} \mathrm{O}_{6}$, crystalline $\mathrm{SiO}_{2}$ and/or zircon as primary phase has a pronounced negative effect on the predicted durability

- Nepheline $\left(\mathrm{NaAlSiO}_{4}\right.$ ), LiAISi $_{2} \mathrm{O}_{6}$, crystalline $\mathrm{SiO}_{2}$ experimentally agrees

- The predicted strong effect of zircon was not observed experimentally 


\section{Results}

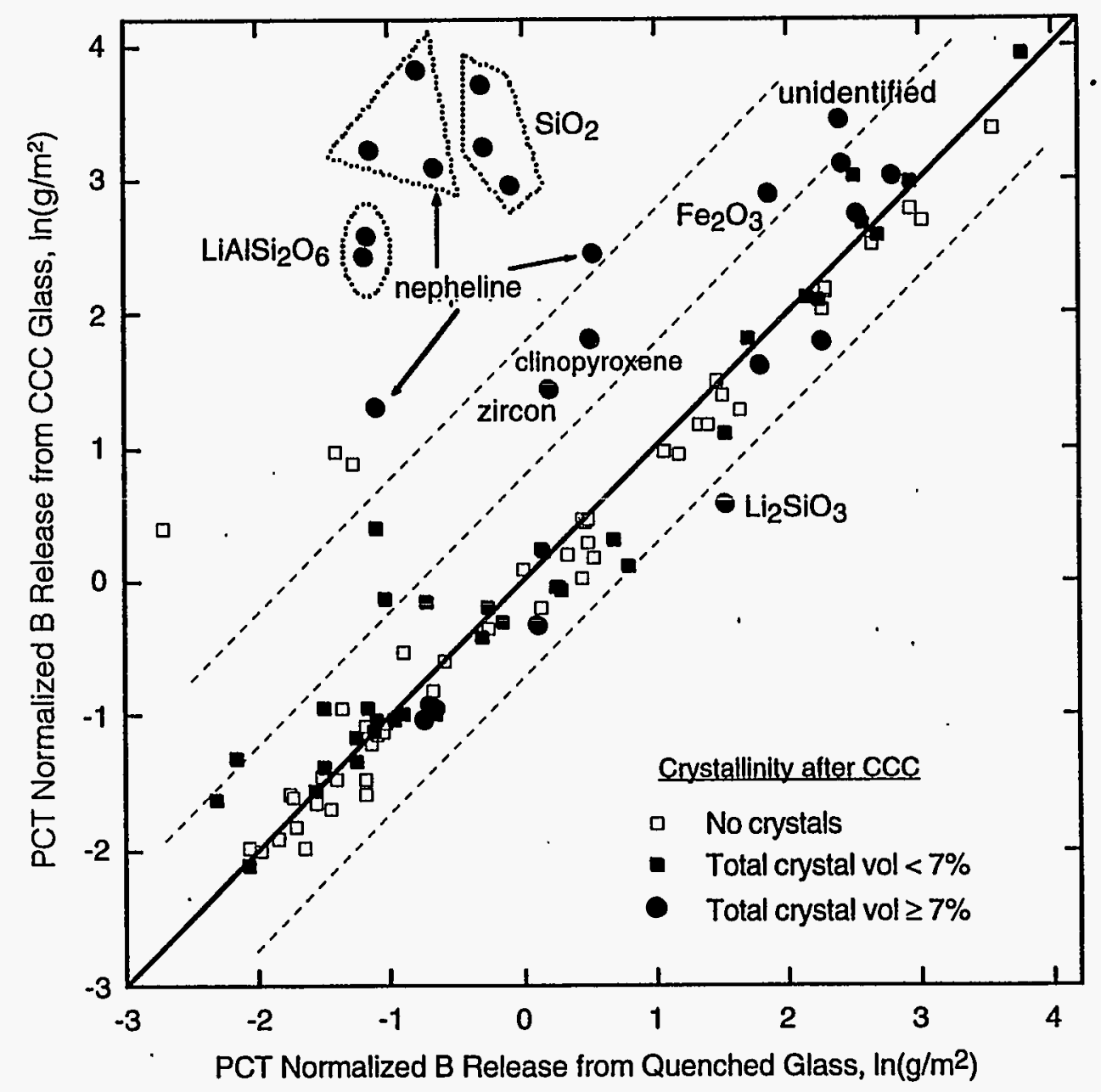




\section{Summary}

- Kinetics of crystallization highly dependent upon thermal history

- Quenched glasses virtually crystal-free, CCC treatment had a higher probability of crystallization

- Effect on durability depends upon the type and extent of crystallization

- Glasses containing Al-bearing crystals (NaAlSiO ${ }_{4}$ and LiAISi ${ }_{2} \mathrm{O}_{6}$ ) and crystalline $\mathrm{SiO}_{2}$ generally produce a high increase in boron release (negative effect on durability)

- Predicted crystallization effects on durability based on residual glass composition calculations generally agree with experimental observations

- Discrepancies between observed and predicted effects suggest that factors other than the change in residual glass composition play a role in defining the overall durability 


\section{Amorphous Phase Separation: Theory, Prediction, and Application}




\section{Inhomogeneous Microstructure Development:}

- Crystallization or devitrification

- crystalline phases nucleate and grow

- Amorphous phase separation

- the separation of a homogeneous melt into two or more liquid phases 


\section{Free Energy of Mixing}

$$
\Delta \mathrm{G}_{\mathrm{M}}=\Delta \mathrm{H}_{\mathrm{M}}-\mathrm{T} \Delta \mathrm{S}_{\mathrm{M}}
$$

where:

$\Delta \mathrm{G}_{\mathrm{M}}=$ free energy of mixing

$\Delta \mathrm{H}_{\mathrm{M}}=$ enthalpy of mixing (heat or bond energy)

$\Delta \mathrm{S}_{\mathrm{M}}=$ entropy of mixing (degree of randomness)

- System can reduce its free energy by separating into two or more phases

- For overall system to reduce free energy $\Delta \mathrm{G}_{\mathrm{M}}$ :

1. $\Delta \mathrm{S}_{\mathrm{M}}$ must increase, or

2. $\Delta \mathrm{H}_{\mathrm{M}}$ must decrease. 
Entropy of Mixing $\left(\Delta \mathrm{S}_{\mathrm{M}}\right)$ in a Two Component (A and B) System:

- Defined as the entropy of mixing (or degree of randomness)

$$
\Delta S_{M}=-R[(1-c) \ln (1-c)+c \operatorname{lnc}]
$$

where:

$$
\begin{aligned}
& \mathrm{R}=\text { gas constant } \\
& \mathrm{c}=\text { mole fraction of component } \mathrm{A}
\end{aligned}
$$

- Since $c<1$, the expression $[(1-c) \ln (1-c)+c \operatorname{lnc}]$ is always a negative number

- The entropy of the system will increase upon mixing 


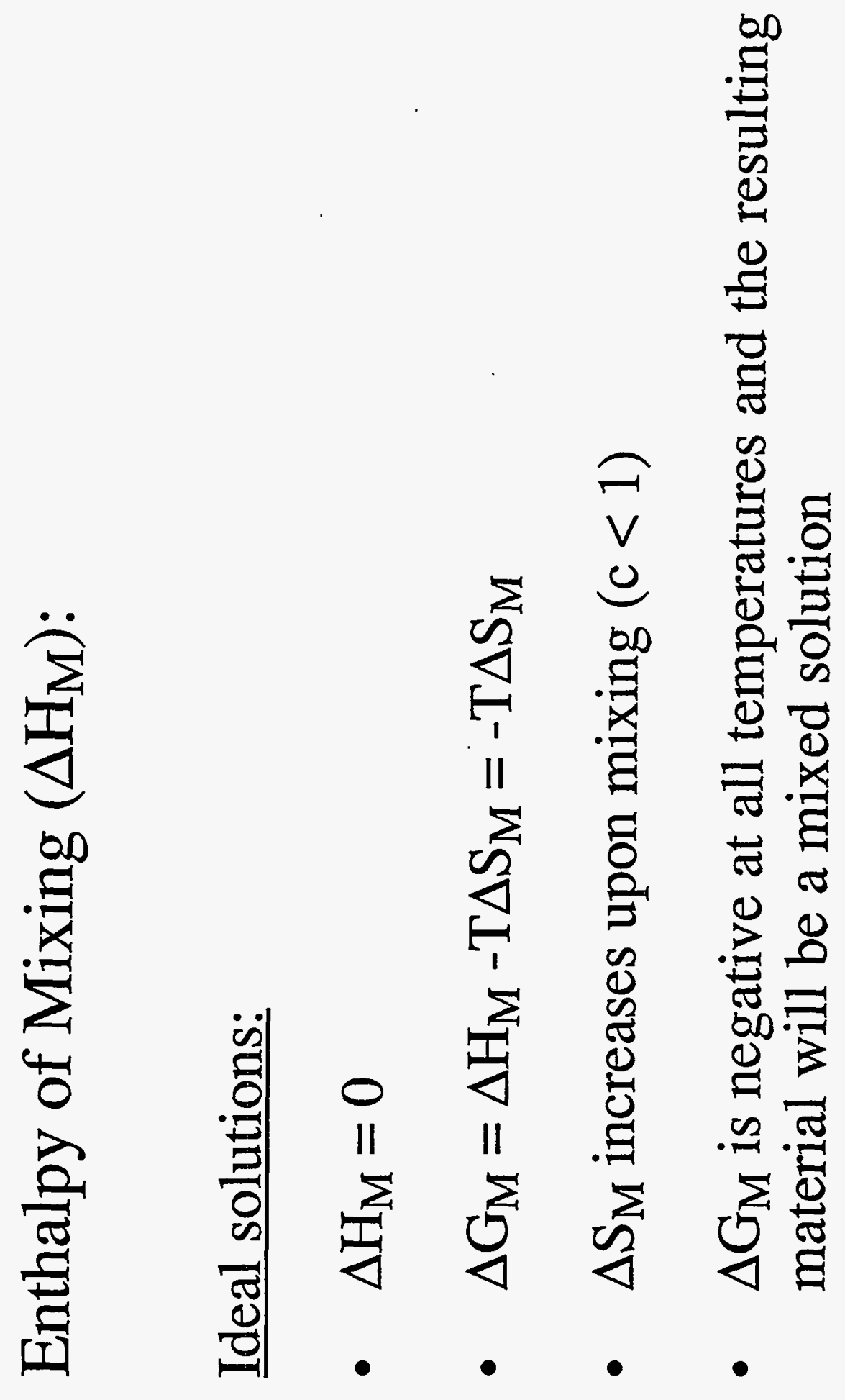


Enthalpy of Mixing $\left(\Delta \mathrm{H}_{\mathrm{M}}\right)$ : (continued)

Regular solutions:

- $\Delta \mathrm{S}_{\mathrm{M}}=-\mathrm{R}[(1-\mathrm{c}) \ln (1-\mathrm{c})+\mathrm{c} \ln \mathrm{c}]$

- $\Delta \mathrm{H}_{\mathrm{M}} \neq 0$, and is given by:

$$
\Delta \mathrm{H}_{\mathrm{M}}=\alpha c(1-\mathrm{c})
$$

$\alpha$ is defined as the excess interaction energy

$$
=N Z\left[E_{A B}-\left(E_{A A}-E_{B B}\right) / 2\right]
$$

where: $\mathrm{N}$ is Avogadro's number

$\mathrm{Z}$ is the coordination number

E's are the energies of the various bonds between atoms (A and B) 
Negative $\Delta \mathrm{H}_{M}(\alpha$ is negative):

- The system gives off heat upon mixing (exothermic)

- $\Delta \mathrm{G}_{\mathrm{M}}=\Delta \mathrm{H}_{\mathrm{M}}-\mathrm{T} \Delta \mathrm{S}_{\mathrm{M}}$ is negative at all temperatures

- Mixing of the system is "encouraged" - (single-phase) thermodynamically favorable

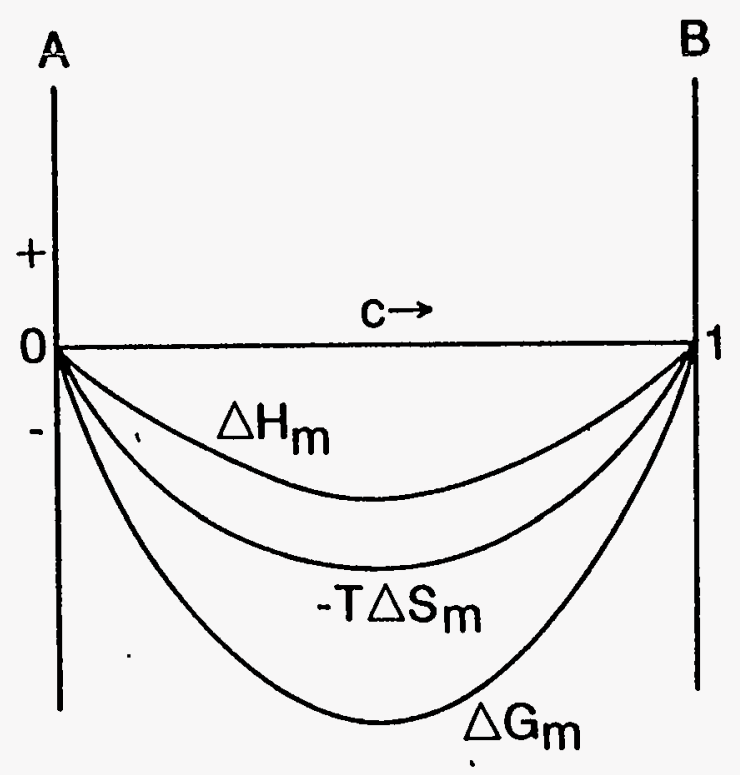




\section{Positive $\Delta \mathrm{H}_{M}(\alpha$ is positive $)$ :}

- The system takes in heat upon mixing (endothermic)

- $\Delta \mathrm{G}_{\mathrm{M}}=\Delta \mathrm{H}_{\mathrm{M}}-\mathrm{T} \Delta \mathrm{S}_{\mathrm{M}}$ :

- the shape of the $\Delta \mathrm{G}_{\mathrm{M}}$ variation with composition (c) depends upon the magnitude of the $\Delta \mathrm{H}_{\mathrm{M}}$ term compared to the $\mathrm{T} \Delta \mathrm{S}_{\mathrm{M}}$ term

- highly dependent upon the temperature 


\section{Positive $\Delta \mathrm{H}_{\mathrm{M}}$ ( $\alpha$ is positive): (continued)}

- At high temperatures, the term - $\mathrm{T} \Delta \mathrm{S}_{\mathrm{M}}$ is greater than the $\Delta \mathrm{H}_{\mathrm{M}}$ term so $\Delta \mathrm{G}_{\mathrm{M}}$ is negative everywhere

- the system is single-phased at sufficiently high temperatures

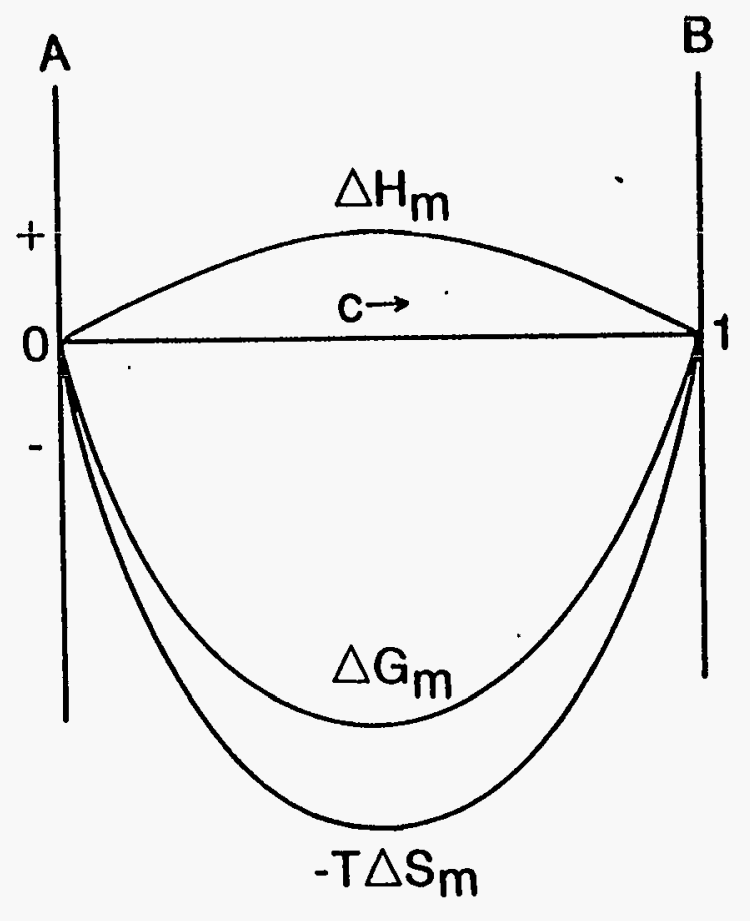




\section{Positive $\Delta H_{M}(\alpha$ is positive): (continued)}

- As the temperature decreases $\left(\mathrm{T}<\mathrm{T}_{\mathrm{c}}\right)$, the $\Delta \mathrm{G}_{\mathrm{M}}$ curve begins to flatten out - "saddle" develops

- $-\mathrm{T} \Delta \mathrm{S}$ term becomes less dominant

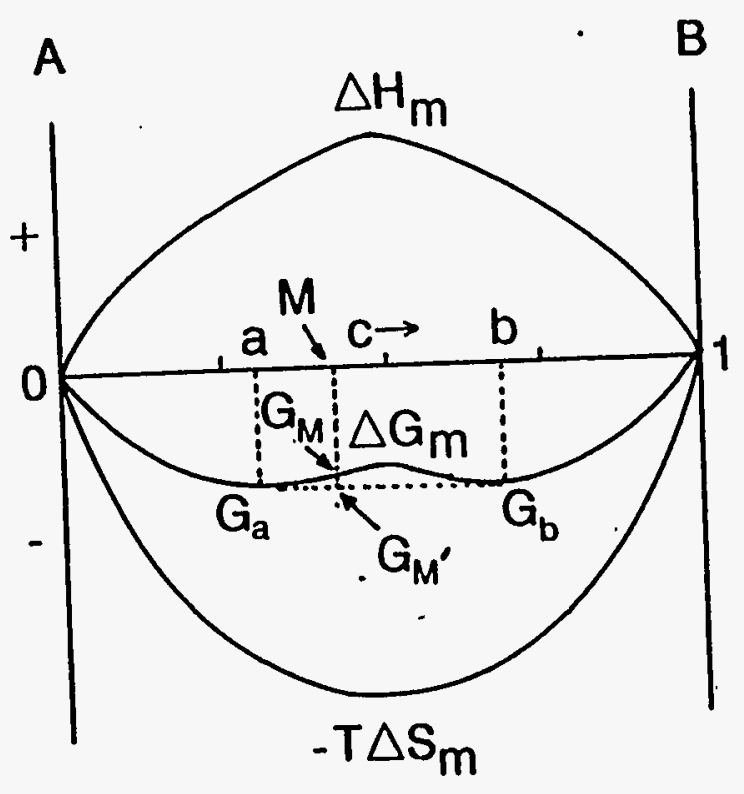


- Although the mixed system has a lower $\Delta \mathrm{G}_{\mathrm{M}}$ than the unmixed end components (A and B), between points " $\mathrm{a}$ " and " $\mathrm{b}$ ", $\Delta \mathrm{G}_{\mathrm{M}}$ of the fully mixed system is higher that those of "a" and "b"

- The free energy $G_{M}$ of composition $M$ (lying between " $a$ " and "b) can be lowered to $\mathrm{G}_{\mathrm{M}}$ by separating into compositions $a$ and $b$.

- Separation into two phases will occur when the total enthalpy increase $\left(+\Delta \mathrm{H}_{\mathrm{M}}\right)$ is greater that the increase in free energy $\left(\Delta \mathrm{G}_{\mathrm{M}}\right)$ due to the entropy $\left(\Delta \mathrm{S}_{\mathrm{M}}\right)$ consideration

- highly dependent upon temperature 


\section{FREE ENERGY VERSUS COMPOSITION}

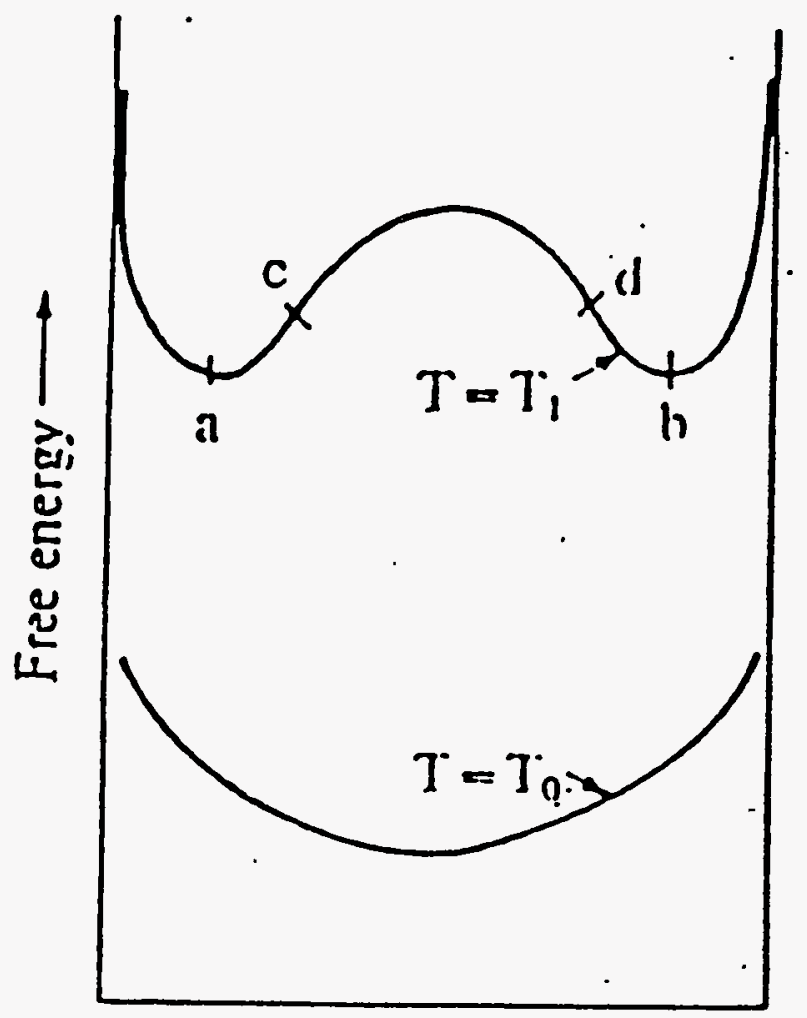

- Above Tc, single phase

- $\Delta \mathrm{G}_{\mathrm{M}}$ has a positive curvature

- As temperature decreases, "saddle" develops between "a" and " $b$ "

- Define position at which $\delta \mathrm{G} / \delta \mathrm{c}=0, \mathrm{~T}=\mathrm{T} 1$

- Immiscibility dome or phase boundary

Composition 


\section{PHASE DIAGRAM}

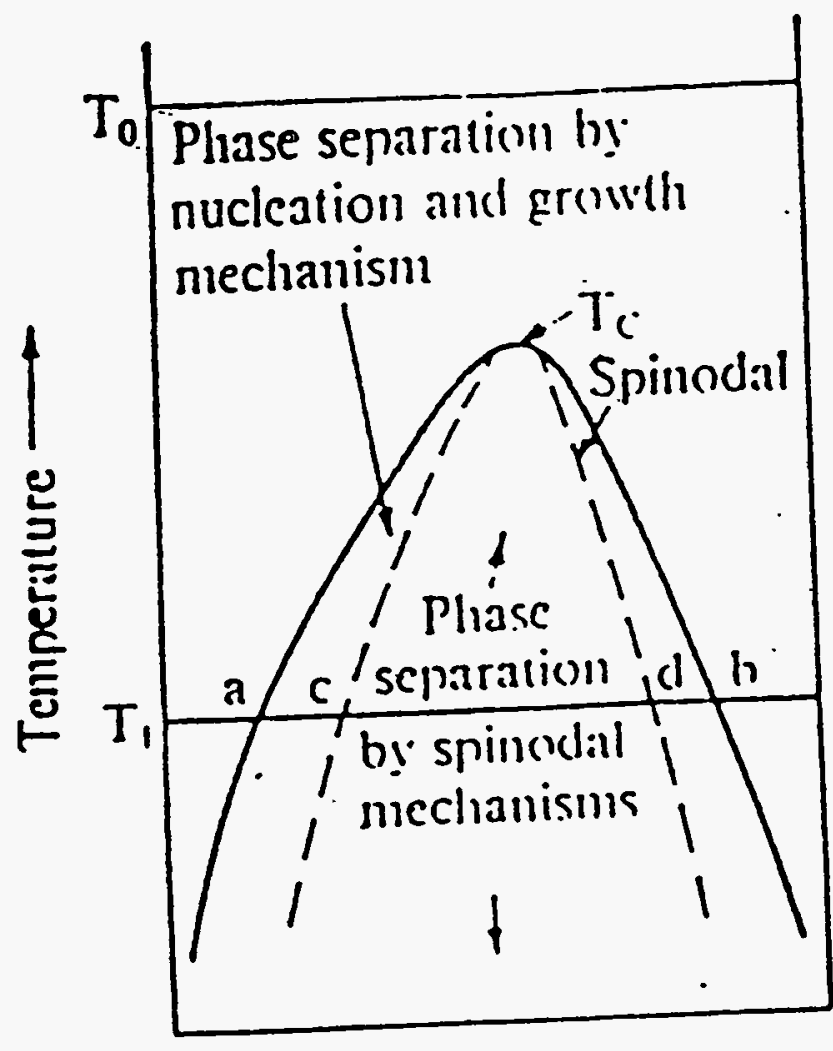

Composition
- $\delta 2 \mathrm{G} / \delta \mathrm{c}^{2}=0, \mathrm{~T}=\mathrm{T}_{1}$ defines points "c" and "d" inflection points

- Inflection points define composition field within the immiscibility dome in which the mechanism of separation differs - morphology changes due to mechanism change

- Nucleation growth versus spinodal decomposition 


\section{THEORY SUMMARY:}

- Relative magnitudes of the $\mathrm{T} \Delta \mathrm{S}_{\mathrm{M}}$ and $\Delta \mathrm{H}_{\mathrm{M}}$ terms determine shape of the $\Delta \mathrm{G}_{\mathrm{M}}$ curve

- Highly dependent upon temperature

- high temperature $-\mathrm{T} \Delta \mathrm{S}_{\mathrm{M}}$ dominants - (single-phase)

- lower temperature $\Delta \mathrm{H}_{\mathrm{M}}$ plays "major role"

- Phase separation can occur if thermodynamically

favorable

- composition dependent

- No assumptions regarding the kinetics of the separation process or the mechanisms have been made 


\section{Nucleation/Growth Mechanism}

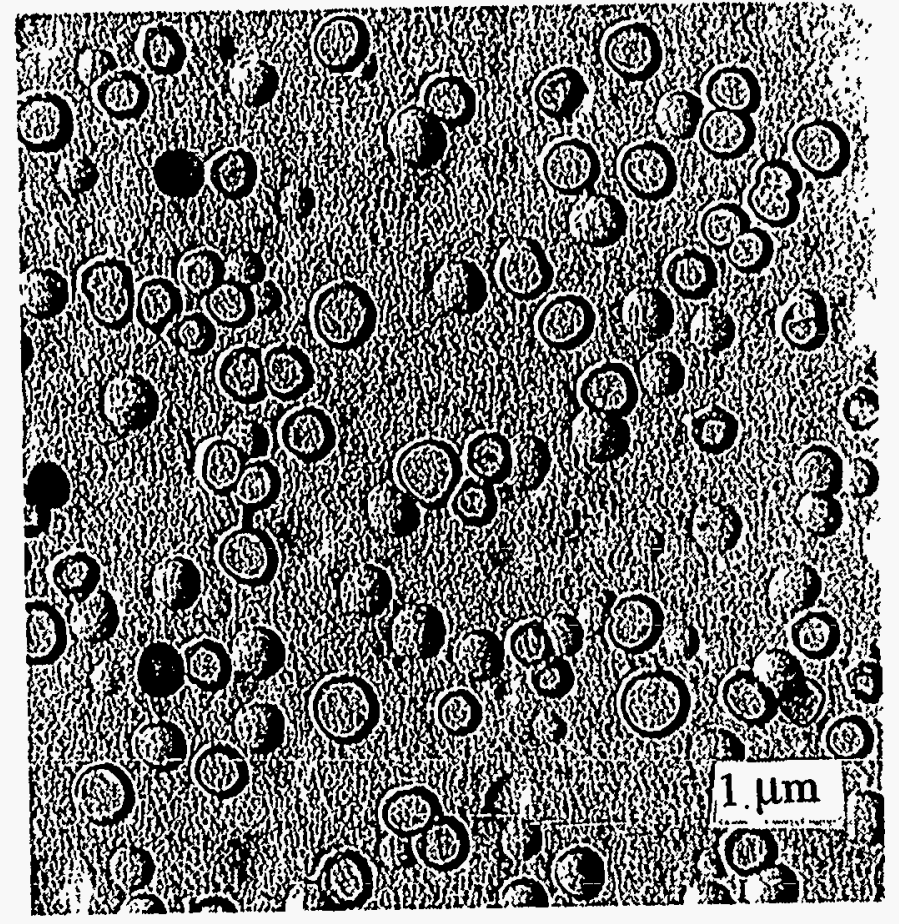

(a)

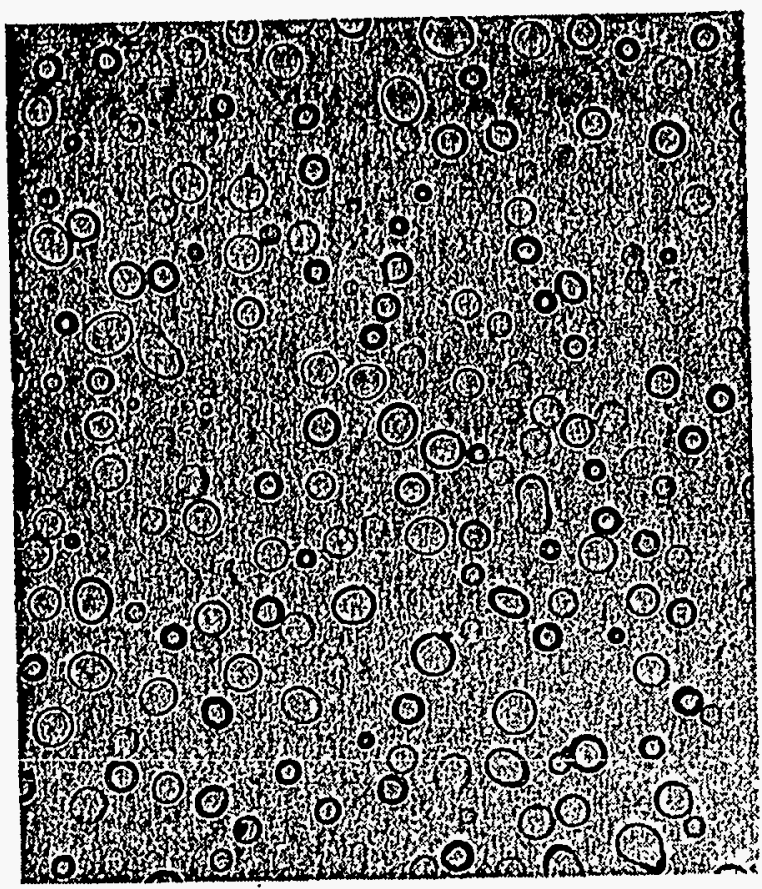

(b)

\section{- Dispersed phase is isolated in continuous matrix}

(a) W. Vogel, Chemistry of Glass, Figure 7.21, p. 11, American Ceramic Society, Columbus, Ohio,1985.

(b) H. Rawson, Properties and Applications of Glass, Figure 10, Elsevier Science Publishers, Amsterdam, Netherlands, 1980. 


\section{Spinodal Decomposition Mechanism:}

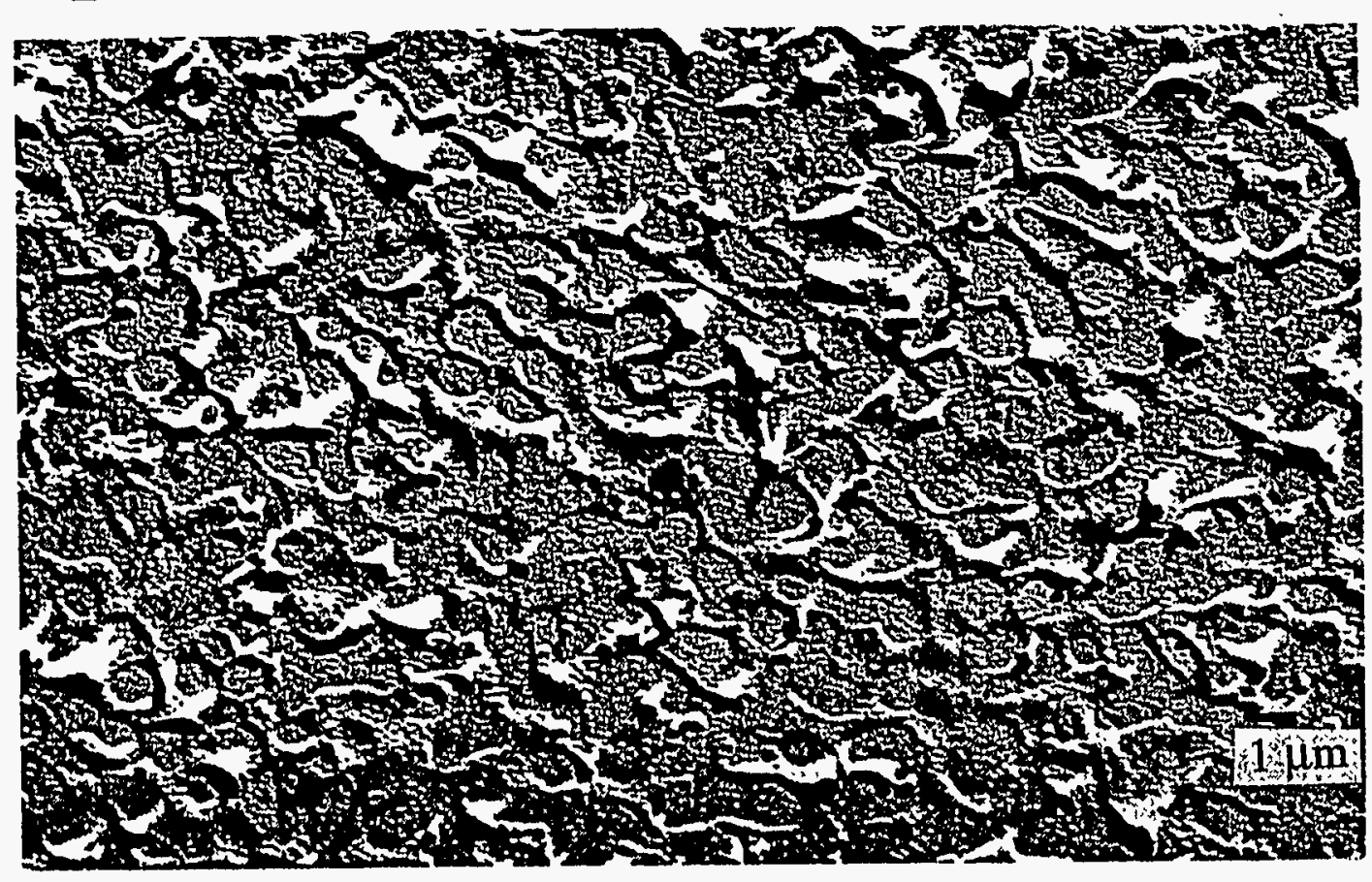

(a)

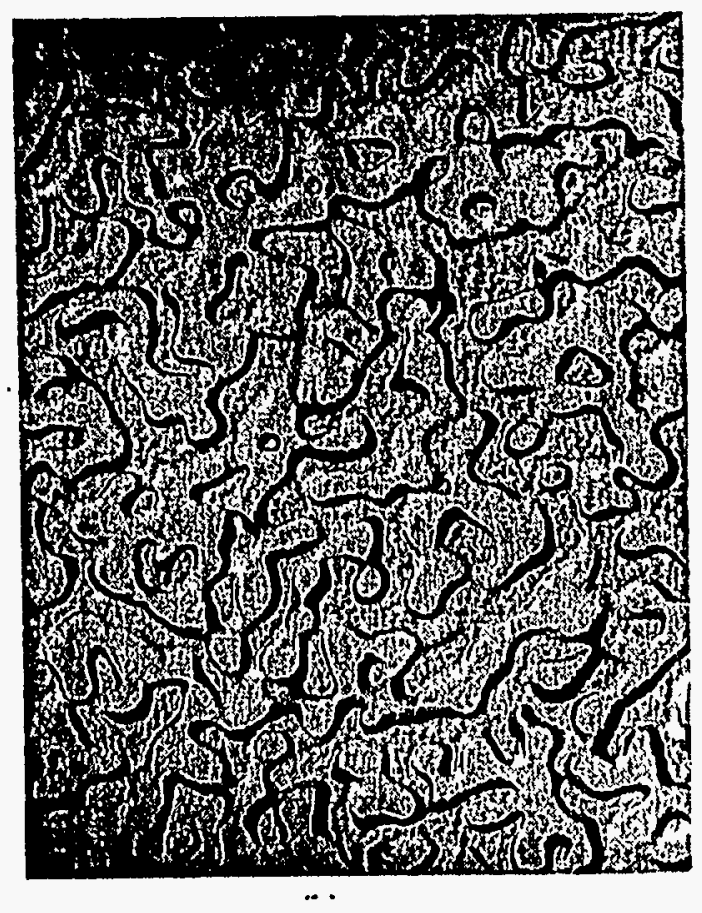

(b)

\section{- Both phases highly continuous}

(a) W. Vogel, Chemistry of Glass, Figure 7.21, p. 11, American Ceramic Society, Columbus, Ohio,1985.

(b) H. Rawson, Properties and Applications of Glass, Figure 10, Elsevier Science Publishers, Amsterdam, Netherlands, 1980. 


\section{Distinction Between Phase Separation Mechanisms}

\section{Nucleation/Growth}

Interface between phases is always same degree of sharpness during growth

Tendency for random distributions of particle sizes and positions in matrix

Tendency for separation of second-phase spherical particles with low connectivity

\section{Spinodal Decomposition}

Interface between phases initially is very diffuse, eventually sharpens

Regularity of second-phase distribution in size and positions characterized by a geometrical spacing

Tendency for separation of second-phase, non-spherical particles with high connectivity

* J.W. Cahn and R.J. Charles, Phys. Chem. Glasses, 6 (5), 181-191, (1965)

* $\quad$ Fundamental of Inorganic Chemistry, A.K. Varshneya, Academic Press, Inc., 1994 


\section{Microstructural Types for Borosilicate Systems:}

Type A: both phase highly interconnected (spinodal decomposition)

Type B: Si-rich dispersed phase, B-rich continuous matrix (nucleation/growth)

Type C: B-rich dispersed phase, Si-rich continuous matrix (nucleation/growth)

* Tomozawa, M., "Phase Separation in Glass," In Treatise on Materials Science and Technology, Vol. 17, Edited by M. Tomozawa and R.H. Doremus, Academic Press, New York, pp. 71-113, (1972). 


\section{Predicting Liquid Immiscibility in Multicomponent Nuclear Waste Glasses}




\section{Predicting Amorphous Phase Separation}

- Commonly used experimental techniques to define immiscibility domes of simple binary and some ternary systems include:

- opalescence method

- SEM/TEM techniques

- Small Angle X-ray Scattering (SAXS)

- As the systems progress from binary through ternary to multicomponent systems, detailed mapping of the immiscibility dome requires the preparation and characterization of a rapidly increasing number of glasses (extremely complex and time consuming)

- Advantageous to predict/model immiscibility in multicomponent systems based on knowledge of the more simple systems 


\section{IMMISCIBILITY IN BINARY SILICATE SYSTEMS}

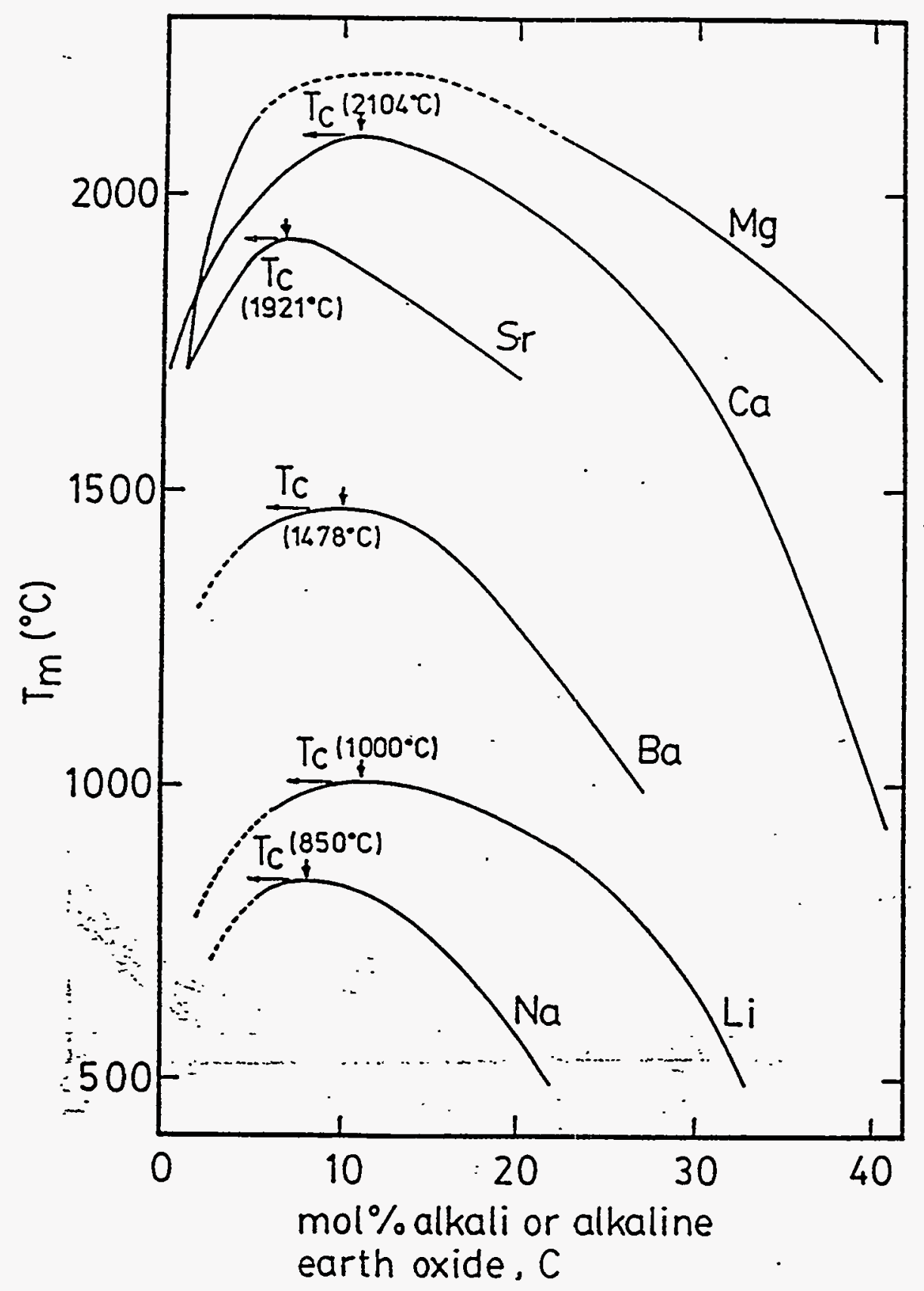

- In general, the greater the polarization power of the cation $\left(\mathrm{Z} / \mathrm{r}^{2}\right)$, the more extensive is the immiscibility gap in terms of both temperature and composition

- $\mathrm{MO}-\mathrm{SiO}_{2}$ systems generally have more extensive immiscibility gaps than the $\mathrm{X}_{2} \mathrm{O}-\mathrm{SiO}_{2}$ systems 

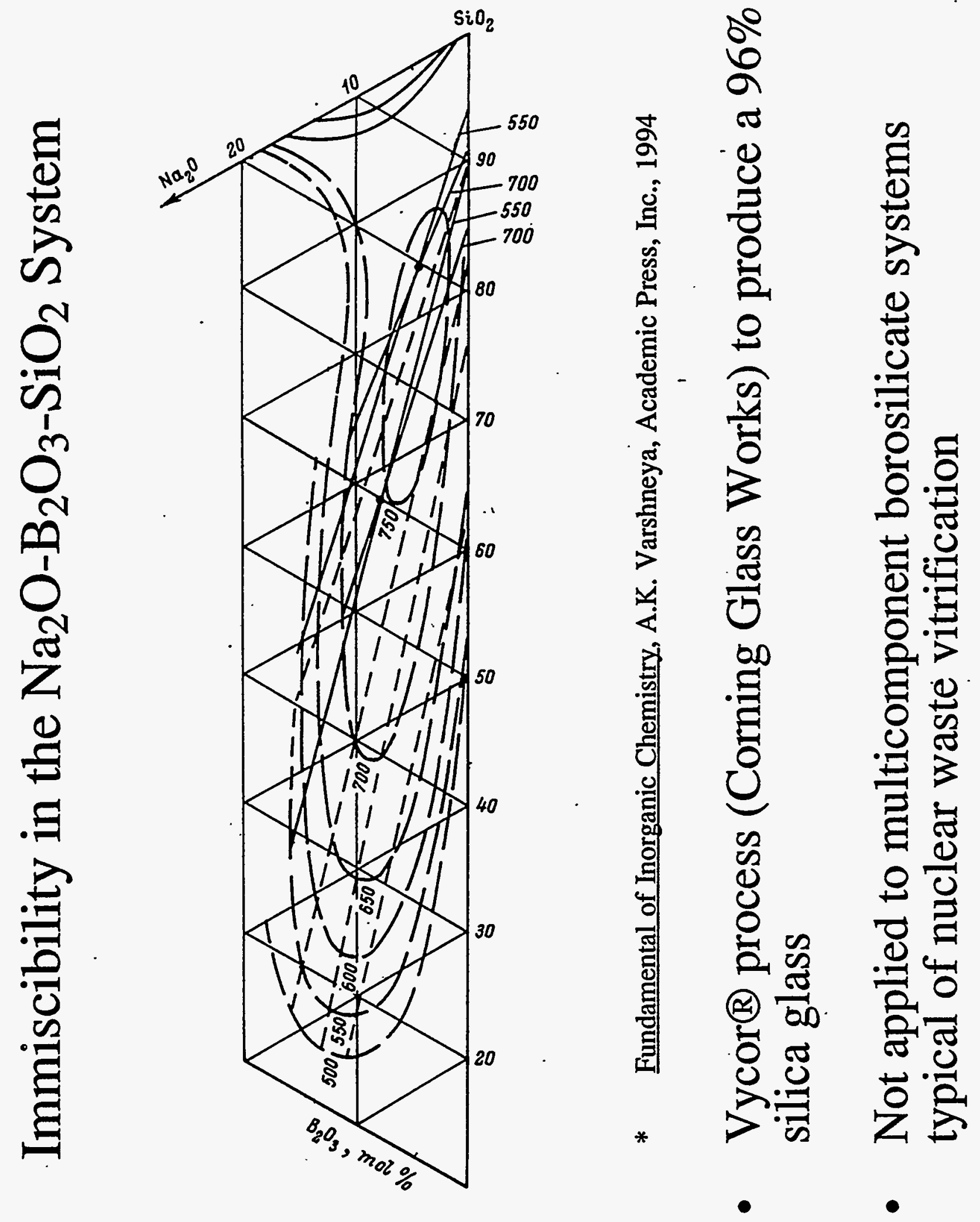


\section{Composition Region of CVS Glasses}

\begin{tabular}{|ll|}
\hline Oxide & Range (wt\%) \\
\hline $\mathrm{SiO}_{2}$ & $42-57$ \\
$\mathrm{~B}_{2} \mathrm{O}_{3}$ & $5-20$ \\
$\mathrm{Na}_{2} \mathrm{O}$ & $5-20$ \\
$\mathrm{Li}_{2} \mathrm{O}$ & $1-7$ \\
$\mathrm{CaO}$ & $0-10$ \\
$\mathrm{MgO}$ & $0-8$ \\
$\mathrm{Fe}_{2} \mathrm{O}_{3}$ & $0.5-15$ \\
$\mathrm{Al}_{2} \mathrm{O}_{3}$ & $0-17$ \\
$\mathrm{ZrO}_{2}$ & $0-13$ \\
"Others" & $1-10$ \\
\hline
\end{tabular}

- "Others" component was composed of $\mathrm{BaO}, \mathrm{CdO}, \mathrm{CeO}_{2}, \mathrm{Cr}_{2} \mathrm{O}_{3}$, $\mathrm{Cs}_{2} \mathrm{O}, \mathrm{CuO}, \mathrm{F}, \mathrm{La}_{2} \mathrm{O}_{3}, \mathrm{MnO}_{2}, \mathrm{MoO}_{3}, \mathrm{Nd}_{2} \mathrm{O}_{3}, \mathrm{NiO}, \mathrm{P}_{2} \mathrm{O}_{5}, \mathrm{PdO}, \mathrm{Pr}_{6} \mathrm{O}_{11}$, $\mathrm{Rb}_{2} \mathrm{O}, \mathrm{Rh}_{2} \mathrm{O}_{3}, \mathrm{RuO}_{2}, \mathrm{SO}_{3}, \mathrm{Sm}_{2} \mathrm{O}_{3}, \mathrm{SrO}$, and $\mathrm{Y}_{2} \mathrm{O}_{3}$. 


\section{Experimental Basis}

- Compositional submixture $\left(\mathrm{Na}_{2} \mathrm{O}-\mathrm{Li}_{2} \mathrm{O}-\mathrm{B}_{2} \mathrm{O}_{3}-\mathrm{SiO}_{2}\right)$

- Compositional subspace embedded in an overall space defining the multicomponent glass composition

- 1 to 1 correspondence between submixture and the multicomponent glass

- NLBS submixture effective in predicting the development of phase separation in multicomponent, canistered glasses and also provides a basis for the composition/durability relationship

- MCC-1 durability data of all quenched and select CCC glasses was used to obtain insight into the relation between composition and durability as a function of thermal history 


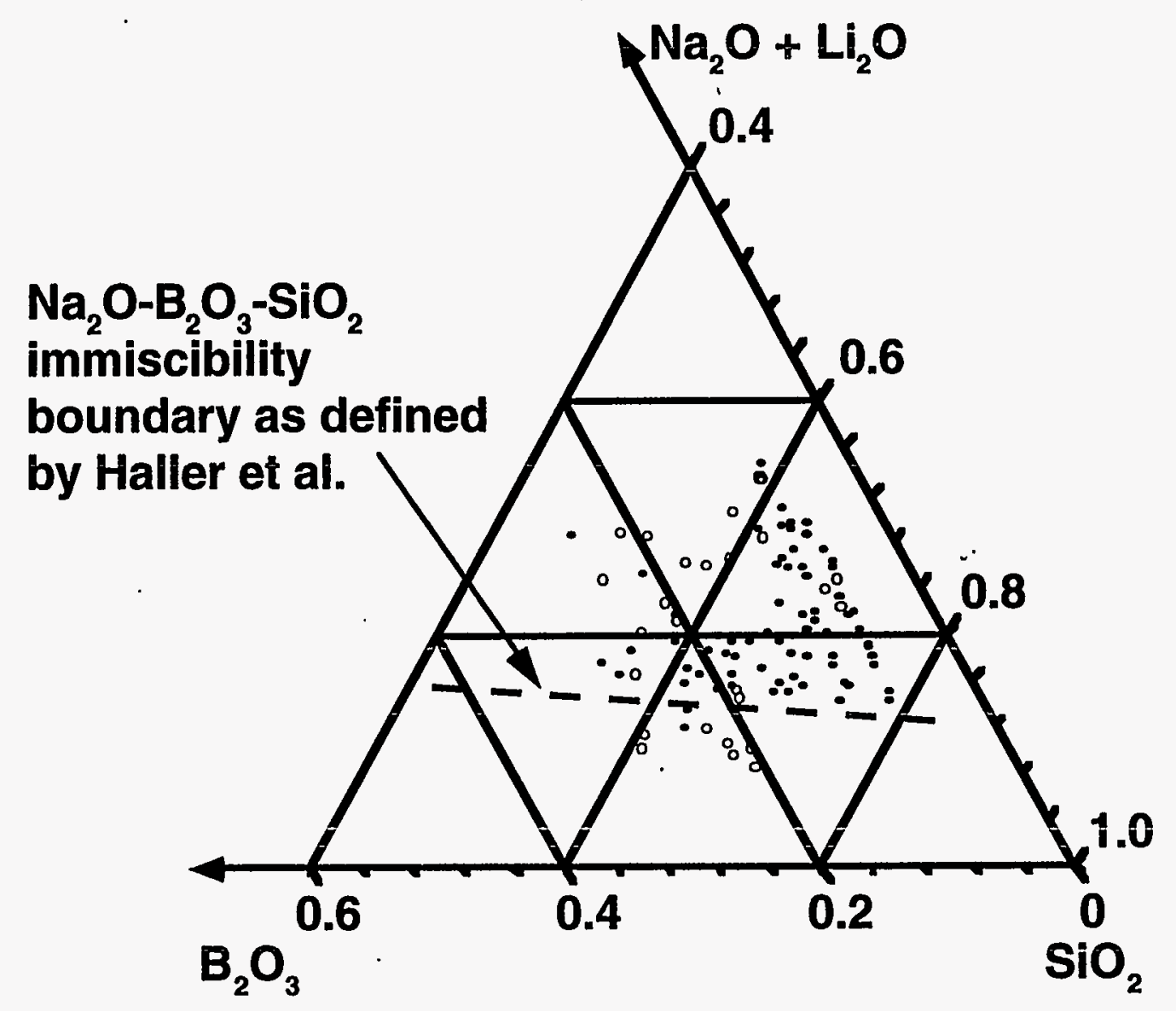

- Distribution of 123 CVS glasses within the normalized NLBS submixture

- Solid ( $\bullet$ ) and open (o) points represent high- and low-durability glasses, respectively

- Durability based on 28-day MCC-1 normalized boron (B) release values

- Three defined regions of durability

- Glasses deviating from this relation within each region 


\section{NBS and NLBS Submixtures}

High Durability

\begin{tabular}{l|c|c|c}
\hline CVS Glass & Microstructure & NBS & NLBS \\
\hline CVS2-30 & - & $Y$ & $Y$ \\
CVS1-11 & - & $Y$ & $Y$ \\
CVS2-52 & - & $Y$ & - \\
CVS2-6 & - & $Y$ & - \\
CVS2-43 & - & $Y$ & - \\
CVS2-74 & - & $Y$ & - \\
CVS2-24 & - & $Y$ & - \\
CVS1-10 & - & $Y$ & - \\
CVS2-12 & - & $Y$ & - \\
CVS2-73 & - & $Y$ & - \\
CVS1-7 & - & - & - \\
CVS2-47 & - & - & - \\
CVS2-38 & - & - & -
\end{tabular}

Low Durability

\begin{tabular}{|c|c|c|c|c|}
\hline CVS Glass & Microstructure & NBS & NLBS & $\begin{array}{l}\text { - Only two glasses } \\
\text { can not be }\end{array}$ \\
\hline $\begin{array}{l}\text { CVS1-4 } \\
\text { CVS2-29 } \\
\text { CVS2-31 } \\
\text { CVS1-9 } \\
\text { CVS2-80 } \\
\text { CVS2-78 } \\
\text { CVS2-90 } \\
\text { CVS2-26 } \\
\text { CVS1-14 } \\
\text { CVS2-25 } \\
\text { CVS2-81 }\end{array}$ & $\begin{array}{l}\text { Y } \\
\text { Y } \\
\text { Y } \\
\mathbf{C} \\
\mathbf{C} \\
\mathbf{C} \\
- \\
- \\
- \\
- \\
-\end{array}$ & $\begin{array}{l}\mathbf{Y} \\
\mathbf{Y} \\
\mathbf{Y} \\
\mathbf{Y} \\
\mathbf{Y} \\
\mathbf{Y} \\
\mathbf{Y} \\
\mathbf{Y} \\
- \\
- \\
-\end{array}$ & $\begin{array}{l}\mathbf{Y} \\
\mathbf{Y} \\
\mathbf{Y} \\
\mathbf{Y} \\
\mathbf{Y} \\
\mathbf{Y} \\
- \\
- \\
- \\
- \\
-\end{array}$ & $\begin{array}{l}\text { accounted tor by } \\
\text { the modified } \\
\text { submixture } \\
\text { (CVS1-11 and } \\
\text { CVS2-30); } \\
\text { borderline } \\
\text { glasses }\end{array}$ \\
\hline
\end{tabular}

- Majority of the high durability, non-phase separated glasses move outside the dome

- Low durability glasses relatively stable (phase separated and extensive crystallization)

- Only two glasses can not be accounted for by the modified submixture (CVS1-11 and CVS2-30); borderline glasses 


\section{Amorphous Phase Separation}

- Some borosilicate glasses are prone to phase separation

- Two domains develop when an alkali-borosilicate glass undergoes phase separation

1. Si-rich phase

2. B-rich phase

- Three microstructural types defined by Tomozawa

- Type A: both phases highly interconnected (spinodal decomposition)

- Type B: Si-rich dispersed phase, B-rich continuous matrix (nucleation/growth)

- Type C: B-rich dispersed phase, Si-rich continuous matrix (nucleation/growth) 


\section{Amorphous Phase Separation (cont.)}

- Type A or Type B: Durability deteriorates since "low-durability" B-rich phase is continuous

- Type C: Little effect on durability, and in some cases, has been shown to improve durability (Si-rich phase is continuous)

- Formation of amorphous phase separation will depend on:

1. Composition, position with respect to immiscibility dome, and

2. Thermal history that will govern kinetics 


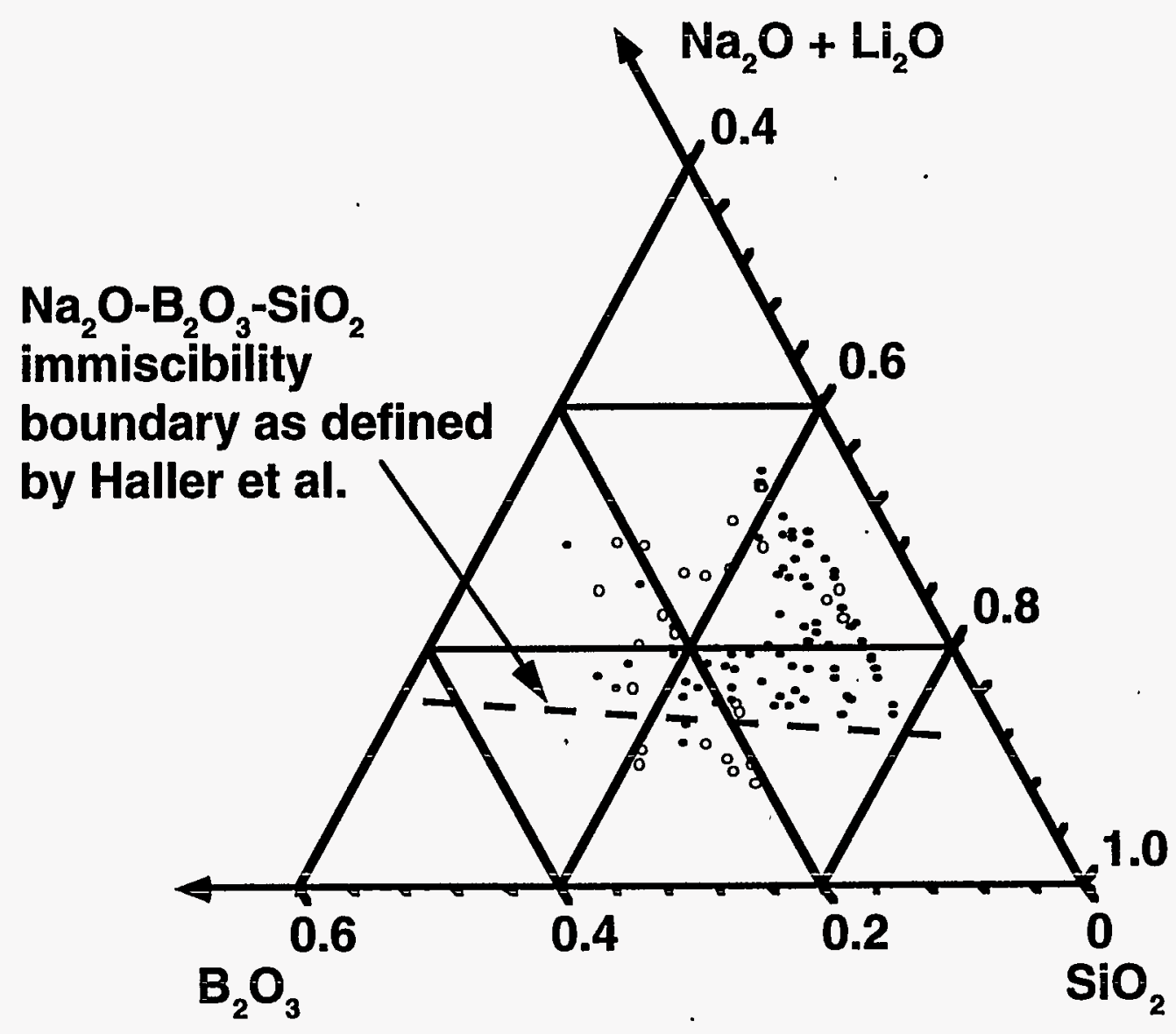

- Nine glasses lying.within the immiscibility dome are compositionally prone to amorphous phase separation

- Majority of glasses within immiscibility dome are low-durability systems

- SEM confirmed development of phase separation in three CCC glasses (CVS1-9, CVS2-29, and CVS2-31)

- Of the remaining six, four were characterized by a high degree of crystallization and two were homogeneous with respect to amorphous phase separation 

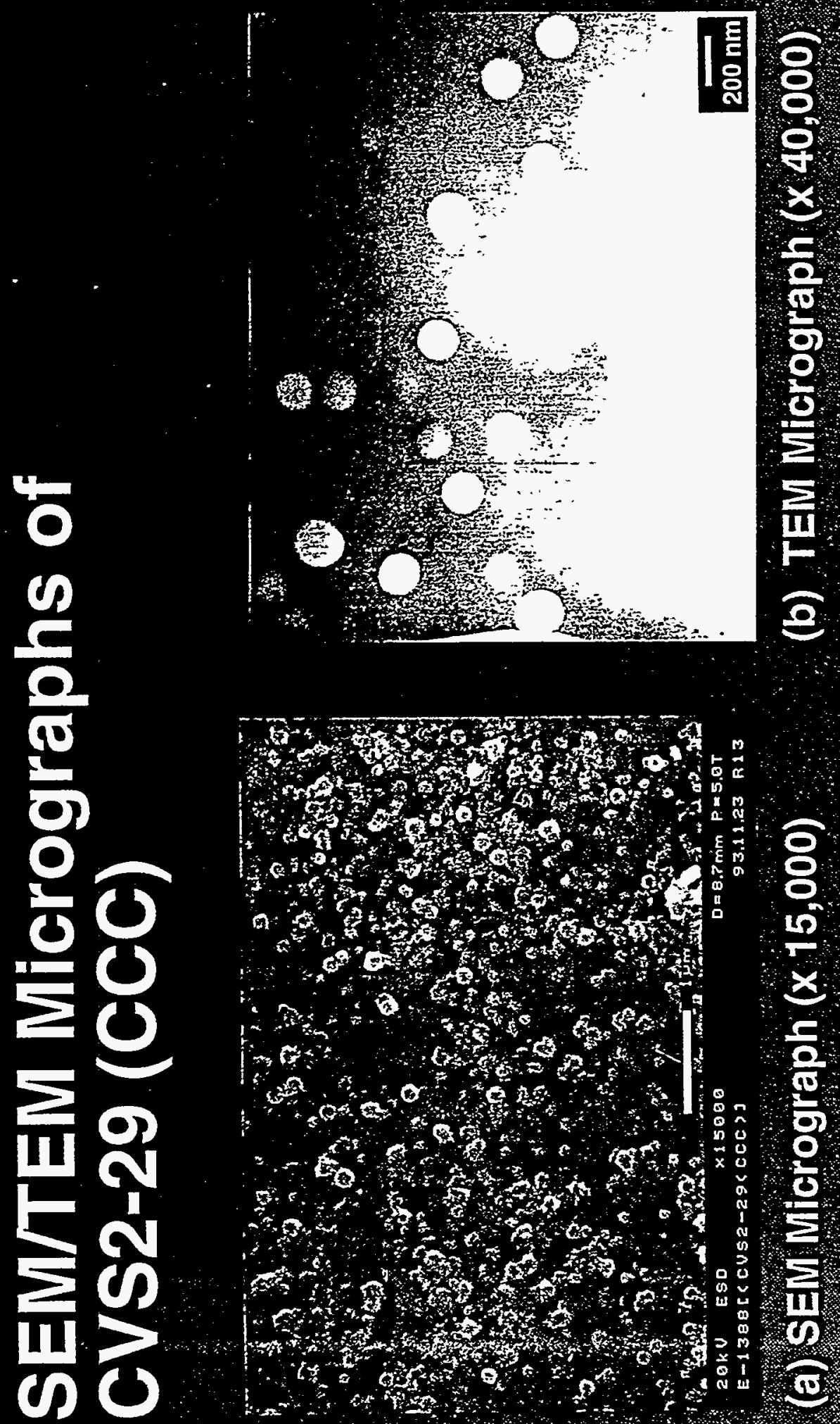

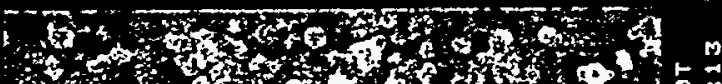

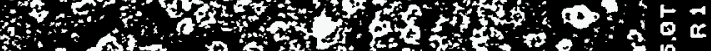

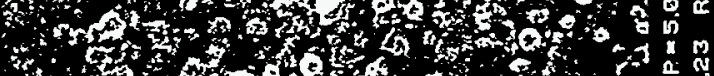

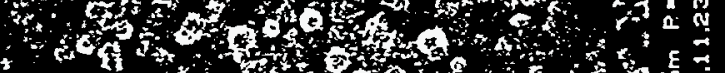

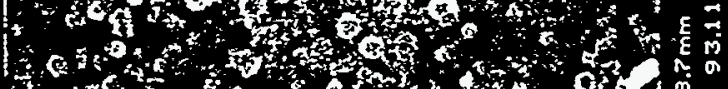

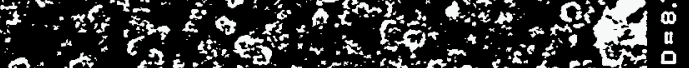

(1) or

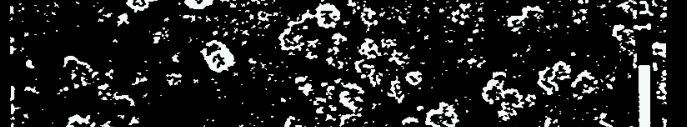

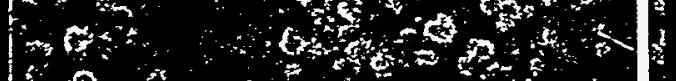

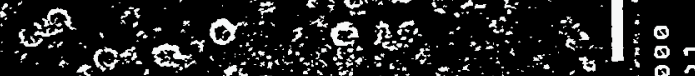

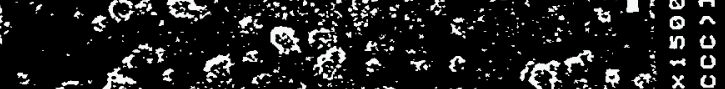

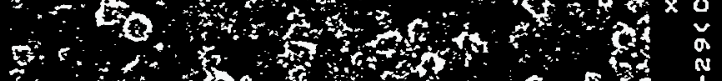

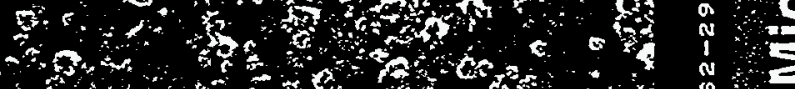

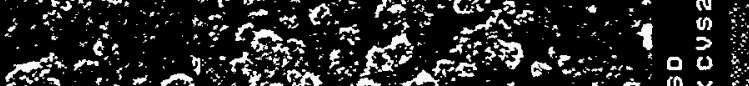

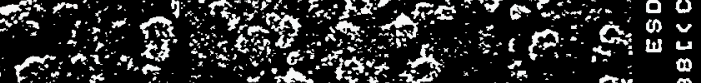

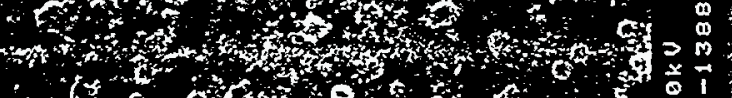

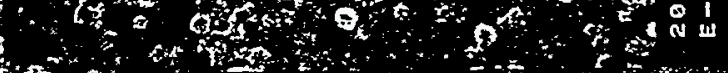

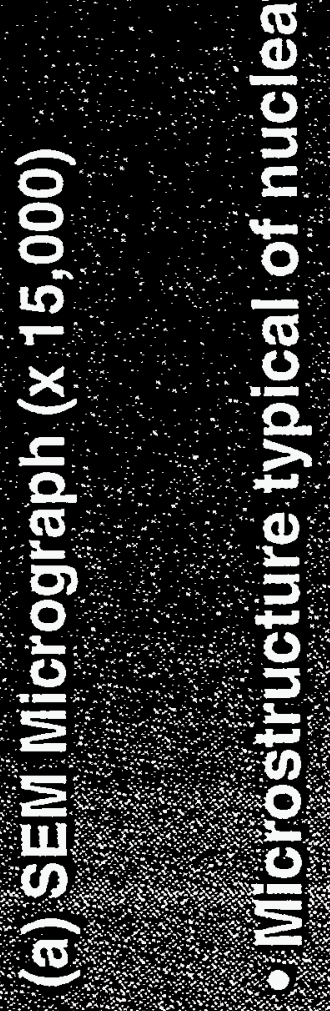




\section{Average TEM EDS Compositional Analysis of CVS2-29}

$\begin{array}{lccc}\text { Element } & \begin{array}{c}\text { Dispersed Phase } \\ (\mathrm{Wt} \%)\end{array} & \begin{array}{c}\text { Matrix Phase } \\ (\mathrm{Wt} \%)\end{array} \\ \text { Na-K } & 2.54 & 6.64 \\ \text { Si-K } & 91.72 & 51.97 \\ \text { Ca-K } & 1.04 & 12.41 \\ \text { Fe-K } & 1.27 & 3.54 \\ \text { Ni-K } & 0.02 & 1.94 \\ \text { Zr-L } & 2.85 & 17.08 \\ \text { Nd-L } & 0.03 & 4.55 \\ \text { Cd-L } & 0.11 & 1.88 \\ \text { B not detected in TEM EDS system; EELS performed }\end{array}$




\section{EELS Spectra for CVS2-29 (CCC)}

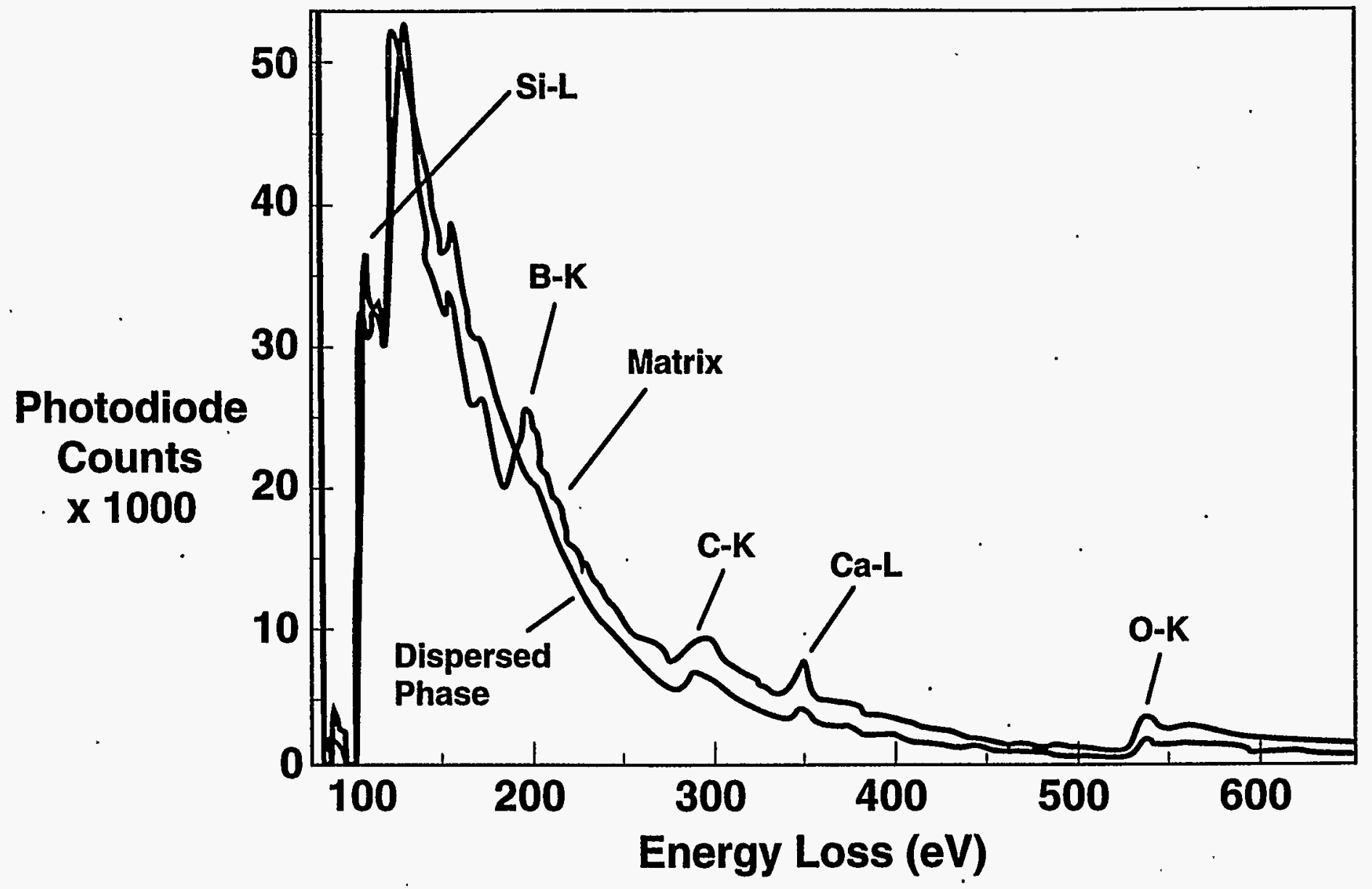

- Confirmation of Type B microstructure: Si-rich dispersed phase and B-rich matrix phase

- Microstructure detrimental to system durability 


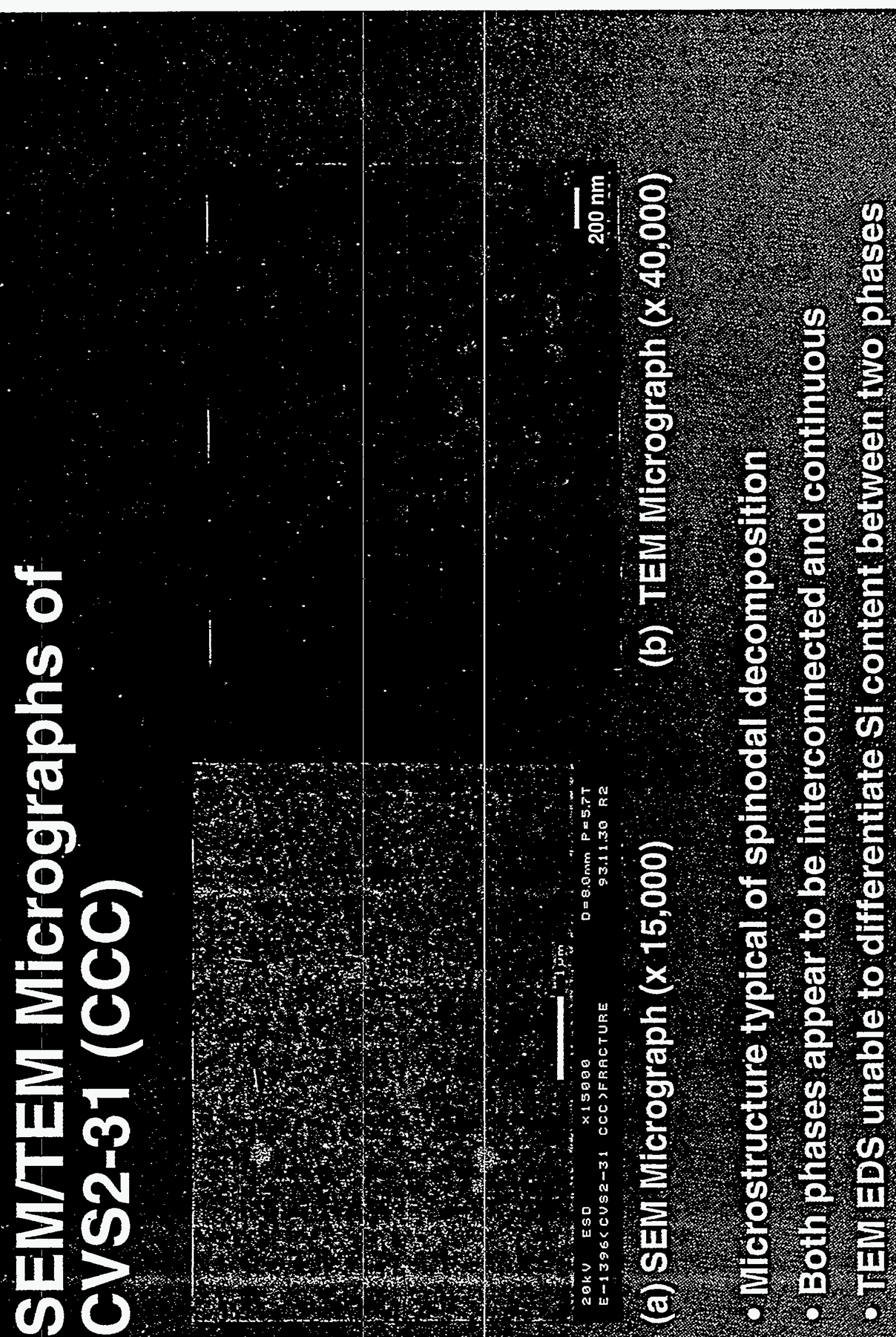




\section{EELS Spectra for CVS2-31 (CCC)}

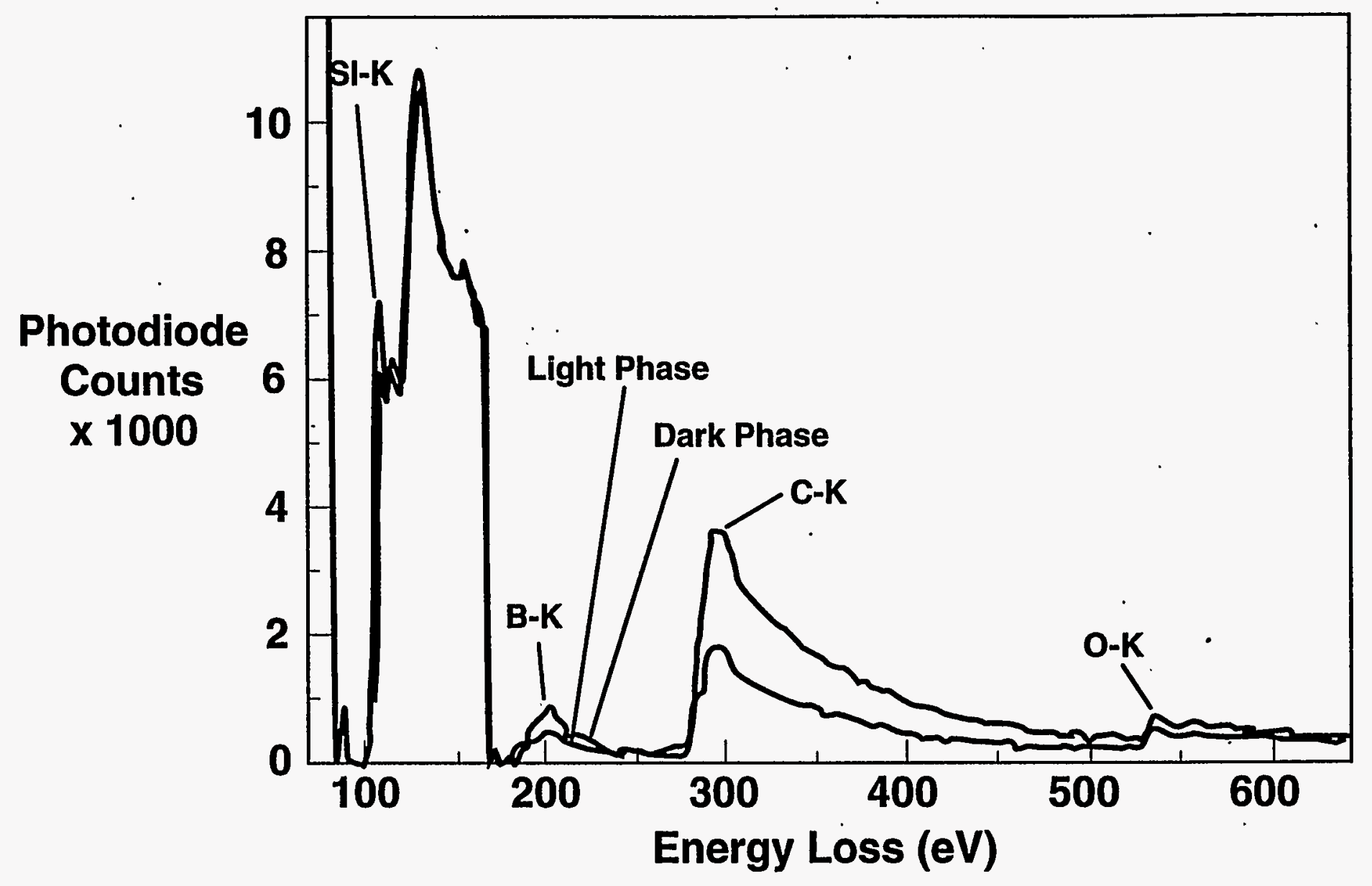

- EELS indicates a boron-rich phase

- Type A microstructure (spinodal decomposition)

- Detrimental to system's durability 


\section{Amorphous Phase Separation}

Durability Data for Two Phase Separated Glasses

- MCC-1 normalized boron released values for CVS2-29 and CVS2-31

\begin{tabular}{|c|c|c|}
\hline Glass & Quenched* & CCC \\
\hline $\begin{array}{l}\text { CVS2-29 } \\
\text { CVS2-31 }\end{array}$ & $\begin{array}{l}42.29 \\
47.02\end{array}$ & $\begin{array}{l}45.10 \\
44.49\end{array}$ \\
\hline
\end{tabular}

*Quenched samples showed no indication of phase separation by SEM

- CCC CVS2-29 (Type B microstructure) shows a slightly higher $B$ release than its counterpart non-phase separated quenched glass

- Indicates that the development of amorphous phase separation may slightly reduce the systems durability

- CCC CVS2-31 (Type C microstructure) unexpectedly shows a slight increase in durability from its counterpart non-phase separated sample

- However, both cooling schedules produce unacceptable glasses in terms of boron release values $\left(>28 \mathrm{~g} / \mathrm{m}^{2}\right)$ 


\section{Amorphous Phase Separation (cont.)}

- Due to only slight differences in release values between quenched (non-phase separated) and CCC (phase separated) samples, there seems to be very little effect of the development of phase separation on the overall durability

- Composition is inherently low in $\mathrm{Al}_{2} \mathrm{O}_{3}$ and /or $\mathrm{ZrO}_{2}$ :

Glass

CVS2-29

CVS2-31

$$
\mathrm{Al}_{2} \mathrm{O}_{3}(\mathrm{wt} \%)
$$

0.0

5.3
$\mathrm{ZrO}_{2}(\mathrm{wt} \%)$

8.3

0.0

- Composition lacks sufficient network forming oxides to provide the required 3-D network

- The effect of structural integrity (or lack thereof) dominates these two glasses not the development of amorphous phase separation

- No crystallization effects 


\section{"Highly" Crystalline Samples}

- Four glasses prone to amorphous phase separation were characterized by a high degree of crystallization (CCC samples)

Primary Phase for "Highly" Crystalline Glasses Prone to Amorphous Phase Separation

\begin{tabular}{|c|c|c|}
\hline Glass & $\begin{array}{c}\text { Primary } \\
\text { Crystalline Phase }\end{array}$ & $\begin{array}{l}\text { Estimated } \\
\text { Volume \% }\end{array}$ \\
\hline $\begin{array}{l}\text { CVS2-78 } \\
\text { CVS2-79 } \\
\text { CVS2-80 } \\
\text { CVS1-9 }\end{array}$ & $\begin{array}{l}\mathrm{SiO}_{2} \text {, cristobalite } \\
\mathrm{SiO}_{2} \text {, cristobalite } \\
\mathrm{SiO}_{2} \text {, cristobalite } \\
\text { Unidentified }\end{array}$ & $\begin{array}{l}22 \\
20 \\
15 \\
5-7\end{array}$ \\
\hline
\end{tabular}

- Early development of a Type B microstructure (Si-rich dispersed phase) may act as a precursor to $\mathrm{SiO}_{2}$ crystallization upon further cooling

- Development of amorphous phase separation may lower the kinetic and thermodynamic barriers to crystallization

- However, internal crystallization can occur without prior phase separation 


\section{REFERENCES}

1. Tomozawa, M., "Phase Separation in Glass," In Treatise on Materials Science and Technology, Vol. 17, Edited by M. Tomozawa and R.H. Doremus, Academic Press, New York, pp. 71-113, (1972).

2. Tomozawa, M., G.M. Singer, Y. Oka, and J.T. Warden, "Phase Separation in Nuclear Waste Glasses," In Ceramics in Nuclear Waste Management, Proceedings of Symposium in Cincinnati, OH, April/May 1979. Edited by T.D. Chikalla and J.E. Mendel, U.S. Dept. of Energy, Tech. Info. Center, pp. 193-197.

3. Peeler, D.K. and P.R. Hrma, "Predicting Liquid Immiscibility in Multicomponent Nuclear Waste Glasses," Ceramic Transaction Series, Environmental and Waste Management in the Ceramic Industry II, Volume 45, pp. 219 - 229 (1994).

4. Piepel, G.F., P.R. Hrma, S.O. Bates, M.J. Schweiger, and D.E. Smith, First-Order Study of Property/Composition Relationships for Hanford Waste Vitrification Plant Glasses, PNL8502, Chapter 12, Section 11.4, Pacific Northwest Laboratory, Richland, Washington, (1993).

5. Ehrt, D., H. Reiss, and W. Vogel, "Microstructural Study of CoO-containing $\mathrm{Na}_{2} \mathrm{O}-\mathrm{B}_{2} \mathrm{O}_{3}$ $\mathrm{SiO}_{2}$ Glasses, Silikattechnik, Vol. 28, pp. 359-364, 1977.

6. Taylor, P., "A Review of Phase Separation in Borosilicate Glasses, with Reference to Nuclear Fuel Waste Immobilization," Whiteshell Nuclear Research Establishment, AECL10173 (1990).

7. Danilova, N.P., O.V. Mazurin, and T.S. Tschomskaya, "The Influence of the Structure of Phase Separated Glasses on Their Chemical Durability," Proc. Int. Cong. Glass (9th), Versailles, pp. 825-841 (1971).

8. Taylor, P., S.D. Ashmore, and D.G. Owen, "Chemical Durability of Some Sodium Borosilicate Glasses Improved by Phase Separation," J. Amer. Ceram. Soc., 70 [5] 333-338 (1987).

9. Dietzel, A., "The Cation Field Strength and the Relation to Devitrifying Processes, to Compound Formation, and to the Melting Points of Silicates," Z. Electrochem., 48 [1] 9 - 23 (1942).

10. Warren, B.E. and A.G Pincus, "Atomic Considerations of Immiscibility in Glass Systems," J. Amer. Ceram. Soc., 23 [10] 301 - 304 (1940).

11. Haller, W., D.H. Blackburn, F.E. Wagstaff, and R.J. Charles, "Metastable Immiscibility Surface in the System $\mathrm{Na}_{2} \mathrm{O}-\mathrm{B}_{2} \mathrm{O}_{3}-\mathrm{SiO}_{2}$, , J. Amer. Ceram. Soc., 53 [1] 34 - 39 (1970).

12. Kawamoto, Y. and M. Tomozawa, "Prediction of Immiscibility Boundaries of Ternary Silicate Glasses," Phys. Chem. Glasses, 22 [1] 11 - 16 (1987).

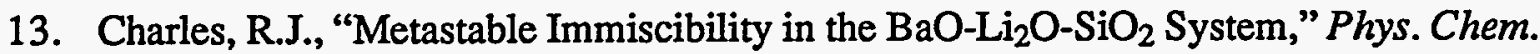
Glasses, 8 [5] 185 - 189 (1967).

14. Levin, E.M. and S. Block, "Structural Interpretation of Immiscibility in Oxide Systems: I, Analysis and Calculation of Immiscibility," J. Amer. Ceram. Soc., 40 [3] 95 - 106 (1957). 
15. Strand, Z. and P. Strand, "Calculation of Metastable Two-Liquid Tie Lines in Ternary GlassForming Systems," J. Amer. Ceram. Soc., 61 [7/8] 283 - 286 (1978).

16. Burnett, D.G. and R.W. Douglas, "Liquid-Liquid Phase Separation in the Soda-Lime-Silica System," Phys. Chem. Glasses, 11 [5] 125 - 135 (1970).

17. Taylor, P. and D.G. Owen, "Liquid Immiscibility in the System $\mathrm{Na}_{2} \mathrm{O}-\mathrm{ZnO}-\mathrm{B}_{2} \mathrm{O}_{3}-\mathrm{SiO}_{2}$," $J$. Amer. Ceram. Soc., 64 [6] 360-367 (1981).

18. Taylor, P., A.B. Campbell, and D.G. Owen, "Liquid Immiscibility in the Systems $\mathrm{X}_{2} \mathrm{O}-\mathrm{MO}$ $\mathrm{B}_{2} \mathrm{O}_{3}-\mathrm{SiO}_{2}(\mathrm{X}=\mathrm{Na}, \mathrm{K} ; \mathrm{M}=\mathrm{Mg}, \mathrm{Ca}, \mathrm{Ba})$ and $\mathrm{Na}_{2} \mathrm{O}-\mathrm{MgO}-\mathrm{BaO}-\mathrm{B}_{2} \mathrm{O}_{3}-\mathrm{SiO}_{2}$,"J. Amer. Ceram. Soc., 66 [5] 347-351 (1983).

19. Taylor, P., S.D. Ashmore, and A.B. Campbell, "Liquid Immiscibility in the Systems $\mathrm{Na}_{2} \mathrm{O}$ $\mathrm{Yb}_{2} \mathrm{O}_{3}-\mathrm{B}_{2} \mathrm{O}_{3}-\mathrm{SiO}_{2}$ and $\mathrm{K}_{2} \mathrm{O}-\mathrm{Yb}_{2} \mathrm{O}_{3}-\mathrm{B}_{2} \mathrm{O}_{3}-\mathrm{SiO}_{2}$," J. Amer. Ceram. Soc., C-186 (1984).

20. Tomozawa, M., "Liquid Phase Separation and Crystal Nucleation in $\mathrm{Li}_{2} \mathrm{O}-\mathrm{SiO}_{2}$ Glasses," Phys. Chem. Glasses, 13, 161 - 166 (1972).

21. Matusita, K., J. Maki, and M. Tashiro, "Effect of Added Oxides on the Crystallization and Phase Separation of $\mathrm{Li}_{2} \mathrm{O}-3 \mathrm{SiO}_{2}$ Glasses," Phys. Chem. Glasses, 15, 106 - 108 (1974).

22. Zanotto, E.D., "The Effect of Amorphous Phase Separation on Crystal Nucleation in BariaSilica and Lithia-Silica Glasses," Ph.D. Thesis, Sheffield University (1981). 


\section{Minor Components in Nuclear Waste Glasses}

Hong $\mathrm{Li}$

June, 1995

Materials Applications Section

Pacific Northwest Laboratory

Richland, Washington 99352 


\section{Collaborators:}

S. Crichton

J. Coleman

J.G. Darab

$X$. Feng

M. Gong

P.R. Hrma

D.S. Kim

M.H. Langowski

D. MaCready

S. Palmer
D.K. Peeler

K. Pool

R. Sanders

M.J. Schweiger

D.E. Smith

P.A. Smith

M. Tomozawa

J.D. Vienna

J.H. Westsik, Jr. 


\section{BACKGROUND}

WHAT DO WE KNOW ABOUT

MINOR COMPONENTS ?

$\mathrm{Cl}, \mathrm{F}$, and $\mathrm{SO}_{3}$ : Volatility

All components : Phase Seg./Sep.

$\mathrm{Cr}_{2} \mathrm{O}_{3}$ : Crystallization

WHAT DO WE NEED TO KNOW ?

Minor component solubility limits as a function of waste glass compositions

Effects on batch melting process

Effects on glass durability 


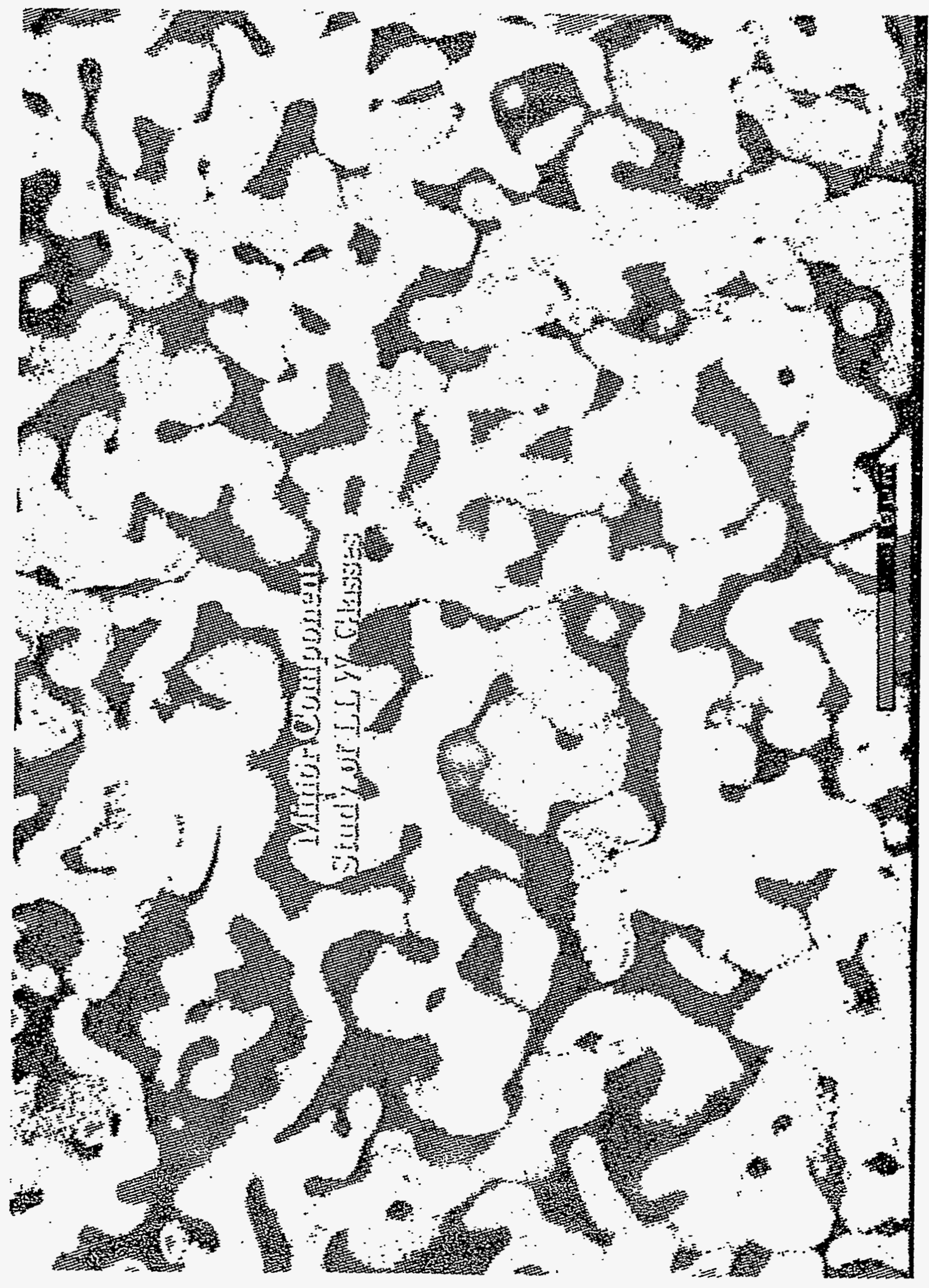




\section{WORKING SCOPE}

Solubility Limits of Minor Components

Glass Melting Process

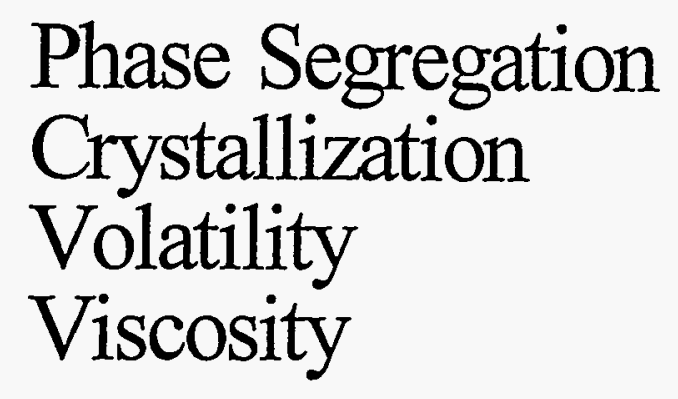

Glass Durability

7-Day Product Consistency Test

Flow-Through Test 
LLW Glass Compositions (wt\%)

\begin{tabular}{|c|c|c|c|c|}
\hline Oxide & L6-5412 & L4-9012 & (L4-909) & (L5-0912) \\
\hline $\mathrm{SiO}_{2}$ & 56.78 & 56.78 & 59.78 & 56.78 \\
\hline $\mathrm{B}_{2} \mathrm{O}_{3}$ & 5.00 & 9.00 & 9.00 & 0.00 \\
\hline $\mathrm{Na}_{2} \mathrm{O}$ & 20.00 & 20.00 & 20.00 & 20.00 \\
\hline $\mathrm{CaO}$ & 4.00 & 0.00 & 0.00 & 9.00 \\
\hline $\mathrm{Al}_{2} \mathrm{O}_{3}$ & 12.00 & 12.00 & 9.00 & 12.00 \\
\hline $\begin{array}{c}\text { Others } \\
\mathrm{Bi}_{2} \mathrm{O}_{3}, \mathrm{Cl}, \mathrm{F}, \\
\mathrm{Fe}_{2} \mathrm{O}_{3}, \mathrm{~K}_{2} \mathrm{O}, \\
\mathrm{MnO}_{2} \mathrm{Nd}_{2} \mathrm{O}_{3}, \\
\mathrm{P}_{2} \mathrm{O}_{5} \mathrm{SO}_{3}, \\
\mathrm{Cr}_{2} \mathrm{O}_{3}, \mathrm{ZrO}_{2}\end{array}$ & $\begin{array}{c}2.20 \\
\text { Spiked with } \\
\mathrm{Cl}, \mathrm{F}, \mathrm{P}_{2} \mathrm{O}_{5}, \\
\mathrm{SO}_{3}, \mathrm{Cr}_{2} \mathrm{O}_{3}\end{array}$ & $\begin{array}{c}2.20 \\
\\
\text { Spiked with } \\
\mathrm{Cl}, \mathrm{F}_{2}, \mathrm{P}_{2} \mathrm{O}_{5}, \\
\mathrm{SO}_{3}, \mathrm{Cr}_{2} \mathrm{O}_{3}\end{array}$ & $\begin{array}{c}2.22 \\
\text { Spiked with } \\
\mathrm{Cl}, \mathrm{F}, \mathrm{P}_{2} \mathrm{O}_{5}, \\
\mathrm{SO}_{3}, \mathrm{Cr}_{2} \mathrm{O}_{3}\end{array}$ & $\begin{array}{c}2.22 \\
\\
\text { Spiked with } \\
\mathrm{Cl}, \mathrm{F}, \mathrm{P}_{2} \mathrm{O}_{5}, \\
\mathrm{SO}_{3}, \mathrm{Cr}_{2} \mathrm{O}_{3}\end{array}$ \\
\hline
\end{tabular}

(Batch: Oxides, Boric Acid and Sodium-Containing Salts) 


\section{- Minor Component Solubility}

Maximum concentration in the glass (quenched and annealed samples) :

free from crystals under an optical microscope

amorphous to x-ray

melted in ambient air 


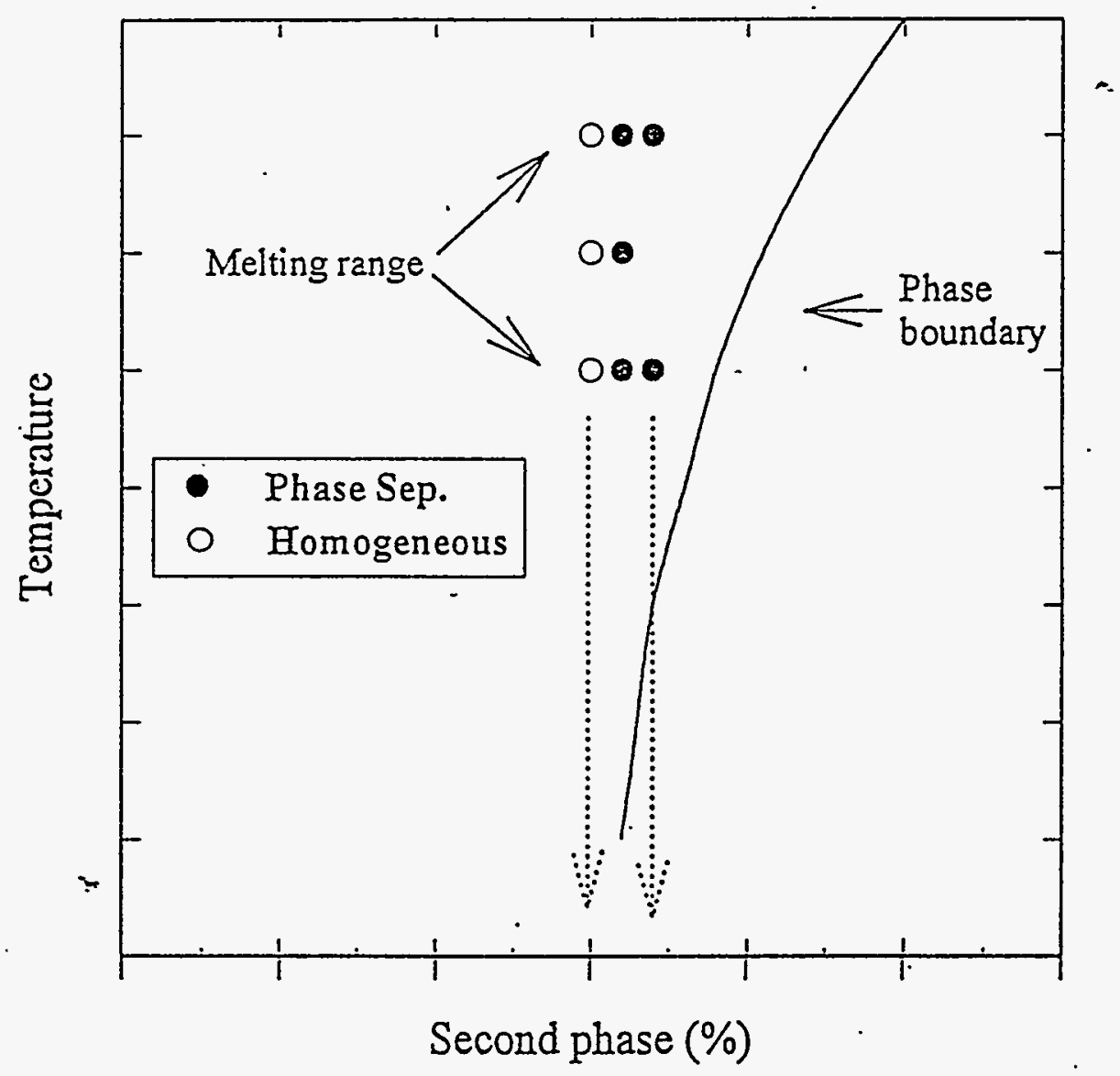

Figure 1. Schematic diagram of a system that is homogeneous in the melting range but becomes phase separated during cooling. The observed solubility is independent of temperature. 

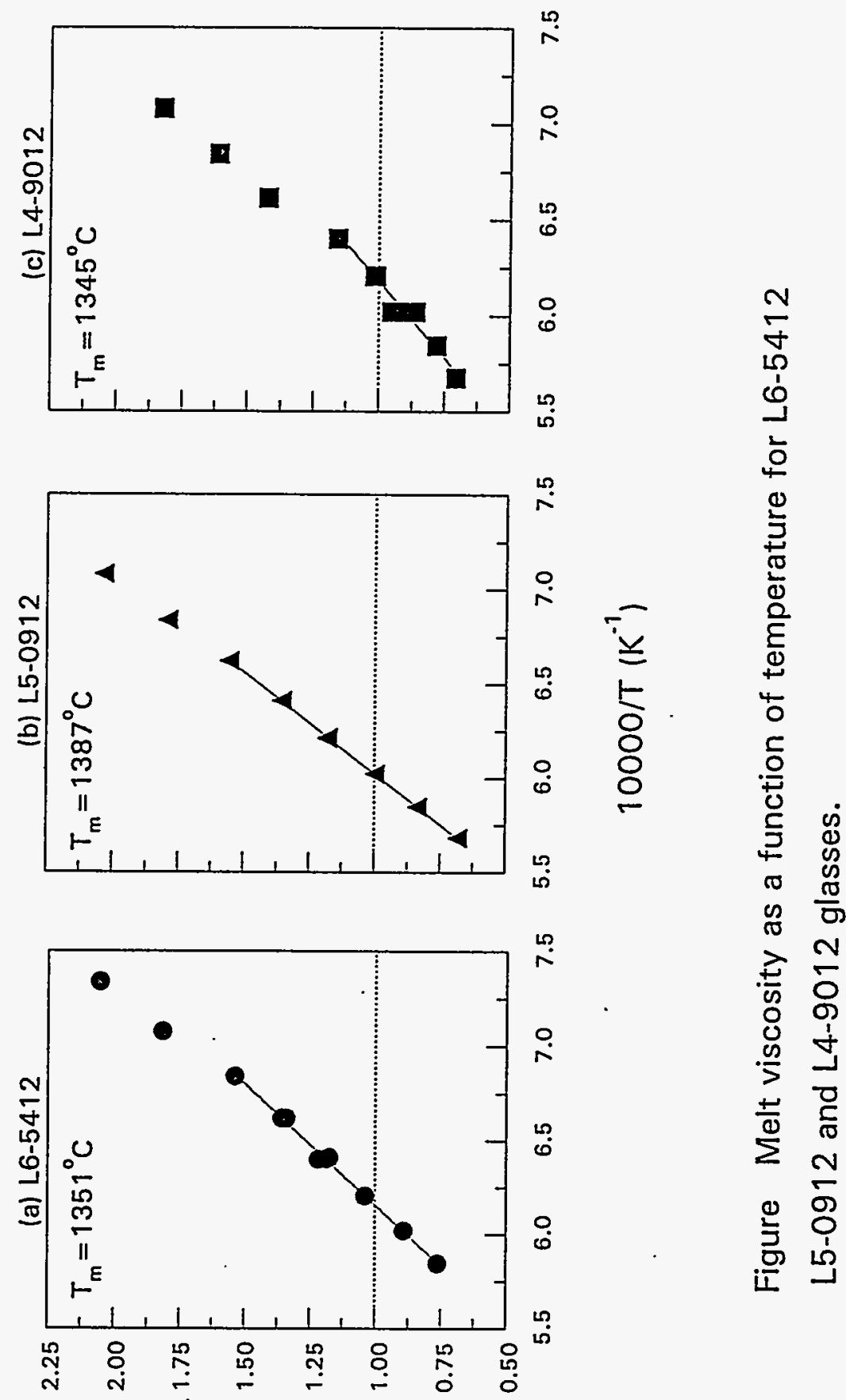

(s.ed ' 


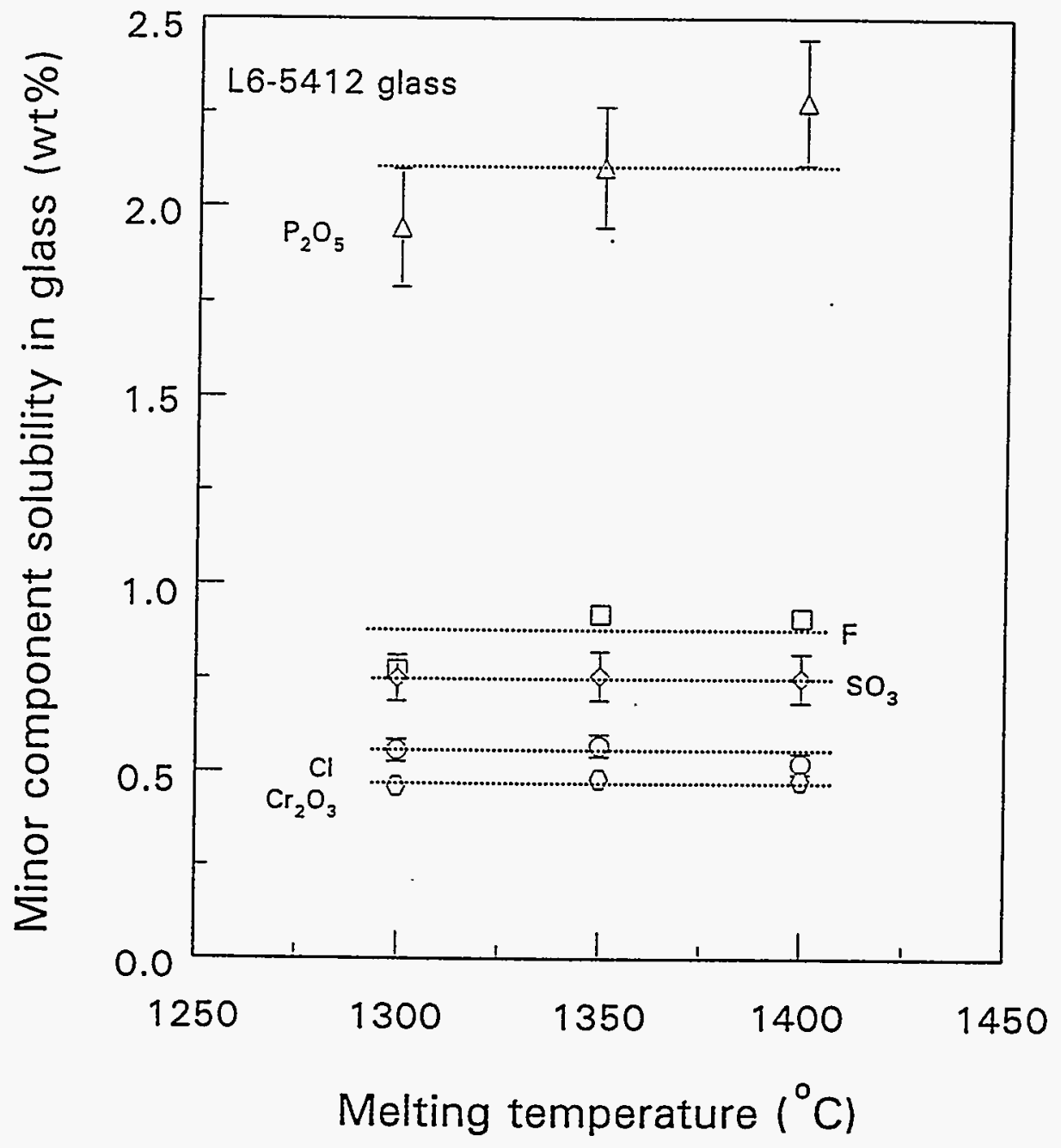


Solubility of Minor Components in LLW Glasses (wt\%)

Tm $=1350$ C / Time $=2 \mathrm{~h}$ (ambient air)
\begin{tabular}{|l|c|c|}
\hline Glass & L6-5412 & L4-9012 \\
\hline CaO $: 4 \mathrm{wt} \%$ & $\begin{array}{c}\mathrm{B} 2 \mathrm{O} 3: 9 \mathrm{wt} \% \\
\mathrm{CaO}: 0 \mathrm{wt} \%\end{array}$ \\
\hline Chlorine, CI & 0.57 & 0.49 \\
\hline Fluorine, F & 0.92 & $1.18<\mathrm{X}<1.45$ \\
\hline Phosphate, P2O5 & 2.10 & $4.72<\mathrm{X}<5.72$ \\
\hline Sulfate, SO3 & 0.75 & 0.47 \\
\hline Chromium Oxide, Cr2O3 & 0.48 & 1.04 \\
\hline
\end{tabular}




\section{Sulfate Solubility in Silicate Glass}

$$
\begin{aligned}
\equiv \mathrm{Si}-\mathrm{O}-\mathrm{Si} \equiv+2 \mathrm{Na}^{+}: \mathrm{O}^{2-} \text { (glass) } \\
\Longleftrightarrow 2\left(\equiv \mathrm{Si}_{-} \mathrm{O}^{-}: \mathrm{Na}^{+}\right) \text {(glass) }
\end{aligned}
$$

$\mathrm{SO}_{3}$ (gas) $+2 \mathrm{Na}^{+}: \mathrm{O}^{2-}$ (molten salt $)$

$$
\Longleftrightarrow 2 \mathrm{Na}^{+}: \mathrm{SO}_{4}{ }^{2-} \text { (molten salt) }
$$

$\left[\mathrm{SO}_{4}^{2-}\right] \propto$

$$
\left.P\left(\mathrm{SO}_{3}\right) *\left[\mathrm{Na}^{+}\right]^{2}\left[\mathrm{ES}-\mathrm{O}^{-}\right]^{2} / \text { [ } \mathrm{ESi}-\mathrm{O}-\mathrm{Si}=\right]
$$

(Ref: K. Papadopoulos, Phys. Chem. Glasses, 14 (1973) 60-65) 


\section{- Volatilization}

Minor Component - $\mathrm{Cl}, \mathrm{F}$, and $\mathrm{SO}_{3}$

High $\mathrm{B}_{2} \mathrm{O}_{3}$ Enhances Volatility of $\mathrm{Cl}, \mathrm{F}$, and $\mathrm{SO}_{3}$ 

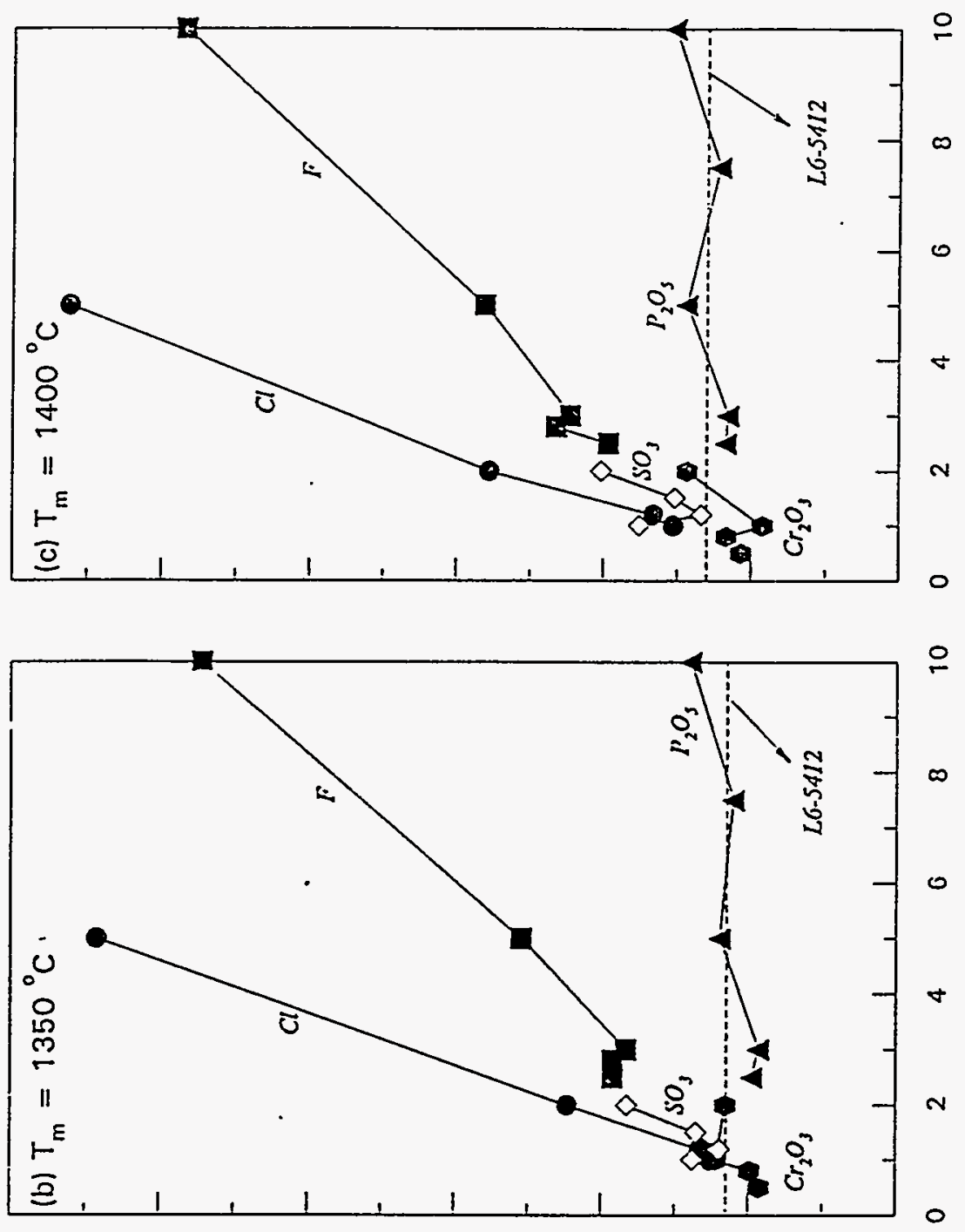

$\therefore-\frac{20}{3}$



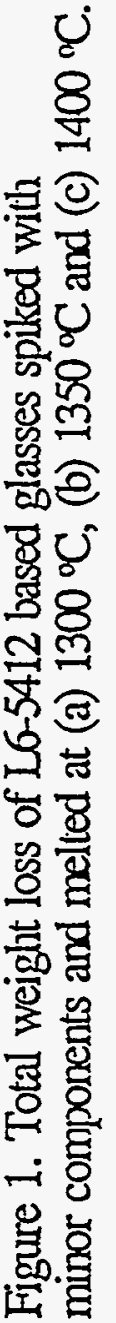

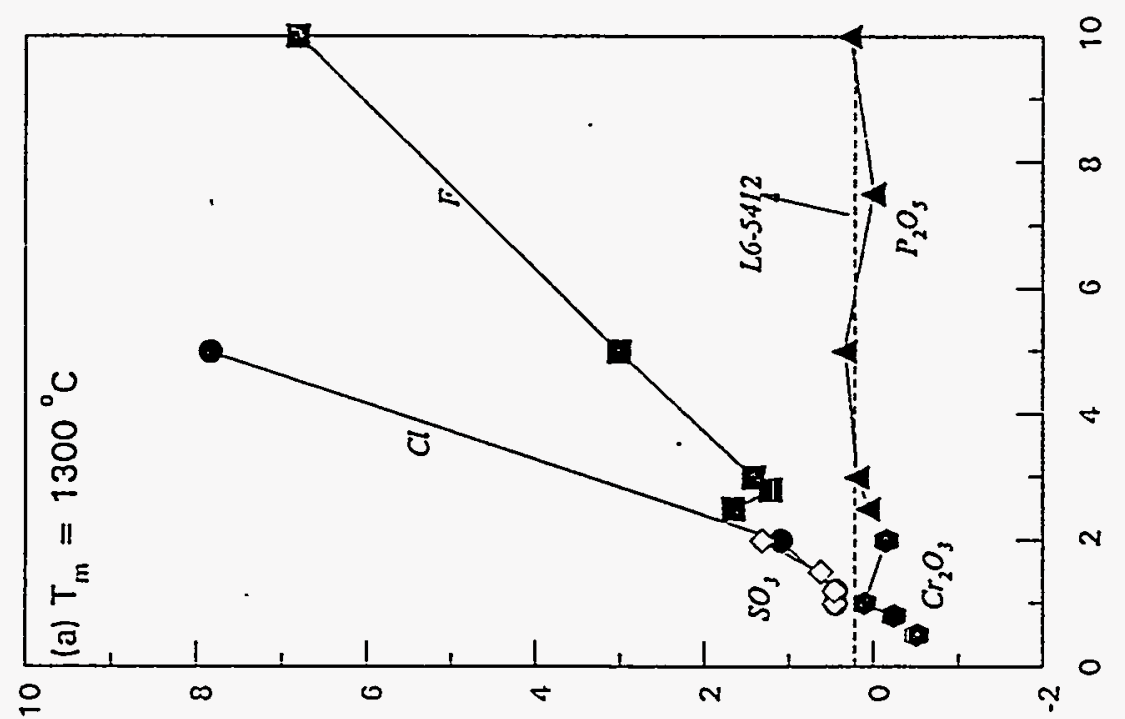

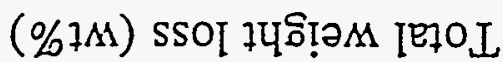




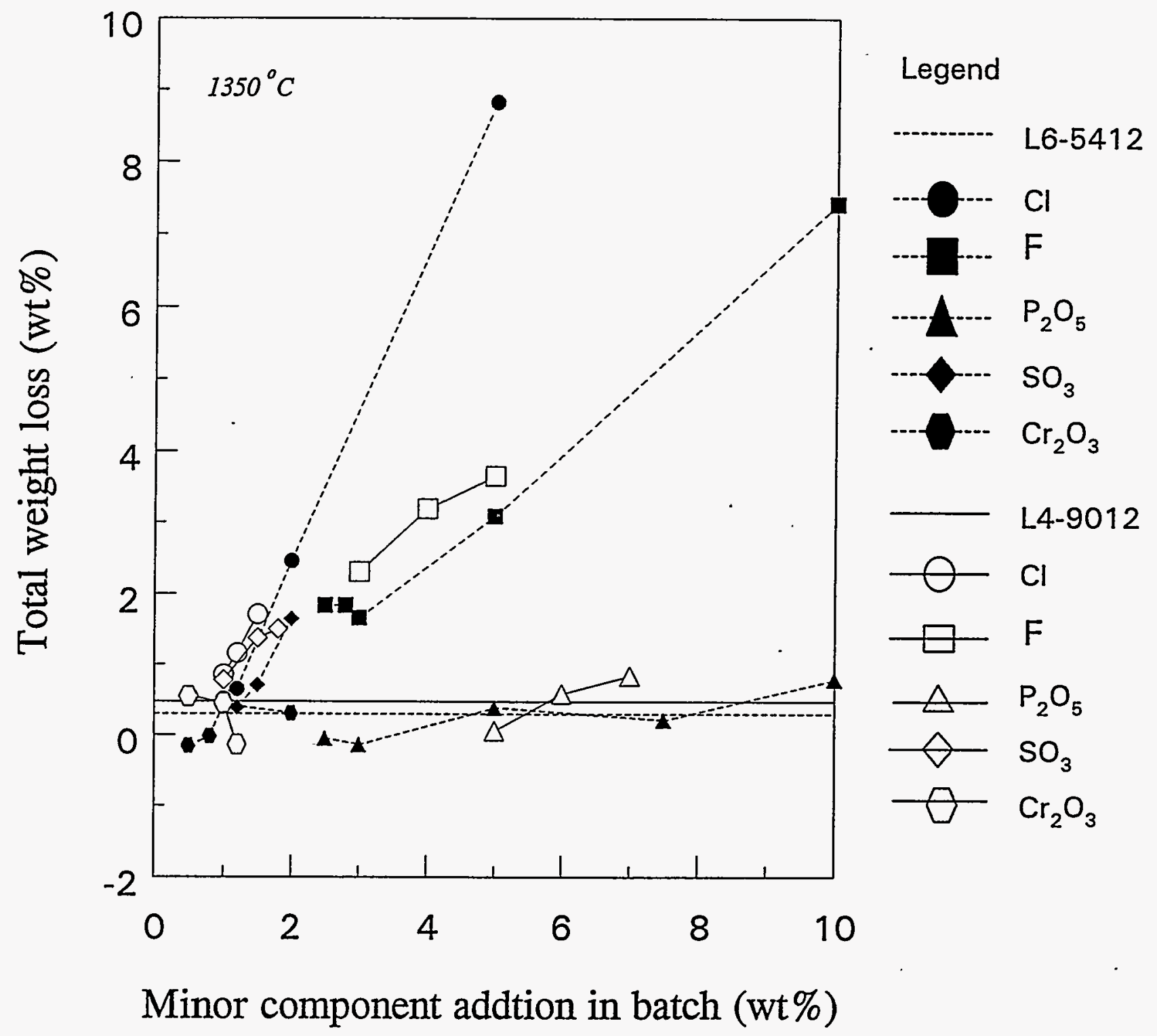


- Crystallization

Crystalline Phases in Na-Ca-Al-B-Si Glass Over-saturated with Minor Components

\begin{tabular}{|l|l|}
\hline $\begin{array}{l}\text { Minor } \\
\text { Component }\end{array}$ & Crystalline Phases \\
\hline Chlorine & $\mathrm{NaCl}$ \\
\hline Fluorine & $\begin{array}{l}\mathrm{NaF} \\
\mathrm{CaF}\end{array}$ \\
\hline Phosphate & $\begin{array}{l}\mathrm{Na}_{3} \mathrm{PO}_{4} \\
\mathrm{Na}_{2} \mathrm{Ca}_{4}\left(\mathrm{PO}_{4}\right)_{2} \mathrm{SiO}_{4}\end{array}$ \\
\hline Sulfate & $\mathrm{Na}_{2} \mathrm{SO}_{4}$ \\
\hline $\begin{array}{l}\text { Chromium } \\
\text { Oxide }\end{array}$ & $\mathrm{Cr}_{2} \mathrm{O}_{3}$ \\
\hline
\end{tabular}

(glass : L6-5412) 


\section{- Phase Segregation}

$\mathrm{Cl}$ and $\mathrm{SO}_{3}$ :

Precipitation from the melt

Accumulation on the melt surface

Occurred at glass processing temperature

$\mathrm{F}$ and $\mathrm{P}_{2} \mathrm{O}_{5}$ :

Precipitation from the melt

Occurred during the melt cooling

$\mathrm{Cr}_{2} \mathrm{O}_{3}$ :

Precipitation from the melt Occurred probably during the melt cooling 


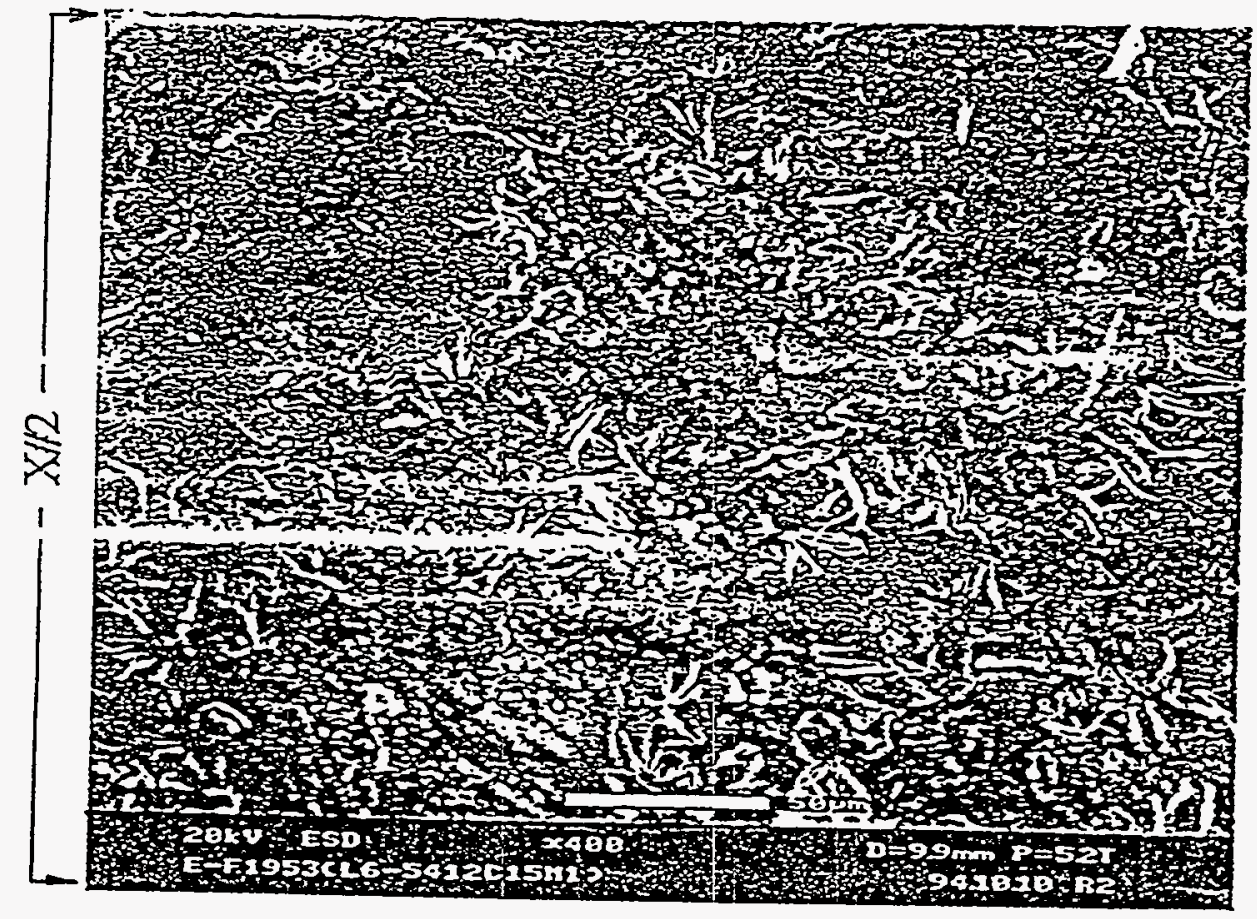

(a)

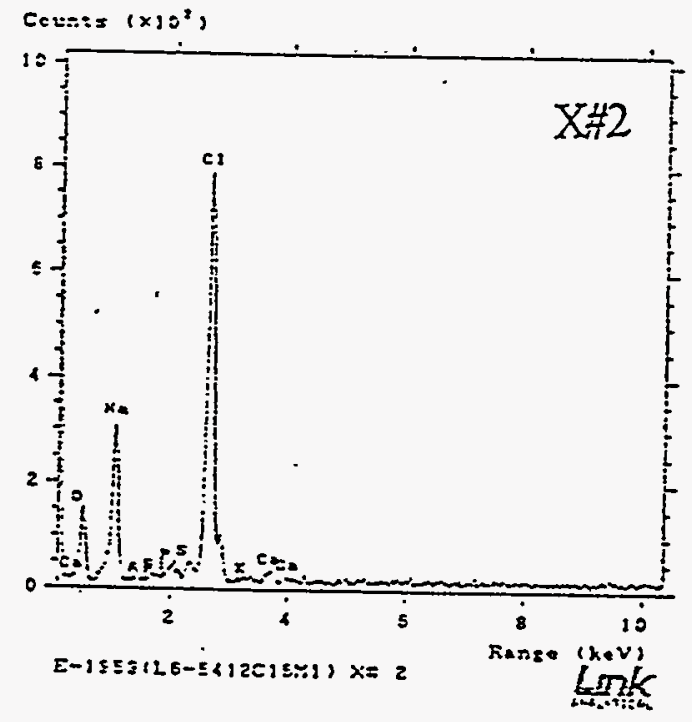

(b)

Figure 3. (a) SEM micrograph of a miolten salt layer and (b) its corresponding ENS pattern for glass spiked with $5.0 \mathrm{wt} \% \mathrm{Cl}$ and melted at $1300^{\circ} \mathrm{C}$. 


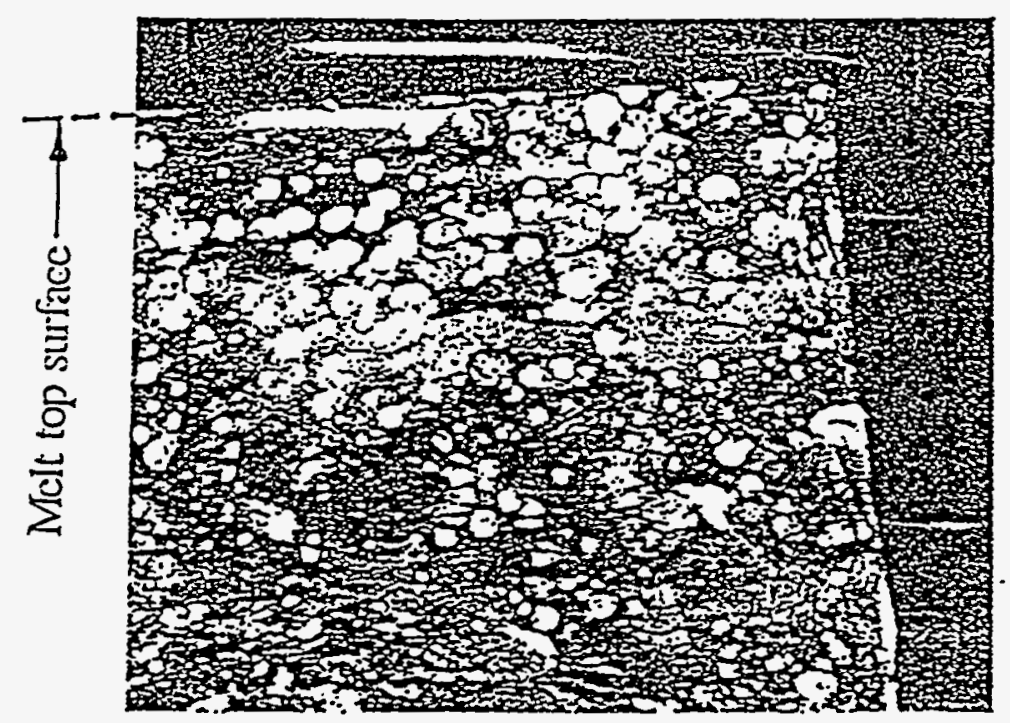

(a)

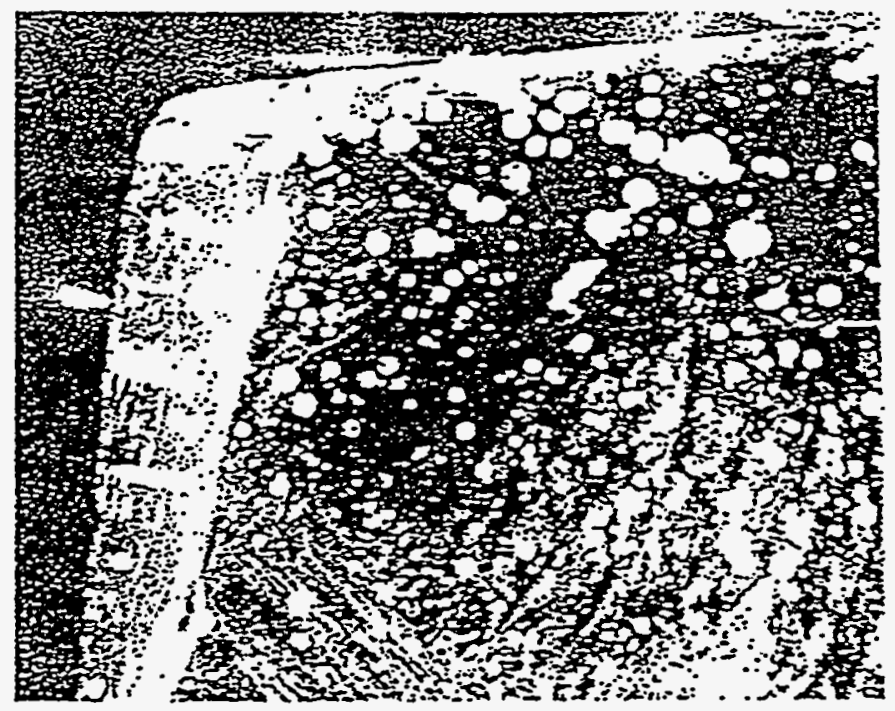

(b)

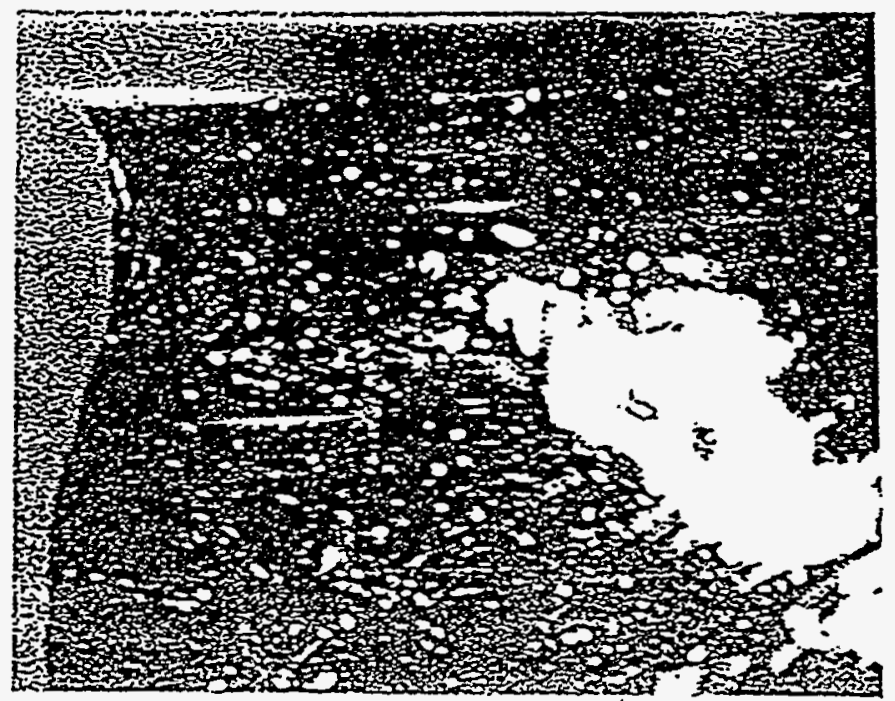

(c)

Figure 2. Optical micrographs of cross sections of quenched glasses melted at (a) $1300^{\circ} \mathrm{C}$, (b) $1350^{\circ} \mathrm{C}$ and (c) $1400^{\circ} \mathrm{C}$ for L6-5412 glass spiked with 5.0 wt\%Cl (nag. 8X). 


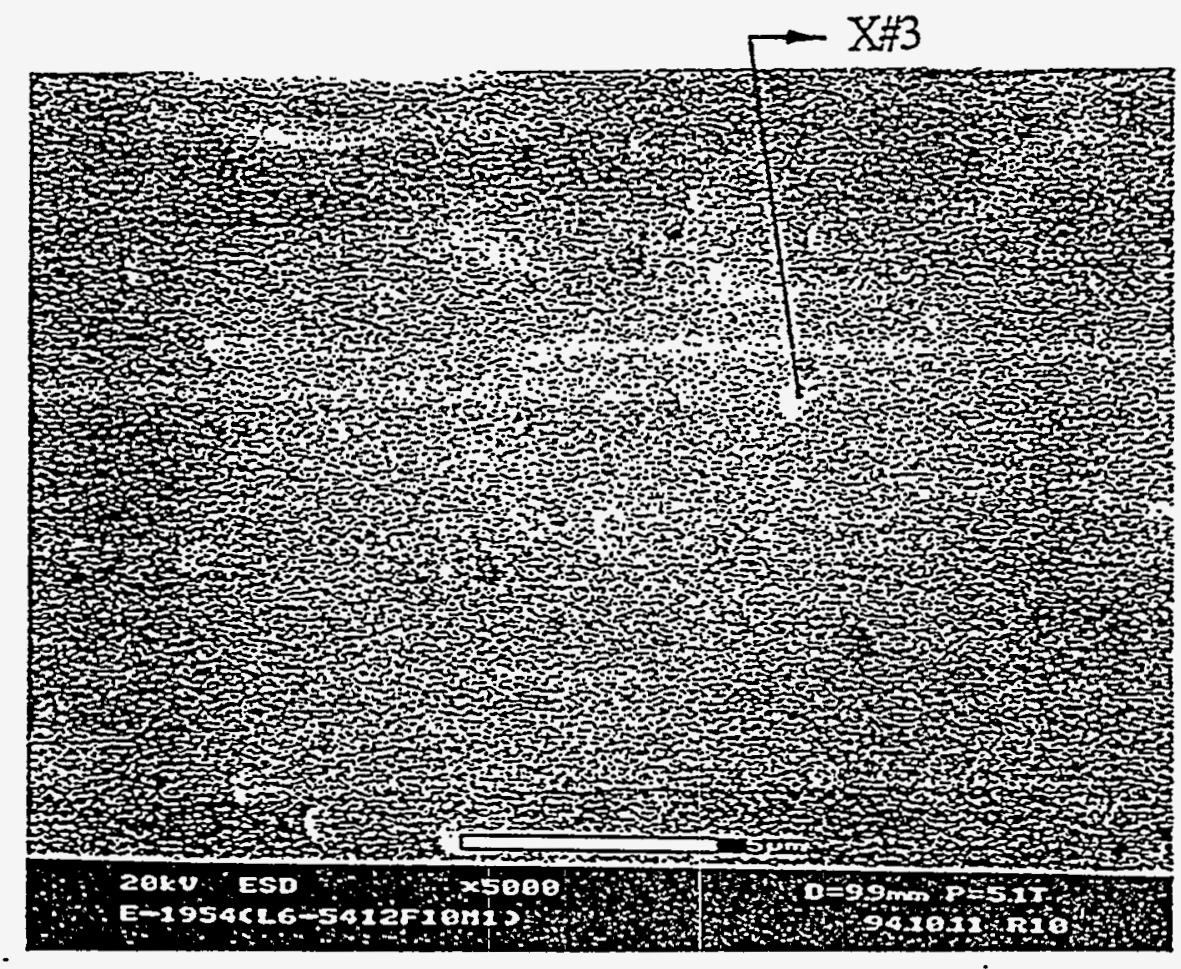

(a)

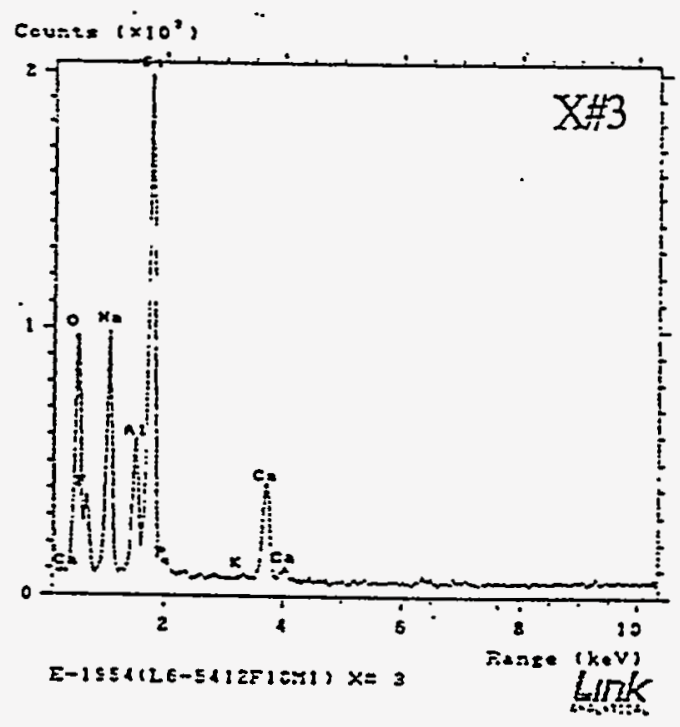

(b)

Figure 7. (a) SEM micrograph of L6-5412 glass spiked with 10.0 wi \%F and melted at $1300^{\circ} \mathrm{C}$ and (b) its corresponding. EDS pattern, $X \pm 3$. 


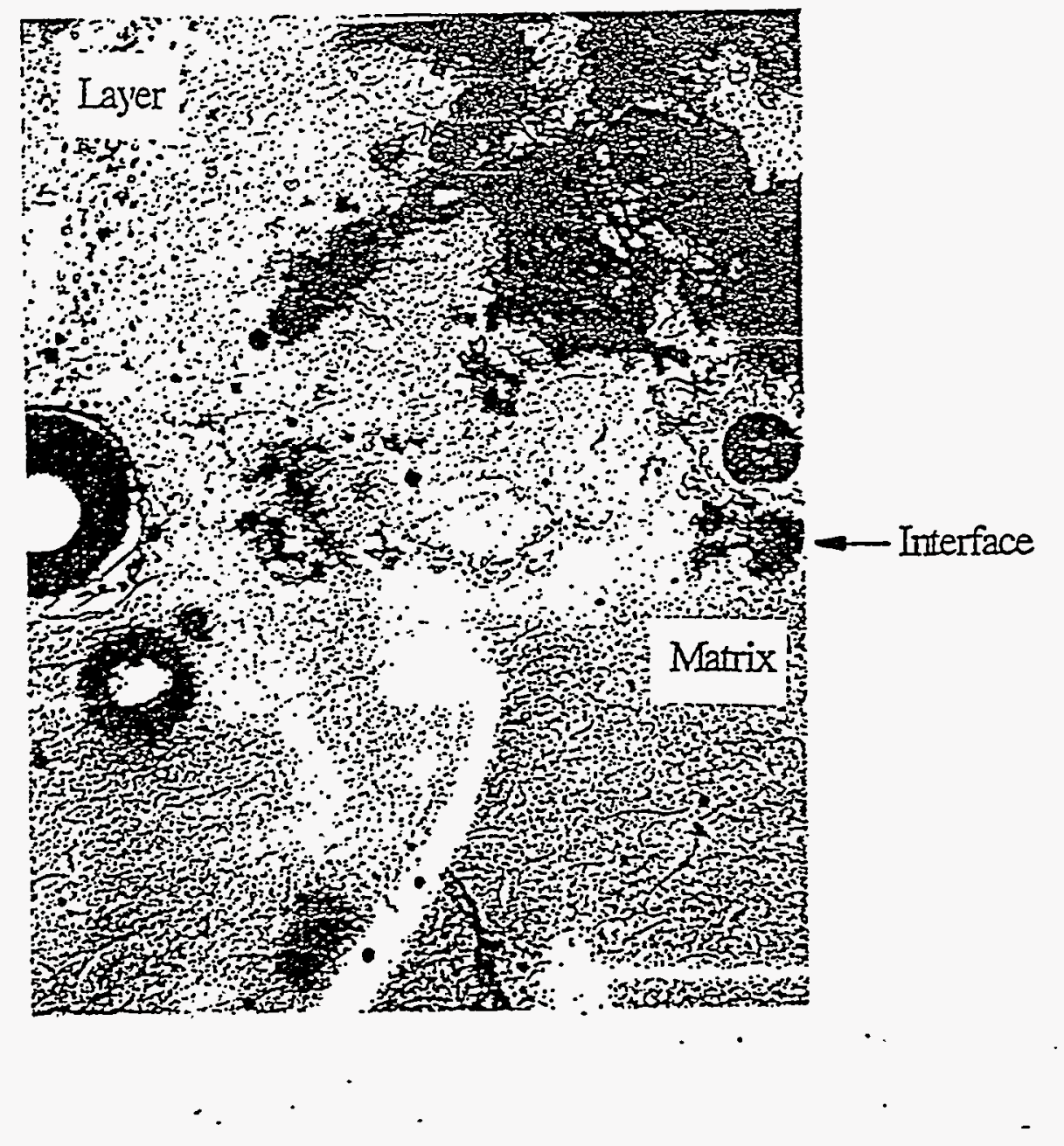

Figure 11. Optical micrograph of L6-5412 glass spiked with 10.0 wit $\% \mathrm{P}_{2} \mathrm{O}_{5}$ and and melted at $130^{\circ} \mathrm{C}$, showing a phase segregated layer at the top of the minlt (mag. 200X). 


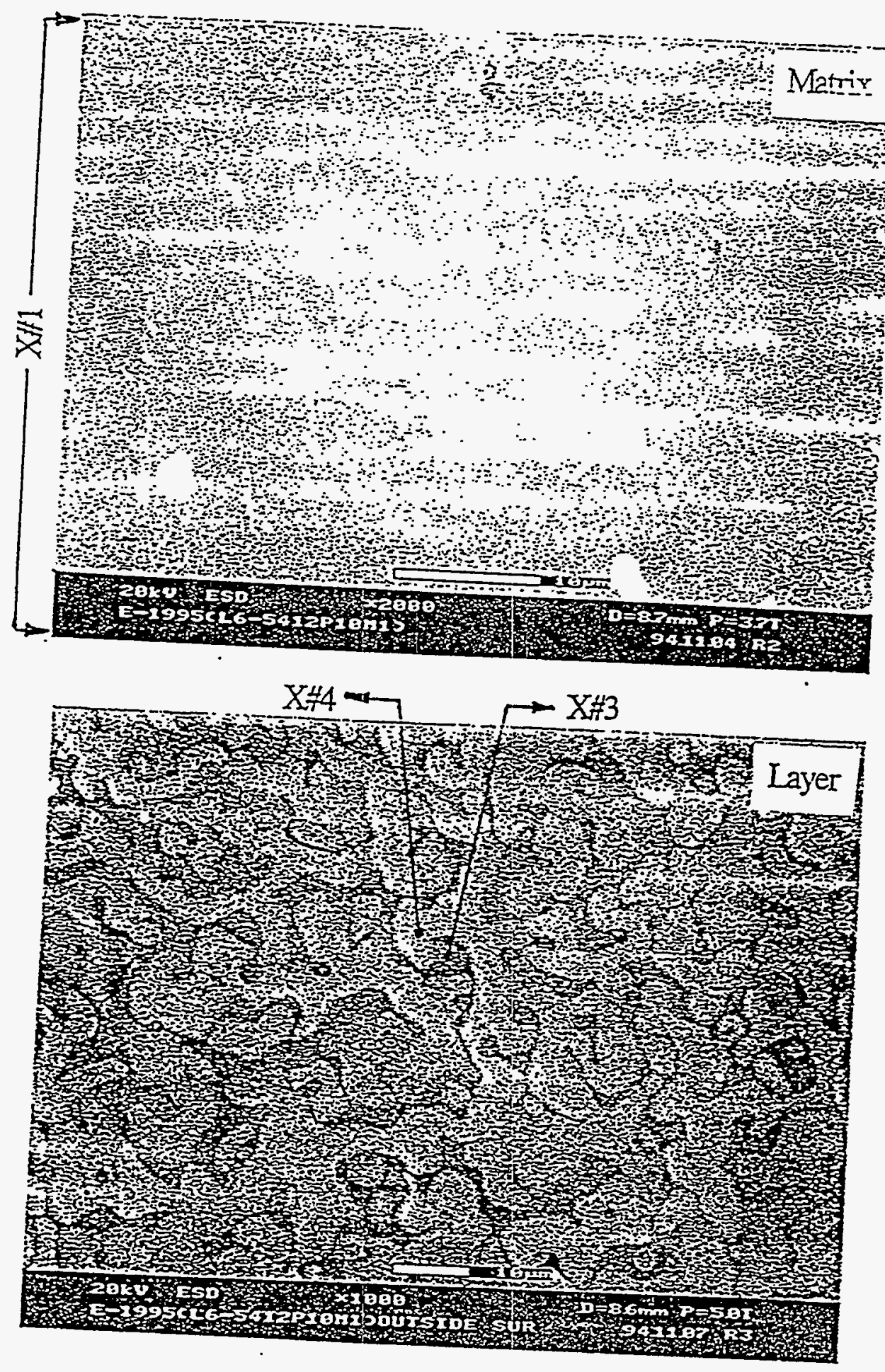

(a)

(b)

Figure 12. SEM micrographs of for L6-5412 glass spiked with $10.0 \mathrm{wt} \% \mathrm{P}_{2} \mathrm{O}_{5}$ and melted at $1300^{\circ} \mathrm{C}$, showing (a) homogeneous matrix, $X \not 11$, and (b) phase separation at the top of the melt, $X^{\prime \prime \prime} 3$ and $X \neq 4$. 


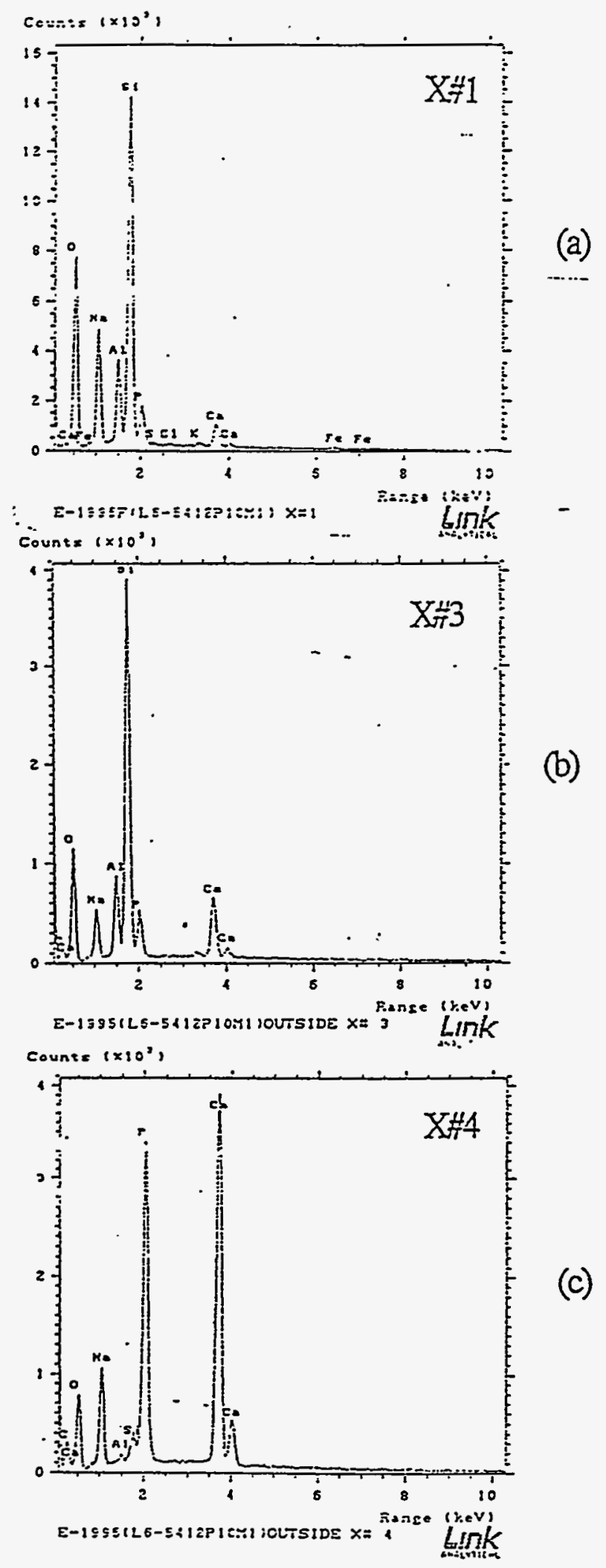

Figure 13. EDS patterns corresponding to the areas, $X \Perp 1,2$, and 3 shown in Figure 12. 


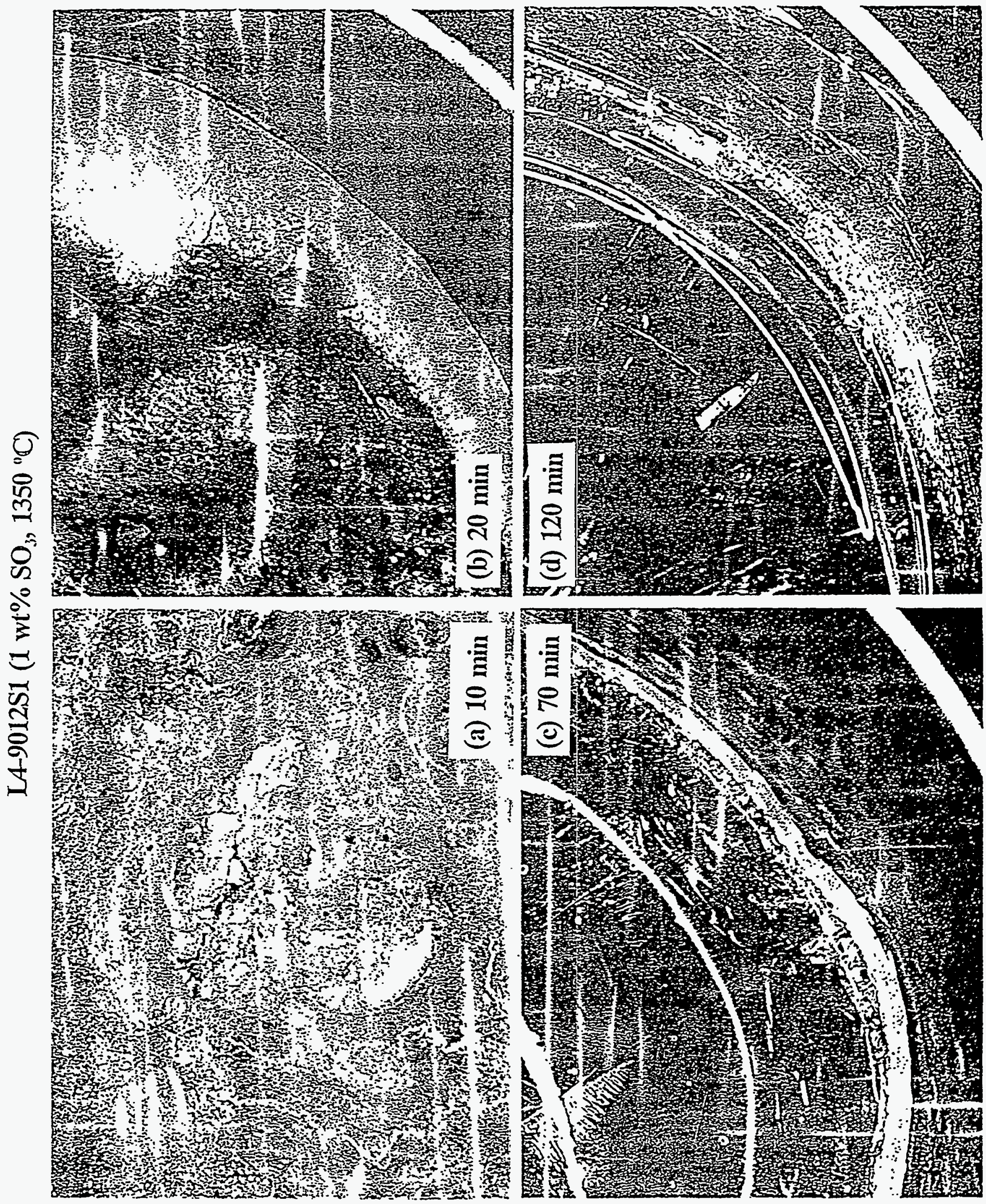




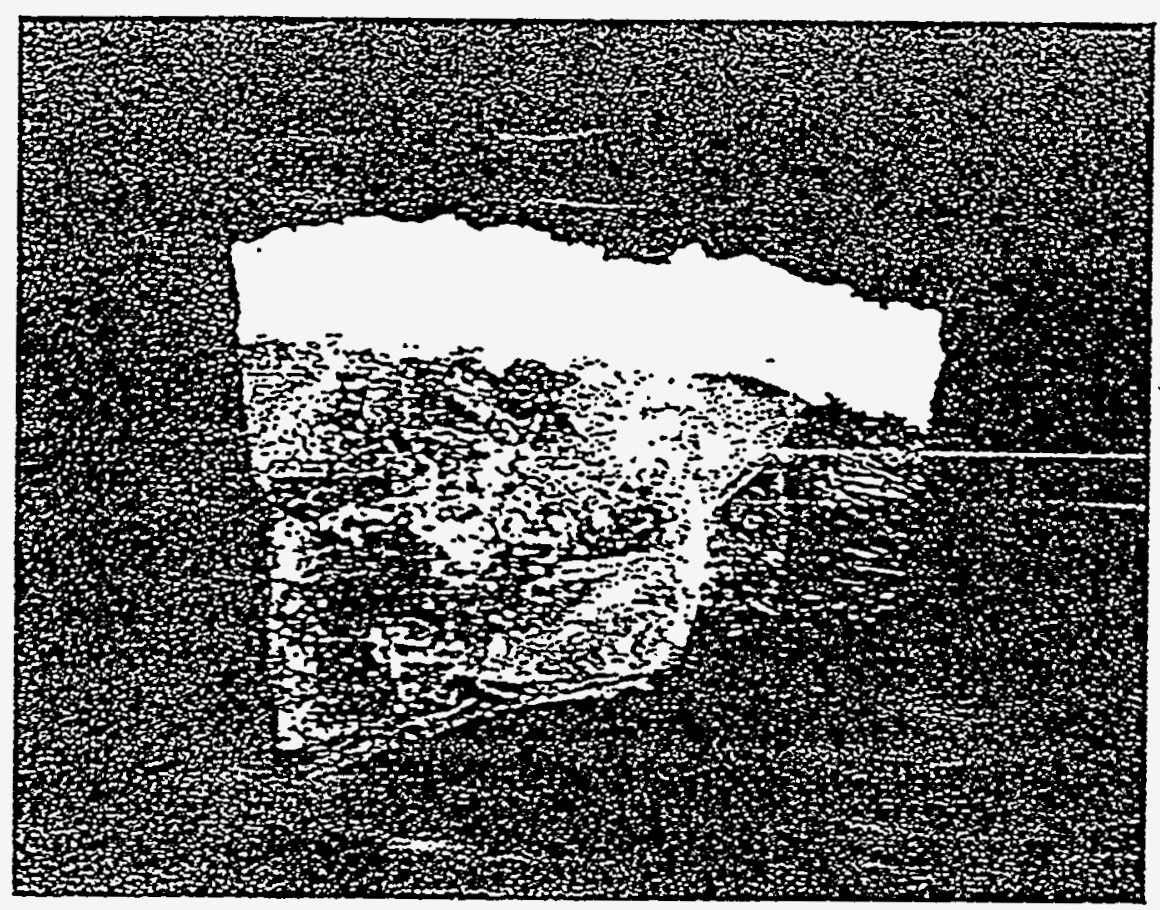

Figure 14. Optical micrograph of L6-5412 glass spiked with $2.0 \mathrm{wt} \% \mathrm{SO}_{3}$ and melted at $1300^{\circ} \mathrm{C}$, showing phase segregation in a meniscus area (mag. 8X). 


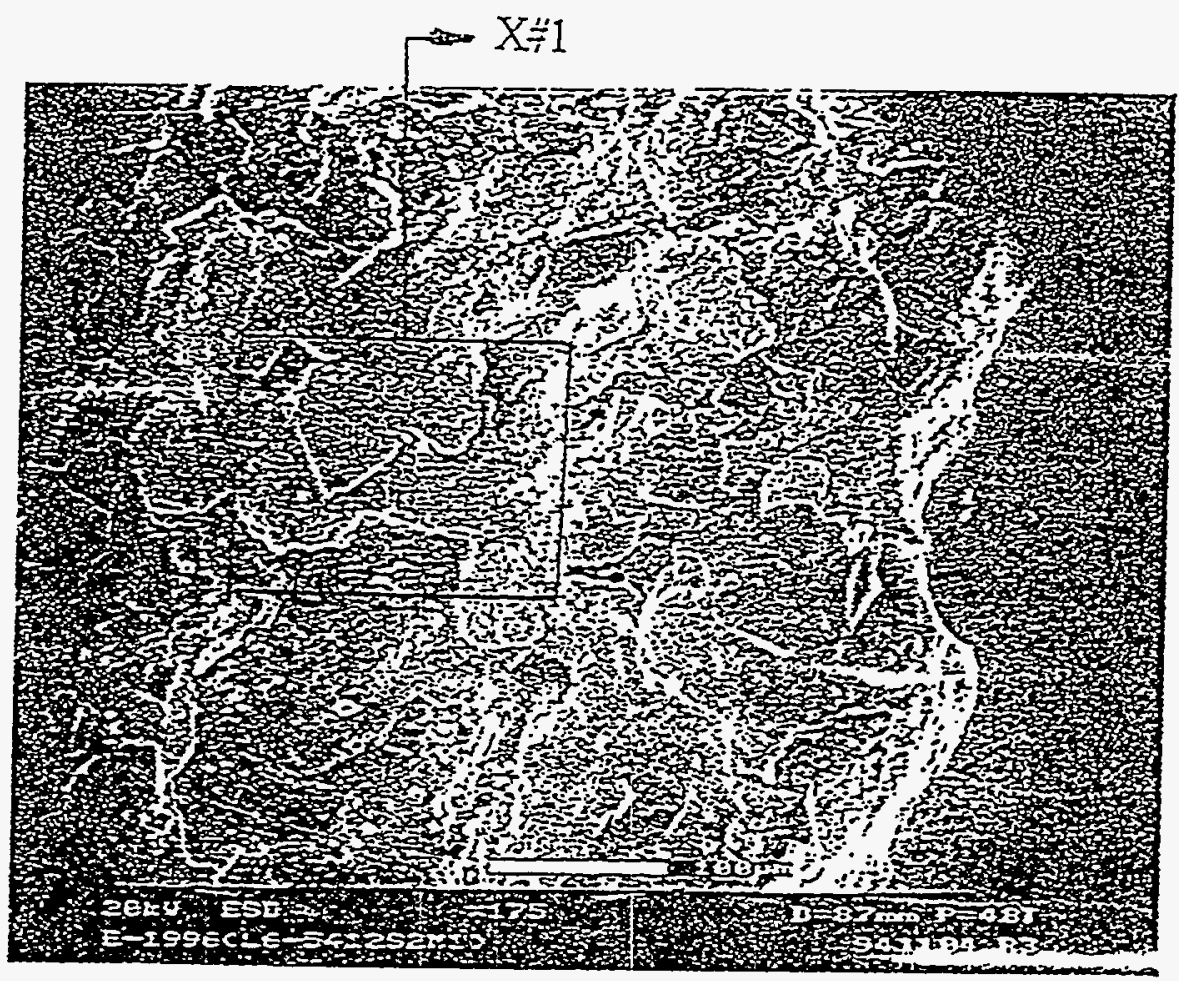

(a)

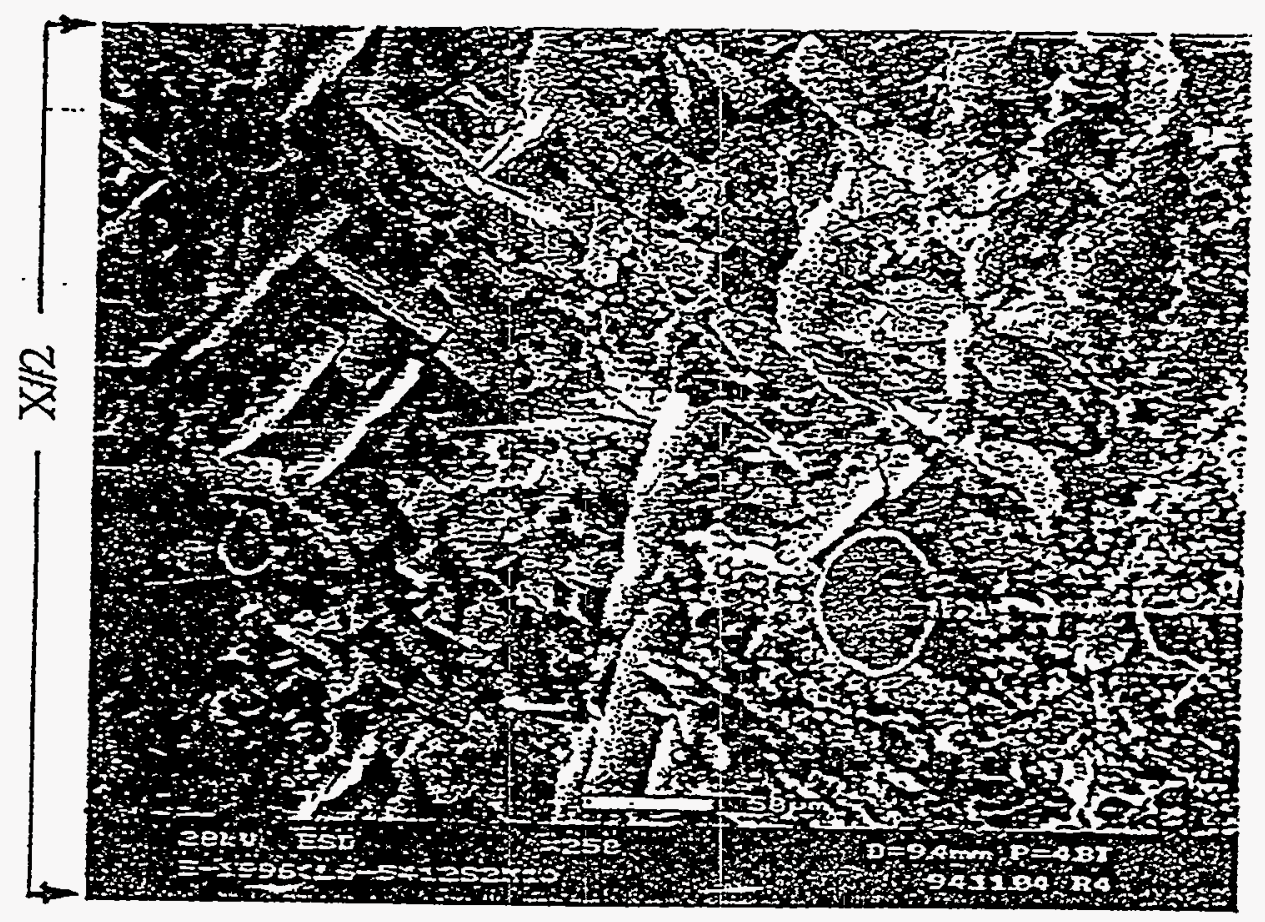

(b)

Figure 16. SEM micrographs of L6-5412 glass spiked with 2.0 wt\% $\% \mathrm{SO}_{3}$ and melted at $1300^{\circ} \mathrm{C}$, showing (a) plate-like, $X \dot{H} 1$, and (b) rod-like crystalline phases, $X \# 2$. 


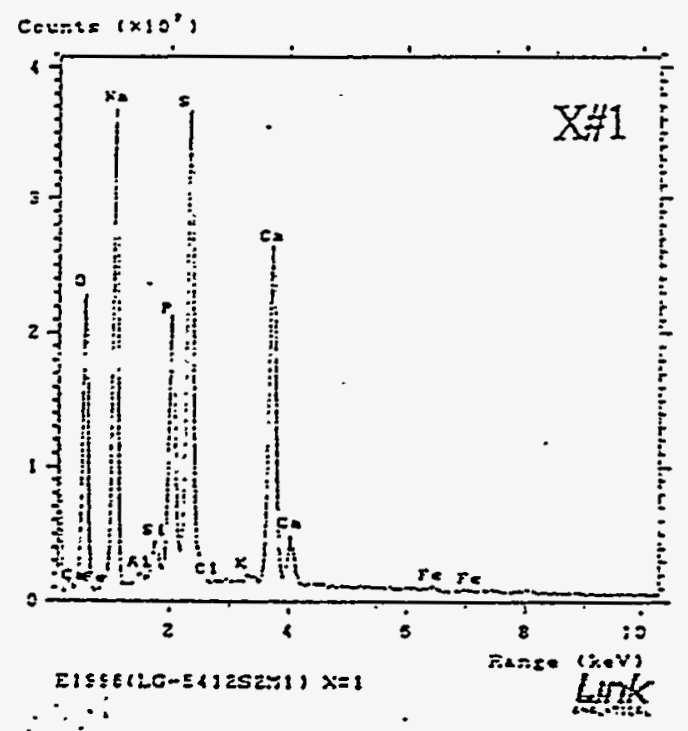

(a)

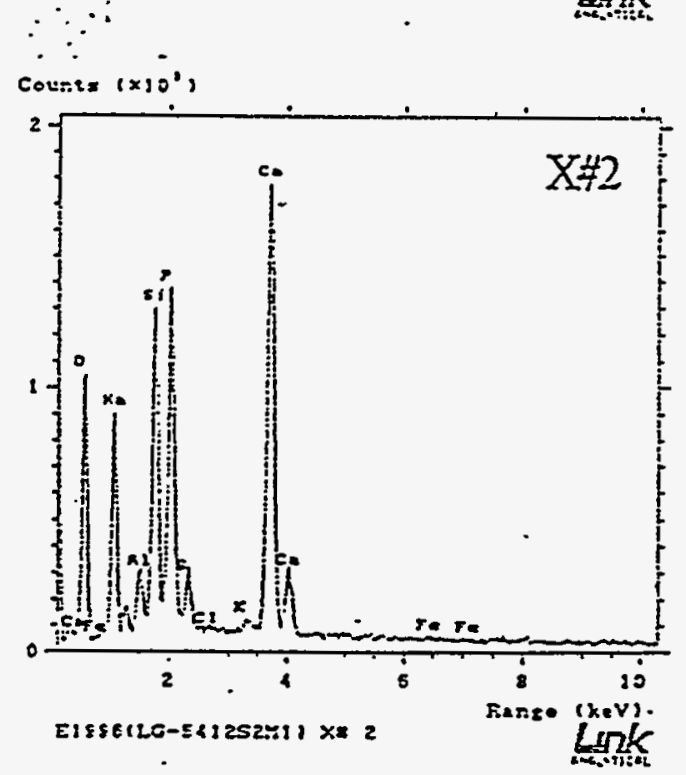

(b)

Figure 17. EDS patterns of (a) plate-like and (b) rod-like crystalline phases shown in Figure 16. 


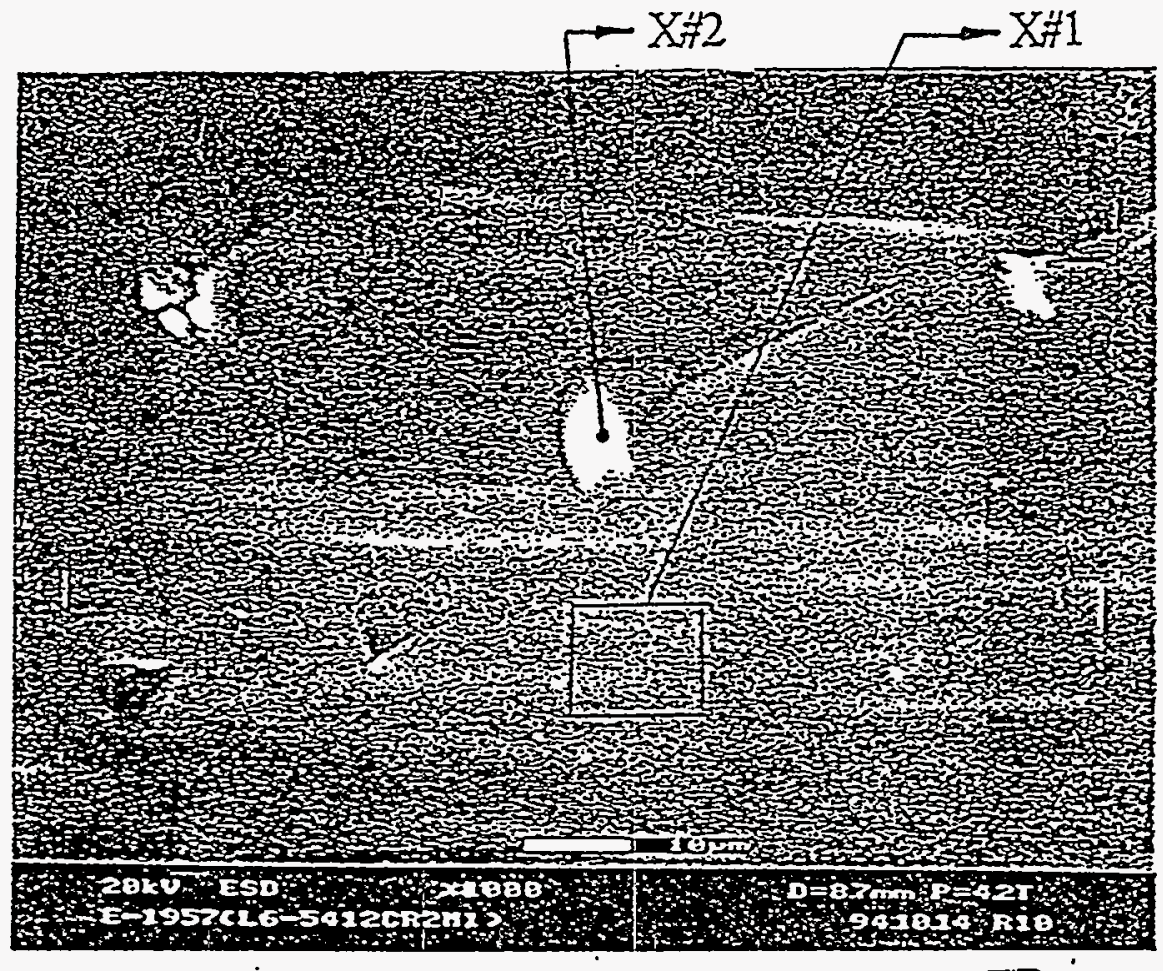

(a)

(b)

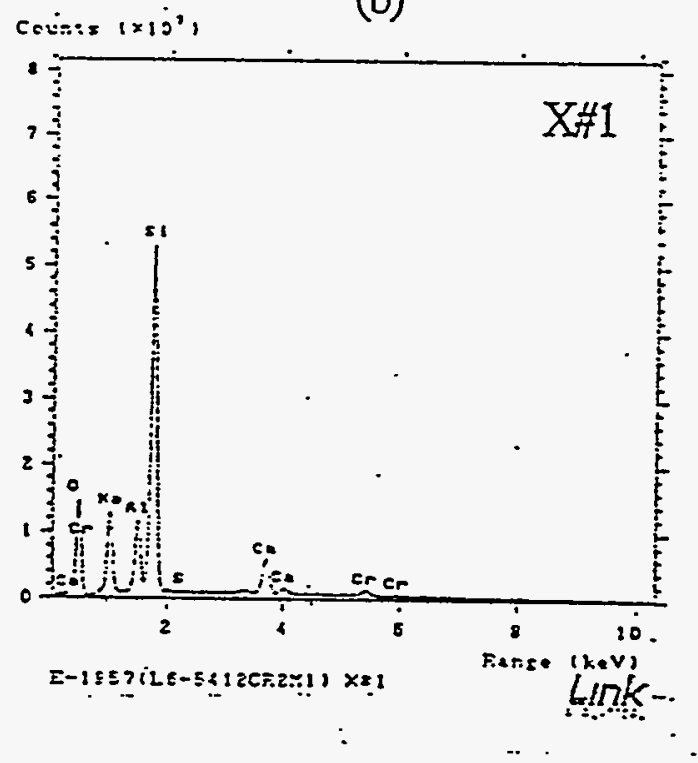

(c)

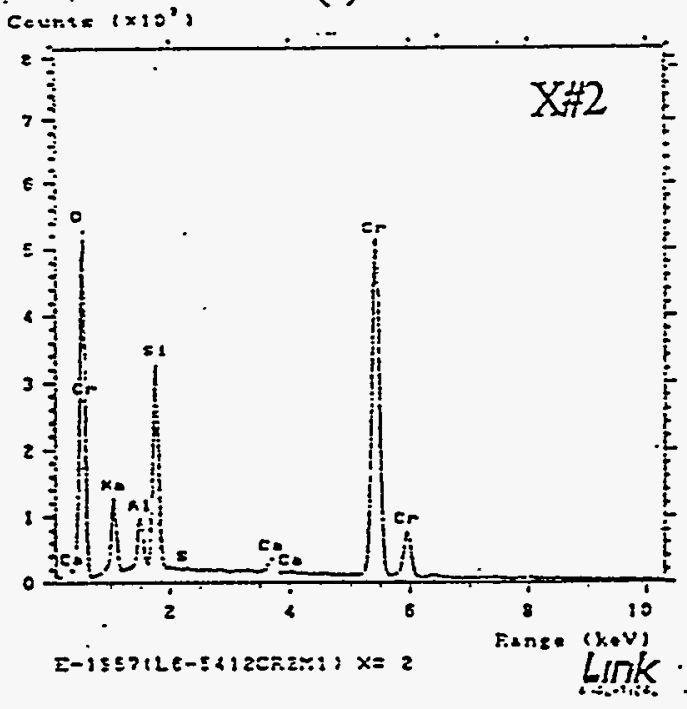

Figure 18. (a) SEM micrograph and (b-c) its corresponding EDS patterns,

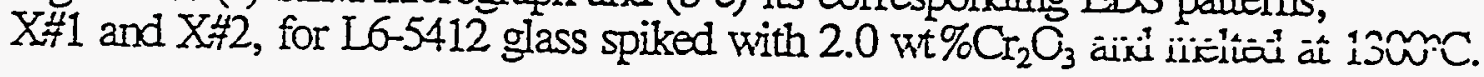


Effect of S-P Mutual Reaction on Melt Phase Segregation and Glass Phase Separation

\begin{tabular}{|l|cc|cc|cc|cc|}
\hline Glass & $\begin{array}{c}\text { L4-9012 } \\
\text { Conc. }\end{array}$ & Solubility & $\begin{array}{c}\text { L4-909 } \\
\text { Conc. }\end{array}$ & Solubility & $\begin{array}{c}\text { L6-5412 } \\
\text { Conc. }\end{array}$ & Solubility & $\begin{array}{c}\text { L5-0912 } \\
\text { Conc. }\end{array}$ & Solubility \\
\hline P2O5 & 2.20 & 4.97 & 2.05 & $(<4.97)$ & 2.24 & 2.50 & 2.29 & $(<2.50)$ \\
SO3 & 0.57 & 0.47 & 0.68 & $(>0.47)$ & 0.88 & 0.75 & 1.00 & $(>1.00)$ \\
\hline Segregation & +++ & & +++ & & ++ & & - & \\
Separation & +++ & & ++ & & + & & - & \\
\hline
\end{tabular}

Segregation : Accumulation of Molten Salts on the Melt Surafce (crystalline phase).

Separation: Two amorphous phases coexist in the bulk of glass, which have different compositions. 


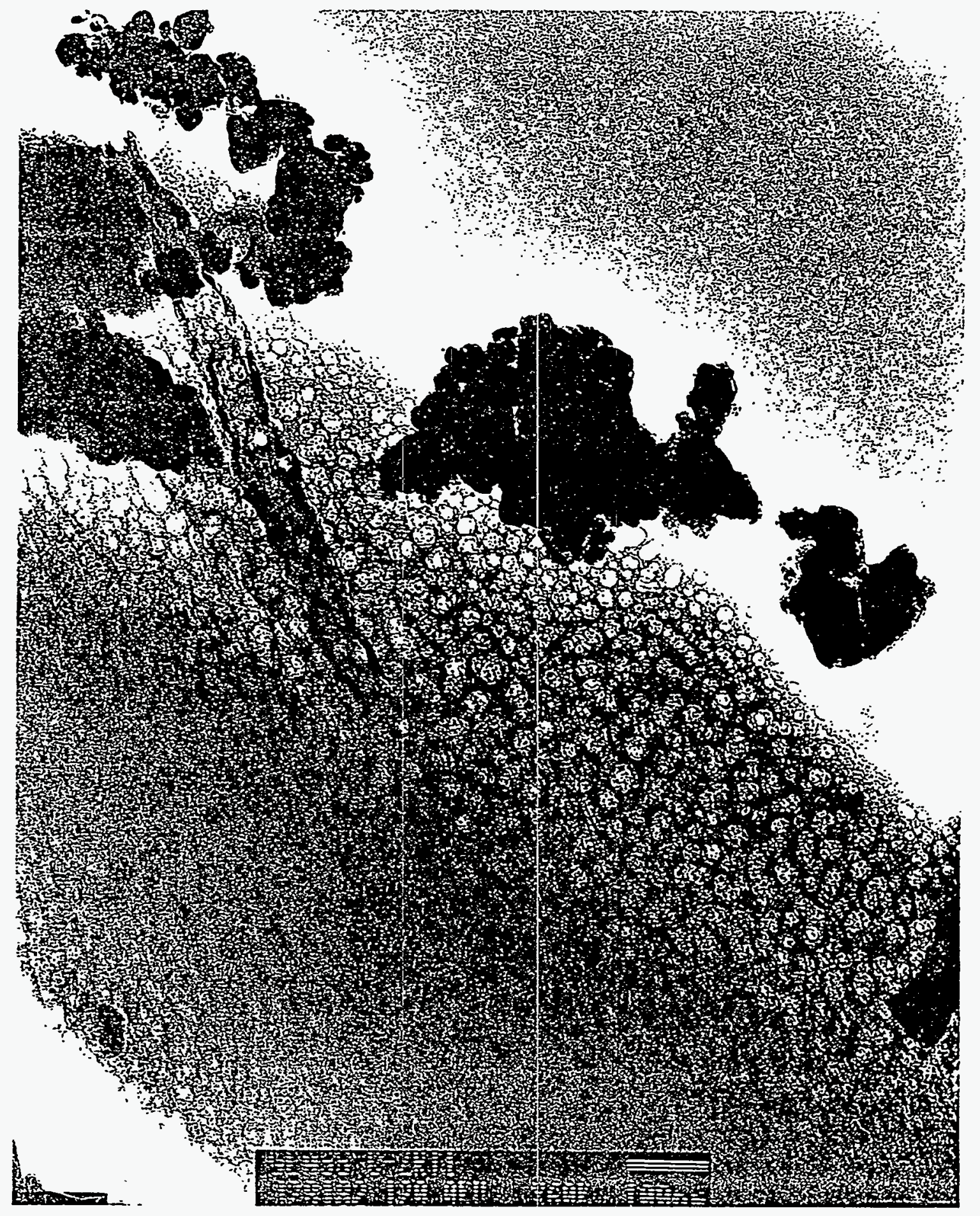




$$
26-5412 \text { GLABS } 1350^{\circ} \mathrm{C}
$$

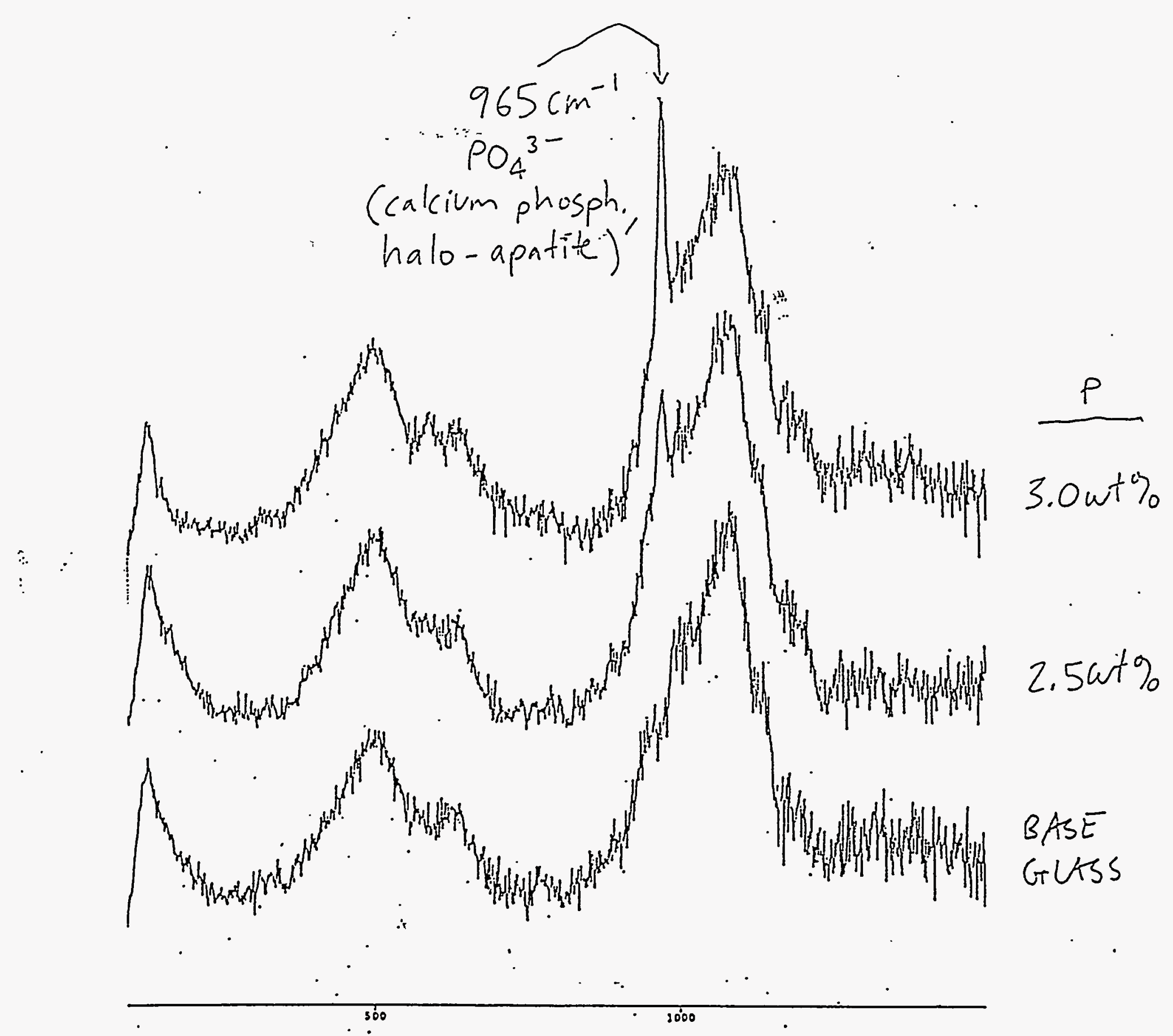




$$
\text { LA-9012 GLASS } 1350^{\circ} \mathrm{C}
$$

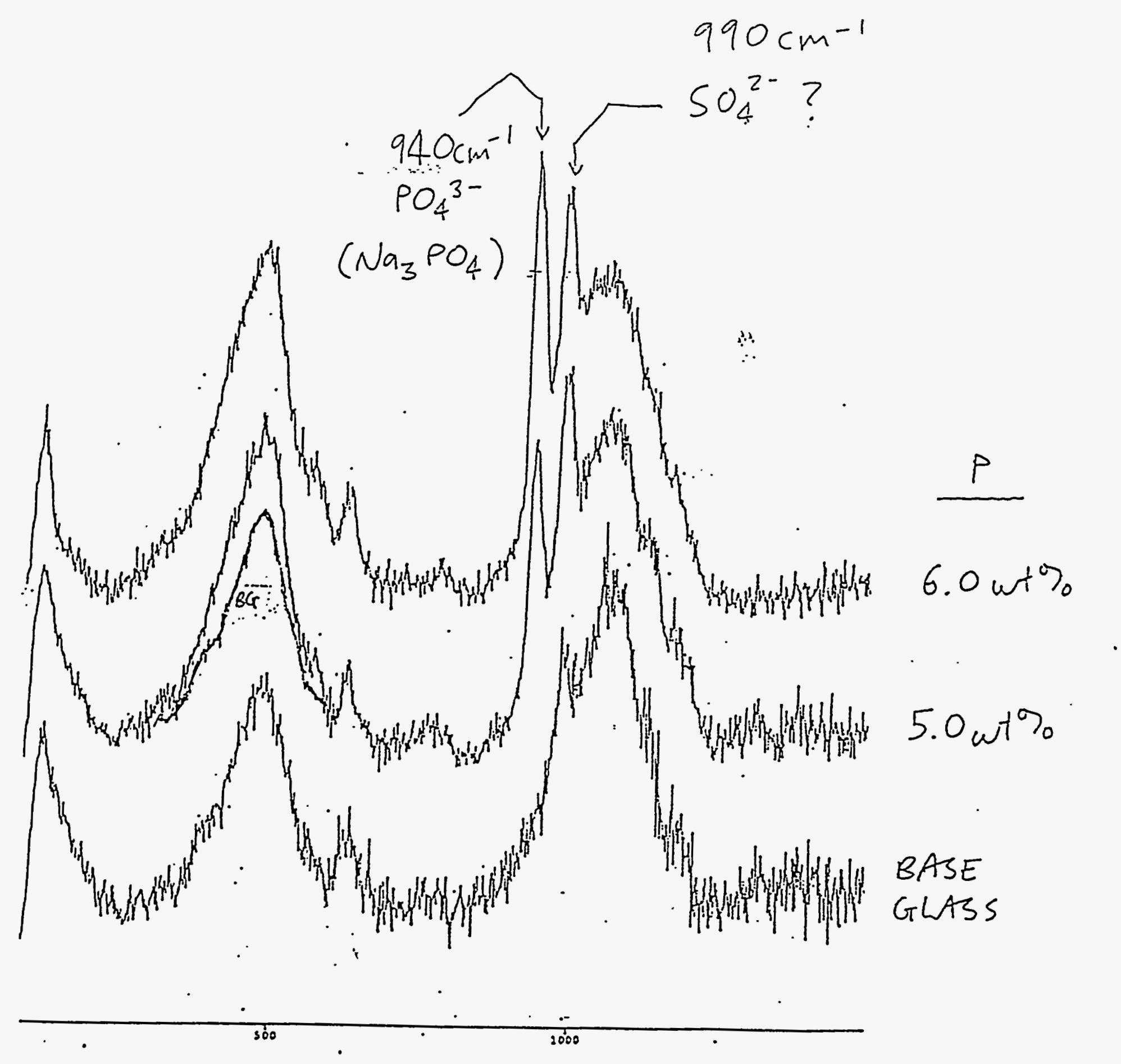




\section{Effect of Minor Components on Glass Melting Temperature}

\begin{tabular}{||l|c|c|c|c||}
\hline \multirow{2}{*}{$\begin{array}{l}\text { Minor } \\
\text { Component }\end{array}$} & \multicolumn{2}{|c|}{$\mathrm{L6-5412}$} & \multicolumn{2}{c|}{$\mathrm{L} 49012$} \\
\cline { 2 - 5 } & $\Delta \mathrm{T}_{\mathrm{m}}$ & $\Delta \mathrm{T}_{\mathrm{m}} / \Delta \mathrm{C}_{\mathrm{MC}}$ & $\Delta \mathrm{T}_{\mathrm{m}}$ & $\Delta \mathrm{T}_{\mathrm{m}} / \Delta \mathrm{C}_{\mathrm{MC}}$ \\
$(\mathrm{K})$ & $(\mathrm{K} / \mathrm{wt} \%)$ & $(\mathrm{K})$ & $(\mathrm{K} / \mathrm{wt} \%)$ \\
\hline $\mathrm{Cl}$ & 23.0 & 48.0 & 7.0 & 18.0 \\
\hline $\mathrm{F}$ & -67.0 & -94.0 & -129.0 & -117.0 \\
\hline $\mathrm{P}_{2} \mathrm{O}_{5}$ & 10.0 & 11.0 & 21.0 & 5.0 \\
\hline $\mathrm{SO}_{3}$ & 10.0 & 23.0 & -3.0 & -23.0 \\
\hline $\mathrm{Cr}_{2} \mathrm{O}_{3}$ & 3.0 & 7.0 & -25.0 & -25.0 \\
\hline
\end{tabular}




\section{Effect of Minor Components on Glass Durability}

\begin{tabular}{||l|c|c|c|c||}
\hline \multirow{2}{*}{$\begin{array}{l}\text { Minor } \\
\text { Component }\end{array}$} & \multicolumn{2}{|c|}{$\mathrm{PCT}$} & \multicolumn{2}{|c|}{$\mathrm{FTT}$} \\
\cline { 2 - 5 } & $\Delta \mathrm{NL}_{\mathrm{Na}}$ & $\begin{array}{c}\Delta \mathrm{NL}_{\mathrm{Na}} / \Delta \mathrm{C}_{\mathrm{MC}} \\
(\%)\end{array}$ & $\begin{array}{c}\Delta \mathrm{NR}_{\mathrm{Na}} \\
(\% \mathrm{wt} \%)\end{array}$ & $\begin{array}{c}\Delta \mathrm{NR}_{\mathrm{Na}} / \Delta \mathrm{C}_{\mathrm{MC}} \\
(\% / \mathrm{wt} \%)\end{array}$ \\
\hline $\mathrm{Cl}$ & 12.0 & 25.0 & -17.0 & -36.0 \\
\hline $\mathrm{F}$ & -9.0 & -13.0 & 110.0 & 155.0 \\
\hline $\mathrm{P}_{2} \mathrm{O}_{5}$ & 20.0 & 21.0 & 6.0 & 7.0 \\
\hline $\mathrm{SO}_{3}$ & 8.0 & 18.0 & 5.0 & 14.0 \\
\hline $\mathrm{Cr}_{2} \mathrm{O}_{3}$ & 25.0 & 57.0 & 13.0 & 30.0 \\
\hline
\end{tabular}




\section{- Glass Melt Viscosity}

$\mathrm{Cl}$ and $\mathrm{P}_{2} \mathrm{O}_{5}$ : Increasing

F : Decreasing

$\mathrm{SO}_{3}$ and $\mathrm{Cr}_{2} \mathrm{O}_{3}$ :

Increasing (low $\mathrm{B}_{2} \mathrm{O}_{3}$ glass)

Decreasing (high $\mathrm{B}_{2} \mathrm{O}_{3}$ glass) 
Effects of Minor Components on Melt Viscosity of L6-5412 Glass

Temperature range : $1200-1450{ }^{\circ} \mathrm{C}$

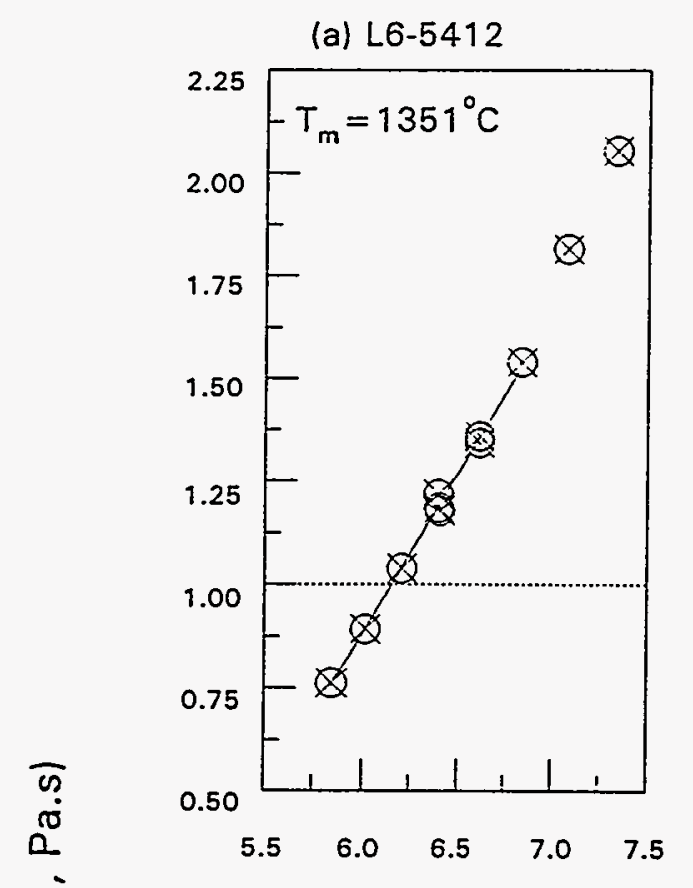

(b) $0.56 w t \% \mathrm{Cl}$

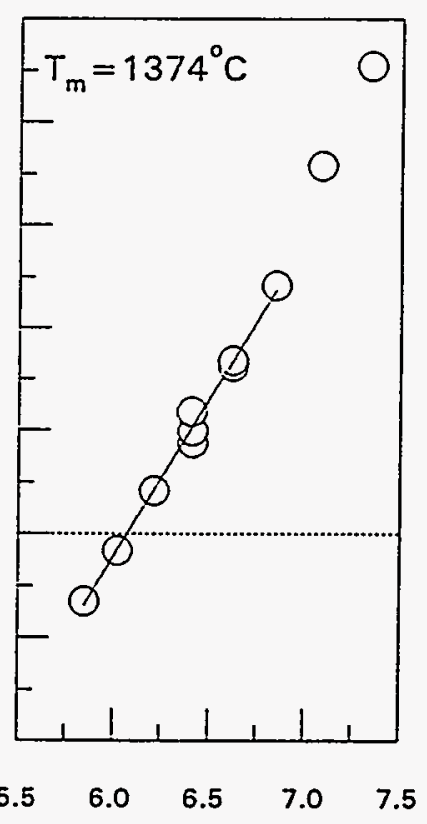

(e) $0.75 w t \% \mathrm{SO}_{3}$

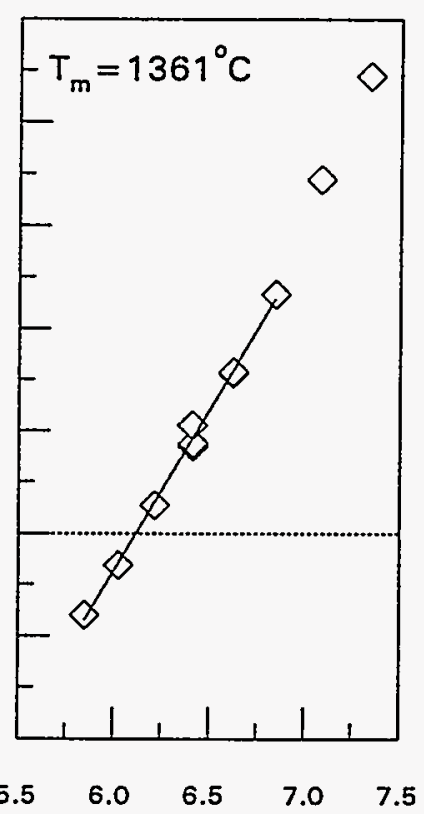

$10000 / \mathrm{T}\left(K^{-1}\right)$ (c) $0.77 w t \% F$

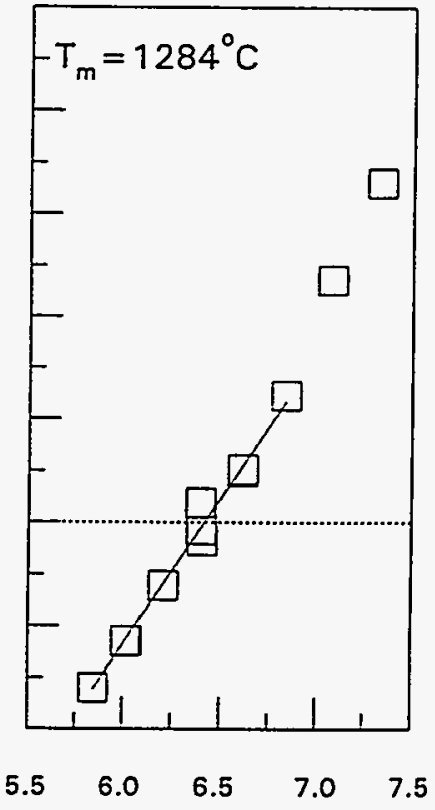

(f) $0.46 \mathrm{wt} \% \mathrm{Cr}_{2} \mathrm{O}_{3}$

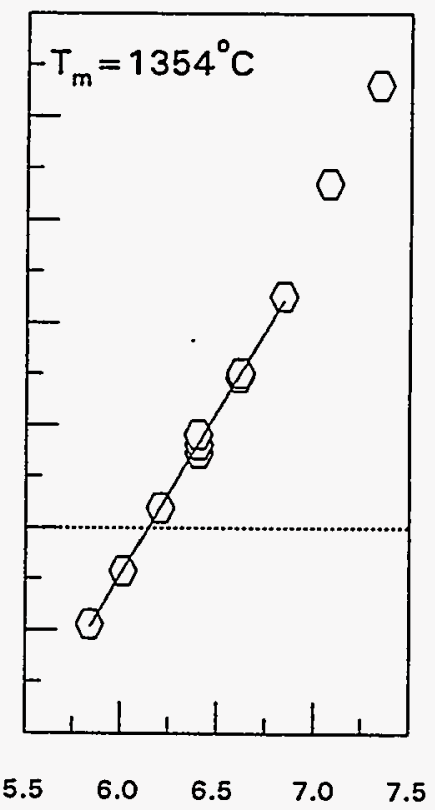

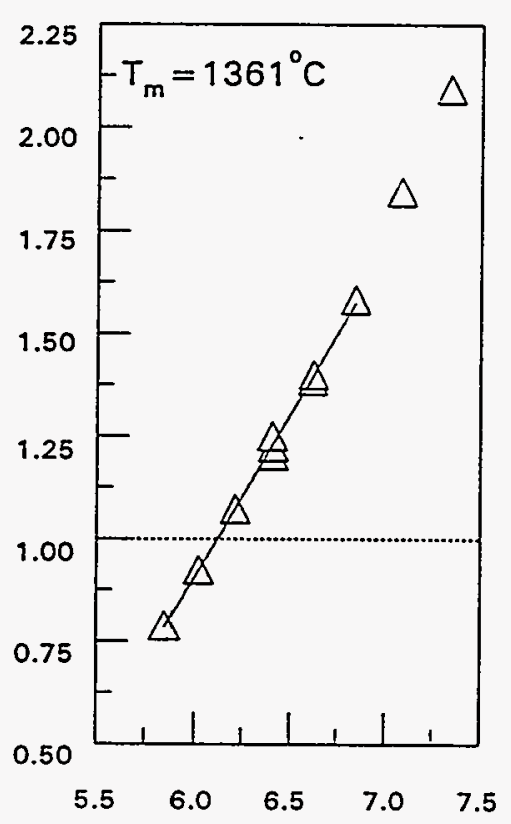


Effects of Minor Components on Melt Viscosity of L4-9012 Glass

Temperature range : $1150-1450{ }^{\circ} \mathrm{C}$

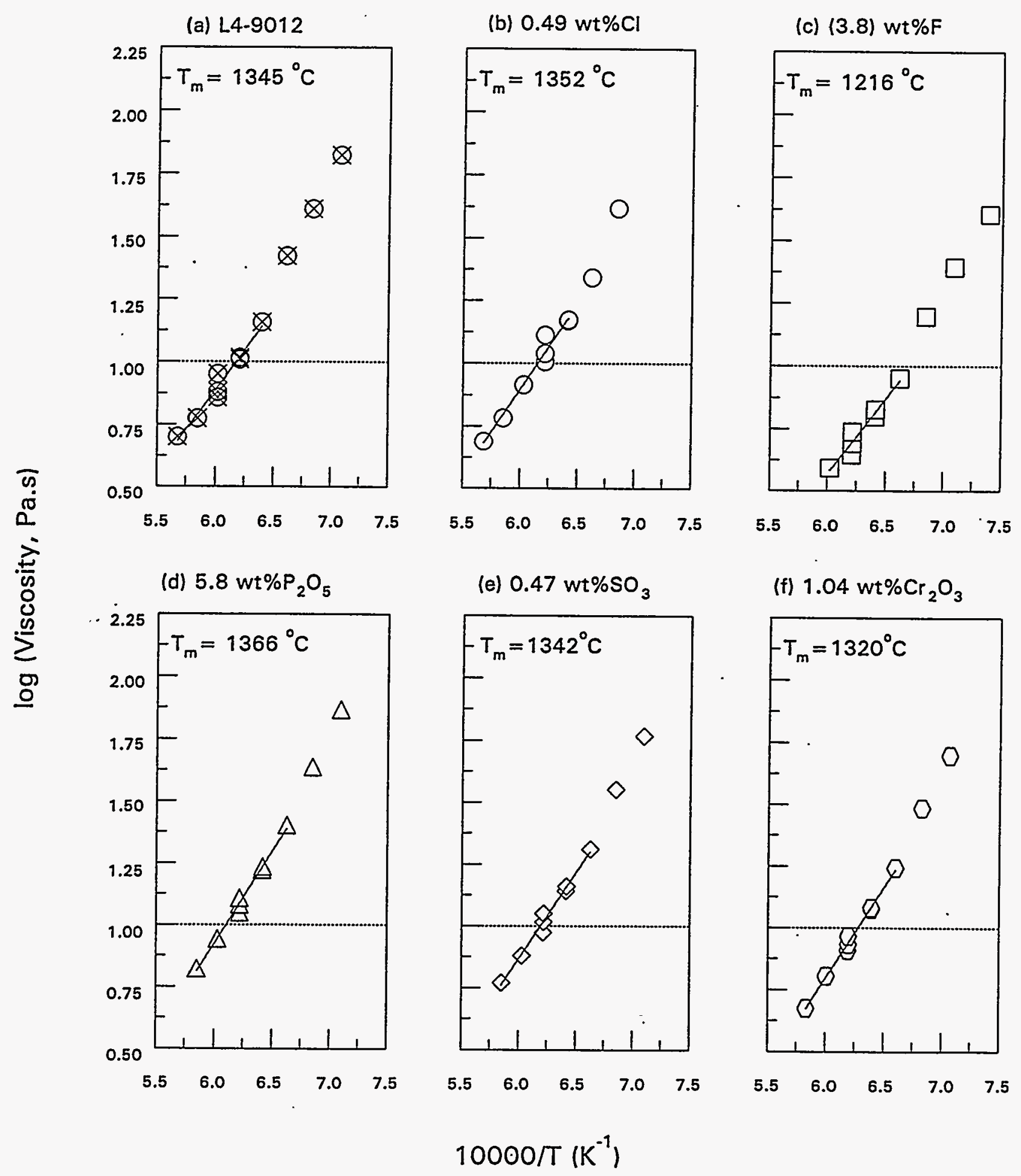



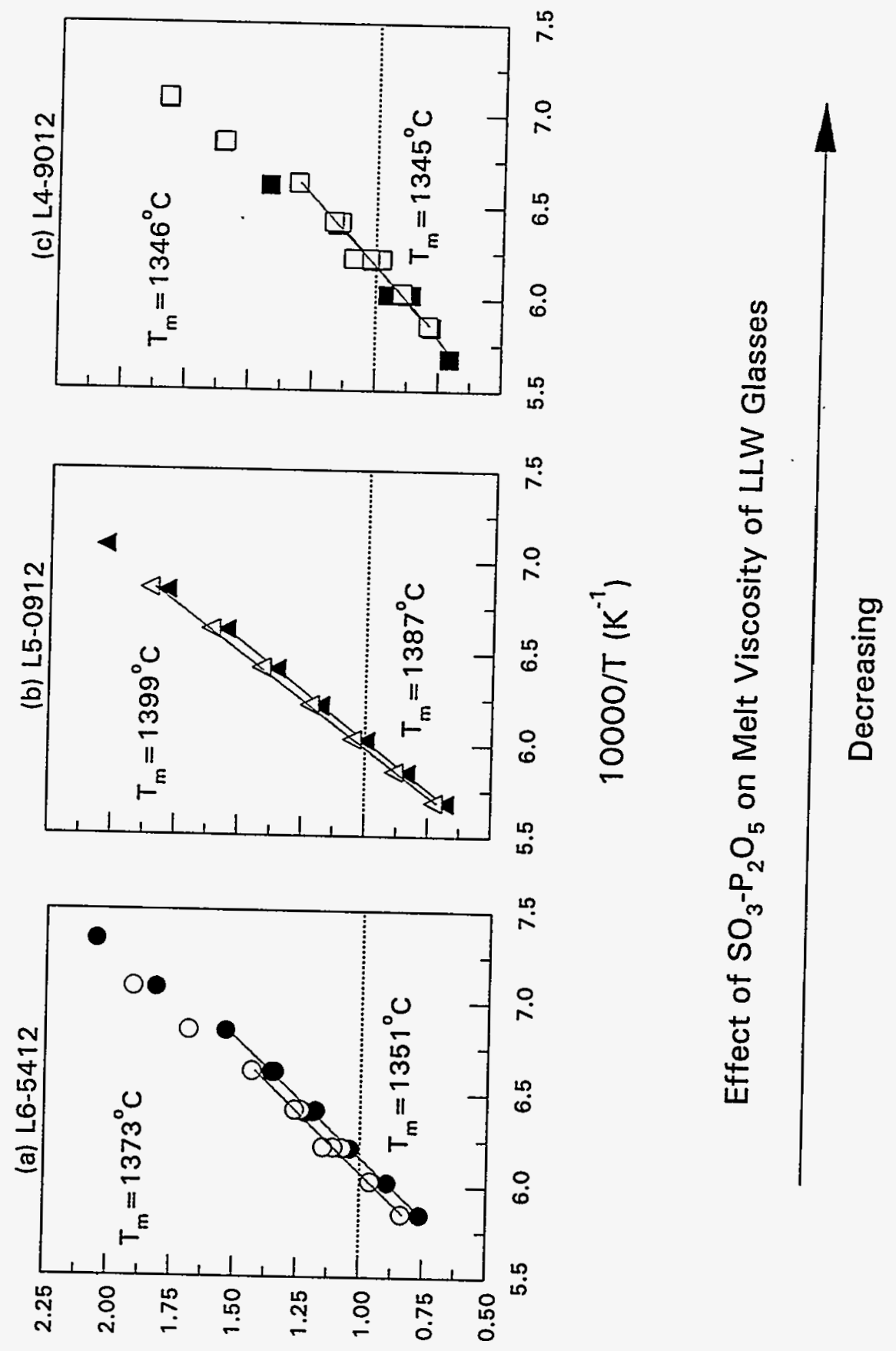

(s.ed 'ht!soss!n) 60 ol 


\section{- Glass Durability}

Product Consistency Test

$\mathrm{F}$ : Increasing

$\mathrm{Cl}, \mathrm{P}_{2} \mathrm{O}_{5}, \mathrm{SO}_{3}$, and $\mathrm{Cr}_{2} \mathrm{O}_{3}$ : Decreasing

Flow-Through Test

$\mathrm{Cl}$ : Increasing

F, $\mathrm{P}_{2} \mathrm{O}_{5}, \mathrm{SO}_{3}$, and $\mathrm{Cr}_{2} \mathrm{O}_{3}$ : Decreasing

(An underline is used for a component affecting the durability the most) 
$\mathrm{pH}$ of leachate at room temperature

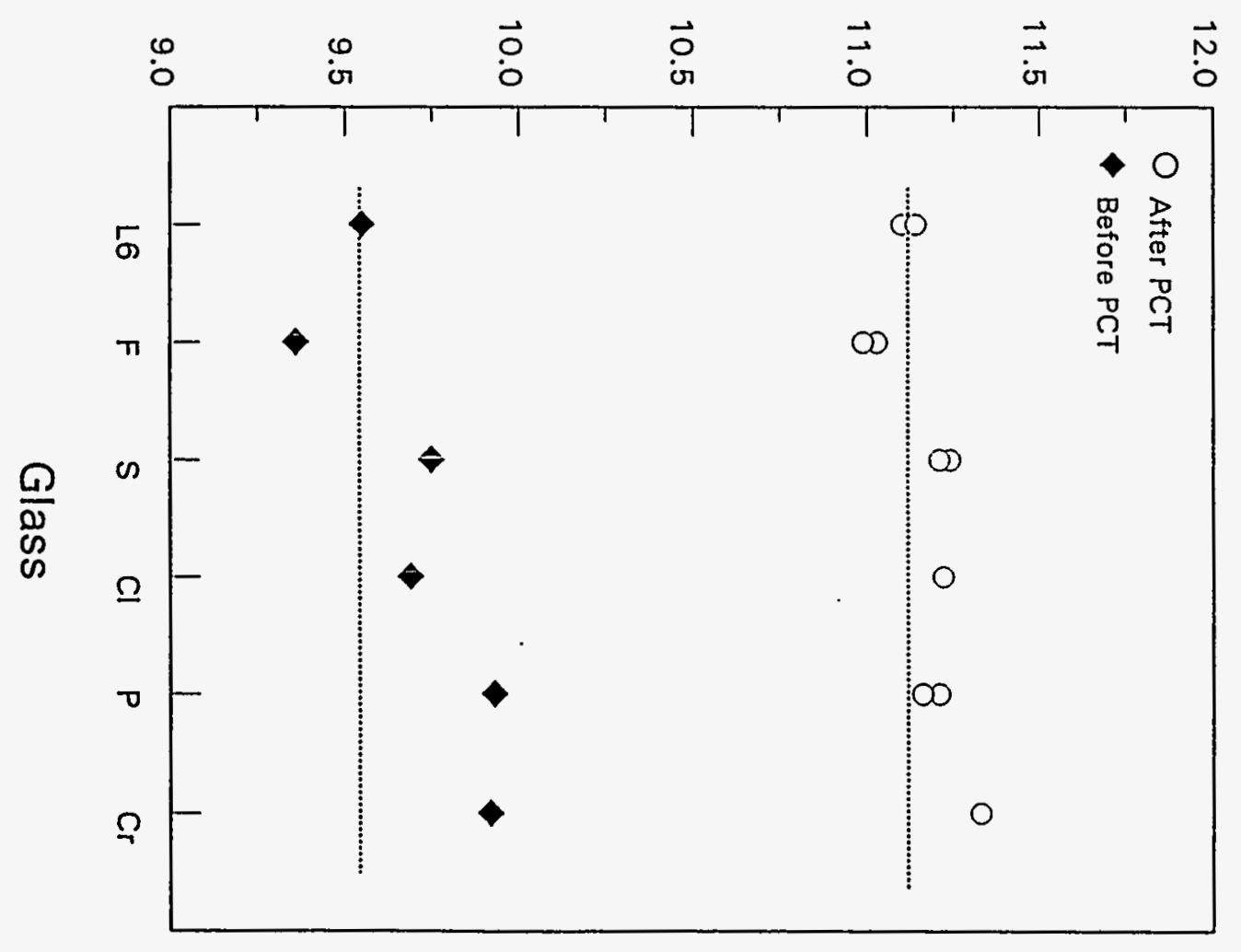




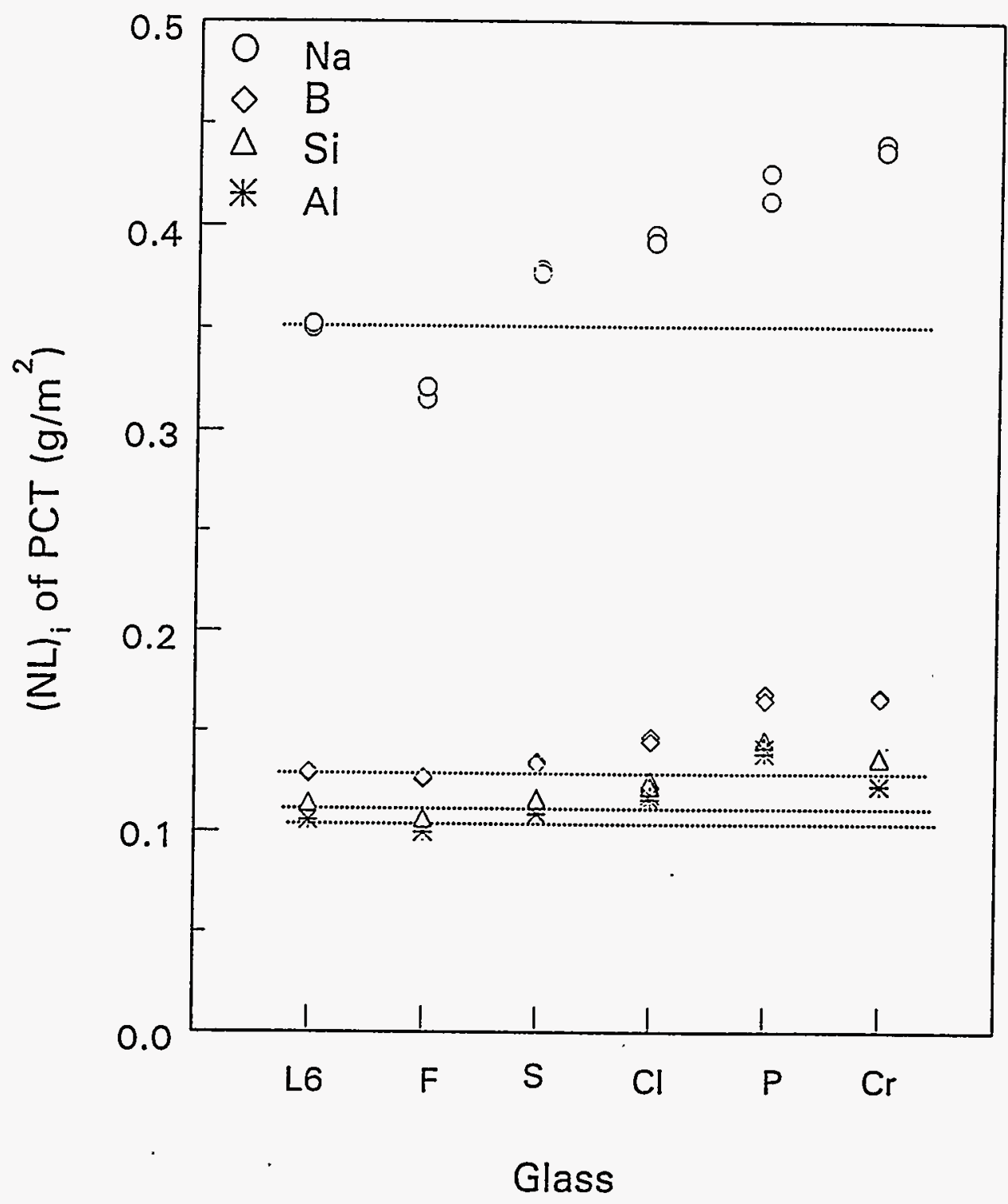




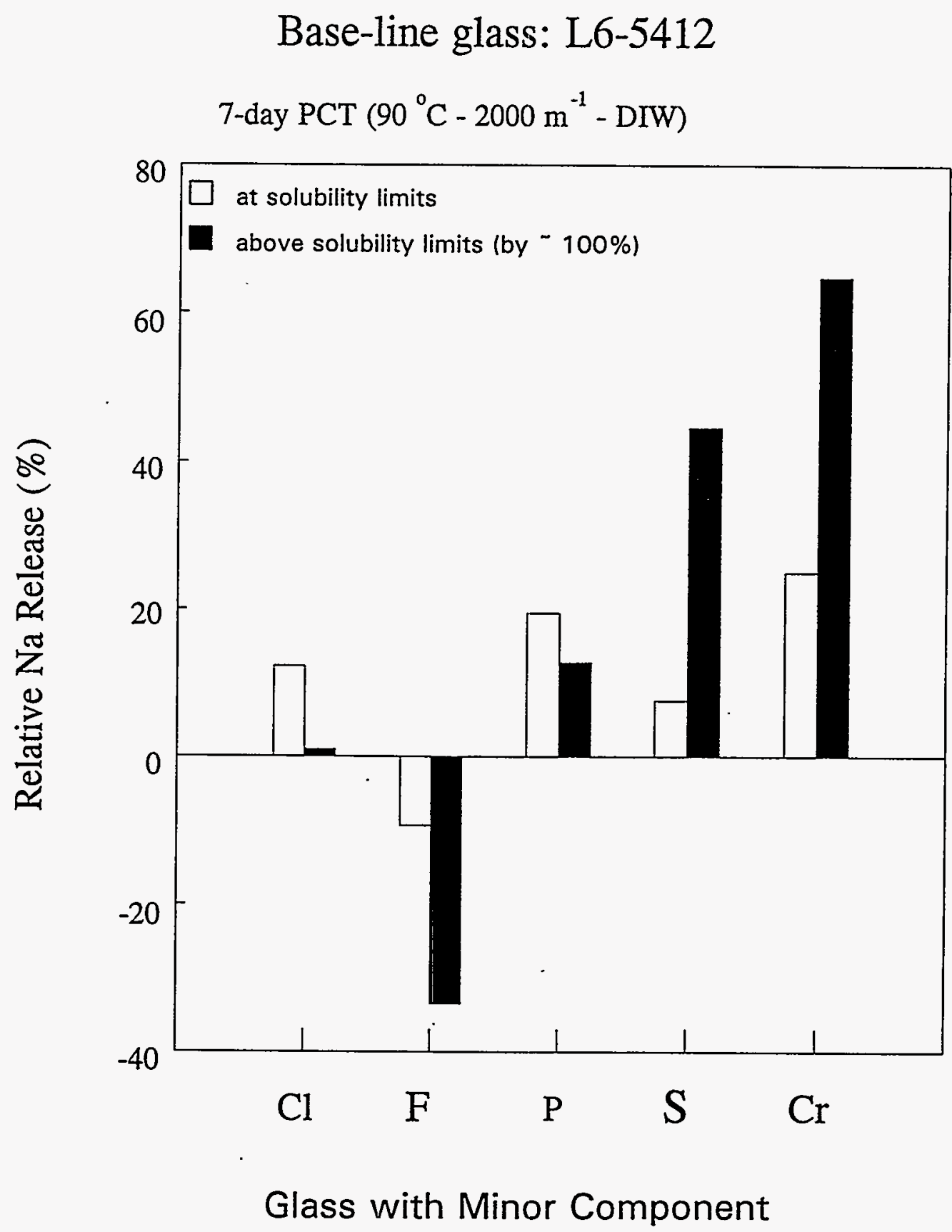




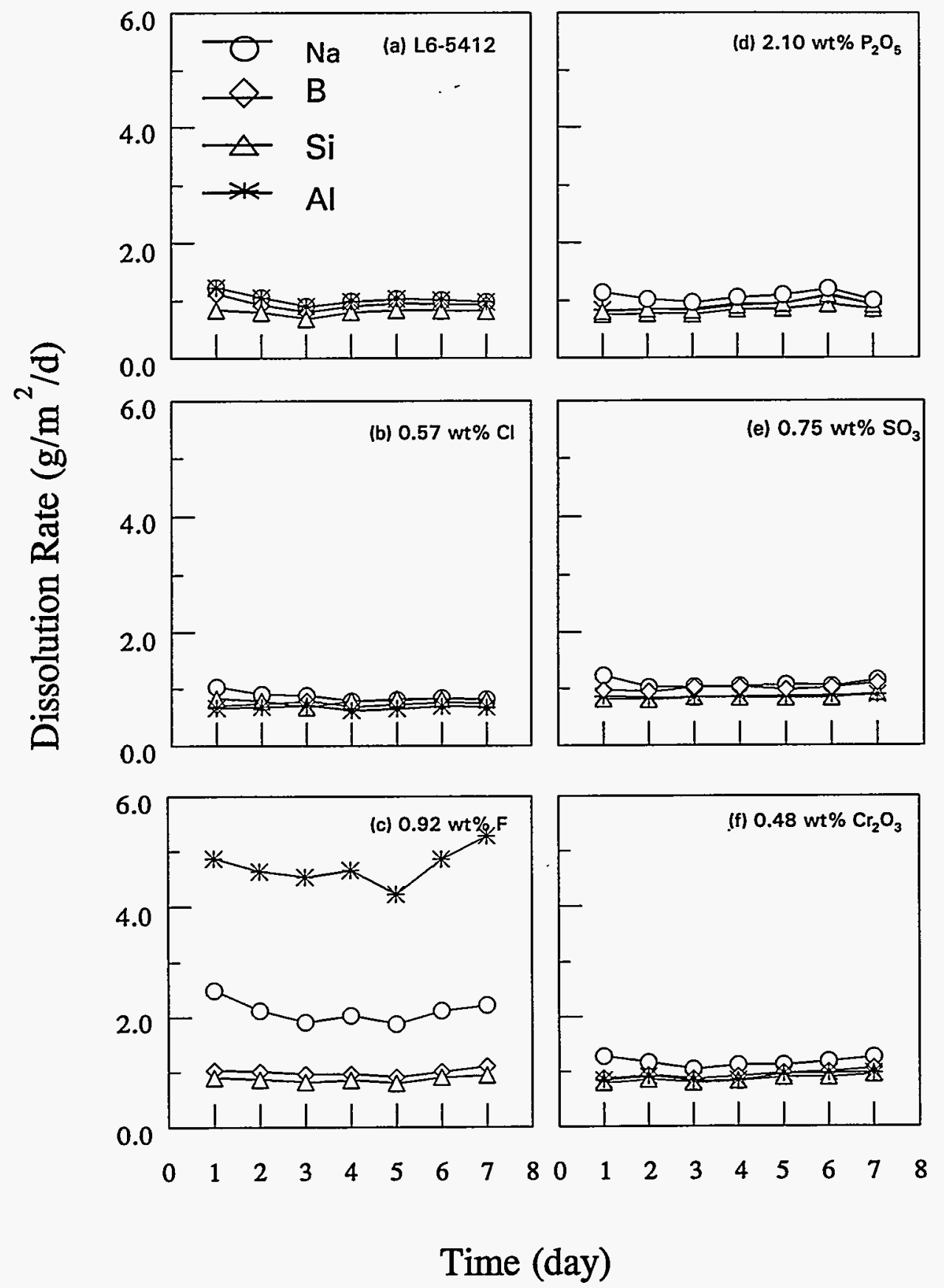




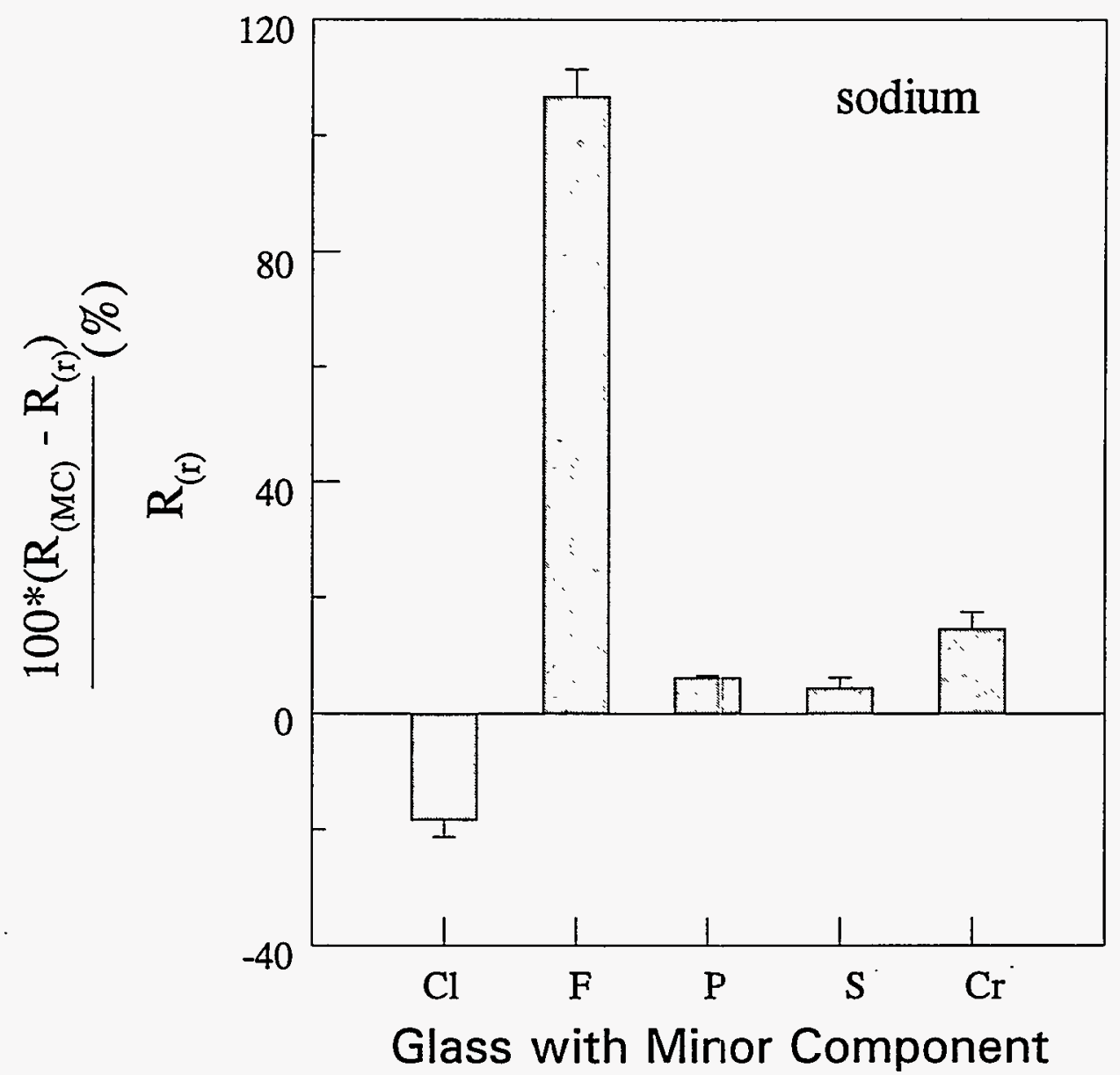




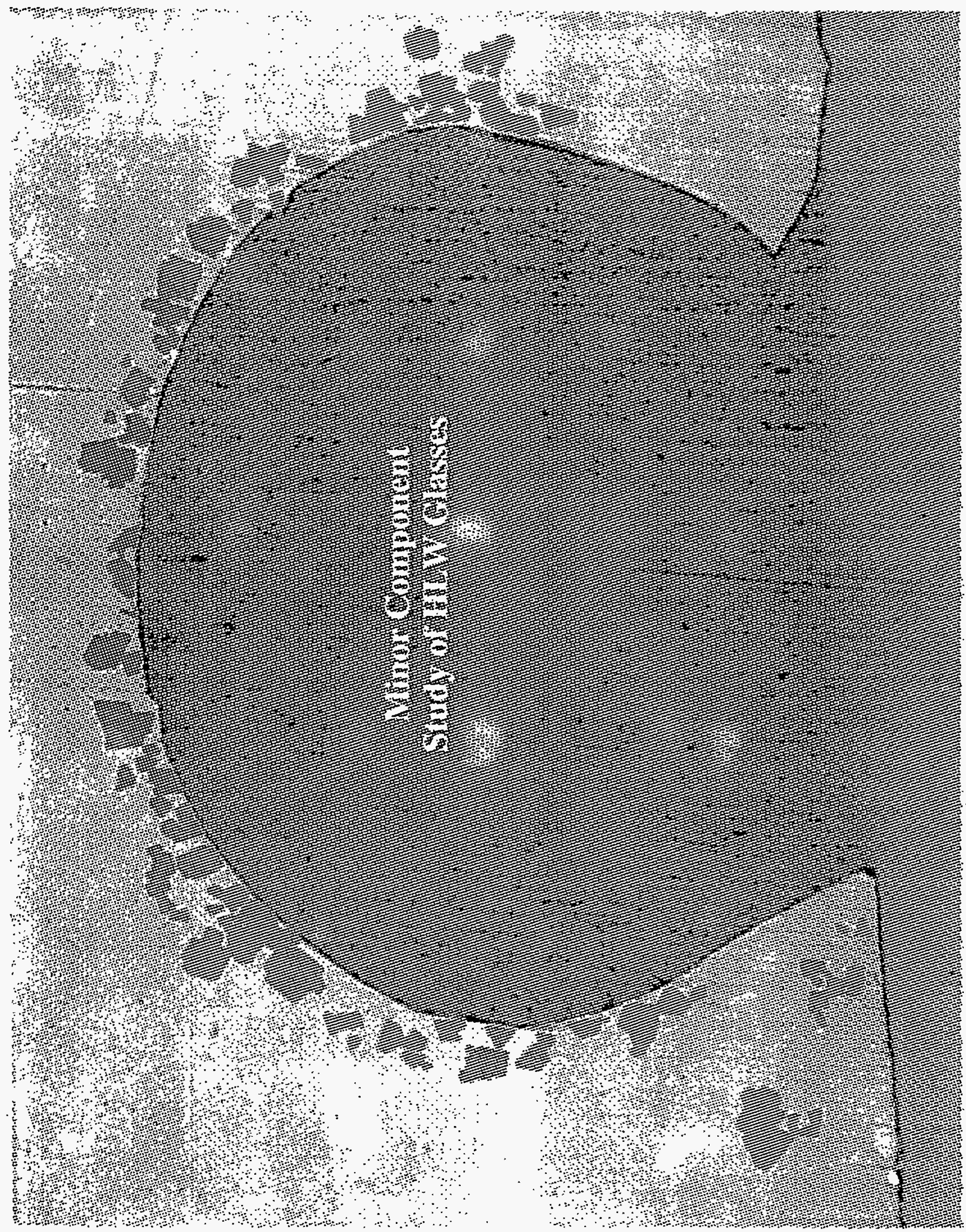




\section{Compositions (mol\%) of PFP Glasses}

Waste Loading - $40.0 \mathrm{wt} \%$

\begin{tabular}{|c|c|c|c|c|c|c|c|}
\hline Glass & $\begin{array}{c}\text { PFP1 } \\
\text { ( high Na }\end{array}$ & PFP2 & PFP3 & \multicolumn{3}{|c|}{ ( low Na2O - high B2O3) } & PFP7 \\
\hline $\mathrm{SiO} 2$ & 46.27 & 47.90 & 48.46 & 44.19 & 44.78 & 45.65 & 48.72 \\
\hline $\mathrm{B2O} 3(\#)$ & 6.46 & 5.53 & 4.36 & 22.66 & 21.35 & 19.40 & 12.55 \\
\hline $\mathrm{Na} 2 \mathrm{O}$ & 21.95 & 20.88 & 20.75 & 6.88 & 6.84 & 6.77 & 6.53 \\
\hline $\mathrm{Li2O}$ & 3.53 & 3.99 & 4.89 & 4.08 & 5.00 & 6.36 & 11.14 \\
\hline $\mathrm{CaO}$ & 1.50 & 1.50 & 1.49 & 1.53 & 1.52 & 1.51 & 1.45 \\
\hline $\mathrm{MgO}$ & 0.73 & 0.74 & 0.73 & 0.75 & 0.75 & 0.74 & 0.71 \\
\hline $\mathrm{Fe} 2 \mathrm{O} 3$ & 2.24 & 2.23 & 2.21 & 2.28 & 2.26 & 2.24 & 2.16 \\
\hline $\mathrm{Al} 2 \mathrm{O} 3$ & 8.46 & 8.43 & 8.38 & 8.62 & 8.56 & 8.48 & 8.18 \\
\hline $\mathrm{ZrO} 2$ & 0.05 & 0.05 & 0.05 & 0.05 & 0.05 & 0.05 & 0.04 \\
\hline P2O5 & 2.34 & 2.33 & 2.31 & 2.38 & 2.36 & 2.34 & 2.26 \\
\hline SO3 & 0.88 & 0.87 & 0.87 & 0.89 & 0.88 & 0.88 & 0.85 \\
\hline Others & 5.59 & 5.56 & 5.53 & 5.69 & .5 .65 & 5.59 & 5.40 \\
\hline SUM & 100.00 & 100.00 & 100.00 & 100.00 & 100.00 & 100.00 & 100.00 \\
\hline
\end{tabular}

\# Boric acid, H3BO3, was used 


\section{Compositions (mol\%) of WV Glasses}

\begin{tabular}{|l|ccc|}
\hline Glass & WV-182 & WV-182Al1 & WV-182Al2 \\
& (Al2O3 increasing ) & \\
\hline $\mathrm{SiO} 2$ & 52.20 & 48.96 & 45.00 \\
$\mathrm{~B} 2 \mathrm{O} 3$ & 13.75 & 13.98 & 14.26 \\
$\mathrm{Na} 2 \mathrm{O}$ & 17.29 & 17.58 & 17.94 \\
$\mathrm{Li} 2 \mathrm{O}$ & 0.10 & 0.10 & 0.10 \\
$\mathrm{CaO}$ & 3.68 & 3.74 & 3.82 \\
$\mathrm{MgO}$ & 0.36 & 0.36 & 0.37 \\
$\mathrm{Fe} 2 \mathrm{O} 3$ & 5.18 & 5.26 & 5.37 \\
$\mathrm{Al} 2 \mathrm{O} 3$ & 1.83 & 4.29 & 7.30 \\
$\mathrm{ZrO} 2$ & 1.19 & 1.21 & 1.23 \\
& & & \\
$\mathrm{P} 2 \mathrm{O} 5$ & 1.34 & 1.36 & 1.39 \\
SO3 & 0.18 & 0.18 & 0.19 \\
Others & 2.92 & 2.97 & 3.03 \\
& \multicolumn{3}{|c}{} \\
\hline SUM & 100.00 & 100.00 & 100.00 \\
\hline
\end{tabular}

Each glass was separately spiked with $1.0,1.5$, and 2.0 wt\%SO3. 
- Laboratory Scale Test

Batch Melting $\left(1150^{\circ} \mathrm{C}\right)$

PFP glasses

Crucible : Pt-10\%Rh

Time: varied, and up to $2 \mathrm{hr}$

Batch Size : $200 \mathrm{~g}$

W glasses

Crucible : $\mathrm{Al}_{2} \mathrm{O}_{3}$

Time : $1 \mathrm{hr}$

Batch Size : $\sim 40 \mathrm{~g}$

Characterizations

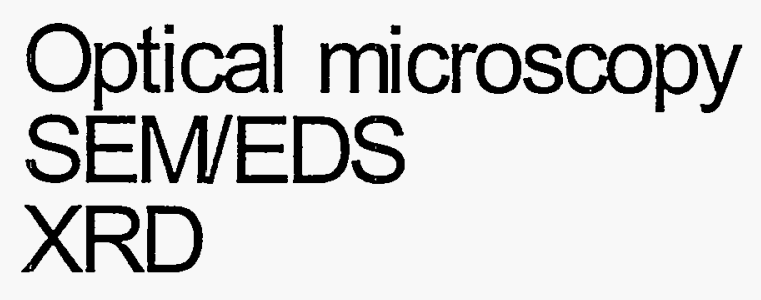




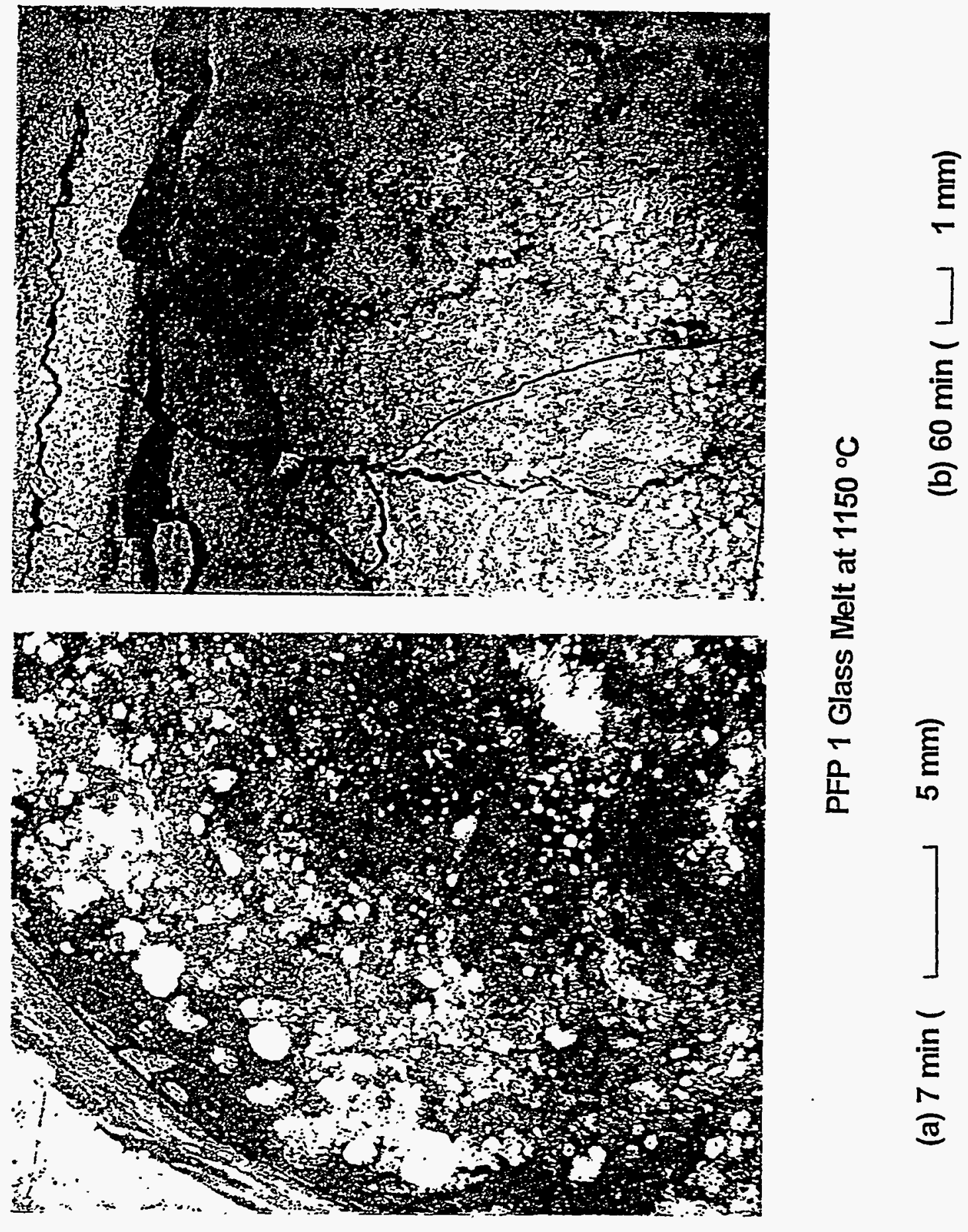


SEMEDS of PFP 1 Glass Melt at $1150^{\circ} \mathrm{C}$ for $7 \mathrm{~min}$

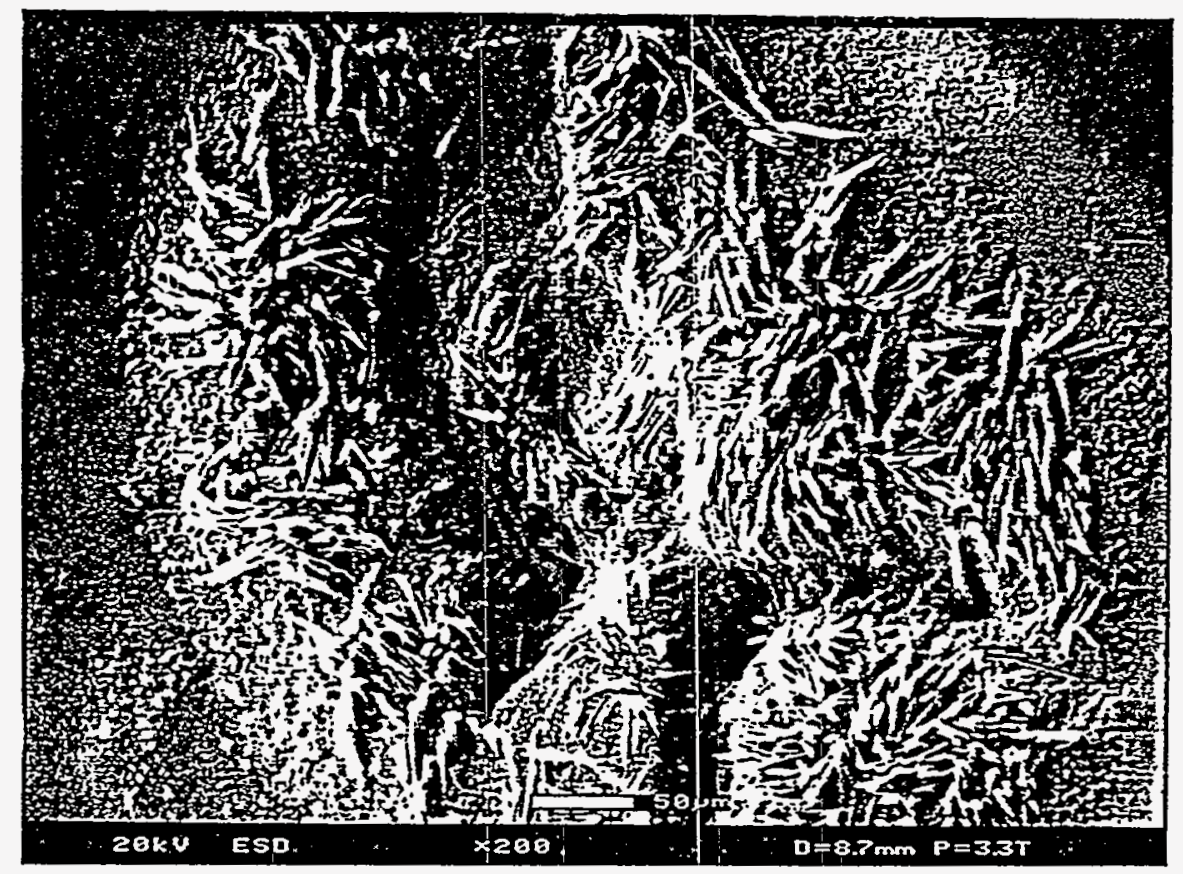

(b) area with segregated phases $\left(\mathrm{Na}_{2} \mathrm{SO}_{4} \& \mathrm{Na}_{3} \mathrm{PO}_{4}\right)$

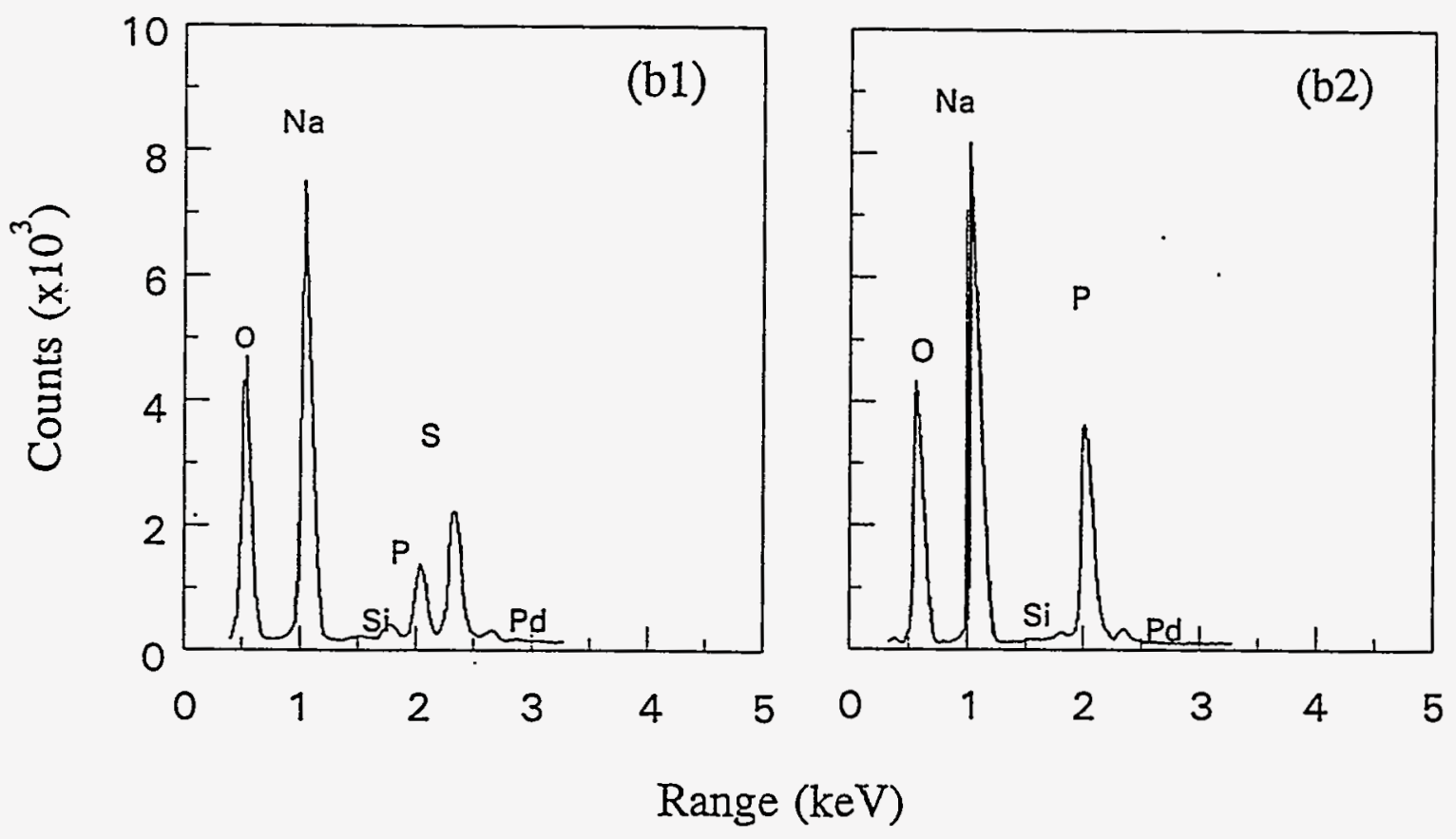




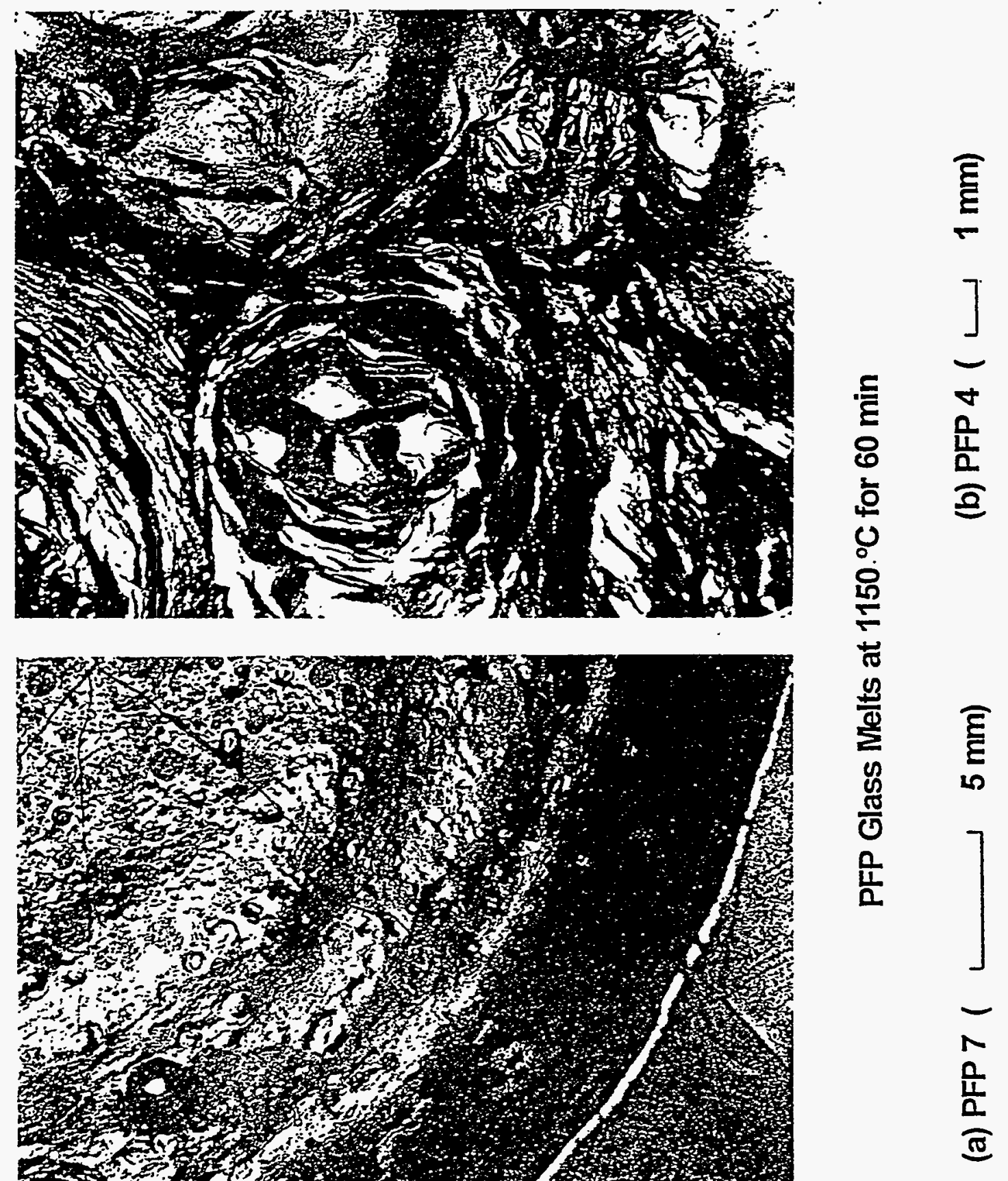




\section{WV Glasses Spiked with $2.0 \mathrm{wt} \% \mathrm{SO}_{3}$}

$\left(1150{ }^{\circ} \mathrm{C}-60 \mathrm{~min}\right)$

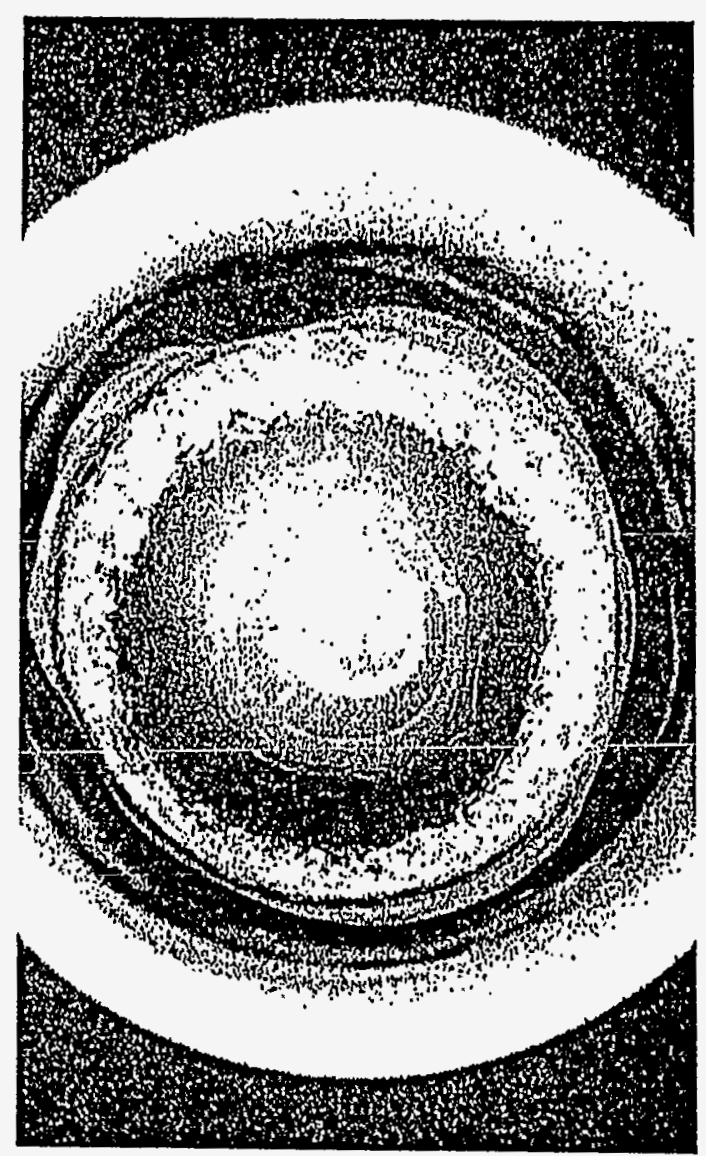

WV-182
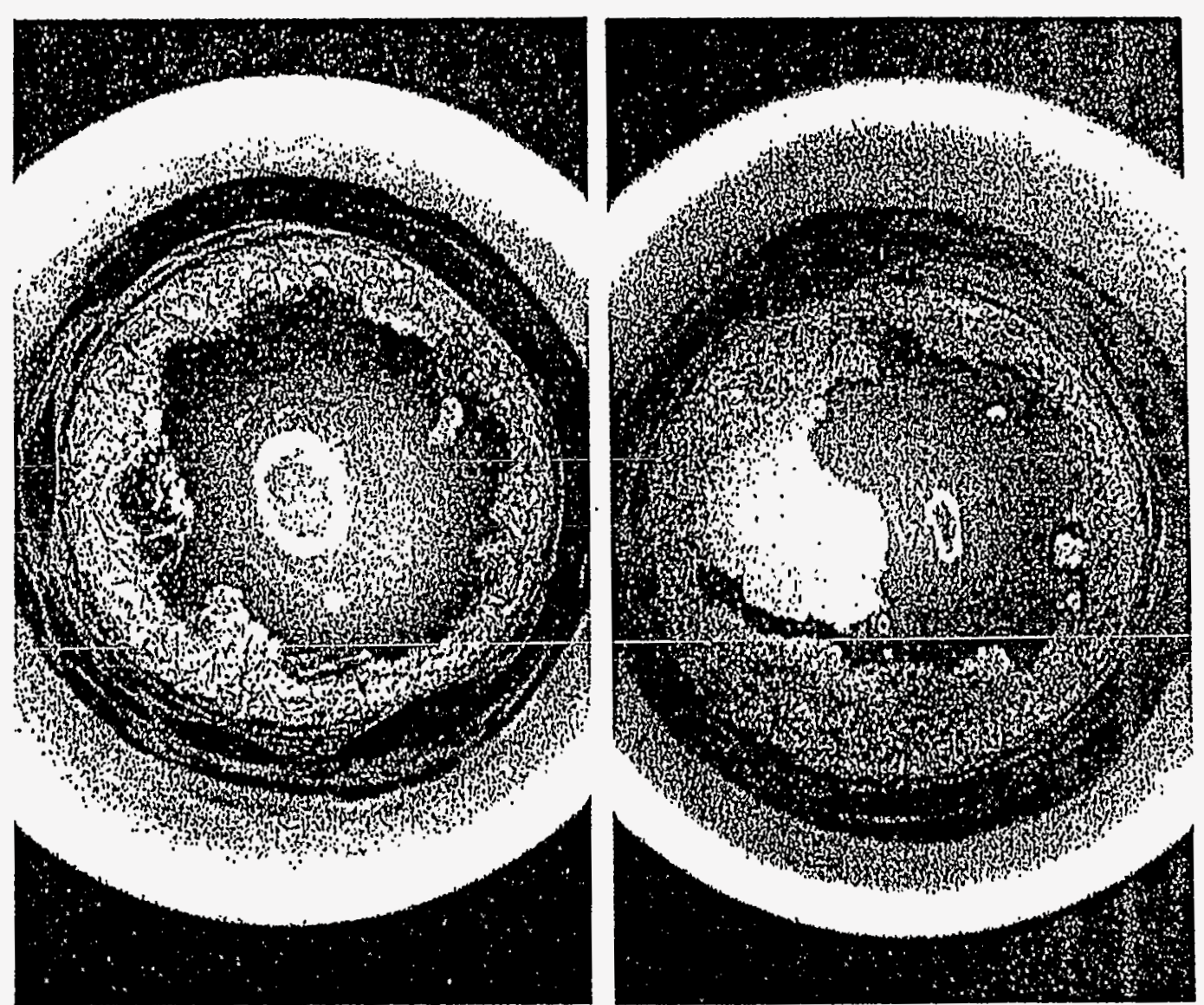

WV-182AI2

$\mathrm{Al}_{2} \mathrm{O}_{3}$ increasing 
For a fixed $\mathrm{P}_{2} \mathrm{O}_{5}$ concentration

Neither sulfate nor phosphate segregated from WW melts with lower $\mathrm{SO}_{3}$ ( about $1.0 \mathrm{wt} \%$ )

Phosphate segregated from $\mathrm{W}$ melts only at higher $\mathrm{SO}_{3}$ (1.5 and $\left.2.0 \mathrm{wt} \%\right)$

No phosphate segregation ocurred in PFP 4 to 7 melts (higher in $\mathrm{H}_{3} \mathrm{BO}_{3}$, but lower in $\mathrm{Na}_{2} \mathrm{O}$ ), in which sulfate segregation was suppressed.

Phosphate segregation occured in PFP 1 to 3 melts (lower in $\mathrm{H}_{3} \mathrm{BO}_{3}$, but higher in $\mathrm{Na}_{2} \mathrm{O}$ ), in which sulfate segregation was also observed.

Phosphate segregation is promoted by the segregated sulfate phase. 


\section{Sulfate Solubility in Silicate Glass}

$$
\begin{aligned}
\equiv \mathrm{Si}-\mathrm{O}-\mathrm{Si} \equiv+2 \mathrm{Na}^{+}: \mathrm{O}^{2-} \text { (glass) } & \\
& \Longleftrightarrow 2\left(\equiv \mathrm{Si}-\mathrm{O}^{-}: \mathrm{Na}^{+}\right) \text {(glass) }
\end{aligned}
$$

$\mathrm{SO}_{3}$ (gas) $+2 \mathrm{Na}^{+}: \mathrm{O}^{2-}$ (molten salt) $\Longleftrightarrow 2 \mathrm{Na}^{+}: \mathrm{SO}_{4}{ }^{2-}$ (molten salt)

$\left[\mathrm{SO}_{4}^{2-}\right] \propto$

$$
P\left(\mathrm{SO}_{3}\right) *\left[\mathrm{Na}^{+}\right]^{2}\left[\mathrm{ES}-\mathrm{O}^{-}\right]^{2} / \text { [ESi-O-Si=] }
$$

(Ref: K. Papadopoulos, Phys. Chem. Glasses, 14 (1973) 60-65) 
Phase segregation is a kinetic process.

Phase segregation initiated at the early stages of batch melting

"High S solubility" batches showed sulfate segregation

(PFP 1 to 3 : higher in $\mathrm{Na}_{2} \mathrm{O}$ and lower in $\mathrm{B}_{2} \mathrm{O}_{3}$ )

No difference in phase segregation was observed among PFP 1, 2, and 3 with increasing $\mathrm{Li}_{2} \mathrm{O}$ (3.5 - $\left.4.9 \mathrm{~mol} \%\right)$ 
- Effect of $\mathrm{H}_{3} \mathrm{BO}_{3}$ on Phase Segregation

Glass $\quad \mathrm{B}_{2} \mathrm{O}_{3} \quad \mathrm{Na}_{2} \mathrm{O} \quad$ Seg. Foam

PFP 1-3 4.4-6.5 22.0-21.0 Yes No

$\begin{array}{lll}\text { WW }^{*} \sim 14.0 & 17.0-18.0 \quad \text { Yes No }\end{array}$

$\begin{array}{lllll}\text { PFP } 4-7 & 23.0-13.0 & \sim 7.0 & \text { No } & \text { Yes }\end{array}$

(\# Batches spiked with 1.5 and $2.0 \mathrm{wt} \% \mathrm{SO}_{3}$ ) 


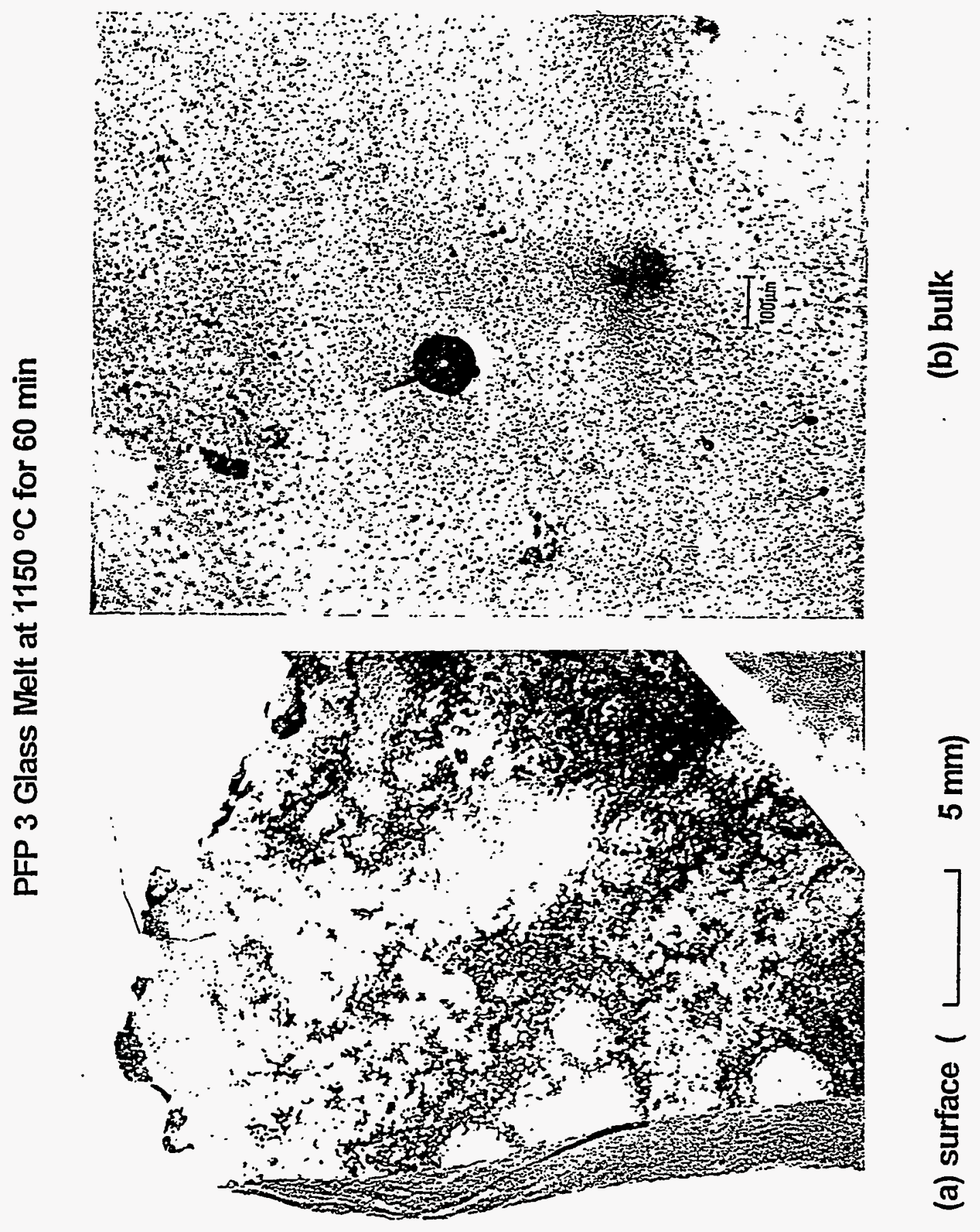




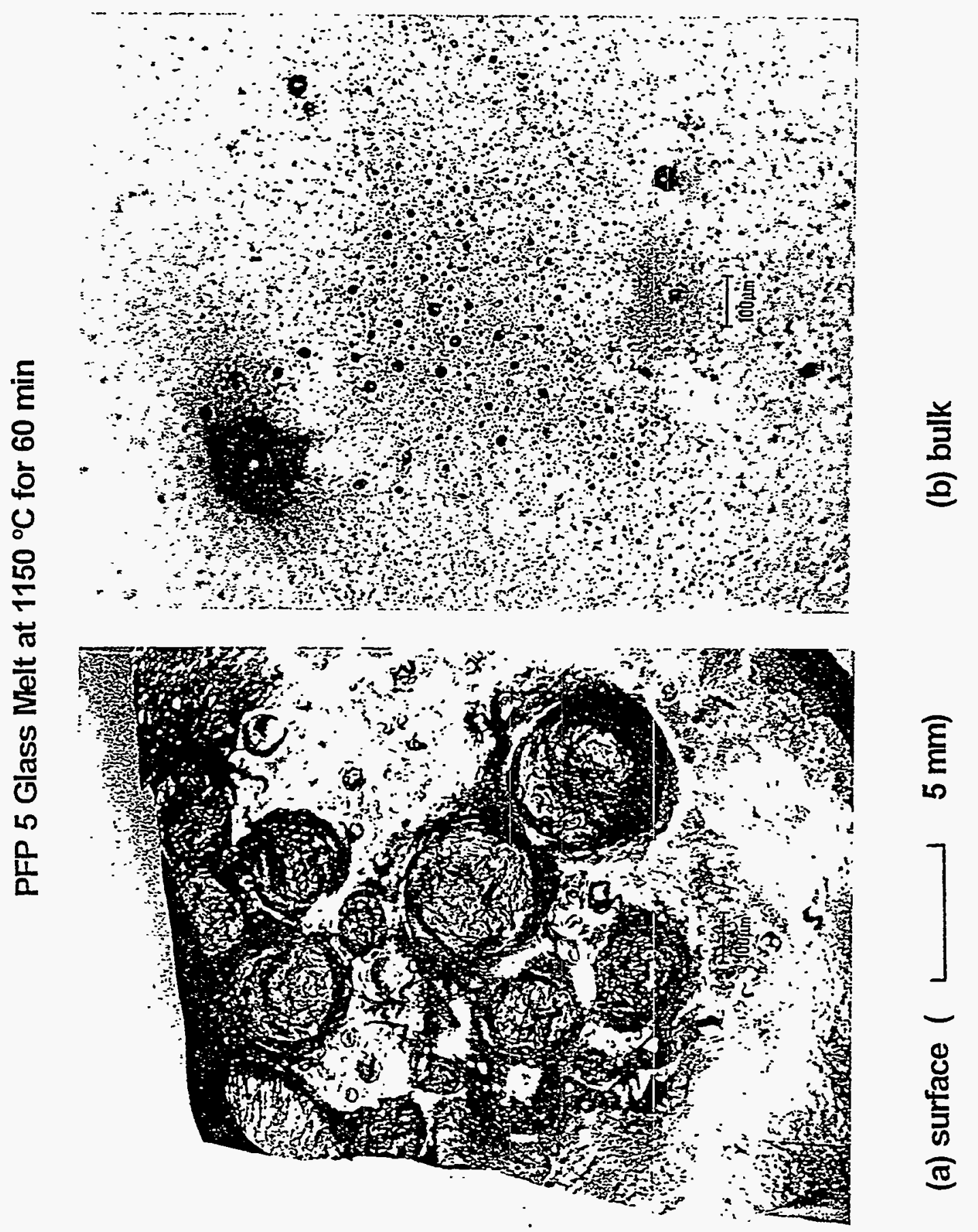




\section{A link between Foaming and Segregation}

Sulfate depresses mild melt foaming (sulfate - foaming breaker)

Ref 1:

D.S. Kim and P.R. Hrma, "Volume Changes

During Batch to Glass Conversion" Ceram. Bull. 6[6] 1039 (1990)

Ref 2:

MJ. Plodinec, "Vitrification of Savannah River Radioactive Waste Process Development Studies, " USDOE Report, DP-MS-79-42, SRL, E.I. du Pont de Nemours \& Co., Wilminton, DE (1987).

Vigorous melt foaming suppresses sulfate segregation $\left(\mathrm{H}_{3} \mathrm{BO}_{3}\right.$ - foaming agent )

Sulfate spreads on large surface area created by foam (or bubbles) and subsequently dissolves in the melt. 


\section{SUMMARY}

- Phase segregation is a kinetic process, which initiated at the early stages of batch melting.

- Segregation of molten sulfate from melt promoted phosphate segregation.

- Phase segregation was suppressed by high $\mathrm{H}_{3} \mathrm{BO}_{3}$-induced vigorous melt foaming.

- Extent of phase segregation increased with an increase of $\mathrm{Al}_{2} \mathrm{O}_{3}$. 


\title{
WHAT IS THE NEXT ?
}

MUTUAL REACTIONS BETWEEN MINOR COMPONENTS

\author{
GLASS COMPOSITION DESIGN TO \\ MINIMIZE THE MUTUAL REACTIONS
}




\title{
Understanding Glass Composition Effects on Chemical Durability
}

\section{Xiangdong Feng}

\author{
June 27, 1995 \\ Glass Science and Engineering Tutorial \\ Westinghouse Hanford Company \\ Richland, Washington
}




\section{Glass Durability}

- The ability of glass to resist corrosion, weathering, or leaching

- It is measured by durability tests and expressed as release rate of glass components or rate of weight loss, or depths of alteration 


\section{Factors Affecting Glass Durability}

- Glass composition

- Individual oxides

- Redox

- Charge and size

- Processing

- Crystallization

- Phase separation

- Glass stress

- Testing parameters

- Methods (PCT, flow-through, vapor-hydration)

- SA/V

- Leachant composition

- Temperature 


\section{Individual Oxide Effects on Glass Durability}

- $\mathrm{SiO}_{2}$

- $\mathrm{Al}_{2} \mathrm{O}_{3}$

- $\mathrm{ZrO}_{2}$

- $\mathrm{B}_{2} \mathrm{O}_{3}$
- $\mathrm{CaO}$

- $\mathrm{Fe}_{2} \mathrm{O}_{3}$

- $\mathrm{Na}_{2} \mathrm{O}$ 


\section{Search for Optimized Glass Composition}

- Which oxide is most effective in improving glass durability?

- Is the effect linear? (i.e. same improvement is expected for equal additions)

- Is the effect always consistent? (i.e., always positive or always negative)

- Does the redox state of the element matter?

- Fe (II) vs. Fe(III) 


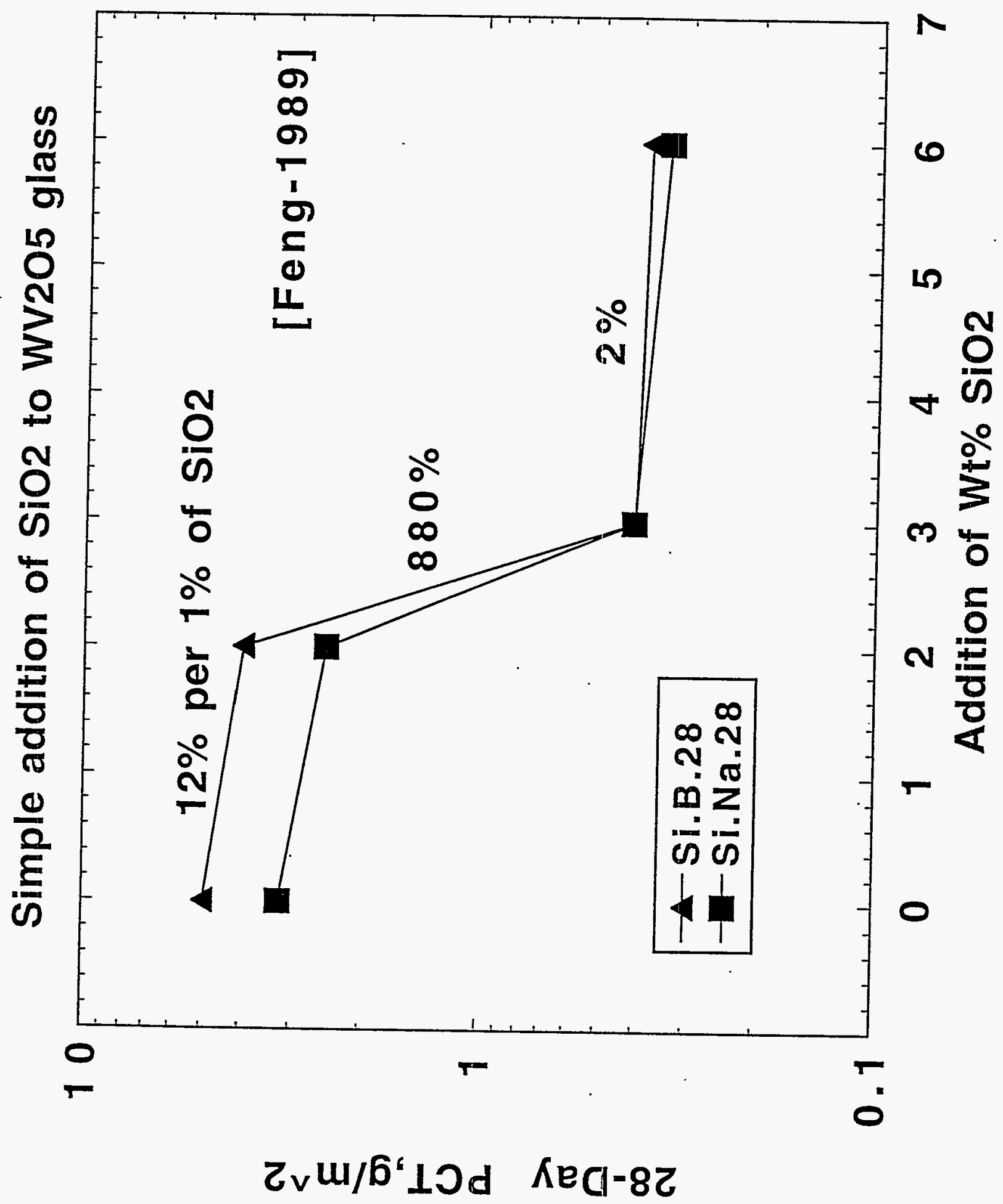


Simple addition of Al2O3 to WV2O5 glass

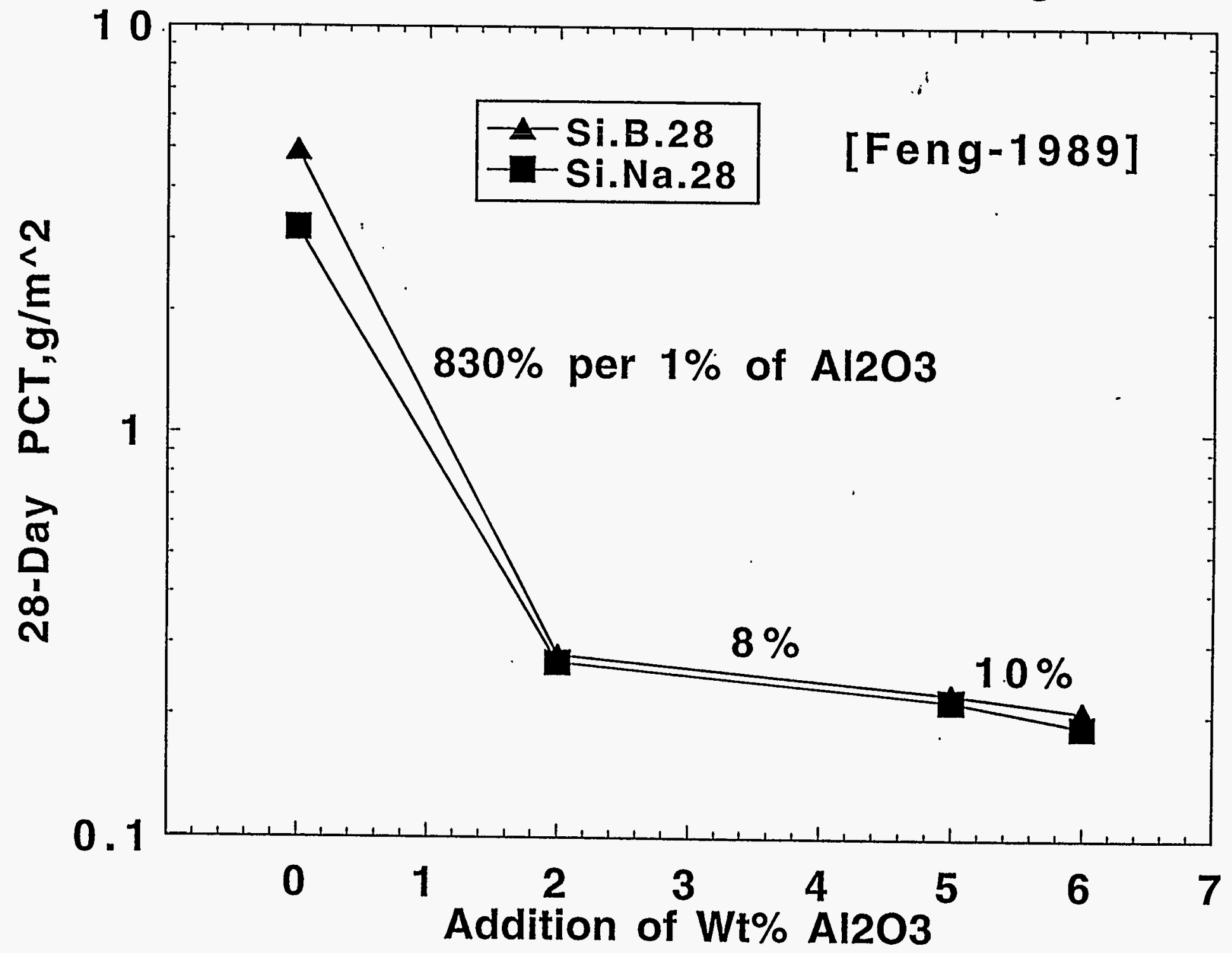




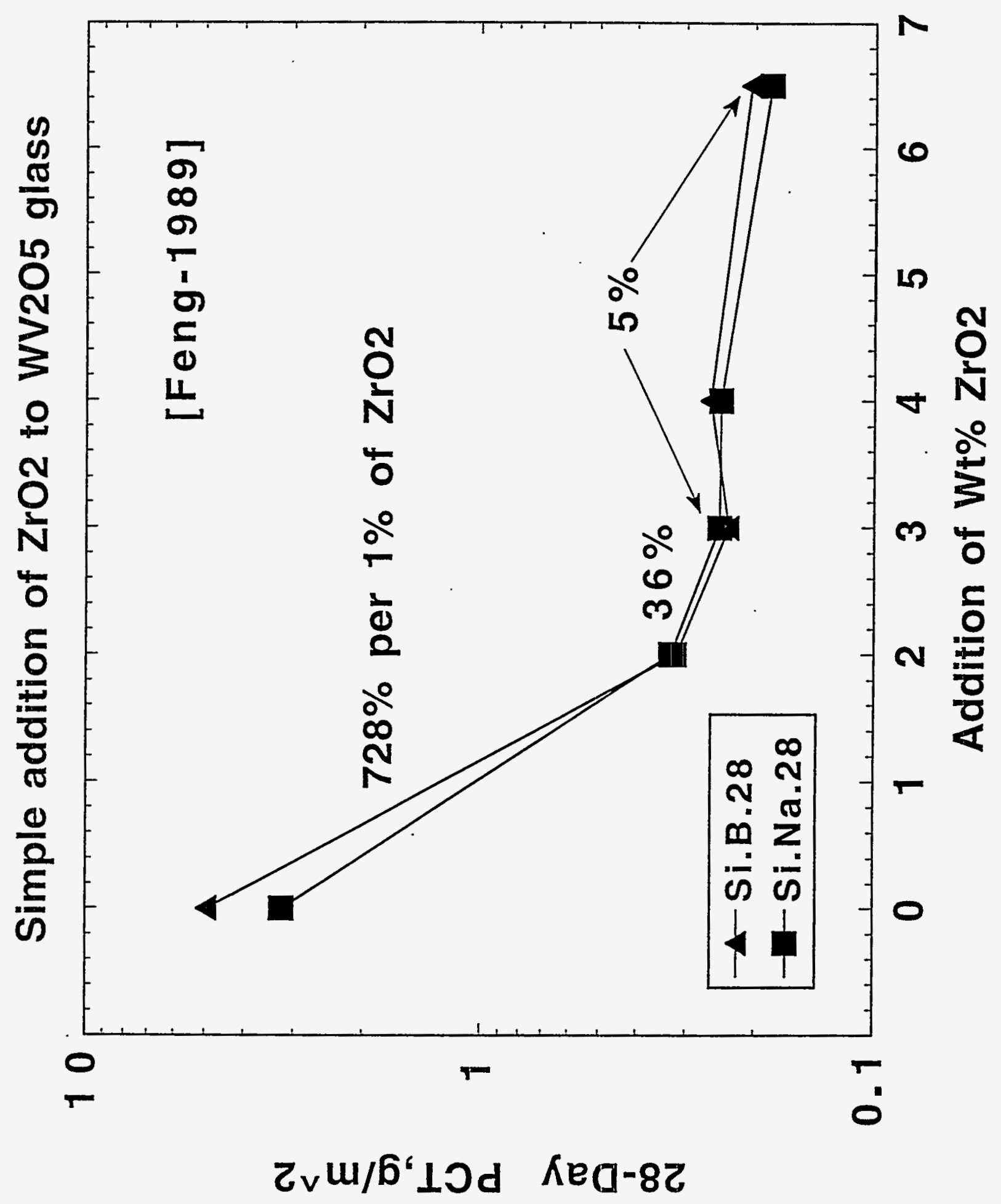




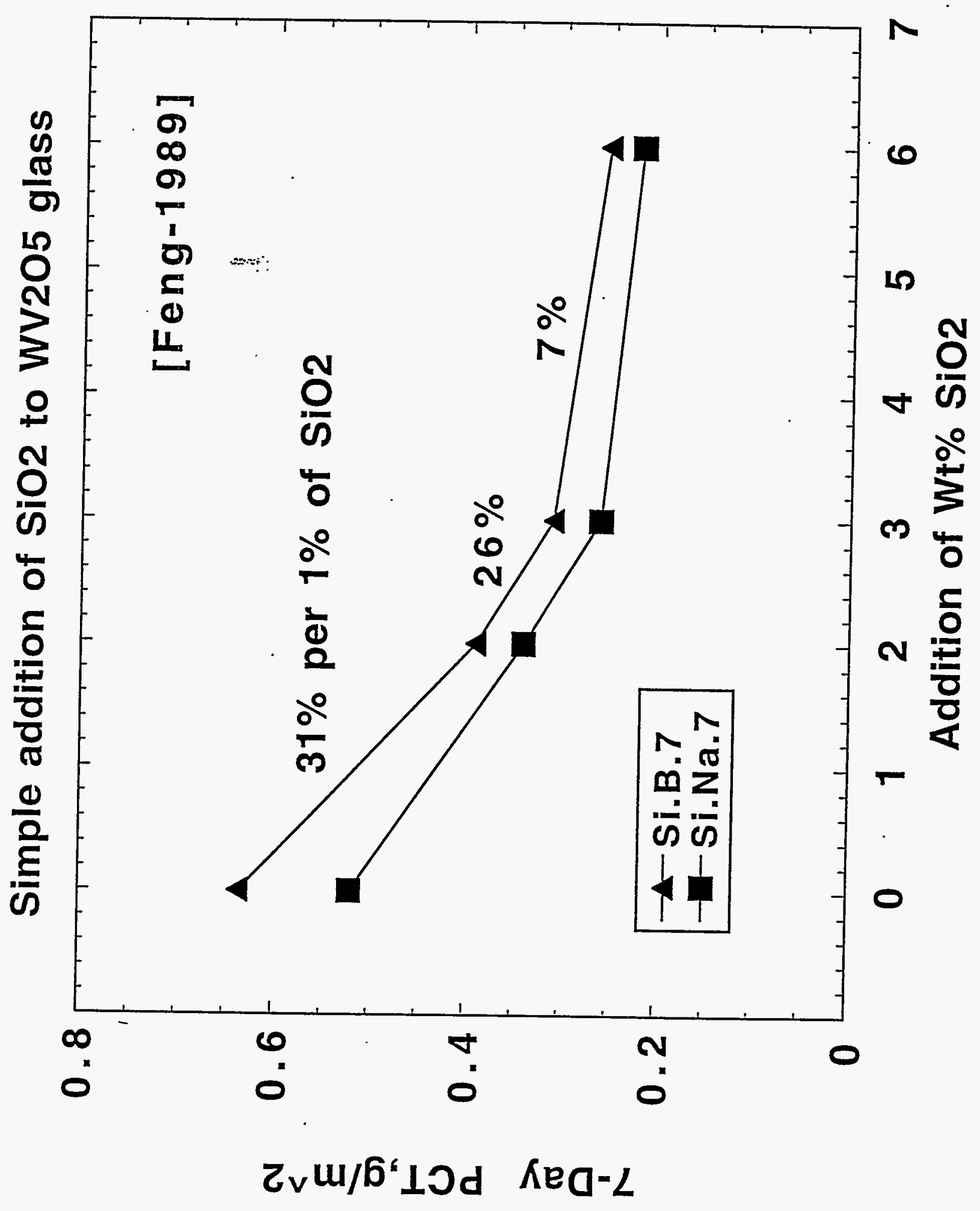




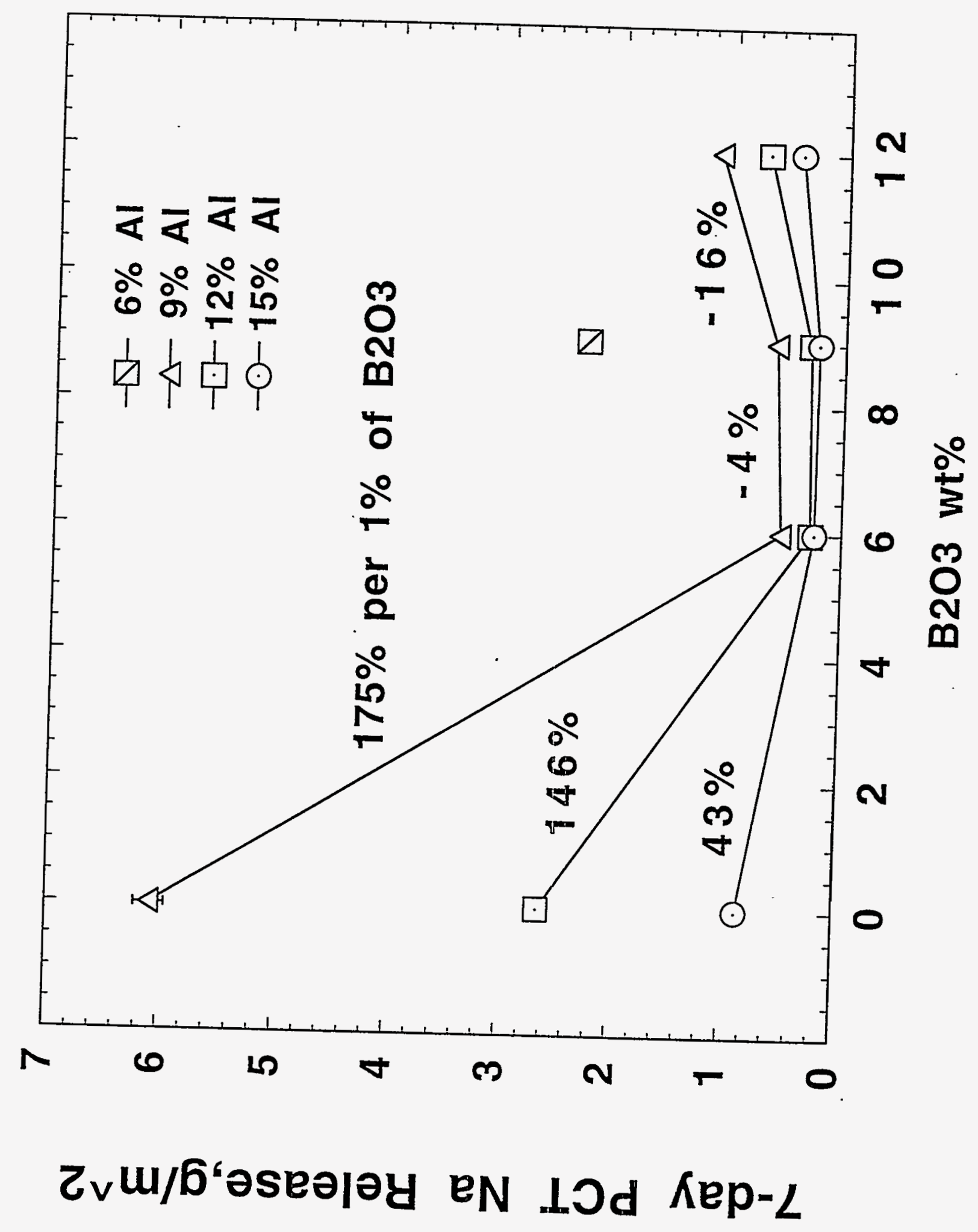




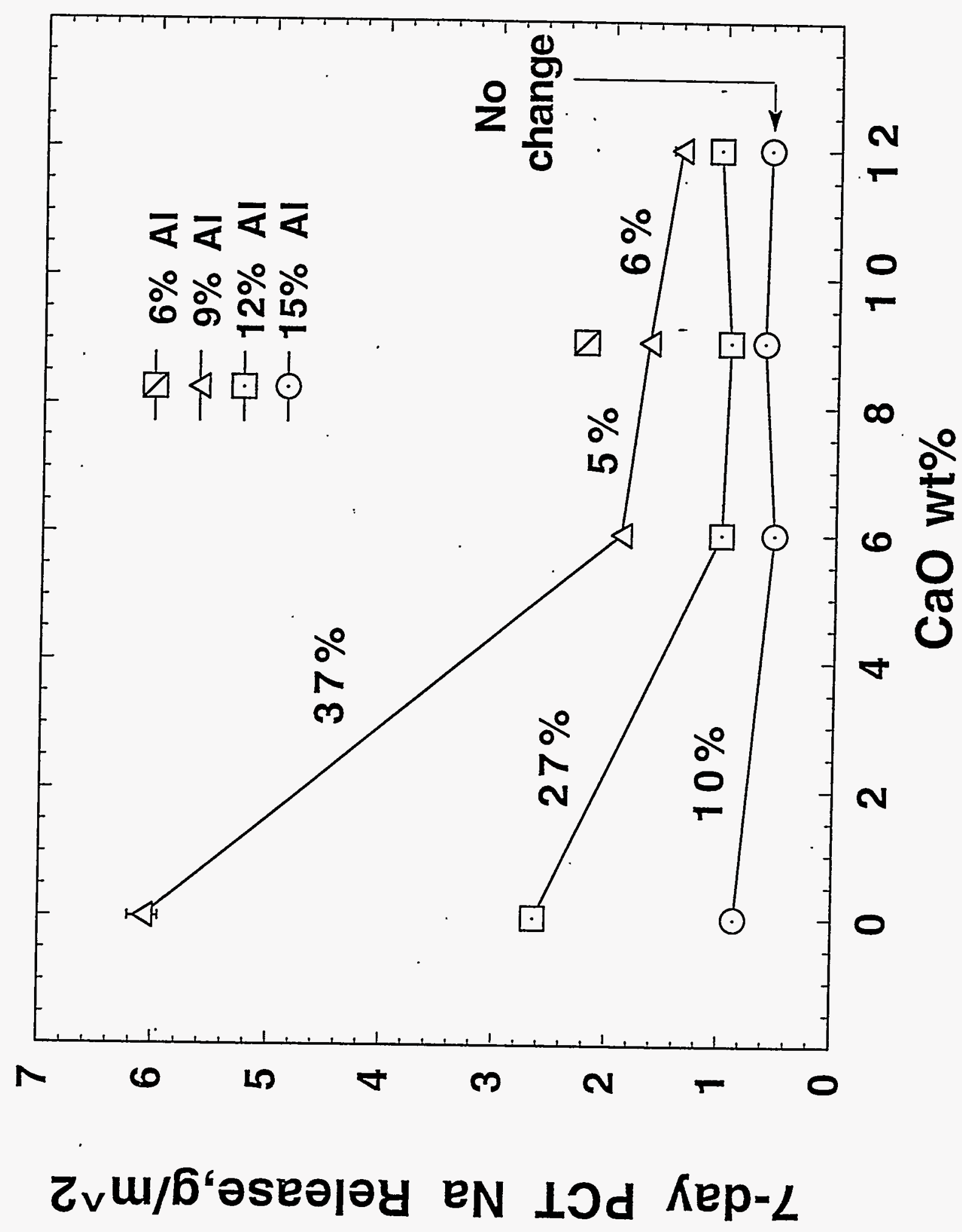




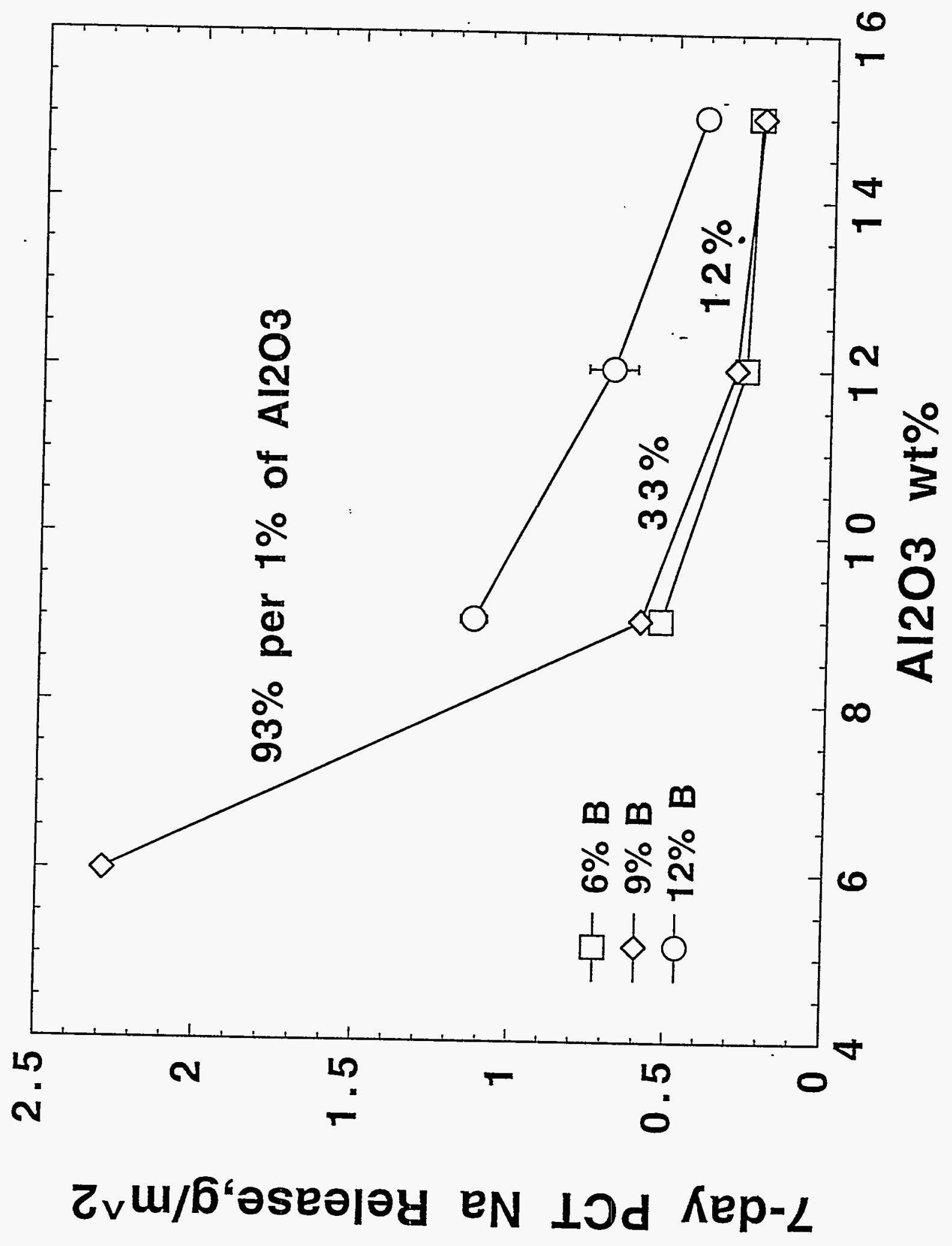




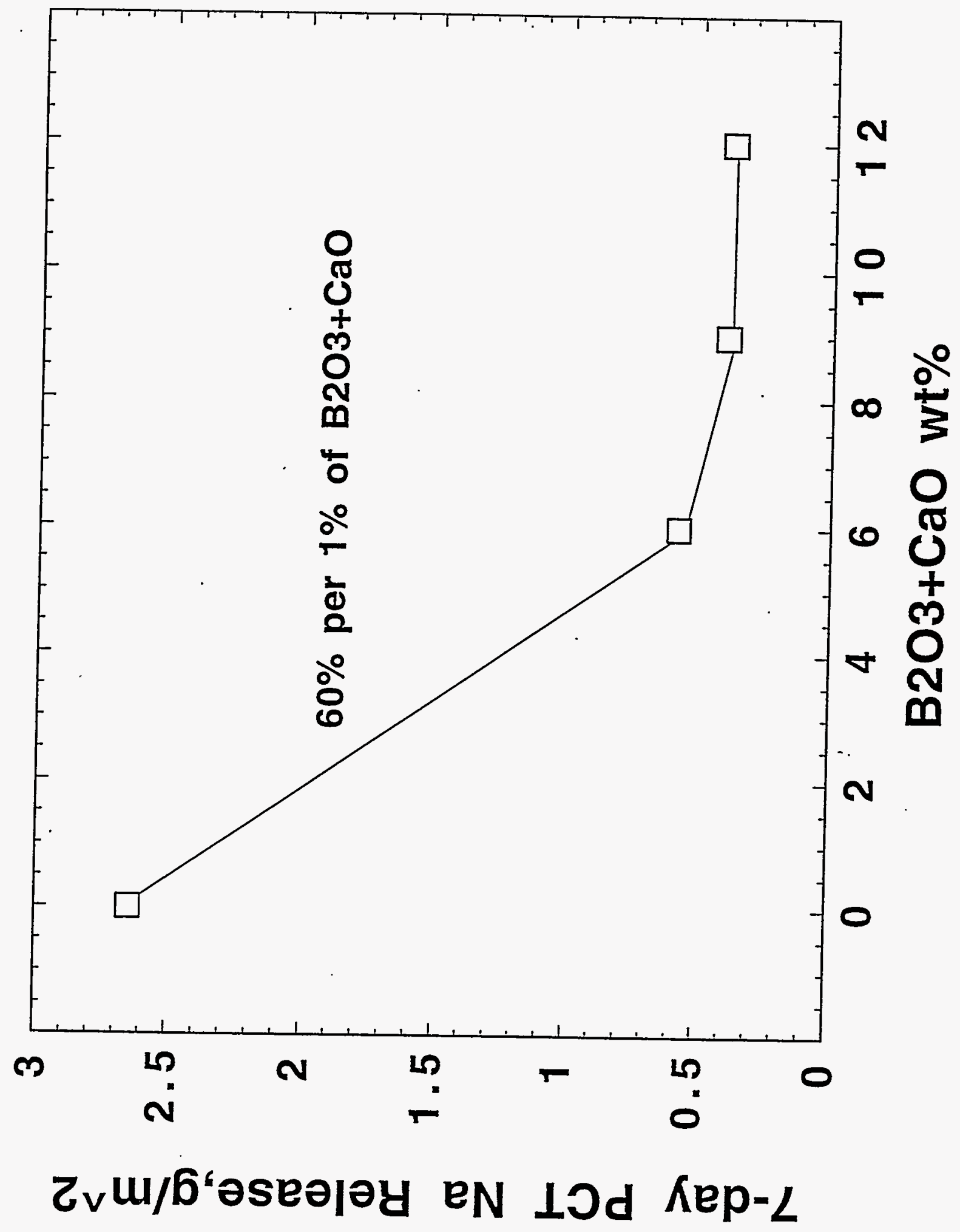




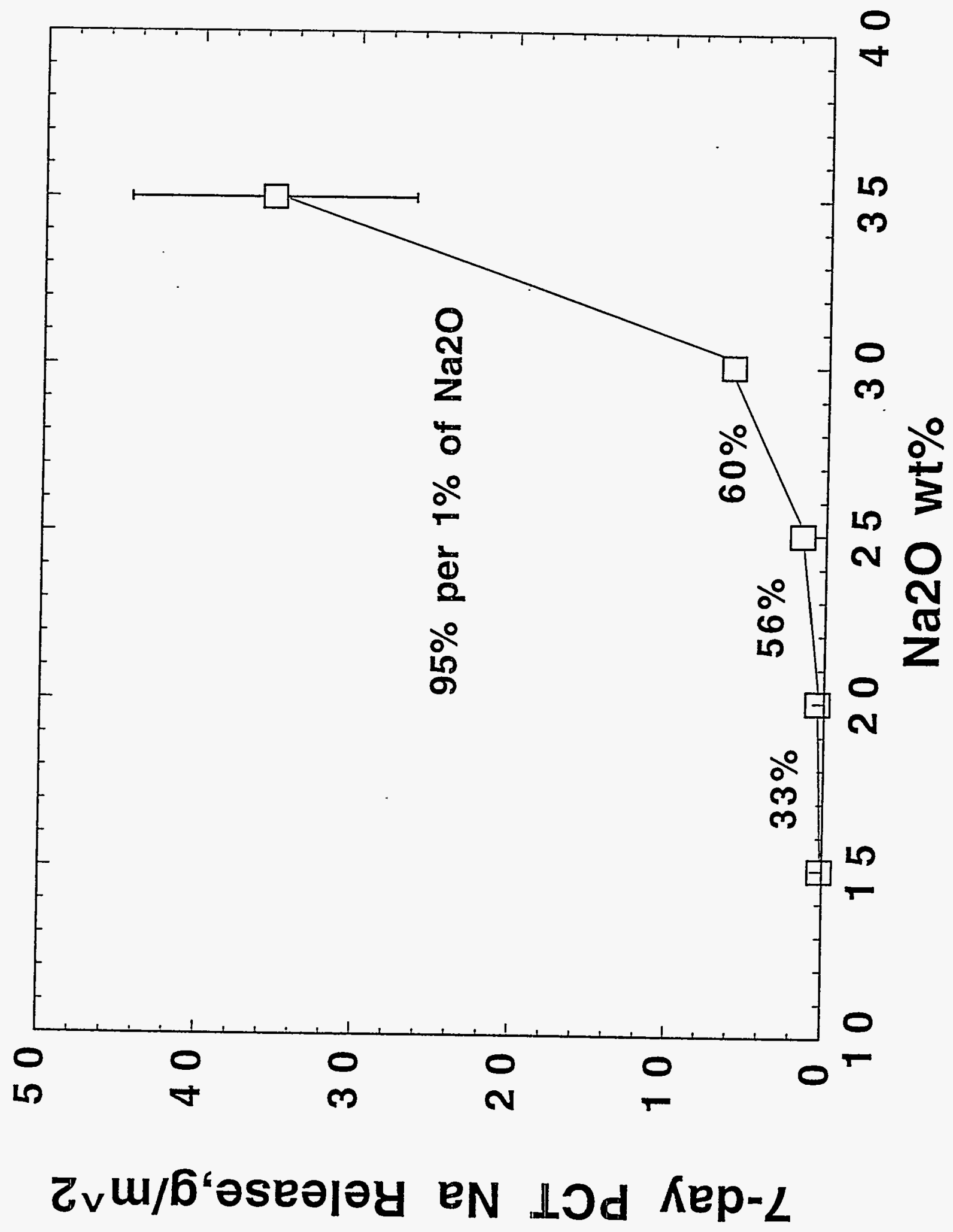




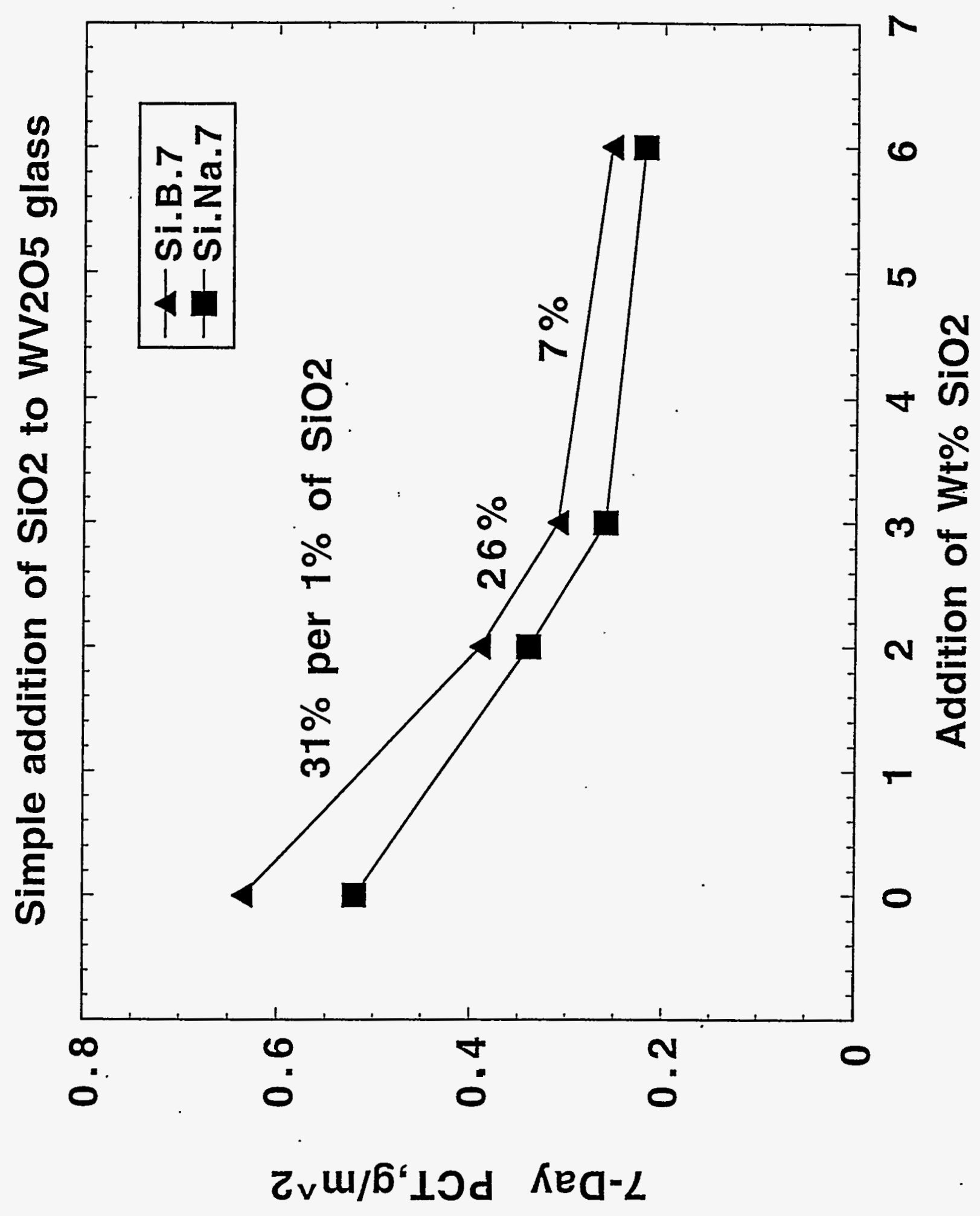


The Effect of Replacing $10 \mathrm{wt} \% \mathrm{SiO}_{2}$ with $10 \%$ $\mathrm{Fe}_{2} \mathrm{O}_{3}$ Resulted in Different Improvement in Durability in Different Glass Systems

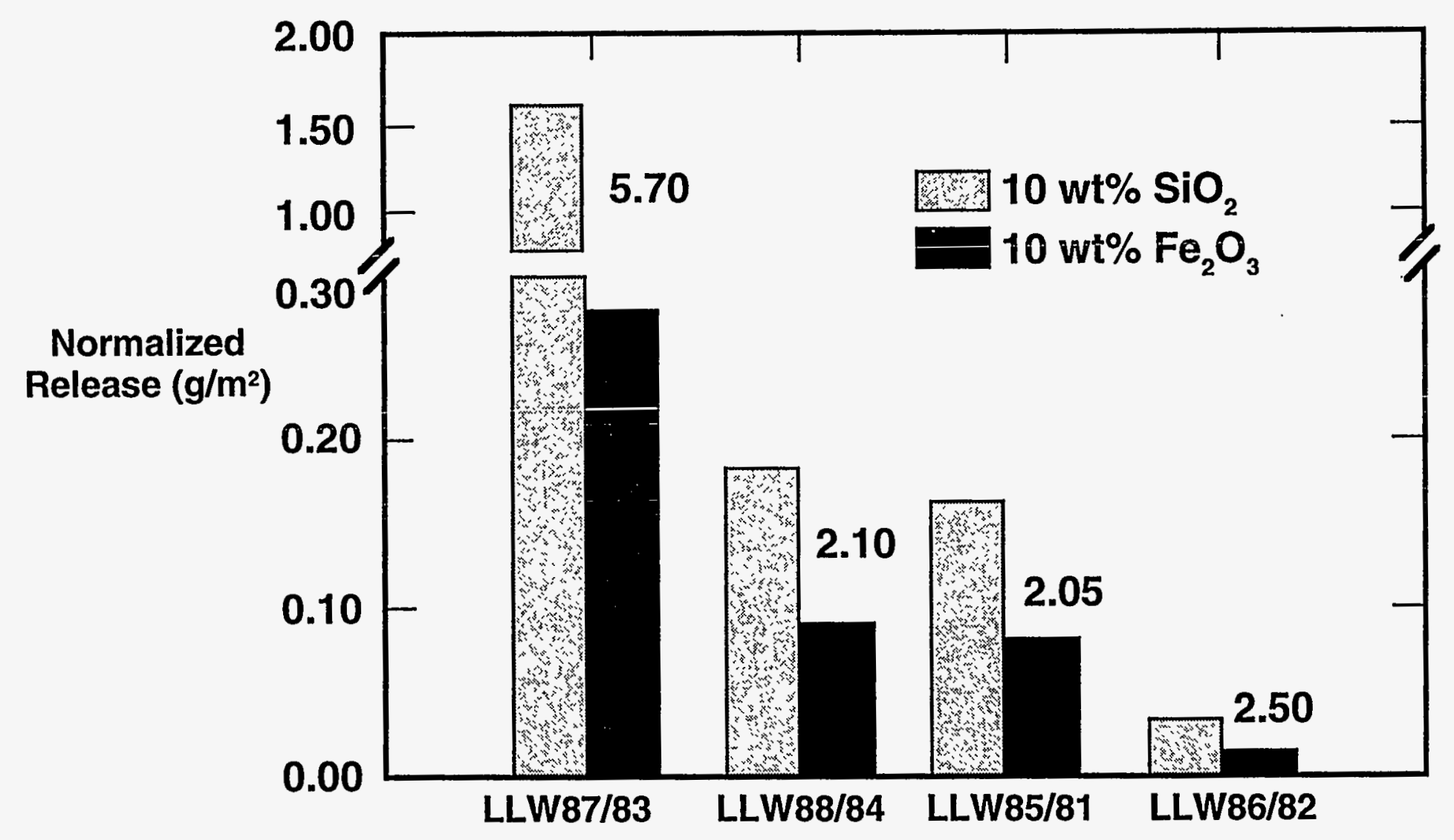


- Are these oxide effects random?

- Incomprehensible?

- Unpredictable? 


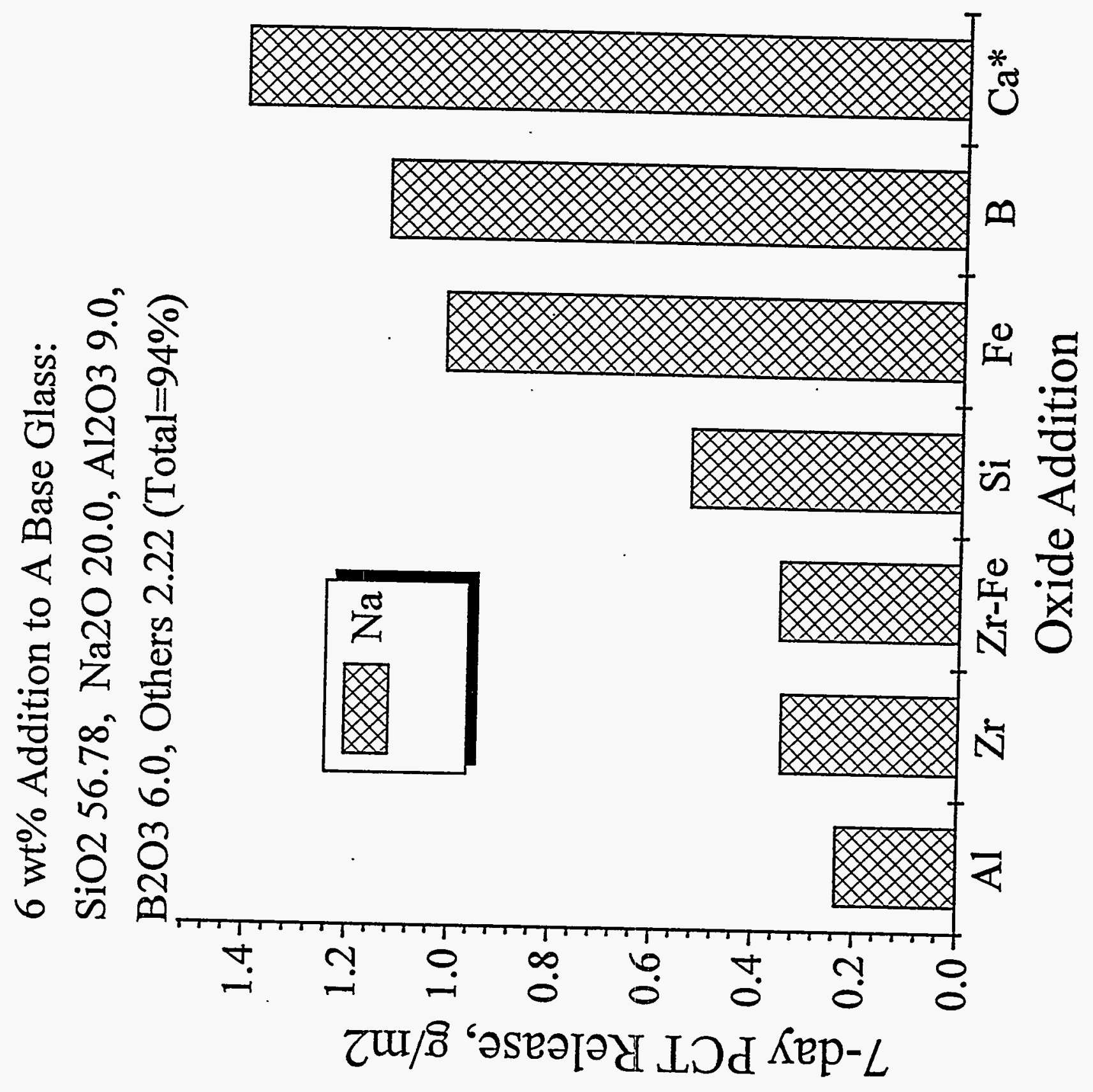




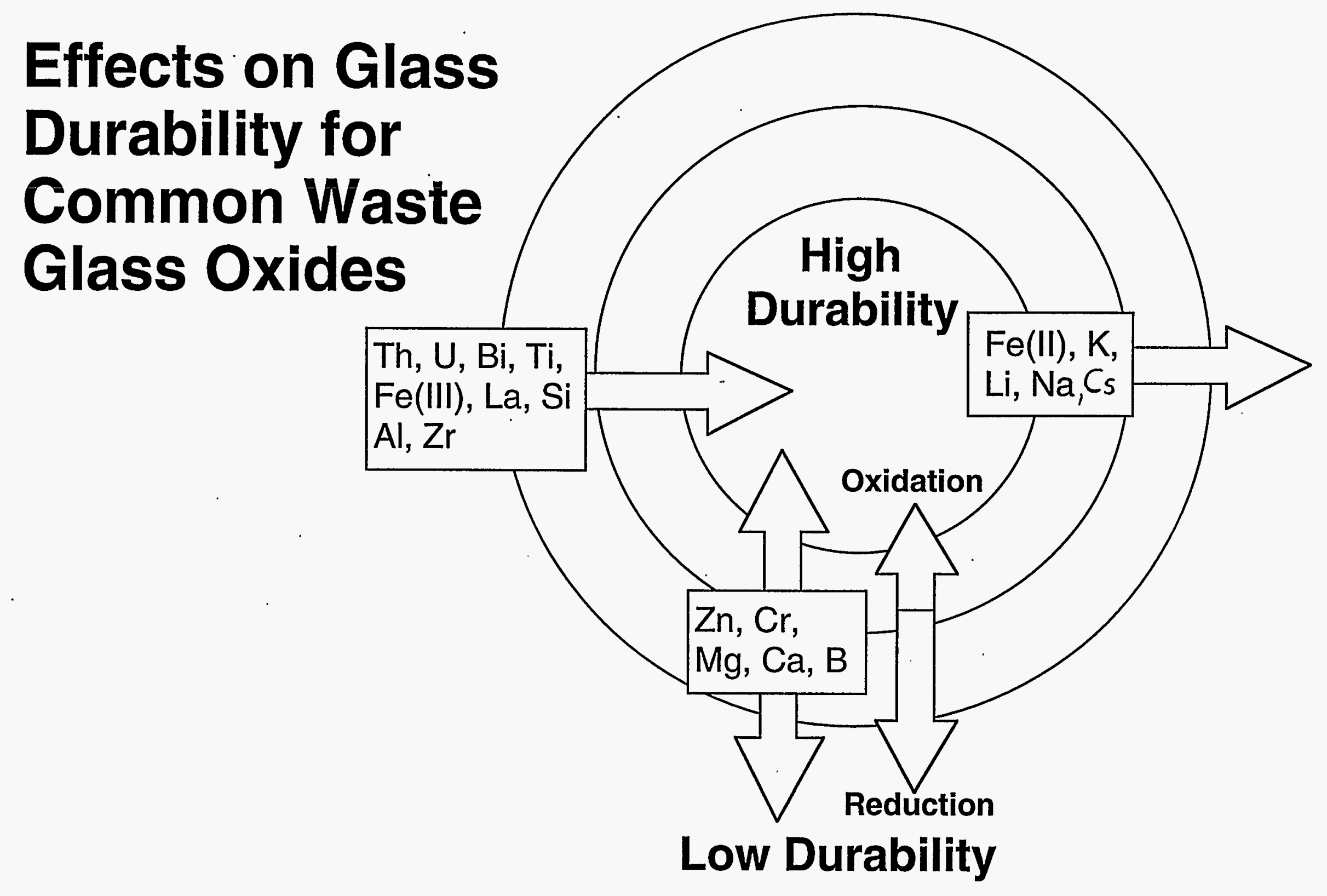

Pacific Northwest Laboratory

R9506086. $8 \mathrm{~A}$ 


\section{A Systematic Way to Present Data:}

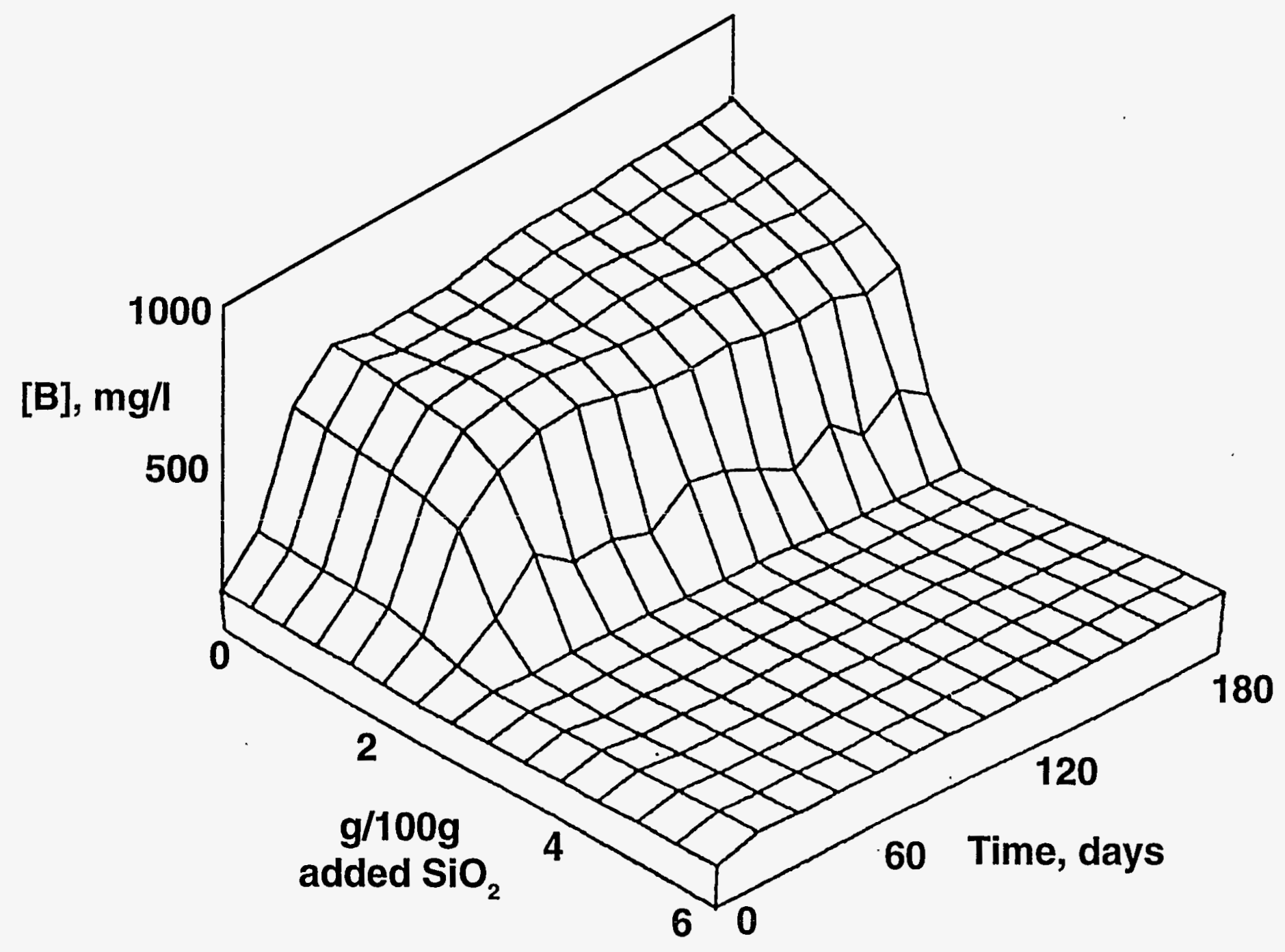




\section{Individual Oxide Effects:}
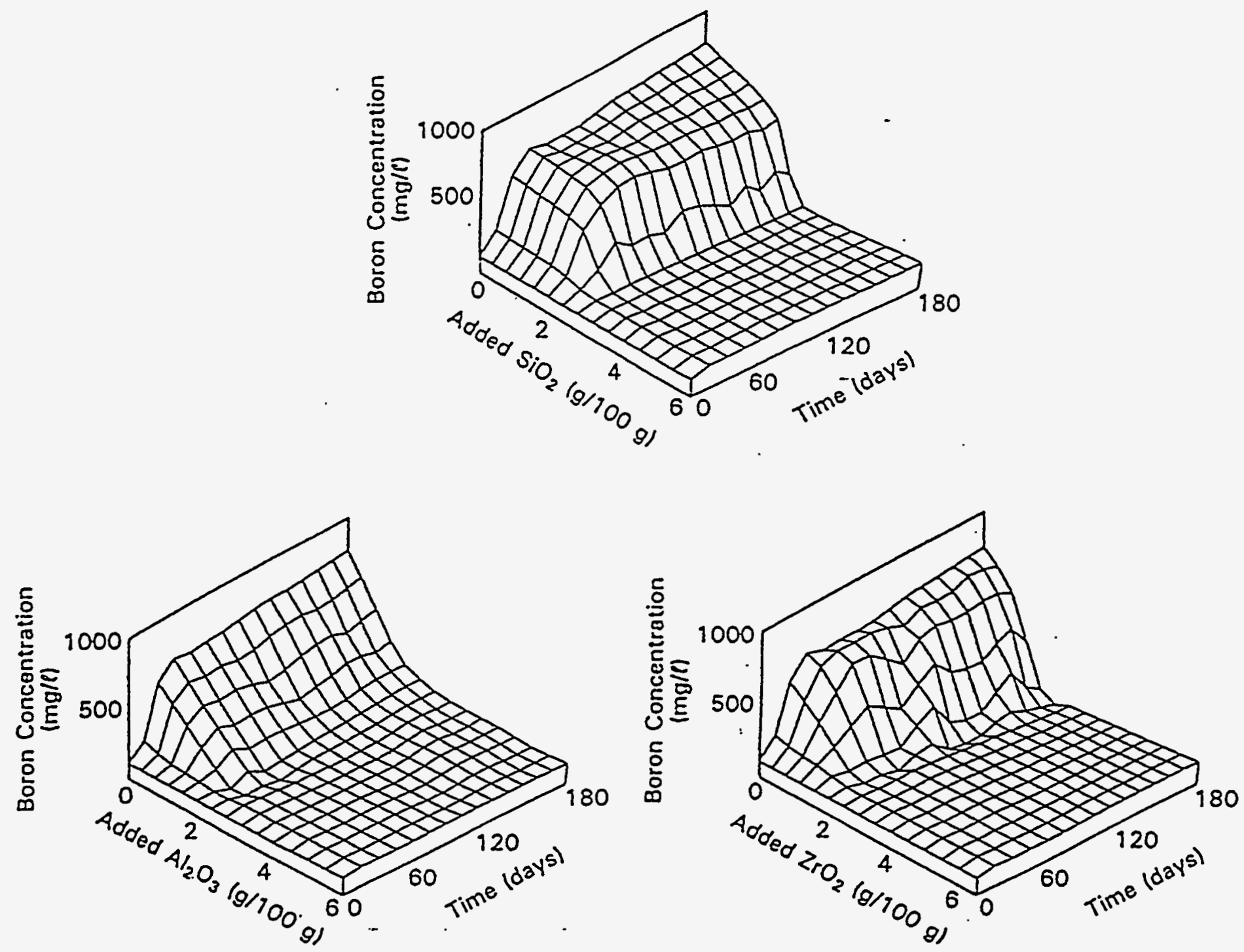

- Very non-linear

Feng et al., Nucl. Techn. (1989) 
Boron Concentration (ppm)

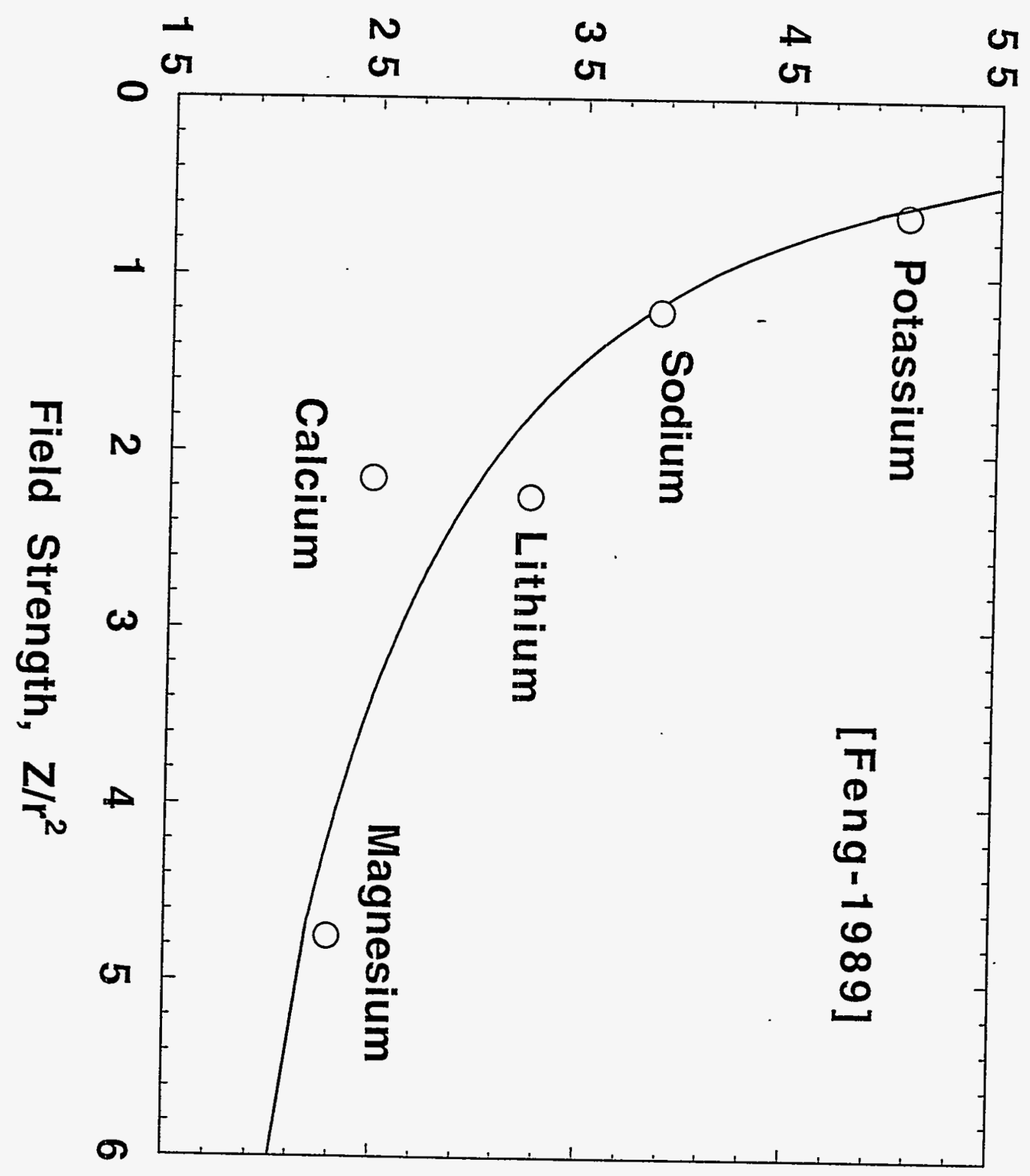




\section{Observation of Individual Oxide Effects:}

- Very non-linear

- Interactive in nature - dependence on the other components in glasses

- Very sensitive in poor durability glasses

- Insensitive in durable glasses

- Desirable to have waste glass composition in durable glass region 


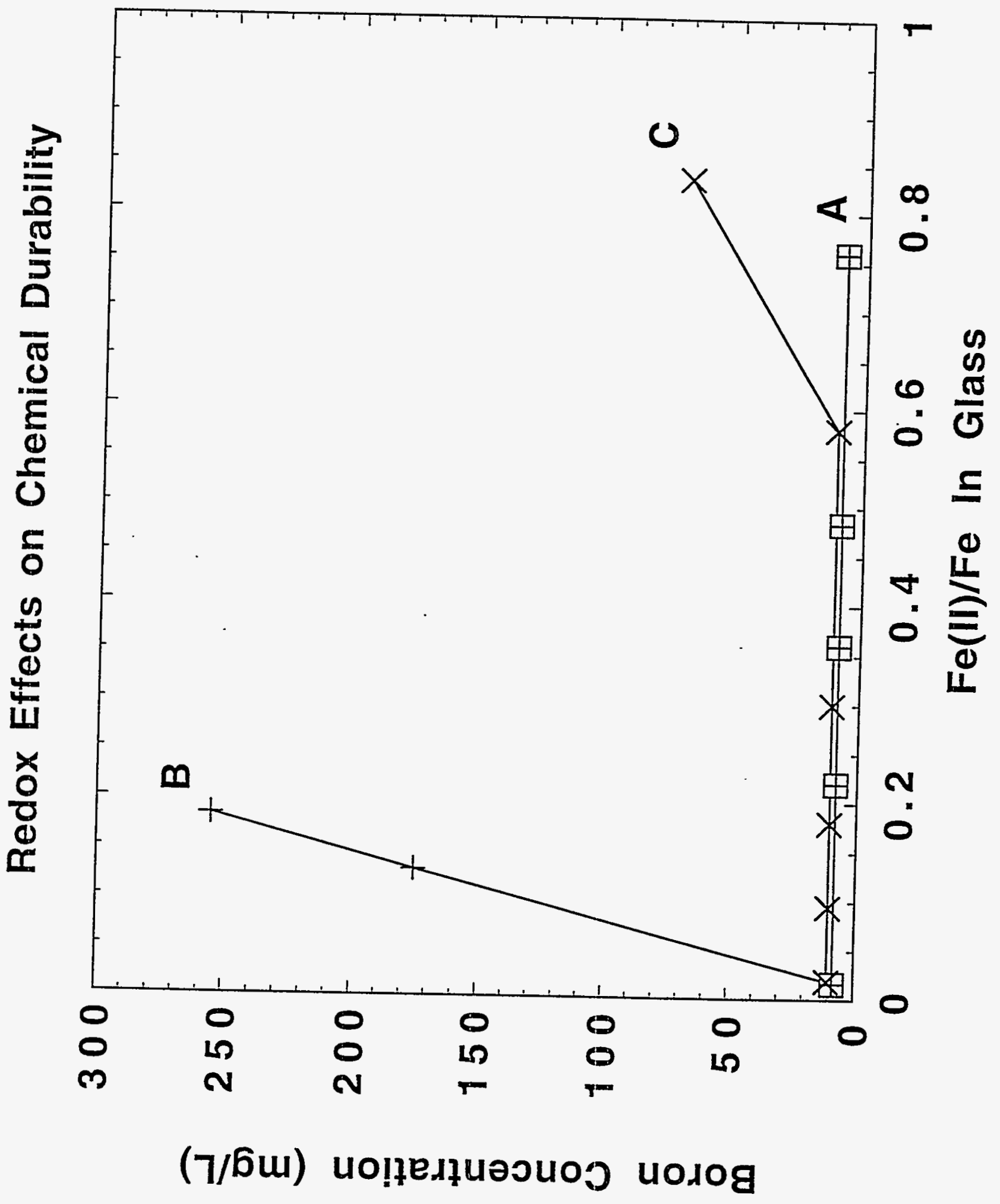




\section{Observation of REDOX Effect on Glass Durability}

- Durability decreases with reduction

- Highly composition-dependent:

- Less sensitive for durable compositions

- Very sensitive for poor durability ones

- Again, effects are very non-linear

Feng 1991 


\section{Why}

- The addition of $\mathrm{B}_{2} \mathrm{O}_{3}$ has different effects

- Increase durability (ID)

- ID first, then no effect

- Decrease durability

- This is true also for $\mathrm{Al}_{2} \mathrm{O}_{3}, \mathrm{CaO}$, etc.

- The effectiveness of ID is:

$-\mathrm{Al}_{2} \mathrm{O}_{3}>\mathrm{B}_{2} \mathrm{O}_{3}>\mathrm{CaO}$

- Etc. 


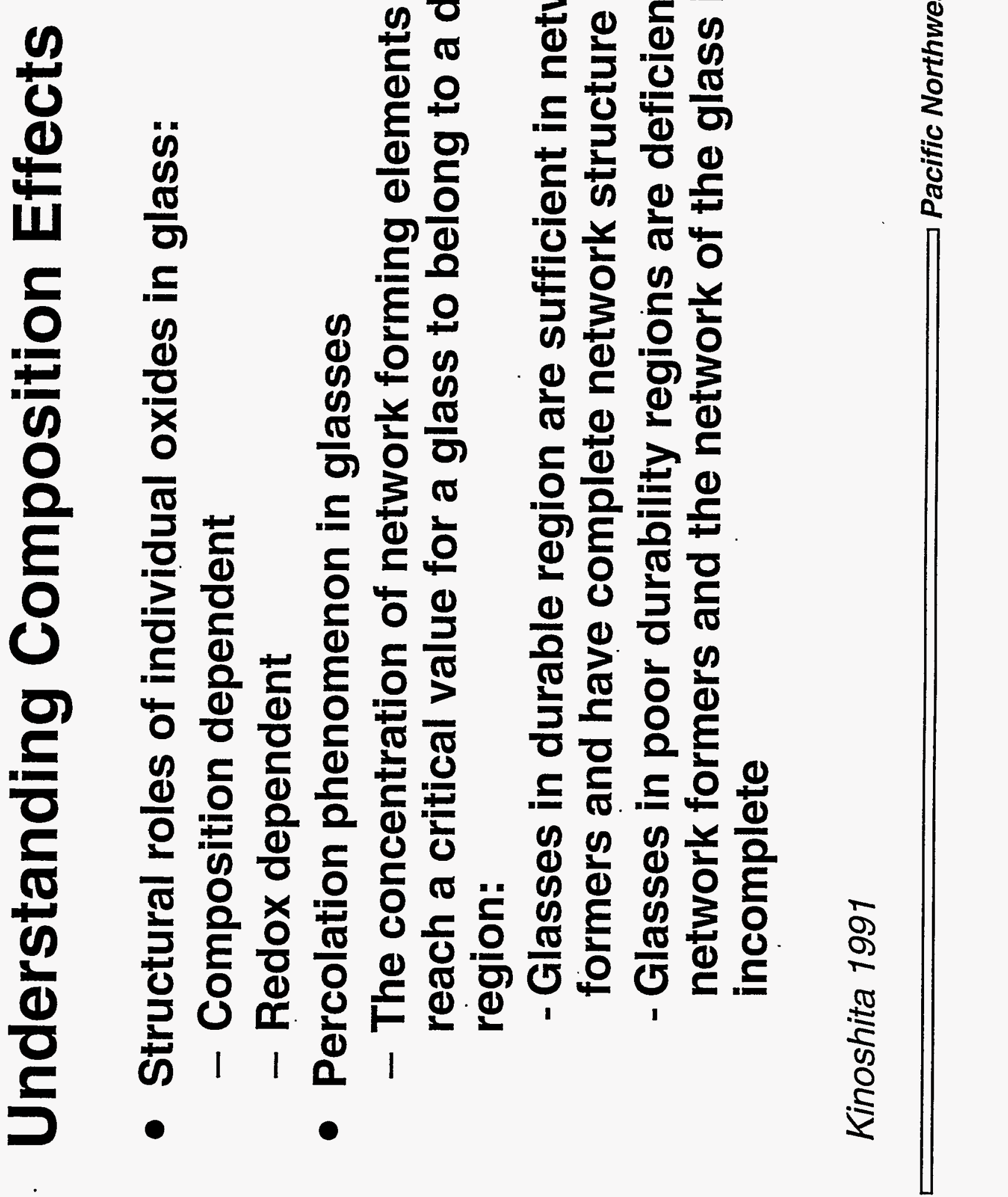



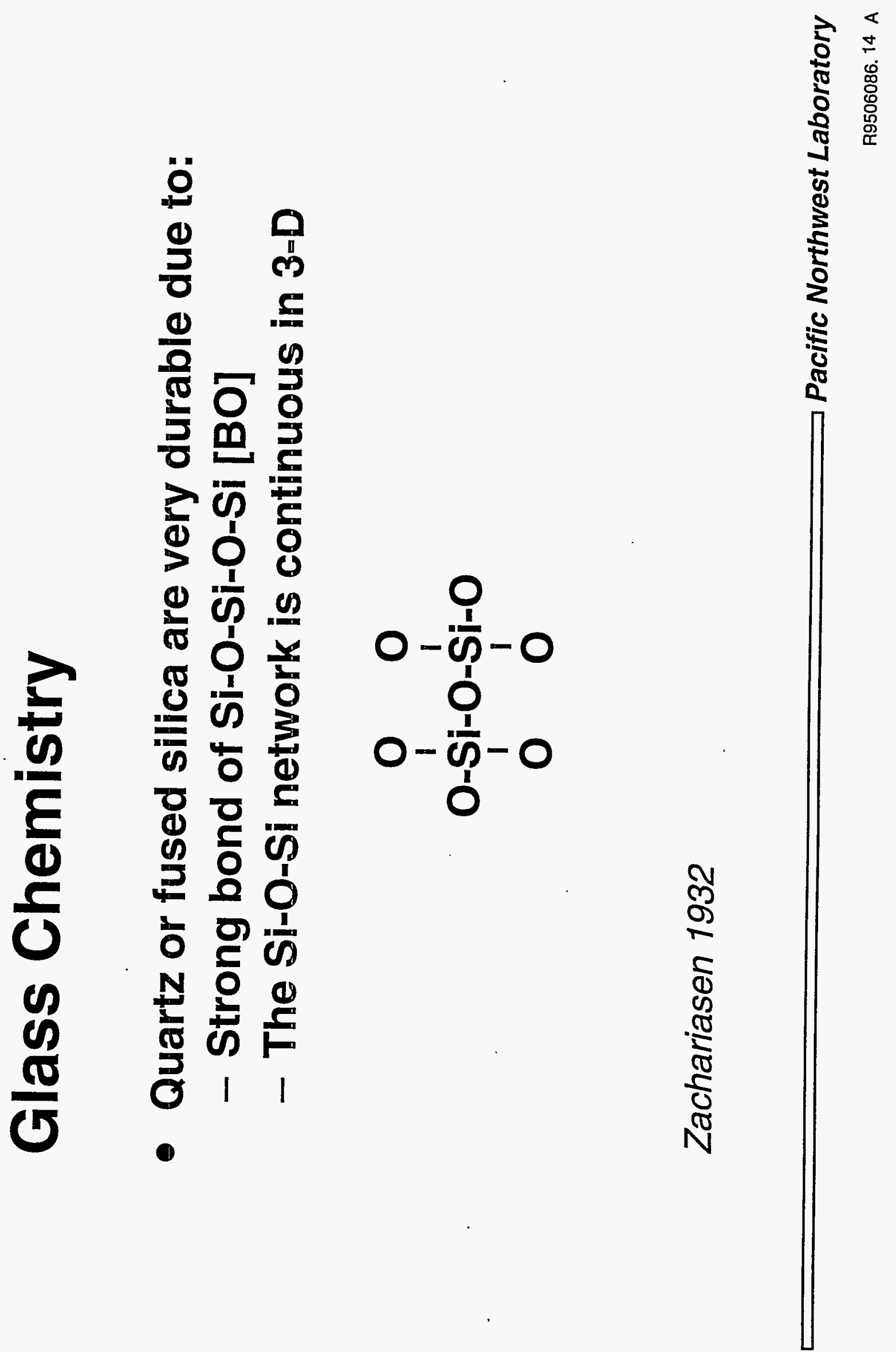


\section{Addition of Alkalis to Fused Silica}

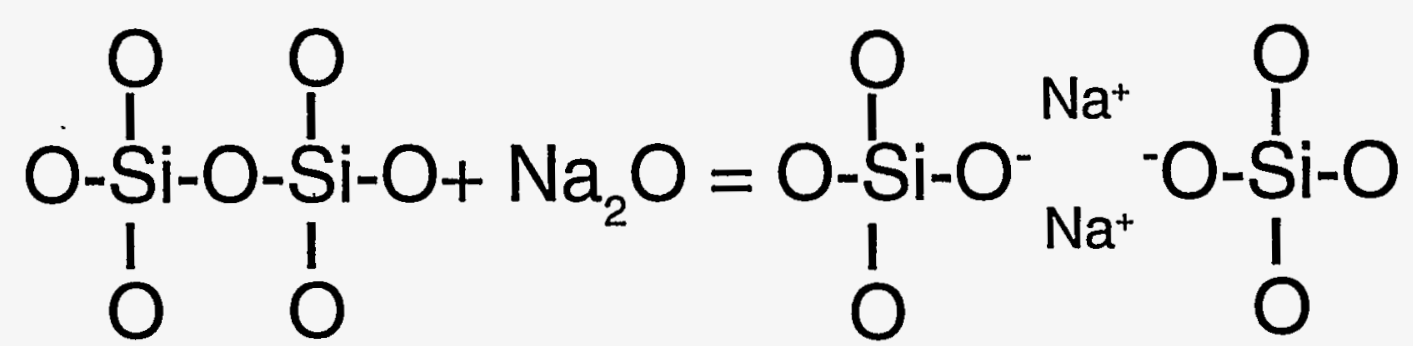

- Break up the continuous network, i.e. destroy BO bonds

- Form weak Non-Bridging Oxygen (NBO) bonds

- Reduce durability

Zachariasen 1932 


\section{Addition of $\mathrm{Al}_{2} \mathrm{O}_{3}$ in a $\mathrm{SiO}_{2}-\mathrm{Na}_{2} \mathrm{O}$ System}

- Reduce NBO bonds:

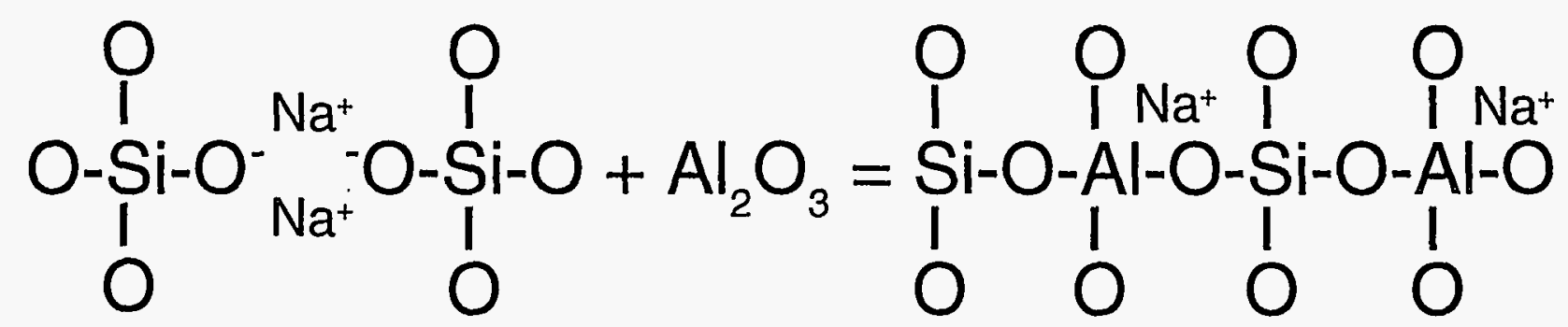

- Increase durability

- Al is tetrahedrally coordinated and charge balanced by alkalis (Alexander, 1986)

- The improvement in durability depends on available NBO bonds

- The above reaction is near completion

- Similar behavior is expected for $\mathrm{Fe}_{2} \mathrm{O}_{3}$

Dickenson 1981, 1986 


\section{Addition of $\mathrm{B}_{2} \mathrm{O}_{3}$ in a $\mathrm{SiO}_{2}-\mathrm{Na}_{2} \mathrm{O}$ System}

- Reduce NBO bonds:

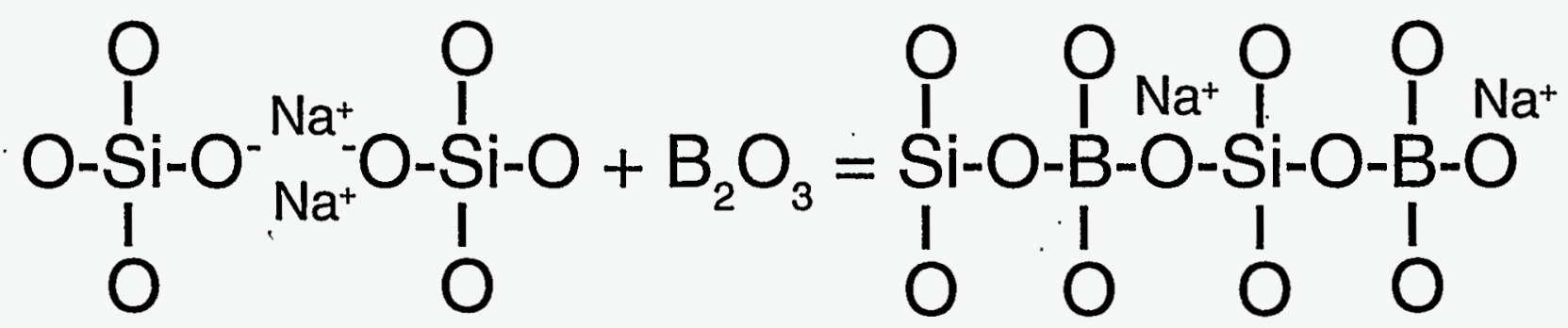

- Increase durability

- Boron is tetrahedrally coordinated and charge balanced by alkalis

- The improvement in durability depends on available NBO bonds

- The above reaction is usually far from completion and is a function of contents of alkalis and silica

Dell 1983 


\section{Addition of $\mathrm{ZrO}_{2}$ in a $\mathrm{SiO}_{2}-\mathrm{Na}_{2} \mathrm{O}$ System}

- Reduce NBO bonds:

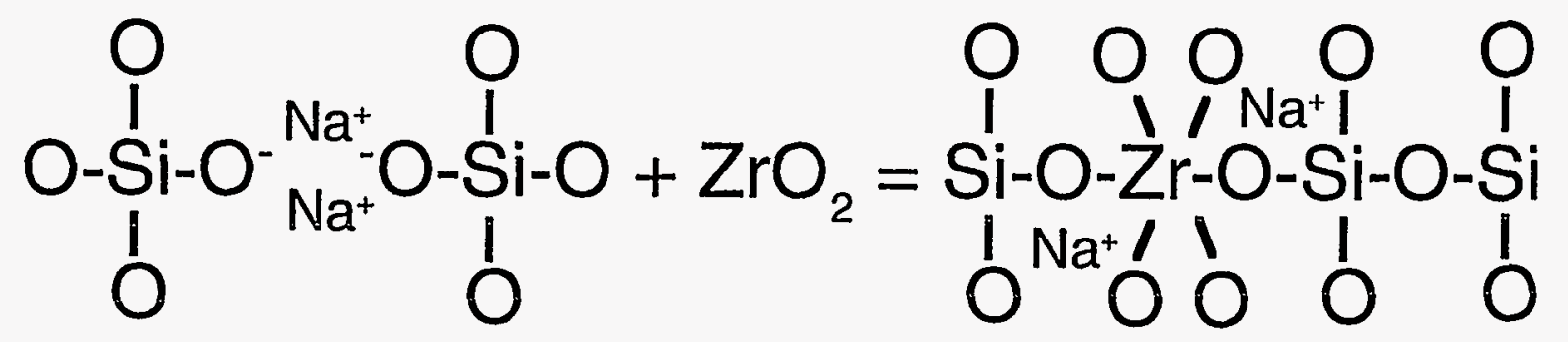

- Increase durability

- $\mathrm{Zr}$ is in 6-coordination and stabilized by alkalis (Farges, 1991)

- The improvement in durability depends on available NBO bonds 


\section{Addition of $\mathrm{B}_{2} \mathrm{O}_{3}, \mathrm{ZrO}_{2}$, and $\mathrm{Fe}_{2} \mathrm{O}_{3}$}

- Reduce NBO bonds

- Improve durability ONLY if there are NBO bonds to be reduced 

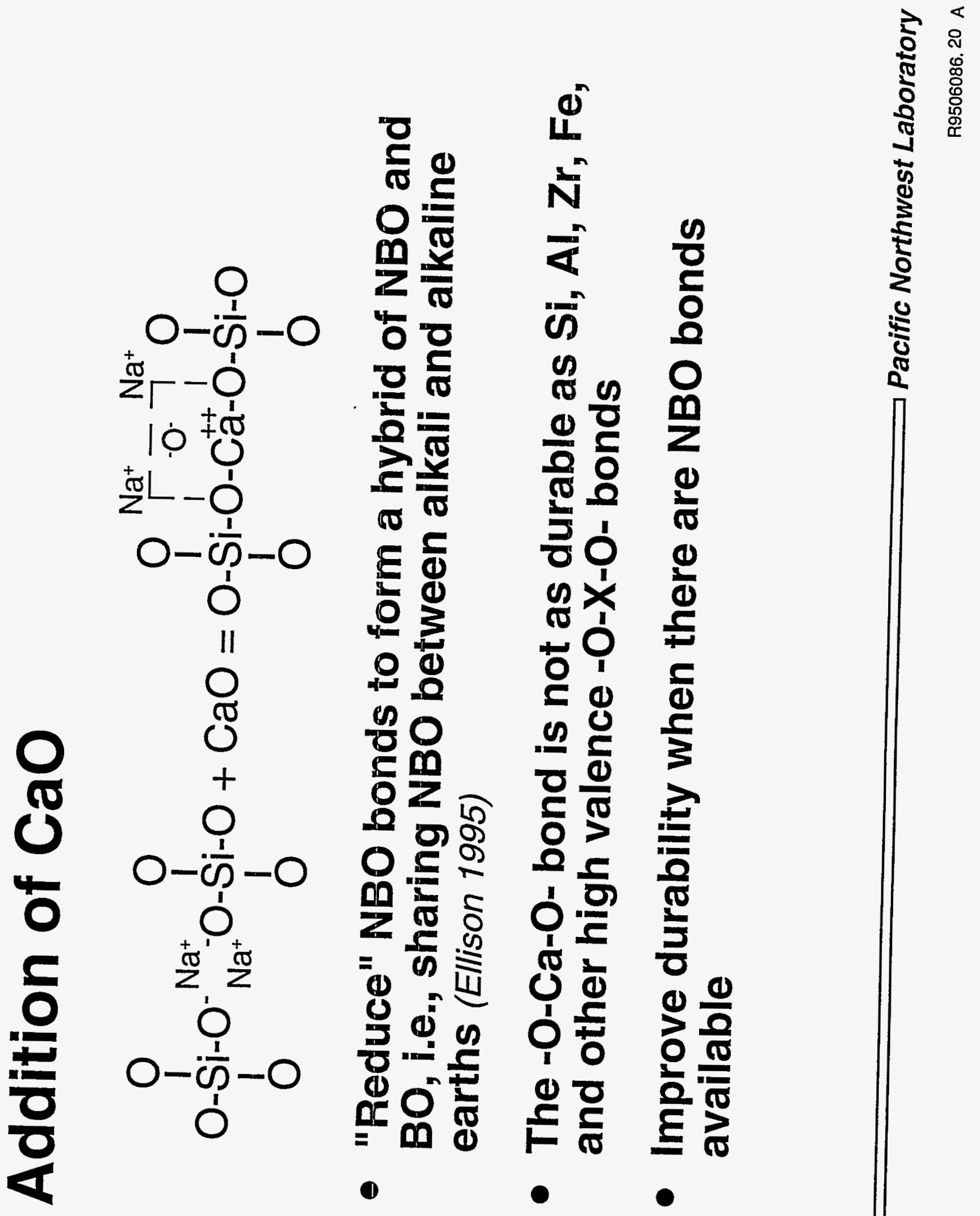


\section{The Binding Order to Alkalis}

- $\mathrm{Al}_{2} \mathrm{O}_{3}>\mathrm{ZrO}_{2}>\mathrm{Fe}_{2} \mathrm{O}_{3}>\mathrm{B}_{2} \mathrm{O}_{3}>\mathrm{CaO}$ (SBS Model) Feng 1988

- This order has significant effect on the observed composition effects

- It will explain most of the non-linear behavior of composition effects

Bobkora 1983, Feng 1994, Ellison 1994 


\section{The Order of Binding Strength to Alkalis}

- $\mathrm{Al}_{2} \mathrm{O}_{3}>\mathrm{ZrO}_{2}>\mathrm{Fe}_{2} \mathrm{O}_{3}>\mathrm{B}_{2} \mathrm{O}_{3}>\mathrm{CaO}$ (SBS Model) Feng 1988

- Corresponding SBS values of the oxides in networking position (Kcal/mole): $801>525>393>304>152$

- This order also has significant effect on the observed composition effects

- It will explain some of the non-linear behavior of composition effects 


\section{Qualitative explanation of durability observation can be obtained through the glass structure considerations discussed above.}




\section{A Systematic Way to Present Data:}

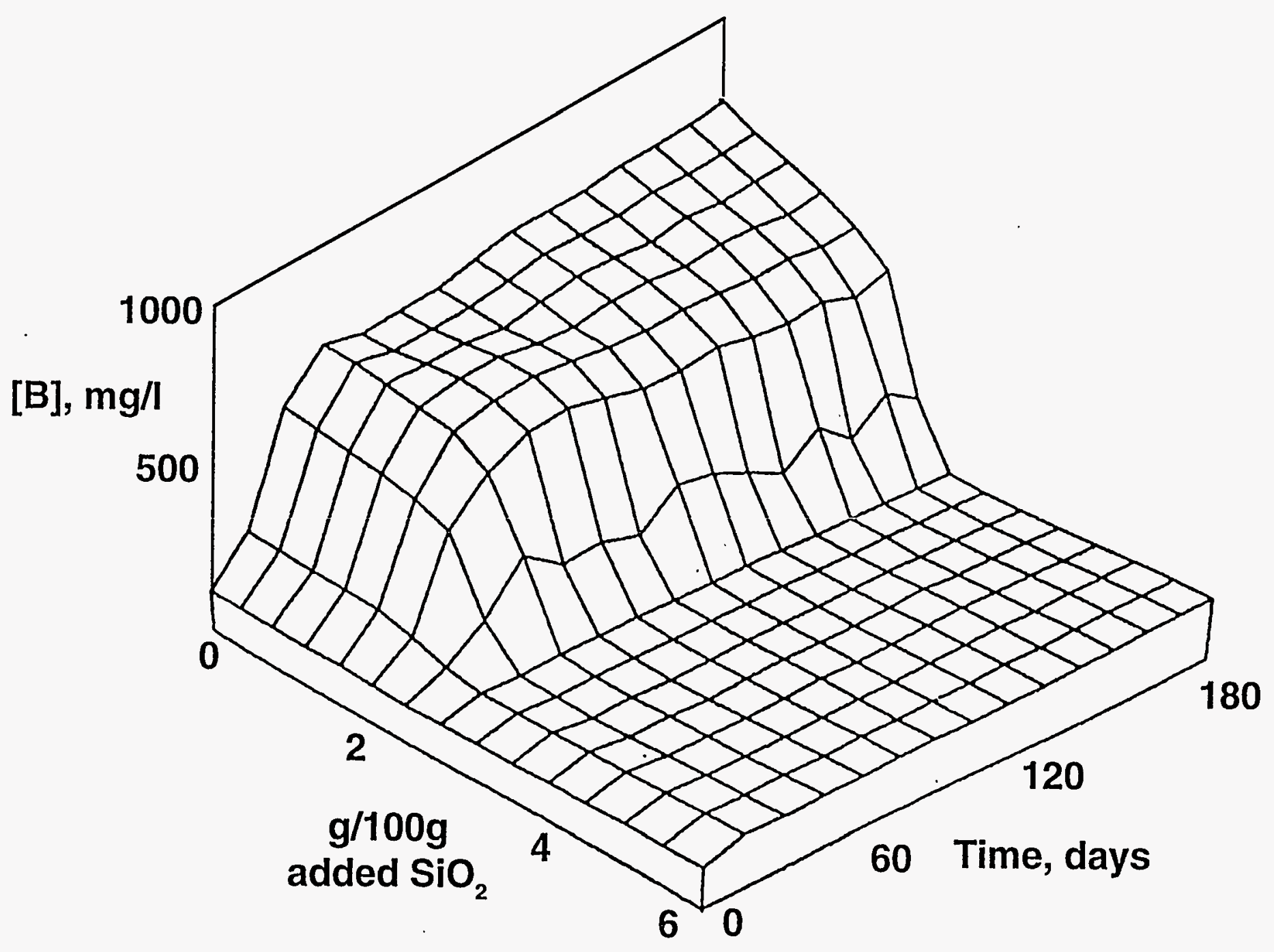

Pacific Northwest Laboratory 


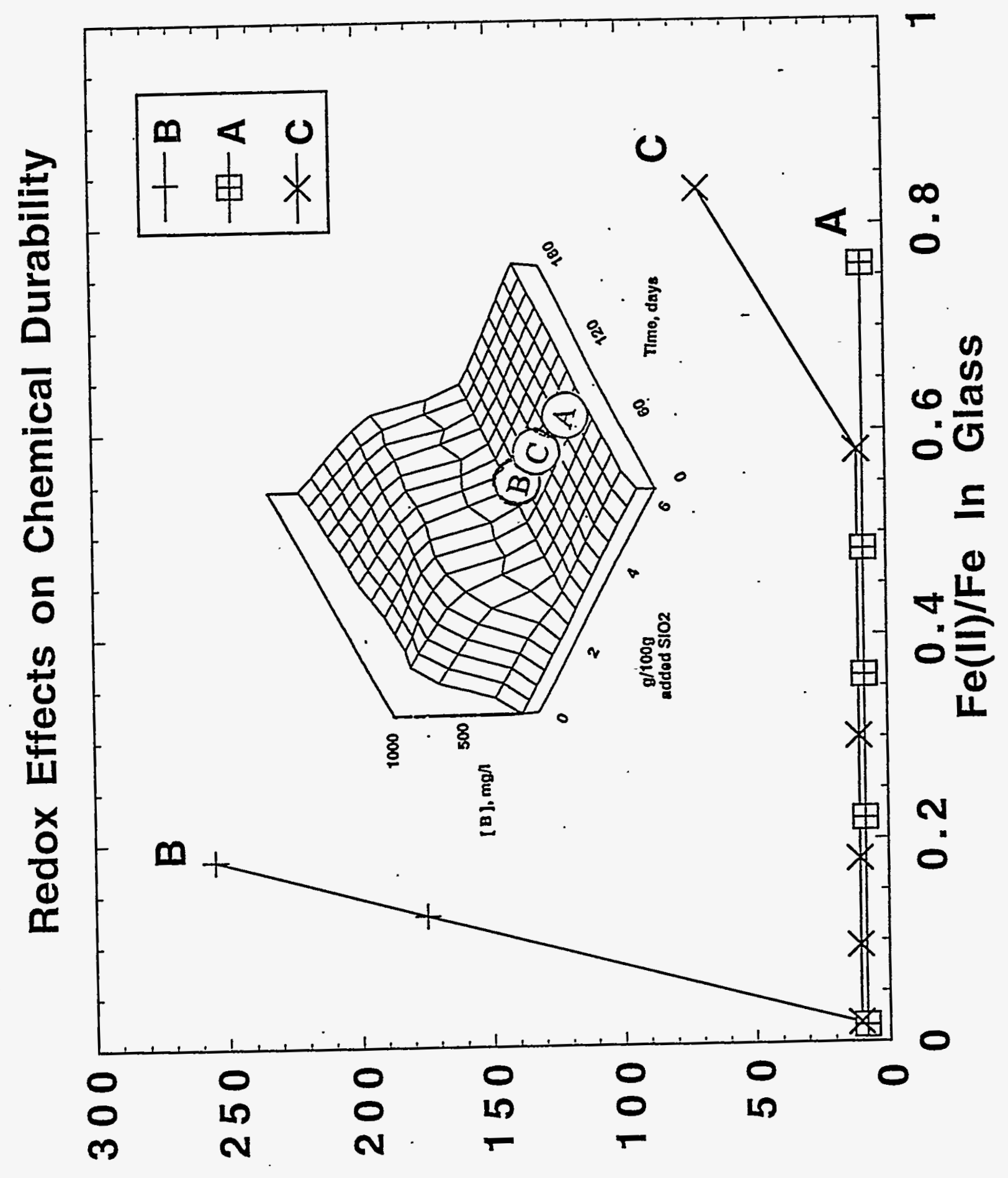

(7/6w) uo!nedłuəouos uodog 

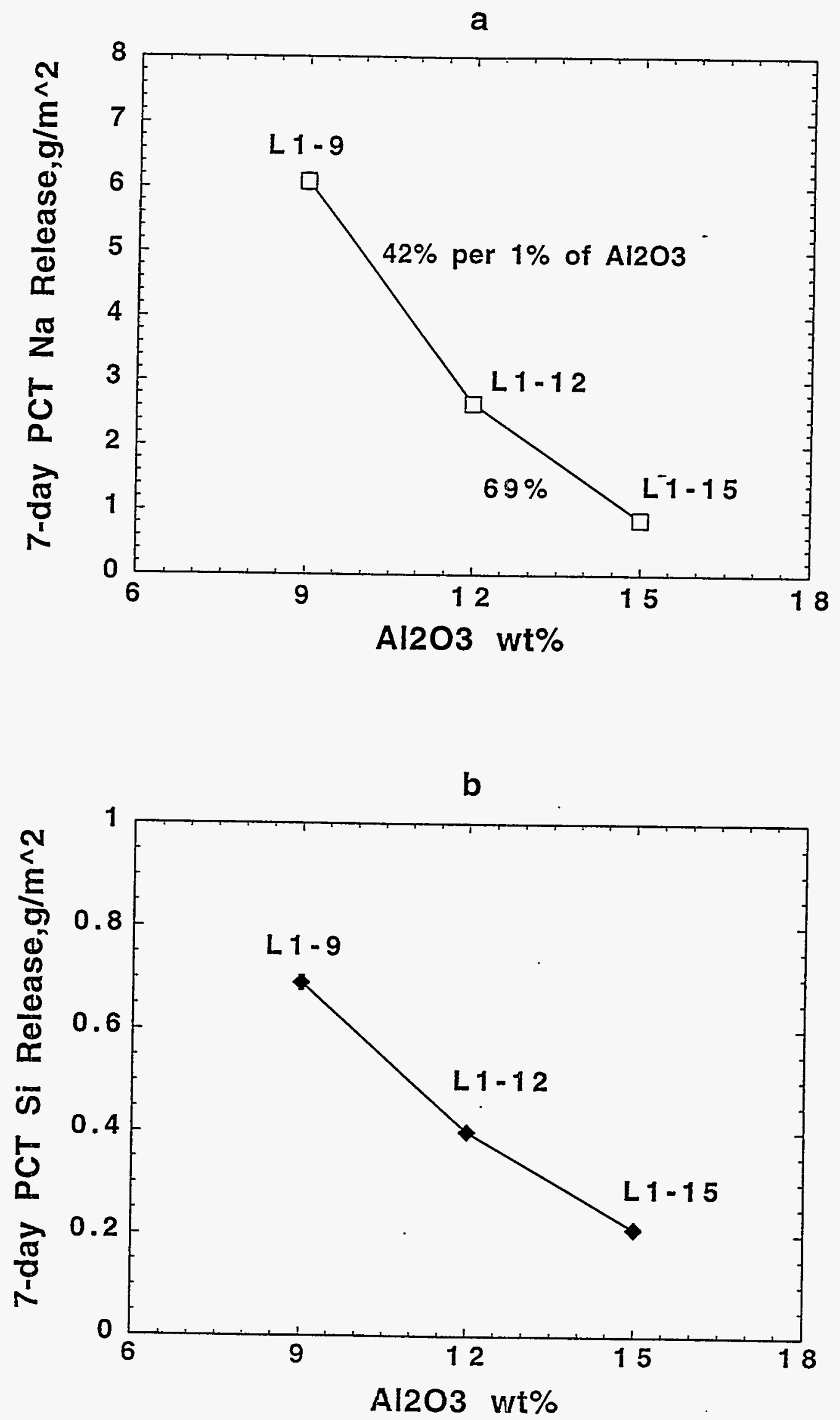

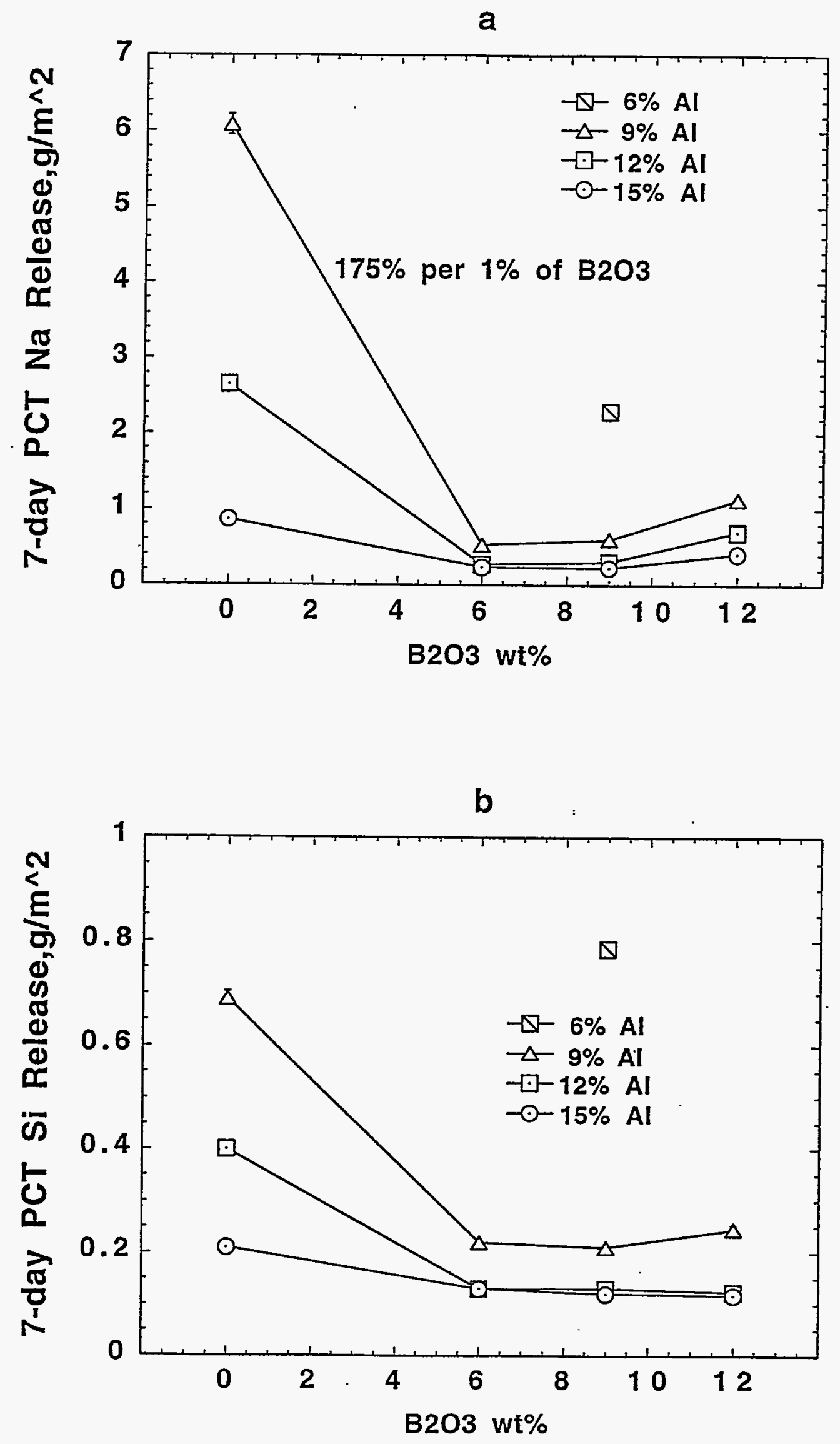

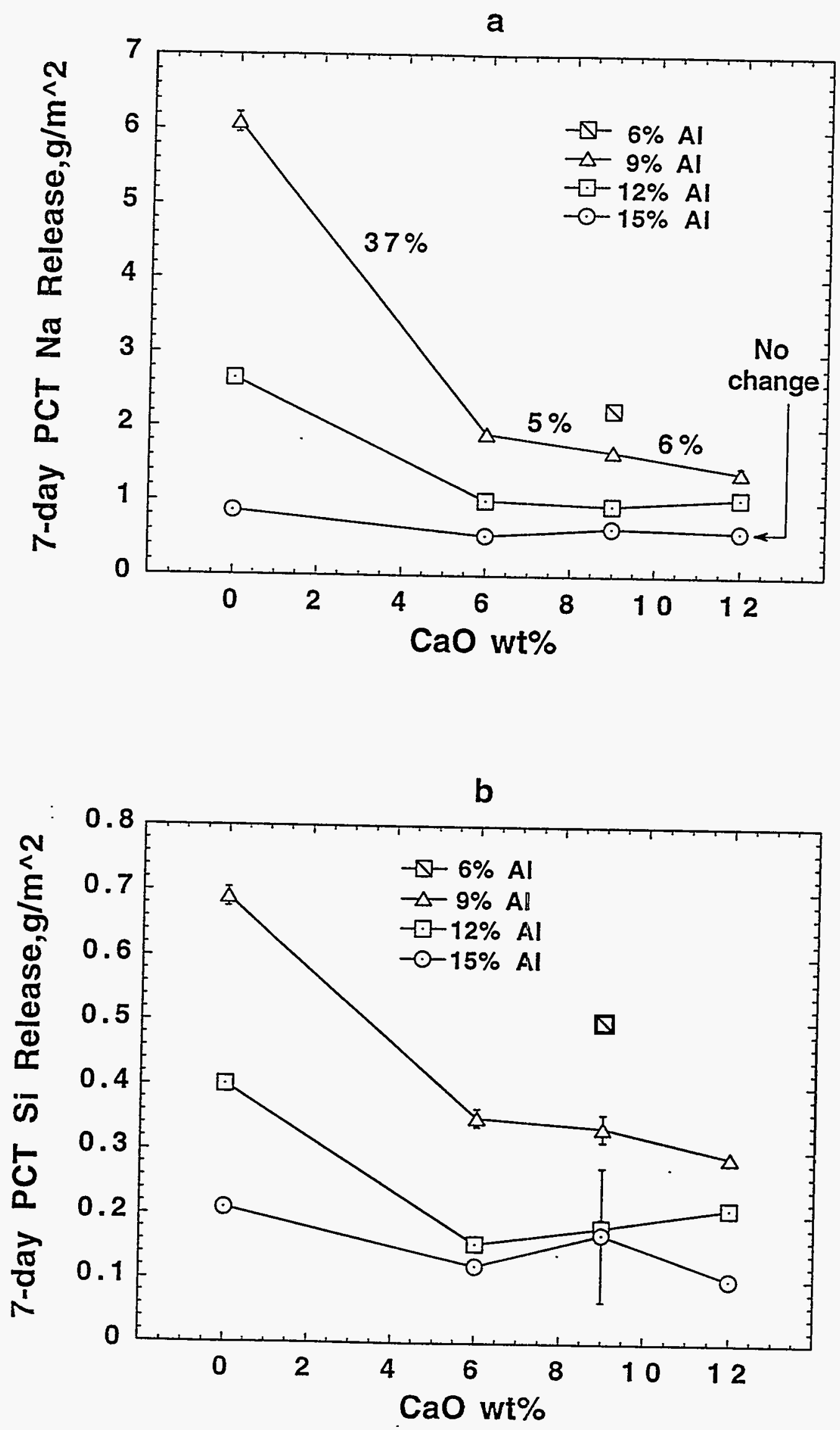


\section{sog soln!!p ${ }^{2}$ OdZ pue ${ }^{\varepsilon} \mathrm{O}^{\tau} \mathrm{I} \forall$ jo ssəox $\exists$ •

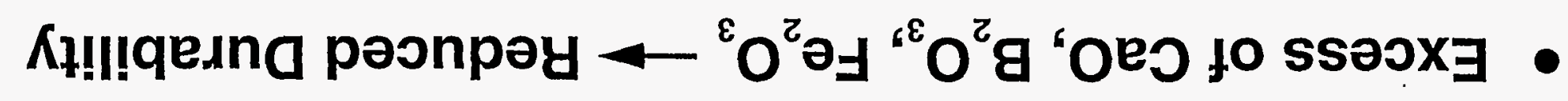

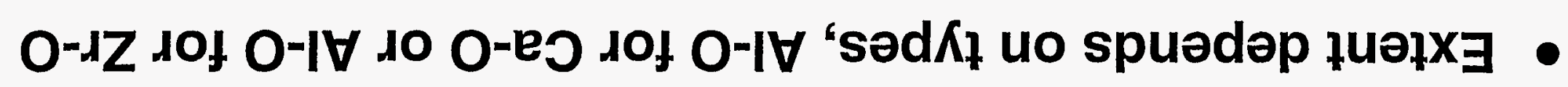 IQ}

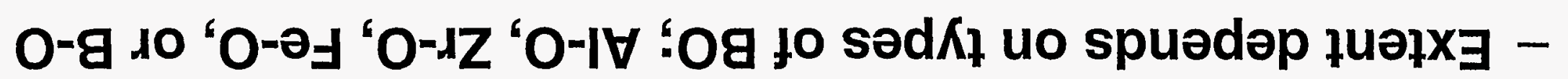

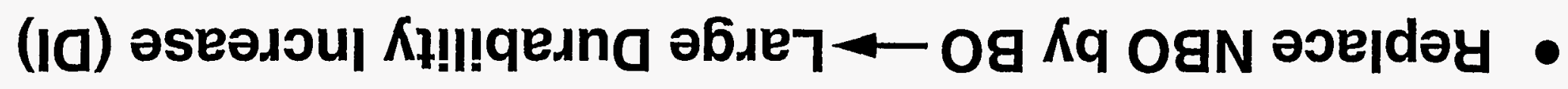

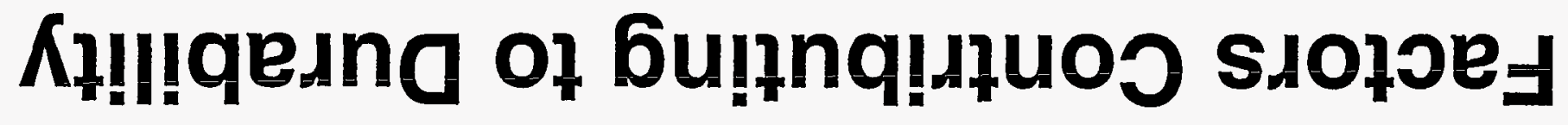




\section{For Quatitative Predictions}

- A model must be able to account for the non-linear composition effects, i.e., the model index (or coefficient) for each oxide should be a function of other compounds and be able to vary from glass to glass

- A model should reflect our current understanding of glass structure and its effect on durability, the model can be improved as our understanding increases 


\section{Structural Bond Strength (SBS) Model Developed for Glass}

- From composition, it predicts:

- Chemical durability

- Melt viscosity vs. temperature

Feng 1988, 1994, 1995 

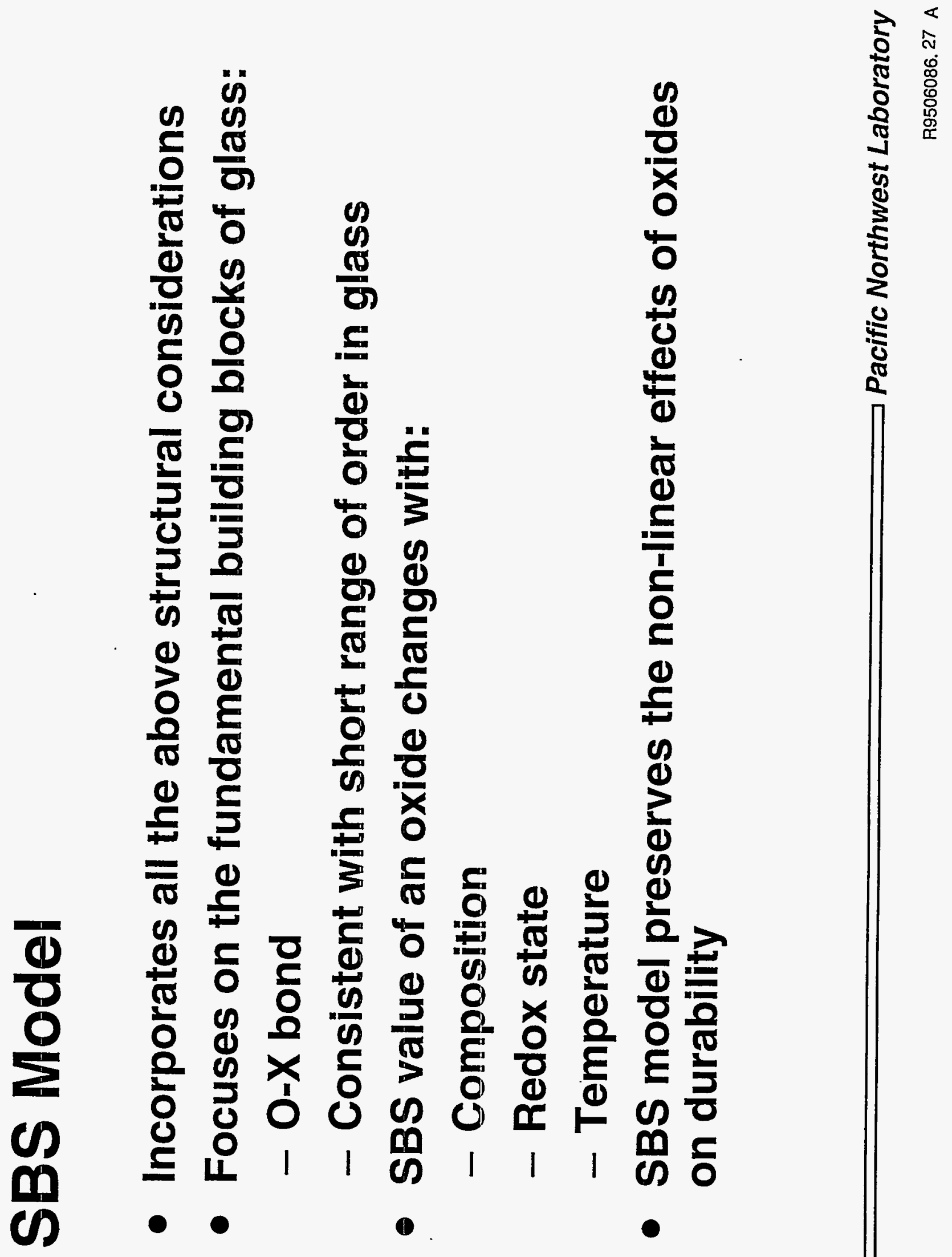


\section{Basic Assumptions of SBS Model}

- The chemical durability and high-temperature viscosity of an oxide waste form are determined by:

- The binding strengths of its most fundamental building blocks: $0-X_{i}$ bonds $\left(X_{i}-\right.$ any element that binds to oxygen)

- Temperature 


\section{Basic Assumptions of SBS Model (cont.)}

- The binding strength (SBS value) of an oxide is a function of its structural role of $X_{i}$

- The structural roles of $X_{i}$ is classified as:

(a) Network formers $\left(\mathrm{Al}_{2} \mathrm{O}_{3}, \mathrm{ZrO}_{2}, \mathrm{Fe}_{2} \mathrm{O}_{3}, \mathrm{~B}_{2} \mathrm{O}_{3}, \mathrm{SiO}_{2}\right.$ and other high valence cations)

(b) Network breakers $\left(\mathrm{Na}_{2} \mathrm{O}, \mathrm{Li}_{2} \mathrm{O}, \mathrm{K}_{2} \mathrm{O}, \mathrm{Rb}_{2} \mathrm{O}\right.$, $\mathrm{Cs}_{2} \mathrm{O}$, and $\mathrm{B}_{2} \mathrm{O}_{3}$ )

(c) Intermediates $\left(\mathrm{Al}_{2} \mathrm{O3}, \mathrm{Fe}_{2} \mathrm{O}_{3}, \mathrm{FeO}, \mathrm{SiO}_{2}, \mathrm{CaO}\right.$ and other oxides not included in (a) or (b) 


\section{Basic Assumptions of SBS Model (cont.)}

- The structural role of $X_{i}$ is:

- Composition dependent

- Redox dependent

- Temperature dependent 


\section{SBS Model Structural Role of $\mathbf{X}_{\mathbf{i}}$ (cont.)}

Composition Dependence:
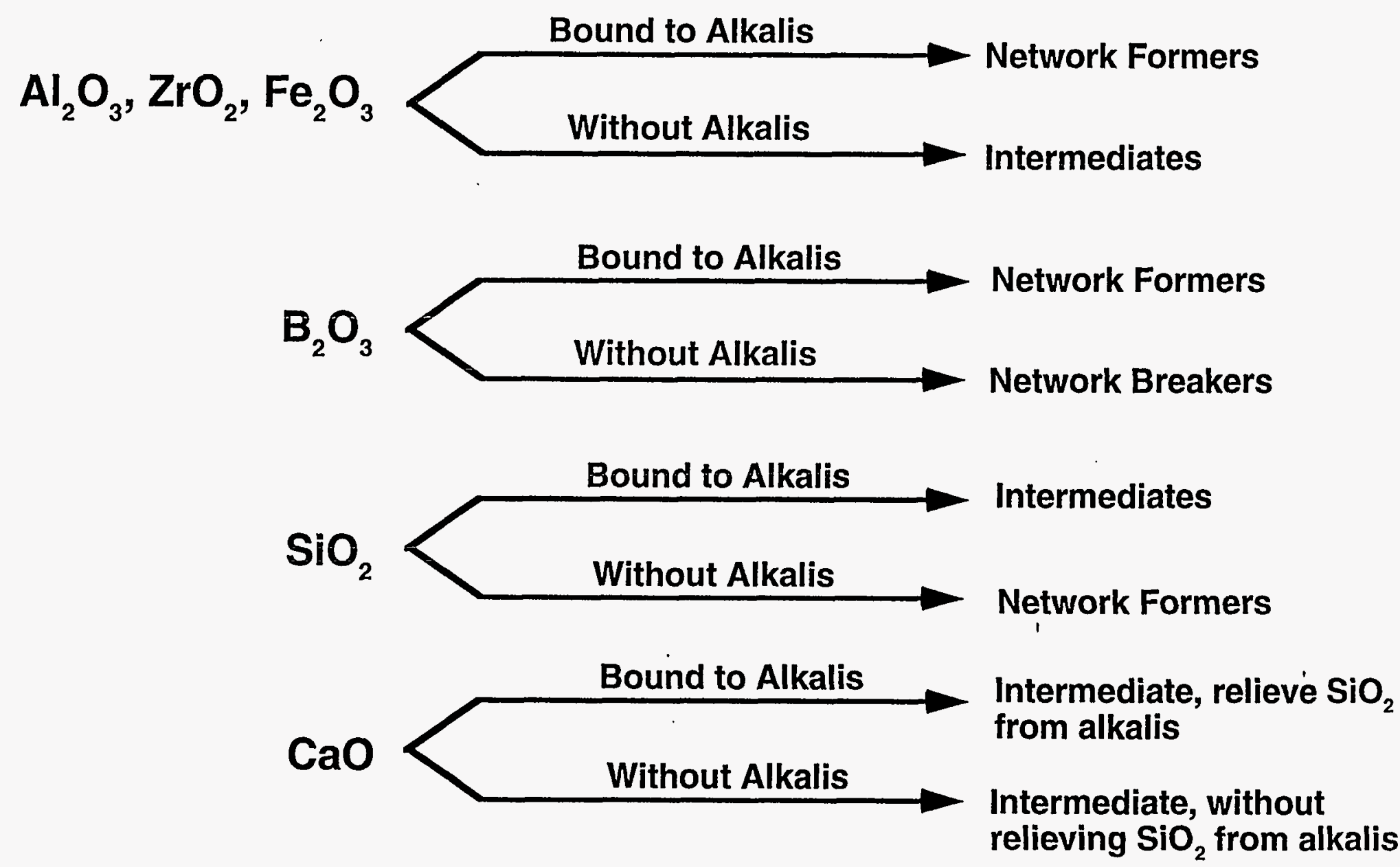

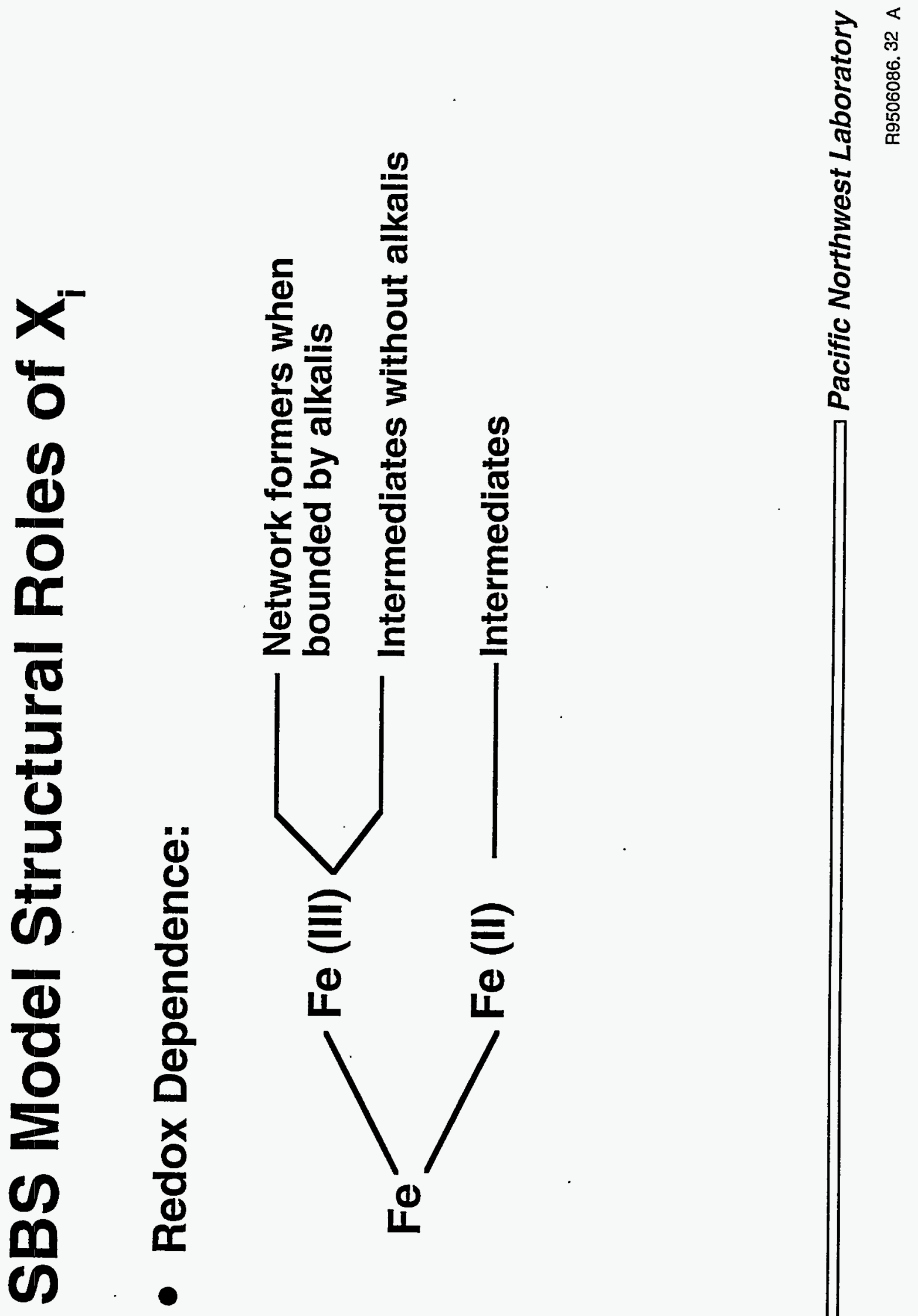


\section{SBS Model Structural Roles of $X_{i}$}

- Temperature Dependence:

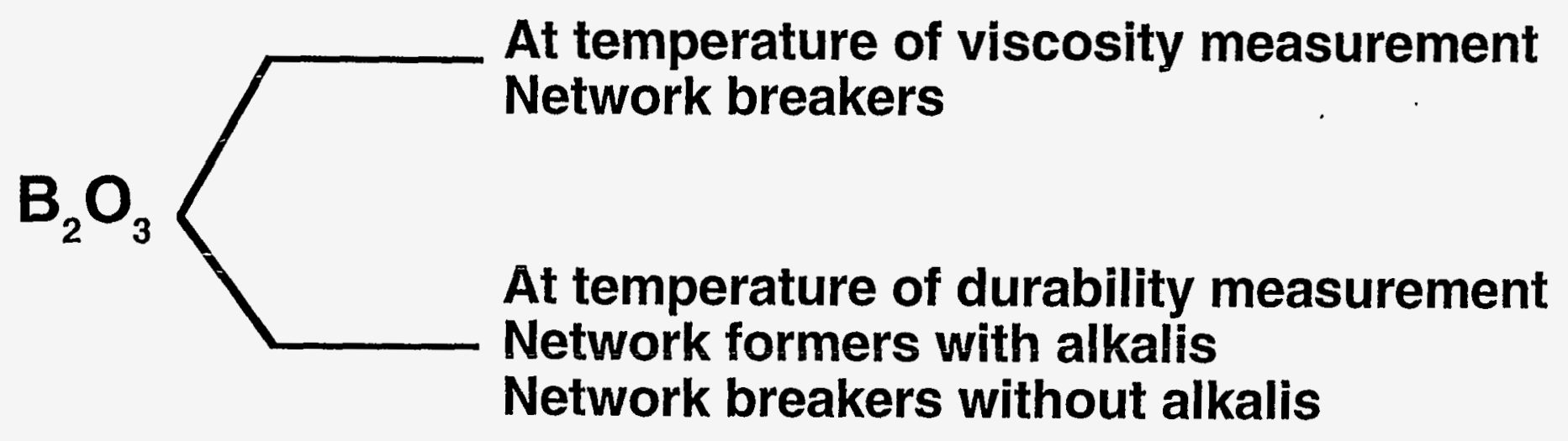




\section{Considerations for Percolation Phenomenon in SBS Model}

- In poor durability glass composition range, the network formers are deficient and are characterized by R:

$$
\mathbf{R}=\frac{\text { total moles of available network formers }}{\text { total alkalis }}
$$

when $\mathbf{R} \leq \mathbf{0 . 4}$, no network formers are considered 


\section{SBS Value Calculations of Each Oxide}

Based on available standard enthalpy of oxide formation, $\Delta \mathbf{H}_{i}$ SBS value $V_{i}$, for oxide $i$

Network formers: $V_{i}=2 \cdot \Delta H i$

Intermediates: $\quad V_{i}=\Delta H i$

Network breakers: $V_{i}=\Delta H i$ - Enet

Where Enet $=$ average bond energy of network formers

$$
E_{n e t}=\frac{\Sigma_{i} m_{i} \cdot V_{i}}{\Sigma_{i} a_{i} \cdot m_{i}}
$$

Where $m_{i}=$ number of moles of oxide $i$ as network formers $a_{i}=$ coordination number of oxide $i$ as network formers 


\section{SBS Model}

- The total SBS value for each glass

$$
V=\sum_{i} m_{i} V_{i}
$$

where $m_{i}=$ the total moles of oxide i per $100 \mathrm{~g}$ of glass $v_{i}=$ the average SBS value of oxide $i$ in the glass

- Correlation with durability In [durability] $=\mathbf{a V}+\mathbf{b}$ where durability - measured durability for a glass

V - calculated SBS value for a glass $a$ and $b$ - fitting coefficients 


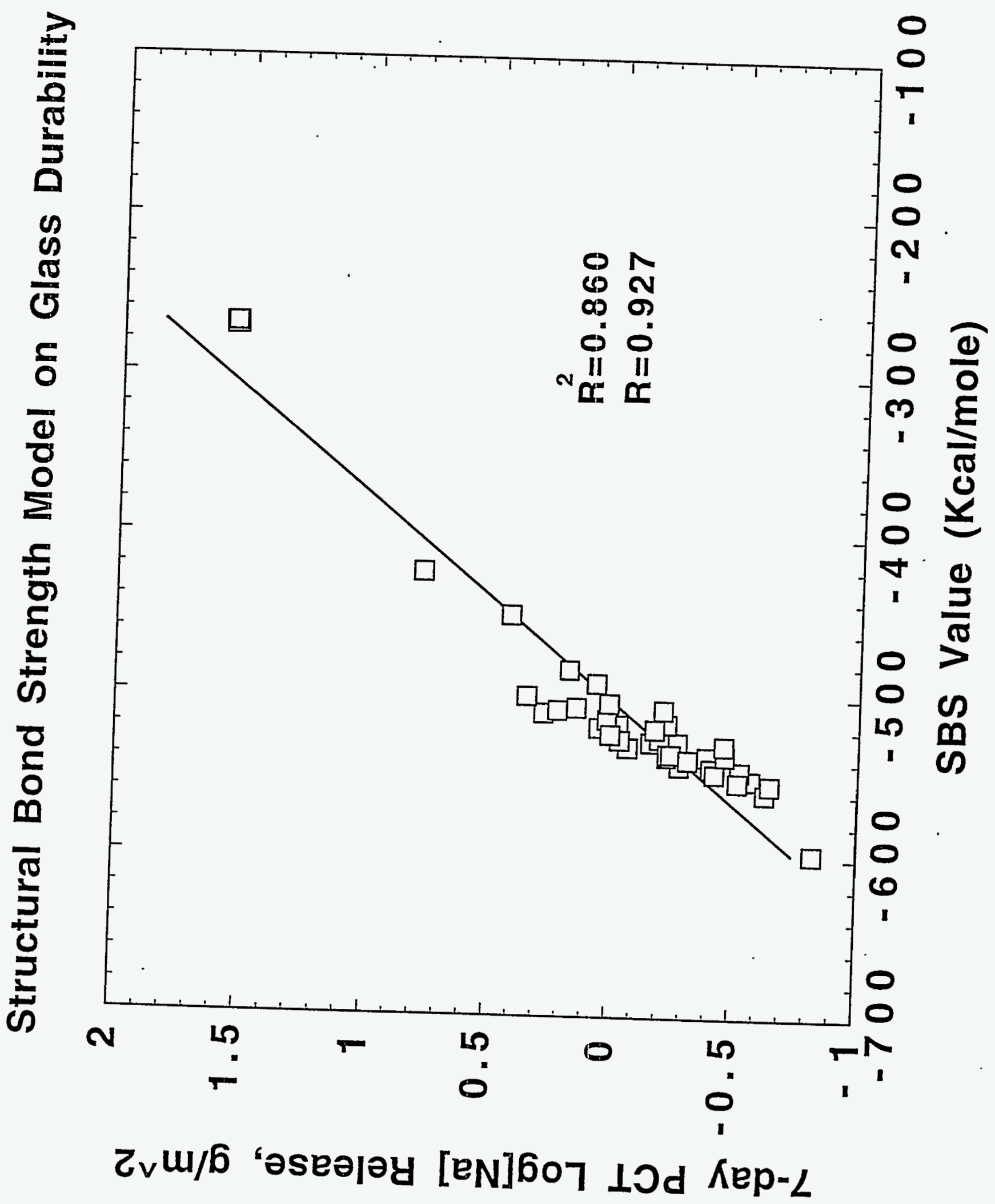


Structural Bond Strength Model on Glass Durability

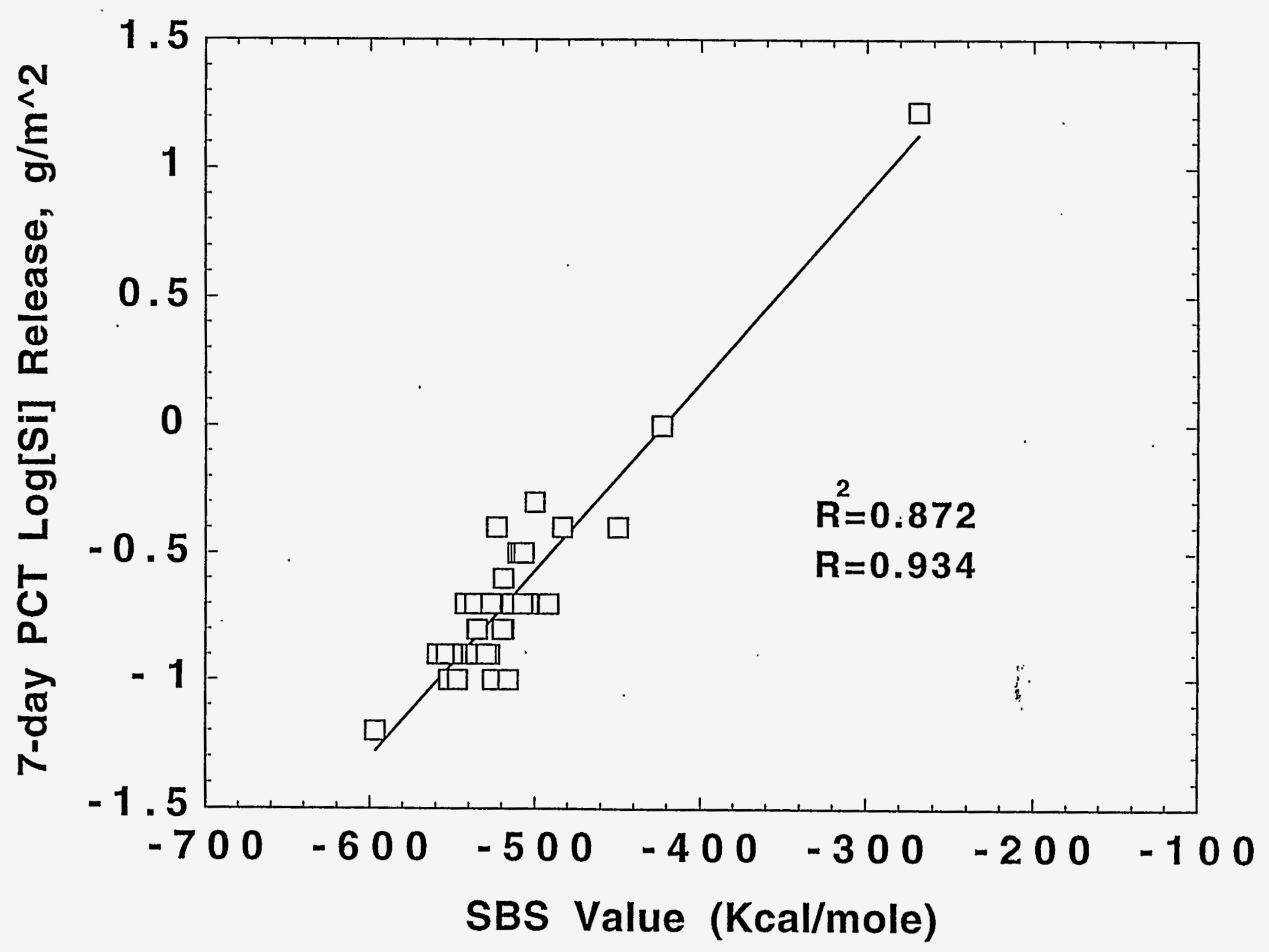




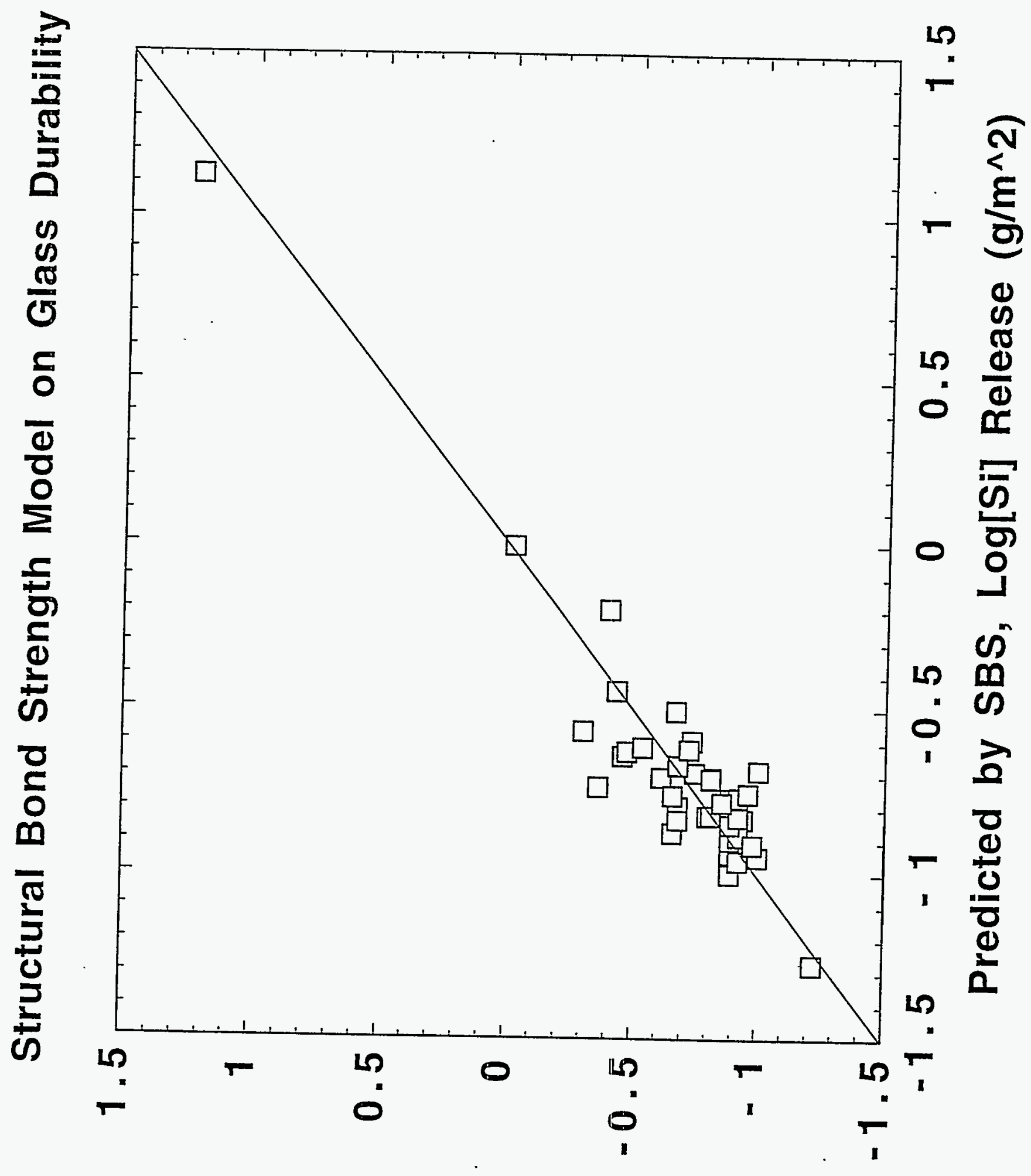

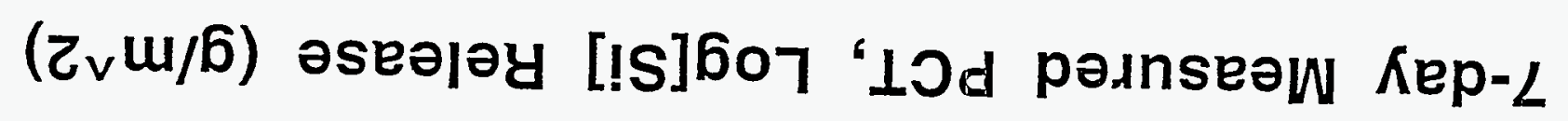




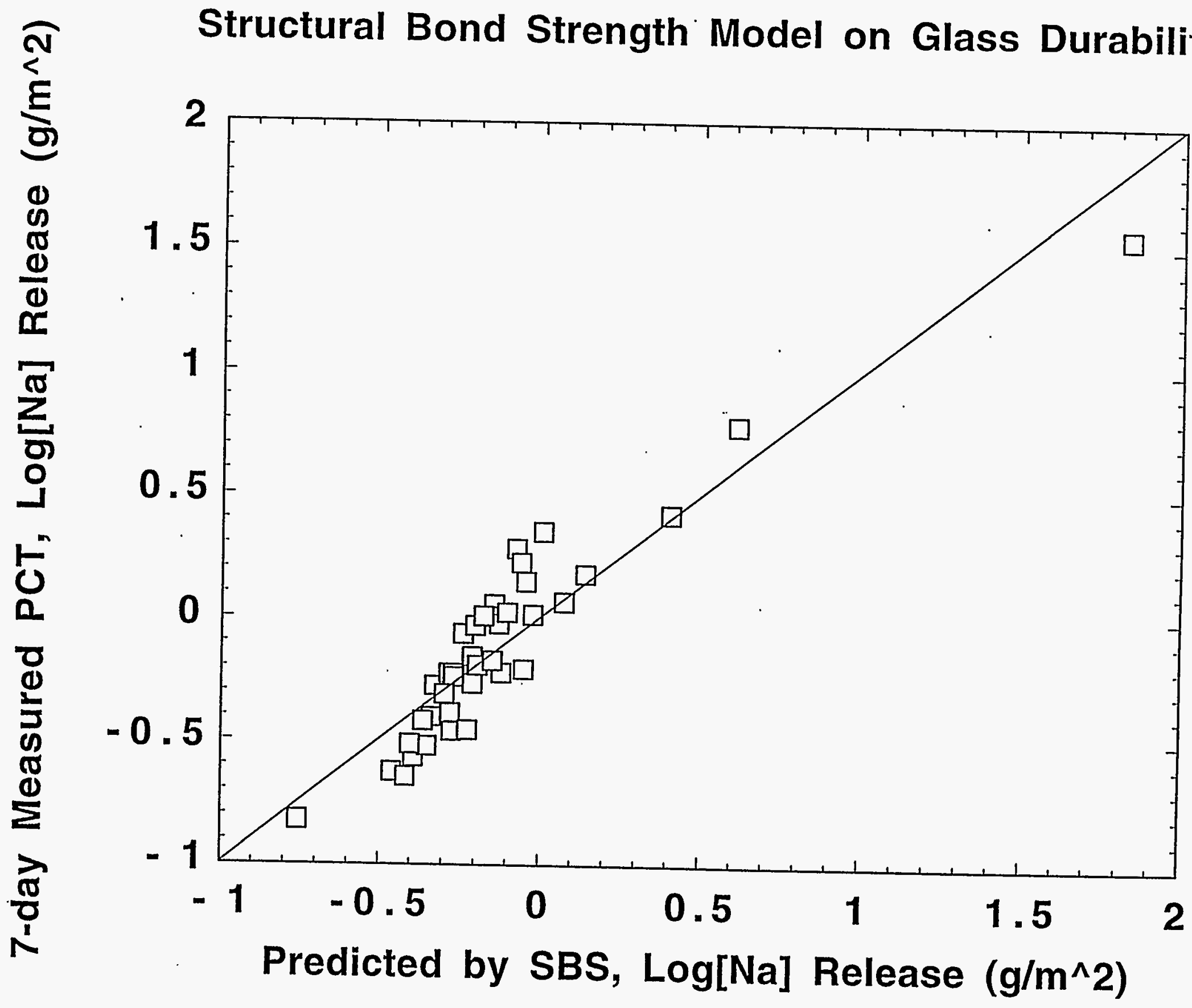


SBS Model Prediction of Glass

Durability at $12 \% \mathrm{Al} 2 \mathrm{O} 3$

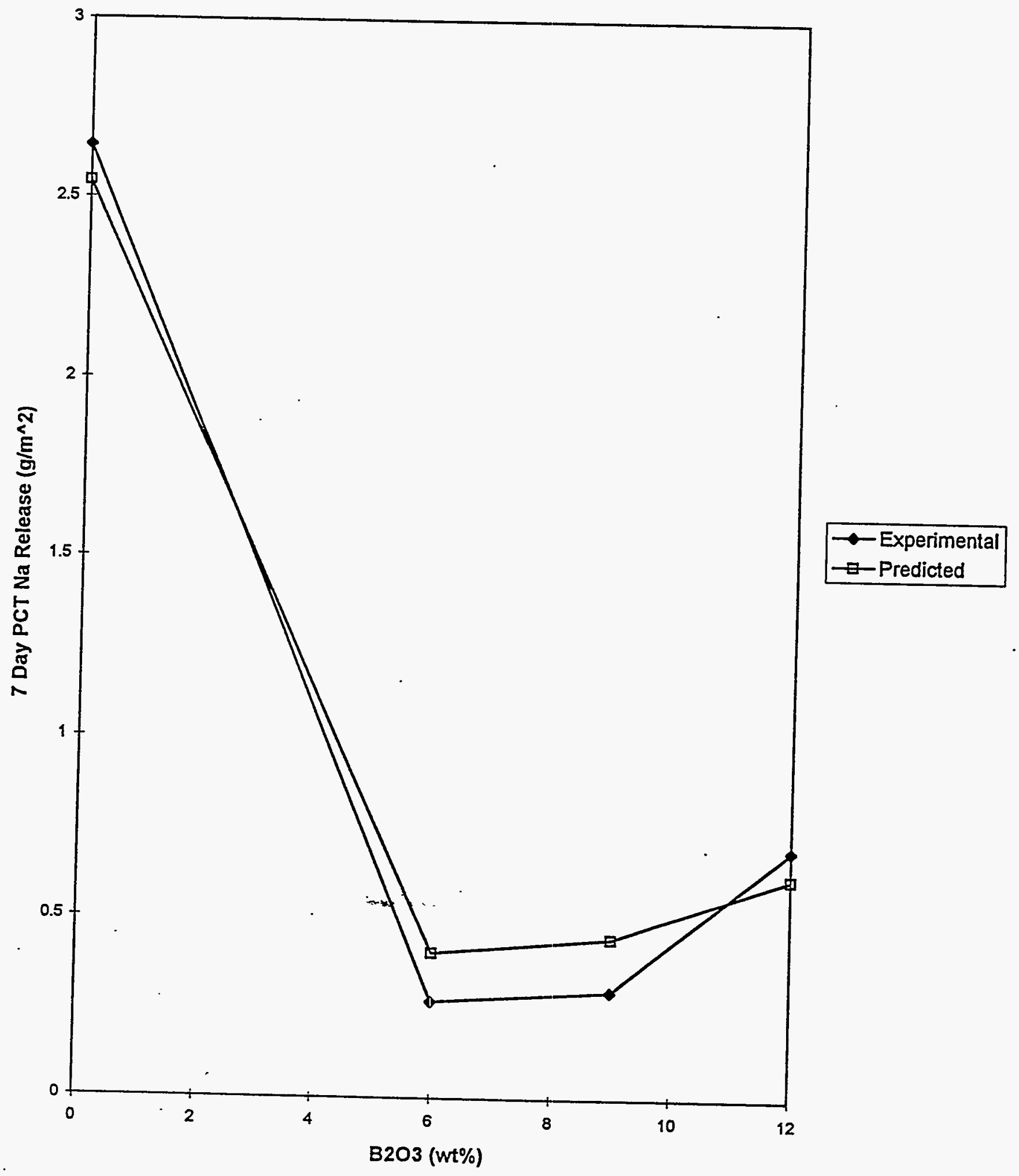

Page 1 


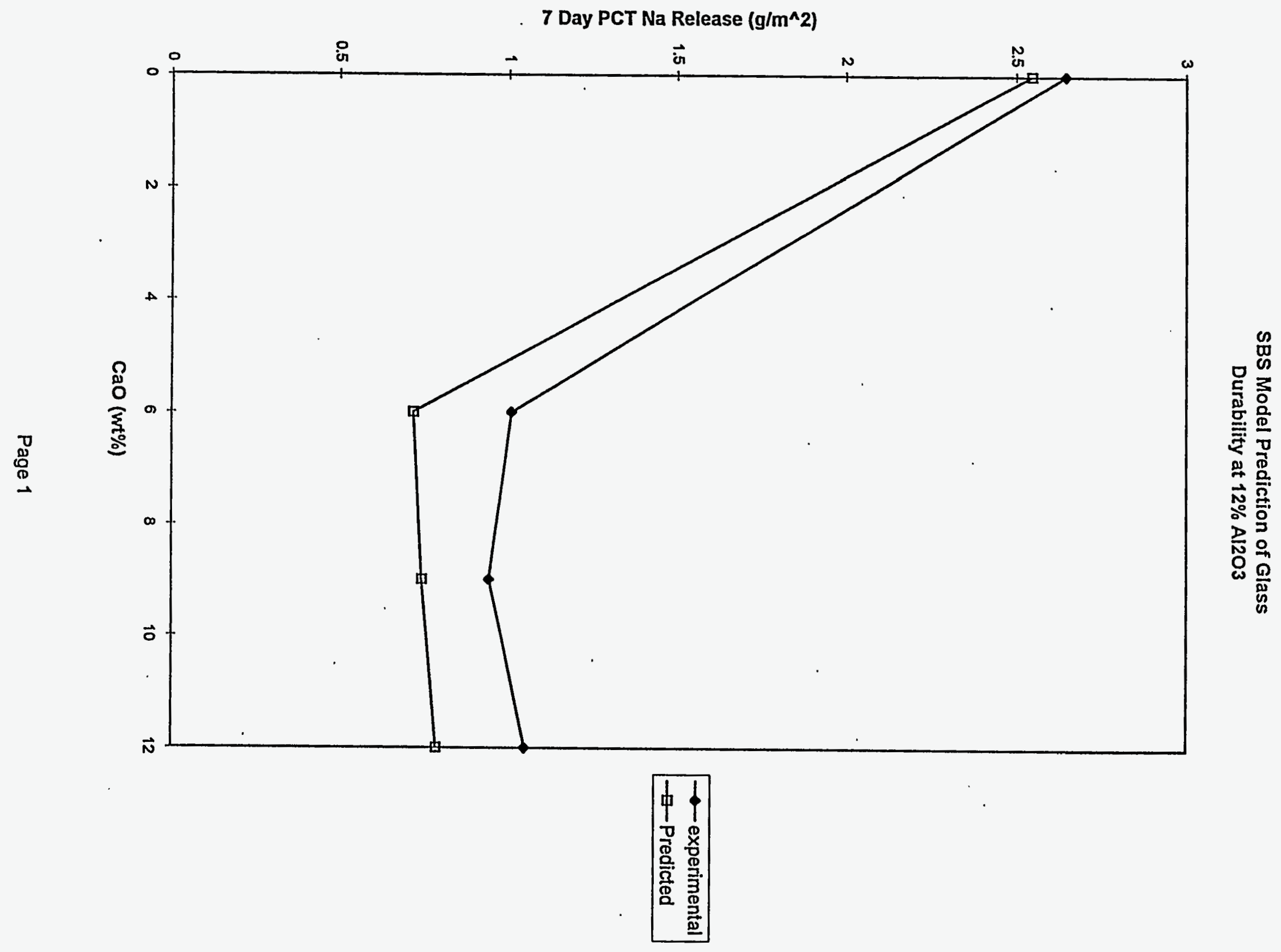


SBS Model Prediction of Glass

Durability at 5\%B2O3, 4\% CaO

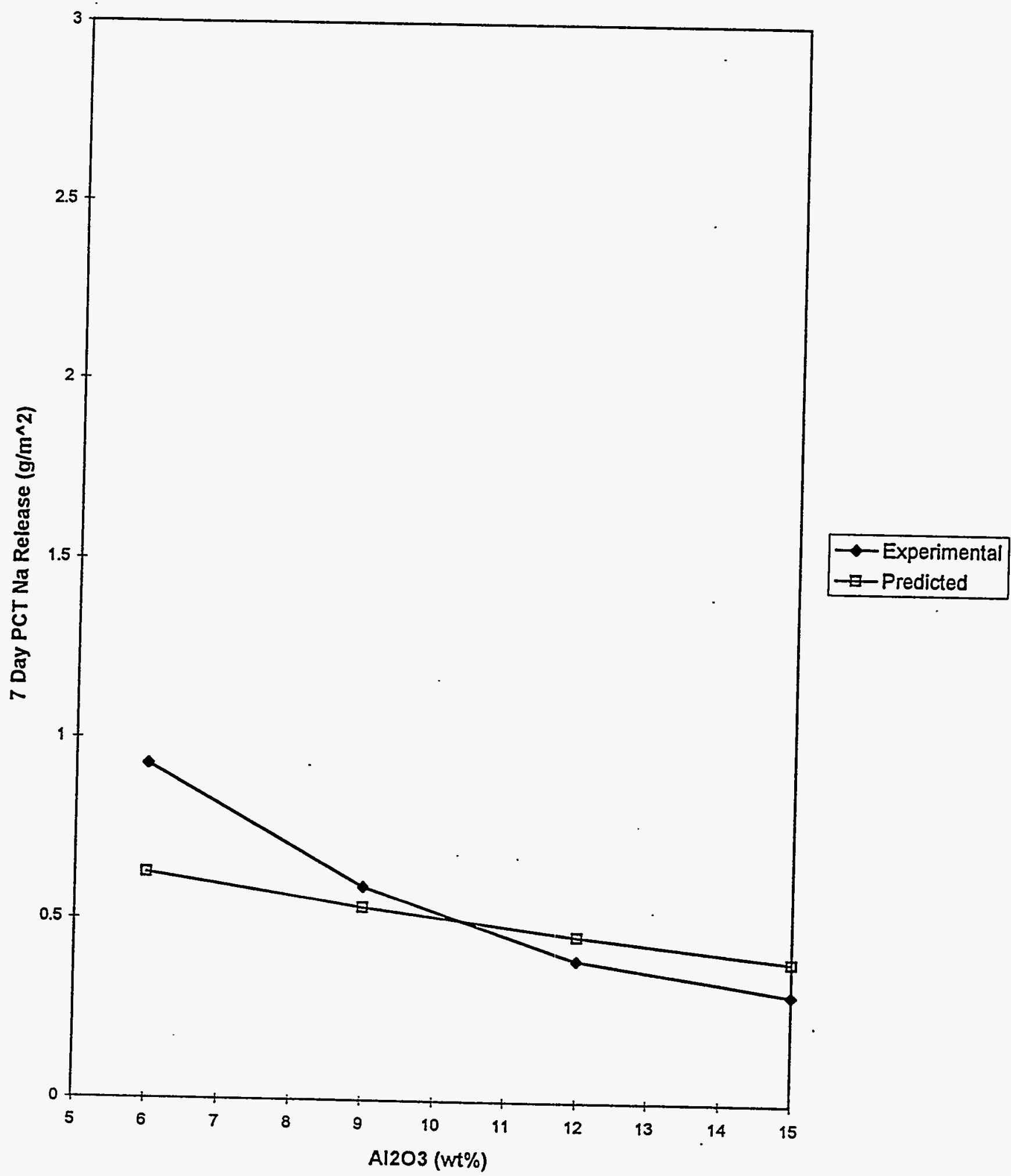


SBS Model Prediction on Glass

Durability-ANL Glasses (166)

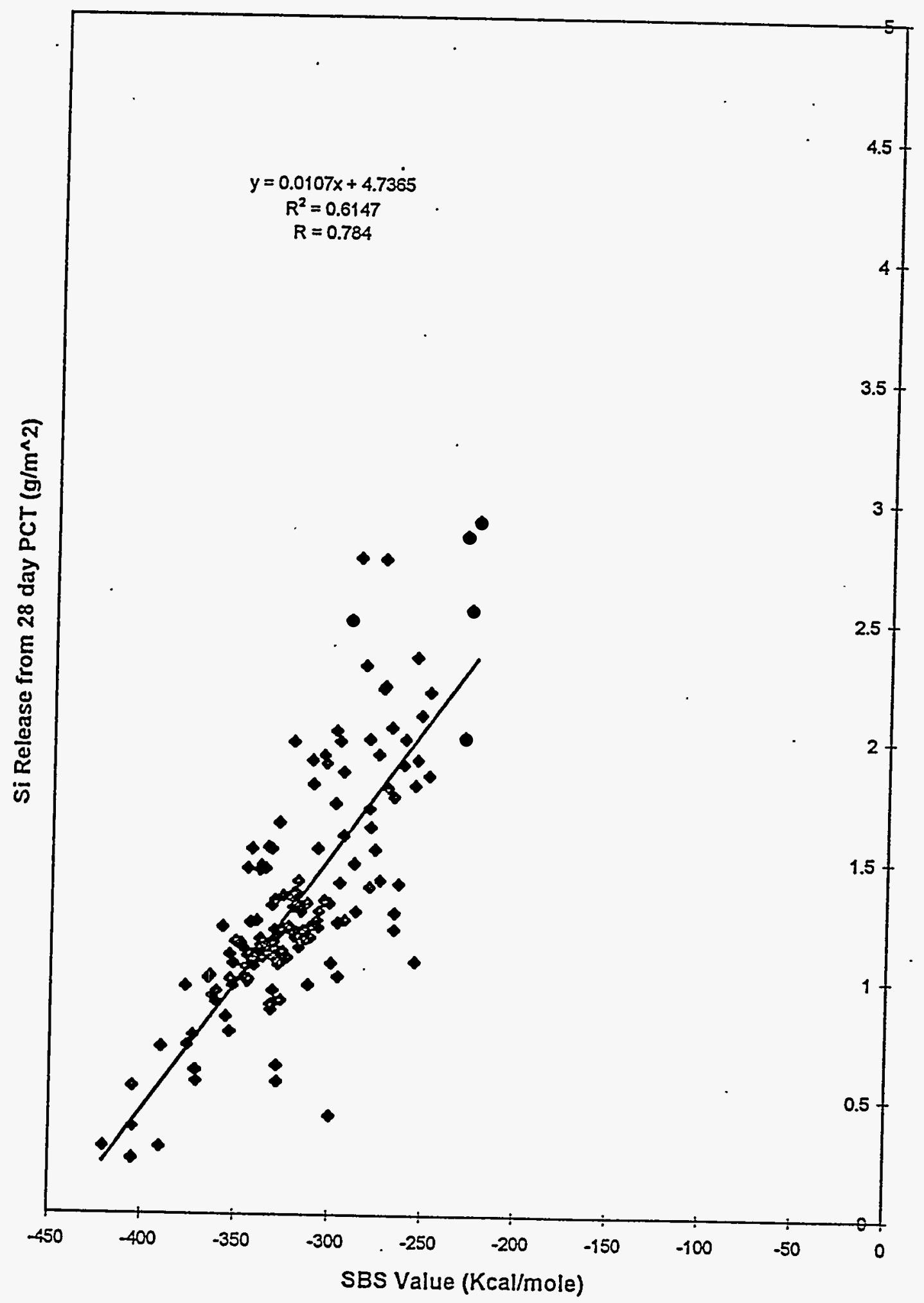




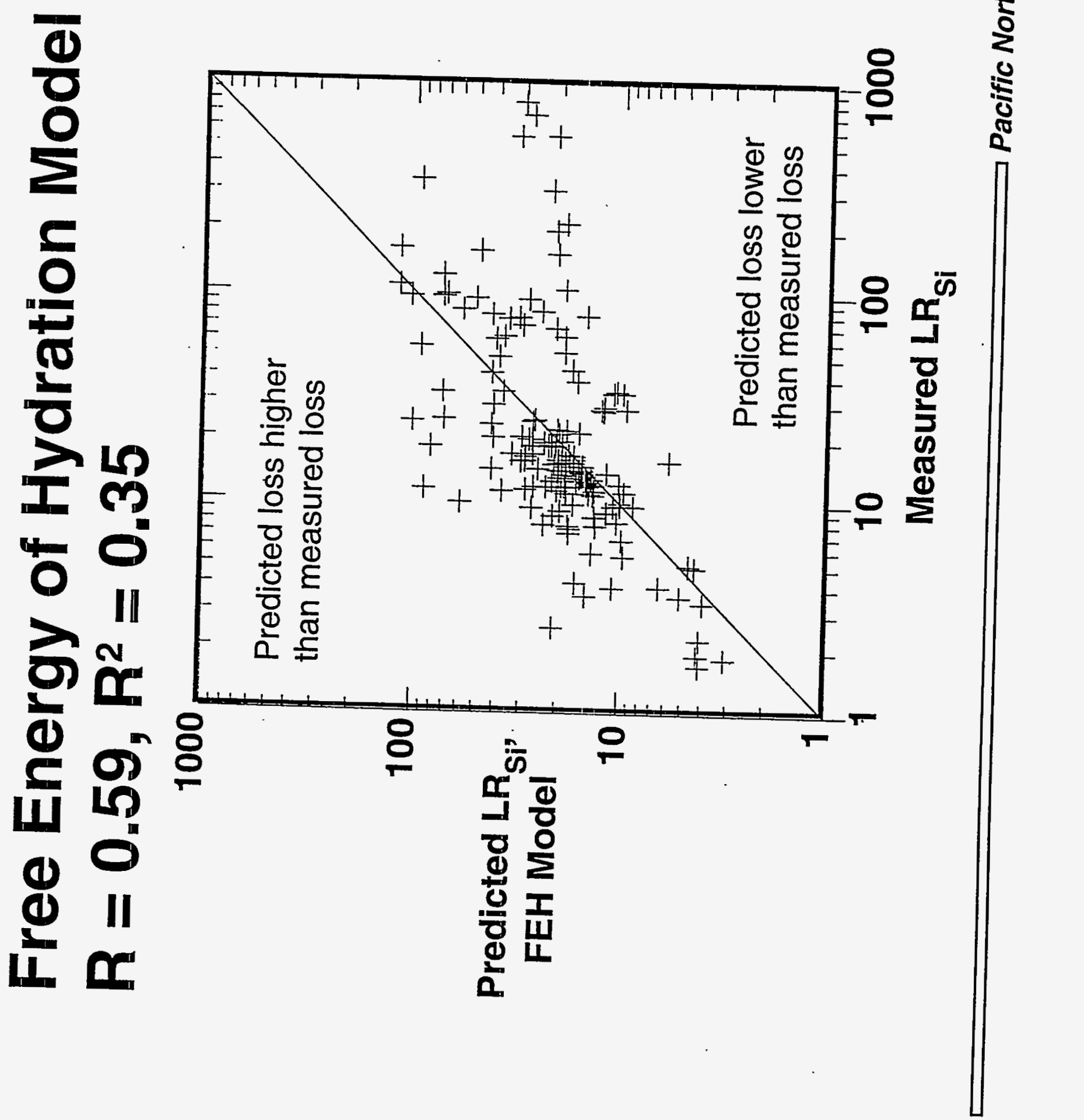



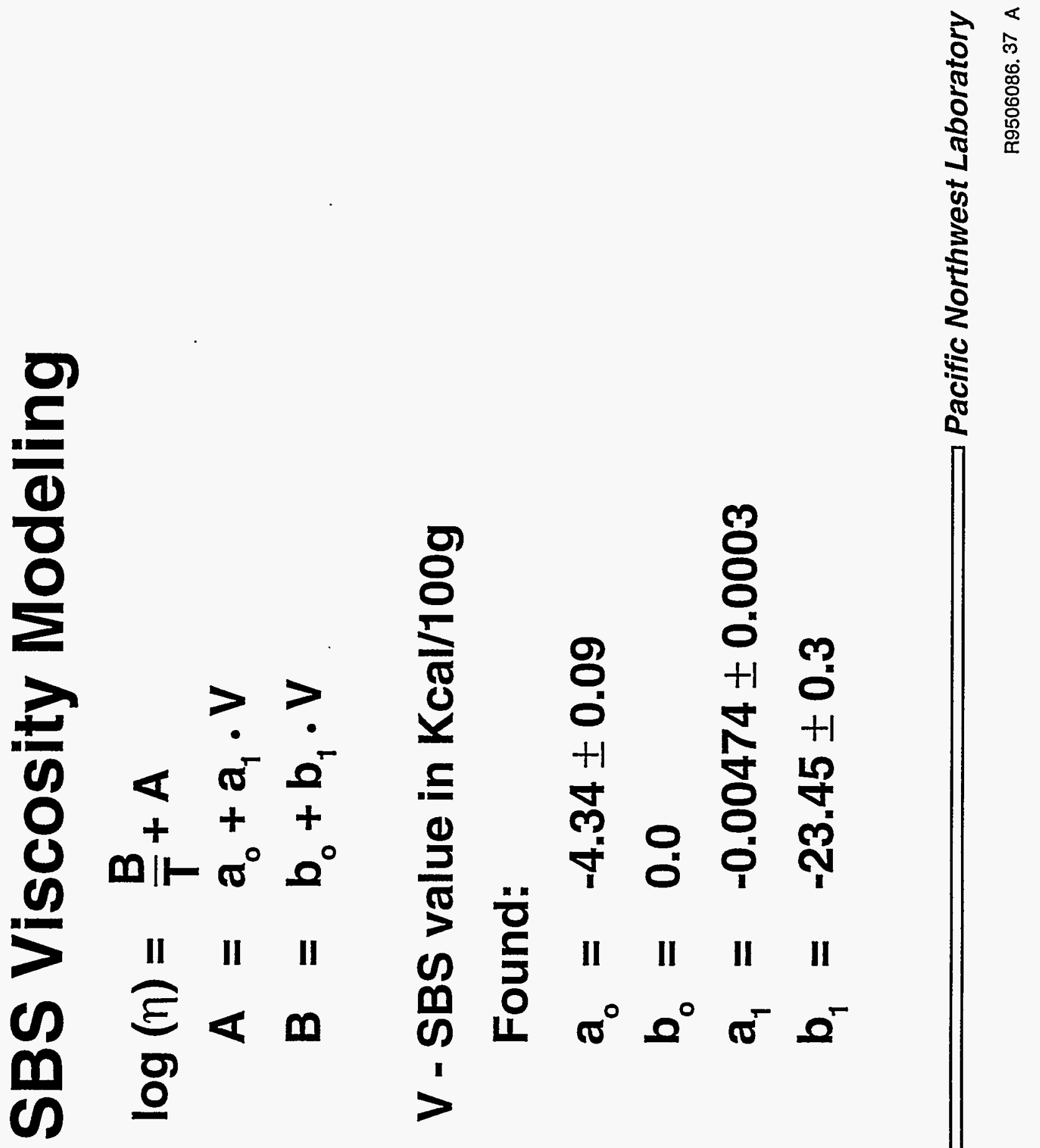


\section{Composition Range, in Wt\%, Covered by This Study}

\begin{tabular}{|c|c|c|c|c|}
\hline $\begin{array}{l}\mathrm{SiO}_{2} \\
17-90\end{array}$ & $\begin{array}{l}\mathrm{B}_{2} \mathrm{O}_{3} \\
0-20\end{array}$ & $\begin{array}{l}\mathrm{Al}_{2} \mathrm{O}_{3} \\
0-56\end{array}$ & $\begin{array}{l}\mathrm{FeO} \\
0-83\end{array}$ & $\begin{array}{l}\mathrm{Fe}_{2} \mathrm{O}_{3} \\
0-24\end{array}$ \\
\hline $\begin{array}{l}\mathrm{ZrO}_{2} \\
0-5.5\end{array}$ & $\begin{array}{l}\mathrm{ThO}_{2} \\
0-5.5\end{array}$ & $\begin{array}{l}\mathrm{UO}_{2} \\
0-1\end{array}$ & $\begin{array}{l}\mathrm{Li}_{2} \mathrm{O} \\
0-33\end{array}$ & $\begin{array}{l}\mathrm{Na}_{2} \mathrm{O} \\
0-36\end{array}$ \\
\hline $\mathrm{MgO}$ & $\mathrm{CaO}$ & SrO & Bao & $\mathrm{PbO}$ \\
\hline $0-44$ & $0-58$ & $0-64$ & $0-72$ & $0-45$ \\
\hline $\begin{array}{l}\text { MnO } \\
0-54\end{array}$ & $\begin{array}{l}\mathrm{TiO}_{2} \\
0-5\end{array}$ & $\begin{array}{l}\mathrm{K}_{2} \mathrm{O} \\
0-35\end{array}$ & $\begin{array}{l}\mathrm{P}_{2} \mathrm{O}_{5} \\
0-3.5\end{array}$ & \\
\hline
\end{tabular}

1671 data points on 372 glasses as 9 individual sets 


\section{EXAMPLES OF APPLICATIONS}

1) 1671 data points on 372 glasses

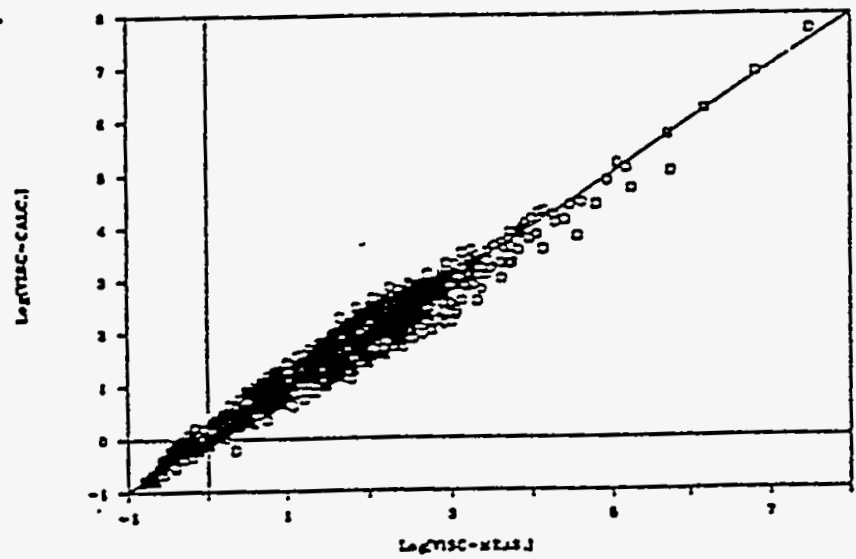

2) On NBS Soda-lime, Lead Silicate and Borosilicate glasses

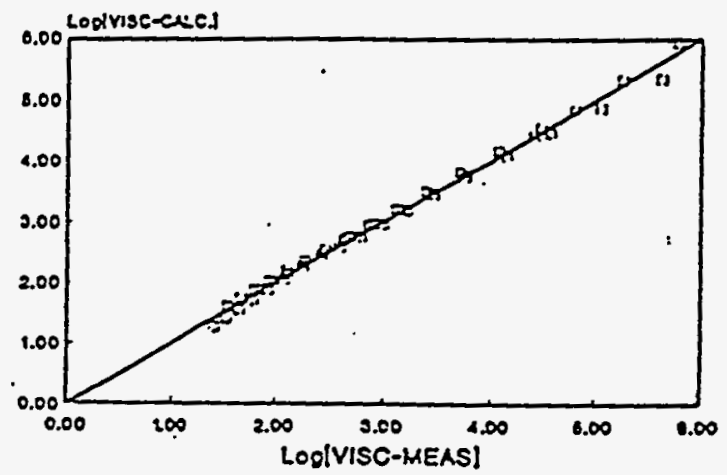

3) On Redox and Silica-Aluminate glasses

VISCOSITIES (poise)

\begin{tabular}{|c|c|c|c|c|}
\hline GLASS & $F_{\bullet}(\cdot 3) / F_{0}$ & MEASURED & PREDICTED & TEMPERATURE \\
\hline \multicolumn{5}{|c|}{ ACAITE at $1430^{\circ} \mathrm{C}$ : } \\
\hline $\begin{array}{l}A C-7 \\
A C-1 \\
A C-2 \\
A C-3 \\
A C-4 \\
A C-B \\
N C-8\end{array}$ & $\begin{array}{l}0.92 \\
1.00 \\
0.82 \\
0.52 \\
0.37 \\
0.25 \\
0.18\end{array}$ & $\begin{array}{l}20.89 \\
22.21 \\
15.49 \\
10.23 \\
9.48 \\
9.48 \\
9.48\end{array}$ & $\begin{array}{l}19.28 \\
21.34 \\
17.00 \\
11.09 \\
10.18 \\
9.00 \\
8.38\end{array}$ & $\begin{array}{l}1430.00 \\
1430.00 \\
1430.00 \\
1430.00 \\
1430.00 \\
1430.00 \\
1430.00\end{array}$ \\
\hline \multicolumn{5}{|c|}{ NSAF 40 at $1200^{\circ} \mathrm{C}$ : } \\
\hline $\begin{array}{l}F<0-1 \\
F<0-7 \\
F<0-2 \\
F<0-8 \\
F<0-3 \\
F<0-5 \\
F<0-4\end{array}$ & $\begin{array}{l}1.00 \\
1.00 \\
0.98 \\
0.83 \\
0.47 \\
0.35 \\
0.28\end{array}$ & $\begin{array}{l}8.49 \\
8.87 \\
7.89 \\
2.23 \\
1.52 \\
1.71 \\
1.38\end{array}$ & $\begin{array}{l}8.05 \\
8.05 \\
7.89 \\
2.87 \\
1.80 \\
1.41 \\
1.18\end{array}$ & $\begin{array}{l}1200.00 \\
1200.00 \\
1200.00 \\
1200.00 \\
1200.00 \\
1200.00 \\
1200.00\end{array}$ \\
\hline & Standard & viation $\cdot 0$. & 057 & \\
\hline
\end{tabular}

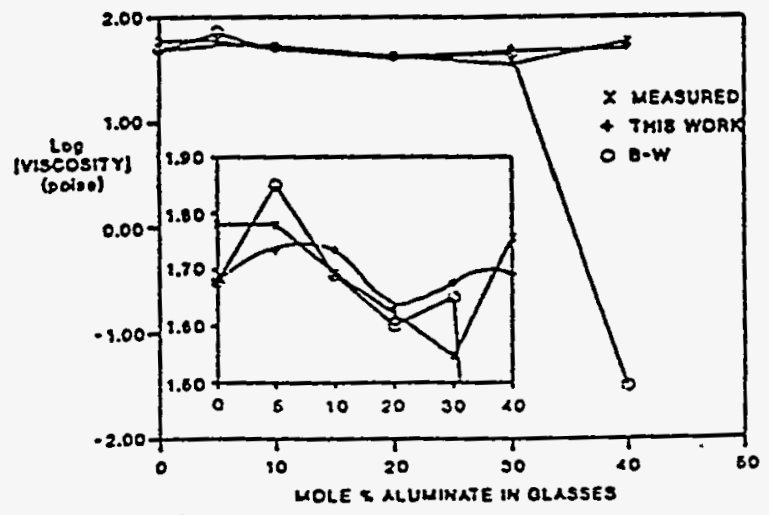




\section{Summary of SBS Model}

- A simple model based on heat of formation and structural role of oxides is developed

- This model is quite successful in representing both a wide range of compositions and detailed effects over small ranges

- It is applicable to relate waste form composition to:

- Durability

- Temperature dependent viscosity

- SBS model is useful for waste form optimization and it reduces the needs of crucible melts, shortens development time, and enhances the understanding of glass composition effects 


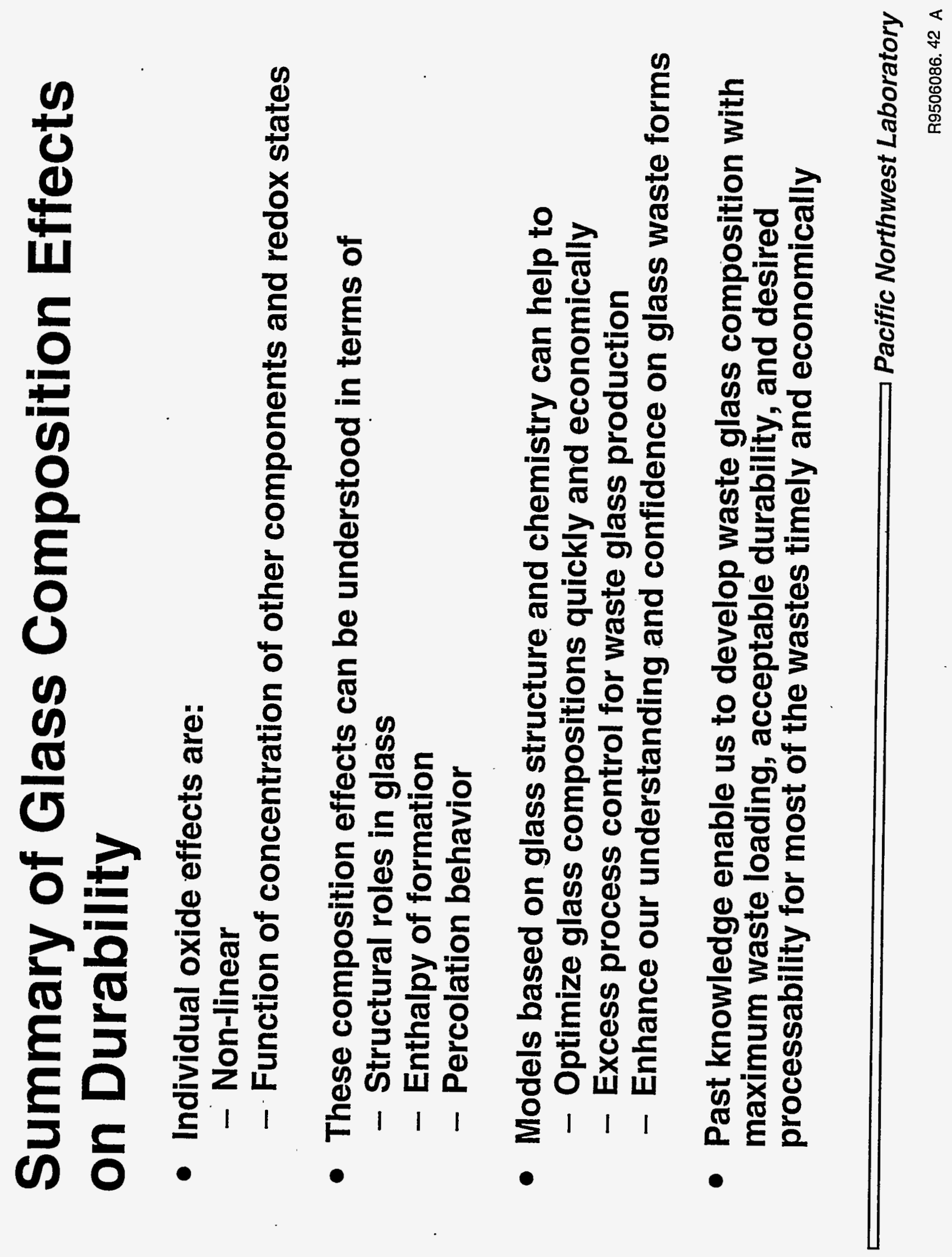


List of References in X. Feng's Talk on June 27, 1995

Alexander-1986

M. N. Alexander, P.I.K. Onorate, C.W. Struck, J.R. Rozen, G.W. Tasker, and D.R.

Uhlmann, J. Non-Crys. Solids, 79, 137-154 (1986).

Bobkova-1983

N.M. Bobkova, O.G. Gorrodetstkaya, S.A. Yankovskay, Z.S. Tizhovka, Fizikai

Hikimiya Stekla $\underline{9}$, 414-419 (1993)

Dell-1983

W.J. Dell, P.J. Bray, and S.Z. Xiao, J. Non-Crysta. Solids $\underline{58}$, 1-16 (1983).

Dickenson-1981

M.P. Dickenson and P.C. Hess, Contrib. Mineral. Petrol. $\underline{78}, 352-357$ (1981)

Dickenson-1986

M.P. Dickenson and P.C. Hess, Contrib. Mineral. Petrol. 92, 207-217 (1986)

Ellison-1994

A.J.G. Ellison, J.J. Mazer, and W.L. Ebert, Effects of Glass Composition on Waste

Form Durability: A Critical Review, Argonne National Laboratory Report \# ANL-

94/28, November 1994.

Feng-1988

X. Feng and A. Barkatt, "A Structural Thermodynamic Model for Durability and

Viscosity of Nuclear Waste Glasses," Scientific Basis for Nuclear Waste Management

XI, Eds., M. J. Apted, and R. E. Westerman, Vol. 112, 543-554 (1988).

Feng-1989

X. Feng, I. L. Pegg, A. Barkatt, P. B. Macedo, S. J. Cucinell, and S. Lai, "Correlation between Composition Effects on Glass Durability and the Structural Role of

Constituent Oxides," Nuclear Technology, Vol. 85(3), 334-345 (1989).

Feng-1990a

X. Feng, E. Saad, and I. L. Pegg, "A Model for the Viscosity of Multicomponent Glass Melts," Ceramic Transactions 9, Nuclear Waste Management III, Ed., G. B.

Mellinger, 457-46 8(1990):

Feng-1990b

X. Feng, I. L. Pegg, E. Saad, S. Cucinell, and Aa. Barkatt, "Redox Effects on the Durability and Viscosity of Nuclear Waste Glasses," Ceramic Transactions $\underline{9}$, Nuclear Waste Management III, Ed., G. B. Mellinger, 165-174 (1990). 
Feng-1994

X. Feng, D. J. Wronkiewicz, J. K. Bates, N. R. Brown, E. C. Buck, N. L. Dietz, M. Gong, and J. W. Emery, "Vitreous ceramic For Minimum Additive Waste Stabilization, Interim Program Report, May 1993 - February 1994," Argonne National Laboratory Report \# ANL-94/24, 1994

Feng-1995

$\mathrm{X}$. Feng and T. Metzger, "Improved Structural Bond Strength Model for Glass Durability and Viscosity," in preparation

Zachariasen-1932

W.H. Zachariasen, J. Am. Chem. Soc., 54, 3841(1932) 


\section{WASTE LOADING MAXIMIZATION}




\section{WASTE LOADING MAXIMIZATION}

reduces demands on repository space, processing time, and reduces overall cost

waste loading constraints

- product quality (EA glass PCT standard)

- ease of processing

- melt viscosity

- glass crystallization

waste composition

Hanford Site double-shell tank/single-shell tank (DST/SST) HL simulated waste (wt \%)

$\begin{array}{llllll}\mathrm{Na} 2 \mathrm{O} & 27.02 & \mathrm{Al}_{2} \mathrm{O} 3 & 13.88 & \mathrm{Fe}_{2} \mathrm{O} 3 & 11.75\end{array}$

$\begin{array}{llllll}\mathrm{SiO}_{2} & 10.68 & \mathrm{Nd} 2 \mathrm{O} 3 & 9.33 & \mathrm{ZrO}_{2} & 7.56\end{array}$

$\begin{array}{llllll}\mathrm{P}_{2} \mathrm{O} 5 & 5.03 & \mathrm{CeO}_{2} & 2.92 & \mathrm{NiO} & 2.42\end{array}$

$\begin{array}{llllll}\mathrm{CaO} & 2.20 & \mathrm{Bi} 2 \mathrm{O} 3 & 2.09 & \mathrm{MnO} & 1.59\end{array}$

$\begin{array}{llllll}F & 0.59 & \mathrm{Cr}_{2} \mathrm{O} 3 & 0.48 & \mathrm{La}_{2} \mathrm{O} 3 & 0.46\end{array}$

$\begin{array}{llllll}\mathrm{SrO} & 0.44 & \mathrm{PbO} & 0.38 & \mathrm{SO}{ }^{3} & 0.36\end{array}$

$\begin{array}{llllll}\mathrm{K}_{2} \mathrm{O} & 0.24 & \mathrm{WO} 3 & 0.19 & \mathrm{CdO} & 0.10\end{array}$

$\begin{array}{llllll}\mathrm{B}_{2} \mathrm{O} 3 & 0.08 & \mathrm{MgO} & 0.08 & \mathrm{MoO} 3 & 0.08\end{array}$

$\mathrm{RuO}_{2} \quad 0.05$ 
GLASSES FOR HIGH-

TEMPERATURE MELTER (HTM)

- glass additives: addition of $\mathrm{SiO}_{2}$ is sufficient to make a durable glass

- melting temperature (the temperature at which viscosity is 4 to $5 \mathrm{~Pa} \cdot \mathrm{s})$ : approx. $1350^{\circ} \mathrm{C}$

effect of crystallization

- liquidus temperature: the maximum temperure at which crystalline phase can exist at quilibrium with melt

- liquidus temperature must be lower than melting temperature minus $100^{\circ} \mathrm{C}$ to avoid crystallization in the melter

- lab testing for melter crystallization: $24 \mathrm{~h}$ heat treatment at $\mathrm{T}=\mathrm{T}_{\mathrm{M}}-100^{\circ} \mathrm{C}$

- no crystalline phases precipitate from SST/DST blend waste glass up to $\mathrm{W}=$ 0.67 (HWVP limit: $\mathrm{W}=0.25$ ) 


\section{CRYSTALLIZATION IN CANISTER}

- crystallinity can develop in the glass during cooling: the slower cooling, the more crystalline phase may precipitate

- canister centerline cooling (CCC) is the slowest cooling the glass experiences

(hence, produces maximum crystallinity)

- CCC schedule:

$$
\begin{array}{lr}
\partial \mathrm{T} / \partial \mathrm{t}=-100^{\circ} \mathrm{C} / \mathrm{h} & 1122-872^{\circ} \mathrm{C} \\
\partial \mathrm{T} / \partial \mathrm{t}=-29^{\circ} \mathrm{C} / \mathrm{h} & 872-669^{\circ} \mathrm{C} \\
\partial \mathrm{T} / \partial \mathrm{t}=-22^{\circ} \mathrm{C} / \mathrm{h} & 669-515^{\circ} \mathrm{C}
\end{array}
$$




\section{CRYSTALLINITY IN GLASS}

is acceptable if it does not decrease glass durability

- refractory components $\left(\mathrm{Al}_{2} \mathrm{O} 3, \mathrm{Fe} 2 \mathrm{O} 3\right.$, $\mathrm{SiO} 2, \mathrm{Nd} 2 \mathrm{O} 3, \mathrm{ZrO} 2, \mathrm{CeO} 2, \mathrm{NiO}$, $\mathrm{Cr} 2 \mathrm{O} 3$ ) are prone to crystallization

- removal of reftactory components by the precipitation of crystalline phases weakens glass matrix and increases concentration of alkali oxides $(\mathrm{Na} 2 \mathrm{O})$ in residual glass; hence, glass durability is likely to be affected

- durability of Hanford Site glasses is decreased by precipitation of

- nepheline (NaAlSiO4)

- eucriptite (LiAlSiO4)

- cristobalite $(\mathrm{SiO} 2)$ 


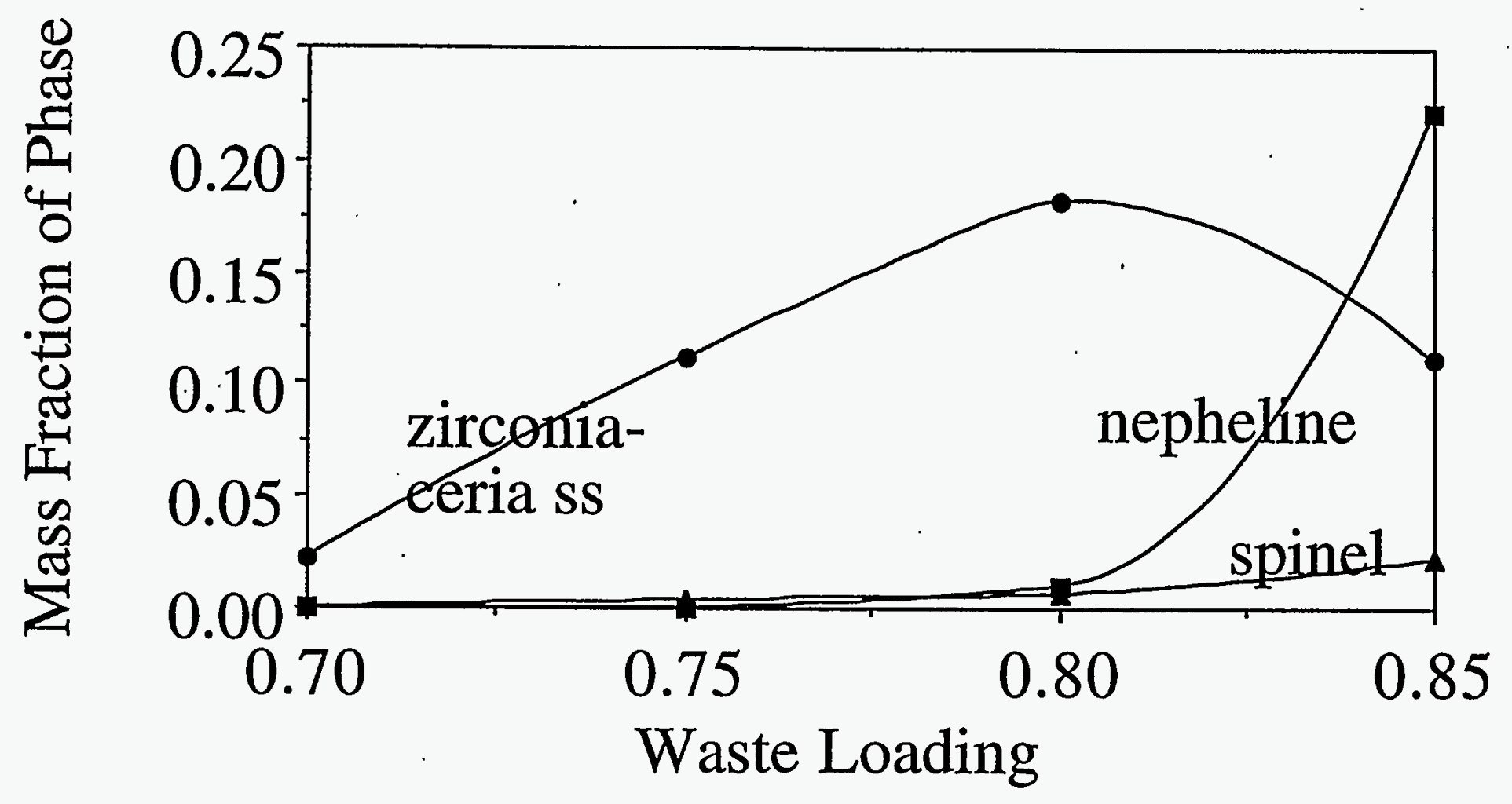

Crystallinity Versus Fraction of Hanford All-Tank Blend HLW in Glass 


\section{ALL-BLEND SIMULATED HLW GLASS CRYSTALLINE PHASES (from quenched melts)}

zirconia-containing crystals $\mathrm{Nd}_{2} \mathrm{O}_{3} . \mathrm{ZrO}_{2}-\mathrm{Ce}_{2} \mathrm{O}_{3} . \mathrm{ZrO}_{2}$ ss $(\mathrm{W} \geq 0.7)$

nepheline

$\mathrm{Na}_{2} \mathrm{O} \cdot \mathrm{Al}_{2} \mathrm{O}_{3} \cdot 2 \mathrm{SiO}_{2}(\mathrm{~W} \geq 0.8)$

spinel

$\mathrm{Fe}_{2} \mathrm{O}_{3} \cdot \mathrm{NiO}-\mathrm{Cr}_{2} \mathrm{O}_{3} \cdot \mathrm{FeO}$ ss $(\mathrm{W} \geq 0.75)$

- crystallization of nepheline $(\mathrm{W}>0.80)$ removes $\mathrm{SiO}_{2}$ and $\mathrm{Al}_{2} \mathrm{O}_{3}$ from residual glass and contributes to the decline in glass corrosion resistance

- both crystalline phases and amorphous phase may affect durability

- difference between the thermal expansion of the residual glass and crystals causes permanent stresses, thus affecting durability

- compositional gradients in residual glass may also impact durability 


\section{7-day Normalized PCT Na Release}

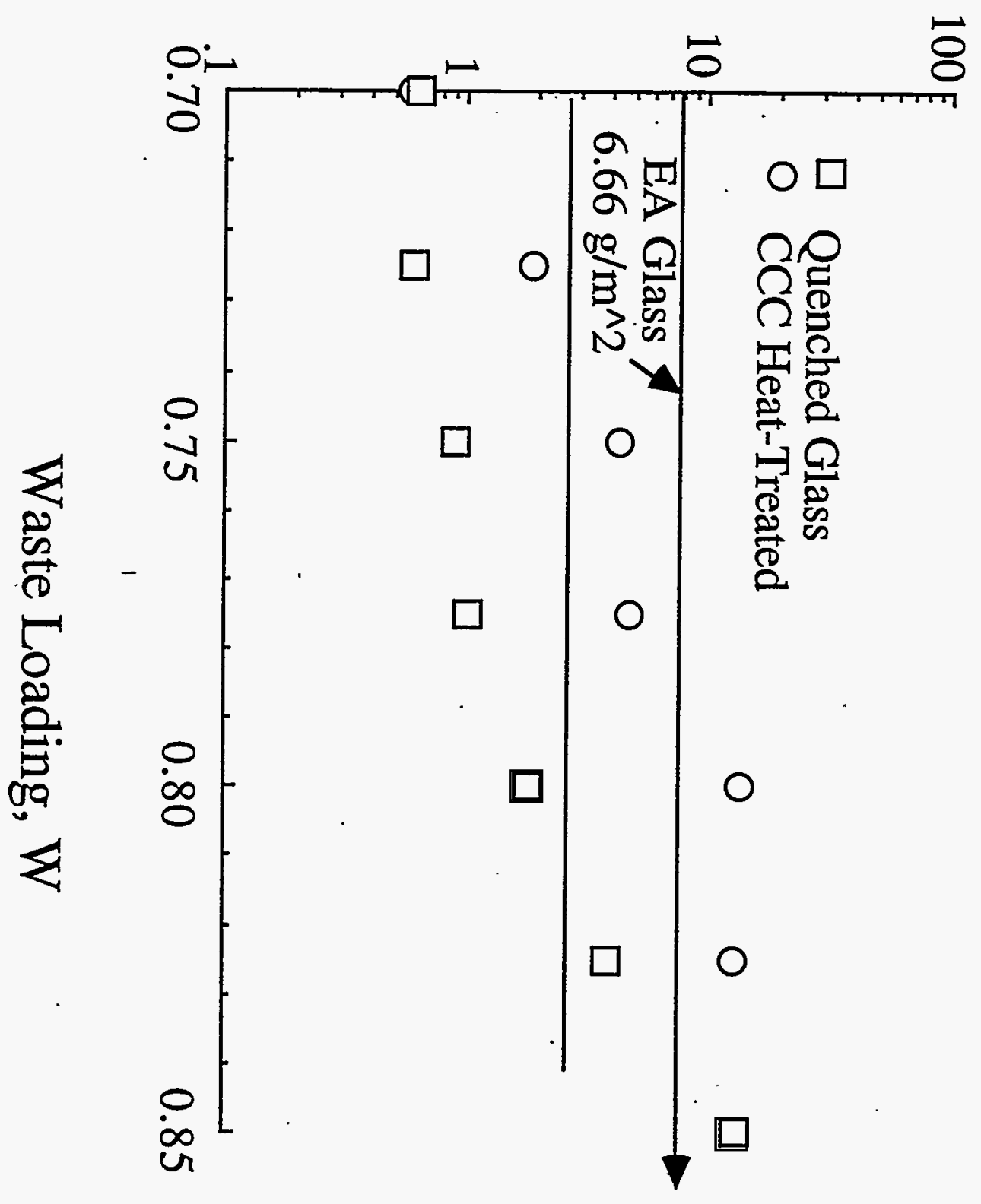




\section{WASTE LOADING LIMITS}

- fine crystallinity limit

- fine $(<10 \mu \mathrm{m})$ and well dispersed crystals (spinel)

- a negligible fraction of fine crystals may settle in melter (?)

- coarse crystallinity limit

- large $(>10 \mu \mathrm{m})$ heavy crystals

(baddeleyite)

- large heavy crystals settle and block melter

- amorphous phase structural breakdown limit

- $\mathrm{Na}_{2} \mathrm{O}$ from waste eventually causes the breakdown of glass structure 


\section{WASTE LOADING FOR HANFORD SITE HLW GLASSES}

- the waste loading that can be achieved for SST/DST blend without a formation of crystalline phases in the melter is 0.67 (0.25 anticipated for HWVP)

- this already high waste loading can be increased by an additional 5 to $15 \%$, dependent on the accepted durability, if crystallinity can be tolerated at glass melting temperatures

- although the current large scale vitrification technology does not tolerate melts with crystals, the potential for waste loading increase may stimulate . future development

- for the LLW glass, the waste loading is limited by the maximum fraction of $\mathrm{Na}_{2} \mathrm{O}$ that the glass network can accommodate while maintaining acceptable performance 
Crystallization - Selected Topics

by John D. Vienna, Research Scientist, Pacific Northwest Laboratory, 372-2807

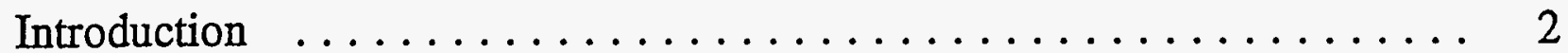

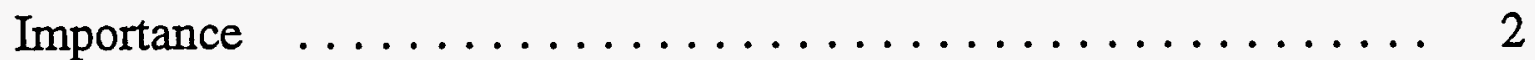

Hanford Needs ...................... 2

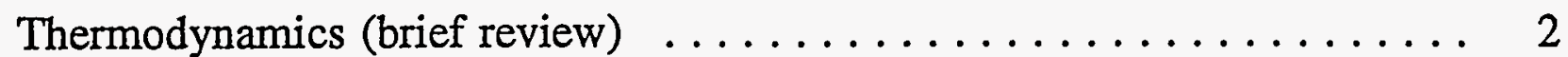

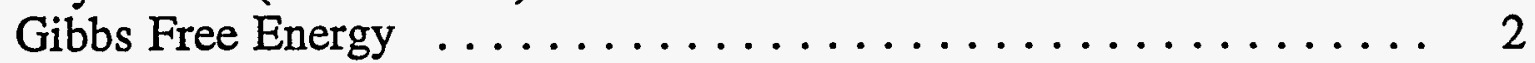

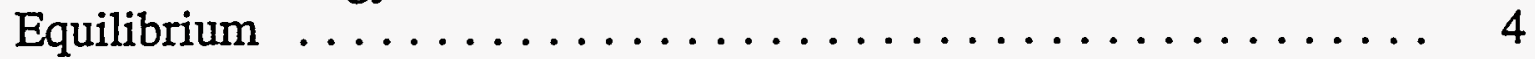

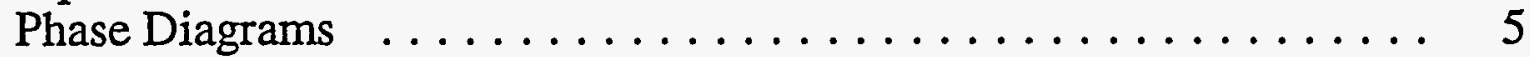

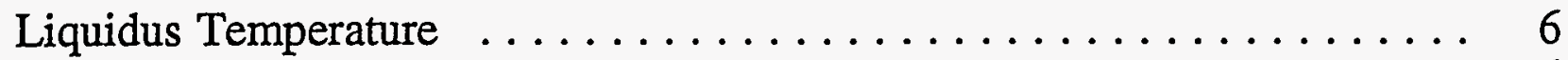

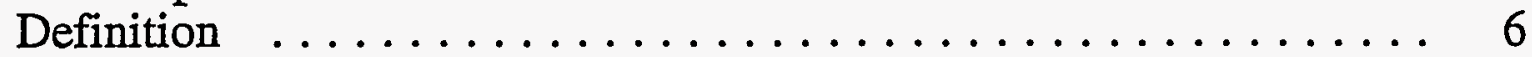

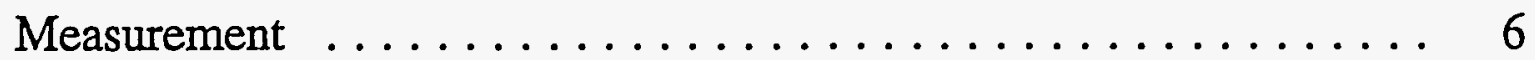

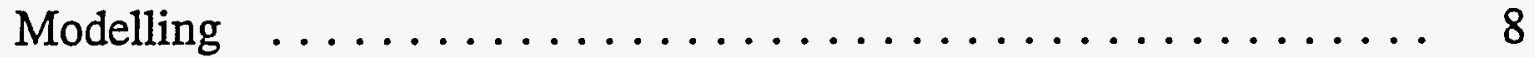

Nuclear Waste Glass $\ldots \ldots \ldots \ldots \ldots \ldots \ldots$

Nucleation and Growth $\ldots \ldots \ldots \ldots \ldots \ldots \ldots \ldots \ldots \ldots$

Classic Nucleation Theory $\ldots \ldots \ldots \ldots \ldots \ldots \ldots \ldots \ldots$

Nucleating Agents . . . . . . . . . . . . . . 15

Nucleation in Waste Glass $\ldots \ldots \ldots \ldots \ldots \ldots \ldots$

Growth in Waste Glass . . . . . . . . . . . . . . . 17

Transformation in Waste Glass $\ldots \ldots \ldots \ldots \ldots \ldots \ldots \ldots$

Measurement: ....................... 18

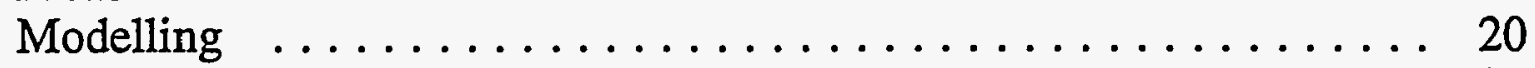

Results ....................... 22

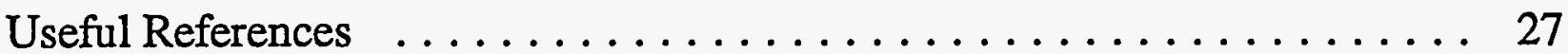

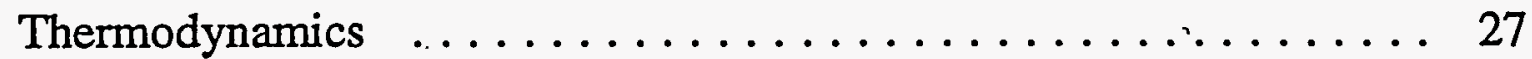

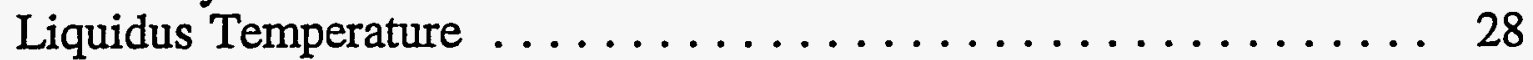

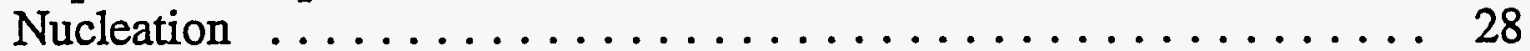

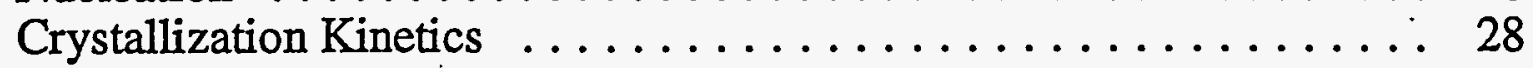




\section{Introduction:}

- Importance:

Crystalline phases precipitated in a continuous melter can cause processing problems, such as sludge formation on the melter bottom or even melter electrode shorting if the phases are highly conductive. In addition, if crystallization occurs during canister cooling, the glass durability may be strongly reduced.

For these reasons, restrictions have been placed on glass to avoid precipitation in the melter and excessive crystallization in the canister. These properties are difficult to estimate. So restrictions on composition must be conservative enough to avoid the problematic events.

- Hanford Needs:

Recent experience with Hanford HLW formulation efforts have shown that crystallinity is the factor that limits waste oxide loading in nearly every case. The ability to accurately predict these phenomena would increase the efficiency of glass formulation efforts and more importantly the overall waste oxide loading of glass produced at Hanford. This would mean a significant decrease in cleanup costs. Our current ability to predict phase transformations in waste glass is limited. To make improvements in our ability to predict these phenomena, we must develop a more complete understanding of them.

\section{Thermodynamics (brief review):}

- Gibbs Free Energy:

The free energy of a system is the energy available to do work. Gibbs free energy is defined in terms of internal energy $(E)$, pressure $(P)$, temperature (T), entropy $(\mathrm{S})$, and enthalpy $(\mathrm{H})$ :

$$
\mathrm{G}=\mathrm{E}+\mathrm{PV}-\mathrm{TS}=\mathrm{H}-\mathrm{TS}
$$

The internal energy is the total energy (including kinetic and potential) of all the atoms or molecules in a system. Although $\mathrm{E}$ cannot be measured, $\Delta \mathrm{E}$ can:

$$
\Delta \mathrm{E}=\mathrm{E}_{2}-\mathrm{E}_{1}=\mathrm{q}-\mathrm{w}
$$

where $\mathrm{q}$ is the heat added to and $\mathrm{w}$ is the work done by the system. $\mathrm{H}$ is a measure of the heat of a system and $\Delta \mathrm{H}$ is the heat absorbed by the system ( $\mathrm{q}=$ 
$\Delta \mathrm{E}+\mathrm{P} \Delta \mathrm{V}=\Delta \mathrm{H})$ assuming only $\mathrm{PdV}$ work.

$\Delta \mathrm{H}$ can be generated by reactions, temperature change, ...

$$
\begin{aligned}
& \Delta \mathrm{H}=\mathrm{H}_{\text {prod }}-\mathrm{H}_{\text {react }} \\
& \Delta \mathrm{H}=\mathrm{H}_{\mathrm{T}_{2}}-\mathrm{H}_{\mathrm{T}_{1}}=\int \mathrm{C}_{\mathrm{P}} \mathrm{dT}
\end{aligned}
$$

Likewise, entropy is a measure of randomness or disorder and is given by:

$$
\begin{aligned}
& \Delta S=S_{\text {prod }}-S_{\text {react }} \\
& \Delta S=S_{T_{2}}-S_{T_{1}}=\frac{\Delta q_{r}}{T}=\int \frac{C_{P}}{T} d T
\end{aligned}
$$

where $C_{P}$ is the constant pressure heat capacity (with a temperature dependence of the form $a+b T+c T^{-2}$ ).

Work can be expressed in the form intensive times differential of like extensive variables:

$$
\mathrm{dw}=\mathrm{PdV}-\sigma \mathrm{d} \varepsilon-\gamma \mathrm{dA}-\sum \mu_{\mathrm{i}} \mathrm{dn}_{\mathrm{i}}-\mathrm{HdM}-\ldots
$$

where the mechanical, strain, surface, chemical, magnetic, and other work terms are summed. Commonly only PdV work is considered at constant pressure. However, for the purpose of phase transformations chemical work is considered. This term is a summation of chemical potentials of all components (n) in a system. Chemical potential is then defined as the partial molar free energy of a component in a system:

$$
\mu_{i}=\left(\frac{d G}{d n_{i}}\right)_{P, T, n_{j 1}}
$$

The free energy change of the system is then given as:

$$
\mathrm{dG}=\mathrm{VdP}-\mathrm{SdT}+\sum_{\mathbf{i}} \mu_{i} \mathrm{dn}
$$

The free energy associated with mixing is given by: 


$$
\Delta \mathrm{G}^{\mathrm{M}}=\mathrm{RT} \sum_{\mathrm{i}} \mathrm{X}_{\mathrm{i}} \ln \mathrm{a}_{\mathrm{i}}
$$

where $X_{i}$ is the mole fraction and $a_{i}$ is the activity of the $i$-th component. The activities of each component in an ideal solution are equal to the mole fractions of components. The deviation from ideality is given by the activity coefficient:

$$
\gamma_{\mathrm{i}}=\mathrm{a}_{\mathrm{i}} / \mathrm{X}_{\mathrm{i}}
$$

For $\gamma_{i}>1$, the driving force for the component to enter solution is less than that for ideal solution. Similarly, if $\gamma_{i}<1$ the driving force is more than that for ideal solution.

Excess free energy (enthalpy and entropy) is the difference between the free energy and that of an ideal solution (mixture):

$$
\mathrm{GE}=\Delta \mathrm{GM}-\Delta \mathrm{GM}, \text { Ideal }
$$

and:

$$
\mathrm{G}^{\mathrm{E}}=\mathrm{RT} \sum_{\mathrm{i}} \mathrm{X}_{\mathrm{i}} \ln \gamma_{\mathrm{i}}, \text { and } \mu_{\mathrm{i}}^{\mathrm{E}}=\mathrm{RT} \ln \gamma_{\mathrm{i}}
$$

\section{- Equilibrium:}

Equilibrium is defined in many ways. For the purposes of this discussion it will be defined by a minimum of system free energy. This minimum is with respect to fluctuations such as $\mathrm{kT}, \mu_{\mathrm{i}}, \mathrm{n}_{\mathrm{i}}$, etc... Such energy minimums if local (and not global) are termed meta-stable equilibriums.

When considering crystallization at constant $\mathrm{P}$ and $\mathrm{T}$, minima in $\mathrm{G}$ define equilibrium. In this case reactions (such as crystallization) will proceed in the direction of negative $\Delta \mathrm{G}$.

The Gibb's Duhem relation yields:

$$
\sum_{i} x_{i} \mathrm{~d} \mu_{i}=0
$$

at equilibrium and for multi-phase systems, the chemical potential of any component is equal in all phases. 
- Phase Diagrams:

Developed using common tangent of free energy curves of all phases at a given temperature.

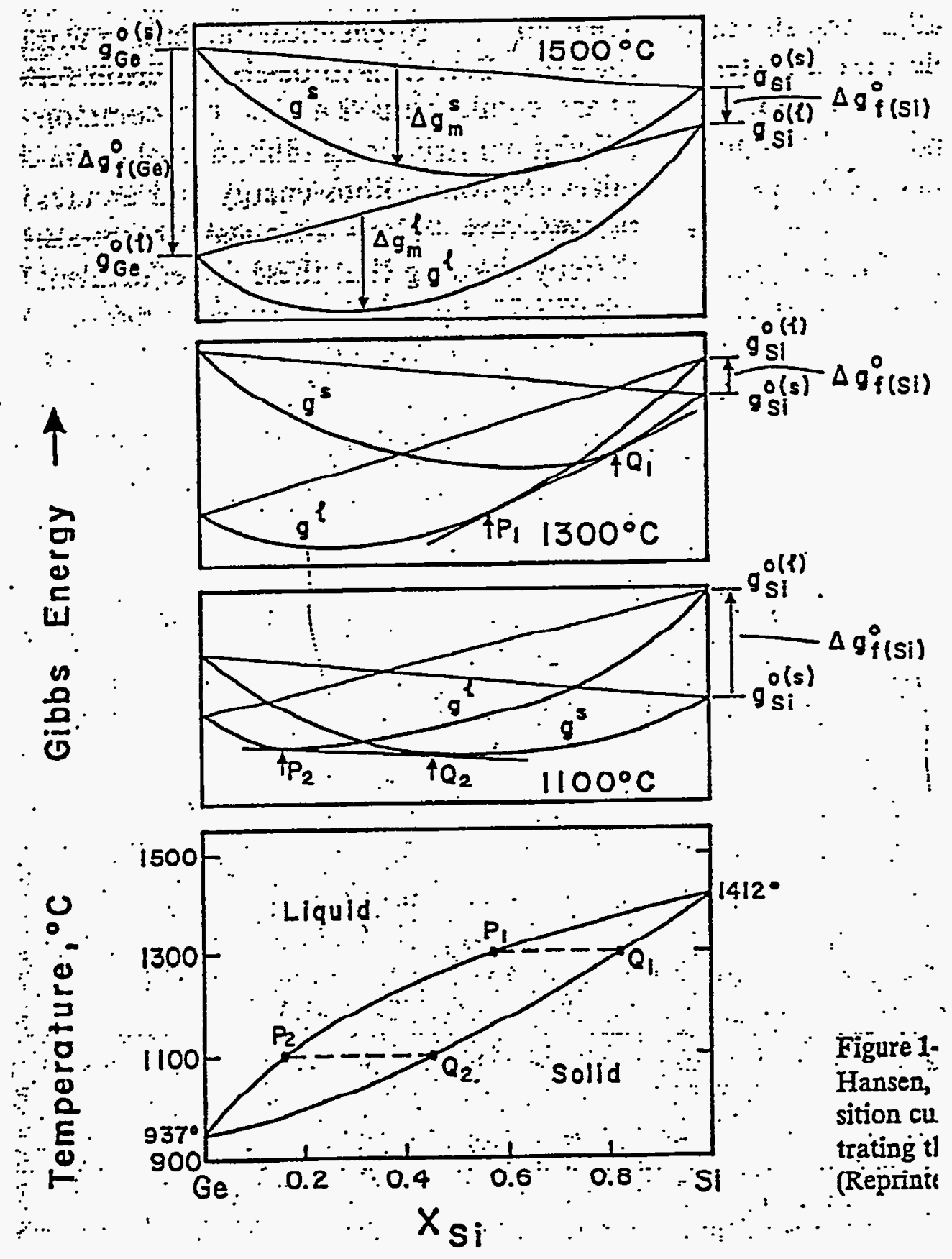



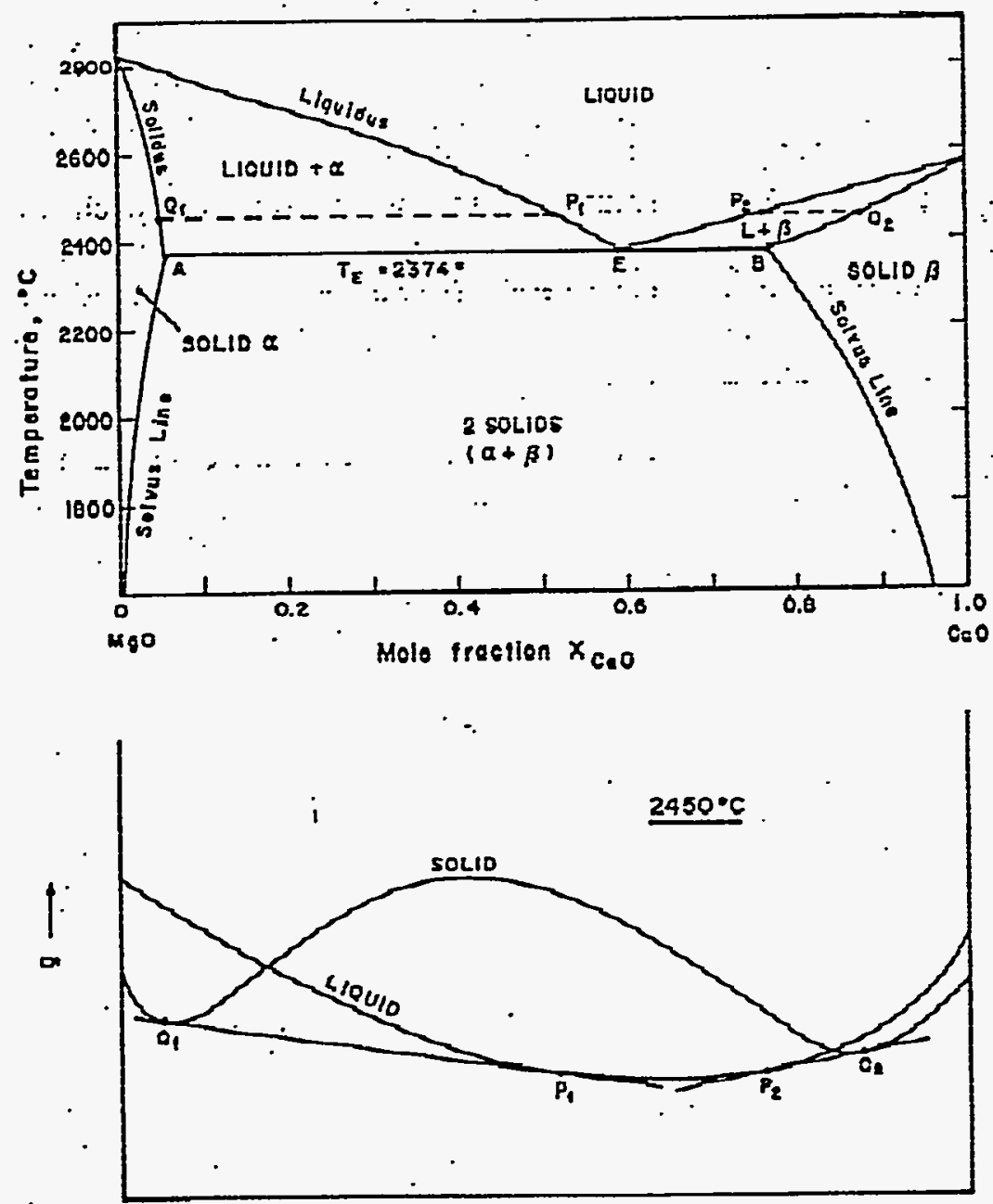

\section{Liquidus Temperature:}

- Definition:

Liquidus temperature $\left(T_{L}\right)$ as seen from phase diagram is the point at which a given composition is first in equilibrium with crystal phase. In reality, there is a range of meta-stable equilibrium of liquid phase below this liquidus temperature.

Effectively, $T_{L}$ is taken at the temperature of crystal precipitation. Precipitation requires there to be a finite driving force $(\Delta G)$. In addition, the additional surface work term must be considered when crystals form in (or at a surface of) a molten bath.

- Measurement: 
Several methods are used to measure $T_{L}$. Factors influencing results include:

- heat treatment as dissolution or crystallization

- heat treatment crucible $\left(\mathrm{Pt}, \mathrm{SiO}_{2}, \mathrm{Al}_{2} \mathrm{O}_{3}\right.$, covered, uncovered,...)

- isothermal vs gradient furnace,

- heat treatment time,

- $\quad$ analysis method (OM, SEM, XRD)

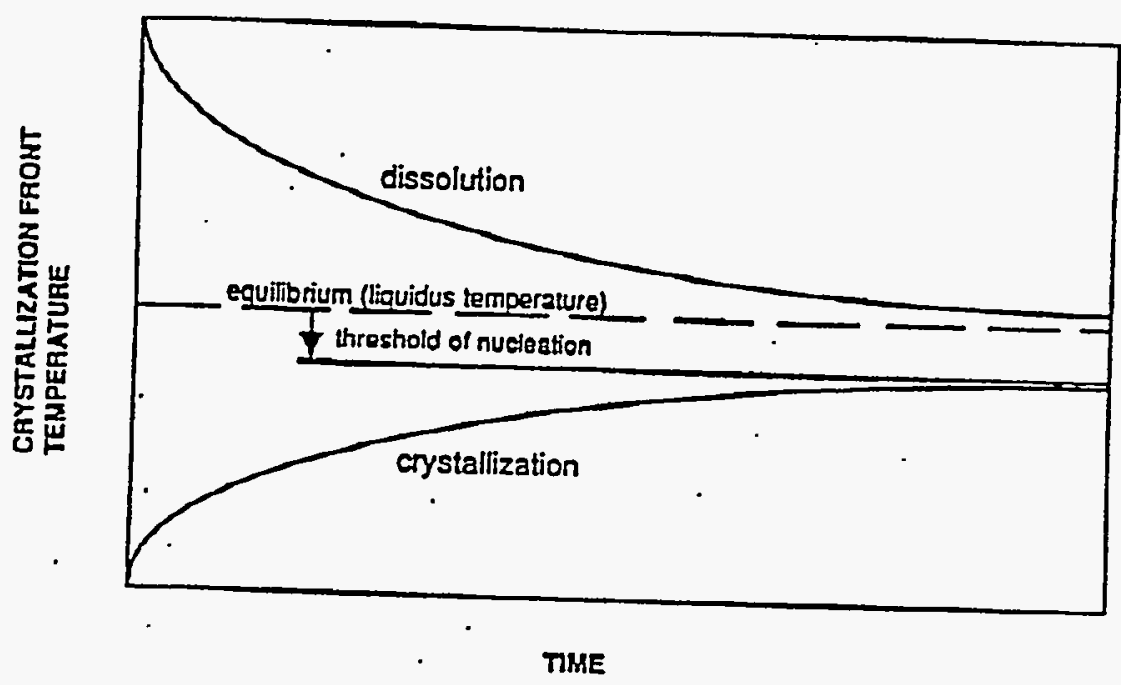

STANDARD GLASS CRYSTALLIZATION FRONT

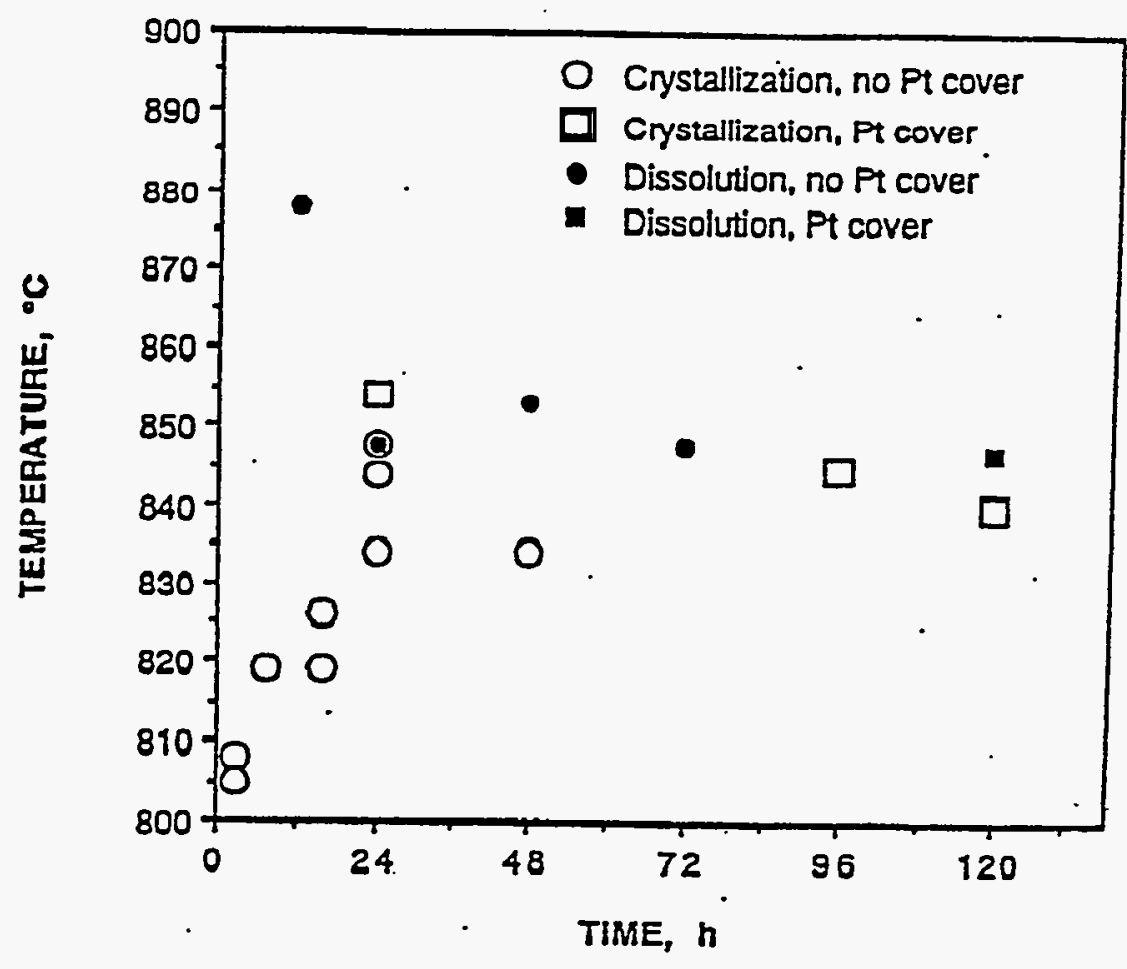


- Modelling:

Liquidus temperature is modelled using free energy estimation techniques. For a given melt composition, the free energy is estimated. That energy is then compared to the energy of crystalline phases in the melt as a function of temperature. The point at which the energy of the melt is equal to that of the crystalline phase $(\Delta G=0)$ is $T_{L}$. This generally doesn't include estimates of surface energy contributions or effects of composition fluctuations within the melt.

The regular solution theory leads to the most commonly used models of free energy of mixtures (such as glass melts). A regular solution is one which follows the simplified relationship:

$$
G^{E}=X_{A} X_{B}(\omega-\eta T)
$$

where $\omega$ and $\eta$ are constants independent of temperature (they analog to excess enthalpy and entropy of mixing). Strictly, this estimation assumes substitutional solution of components with like charge, coordination, and size such that there is no configurational entropy change and bond energy is the some of nearest neighbor (NN) pairs (independent of $T$ and composition). In this case, excess energy is due to the enthalpy of mixing, which is assumed to be the average of the change in NN bond energy.

According to the regular solution theory, the activity coefficient is given as a polynomial of composition:

$$
\mathrm{g}_{\mathrm{A}}^{\mathrm{R}}=\mathrm{X}_{\mathrm{B}}^{2}(\omega-\eta \mathrm{T})=\mathrm{RT} \ln \gamma_{\mathrm{A}}
$$

Constant temperature estimates of excess free energy consider only $\omega$ which can be estimated by bond strength, deduced from thermodynamic data, or fit empirically.

For ionic solutions, $X_{i}$ is taken as charge equivalents rather than mole fractions and second NN interactions are important. A "quasichemical model" (QCM) has been proposed as an extension of the regular solution theory for free energy prediction in oxide and salt melts.

The QCM assumes that second NN's are like charged and can segregate according in the interaction energy. A quasi-chemical reaction is written such as:

$$
\mathrm{X}_{\mathrm{AA}}+\mathrm{X}_{\mathrm{BB}} \Leftrightarrow 2 \mathrm{X}_{\mathrm{AB}}
$$


with a reaction constant $\mathrm{k}$ given by:

$$
k=\frac{X_{A B}^{2}}{X_{A A} X_{B B}}=4 \operatorname{Exp}\left[-\frac{2(\omega-\eta T)}{Z R T}\right]
$$

The excess energy terms $\omega$ and $\eta$ are of the form:

$$
\omega_{i j}=\omega_{0(i j)}+\omega_{1(j)} X_{j}+\omega_{2(i j)} X_{j}^{2}+\omega_{3(i j)} X_{j}^{3}+\ldots
$$

where $\omega_{\mathrm{ij}}$ are obtained from least squares fitting of binary phase diagrams. The extension of these terms to ternary and higher system requires development out of the scope of this discussion (see literature on quasichemical model).

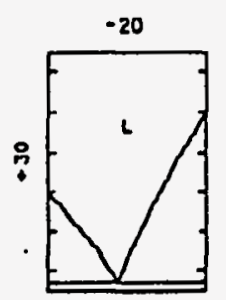

(a)

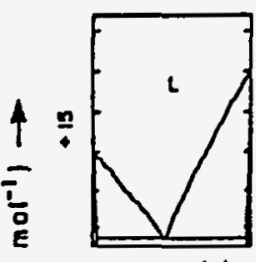

(1)

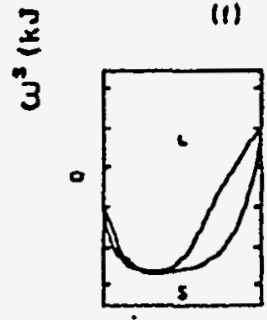

(I)

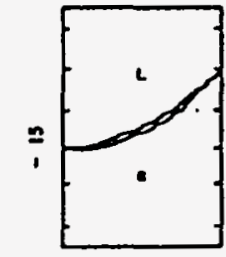

(p)

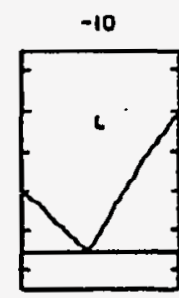

(a)

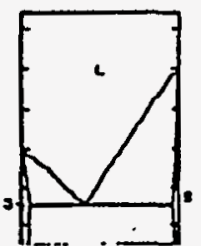

(o)
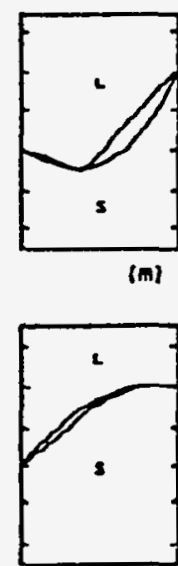

(q) $\omega^{r}\left(k J \mathrm{~mol}^{-1}\right) \rightarrow$

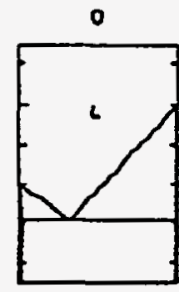

(e)

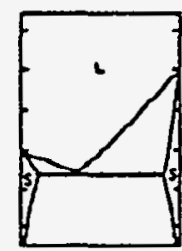

(h)

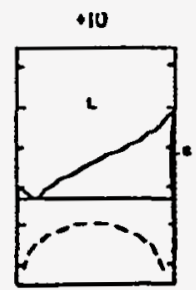

(4)

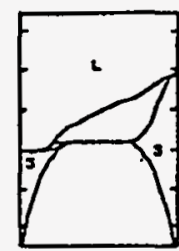

(i)
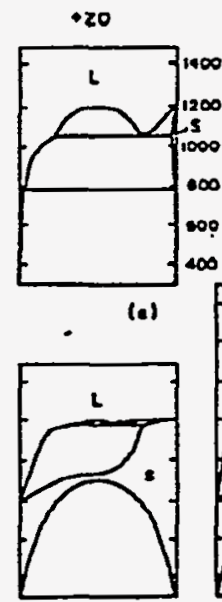

(i)
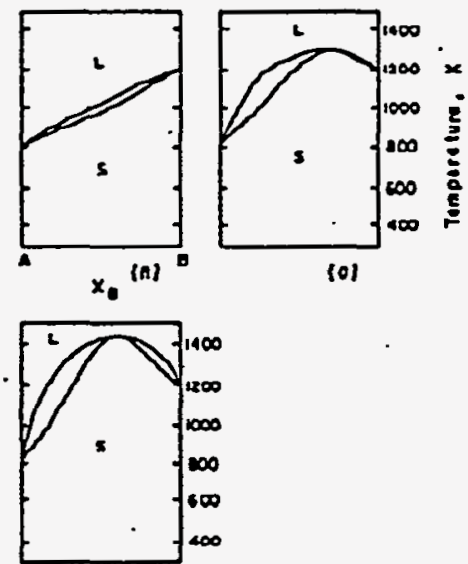

(r)

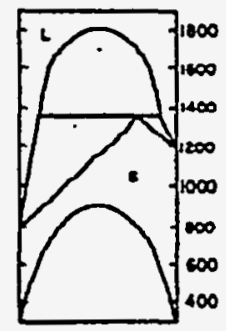

(k)

Figure 1-14. Topological changes in the phase diegram for a syctem A. B with regular solld and liquid phases. brought about by systematic changes in the reguiar solution parameters $\omega^{*}$ and $w^{\prime}$. Melting points of pure $A$ and $B$ are $800 \mathrm{~K}$ and $1200 \mathrm{~K}$. Entropies of fusion of both $A$ and $B$ are $10.0 \mathrm{~J} / \mathrm{mol} \mathrm{K}$ (Pclion and Thompson. 1975). Dolted curve in panel (d) is metastable liquid-liquid miscibility gap (Reprinted from Pelton, 1983). 


\section{- Nuclear Waste Glass}

The QCM has been successful in the prediction of multi-component phase diagrams of simple systems. HLW glass however contains $30+$ components many of which are not commonly found in thermodynamic data or in nature for that matter. An additional complication is the effect of oxygen activity in the HLW glass melt. Transition elements such as $\mathrm{Cr}, \mathrm{Fe}, \mathrm{Mn}, \mathrm{Ce}$ are active redox elements in the temperature and composition ranges considered.

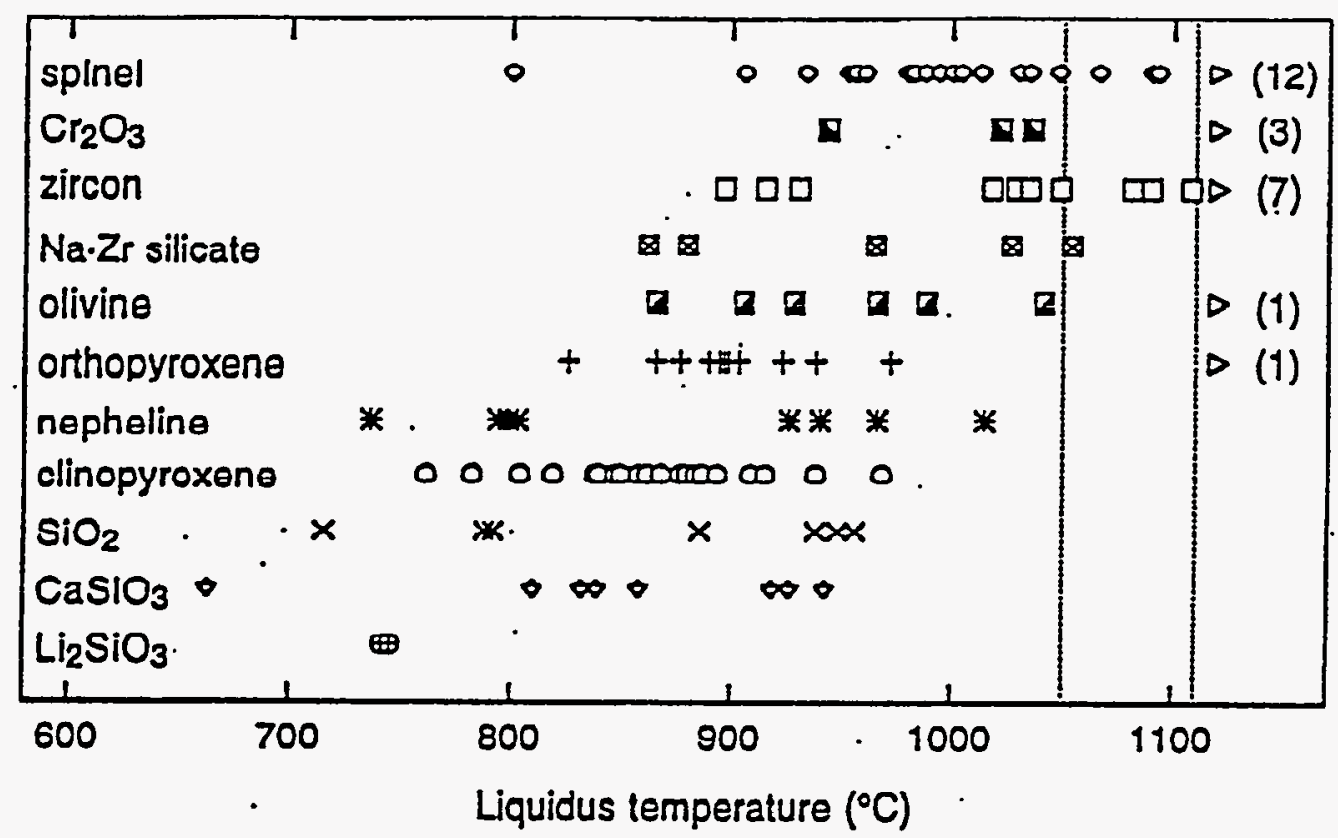

Several attempts have been made to predict $T_{L}$ in HLW glass:

- concentrations of limiting components (strict single and multiple component concentrations, component ratios, tree type models, ...)

- $\quad$ first-order models of some major components

- preliminary QCM's 


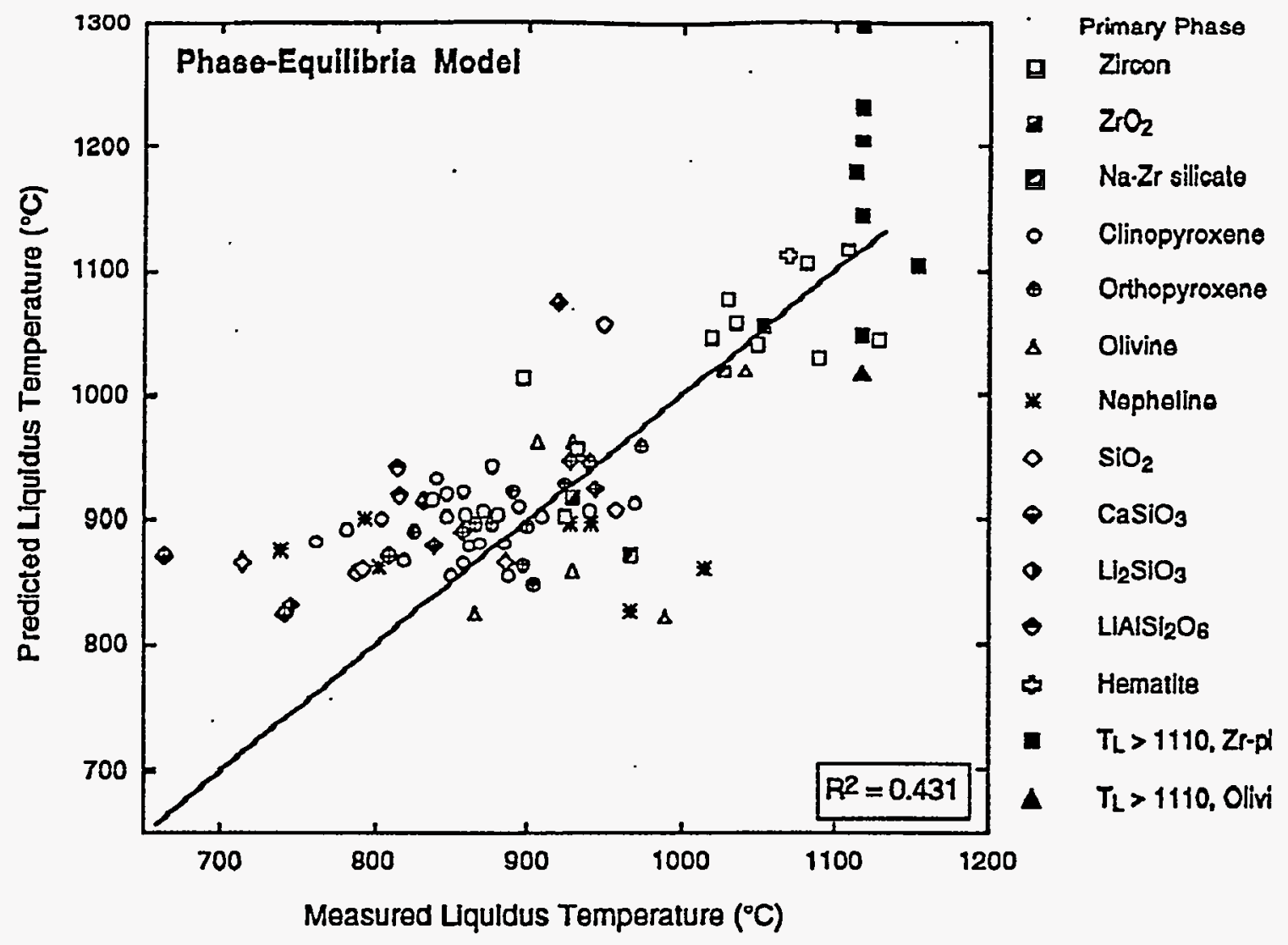




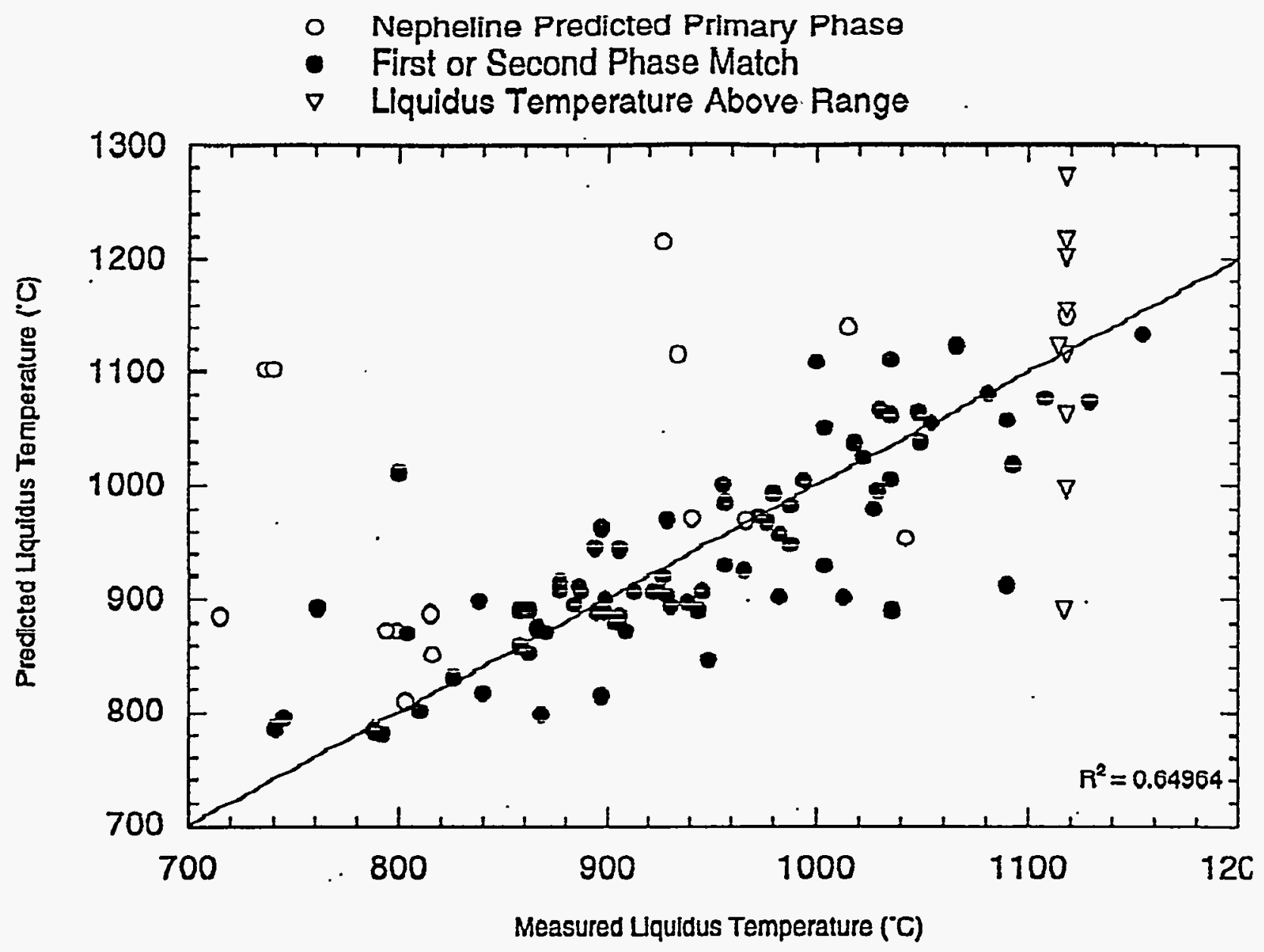

Nucleation and Growth:

- $\quad$ Classic Nucleation Theory

Crystallization occurs via a two stage process, nucleation and growth. Nucleation is the formation of a crystal "seed" large enough to be energetically stable. This nucleus then grows into a crystal.

Consider the formation of a spherical nucleus through random particle motion. As the nucleus forms the system free energy is lowered by:

$$
\Delta \mathrm{Gv}_{\mathrm{v}}=4 / 3 \pi \mathrm{r}^{3} \Delta \mathrm{g}_{\mathrm{v}}
$$

and raised by:

$$
\Delta \mathrm{G}_{\mathrm{S}}=4 \pi \mathrm{r}^{2} \gamma
$$

combining these terms leads to the following relationship between radius and 
energy:

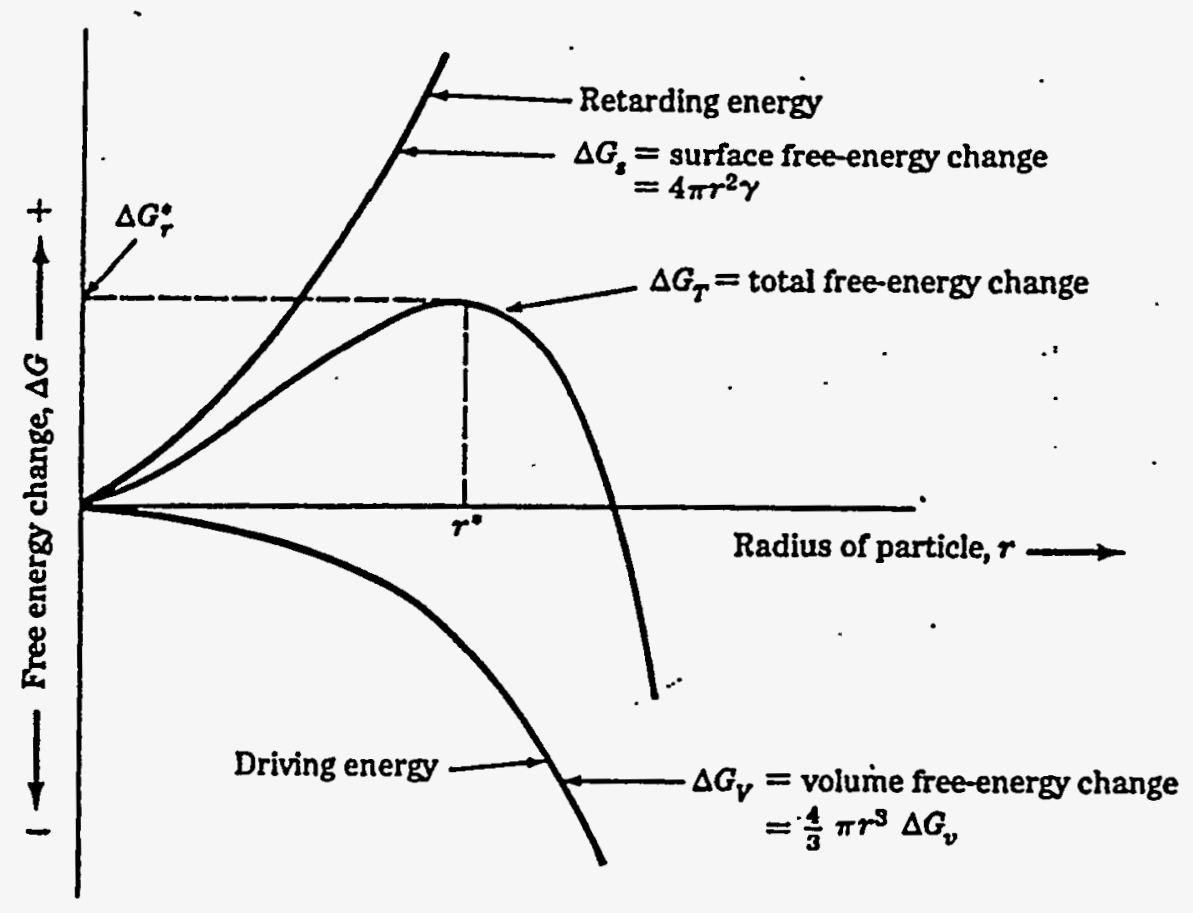

The critical radius $\left(\mathrm{r}^{*}\right)$ changes with under cooling according to:

$\mathrm{r} *=\frac{2 \gamma \mathrm{T}_{\mathrm{L}}}{\Delta \mathrm{H}_{\mathrm{f}} \Delta \mathrm{T}}$ 


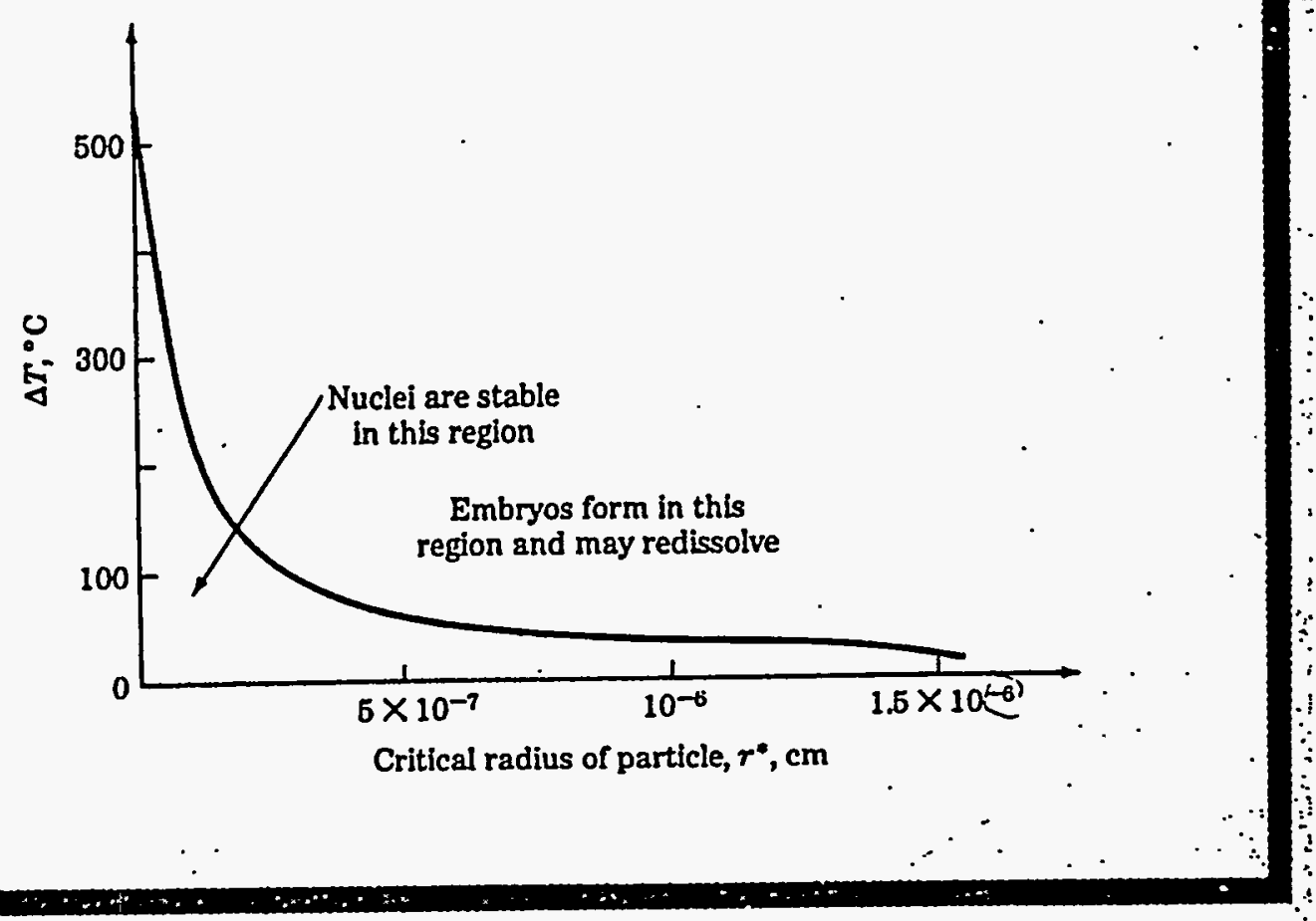

The rate of nucleation is proportional to the driving force and rate of particle motion. A commonly used equation for steady state nucleation is:

$$
I^{S S}=2 c n_{v} \frac{k T}{\eta} \operatorname{Exp}\left[\frac{\Delta G_{T}+Q_{D}}{k T}\right]
$$

where $Q_{D}$ is the activation energy for oxygen diffusion. For transient nucleation, the Zeldovitch-Frenkel theory must be applied:

$$
I=I^{S S}\left[1+2 \sum_{\alpha}(-1)^{\alpha} \operatorname{Exp}\left(\frac{-\alpha^{2} t}{\tau}\right)\right]
$$

where the time constant, $\tau$, is related to the free energy required to form a cluster of a given size and the attachment rate of atoms to the cluster.

The theory of nucleation in glass has held up very well to experimental results for simple glass systems which nucleate homogeneously. Examples of such systems are:

$\mathrm{BaO} \cdot 2 \mathrm{SiO}_{2}$

$\mathrm{Na}_{2} \mathrm{O} \cdot 2 \mathrm{CaO} \cdot 3 \mathrm{SiO}_{2}$ 


$\mathrm{CaO} \cdot \mathrm{Al}_{2} \mathrm{O}_{3} \cdot 2 \mathrm{SiO}_{2}$
$\mathrm{Na}_{2} \mathrm{O} \cdot \mathrm{SiO}_{2}$
$2 \mathrm{Na} \mathrm{Na}_{2} \mathrm{O} \cdot \mathrm{CaO} \cdot 3 \mathrm{SiO}_{2}$
$\mathrm{Li} 2 \mathrm{O} \cdot 2 \mathrm{SiO}_{2}$
$\mathrm{CaO} \cdot \mathrm{SiO}_{2}$
$\mathrm{Li}_{2} \mathrm{O} \cdot \mathrm{SiO}_{2}$
$\mathrm{Li}_{2} \mathrm{O} \cdot 2 \mathrm{~B}_{2} \mathrm{O}_{3}$

Homogeneous nucleation occurs in only a limited number of glass systems. Four 'rules of thumb' apply to glasses which nucleate homogeneously (Zanotto and Muller, 1991):

- Crystal composition must be close to that of glass matrix composition.

- Both cation and anion arrangements in glass are similar to those in the crystal.

- The reduced glass transition temperature $\left(T_{g} / T_{L}\right)$ is less than $0.6\left(T_{g}\right.$ is the glass transition temperature).

- The mass density of crystal must be similar to that of glass matrix.

A majority of glass systems (including nuclear waste glass) nucleate heterogeneously on impurity particles, surfaces, and/or areas of concentration fluctuations. Heterogeneous nucleation sites lower the thermodynamic barrier $\left(\Delta \mathrm{G}_{\mathrm{T}}{ }^{*}\right)$ by decreasing the surface energy associated with embryo formation. The change in thermodynamic barrier is a function of contact angle $(\varnothing)$ as follows:

$$
\Delta \mathrm{G}_{\mathrm{T}, \mathrm{h}}=\Delta \mathrm{G}_{\mathrm{T}} f(\varnothing)
$$

The surface factor $f(\varnothing)$ is a function of embryo shape. Given for a spherical cap geometry as:

$$
f(\varnothing)=(2+\operatorname{Cos} \varnothing)(1-\operatorname{Cos} \varnothing)^{2} / 4
$$

The contact angle is related to the surface energy of the glass - surface interface $\left(\gamma_{g s}\right)$, crystal or nucleus - surface interface $\left(\gamma_{s c}\right)$, and the crystal - glass interface $\left(\gamma_{c g}\right)$.

$$
\operatorname{Cos} \varnothing=\frac{\gamma_{g s}-\gamma_{s c}}{\gamma_{c g}}
$$

- Nucleating Agents: 
The above treatment assumes a flat surface or a very large radius of curvature for the substrate surface in relationship to $\mathrm{r}^{*}$. The thermodynamic barrier $\left(\Delta \mathrm{G}_{\mathrm{T}}^{*}\right)$ will increase if surface is concave downward (i.e. very small particle), reducing the ability to nucleate. Likewise, if the surface is concave upward (i.e. scratch or cavity), the ability to nucleate is increased. Hence, nucleation is more likely on large impurity particles.

Nucleating agents are added to glass in the manufacture of glass ceramics, and in the study of crystallization kinetics. Common agents used to nucleate crystals in glass are: $\mathrm{Au}, \mathrm{Ag}, \mathrm{Ti}, \mathrm{Pd}$, and Pt. In addition to nucleating agents, enhanced nucleation often occurs on interfaces of amorphous phase separation, chemical inhomogeneities, glass particle surfaces, and interfaces with crucible or melter walls.

- $\quad$ Nucleation in Waste Glass

Nuclear waste glass generally contains a large number of solid inclusions. These inclusions include noble metal particles, undissolved refractory oxides, and other crystals such as spinel. To predict the effects of nucleating agents on crystallization in the melter and canister, preliminary studies have been undertaken.

It was found that crystals nucleate on solid inclusions in simulated nuclear waste glass. Generally, the higher concentration of nucleation sites, the higher crystallinity in the glass after heat treatment. 


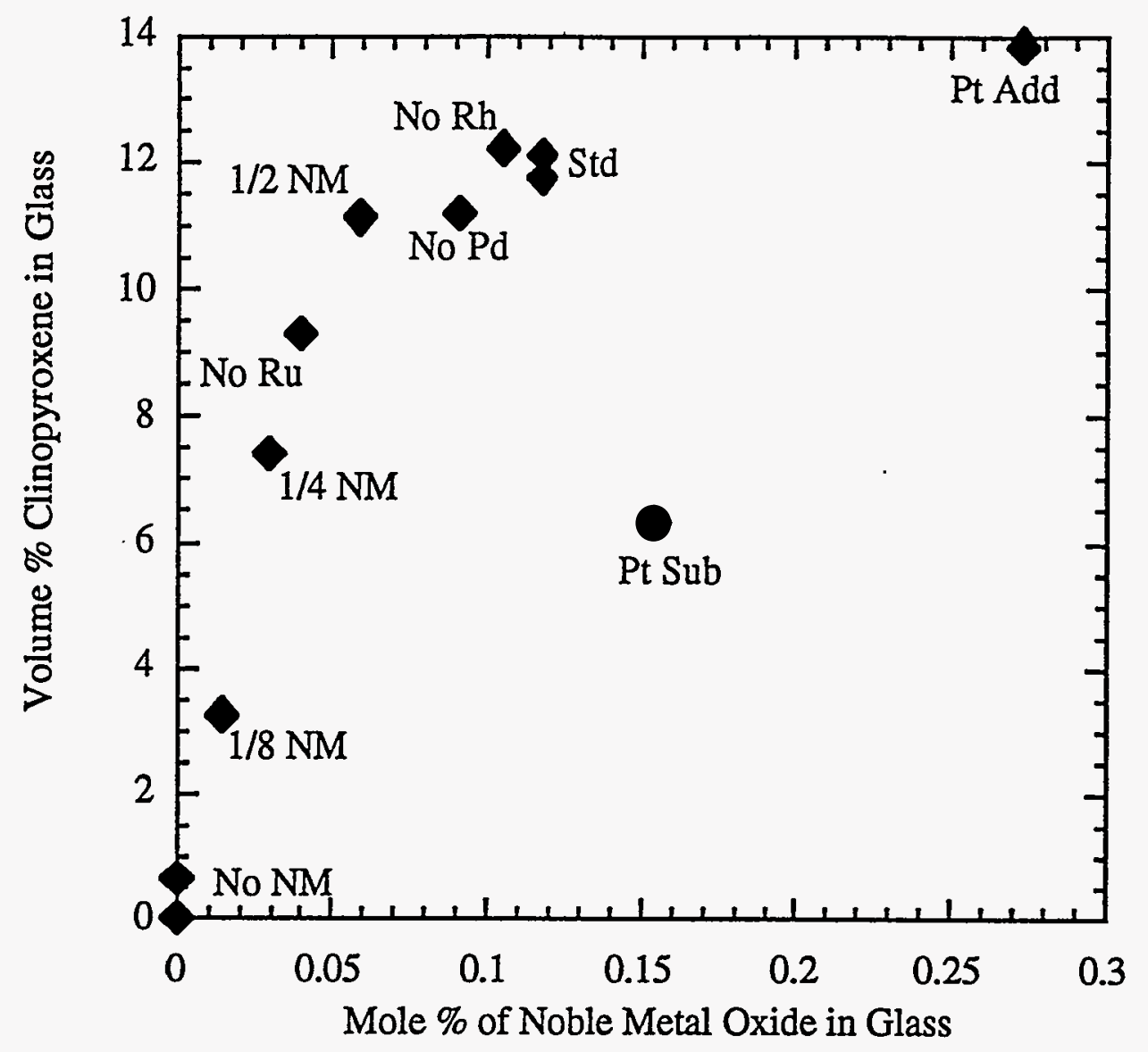

The tank waste will have varied amount of nucleating agents (such as noble metals). The size of nucleating agent agglomeration is an unknown which has been shown to change with time in the melter. These uncertainties coupled with uncertain effects of each agent causes complications in the characterization of crystallization rate in the melt.

The conservative approach is to assume a worse case scenario of unlimited nucleating sites. The above fig illustrates the effect of noble metal additions to the crystallinity of a simulated nuclear waste glass (HW39-4). As the picture shows an increase in crystallinity with increasing NM content. This increase levels off a relatively small NM concentration. Crystallinity testing can be conducted with the addition of 0.3 mole \% NM's to remove the effect of nucleating sites on crystallinity.

- Growth in Waste Glass

The growth of crystals in glass has been studied extensively for simple 
glasses. When crystal composition differs significantly from glass matrix composition growth is likely controlled by diffusion of the slowest glass component (needed for crystallization) to the crystal/glass interface. The rate of diffusion controlled growth can be described as follows:

$$
u=\frac{D}{\delta} \frac{C-C_{e}}{1-C_{e}}
$$

where $\mathrm{D}$ is the chemical inter-diffusion coefficient for the slowest species, $\delta$ is the interfacial boundary thickness, $\mathrm{C}$ is the concentration of that species the bulk liquid and $\mathrm{C}_{\mathrm{e}}$ is the equilibrium (liquidus) concentration.

Reasonable agreement between this model and experimental results confirm the theory of diffusion controlled growth in many component glasses. However, direct use of this model to the prediction of crystallinity in nuclear waste glass is prevented by the inability to accurately measure $\delta$ and by the fact that changing composition in both the matrix glass and the crystal affect $D$.

\section{Transformation in Waste Glass:}

\section{- Measurement:}

The measurement procedures for transformation of glass to crystal include both isothermal transformation kinetics which can be measured using a gradient furnace or isotherm furnace in which samples are heat treated isothermally at several temperatures for a range of times. The samples are then characterized for crystal volume fraction using OM and SEM with image analysis and/or XRD calibrated for quantitative measurements. An example of the measured isothermal transformation of HW39-4 is shown: 


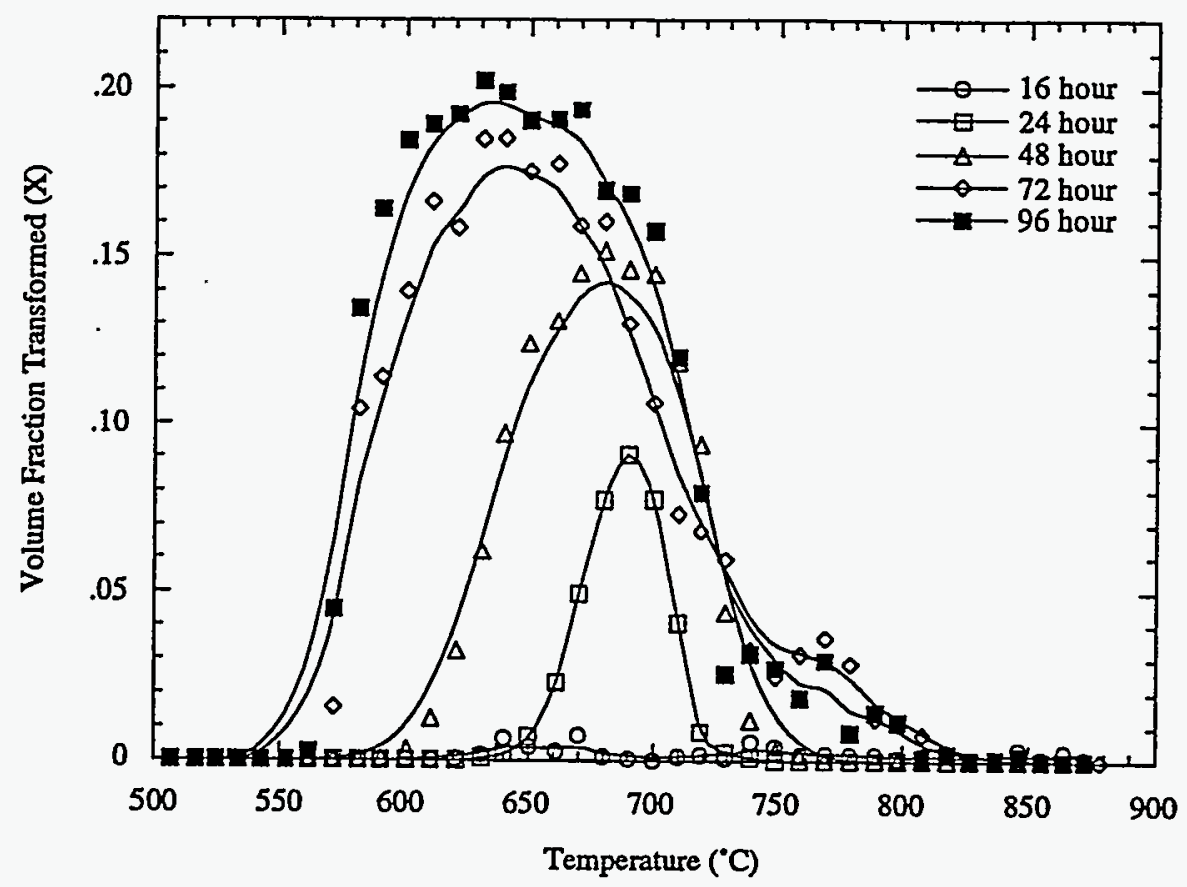

Nonisothermal transformations are measured in two common ways, the first way is to place the samples in a furnace with a scheduled heating or cooling rate. This rate can be constant (linear change in temperature with time), or logrithmic. Several samples are measured with varying rates and dwell times. Like the isothermal method, the samples are then analysed for crystal volume fraction. An example is given below: 


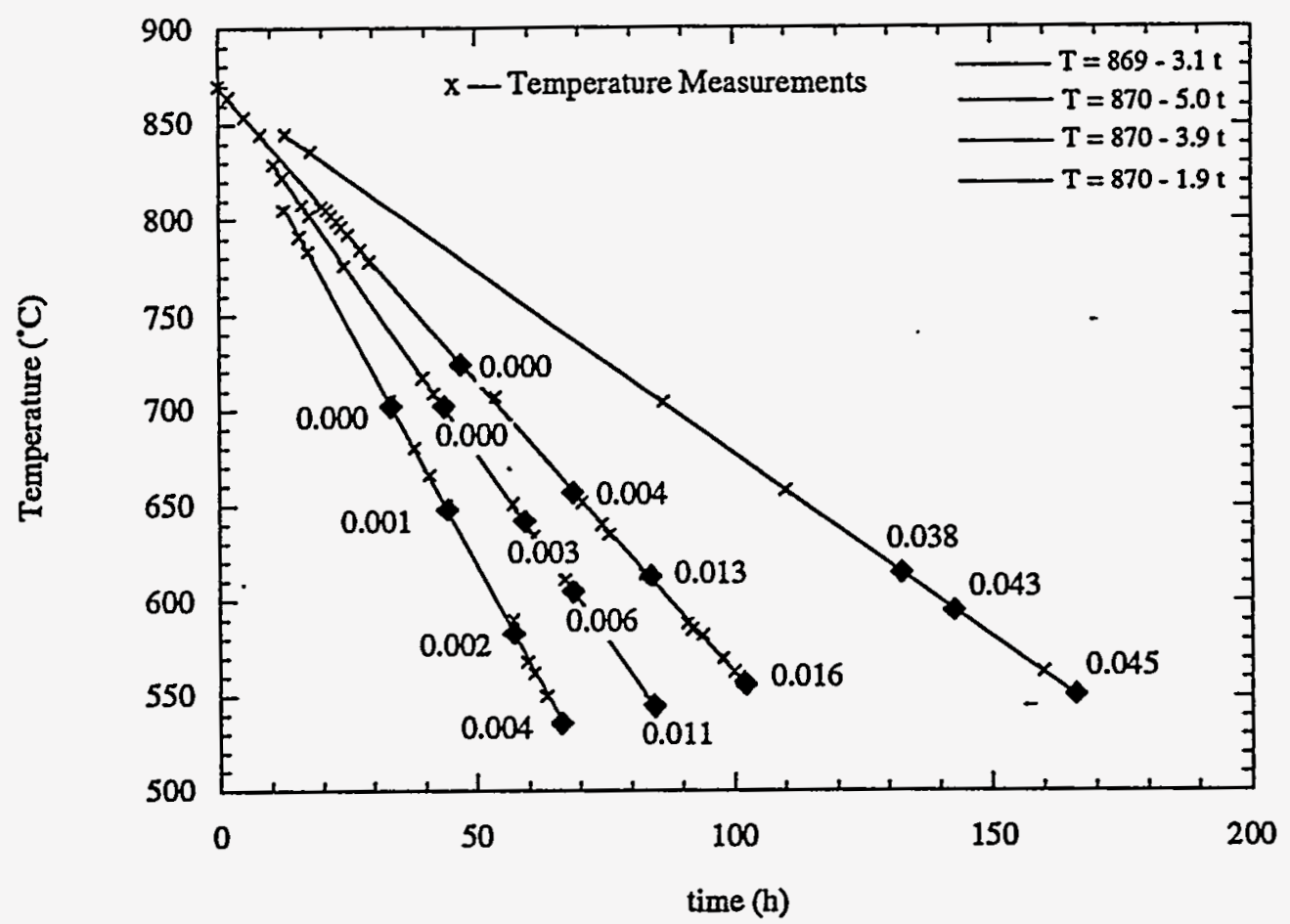

The second method to measure nonisotherm transformation kinetics entails the use of thermoanalytical devices (DSC and DTA). By this method, small samples are heated or cooled at constant rates while measuring the amount of enthalpy change in the sample. The crystallization exotherm is then characterized. The exotherm peak location and area are compared for samples with different rates. The total enthalpy (or peak area) is related to the amout of crystal formation and the peak location (measured as the temperature at the peak maximum) is related to crystallization rate.

For thourogh analysis of crystallization kinetics, the above methods should be combined. Isothermal kinetics can be used to estimate nonisothermal crystallization and vise versa for some glasses (depending on crystallization mechanisms). This will be shown in the next section.

\section{- Modelling}

Crystallization kinetic modelling generally follows the work of Johnson, Mehl, and Avrami. Johnson and Mehl developed a model based on the current theory of crystallization mechanisms to estimate the crystallization. The resulting model was successfully applied to experimental results with small volume fraction transformed but fell apart when the volume fraction increased. Avrami then modified their basic model by accounting for crystal impingement (both soft and hard impingement). The resulting model refered to as the Avrami model or 
Johnson, Mehl, Avrami model is the general basis of crystallization modelling today (with some exceptions) given here for three dimmesional growth:

$$
\frac{V_{C}}{V}=1-\operatorname{Exp}\left[-\int_{0}^{t} I_{V}\left(\int_{t^{\prime}}^{t} u d \tau\right)^{3} d t^{\prime}\right]
$$

This model cannot generally be solved analytically. Ulhmann and others give examples of numeric solutions to the model. By assuming simply activated growth and nucleation kinetics the model has been integrated for isothermal crystallization to yield:

$$
\frac{\mathrm{V}_{\mathrm{C}}}{\mathrm{V}}=1-\mathrm{e}^{-(\mathrm{Kt})^{\mathrm{n}}}
$$

where $\mathrm{K}$ is the kinetic parameter and $\mathrm{n}$ is the time exponent (better known as the Avrami number). The Avrami number is related to the mechanism of crystallization as follows:

\section{Values of ' $n$ ' for different growth and nucleation conditions}

(DR MacFarelane \& M Fragoulis, "Theory of devitrification in multi-component glass forming systems under diffusion control," Phys. Chem. Glass. 27[6] 1986.

Crystallization Mechanism Diffusion Interface

Constant nucleation rate

3-dimensional growth

2-dimensional growth

1-dimensional growth

$5 / 2$

$3 / 2$

$1 / 2$

Constant particle number

3-dimensional growth

2-dimensional growth

1-dimensional growth

Surface nucleation
$3 / 2$

$2 / 2$

$1 / 2$

$1 / 2$
4

3

2

Although the assumptions implicit in the integrated rate equation above are very restrictive in the temperature and time dependance of $\mathrm{K}$ (see Uhlmann or Weinberg), the use of this model form for emperical modelling has been 
successfully demonstrated and is promising for use with nuclear waste glass.

The temperature dependence of $\mathrm{K}$ and the transformation of this kinetic factor to nonisothermal testing is the subject of controversy. Experience has shown (see results) that $\mathrm{K}$ can be assumed to depend on temperature in an Arrenius mannor:

$$
\mathrm{K}=\mathrm{K}_{0} \operatorname{Exp}\left(\frac{\mathrm{B}_{\mathrm{K}}}{\mathrm{T}}\right)
$$

Theoretically, the value of B combines the enthalpy of crystallization, the activation energy for viscous flow, the temperature dependance of 'jump frequency at the glass crystal interface, and several other physical factors. Practically, this value can give insight to which mechanism dominates crystallization.

$\mathrm{K}$ and $\mathrm{n}$ are commonly assumed to be time independent this is not always the case with 'real' crystallization results. These assumptions can be used to very closely estimate crystallinity.

The relationship between isothermal and non-isothermal crystallization kinetics was explored by Grange and Keifer who successfully applied an empirical approach. Assuming Arrhenian growth kinetics, several experimenters have employed non-isothermal thermoanalytic methods to describe crystallization. The following equation is used for non-isothermal kinetics following the work of MacFarlane and Fragoulis who assumed Arrhenius approximation for $u$ and its integral, and $\mathrm{k}$ is independent of $\mathrm{t}$.

$$
\frac{\mathrm{V}_{\mathrm{C}}}{\mathrm{V}}=1-\operatorname{Exp}\left(-\left(\frac{\Theta_{0}}{\Theta}\right)^{\mathrm{n}} \operatorname{Exp}\left[-\frac{(\mathrm{n}-1) \mathrm{B}_{\mathrm{K}}}{\mathrm{T}}\right]\right)
$$

where $\Theta_{0}$ is a constant and $\Theta$ is the linear temperature rate.

- Results for a Simulated Nuclear Waste Glass

To calculate $X_{\mathrm{e}}$, plots of $X$ vs. $\ln (t)$ are constructed at each temperature. The crystal volume fractions approach the equilibrium value as $\ln t$ goes to infinity

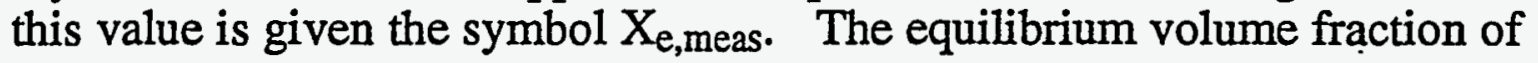
crystals is related to temperature according to:

$$
\frac{\mathrm{X}_{\mathrm{e}}}{\mathrm{X}_{\mathrm{e} 0}}=1-\operatorname{Exp}\left[-\mathrm{B}_{\mathrm{Xe}}\left(\frac{1}{\mathrm{~T}}-\frac{1}{\mathrm{~T}_{\mathrm{L}}}\right)\right]
$$


where the equilibrium factor $\left(\mathrm{B}_{\mathrm{Xe}}\right)$ and $\mathrm{T}_{L}$ are calculated from a plot of $\ln (1-$ $\mathrm{X}_{\mathrm{e}, \text { meas }}$ ) vs. $1 / \mathrm{T}$. The observed values of $44,302 \mathrm{~K}$ for $\mathrm{B}_{\mathrm{Xe}}$ and $1,004 \mathrm{~K}$ for $\mathrm{T}_{\mathrm{L}}$ are taken from the slope and intercept of this data (assuming the occlusion of the high temperature high chromium 'shoulder'). $\mathrm{X}_{\mathrm{e} 0}$ is the equilibrium volume fraction of crystal at room temperature measured by the extension of the $X_{e, m e a s}$ data to room temperature and was determined to be 0.203 . The equilibrium fraction transformed is shown in Figure 3. A thermodynamic model (FACT ${ }^{\mathrm{TM}}$ ) has also been used to predict $\mathrm{X}_{\mathrm{e}}$ of acmite in HW39-4 glass. 26 The thermodynamic calculation of $\mathrm{B}_{\mathrm{Xe}}(48,380 \mathrm{~K})$ matches closely that measured, however the calculated $\mathrm{T}_{\mathrm{L}}(1,148 \mathrm{~K})$ is higher.

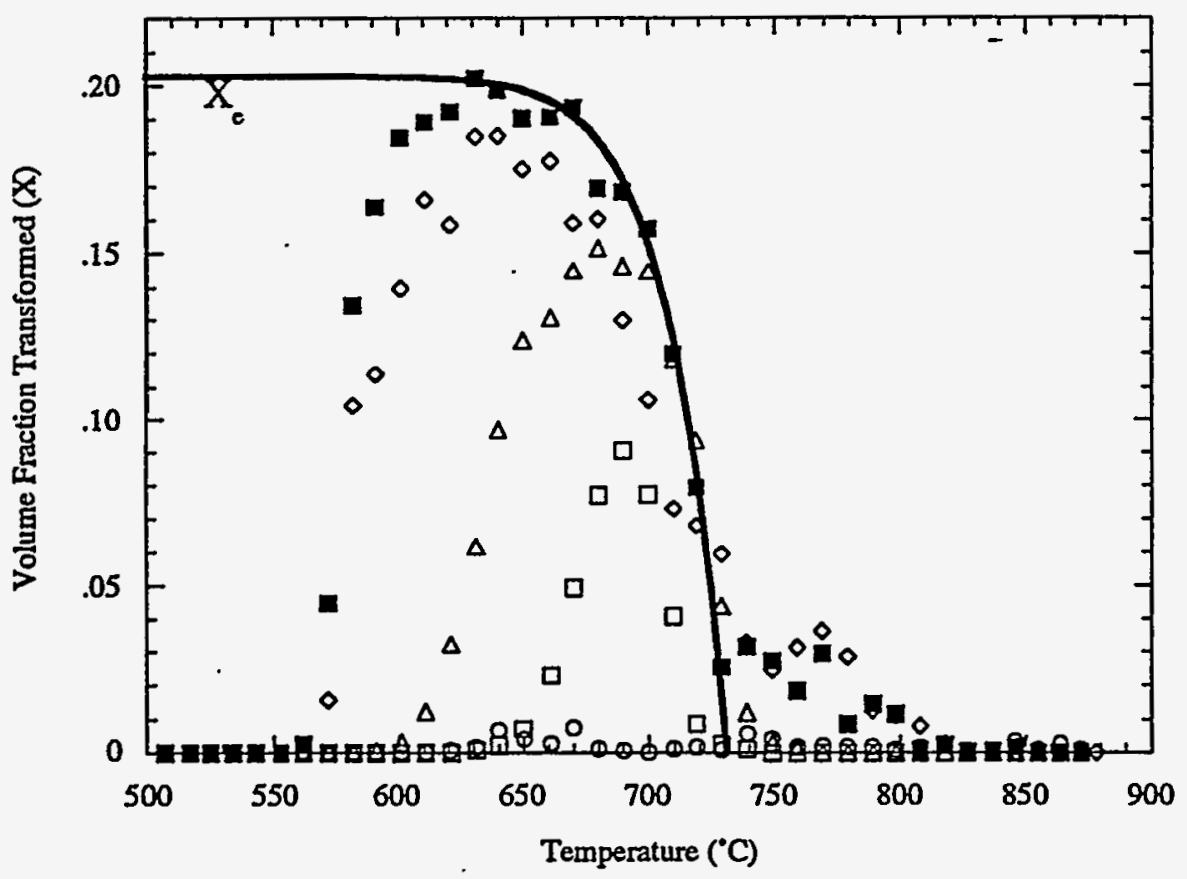

Many glasses including HW39-4 show a very distinct induction time $(\sigma)$ for crystallization. This induction time is estimated by the extrapolated intercept of the linear portion of $\xi$ vs. In $t$ curves as described by Weinberg.27 Effectively $\sigma$ is a combined effect of the induction time for nucleation and for growth. It was shown by Weinberg that this induction time is not uniquely determined and is dependent on experimental conditions. 26 In the case of HW39-4, $\sigma$ is Arrhenian in nature (as seen in Figure 4 ) with a preexponential $\sigma_{0}$ of $1.845 \times 10-3$ and a temperature coefficient $\mathrm{B}_{\sigma}$ of $15,600 \mathrm{~K}$ : 


$$
\sigma=\sigma_{0} \operatorname{Exp}\left(\frac{\mathrm{B}}{\mathrm{\sigma}}\right) .
$$

The relationship between $\sigma, t^{\prime}$, and $t$ follows:

$$
\mathrm{t}=\mathrm{t}^{\prime}-\sigma
$$

where $t$ ' is the time each sample is exposed to heat treatment temperature and $t$ is the effective time used in Avrami equation.

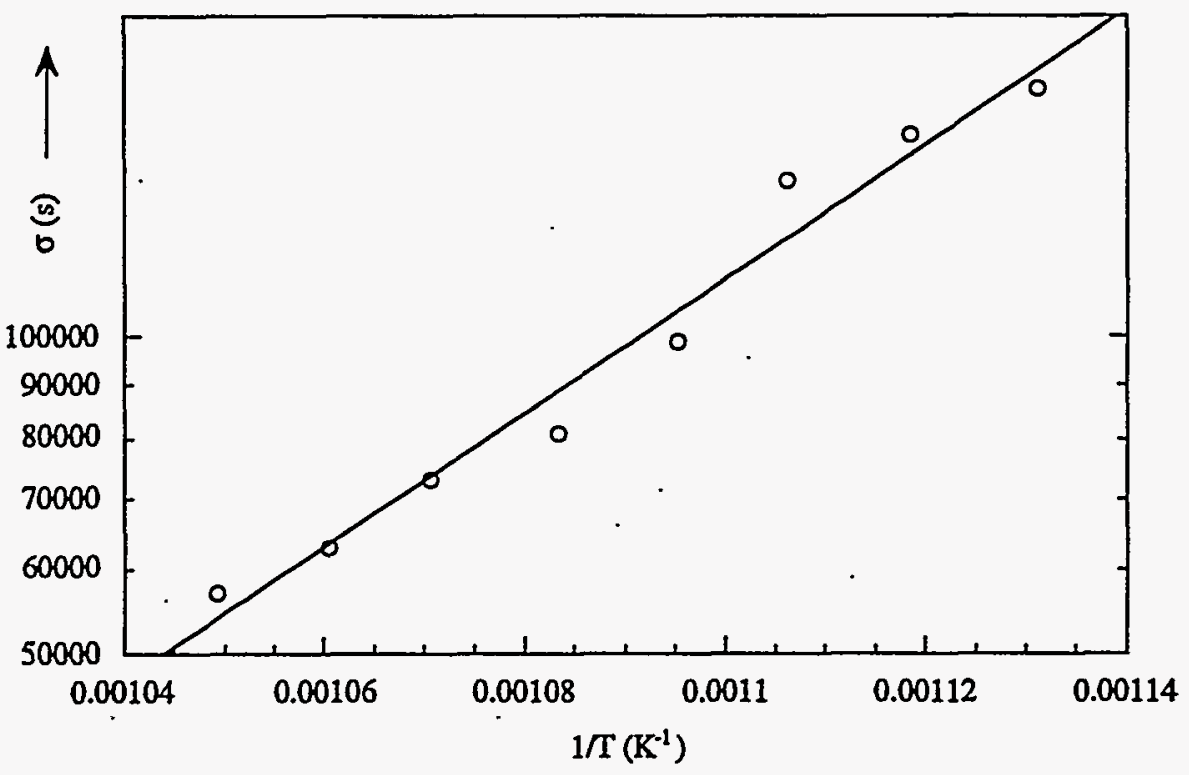

The Avrami number (n from eqns. 1, 2, and 5) is calculated from the slope of $\ln (-\ln (1-\xi))$ vs $\ln (t)$ plots at constant temperature. Using this method, an average value of 2.52 was calculated for $n$. Assuming three dimensional diffusion controlled growth with constant nucleation, the corresponding theoretical $\mathrm{n}$ value is 2.5 (this value is used in calculations shown here).

The kinetic constant $(k)$ is then calculated from plots of $\ln (-\ln (1-\xi))$ vs $1 / \mathrm{T}$ at constant times. From this treatment, $\mathrm{nB}_{\mathrm{k}}$ is given as the slope of each curve. Using 2.5 as $\mathrm{n}$, b was found to be $5848.9 \mathrm{~K}$ and $\mathrm{k}_{0}$ was fit by standard non-linear fit methods (using least squares of $X$ predicted vs $X$ measured) to be $4.92 \times 10^{-3} \mathrm{~s}^{-}$ 1. 
The following figure shows a comparison of predicted and measured crystallinity.

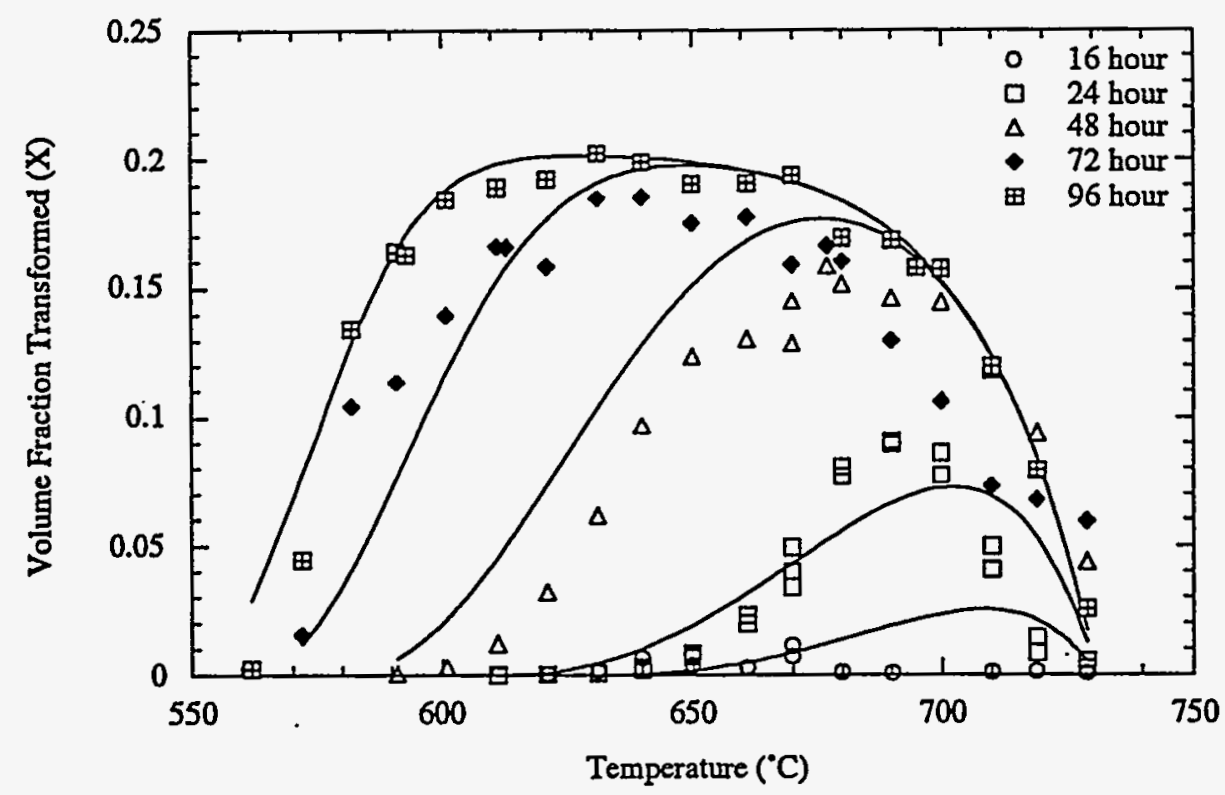

Using the characteristic temperature value $\left(B_{k}\right)$ from isothermal kinetics, the non-isothermal data was fit to the nonisothermal equation. The value $A$ is fit by standard non-linear fit methods (using least squares of $X$ predicted vs $X$ measured) of all non-isothermal crystallinity data. Also shown on the plot are the extreme outside boarders of predicted vs. measured $X$ calculated from $A$ values fit to only one non-isothermal $X$ point at a time. From the narrow range outlined by these two lines it can be seen that kinetic parameters fit to isothermal crystallization data can be used to predict nonisothermal crystallization. 


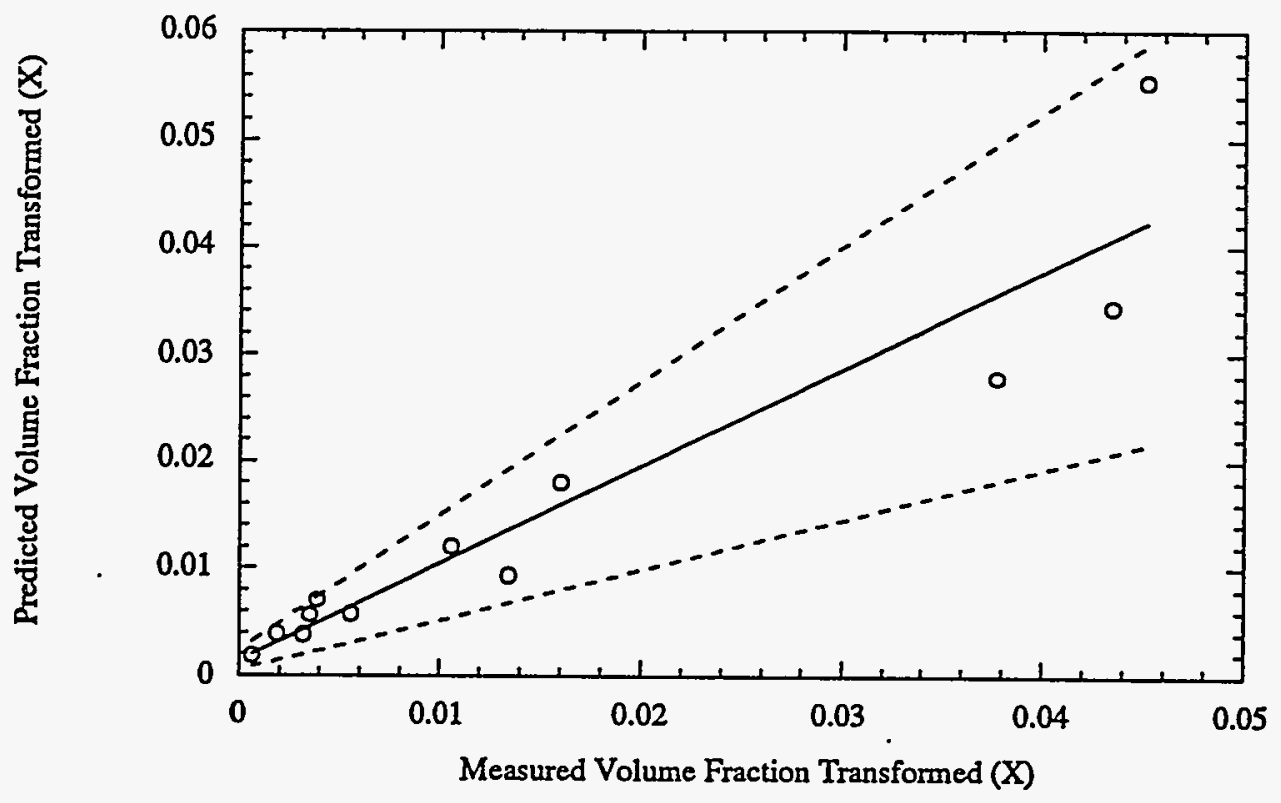

The affect of simple temperature histories (isothermal and constant cooling rate) on volume fraction of crystals can be predicted using classical model forms fit empirically to experimental data covering the representative range of time and temperature. Isothermal crystallinity data were successfully used to fit the characteristic temperature term in a non-isothermal kinetics equation. TTT diagrams were constructed from both. 


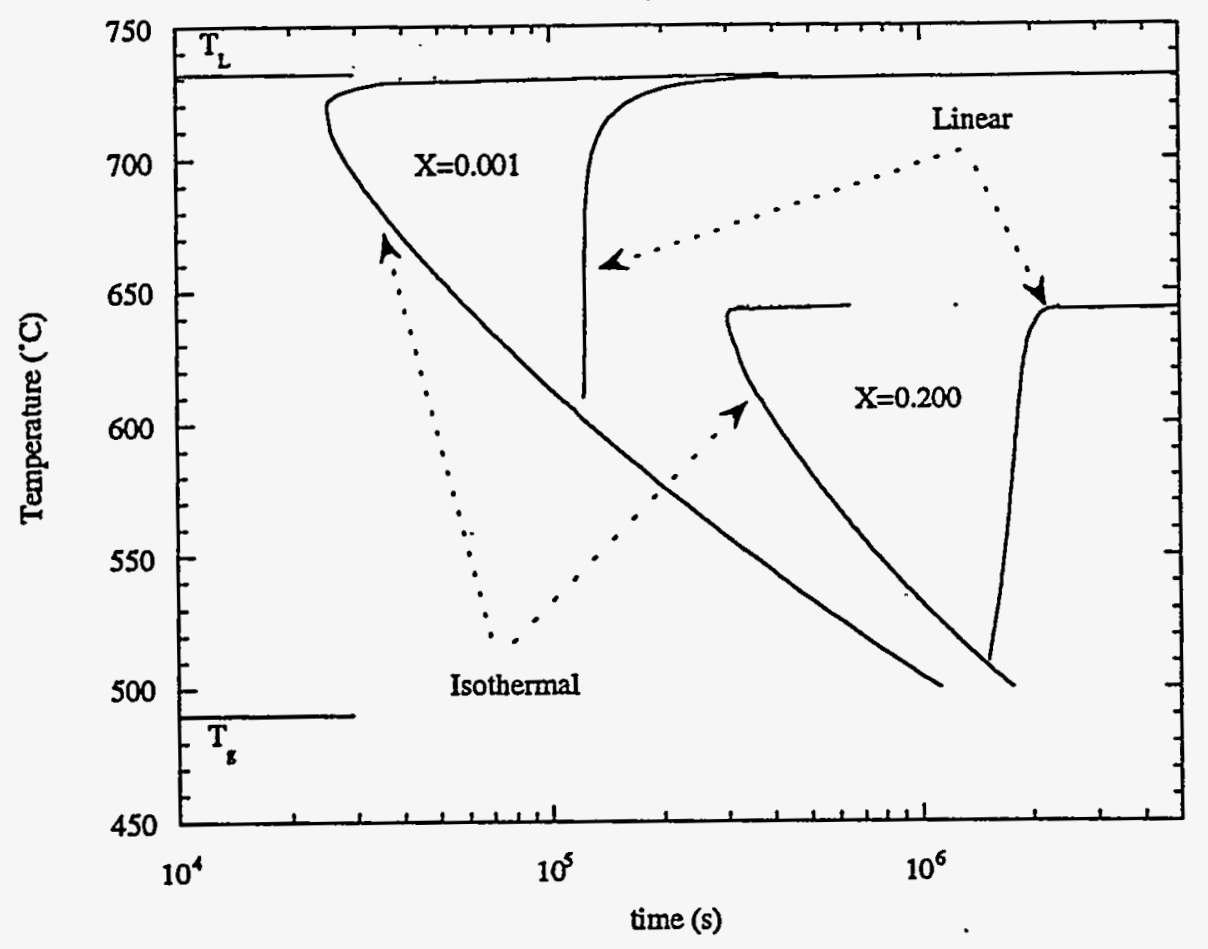

The above figure shows both isothermal and nonisothermal TTT diagrams for acmite in HW39-4 glass. This diagram can be used to estimate the amount of crystallinity in a sample heat treated for a known rate for any given time. The use of this diagram and the Avrami equation used to fit it will give quantitative crystal fractions as a function of temperature and time held at elevated temperatures either in the glass plant or in a geological repository.

\section{Useful References:}

- Thermodynamics

JW Gibbs, "The Collected Works," Green \& Co. (1931).

DR Gaskell, "Introduction to Metallurgical Thermodynamics," McGraw Hill (1981).

CHP Lupis, "Chemical Thermodynamics of Materials," Prentice Hall (1983).

GM Barrow, "Physical Chemistry," McGraw Hill (1988).

LS Darken and RW Gurry, "Physical Chemistry of Metals," McGraw Hill (1953). 
- Liquidus Temperature

CG Bergeron and SH Risbud, "Introduction to Phase Equilibria in Ceramics," Amcerican Ceramic Soc. (1984).

P Haasen, "Materials Science and Technology Vol 5.: Phase Transformations in Materials," VCH Publishers (1991).

K.-S. Kim and P. Hrma, "Models for Liquidus Temperature of Nuclear Waste Glasses," Ceram. Trans. 45, 327-337 (1994).

P. Hrma, G. F. Piepel, M. J. Schweiger, D. E. Smith, D.-S. Kim, P. E. Redgate, J. D. Vienna, C. A. LoPresti, D. B. Simpson, D. K. Peeler, and M. H. Langowski, "Property/Composition Relationships for Hanford High-Level Waste Glasses Melting at $1150^{\circ} \mathrm{C}$," PNL-10359, Vol. 1 and 2, Pacific Northwest Laboratory, Richland, Washington (1994).

- Nucleation

JW Christian, "The Theory of Phase Transformations in Metals and Alloys," Pergamon Press (1965).

PIK Onorato and DR Uhlmann, "Nucleating Heterogeneities and Glass Formation," J. Non-Cryst. Sol. [22] 367-78 (1976).

JW Cahn and JE Hillard, "Free Energy of a Nonuniform System. III. Nucleation in a Two-Component Incompressible Fluid," J. Chem. Phys., [31] 688-99 (1959).

- Crystallization Kinetics

JW Christian, "The Theory of Phase Transformations in Metals and Alloys," Pergamon Press (1965).

J. D. Vienna, D. E. Smith, and P. Hrma, "Crystallization Kinetics in Nuclear Waste Glasses: A Modeling Approach," in preparation.

DR Uhlmann and H Yinnon, "The Formation of Glasses," in Glass Science and Technology, Vol 1, DR Uhlmann and NJ Kreidl eds., (1983).

M Weinberg and R Kapral, "Phase Transformation Kinètics in Finite Inhomogeneously Nucleated Systems," J. Chem Phys., [91] 7147-52 (1989).

JH Simmons, DR Uhlmain, and GH Beall, "Nucleation and Crystallization in 
Glasses," American Ceramic Society (1982). 


\section{STATISTICAL APPROACH TO GLASS DEVELOPMENT}

Greg Piepel \& Trish Redgate

Pacific Northwest Laboratory

Richland, Washington

presented at tutorial

"Waste Glass Technology for Hanford" June 27-28, 1995 


\section{OUTLINE}

$\star$ Statistics and its roles

$\star$ Statistics in glass development

$\star$ Experimental design

$\star$ Data analysis and property modeling

$\star$ Accounting for uncertainty

$\star$ Summary 


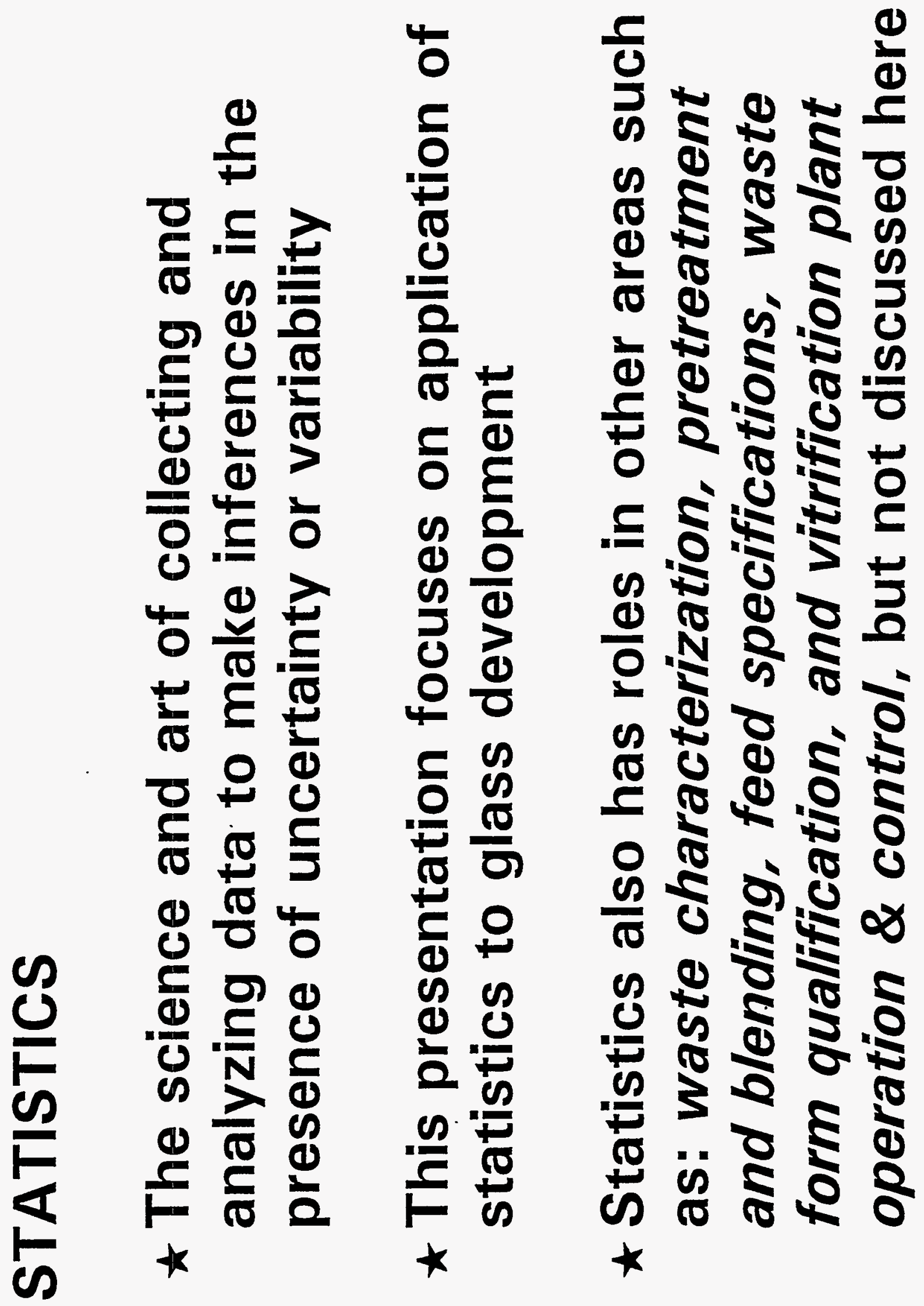




\section{VARIATIONS IN WASTE AND GLASS COMPOSITIONS}

$\star$ Waste feed compositions to HLW melter will vary considerably

$\star$ Glass compositions for different waste types will vary considerably

$\star$ For a given waste type, composition of glass will vary due to variations in feed and processing 


\section{COMPOSITION AND GLASS PROPERTIES}

$\star$ Changes in glass composition affect glass properties, e.g.

-- viscosity

-- electrical conductivity

-- liquidus temperature

-- solubility, crystallinity, and phase behavior

-- chemical durability 


\section{GLASS DEVELOPMENT}

$\star$ HLW glass systems are complex, and existing theory and knowledge are not sufficient for predicting glass properties as functions of composition (and temperature, where appropriate)

$\star$ Need to perform experiments and collect data to understand and relate glass properties to composition and temperature 


\section{GLASS DEVELOPMENT APPROACH}

* If waste types to be processed in melter were already "known", ideal approach would be to develop an "optimal" glass composition for each waste type

$\star$ Waste types not yet "known", and glass compositions expected to vary

* Composition Variation Study (CVS) or composition envelope approach used to provide basis for developing glasses over . a region of possible glass compositions 


\section{GLASS DEVELOPMENT APPROACH (cont.)}

Until waste types determined, strategy is to:

$\star$ Use CVS/composition envelope approach to study region(s) of potential glass compositions

$\star$ Formulate glasses for and perform some studies on selected "best-guess-at-thistime" waste compositions 


\section{GLASS DEVELOPMENT APPROACH (cont.)}

When waste types determined:

$\star$ Use "global CVS" results to select preliminary glass formulation for a waste type

$\star$ Perform "mini CVS" around preliminary glass formulation to confirm or fine-tune formulation and property models from "global CVS" 


\section{STATISTICS \& GLASS DEVELOPMENT}

$\star$ Statistical experimental design selects glass compositions to efficiently study dependence of glass properties on composition

$\star$ Statistical graphics and data analysis help interpret results given data uncertainty

$\star$ Statistical model development techniques provide for predicting glass properties for compositions and temperatures not experimentally tested 


\section{STATISTICS \& GLASS DEVELOPMENT}

(cont.)

$\star$ Glass property models and corresponding uncertainty expressions can be used to formulate (with high confidence) glasses with desired/acceptable properties

$\star$ Glass property models and uncertainty expressions can be used for other purposes besides glass development (e.g., waste pretreatment and blending, plant operation and control, waste form qualification) 


\section{MIXTURE EXPERIMENTS}

$\star$ A mixture experiment involves mixing components in various proportions and studying the effects of changing composition on properties of interest

$\star$ Proportions of mixture components sum to 1 (or percentages to $100 \%$ )

$\star$ Techniques for experimental design, data analysis, and modeling of mixture data in statistics literature since late 1950s 


\section{EXPERIMENTAL DESIGN STEPS}

* Select components to experimentally vary that will vary in waste glasses and affect glass properties

$\star$ Specify composition region of interest

-- Lower and upper bounds on components

-- Property constraints implemented via property models

-- Multicomponent constraints as necessary to eliminate undesirable combinations of components 


\section{EXPERIMENTAL DESIGN STEPS (cont.)}

$\star$ Statistically select compositions to:

-- adequately cover the (boundary and interior of) composition region of interest

-- study component or other variable effects of particular interest

-- support developing property models to minimize uncertainty of predictions

$\star$ Compositions selected via special software for statistical mixture experiment design and optimal experimental design 


\section{EXPERIMENTAL DESIGN (cont.)}

$\star$ Varying components many/all-at-a-time provides information about "average" effect of each component and information about interactions of components

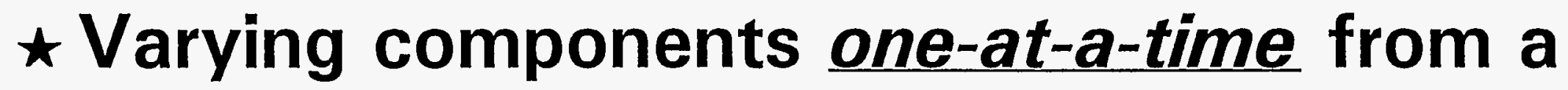
base composition provides information about the specific effects of components when added to or subtracted from the base composition 


\section{CVS (LTM) EXPERIMENTAL DESIGN}

$\star$ Designed in 5 phases, with results of earlier phases used to design later phases

$\star 147$ glasses, including 14 replicates

$\star$ CVS-I a 10-component screening study and 4 phases of CVS-II with same components

$\star$ Boundary and interior compositions

$\star$ Many-at-a-time, one-at-a-time, and special interest compositions 


\section{CVS (LTM) COMPONENT BOUNDS}

Component

$\mathrm{SiO}_{2}$

$\mathrm{B}_{2} \mathrm{O}_{3}$

$\mathrm{Na}_{2} \mathrm{O}$

$\mathrm{Li}_{2} \mathrm{O}$

$\mathrm{CaO}$

$\mathrm{MgO}$

$\mathrm{Fe}_{2} \mathrm{O}_{3}$

$\mathrm{Al}_{2} \mathrm{O}_{3}$

$\mathrm{ZrO}_{2}$

Others
Mass Fraction Bounds

\begin{tabular}{cc} 
Lower & Upper \\
\hline .42 & .57 \\
.05 & .20 \\
.05 & .20 \\
.01 & .07 \\
0 & .10 \\
0 & .08 \\
0 & .15 \\
0 & .17 \\
0 & .13 \\
.01 & .10
\end{tabular}

Also different property and multicomponent constraints were applied in the 5 phases 


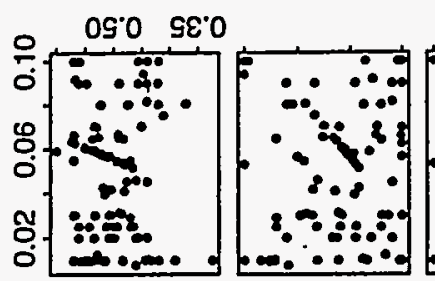

St.0 $90^{\circ} 0$

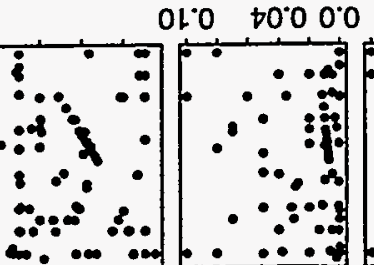

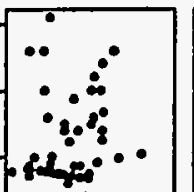

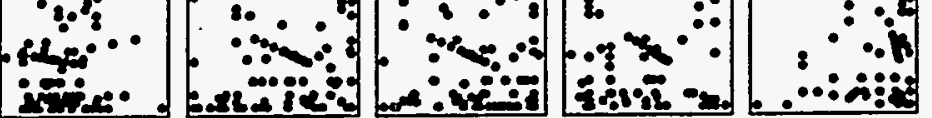

웅

뭉

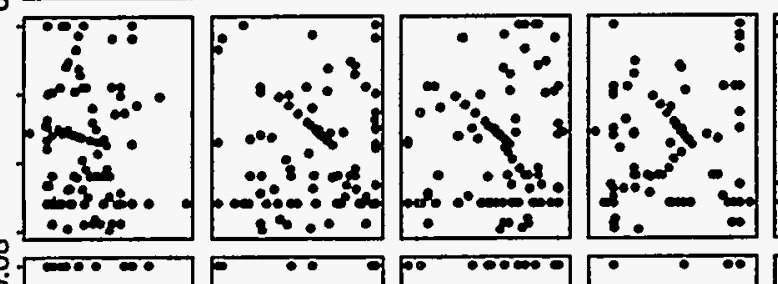

(1)
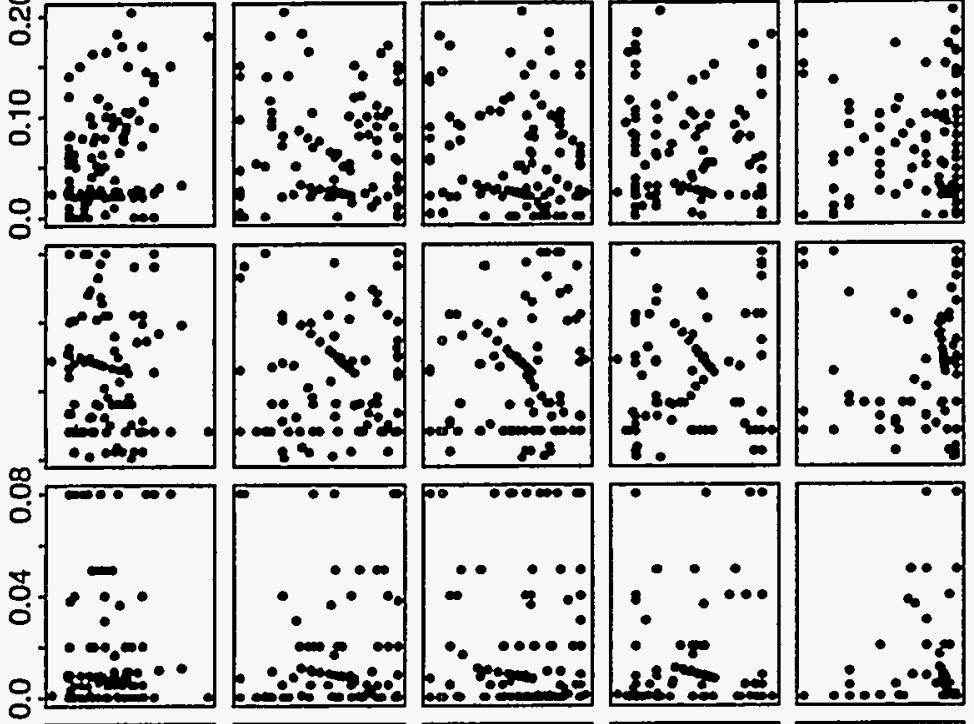
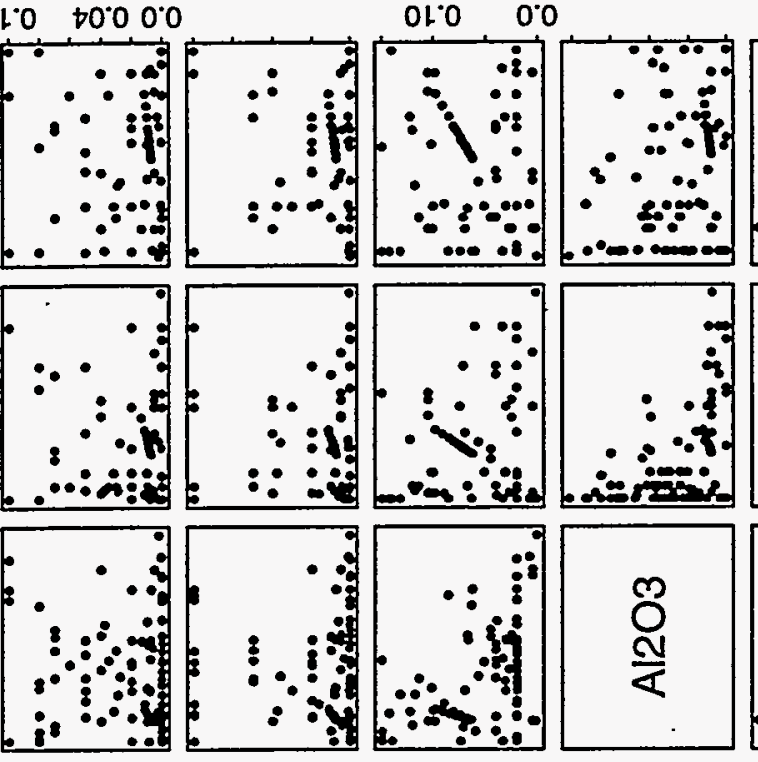

OL. 0.0
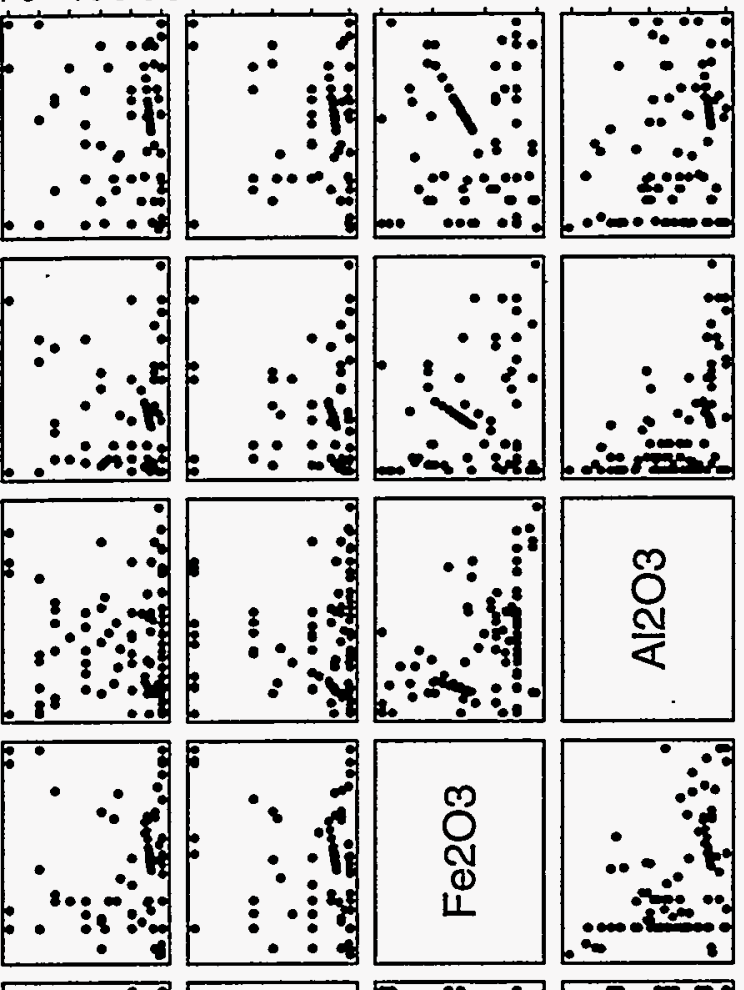

Dio: ind
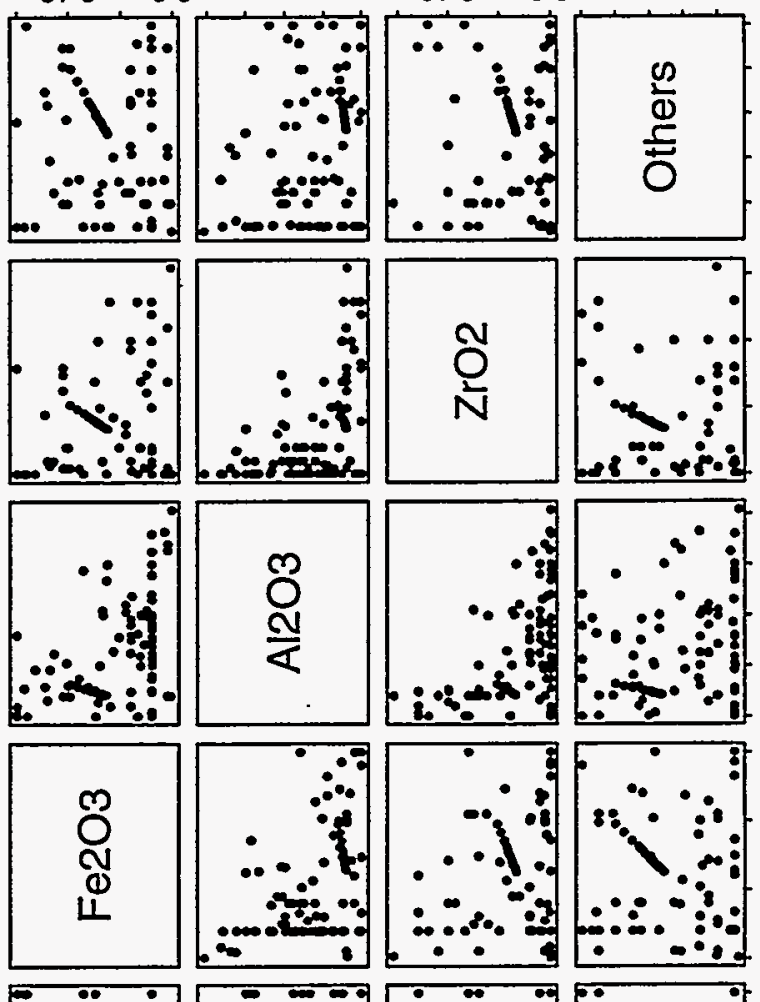

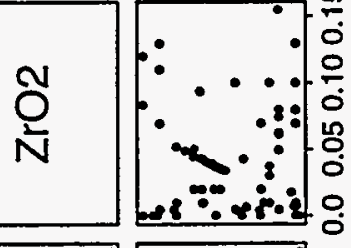

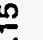




\section{STATISTICAL DATA ANALYSES}

$\star$ Assess outlying/influential data

$\star$ Compare target and analyzed glass compositions

$\star$ Quantify experimental uncertainty using replicate data

$\star$ Develop and validate property models and uncertainty expressions

$\star$ Compare empirical \& semi-empirical models 


\section{GLASS PROPERTY MODELING}

* Ideally, would prefer mechanistic models based on glass theory/structure/knowledge

$\star$ However, waste glasses are complex systems with many components, and the theory and knowledge is insufficient to yield such mechanistic models

$\star$ Consider empirical and semi-empirical models 


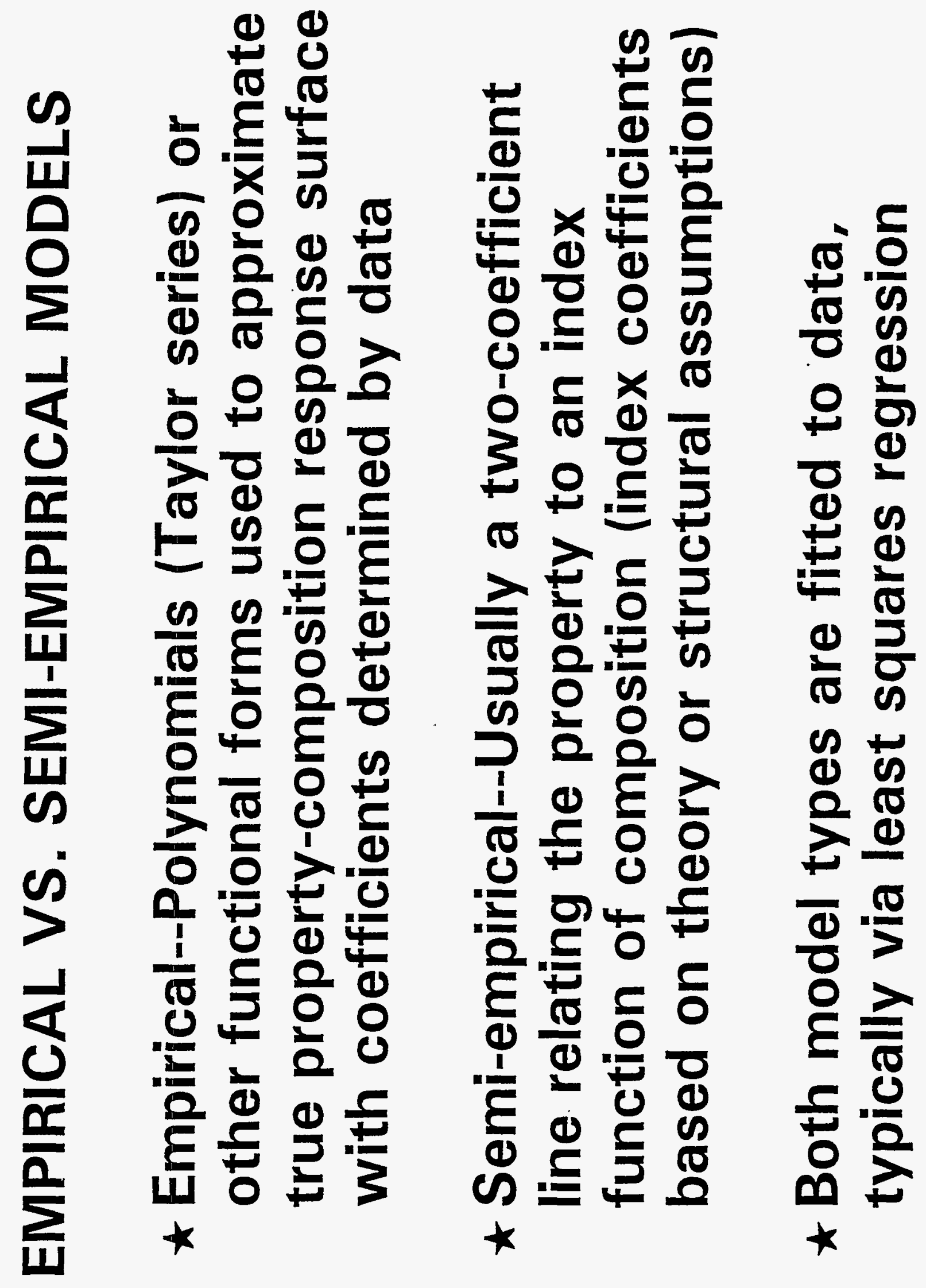




\section{MIXTURE MODELS}

$\star$ First- and second-order mixture models

$$
\begin{gathered}
f(\text { Property })=\sum_{i=1}^{10} b_{i} x_{i} \\
f(\text { Property })=\sum_{i=1}^{10} b_{i} x_{i}+\text { selected terms } \\
\text { of } \sum_{i<j} \sum_{i=j}^{10} b_{i j} x_{i} x_{j}+\sum_{i=1}^{10} b_{i i} x_{i}^{2}
\end{gathered}
$$

$\star$ Second-order terms handle curvature and interactive effects of components 


\section{MODEL GOODNESS-OF-FIT}

$\star R^{2}=$ proportion of variation in property data accounted for by the model $0 \leq R^{2} \leq 1$, with closer to 1 better. Generally, want $R^{2}>.85-.95$

$\star$ "Predicted versus measured" plots

$\star$ Statistical lack-of-fit and validation tests

-- Test LOF vs. experimental variation

-- Validate models using data not used to develop them 


\section{MIXTURE MODELS FOR LTM CVS}

$\star$ First- and second-order mixture models fitted for durability (PCT and MCC-1), viscosity, electrical conductivity, transition temperature, liquidus temperature, etc.

$\star$ Later sections of tutorial will show results, including comparison of empirical mixture to semi-empirical free energy of hydration models for PCT durability

$\star$ A few examples here, however 


\section{ST-ORDER MODEL, CVS $\eta_{1150}$ DATA}

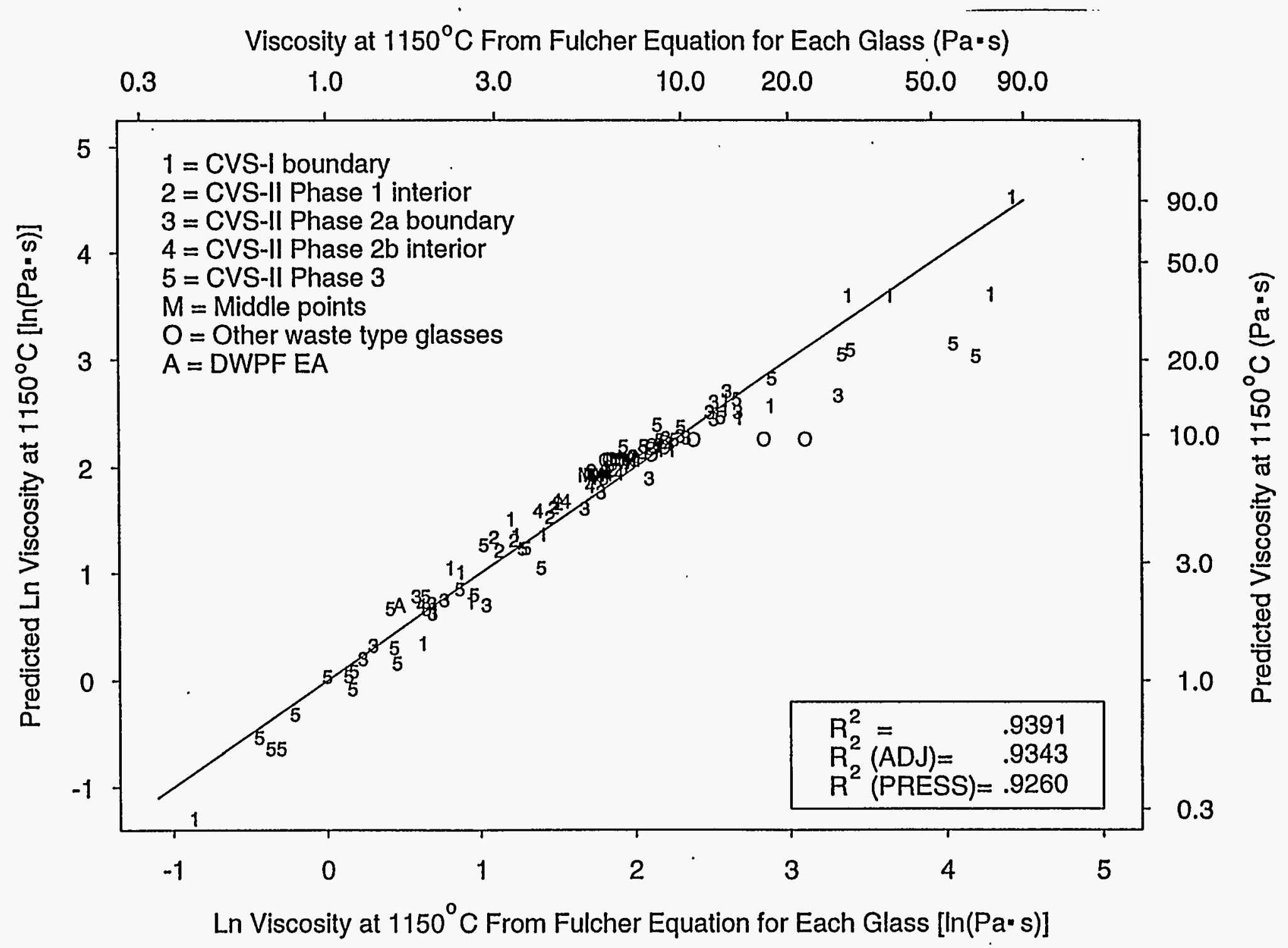




\section{ND-ORDER MODEL, CVS $\eta_{1150}$ DATA}

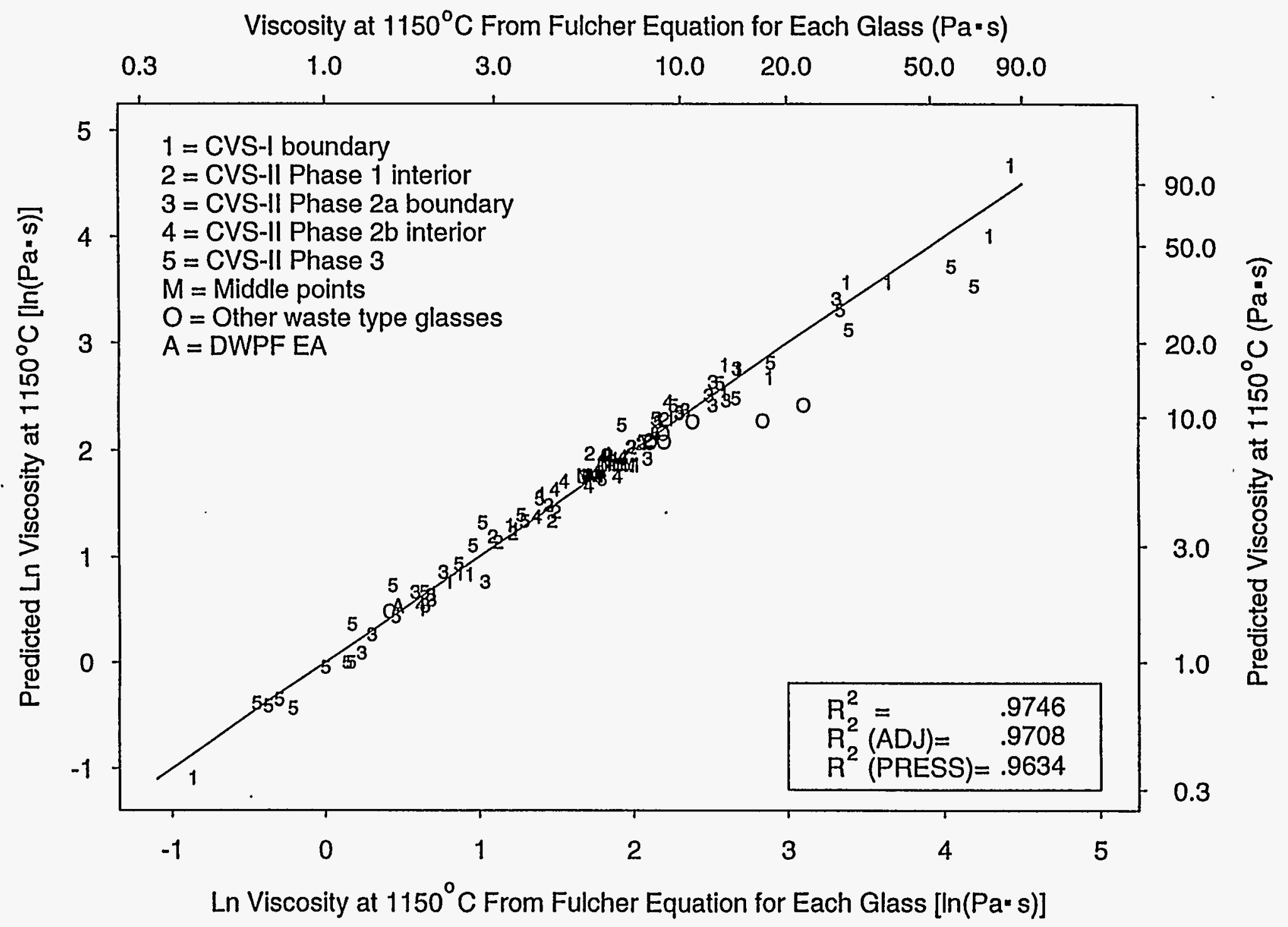




\section{COMPONENT EFFECTS, 1ST-ORDER $\boldsymbol{\eta}_{1150}$}

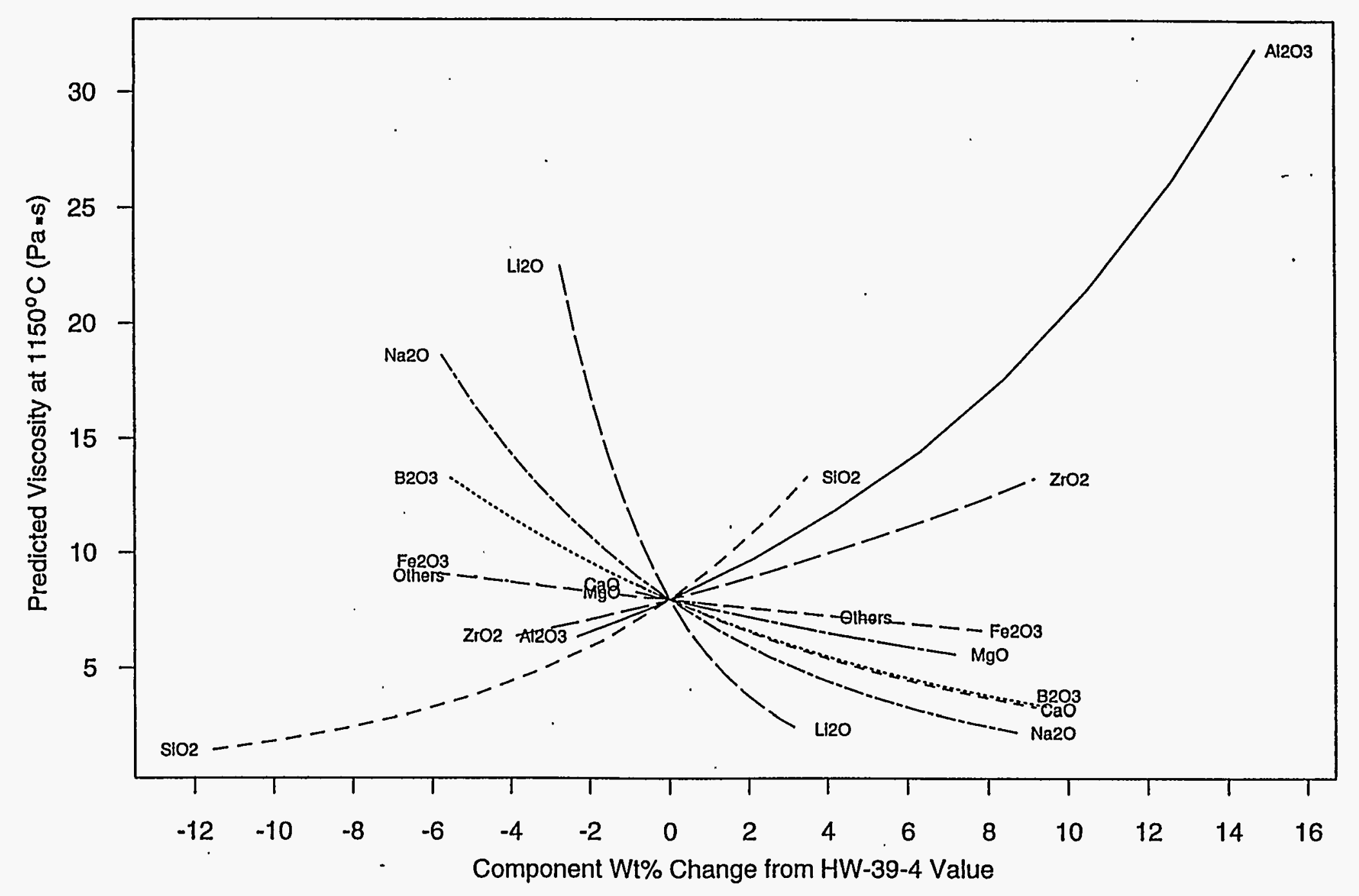




\section{VALIDATION OF 1ST-ORDER $\eta_{1150}$ MODEL, HISTORICAL DATA}

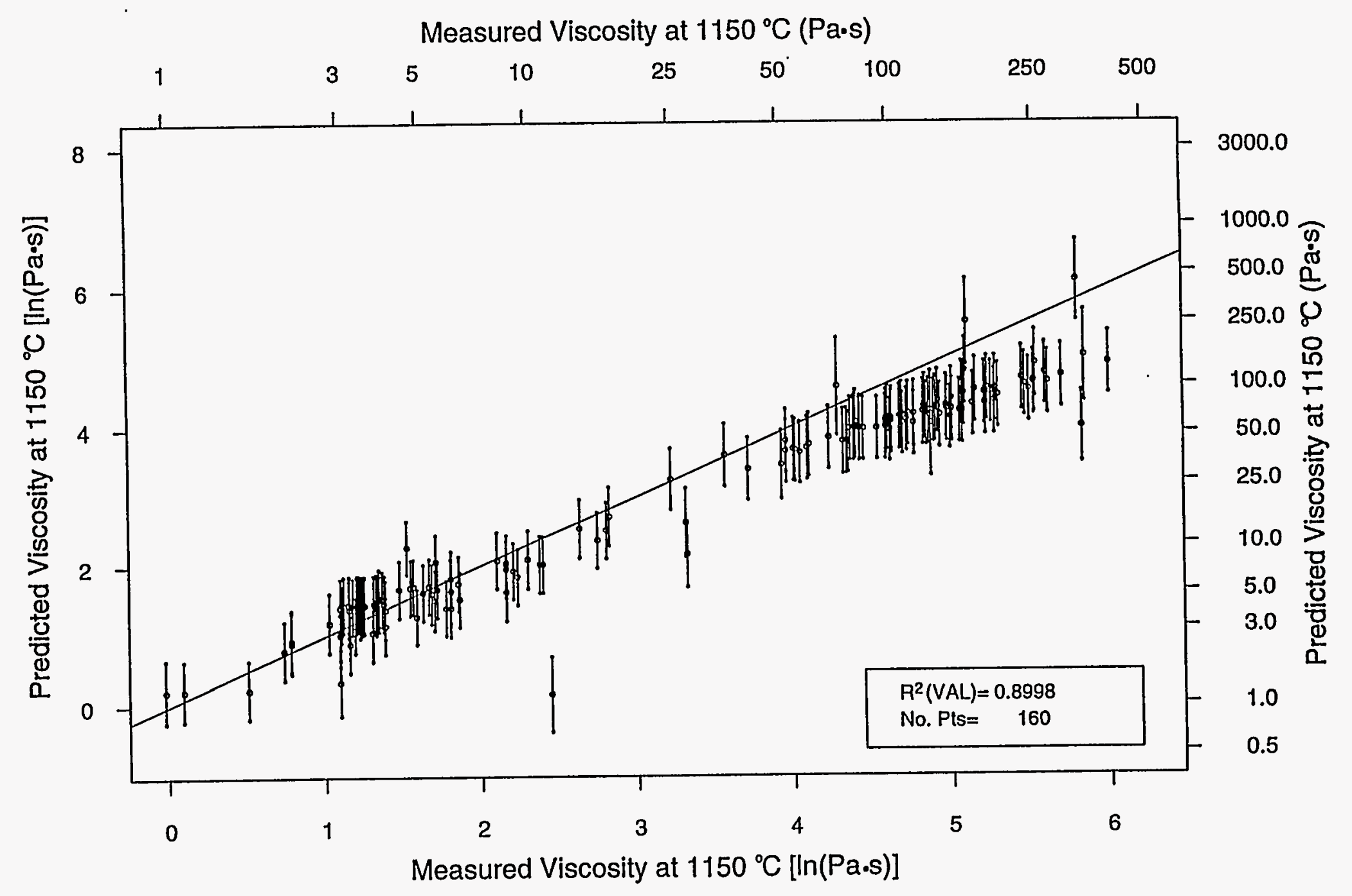




\section{TREE MODELS}

$\star$ Do not require assuming a particular model form

$\star$ Do require sufficient data to build the tree model

$\star$ Can be used for continuous or categorical response variables (properties)

$\star$ Can perform much better than parametric models when the property-composition relationship is complex 


\section{TREE MODEL, $\mathrm{T}_{\mathrm{L}}<\mathrm{OR}>1050^{\circ} \mathrm{C}$}

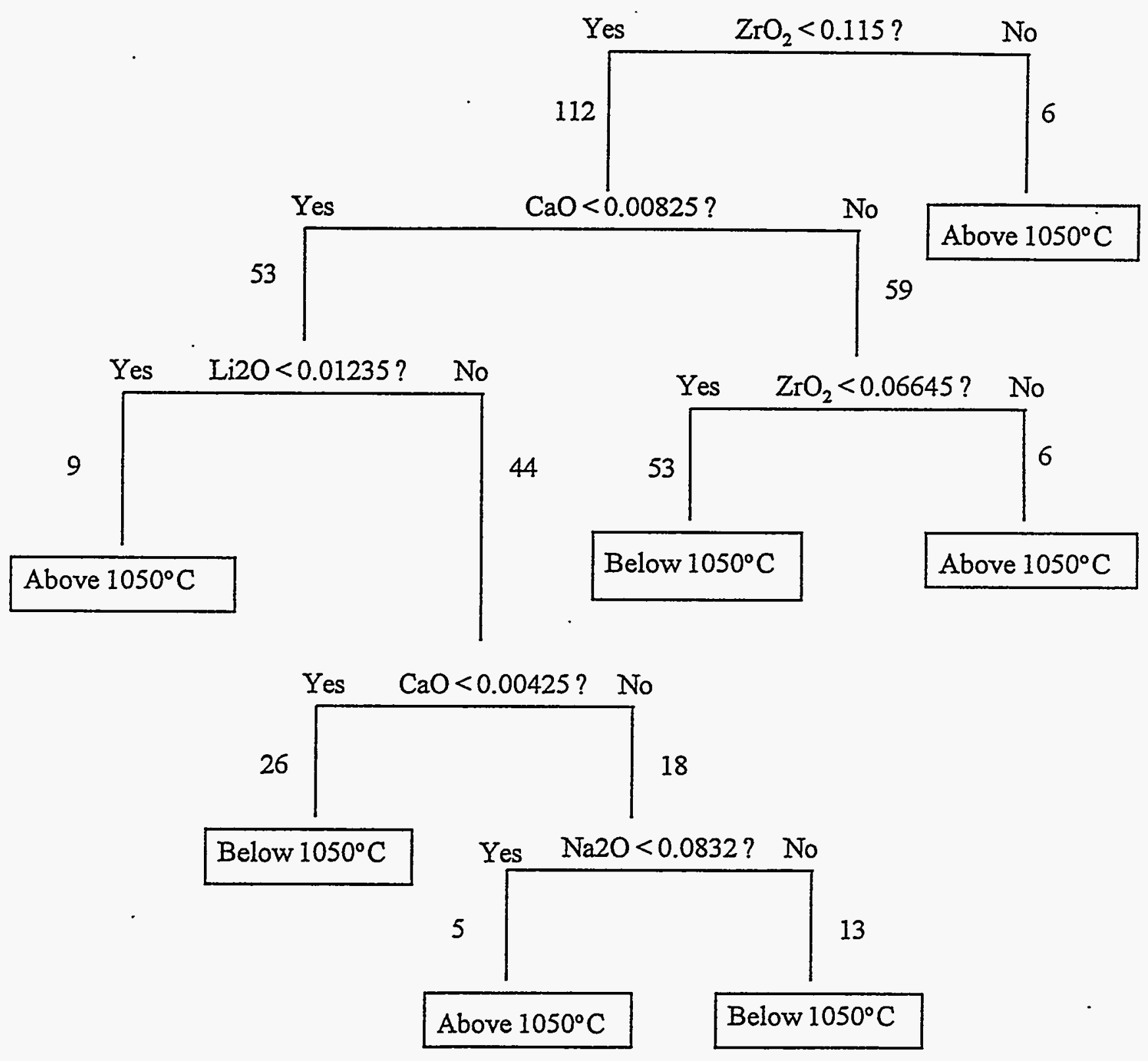

\section{Mis-classification rate $=11 \%$}




\section{ACCOUNTING FOR UNCERTAINTY}

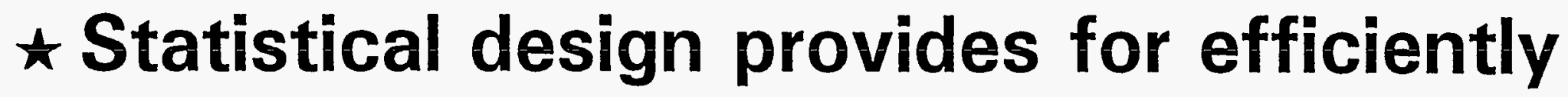
and correctly assessing effects of experimental variables (e.g., composition) in the presence of uncertainty

$\star$ Statistical data analyses account for uncertainty in determining significance of experimental effects 


\section{ACCOUNTING FOR UNCERTAINTY (cont.)}

$\star$ Statistical intervals (e.g., confidence or prediction intervals) on property model predictions

$$
\text { Interval }=\hat{y} \pm K * \operatorname{sd}(\hat{y})
$$

account for data and model uncertainty in assessing glass acceptability

$\star$ Statistical intervals useful in glass development and many other areas 


\section{SUMMARY}

Statistical experimental design, data analysis, and property modeling techniques applied in glass development work yield data and other results that serve as fundamental "building blocks" for:

-- glass formulation/optimization

-- other purposes (e.g., pretreatment and blending, feed specifications, waste form qualification, and vitrification plant operation \& control) 


\title{
MODEL COMPARISONS:
}

\section{EMPIRICAL MIXTURE \& FREE ENERGY OF HYDRATION MODELS}

Greg Piepel \& Trish Redgate

\author{
Pacific Northwest Laboratory \\ Richland, Washington
}

presented at tutorial

"Waste Glass Technology for Hanford"

June 27-28, 1995 


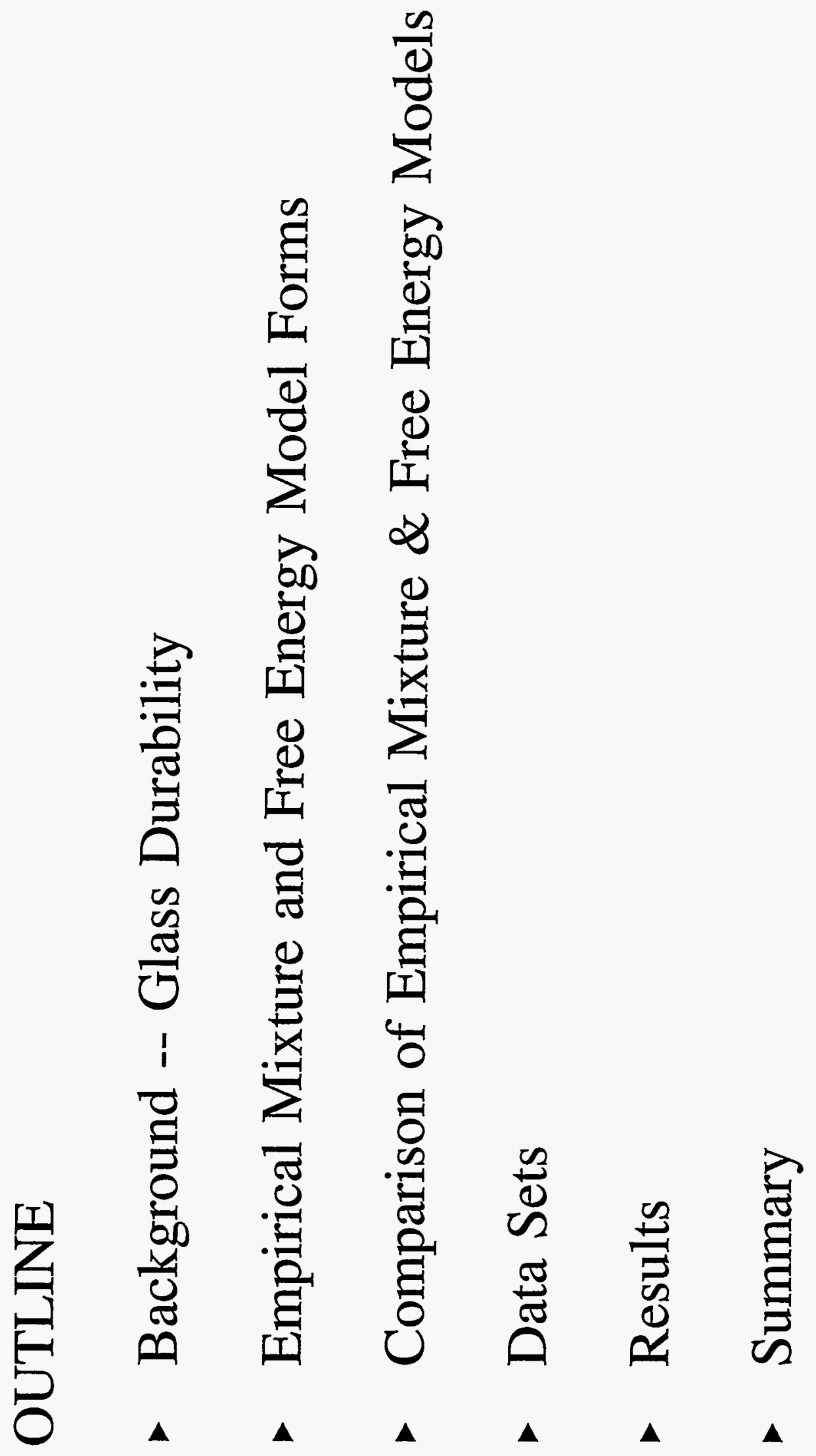




\section{Background -- Glass Durability}

- DOE-EM WAPS 1.3 Product Consistency Specification requires final waste form to be judged on the Product Consistency Test (PCT) of the glass

- Acceptable waste glass must be more durable than waste glass identified in the DWPF Environmental Assessment (EA)

- Need to evaluate glass durability before glass is vitrified 


\section{Background -- Glass Durability (cont)}

- Achieved by modeling glass durability as a function of composition

- SRTC developed Free Energy of Hydration Model

- PNL has tried several model forms and chose to use Empirical Mixture Models

- PNL and SRTC working jointly to understand differences between models 


\section{Empirical Mixture Models}

First-Order:

$$
\ln (N R)=\sum_{i=1}^{q} b_{i} x_{i}
$$

where,

$\ln (\mathrm{NR})=$ natural logarithm of a normalized elemental release,

$\mathrm{x}_{\mathrm{i}}=$ mole fraction of $\mathrm{i}$-th glass component such that $\mathrm{x}_{1}+\mathrm{x}_{2}+\mathrm{x}_{3}+\ldots+\mathrm{x}_{\mathrm{q}}=1$,

$b_{i}{ }^{\prime} s=$ coefficients estimated from data. 


\section{Empirical Mixture Models (cont)}

Second-Order:

$$
\begin{aligned}
\ln (N R)= & \sum_{i=1}^{10} b_{i} x_{i}+\text { selected terms } \\
& \text { of } \sum_{i<j} \sum_{i j}^{10} b_{i j} x_{i} x_{j}+\sum_{i=1}^{10} b_{i i} x_{i}^{2}
\end{aligned}
$$

- Second-order terms handle curvature and interactive effects of components 
Free Energy of Hydration Model:

$$
\ln (N R)=a+b\left\{\sum_{i \neq S i_{2}}\left(\Delta G_{i}\right) x_{i}+\left(\Delta G_{S i O_{2}}\right)\left[x_{S i O_{2}}-\sum_{i \in S} x_{i}\right]\right\}
$$

where,

$\ln (\mathrm{NR})=$ natural logarithm of a normalized elemental release from the Product Consistency Test (PCT),

$\mathrm{x}_{\mathrm{i}} \quad=$ mole fraction of $\mathrm{i}$-th glass component such that $\mathrm{x}_{1}+\mathrm{x}_{2}+\mathrm{x}_{3}+\ldots+\mathrm{x}_{\mathrm{q}}=1$,

$\Delta G_{i} \quad=\begin{aligned} & \text { free energy of hydration value for i-th glass } \\ & \text { component, }\end{aligned}$

$\mathrm{a}, \mathrm{b}=$ coefficients determined empirically by fitting model. 


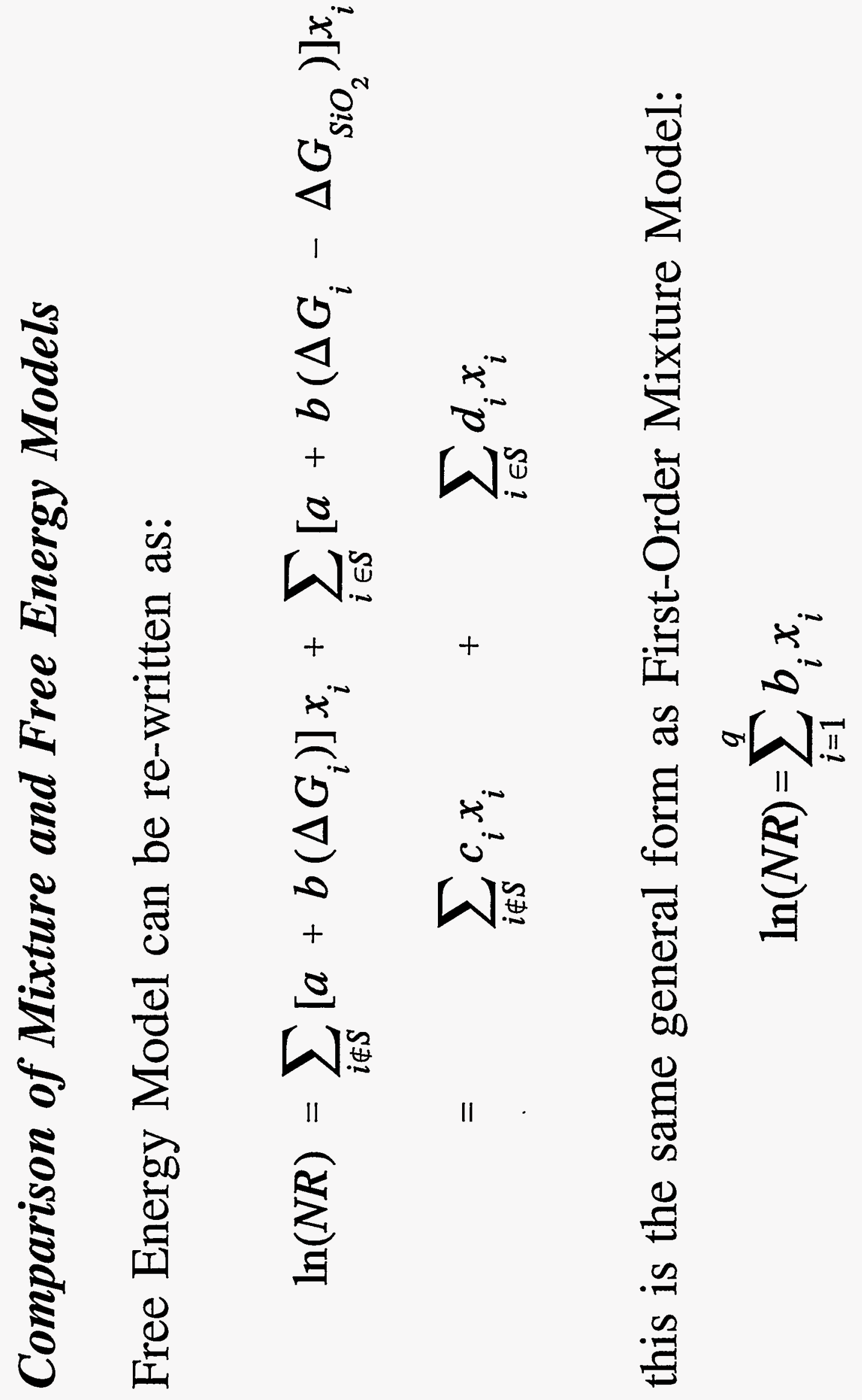


Comparison of Mixture and Free Energy Models (cont)

- The $b_{i}$ coefficient for each component in First-Order Mixture Model can be compared with $c_{i}$ or $d_{i}$ from Free Energy of Hydration Model.

\section{Main Difference:}

- Free Energy of Hydration uses assumed/calculated free energy of hydrations for each component.

- Empirical Mixture estimates the component of free energy of hydration values using data for composition region. 


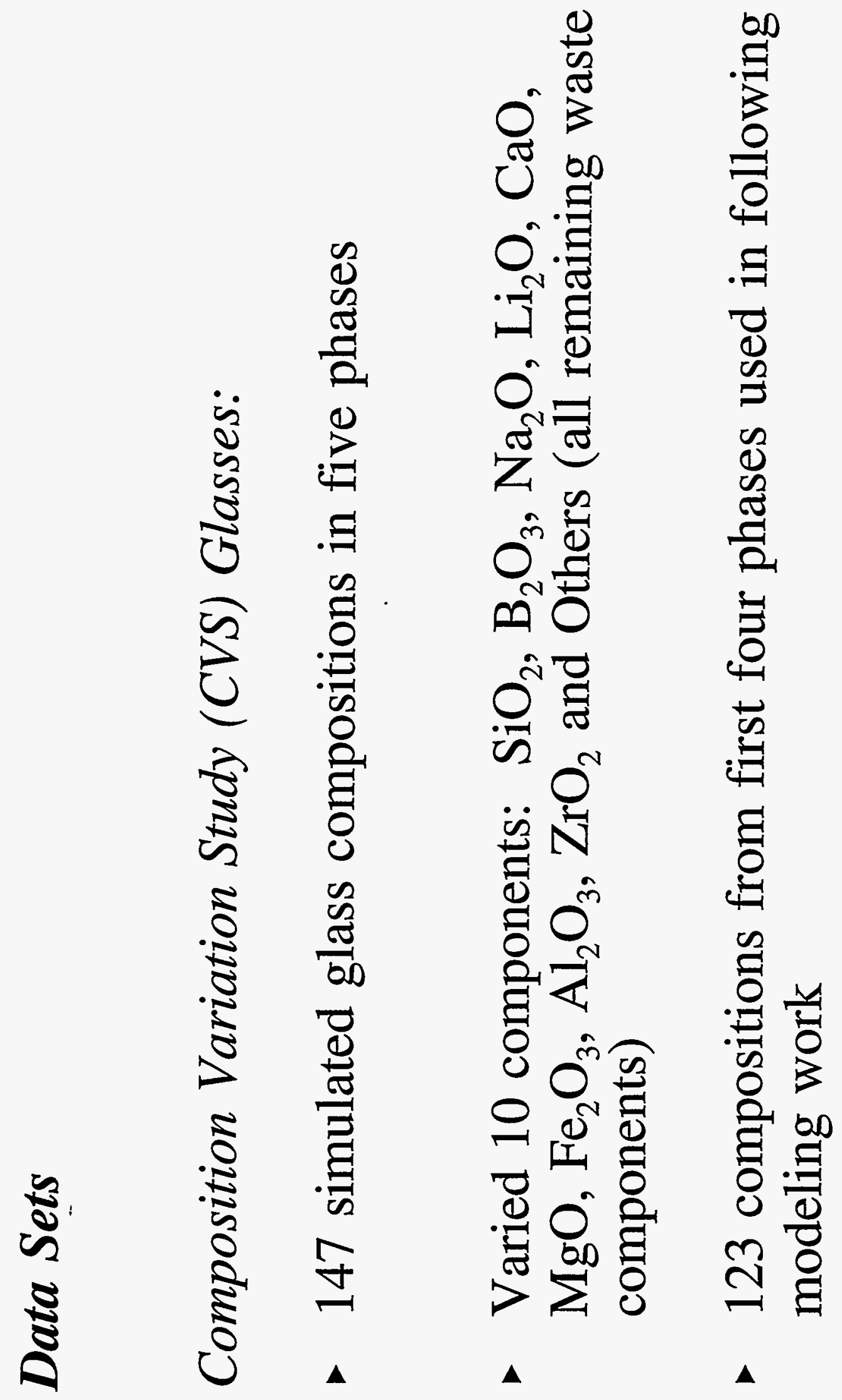




\section{Data Sets (cont)}

SRTC / DWPF Homogeneous \& Inhomogeneous Glasses:

- Homogeneous: no crystalline species \& no liquid-liquid phase separation -- 137 glasses including 43 replicates

- Inhomogeneous: crystallinity or phase separation--28 glasses

- SRTC data covers a smaller composition region than CVS data 


\section{Model Fitting Results}

$$
R^{2}=1-\frac{\sum_{i=1}^{n}\left(y_{i}-\hat{y}_{i}\right)^{2}}{\sum_{i=1}^{n}\left(y_{i}-\bar{y}\right)^{2}}
$$

- Unitless number between 0 and 1.

- Proportion of variation in $\ln (\mathrm{NR})$ release values for data set which is accounted for by a model fitted to the data set.

- Focus on $\ln \left(\right.$ Boron Release in $\left.\mathrm{g} / \mathrm{m}^{2}\right)$. 
Model Fitting Results (cont)

Data Set Used in Fit

CVS

SRTC Homogeneous

SRTC Inhomogeneous
Model Form

Free Energy of

Hydration

First-Order Mixture

Free Energy of

Hydration

First-Order Mixture

Free Energy of

Hydration

First-Order Mixture
$\underline{\mathrm{R}^{2}}$

.3316

.8057

.7659

.9703

.8924

.9868 


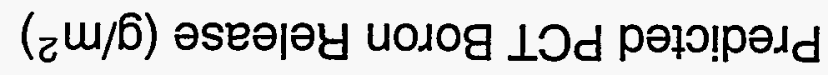

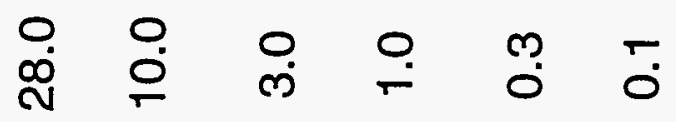

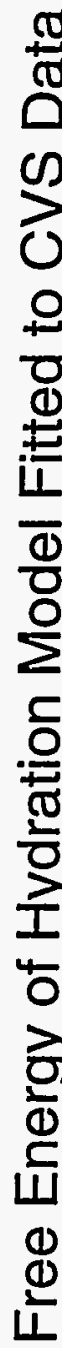

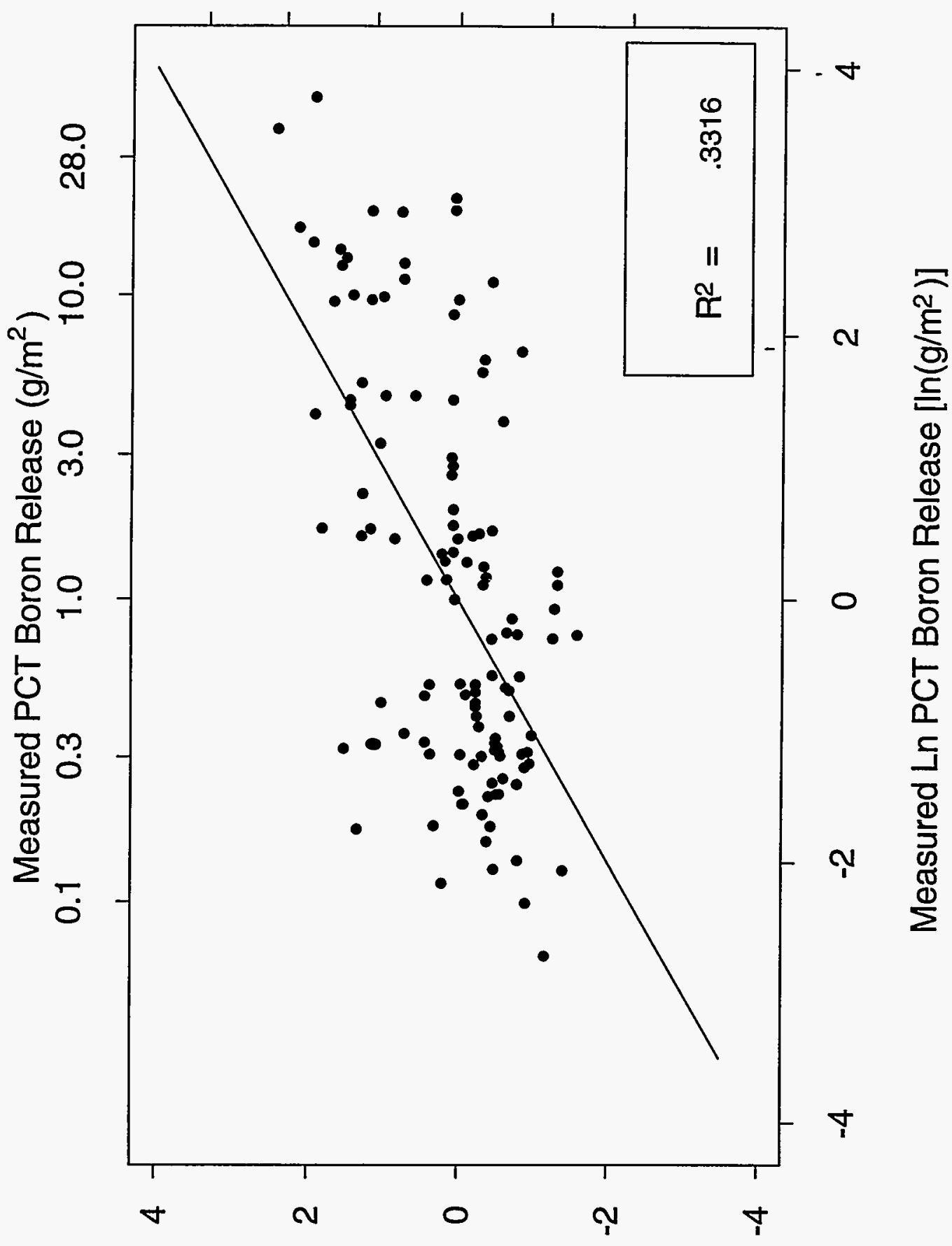

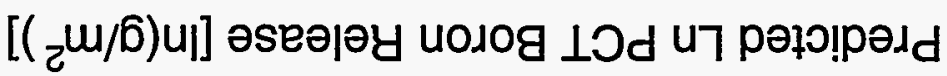




\section{First-Order Mixture Model Fitted to CVS Data}

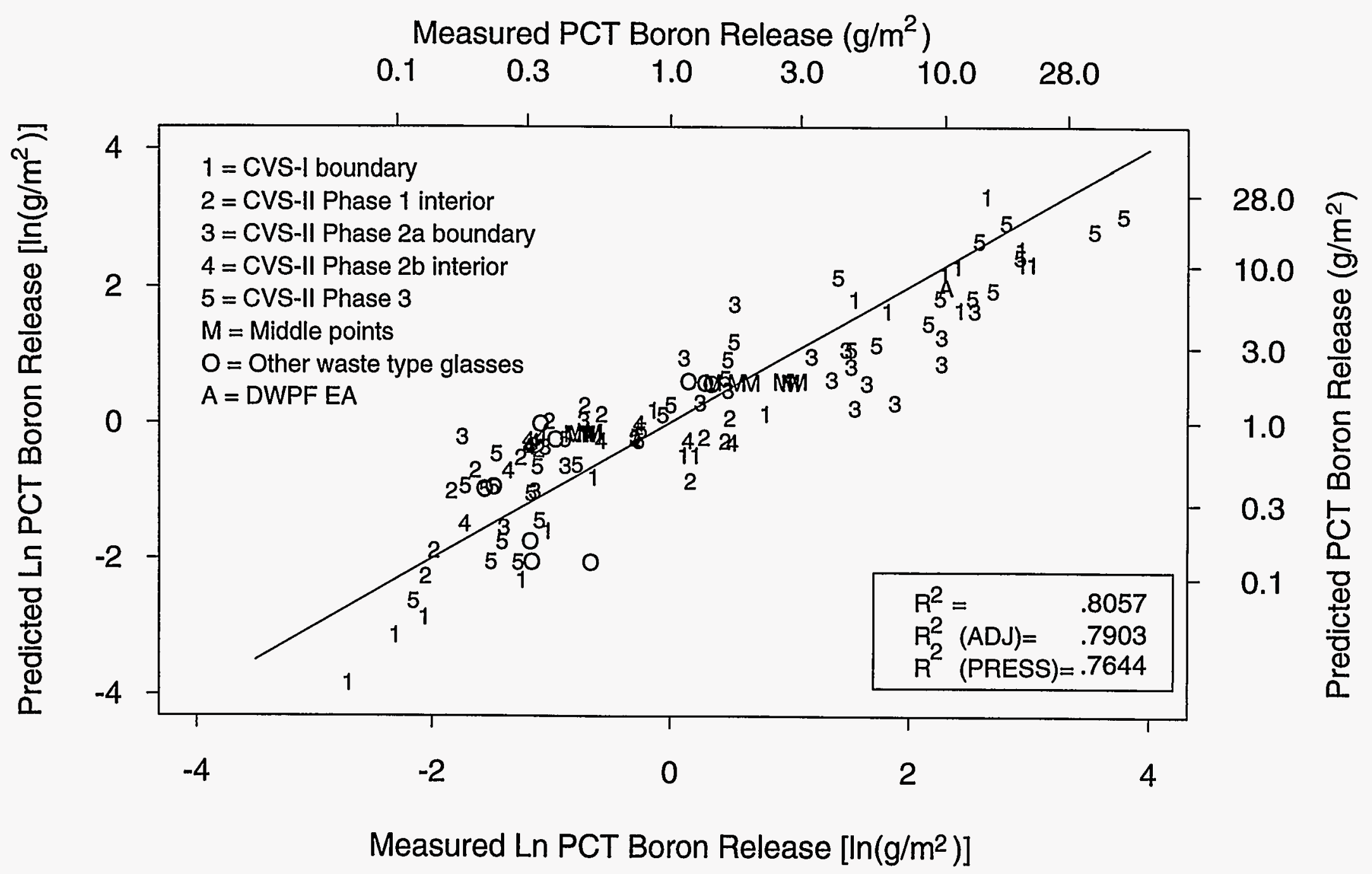


Free Energy of Hydration Model Fitted to SRTC Data

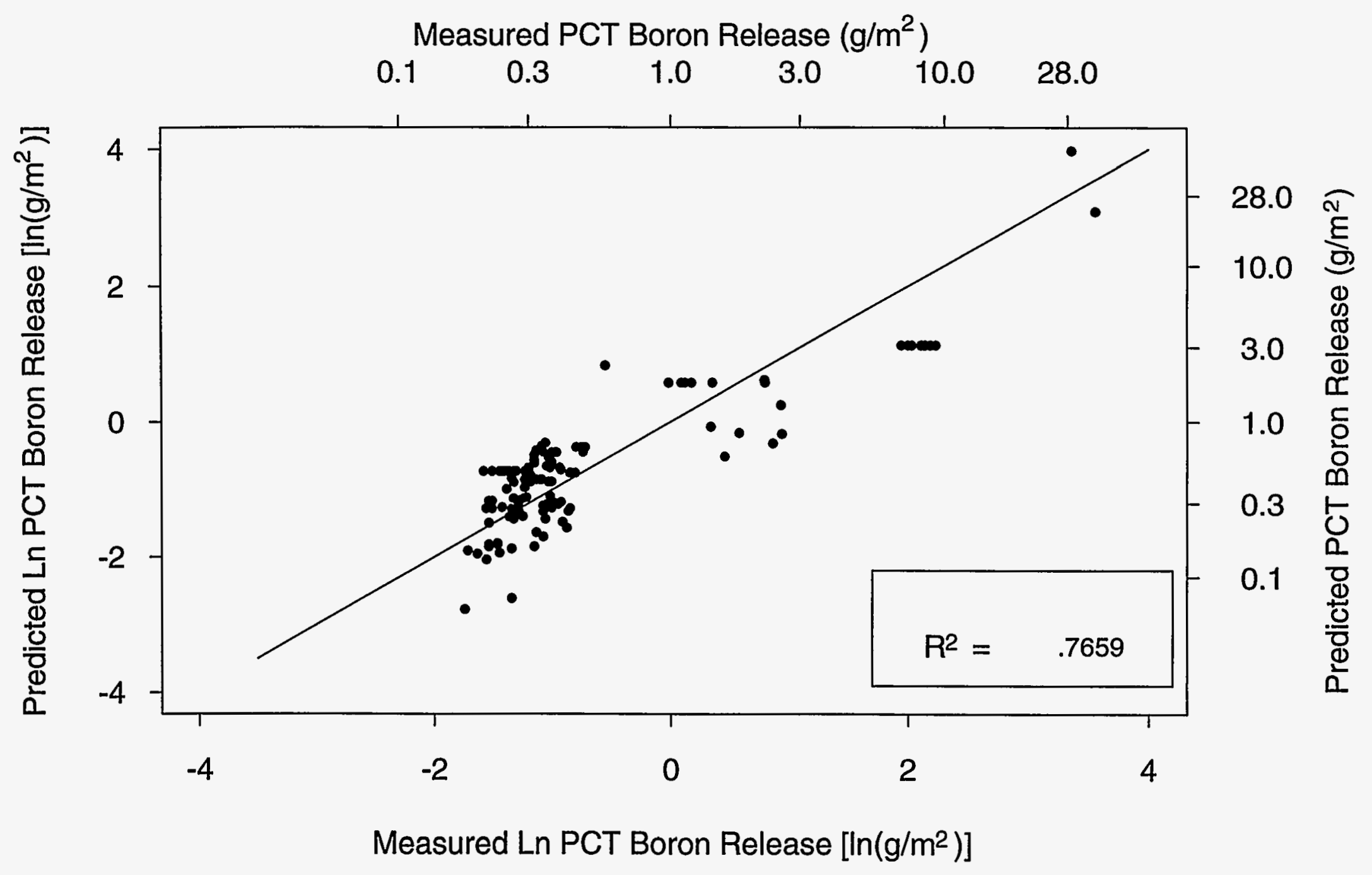


First-Order Mixture Model Fitted to SRTC Data

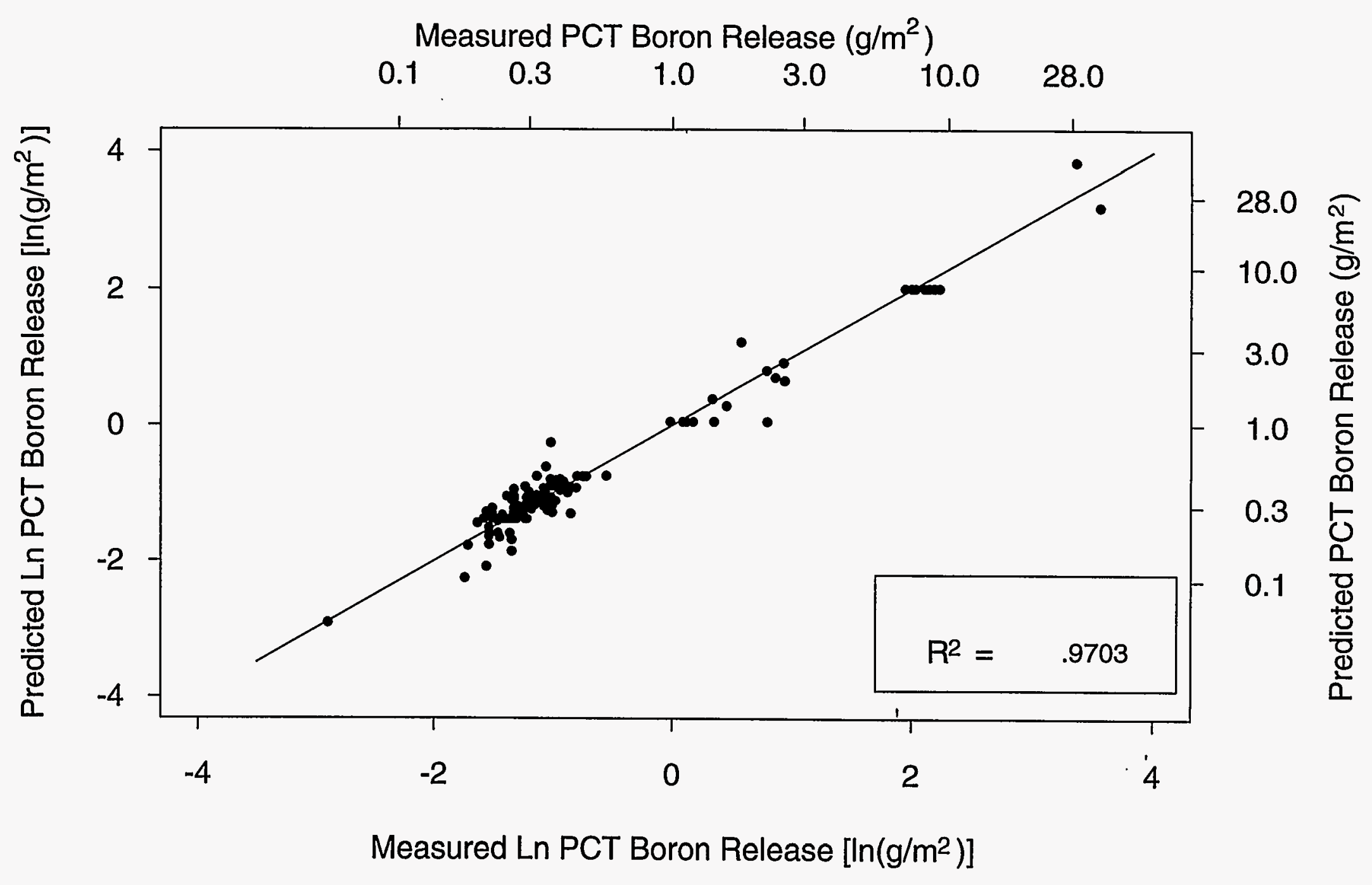


Coefficients for Models Using CVS Data

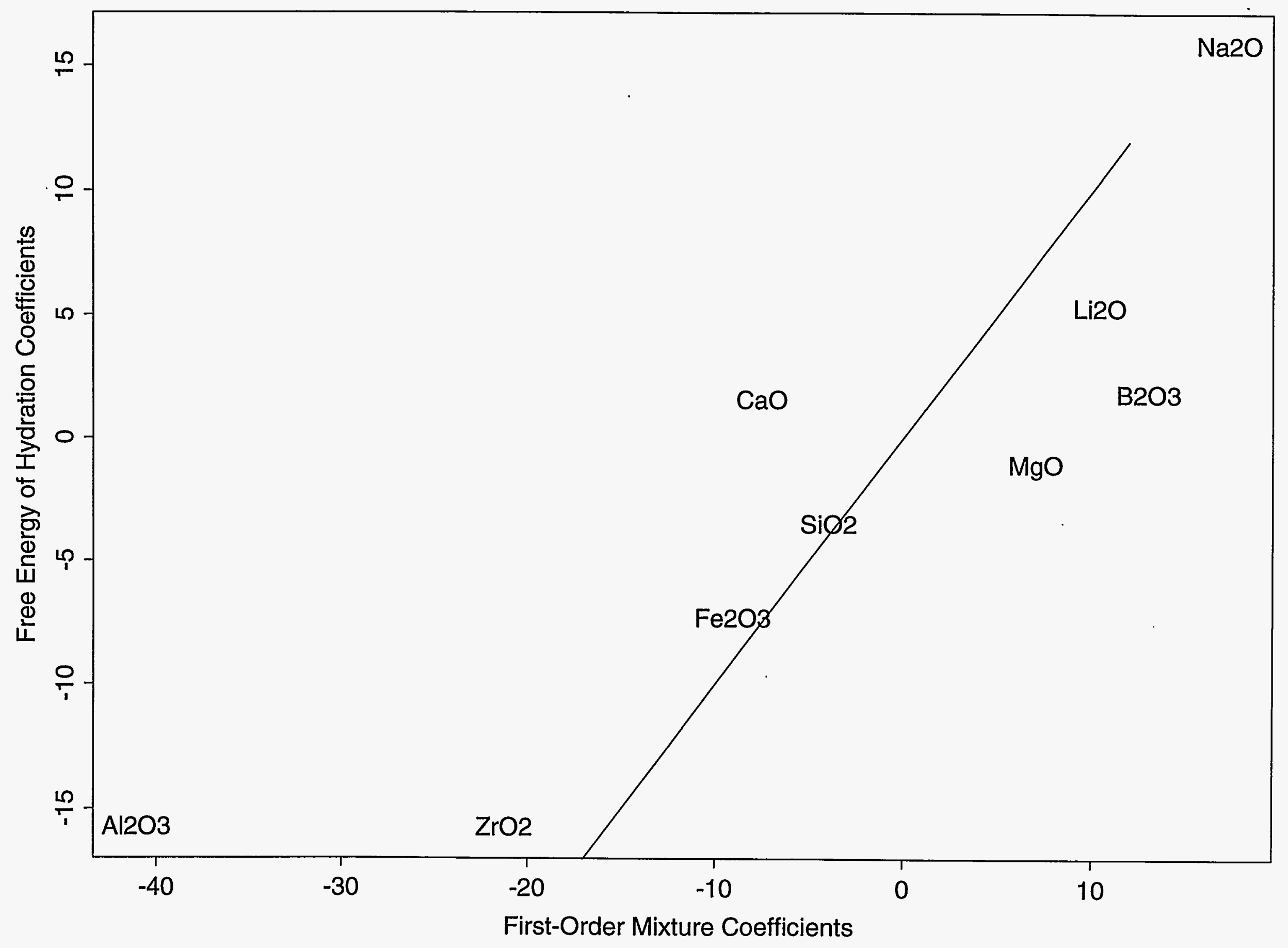




\section{Summary}

- Free Energy of Hydration Model performs well for SRTC data, but not for CVS data

- First-Order Mixture Model performs well for CVS and SRTC data

- CVS data covers a larger composition region

- Both First-Order Mixture and Free Energy of Hydration cannot account for nonlinear and interactive effects of components

- Second-Order Mixture Models and other nonlinear model forms (e.g., Tree Models) are being investigated at PNL

- Investigation of differences between models will continue jointly with PNL and SRTC 


\section{HANFORD LOW-LEVEL WASTE GLASS: STRUCTURE AND CHEMISTRY}

John G. Darab, Hong Li, John C. Linehan*, Dean W. Matson, Shiv K. Sharma** and Peter A. Smith

Materials Sciences Department

Pacific Northwest Laboratory

Richland, WA 99352

Robert K. MacCrone

Materials Engineering Department

Rensselaer Polytechnic Institute

Troy, $N Y 12181$

Chemical Sciences Bepartment

* On leave from Hawail Institute of Geophysics, University

of Hawail Honolulu, HI 


\section{OUTLINE}

$\sim$ What is glass?

$\sim$ Glass structure and chemistry

$\sim$ Why do we want to study the structure and chemistry of glass?

- How do we go about studying glass structure and chemistry?

- Case studies of glass structure and chemistry 


\section{WHAT IS GLASS?}

\section{Structural and Chemical Definition}

Concept of "motif"

7 motif for designing fabric, wall paper, etc.

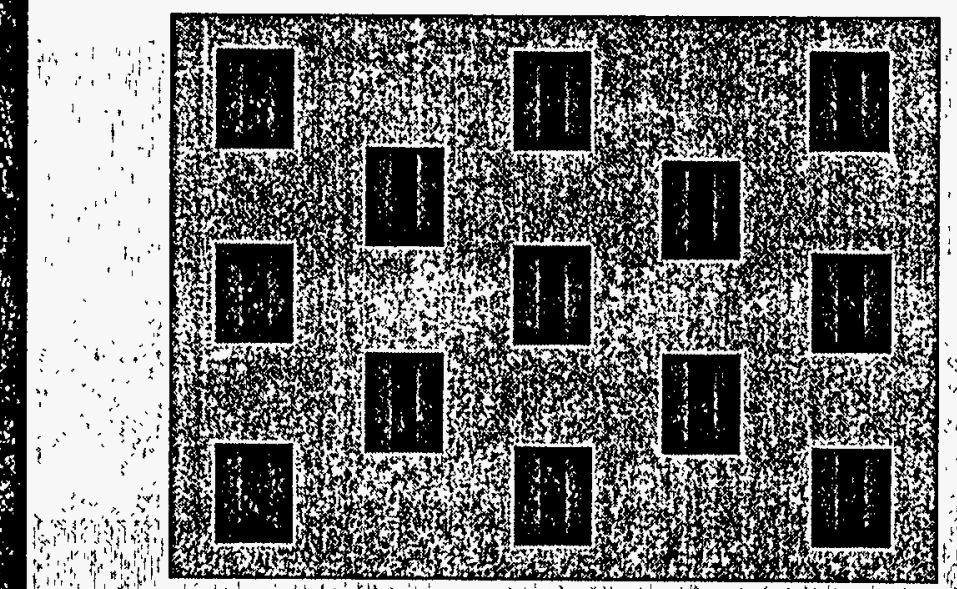

Ordered arrangement of motif- "crystalline"

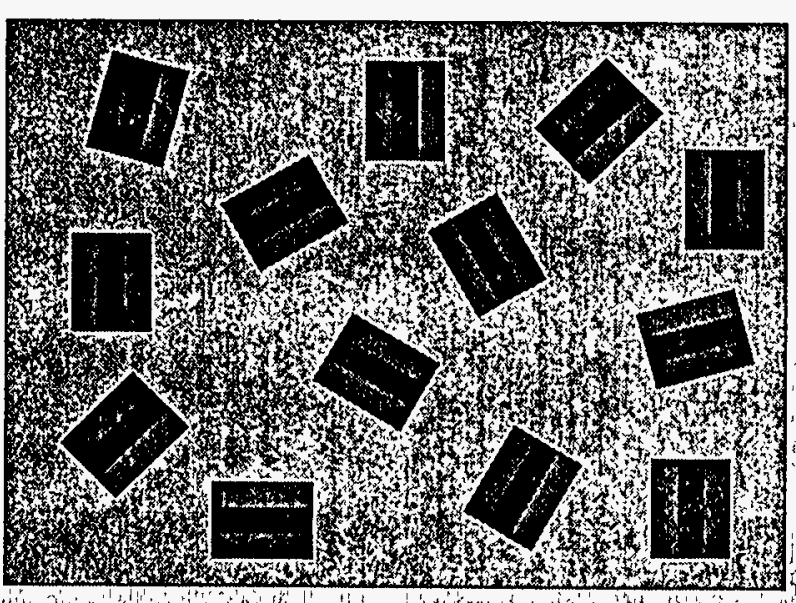

Random arrangement of motif " amorphous"

Pacific Northwest Laboratory 


\section{WHAT IS GLASS?}

Example: Silicon Dioxide ( $\mathrm{SiO} 2$, Silica)

Concept of "motif"

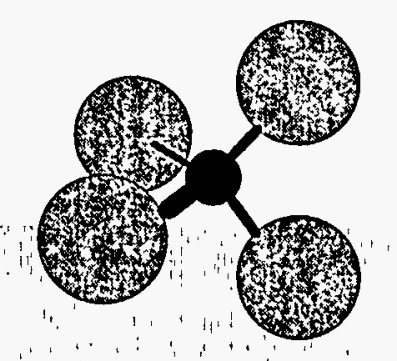

structural and chemical motif:

$$
\begin{array}{l|l}
\text { - Si i tetrahedrally } \\
\text { coordinated to four } \\
\text { forming the orthosilicate } \\
\text { nonomer }
\end{array}
$$

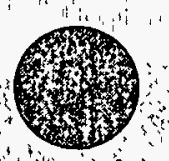 forming the orthosilicate monomer

$\sim$ Ordered arrangement of orthosilicate motifcrystalline $\mathrm{SiO}_{2}$.

ح Random arrangement of orthosilicate motifamorphous $\mathrm{SiO}_{2}$. 


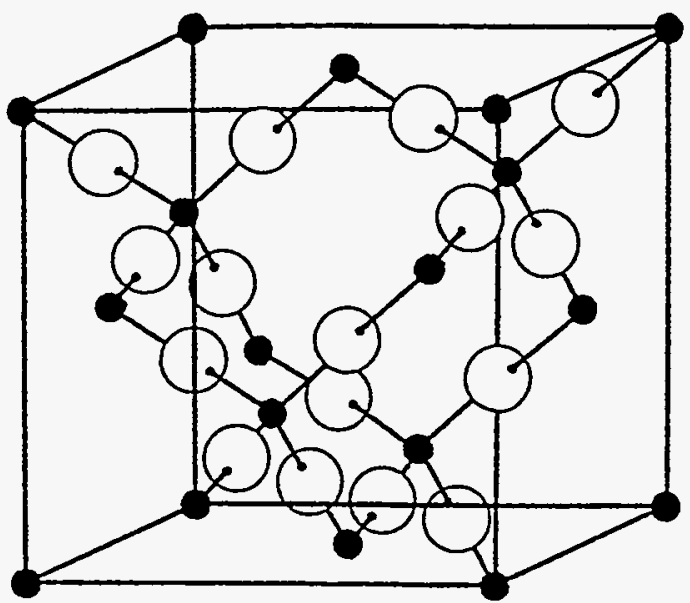

Fig. 1 The crystal structure of high cristobalite, showing the organization of tetrahedral units of silicon (black dots) and oxygen (O). Reprinted from Ref. 6 a with permission from Elsevier.

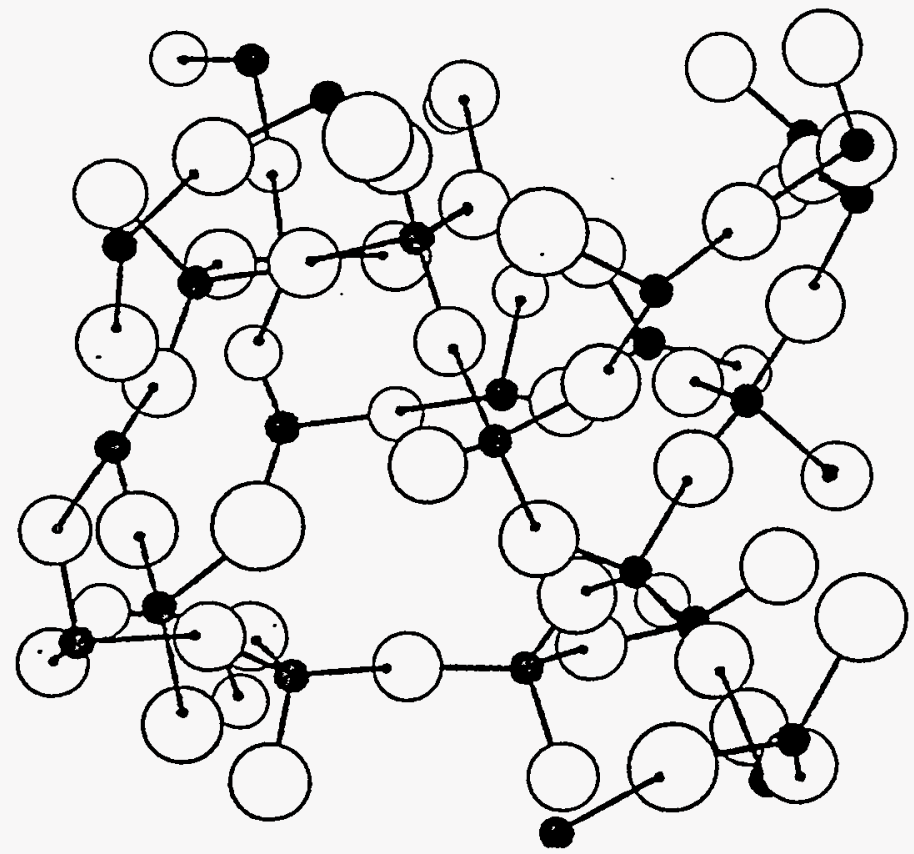

Fig. 2 A schematic diagram of vitreous silica, showing silica tetrahedra linked at corners to form a random network with rings and cages. Reprinted from Ref. 6 a with permission from Elsevier. 


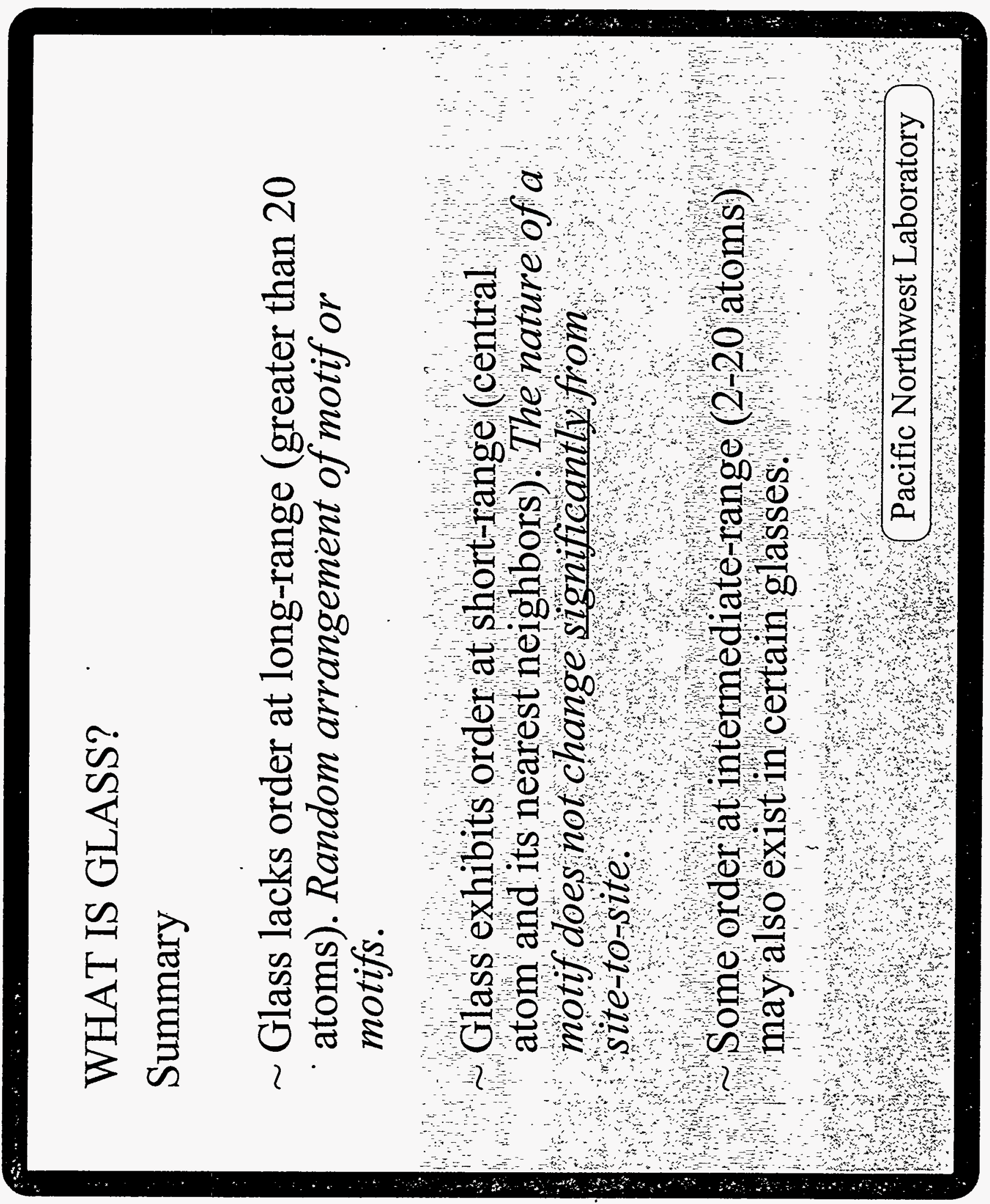




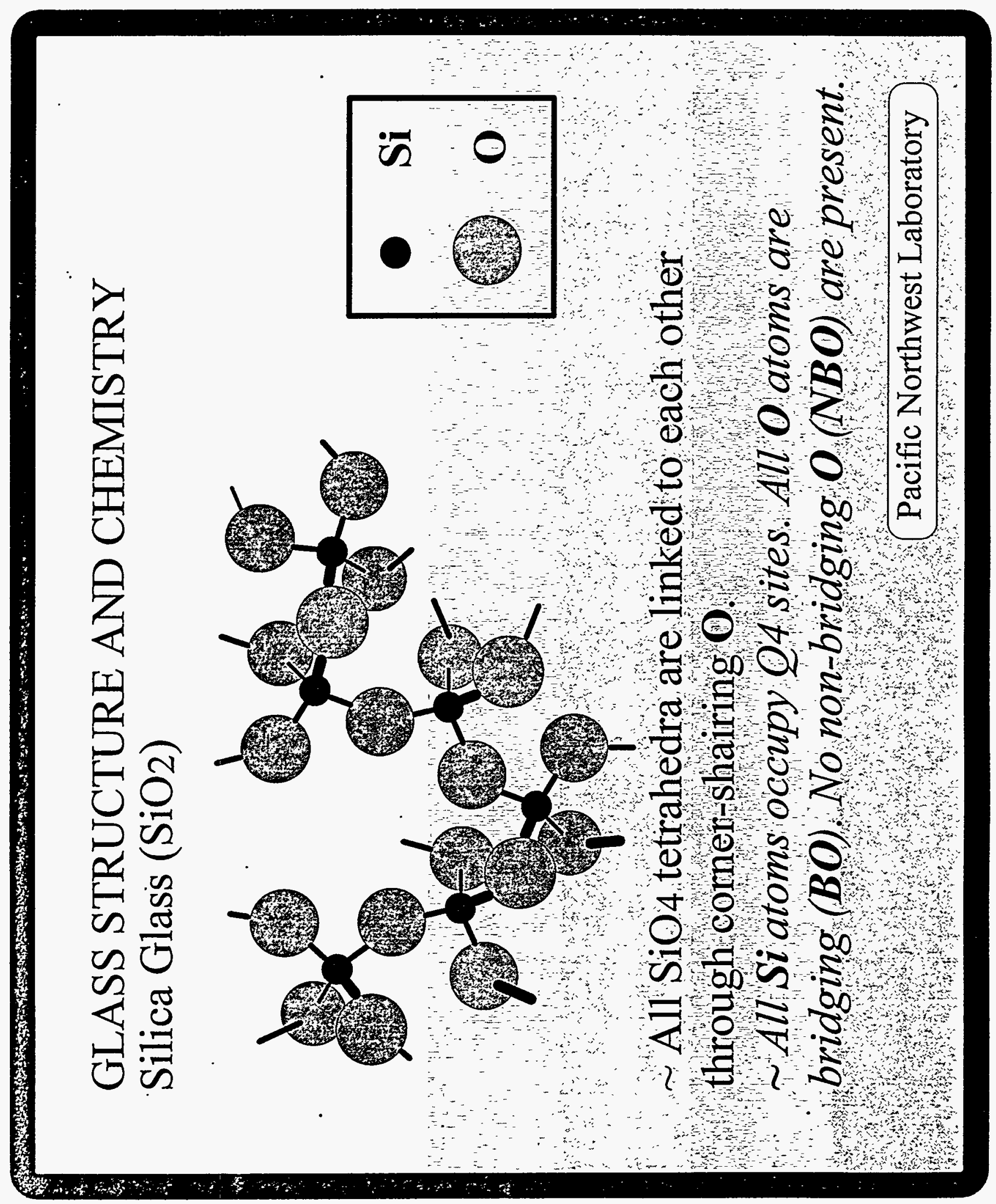




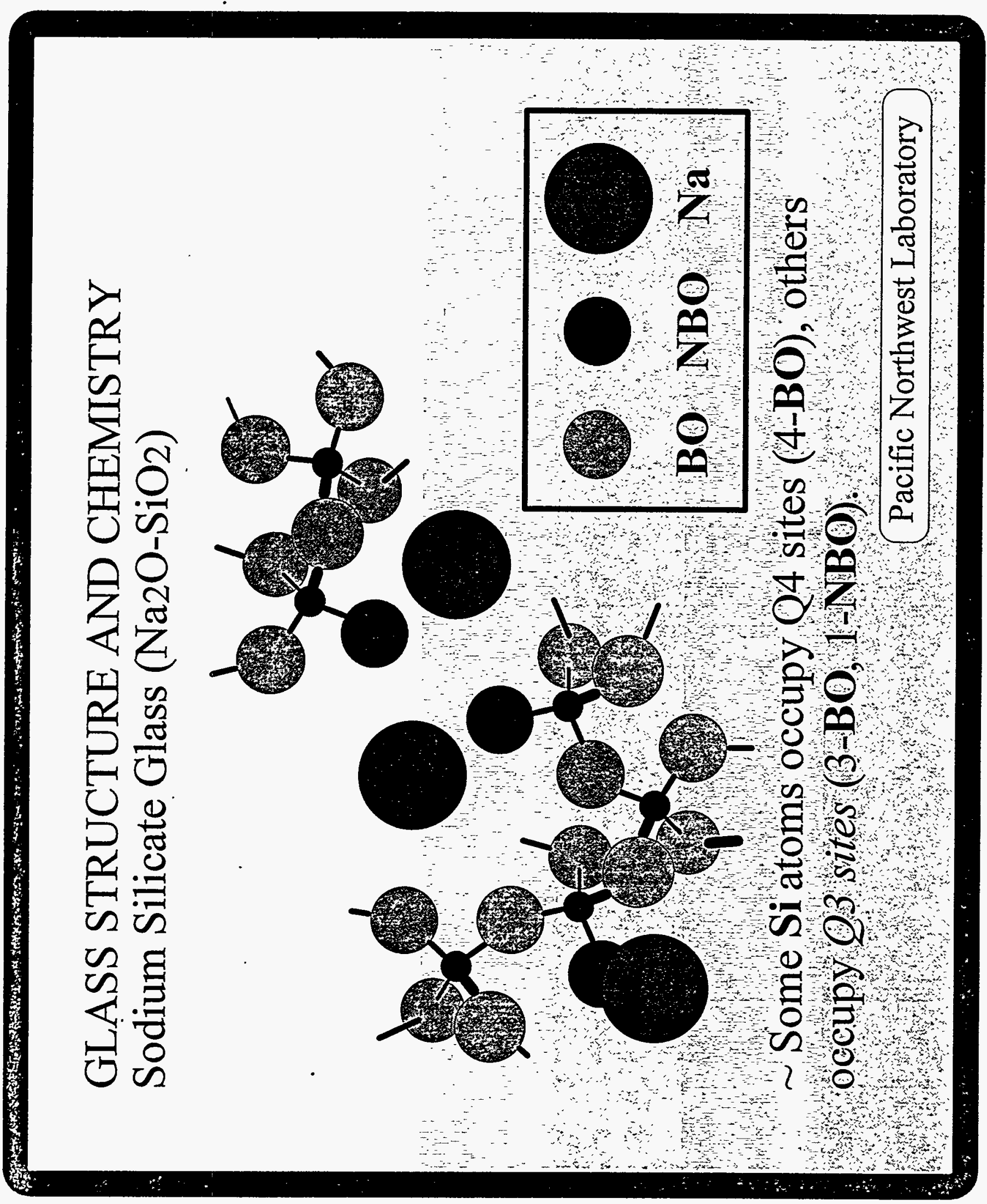




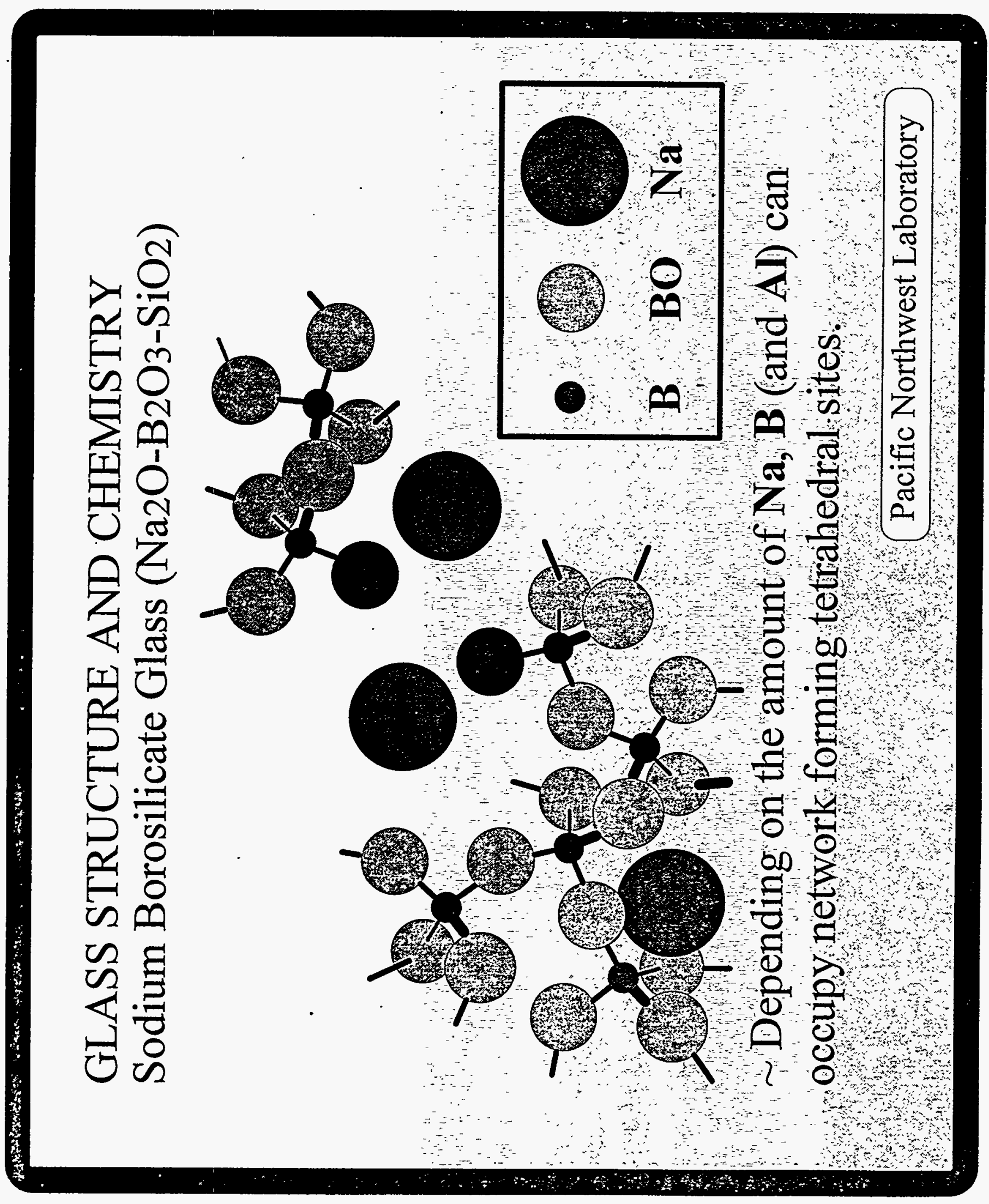




\section{Oxide-equivalent compositions of glasses studied in this work.}

\begin{tabular}{|c|c|c|c|c|c|}
\hline Oxide & $\begin{array}{c}\text { LD6-5510 } \\
\text { CBC } \\
\text { (wt\%) }\end{array}$ & $\begin{array}{c}\text { L4-9012 } \\
\text { CBC } \\
(w t \%)\end{array}$ & $\begin{array}{c}\text { L6-5412 } \\
\text { CBC } \\
\text { (wt\%) }\end{array}$ & $\begin{array}{l}\text { L6-5412 } \\
\text { TMF } \\
\text { (wt\%) }\end{array}$ & $\begin{array}{c}\text { L6-5412 } \\
\text { MCF } \\
(w t \%)\end{array}$ \\
\hline $\mathrm{SiO}_{2}$ & 56.79 & 56.78 & 56.78 & 56.83 & 58.08 \\
\hline $\mathrm{Na}_{2} \mathrm{O}$ & 20.00 & 20.00 & 20.00 & 20.02 & 20.45 \\
\hline $\mathrm{B}_{2} \mathrm{O}_{3}$ & 5.00 & 9.00 & 5.00 & 5.00 & 5.11 \\
\hline $\mathrm{CaO}$ & 5.00 & & 4.00 & 4.00 & 4.09 \\
\hline $\mathrm{Al}_{2} \mathrm{O}_{3}$ & 10.00 & 12.00 & 12.00 & 12.01 & 12.27 \\
\hline Others* & 3.21 & 2.22 & 2.22 & 2.14 & 0.00 \\
\hline Total & 100.00 & 100.00 & 100.00 & 100.00 & 100.00 \\
\hline \multicolumn{6}{|l|}{${ }^{*}$ Others } \\
\hline $\mathrm{Cl}$ & 0.36 & 0.09 & 0.09 & 0.09 & \\
\hline $\mathrm{F}$ & 0.31 & 0.21 & 0.21 & 0.21 & \\
\hline I & 0.14 & & & & \\
\hline $\mathrm{Cr}_{2} \mathrm{O}_{3}$ & 0.04 & 0.04 & 0.04 & & \\
\hline $\mathrm{Fe}_{2} \mathrm{O}_{3}$ & 0.005 & 0.005 & 0.005 & & \\
\hline $\mathrm{MoO}_{3}$ & 0.16 & & & & \\
\hline $\mathrm{K}_{2} \mathrm{O}$ & 1.51 & 0.33 & 0.33 & 0.33 & \\
\hline $\mathrm{MnO}$ & 0.002 & 0.007 & 0.007 & & \\
\hline $\mathrm{MgO}$ & 0.003 & & & & \\
\hline $\mathrm{P}_{2} \mathrm{O}_{5}$ & 0.19 & 1.19 & 1.19 & 1.19 & \\
\hline $\mathrm{SO}_{3}$ & 0.22 & 0.32 & 0.32 & 0.32 & \\
\hline $\mathrm{Bi}_{2} \mathrm{O}_{3}$ & & 0.014 & 0.014 & & \\
\hline $\mathrm{ZrO}_{2}$ & & 0.005 & 0.005 & & \\
\hline $\mathrm{SrO}$ & 0.12 & & & & \\
\hline $\mathrm{Cs}_{2} \mathrm{O}$ & 0.15 & & & & \\
\hline Total & 3.21 & 2.217 & 2.217 & 2.140 & 0.00 \\
\hline
\end{tabular}




\section{GLASS STRUCTURE AND CHEMISTRY}

Hanford Low-Level Waste Glass-Major Components

Component Structural \& Chemical Issues

$\mathrm{SiO}_{2}$

$\mathrm{Al}_{2} \mathrm{O}_{3}$

$\mathrm{B}_{2} \mathrm{O}_{3}$

$\mathrm{Na} 2 \mathrm{O}, \mathrm{CaO}$
Distribution of Q4, Q3, \& Q2 sites.

Distribution of 4-coord. network former \& 6 coord network intermediate sites.

Distribution of 4-coord. network former \& 3 coord network intermediate sites. Intermediate-range interactions? 


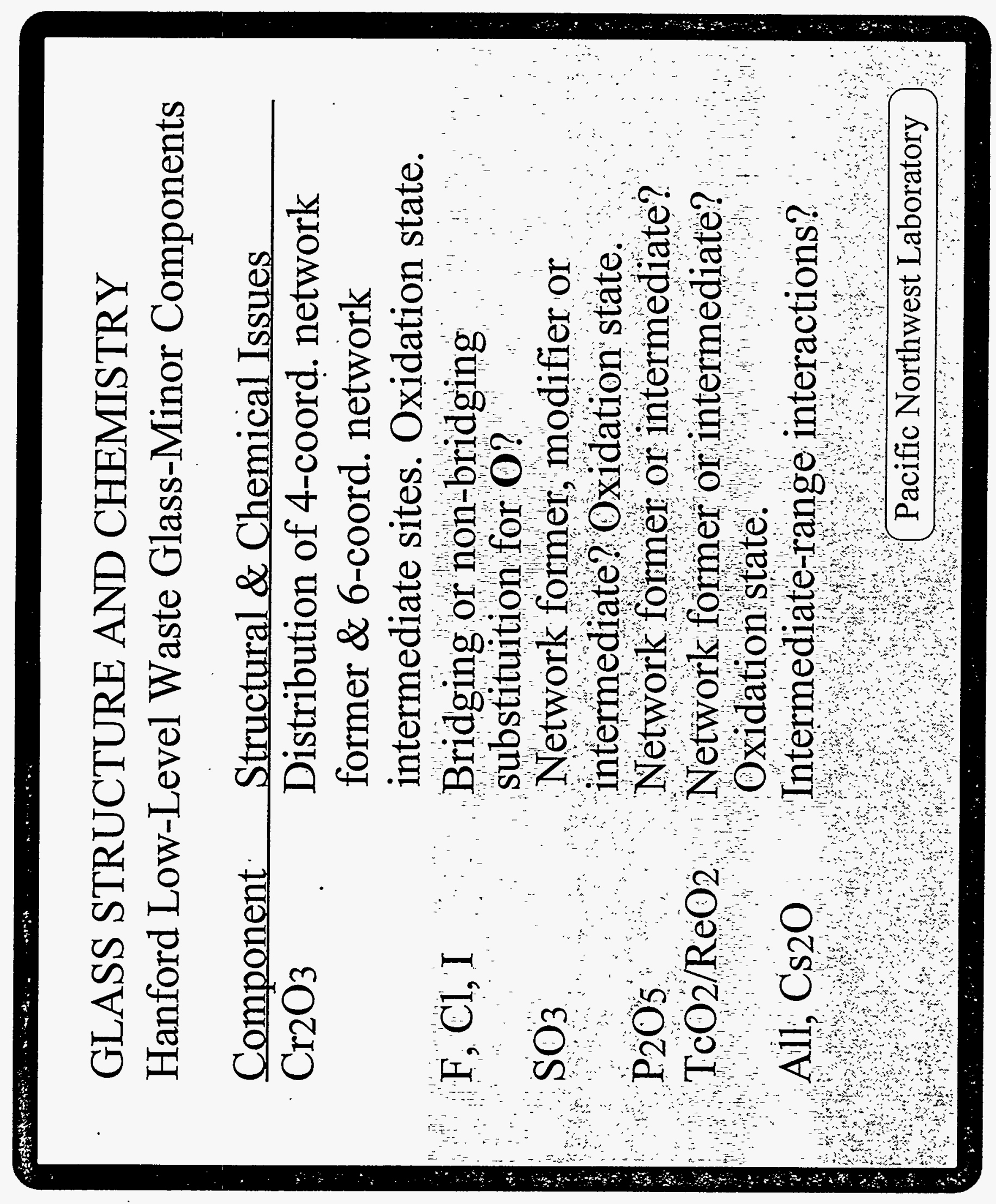




\section{WHY STUDY GLASS STRUCTURE AND CHEMISTRY?}

A Few Things Structure and Chemistry Influence in Glass and Glass Manufacture:

$\sim$ Durability

$\sim$ Melt viscosity

$\sim$ Volatility

Optical, magnetic, and electronic properties 


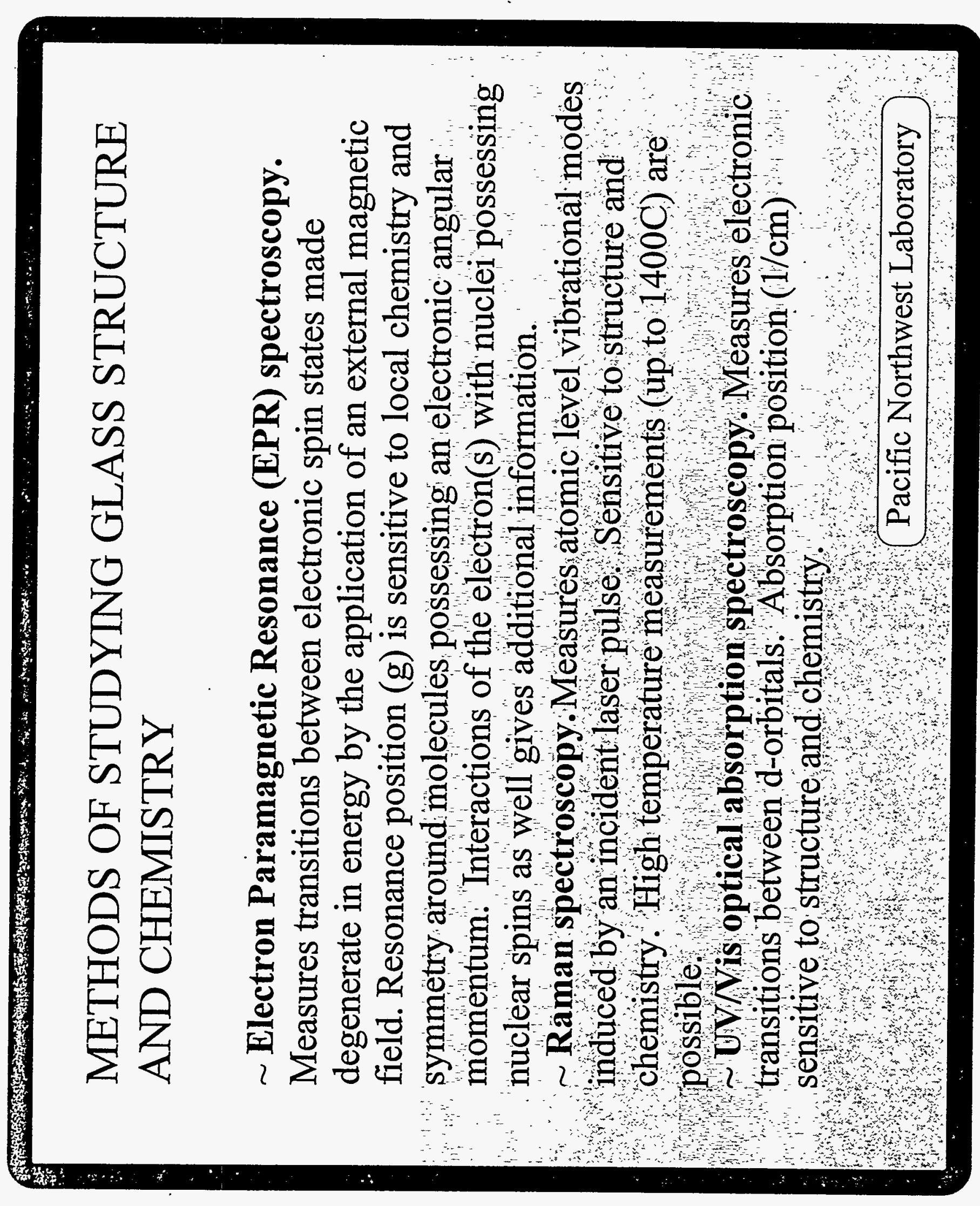




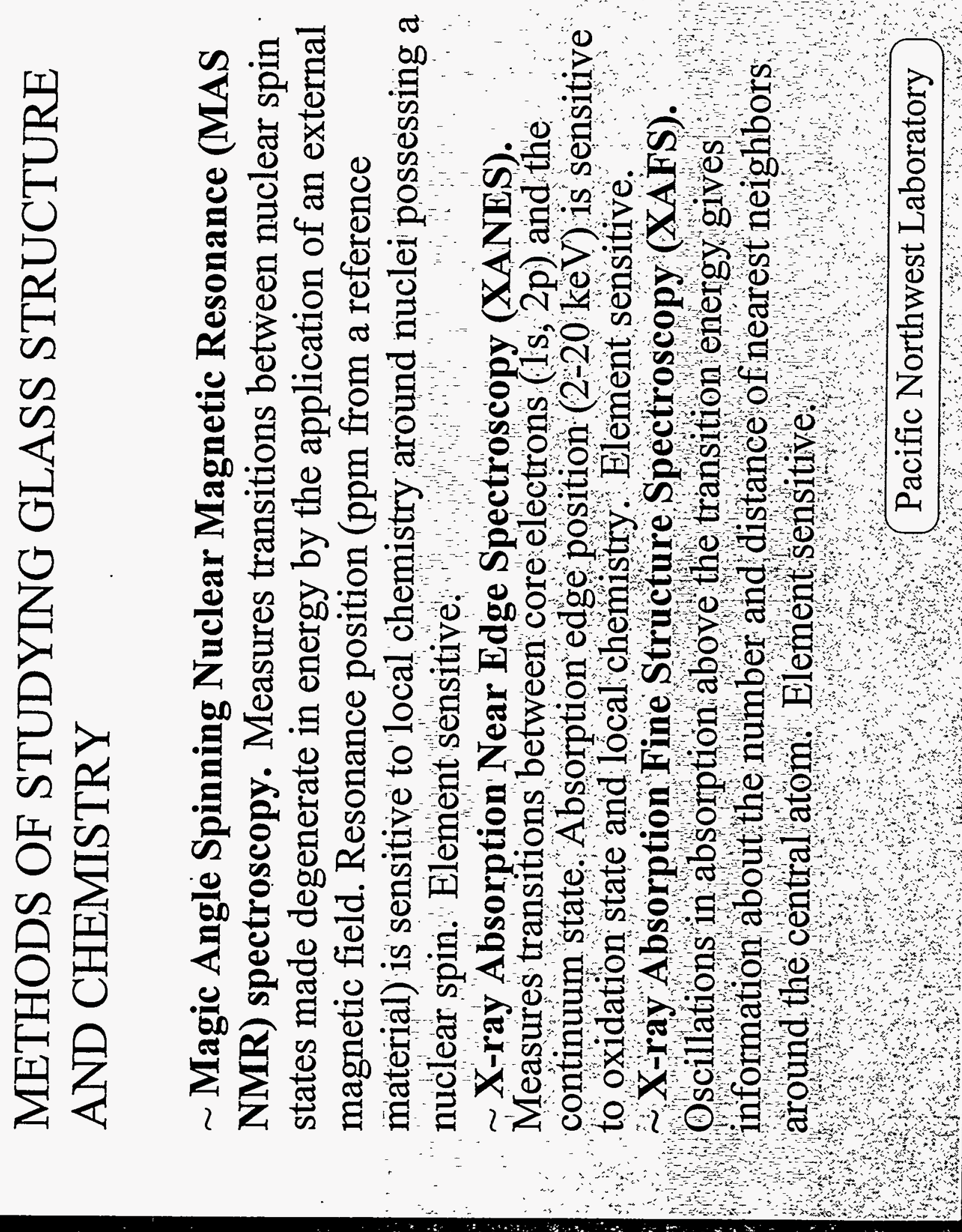




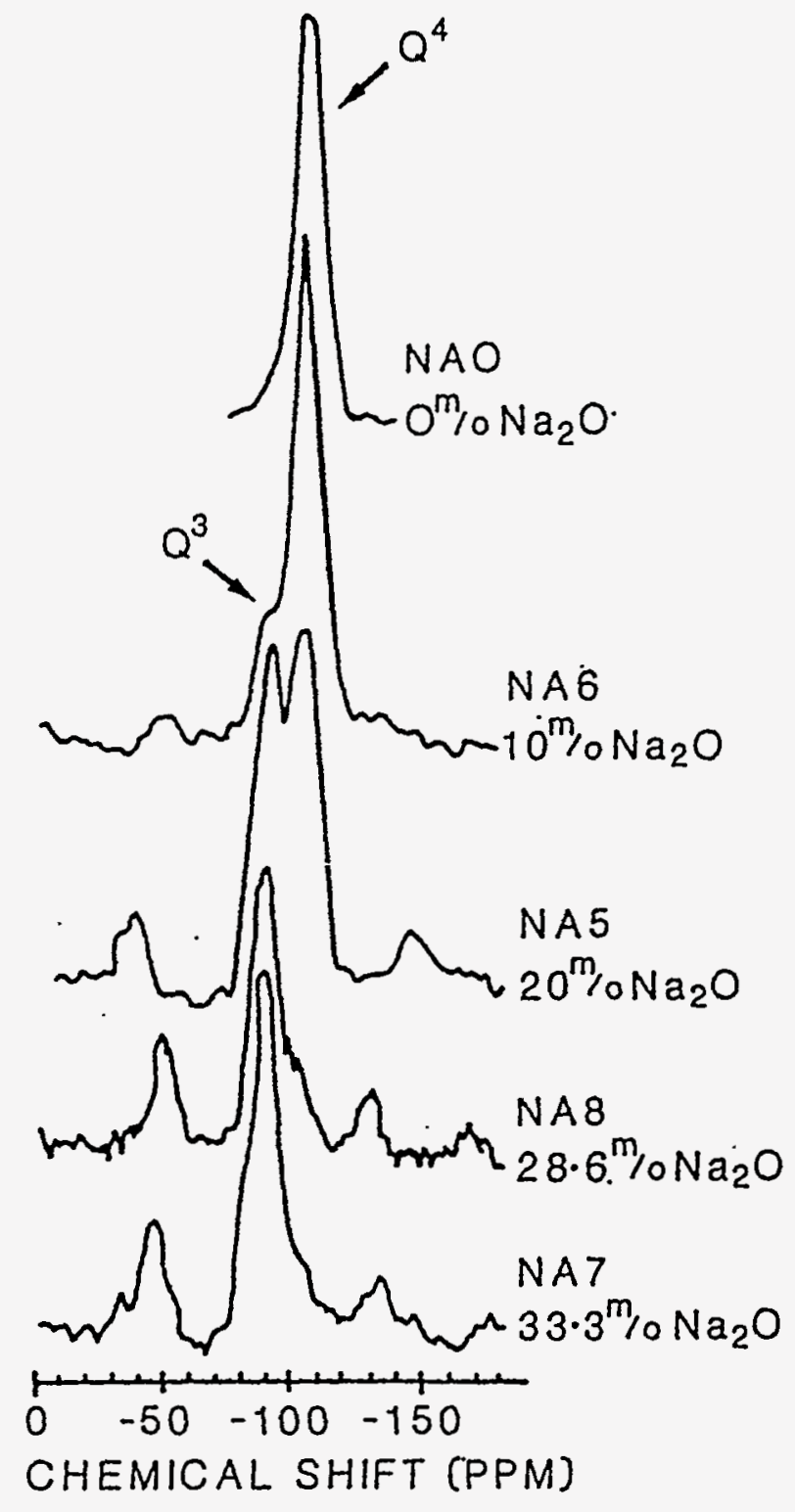

Figure 34. ${ }^{20} \mathrm{Si} \mathrm{MAS} N \mathrm{NMR}$ spectra of glasses in the $\mathrm{Na}_{2} \mathrm{O}-\mathrm{SiO}_{3}$ system. Note the presence of peaks for Si-sites with $Q^{4}(-111 \mathrm{ppm})$ and $Q^{3}(-85 \mathrm{ppm})$ polymerizations. After Dupree et al. (1984). 


\section{LD6-5510 SI29 MAS NMR}

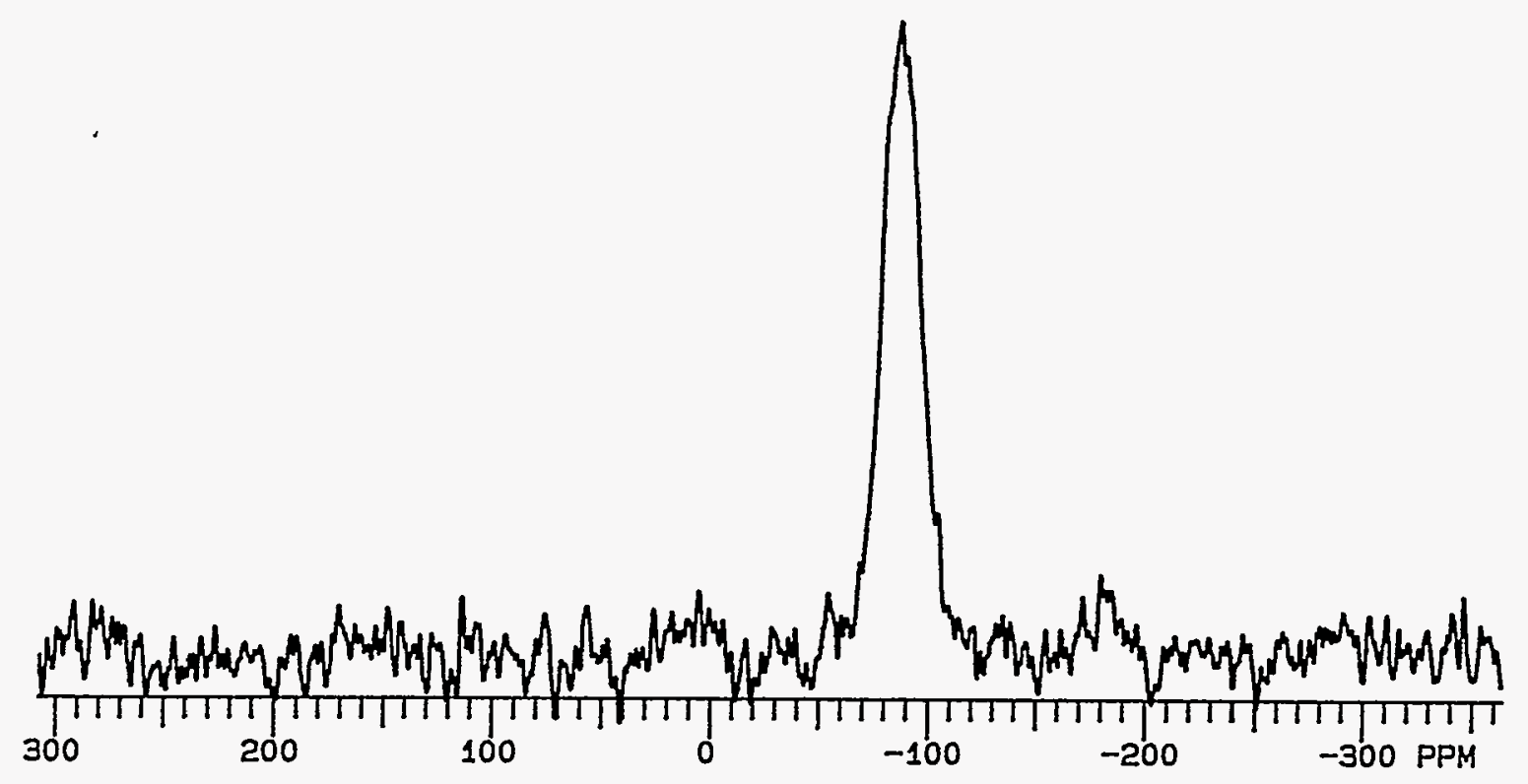




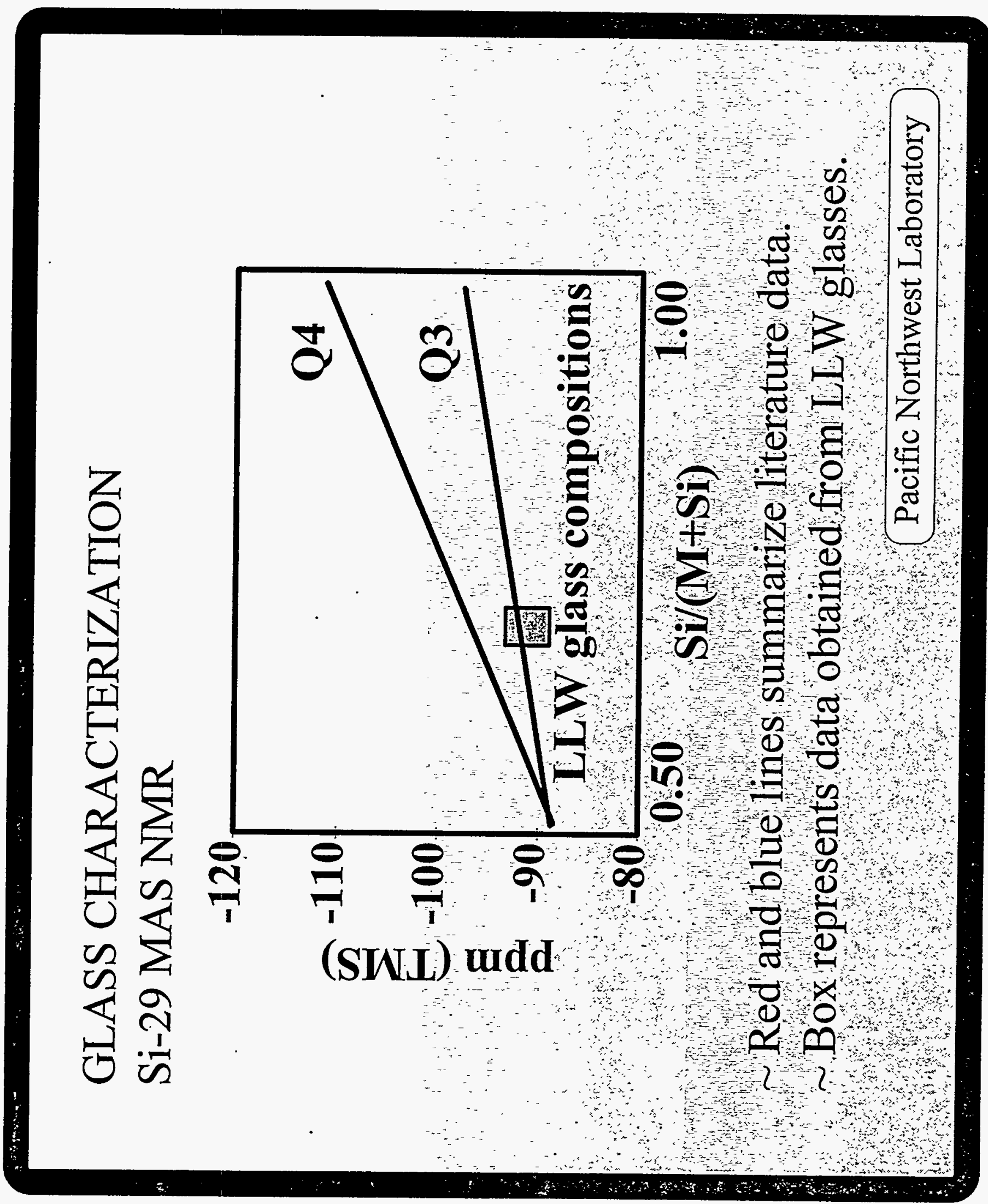




\section{ALUMINUM-27}

A

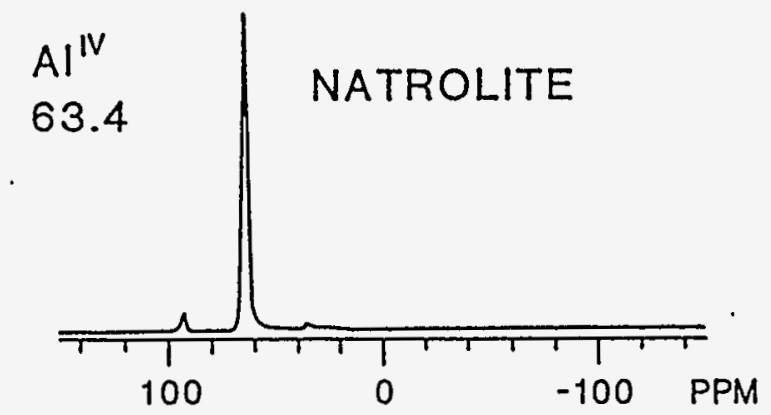

C

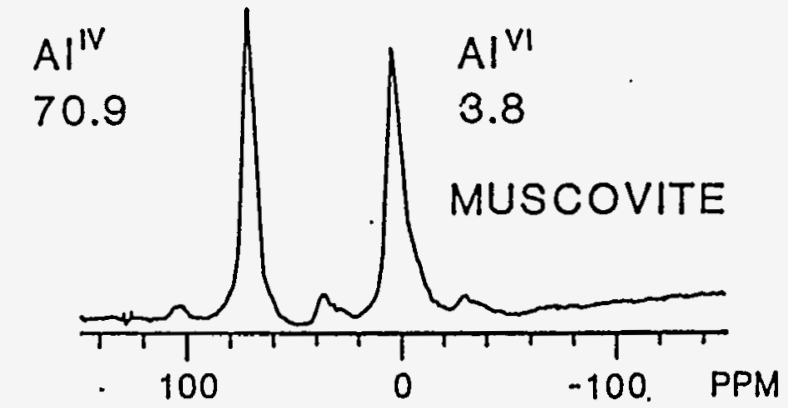

B

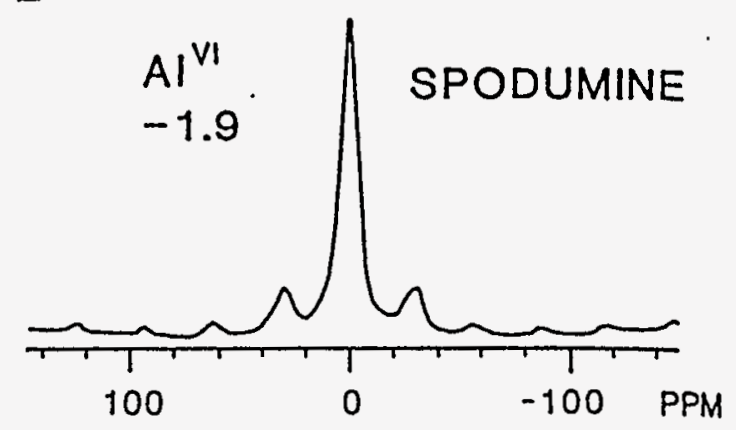

D

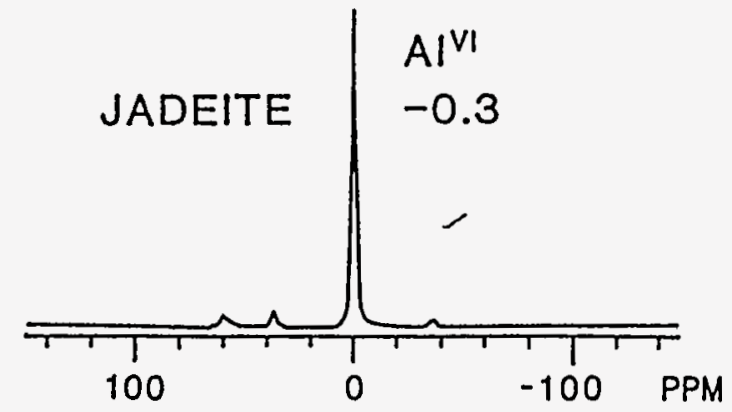

Figure 14. ${ }^{27} \mathrm{Al}$ MAS NMR spectra of aluminosilicate crystals, showing the excellent resolution of signals for $\mathrm{AlV}^{\mathrm{IV}}$ and $A \mathrm{I}^{\mathrm{VI}}$. A $\mathrm{I}^{\mathrm{IV}}$ falls in the range +50 to $+80 \mathrm{ppm}$, and Alv in the range -10 to $+20 \mathrm{ppm}$ at $\mathrm{H}_{0}=11.7 \mathrm{~T}$. Alv falls in the range of about +30 to $+40 \mathrm{ppm}$. 


\section{LD6-5510 AL27 MAS NMR}

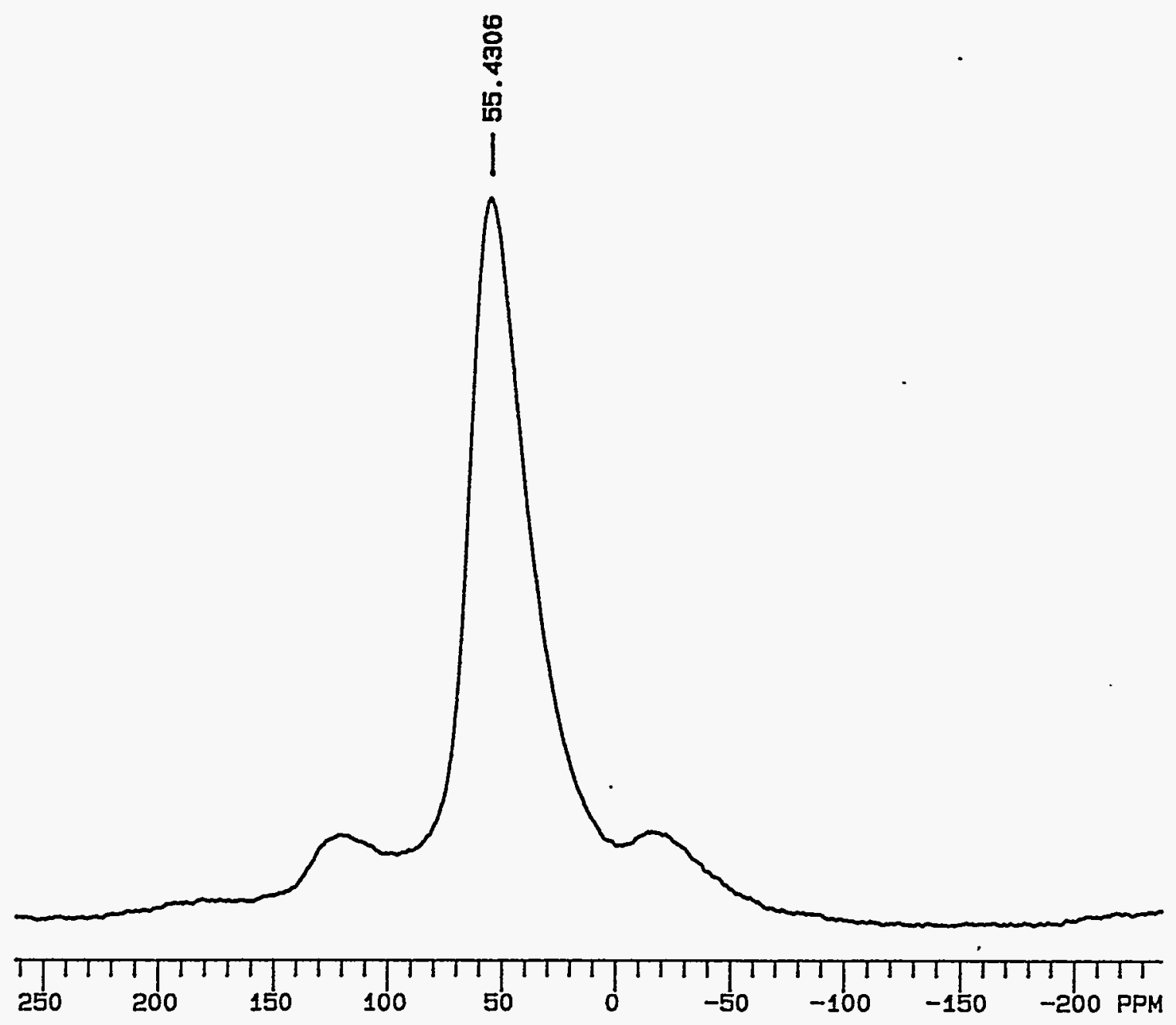




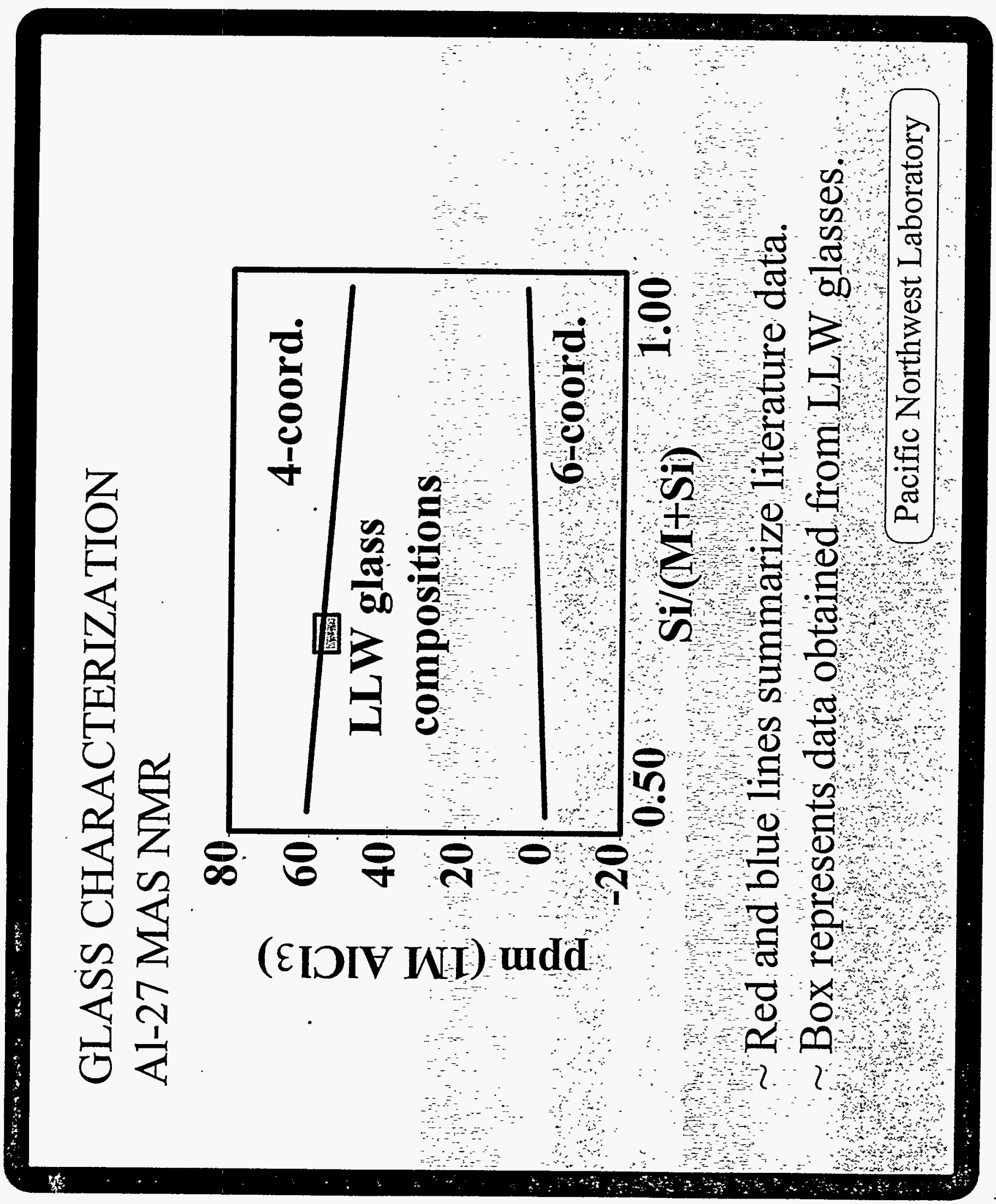




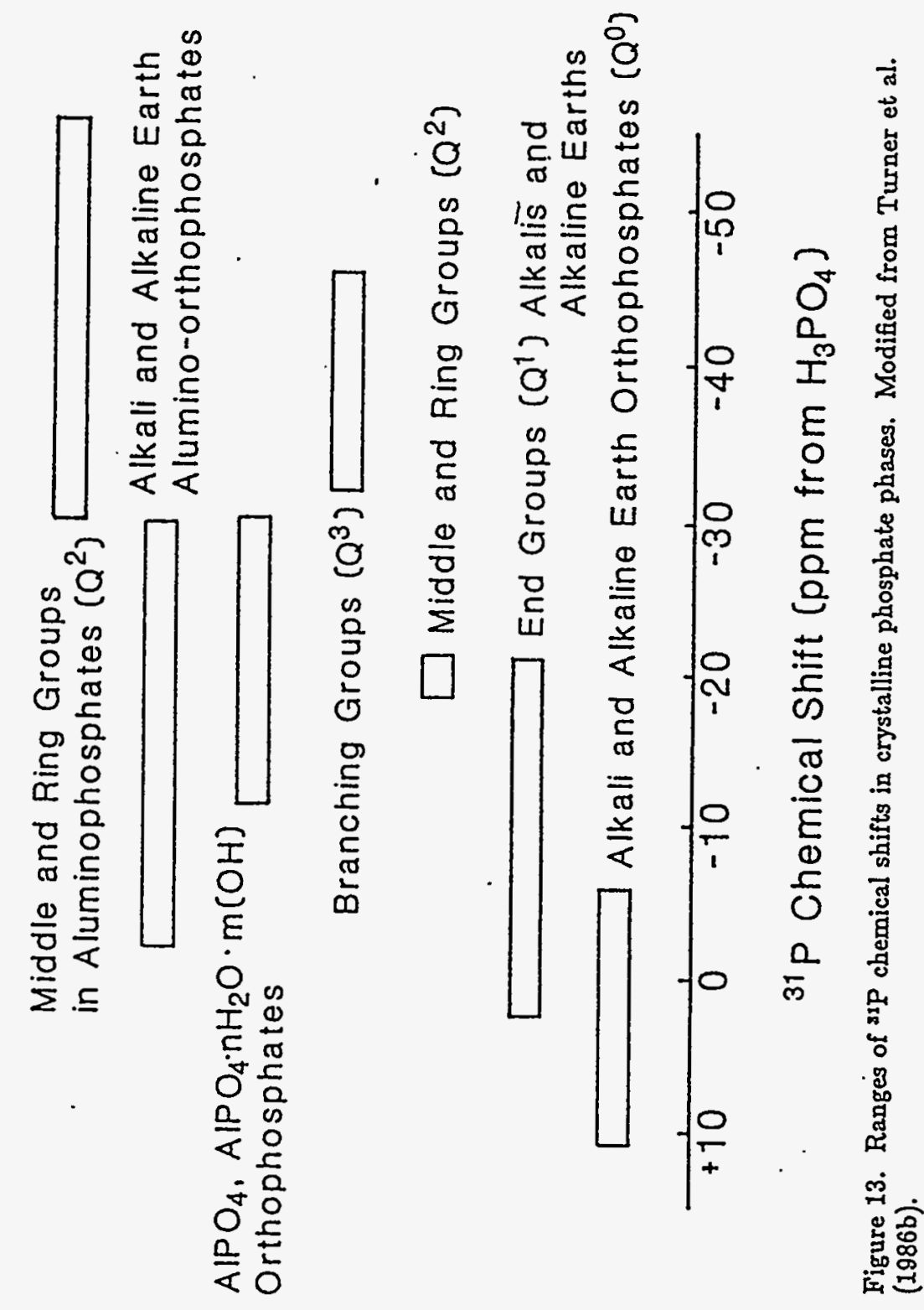


L4-9012 W/S AND P ADD., P31 MAS NMR

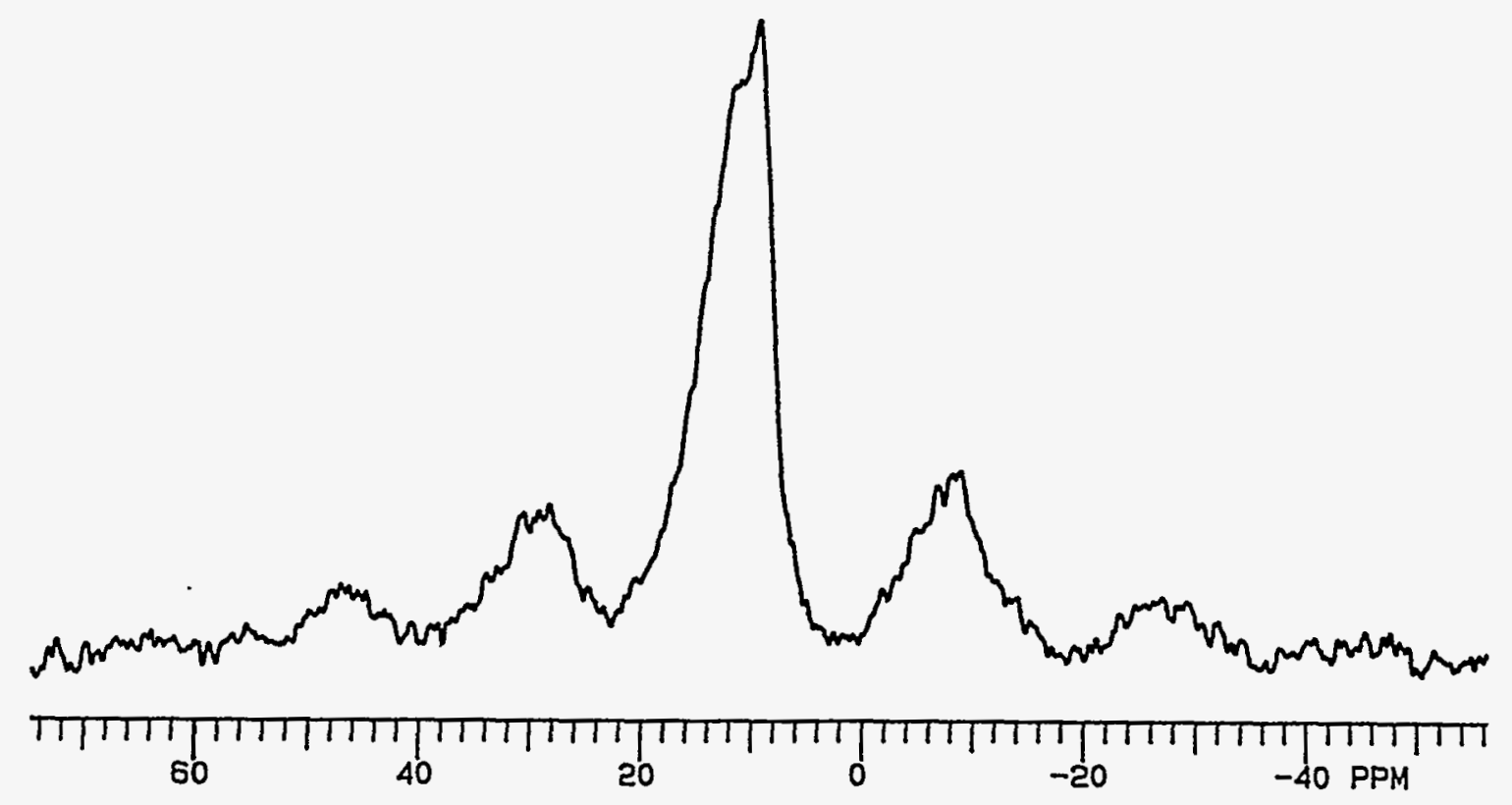




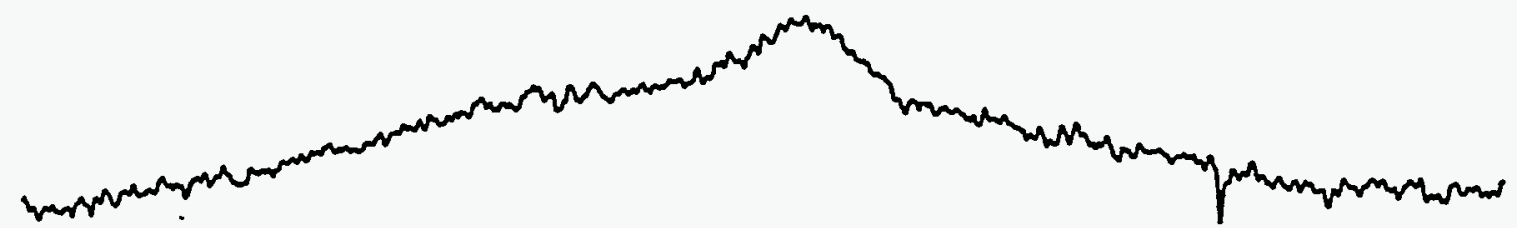

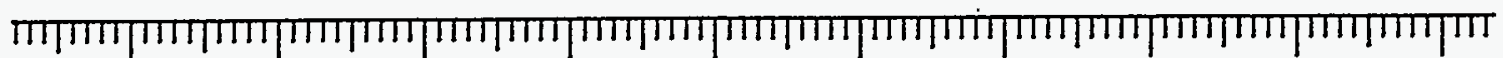

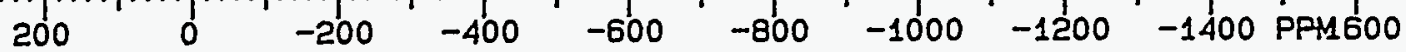




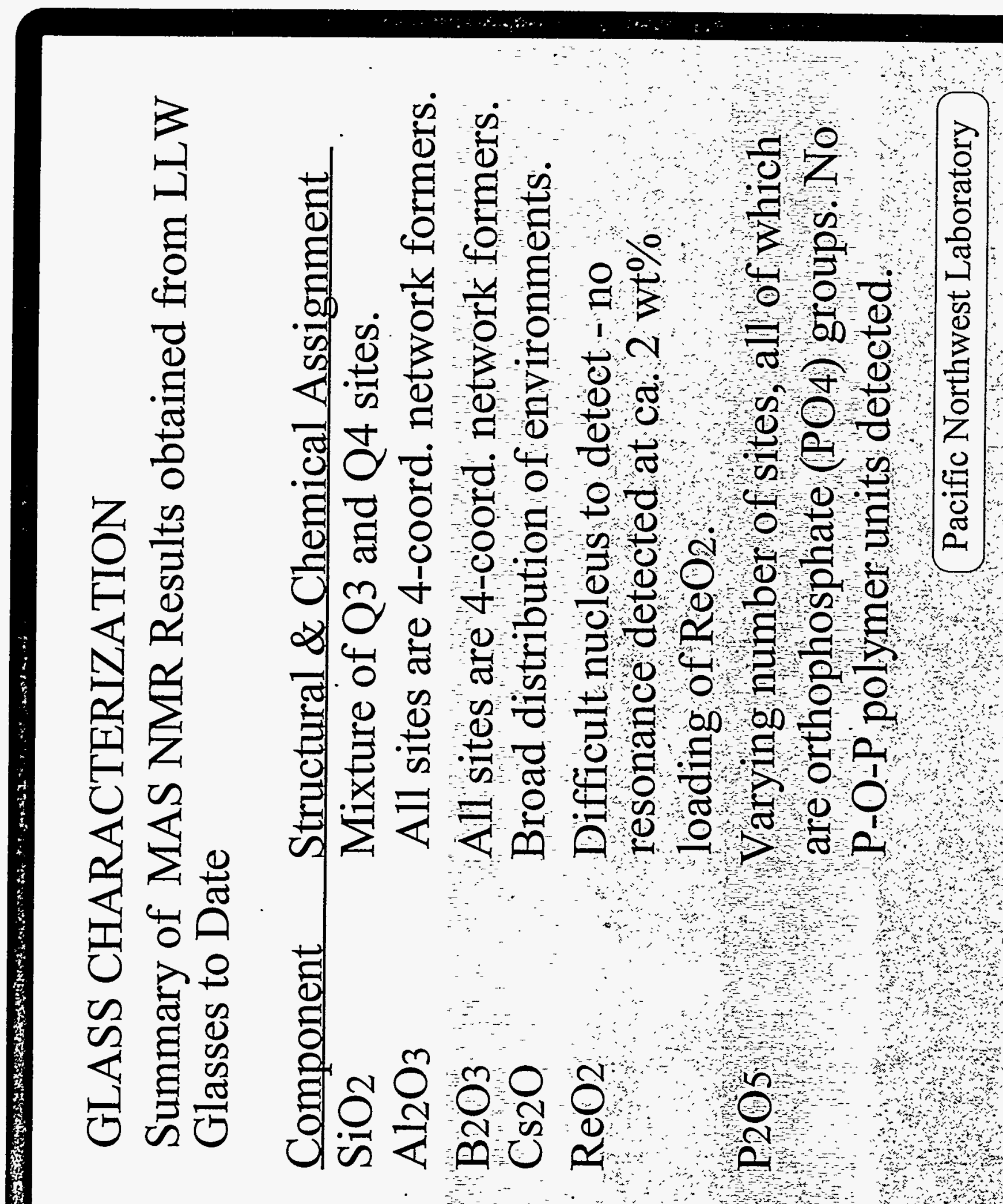




\section{Cr K-Edge Features of Simulated Hanford L6-5412 Based Low-Level Waste Glasses Batched from Various Amounts of $\mathrm{Cr}_{2} \mathrm{O}_{3}$.}

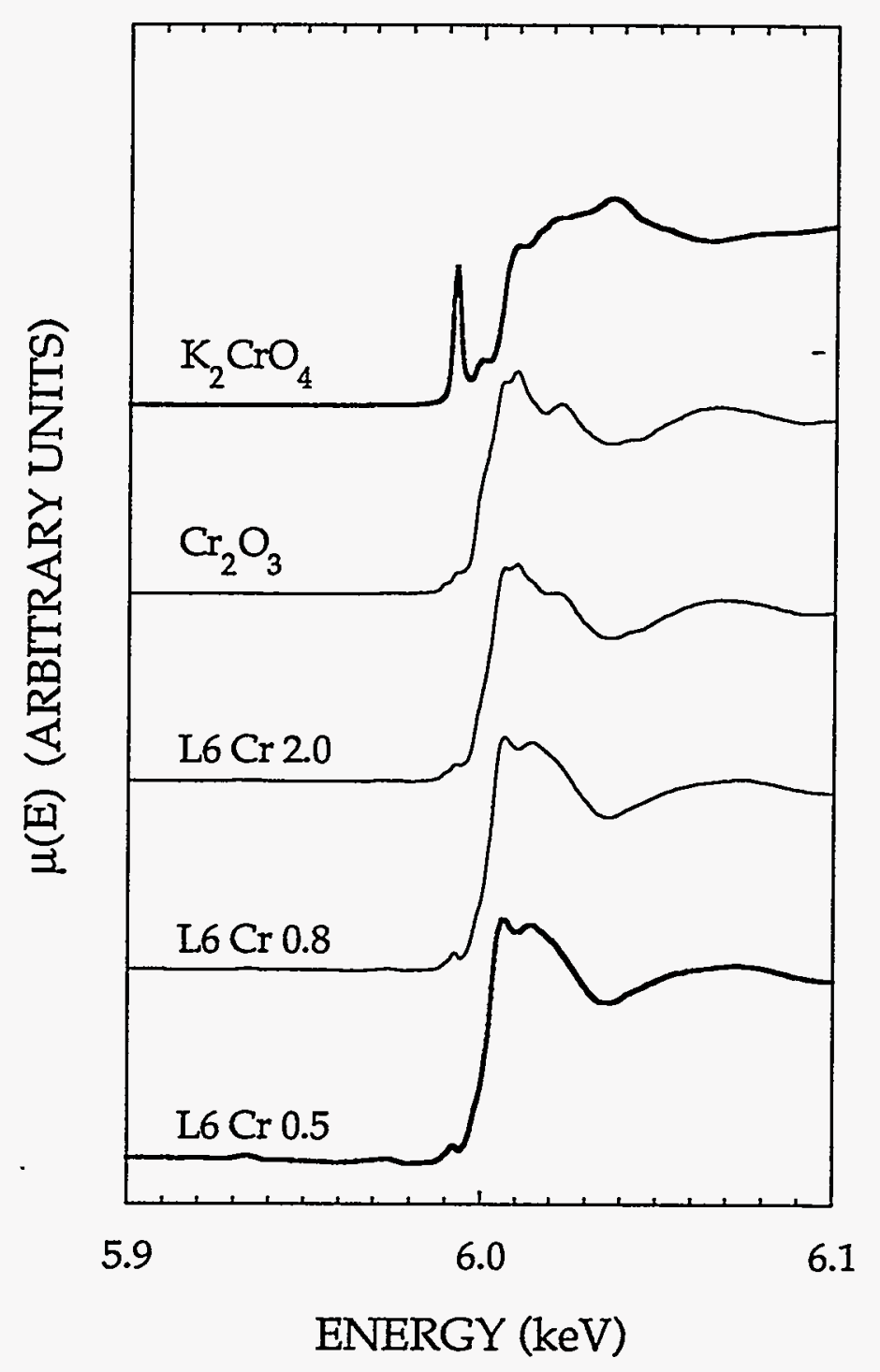

$\sim$ Edge energy is sensitive to oxidation state. $\sim$ Pre-edge feature is sensitive to coordination symmetry and oxidation state. 


\section{Cr K-Edge and XAFS of $\mathrm{K}_{2} \mathrm{CrO}_{4}$.}

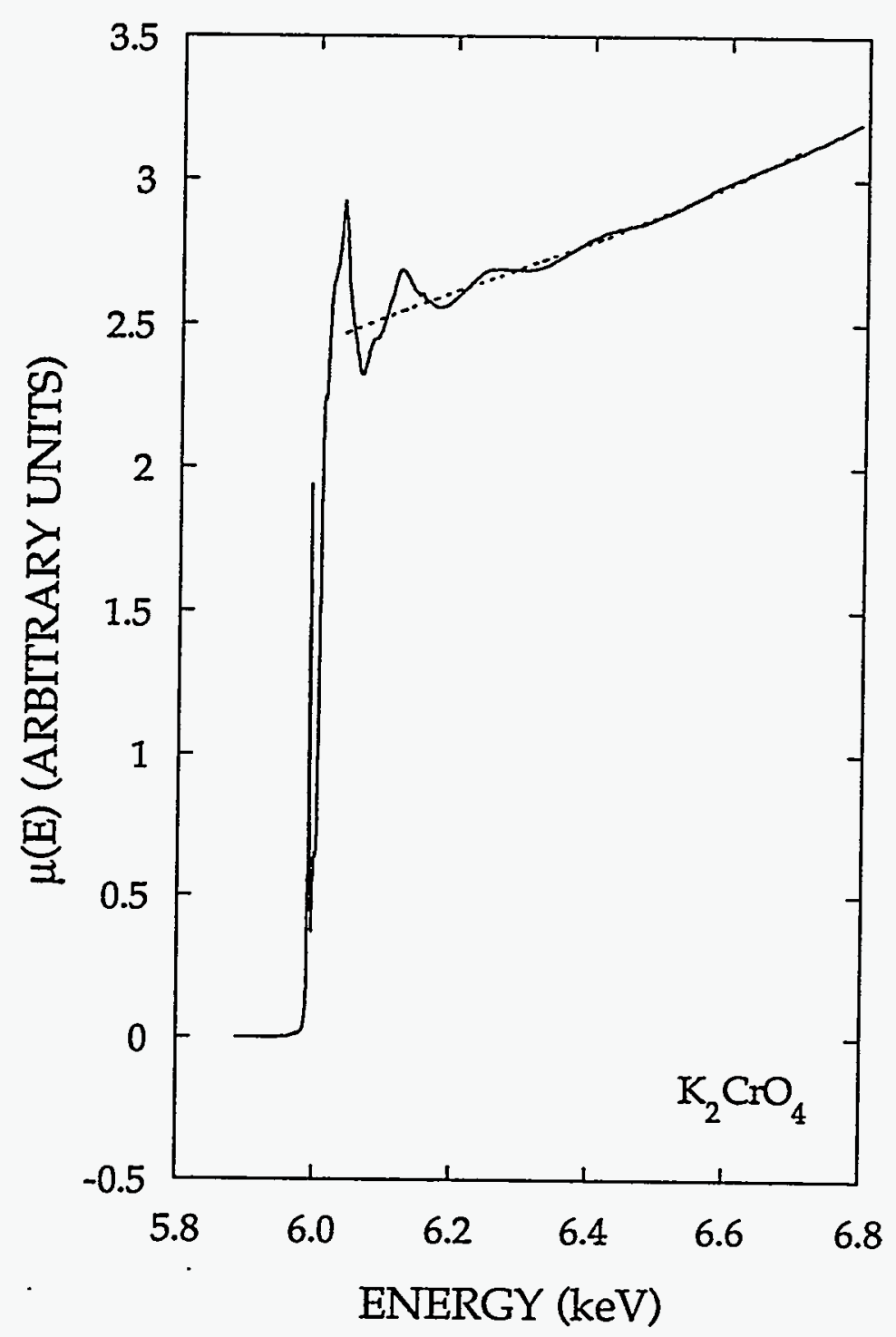

$\sim$ X-ray absorption coefficient, $\mu(\mathrm{E})$

$\sim$ Edge energy, $\mathrm{E}_{0}\left(=6008 \mathrm{eV}\right.$ for $\left.\mathrm{K}_{2} \mathrm{CrO}_{4}\right)$

$\sim$ Background $X$-ray absorption coefficient

(dashed line), $\mu_{0}(\mathrm{E})$

$\sim$ XAFS region starts $\approx 30 \mathrm{eV}$ above $\mathrm{E}_{0}$. 


\section{Extracted XAFS Data for $\mathrm{K}_{2} \mathrm{CrO}_{4}$.}

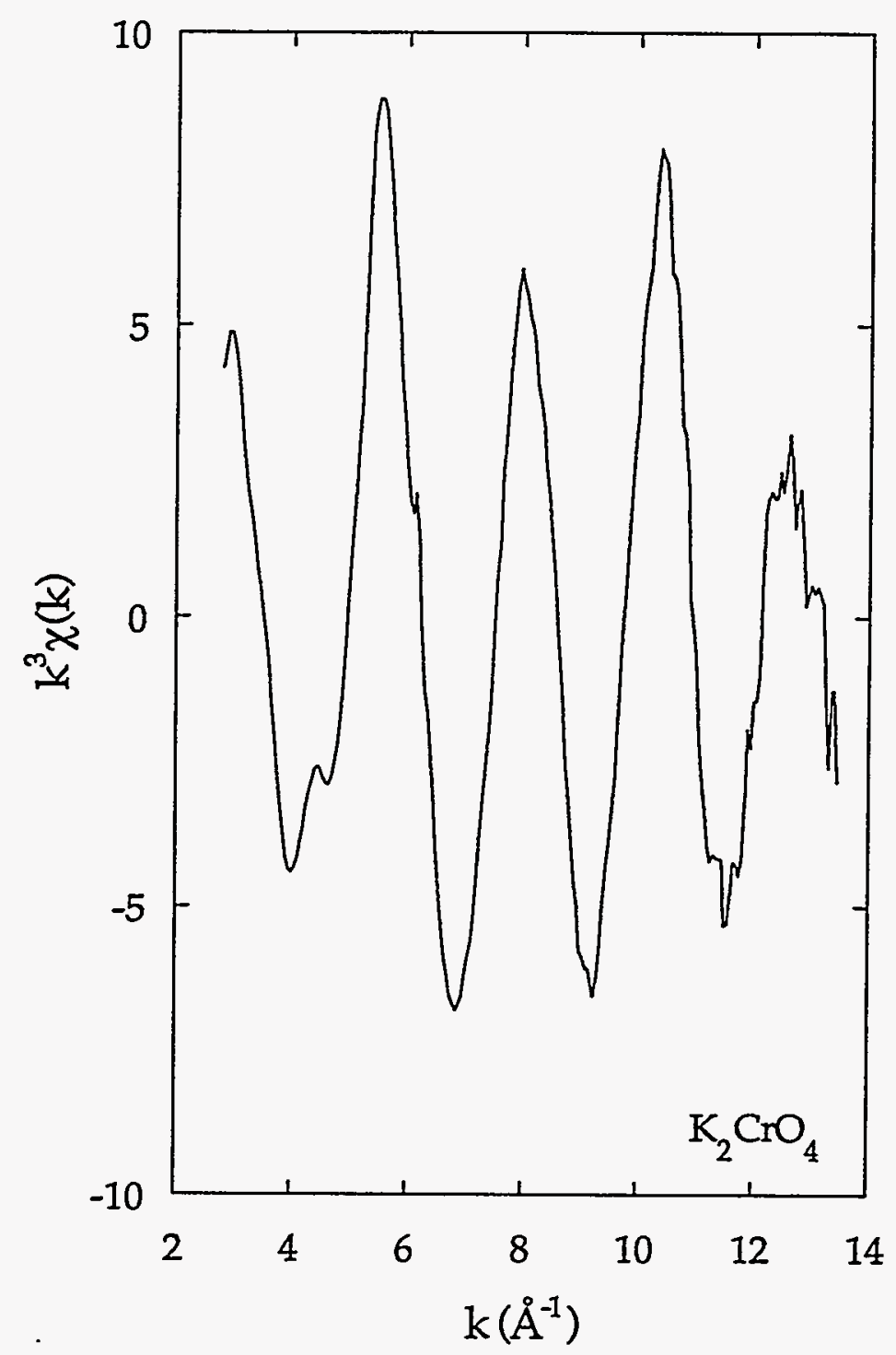

$\sim$ XAFS, $\chi(\mathrm{k})$, is obtained from $\chi(\mathrm{E})$, which equals $\left[\mu(E)-\mu_{0}(E)\right] / \mu_{0}(E)$.

$\sim$ Wave vector, $k$, equals $\left\{\left[2 \mathrm{~m}\left(\mathrm{E}-\mathrm{E}_{0}\right)\right] / \mathrm{h} 2\right\} 1 / 2$.

$\sim$ The amplitude and phase of $\chi(\mathrm{k})$ are related to the number and distance of the nearest neighbors $(\mathrm{NN})$. 


\section{Extracted $\chi(\mathrm{k})$ Data for Simulated Hanford L6-5412 Based Low-Level Waste Glass Batched from 0.5wt\% $\mathrm{Cr}_{2} \mathrm{O}_{3}$.}

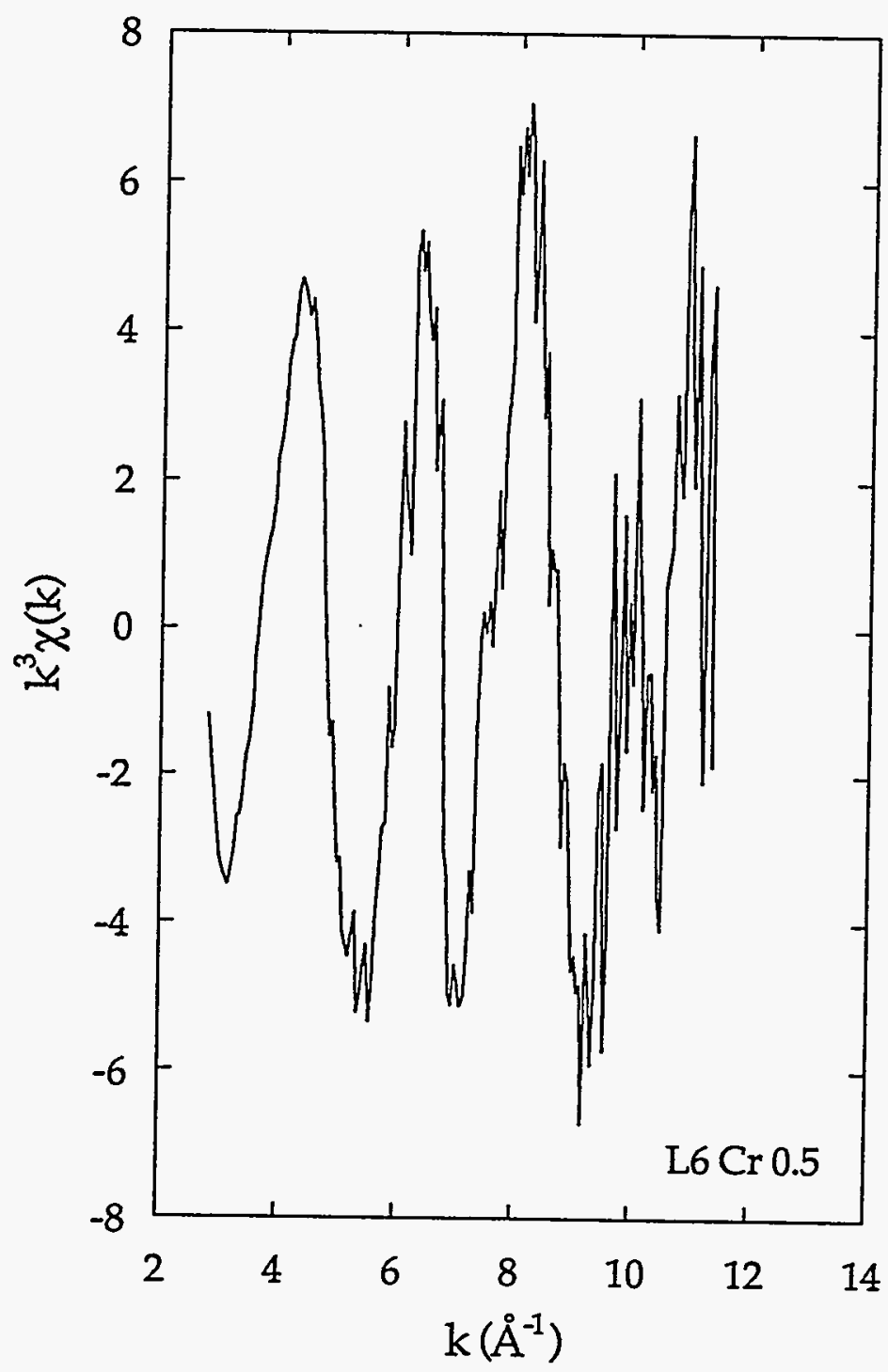

$\sim$ Fourier transformation of $\chi(\mathrm{k})$ gives a radial structure plot. 
Radial Structure Plots of $\mathrm{Cr}$ in Simulated Hanford L6-5412 Based Low-Level Waste Glasses Batched from Various Amounts of $\mathrm{Cr}_{2} \mathrm{O}_{3}$.

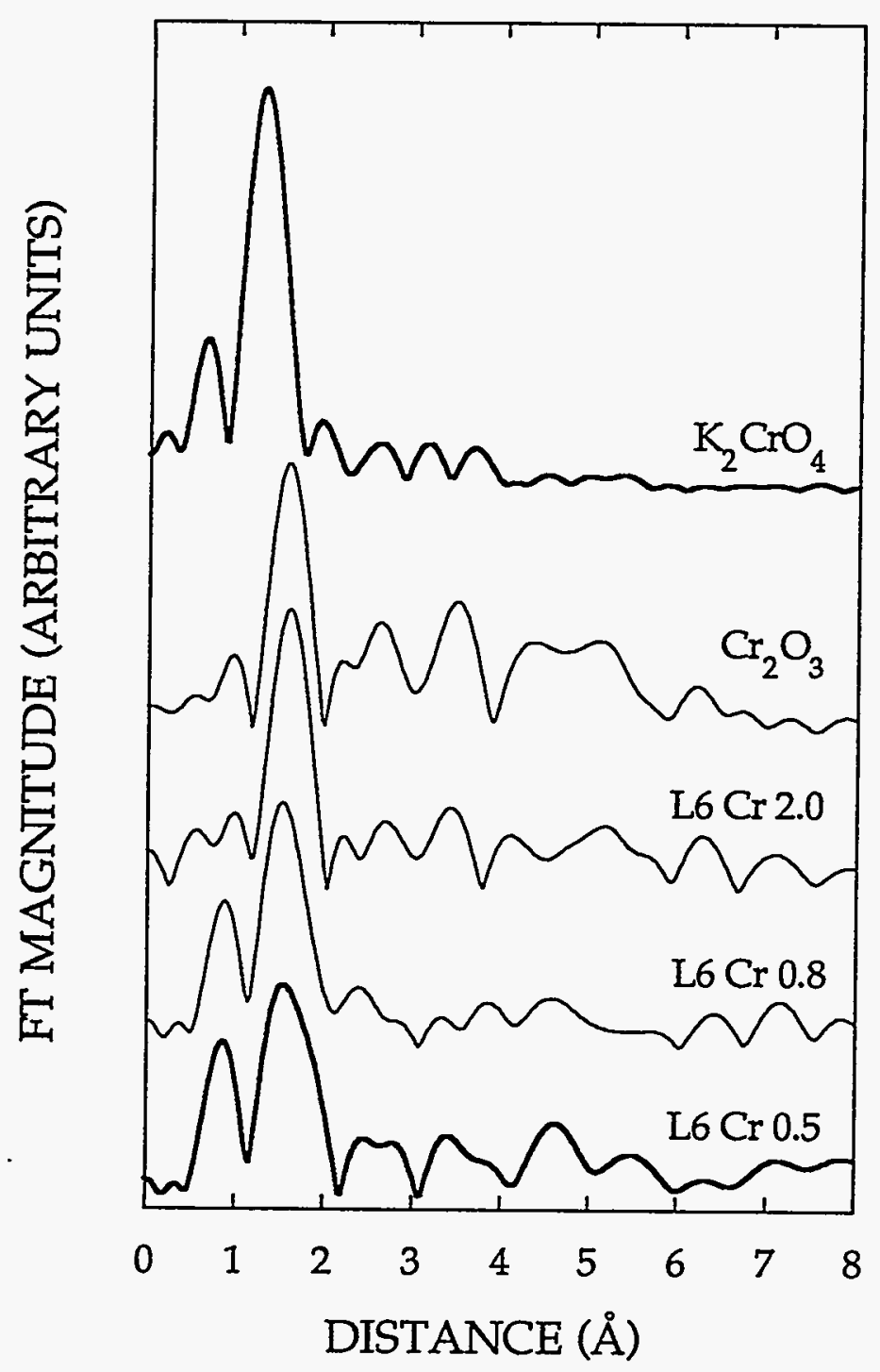

$\sim$ The peak at about $1-2 \AA$ is due to the "shell" of first NNs.

$\sim$ The peak at $<1 \AA$ is an artifact caused by the background subtraction. 


\section{NN Shell Phase Difference and Amplitude Ratio Results For Simulated Hanford Based LLW Glasses using $\mathrm{K}_{2} \mathrm{CrO}_{4}$ as a Standard.}

\begin{tabular}{ccc} 
COMPOUND & $\mathrm{N}$ & $\mathrm{R}(\AA)$ \\
\hline $\mathrm{K}_{2} \mathrm{CrO}_{4}$ & 4.00 & 1.700 \\
$\mathrm{~L} 6 \mathrm{Cr} 2.0$ & 5.3 & 2.01 \\
$\mathrm{~L} 6 \mathrm{Cr} 0.8$ & 5.7 & 2.00 \\
$\mathrm{~L} 6 \mathrm{Cr} 0.5$ & 5.8 & 2.01 \\
$\mathrm{~L} 4 \mathrm{Cr} 1.0$ & 5.2 & 1.99
\end{tabular}




\section{Fit of Back Fourier Transformed NN Shell of Simulated Hanford L6-5412 Based LLW 0.5wt\% $\mathrm{Cr}_{2} \mathrm{O}_{3}$ Glass Using Two Coordination Environments.}

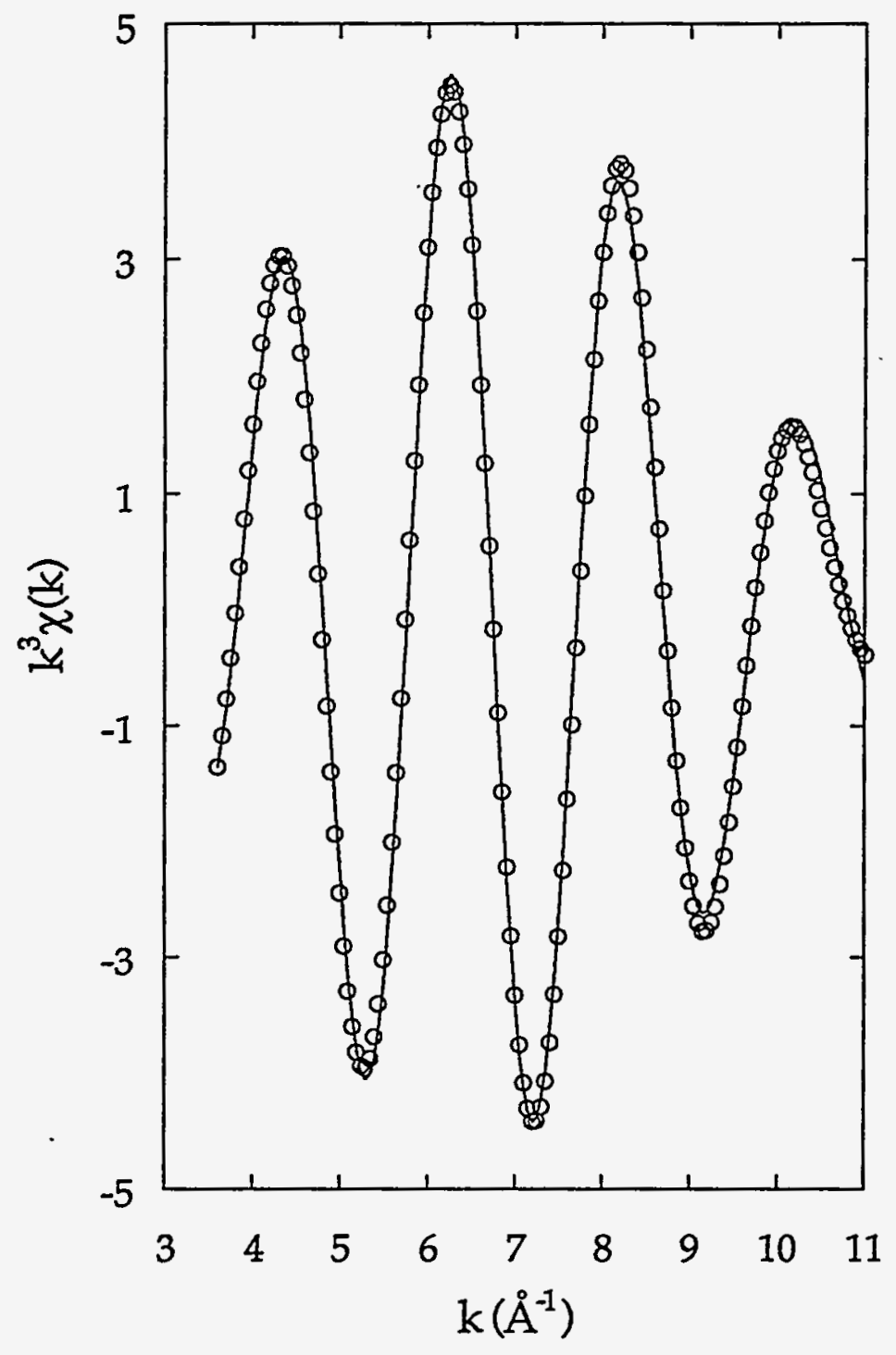

Site 1: $N_{1}=4.8 @ R_{1}=2.11 \AA$ Site 2: $\mathrm{N}_{2}=1.5 @ \mathrm{R}_{2}=2.06 \AA$ Mean : $\mathrm{N}_{\mathrm{T}}=6.3 @ \mathrm{R}_{\mathrm{M}}=2.08 \AA$ 


\section{Correlation between S K-Edge Chemical Shifts and S Formal Oxidation State for Various Inorganic Sulfur-Oxygen Compounds.}

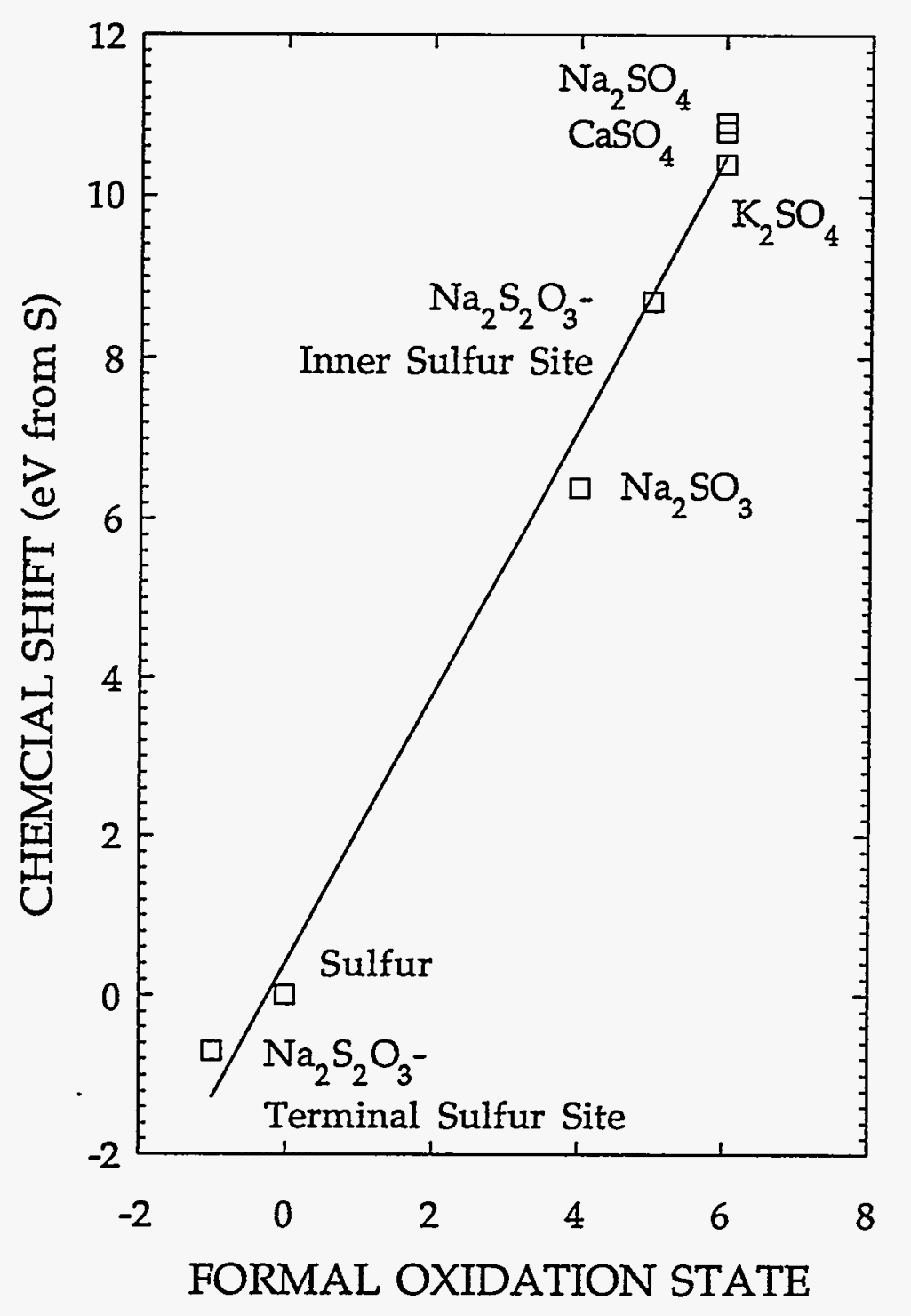

$\sim$ Sulfur chemical shift in LLW glasses $\approx 10.8 \mathrm{eV}$ 
$\mathrm{Cl}$ First Derivative K-Edge Features of Simulated Hanford L6-5412 Based Low-Level Waste Glasses Batched from Various Amounts of $\mathrm{NaCl}$.

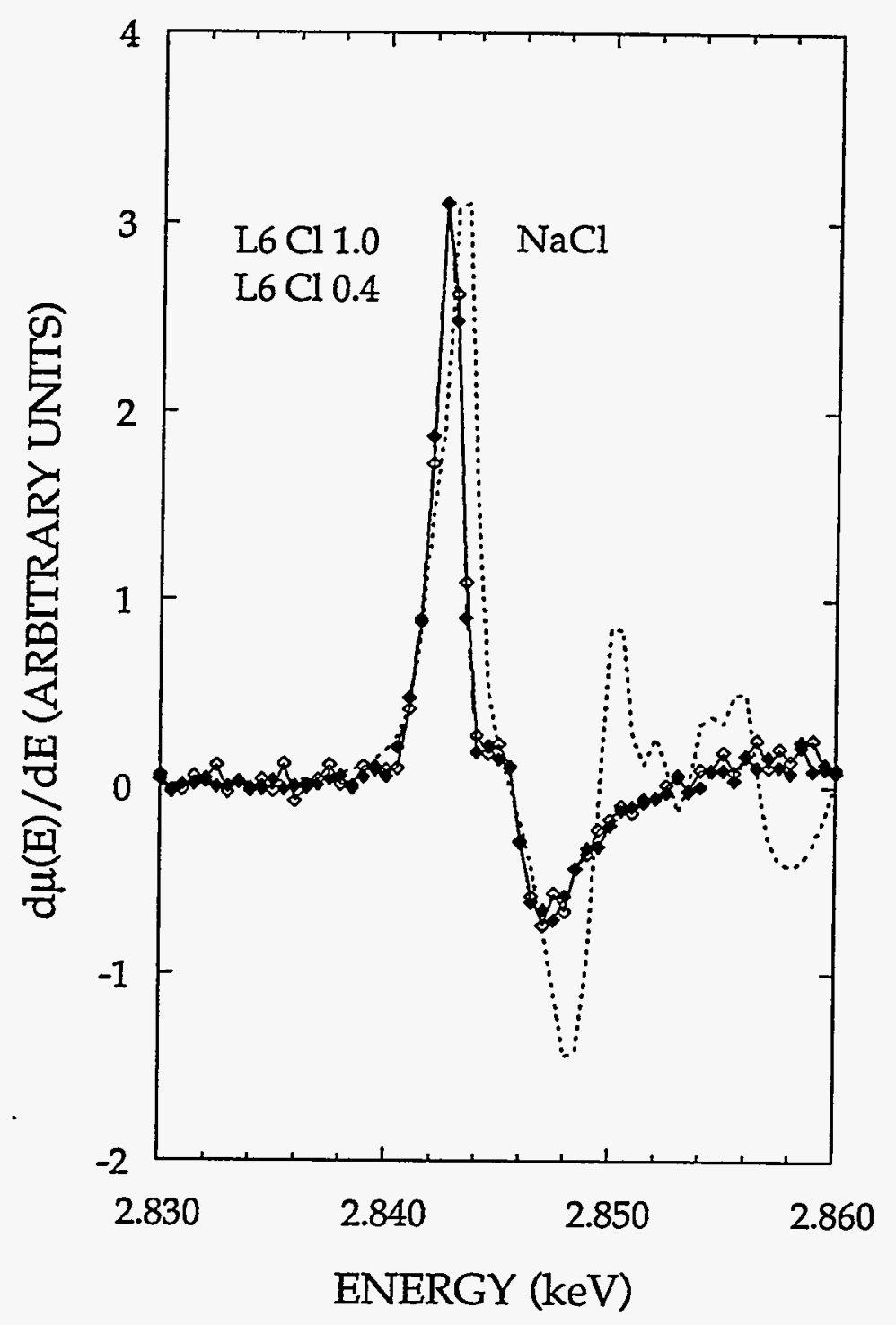

$\sim$ Oxidation state of $\mathrm{Cl}$ in L6-5412 glasses $\approx-1$ ? 


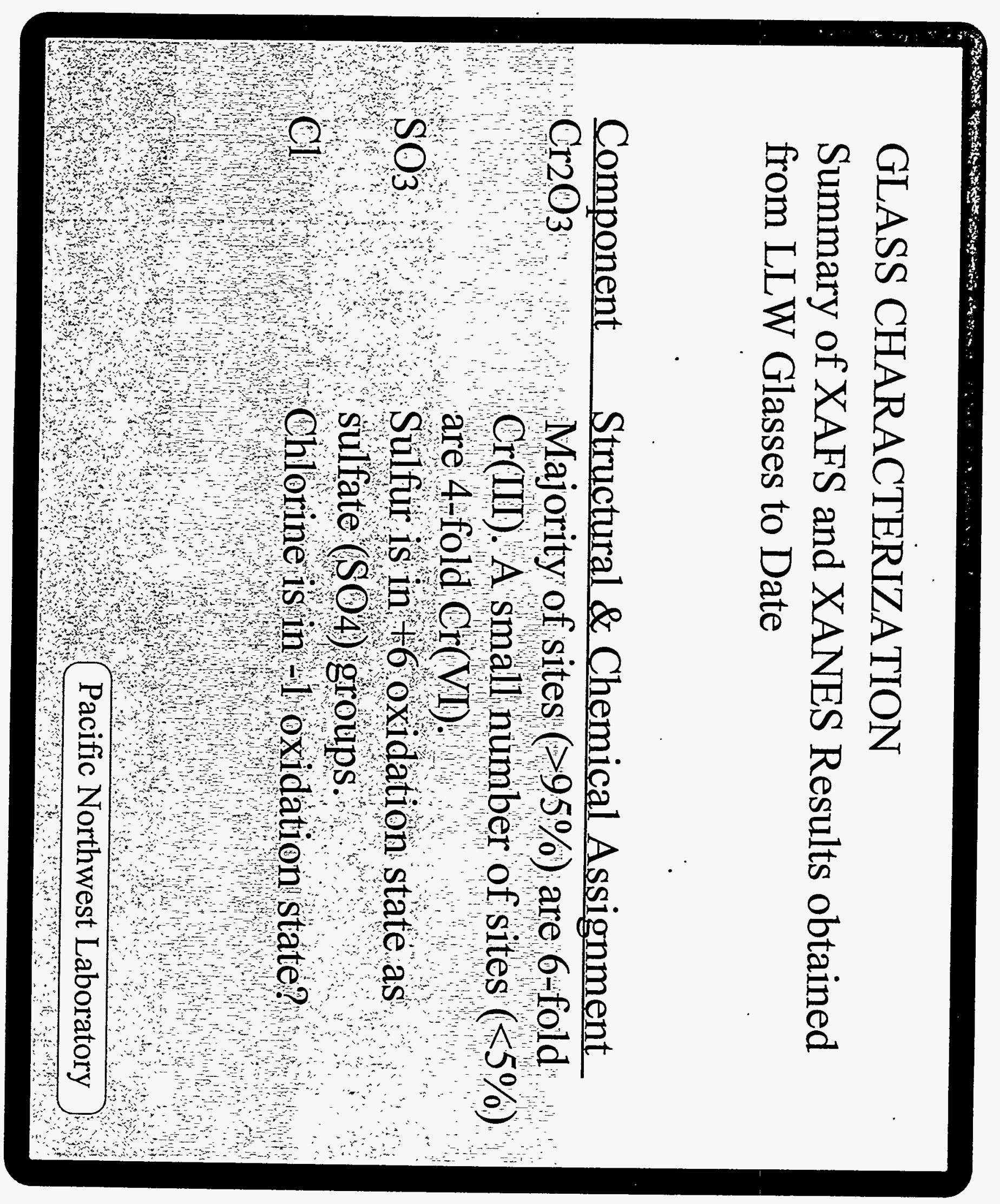




\title{
Corrosion of Electrodes and Refractories in Waste Vitrification Technology
}

To

Westinghouse Hanford Company

June 27-28, 1995

\author{
By \\ S. K. Sundaram*
}

Coauthors: D. A. Lamar, G. L. Smith, and P. A. Smith

Pacific Northwest Laboratories

Richland, Washington

* Supported by AWU, NW under Grant DE-FG06-89ER-75522 or DE-FG06-92RL-12451 with the U. S. Department of Energy. P 


\section{Outline}

- Melter Technology

- Big Picture

- Electrode Corrosion

Testing

Materials

Glasses

Corrosion Rates

Summary

- Refractory Corrosion

Testing

Materials

Glasses

Corrosion Rates

Summary

- Future Trend 


\section{Melter Technology Chronological Review}

\begin{tabular}{|c|c|c|}
\hline Melter & $\begin{array}{l}\text { Electrode Corrosion } \\
\text { (mils/day) }\end{array}$ & $\begin{array}{l}\text { Refractory Corrosion } \\
\text { (mils/day) }\end{array}$ \\
\hline Engineering Scale & Nickel-chrome alloy & Monofrax E \\
\hline Ceramic Melter(1976) & 2.4-27.3 wt\% & \\
\hline Calcined Fed Melter & Inconel 690 rods & Monofrax K3 \\
\hline (CFM, SRL) (1983) & 0.50 & 2.76 \\
\hline Small Cyl. Melter-2 & Inconel 690 & \\
\hline$(\mathrm{SCM}-2, \mathrm{SRL})(1983)$ & $0.07-1.51$ & \\
\hline Large Scale Melter & Inconel 690 & Monofrax K3 \\
\hline$(\mathrm{SRL})(1984)$ & 0.54 & 2.70 \\
\hline Pilost-Scale Field Test & Graphite & \\
\hline (PSFT, PNL)(1984) & $\begin{array}{l}\text { Molybdenum } \\
11.34-48.03 \\
\text { nominal-pitting }\end{array}$ & \\
\hline $\begin{array}{l}\text { Small Cyl. Melter } \\
\text { (SCM, SRL)(1985) }\end{array}$ & $\begin{array}{c}\text { Inconel } 690 \\
0.27-1.50\end{array}$ & $\begin{array}{l}\text { Monofrax K3 } \\
1.81-5.53\end{array}$ \\
\hline $\begin{array}{l}\text { Penberthy joule-heated } \\
\text { melter }(M R C)(1985)\end{array}$ & High purity iron & $\begin{array}{l}\text { Fused cast AZS } \\
0.19\end{array}$ \\
\hline Large Slurry Fed Melter & Inconel 690 & Monofrax K3 \\
\hline (LSFM, SRL)(1985) & $\begin{array}{l}0.30,0.12-0.20 \text { (thermo- } \\
\text { well, } 302 \text { days) }\end{array}$ & 0.98 \\
\hline Pilot Scale Ceramic & Inconel 690 & Monofrax K3 \\
\hline Mleter (PSCM,PNL)(1986) & $(6.8 \%)$ & $\begin{array}{l}0.52 \text { Melt line } \\
0.26 \text { Half-down }\end{array}$ \\
\hline Liquid· Fed Ceramic & Inconel 690 & Monofrax K3 \\
\hline Melter (LFCM, PNL)(1986) & 0.12 & 0.92 \\
\hline $\begin{array}{l}\text { Joule Ceramic Melter } \\
\text { (JCM, Harwell, UK)(1986) } \\
\text { Cogema Vitrification } \\
\text { (French)(1986) }\end{array}$ & $\begin{array}{l}\text { Inconel } 690 \\
4.2-14.6 \% \\
\text { Inconel (melt } \\
\text { containment) }\end{array}$ & Monofrax K3 \\
\hline $\begin{array}{l}\text { Liquid Active Waste } \\
\text { (Russian)(1990) }\end{array}$ & $\begin{array}{l}\mathrm{SnO} \mathrm{O}_{2} \text { with } \mathrm{Monel}(70 \% \mathrm{Ni}- \\
30 \% \mathrm{Cu}) \text { or } 70 \% \mathrm{Ni}-15-17 \% \\
\mathrm{Cr}-\mathrm{Balance} \mathrm{Ti}) 0.38-0.76\end{array}$ & $\begin{array}{l}\text { XAU,1.1-1.5 } \\
\text { Bakor-33 ,3.8-5.3 } \\
\text { Chamotte,7.6-9.5 }\end{array}$ \\
\hline PSCM,PNL (1990) & Inconel 690 & \\
\hline $\begin{array}{l}\text { EhP-500 Radiactive } \\
\text { Melter (USSR)(1990) }\end{array}$ & Molybdenum & $\begin{array}{l}\text { Aluminozircon } \\
\text { Bakor-30 }\end{array}$ \\
\hline Joule Heated Melter & Molybdenum & Monofrax K3 \\
\hline (JHM, INEL)(1992) & Serious oxidation & 1.3, Monofrax E 0.3 \\
\hline 1994-95 - - & & \\
\hline Terra-Vit (PNL) & Graphite & \\
\hline $\begin{array}{l}\text { DC Arc (PNL- } \\
\text { EPI-MIT) }\end{array}$ & Graphite & \\
\hline $\begin{array}{l}\text { Research Scale Melter } \\
\text { (RSM,PNL) }\end{array}$ & Inconel 690 & Monofrax K3 \\
\hline SSHTM, PNL & Refractory oxide Monofrax $\mathrm{K} 3$ & \\
\hline HTM, PNL & $\begin{array}{l}\text { Refractory oxide Monofrax K3 } \\
\text { Molybdenum }\end{array}$ & \\
\hline
\end{tabular}
Molybdenum 


\section{Big Picture}

Low temperature vitrification $\left(<1200^{\circ} \mathrm{C}\right)$ :

Electrode

Refractory
Inconel 690, No protection

Corrosion rates 0-7.2 mils/day

Monofrax K3

Corrosion rates 0.9-6.0 mils/day

High temperature vitrification

Electrode

Refractory
$\mathrm{Mo}, \mathrm{Ta}, \mathrm{Cr}, \mathrm{Cr}-\mathrm{Al}_{2} \mathrm{O}_{3}, \mathrm{SnO}_{2}$, Pt-10\%Rh, refractory oxide, Protection?

Corrosion rate?

Monofrax K3, C1215Z

Corrosion rate? 


\section{Effect of Temperature on Corrosion}

\section{REFRACTORIES:}

- Temperature dependence (Arrhenius equation): Corrosion rate $=\mathrm{A} \exp (-\mathrm{E} / \mathrm{RT})$

-Corrosion rate doubles for each $50-100^{\circ} \mathrm{C}$ increase in interface temperature $\left(\mathrm{T}_{\mathrm{j}}\right)$. (Trier, 1987)

- Glass fluidity doubles for each $50-100^{\circ} \mathrm{C}$ increase in $\mathrm{T}_{\mathrm{i}}$.

- Flow raises $T_{i}$ enhancing corrosion

- Corrosion rate is roughly proportional to glass fluidity, for a refractory corroded by various glasses of the same chemical family. (Woolley, 1989)

\section{ELECTRODES:}

- Oxidation of metal

-Kinetics: Linear, $x=\mathrm{k}_{\mathrm{L}} \mathrm{t}$; Logarithmic, $\mathrm{x}=\mathrm{k}_{\mathrm{e}} \log (\mathrm{at}+1)$; Inverse logarithmic, $1 / \mathrm{x}=\mathrm{b}-\mathrm{k}_{\mathrm{i}} \log \mathrm{t}$;

Parabolic, $x^{2}=\left(k_{p} / 2\right) t$; Cubic, $x^{3}=k^{\prime} t$. $(x=$ thickness or mass of oxide, $t=$ time $)$

-Protecting/non-protecting

- High temperature creep: logarithmic relationship between stress and creep rate as a function of temperature

- Alloying/eutectic formation 


\section{Electrode Corrosion Test Methods}

Static/Dynamic Isothermal

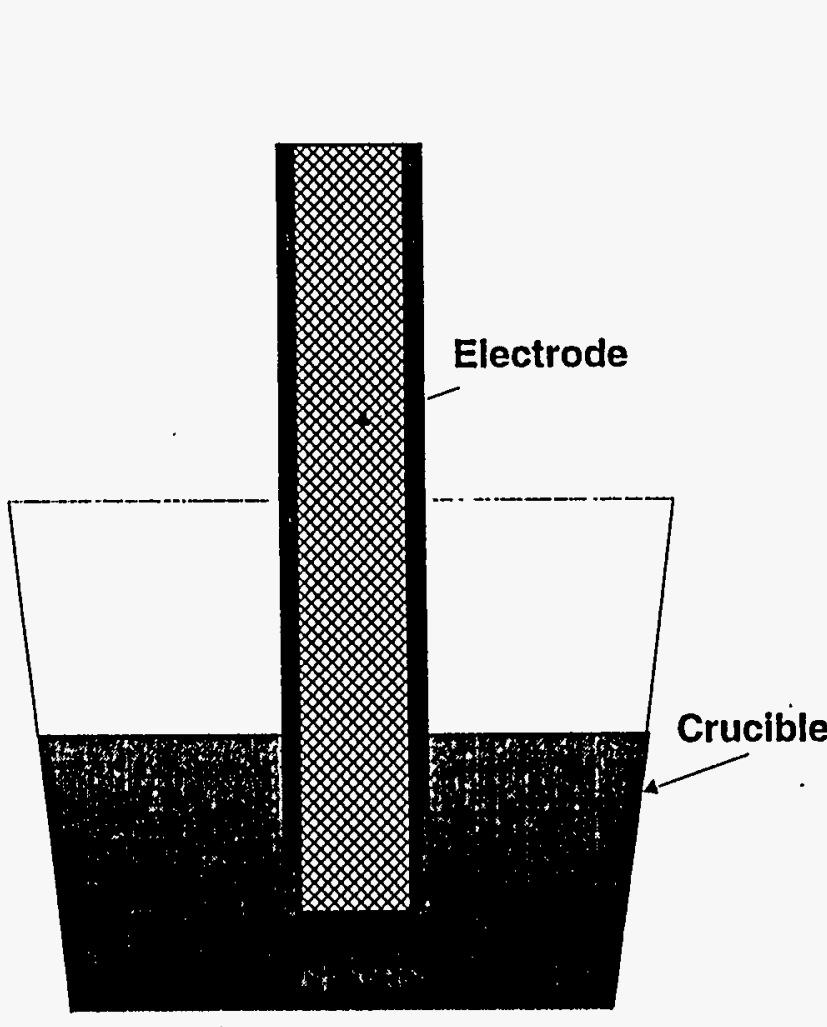

Powered Electrode Test

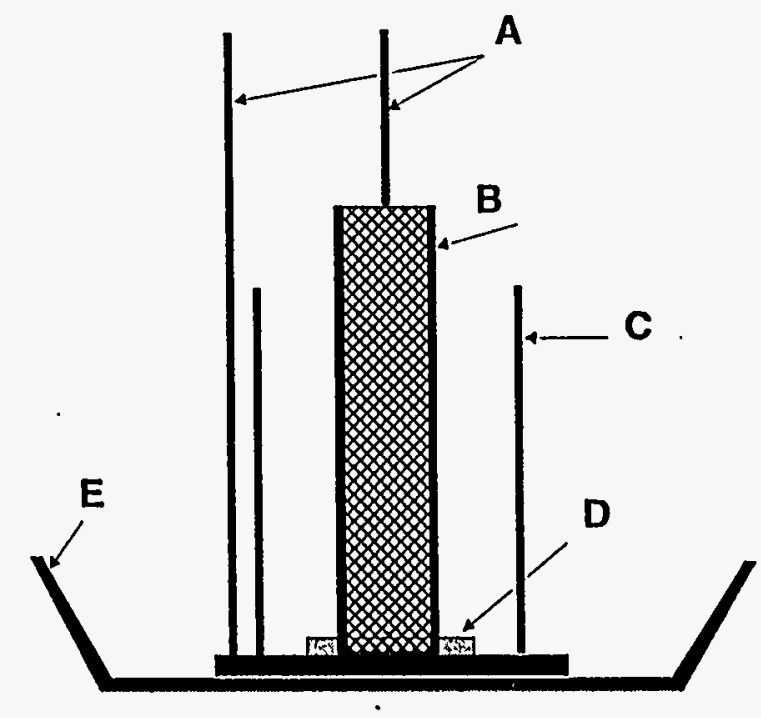

A - Leads from power supply to speciment and crucible (inconel welding rod).

B - Electrode Specimen

C - Crucible made of same material as specimen

D - Alumina insulating disk to prevent shorting and eliminate end effects of current

E - Alumina over flow basin
Service Test

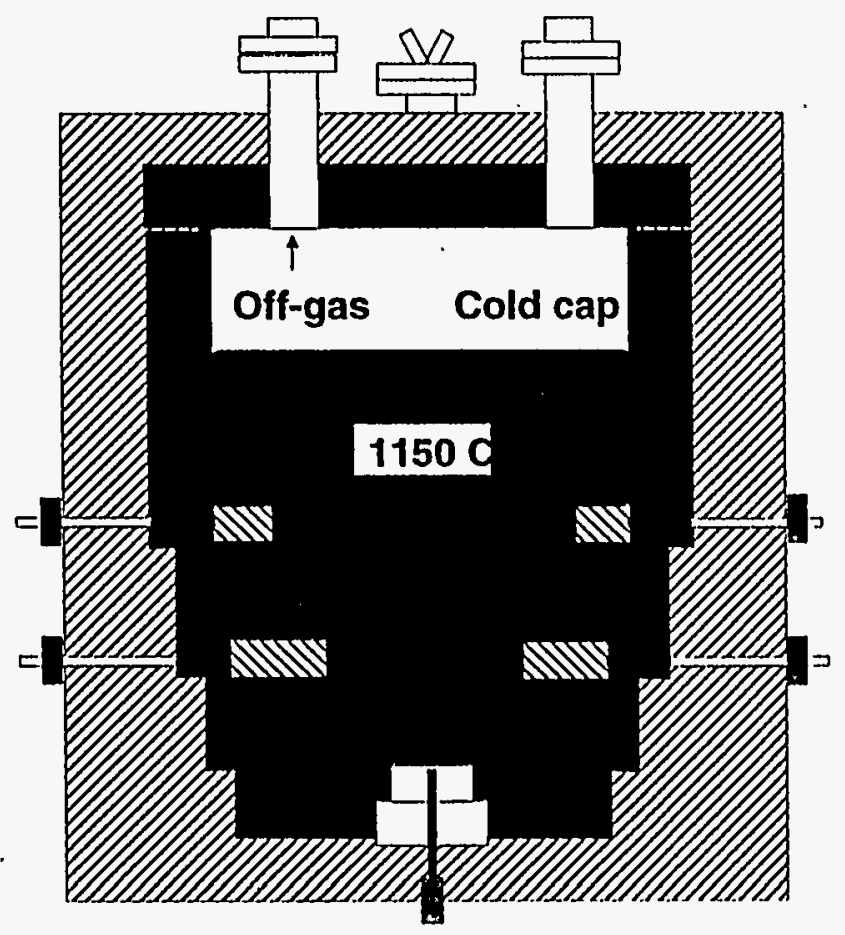




\section{Electrochemical Corrosion Testing}

(ASTM G5-87 \& G3-89)

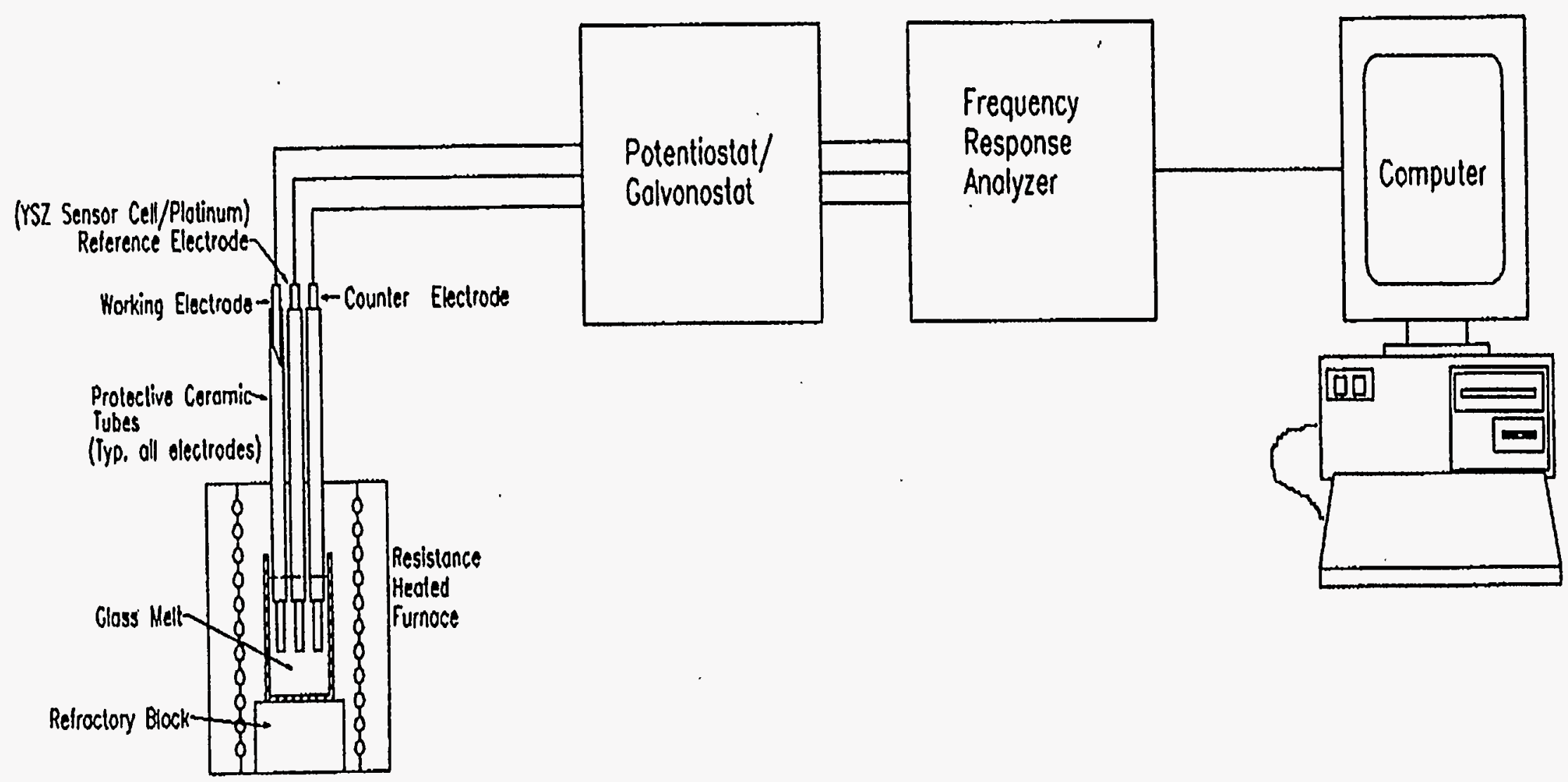

Electrochemical corrosion rate Protection potential (cathodic/anodic) 

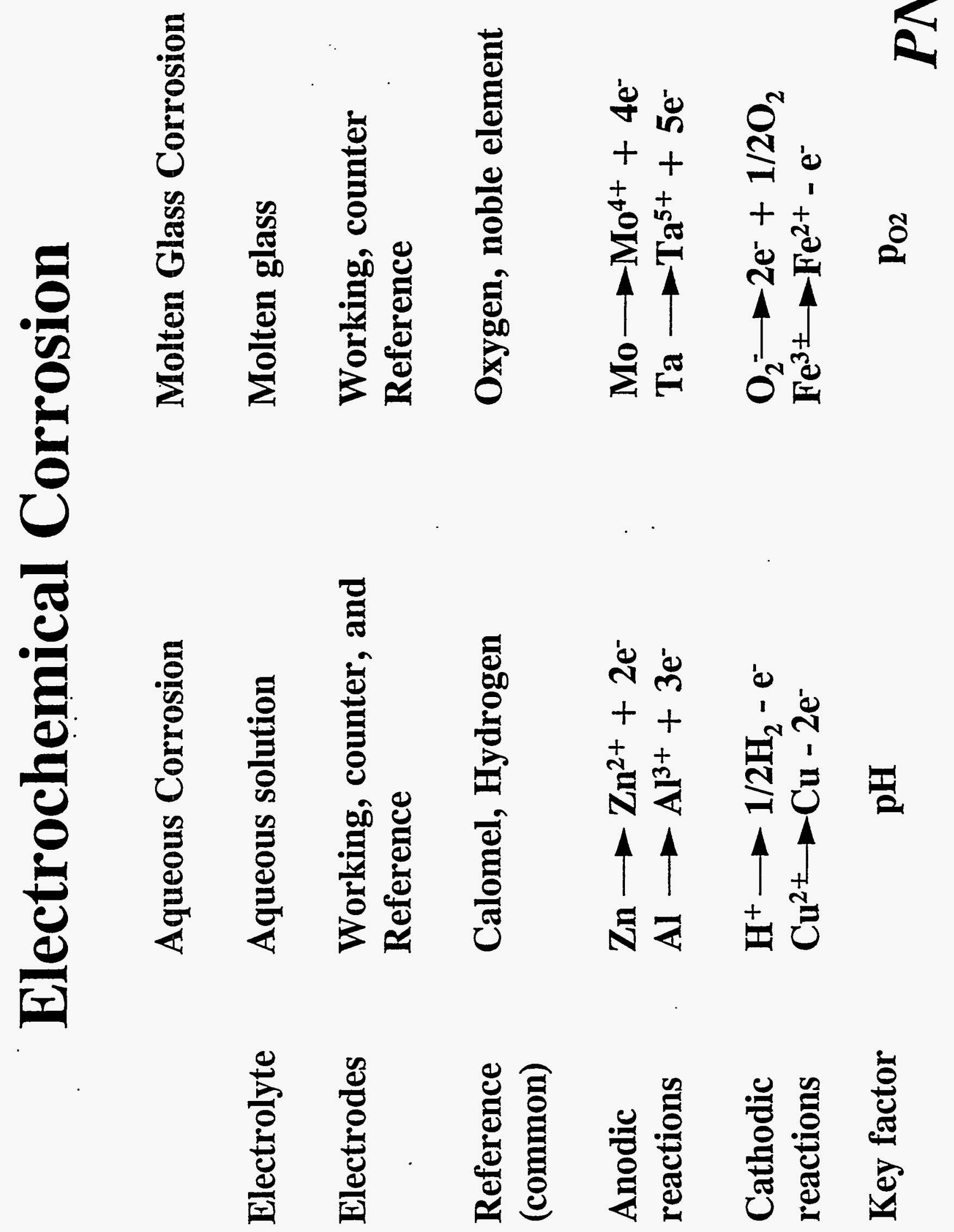


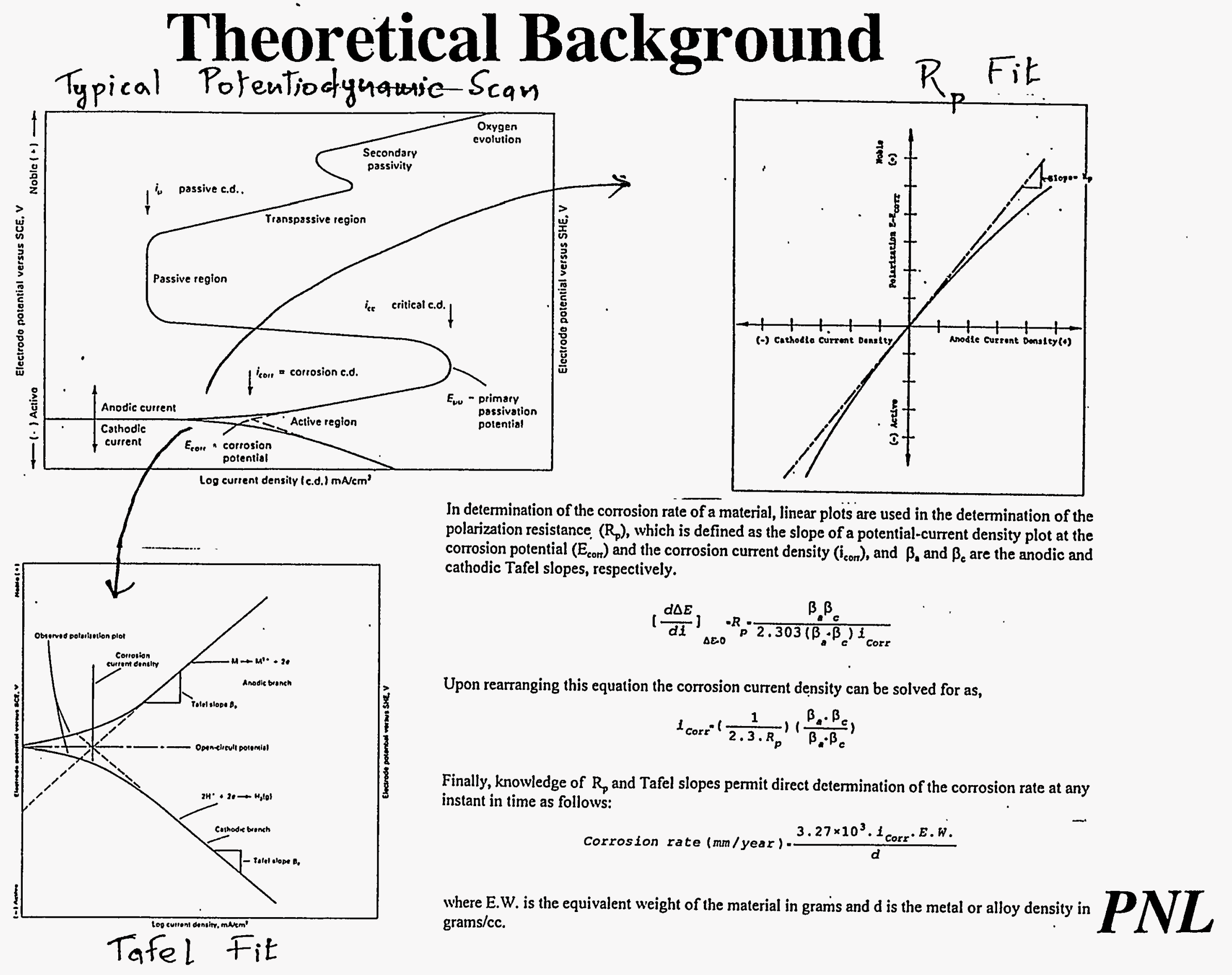




\section{Nominal Composition of Alloys Used for Electrode Corrosion Testing}

wt\% Elements

\begin{tabular}{|c|c|c|c|c|c|c|c|}
\hline \multicolumn{2}{|l|}{ Material } & $\mathrm{Cr}$ & $\mathrm{Ni}$ & $\mathrm{Fe}$ & $\underline{\mathrm{C}}$ & Me & Others \\
\hline \multicolumn{2}{|l|}{ 304L SS } & 20 & 9 & Balance & 0.03 & & \\
\hline \multicolumn{2}{|l|}{310} & 25 & 20 & Balance & 0.25 & & \\
\hline \multicolumn{2}{|l|}{330} & 18 & 35 & 47 & & & \\
\hline \multicolumn{2}{|l|}{347} & 17 & 9 & Balance & 0.15 & & \\
\hline \multicolumn{2}{|l|}{410} & 12 & & Balance & 0.15 & & \\
\hline \multicolumn{2}{|l|}{446} & 25 & 75 & & & & \\
\hline \multirow[t]{6}{*}{ Inconel } & 600 & 15.5 & 76 & 8 & & & \\
\hline & 601 & 23 & 60 & 14 & 0.15 & & $1.4 \mathrm{Al}$ \\
\hline & 617 & 22 & 54 & & & 9 & $1 \mathrm{Al}, 12.5 \mathrm{Co}$ \\
\hline & 625 & 21 & 61 & 2.5 & & 9 & $3.7 \mathrm{Nb}$ and $\mathrm{Ta}$ \\
\hline & 671 & 48 & 50 & & & & $0.35 \mathrm{Ti}$ \\
\hline & 690 & 30 & 60 & 10 & & & \\
\hline \multirow[t]{2}{*}{ Incoloy } & 801 & 20 & 32 & 44 & & & 1.13 \\
\hline & 802 & 21 & 32 & 46 & & & \\
\hline \multirow[t]{2}{*}{ Hastelloy } & C-4 & 18 & Balance & 3 & 0.02 & 17 & $0.7 \mathrm{Ti}, 1 \mathrm{Mn}$ \\
\hline & $\mathrm{X}$ & 22 & Balance & 18 & 0.1 & 9 & $1 \mathrm{~W}, 2 \mathrm{Co}$ \\
\hline \multirow[t]{2}{*}{ Haynes } & 188 & 24 & 24 & 3 & 0.2 & & $\begin{array}{l}31 \mathrm{Co}, 16 \mathrm{~W}, 1.2 \mathrm{Mn} \text {, } \\
0.4 \mathrm{La}\end{array}$ \\
\hline & 25 & 21 & 10 & 3 & & & $54 \mathrm{Co}, 15 \mathrm{~W}$ \\
\hline \multirow{2}{*}{\multicolumn{2}{|c|}{ UCAR LT-1 }} & 31 & 56 & & & 10 & $2 \mathrm{~W}, 0.25 \mathrm{Ti}, 0.25 \mathrm{Al}$ \\
\hline & & 77 & & & & & $22 \mathrm{Al}_{2} \mathrm{O}_{3}$ \\
\hline
\end{tabular}

Other materials: Ti, Ta, Pt, $\mathrm{Mo}, \mathrm{SnO}_{2}, \mathrm{TiB}_{2}, \mathrm{Cr}$

Corbett, Bickford, and Morrison (1986). 
Glass Compositions Used for Electrode Corrosion Testing $\mathrm{wt} \%$ Oxides

Compound

\begin{tabular}{|c|c|c|c|c|}
\hline SBS & SBSR & SBSF & $\mathrm{ABS}$ & SLS \\
\hline $35-58$ & $40-55$ & 38.6 & 63 & 70.5 \\
\hline $1-11$ & $0.1-3.6$ & 5.9 & 17.3 & \\
\hline \multirow{2}{*}{$9-14$} & $5.8-7.8$ & 9.4 & 10 & \\
\hline & $2.3-3.6$ & 1.3 & 5.8 & \\
\hline $0.2-5.8$ & $12.6-15.2$ & & & $0.02,(1.28)$ \\
\hline $0.4-3.6$ & $2-5.2$ & 0.03 & & $11.6,-,-$ \\
\hline \multirow[t]{2}{*}{$2-14$} & $\begin{array}{l}1-15 \\
0.1\end{array}$ & $0.03-16$ & $0.4-0.9$ & $\begin{array}{l}8.7,7.7,- \\
0.2\end{array}$ \\
\hline & 1.8 & 18.3 & 2 & \\
\hline $0.9-6$ & 1.1 & 6.7 & & \\
\hline $2.5-5.3$ & 0.1 & 5 & & \\
\hline $0.3-15$ & $0.4-4$ & & & \\
\hline
\end{tabular}

SBS $=$ Sodium Boro Silicate

SBSR = Sodium Boro Silicate (with $\mathrm{R}_{2} \mathrm{O}_{3}$ )

SBSF $=$ Sodium Boro Silicate (with F)

$\mathrm{ABS}=$ Alumino Boro Silicate

SLS = Soda-Lime-Silicate, container glass composition, SRM 710 from NIST $\left(\mathrm{R}_{2} \mathrm{O}_{3}\right)$ 


\section{Corrosion of Electrode Materials in Various Glasses}

Static "C 621" Type Isothermal Testing (1050-1400 C, 7 days)

(Corrosion* in mils/day)

\begin{tabular}{|c|c|c|c|c|c|c|c|c|c|}
\hline Electrode & $\mathrm{T}^{\circ} \mathrm{C}$ & SBS & & SBSR & & & & & \\
\hline & & ML & IM & ML & IM & ML & IM & $\mathrm{ML}$ & IM \\
\hline Molybdenum & 1200 & & 0 & & $0-1.93$ & & & & \\
\hline & 1300 & & 0 & & $1.14-2.13$ & & & & \\
\hline & 1400 & & $0-0.08$ & & $0.75-3.66$ & & & & \\
\hline Inconel 690 & 1050 & 0 & $0.16-0.20$ & $0-1.14$ & 0 & 0.51 & 0 & 0.59 & 0 \\
\hline & 1150 & $0.16-0.20$ & $0-0.28$ & $0.08-0.28$ & 0 & 0.16 & 0.08 & 0.28 & 0 \\
\hline & 1200 & 0 & 0 & $0-1.14$ & $0-0.47$ & & & & \\
\hline & 1300 & $0.83-1.34$ & 0 & $2.68-7.24$ & $1.02-6.10$ & & & & \\
\hline Inconel 601 & 1050 & 0.71 & $0.2-0.59$ & $0.16-0.51$ & $0-0.20$ & 0.28 & 0.20 & 0.51 & 0.20 \\
\hline & 1150 & $1.06-1.65$ & $0.51-1.30$ & $0-0.16$ & 0 & 0.28 & 0 & 0.59 & 0 \\
\hline $\mathrm{SnO}_{2}$ & 1050 & 0.35 & $0.16-0.35$ & $0.20-0.59$ & $0.08-0.20$ & 0.20 & 0.16 & 0.35 & 0.35 \\
\hline & 1150 & 0.59 & 0 & $0.59-0.71$ & $0-0.59$ & 0.43 & 0.28 & 0.59 & 0 \\
\hline & 1200 & $0.71-2.24$ & $0.39-0.98$ & $1.85-4.45$ & $0.43-1.34$ & & & & \\
\hline & 1300 & $1.93-3.19$ & $0.71-1.38$ & $3.5-5.75$ & $2.44-2.91$ & & & & \\
\hline & 1400 & $3.98-5.75$ & $1.38-3.90$ & 10.98 & $3.15-5.20$ & & & & \\
\hline 304-L-SS & 1050 & $2.01-2.28$ & $0.35-2.72$ & $0.35-0.51$ & $0-0.08$ & 2.01 & 0.79 & 1.85 & 0.08 \\
\hline & 1150 & $6.93-7.99$ & $3.43-3.94$ & $1.22-3.07$ & $0.43-0.71$ & 3.94 & 1.85 & 1.65 & 0.35 \\
\hline $\begin{array}{l}\text { ML = Melt L } \\
\text { IM - In-Melt }\end{array}$ & & & & & & & & & \\
\hline
\end{tabular}




\section{Corrosion of Electrode Materials in Various Glasses}

Powered Electrode Testing, 5A/inch ${ }^{2 *}$

(Corrosion in mils/day)

Electrode $T^{\circ} \mathrm{C}$

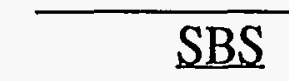

SBS

SBSR

$\mathrm{ABS}$

SLS

$\begin{array}{lllllllll} & & \mathrm{ML} & \mathrm{IM} & \mathrm{ML} & \mathrm{IM} & \mathrm{ML} & \mathrm{IM} & \mathrm{IM} \\ \text { 304-L SS } & 1050 & 3.54 & 3.54 & & & & & \\ \text { Inconel 601 } 1050 & 0.71 & 0.71 & & & & \\ \text { Inconel 690 } 1050 & 0.16-0.43 & 0.08-0.35 & 0.08 & 0 & & \end{array}$

Nickel-base alloy** Sodium Calcium Silicate Glass with Fe \& S, $1150^{\circ} \mathrm{C}, 0.3 \mathrm{~A} / \mathrm{cm}^{2}, 31$ hours $\quad 0.82$

Chromium-base alloy** Sodium Calcium Silicate Glass with Fe \& S, $1150^{\circ} \mathrm{C}, 0.3 \mathrm{~A} / \mathrm{cm}^{2}, 80$ hours

$\mathrm{SnO}_{2}^{* *}$

Sodium Alumino Phosphate Glass with Fe \& S, $1150^{\circ} \mathrm{C}, 1.0 \mathrm{~A} / \mathrm{cm}^{2}, 100$ hours 0.45

Molybdenum*** Soda Lime Silicate Glass, $1430^{\circ} \mathrm{C}, 1 \mathrm{~A} / \mathrm{cm}^{2}$

Soda Lime Silicate Glass $+0.4 \mathrm{~mol} \% \mathrm{Sb}_{2} \mathrm{O}_{3}, 1430^{\circ} \mathrm{C}, 1 \mathrm{~A} / \mathrm{cm}^{2}$

Soda Lime Silicate Glass $+2 \mathrm{~mol} \% \mathrm{Fe}_{2} \mathrm{O}_{3}, 1430^{\circ} \mathrm{C}, 1 \mathrm{~A} / \mathrm{cm}^{2} 5.48$ (Lead Glass, $1350^{\circ} \mathrm{C}, 1 \mathrm{~A} / \mathrm{cm}^{2}$ )

(Lead Glass, $1350^{\circ} \mathrm{C}+1 \mathrm{~mol} \% \mathrm{Sb}_{2} \mathrm{O}_{3}, 1 \mathrm{~A} / \mathrm{cm}^{2}$ )

$\mathrm{ML}=$ Melt Line

IM - In-Melt

*Data from M. R. Elmore (1979).

**Data from A. S. Polyakov et.al. (1989).

***Data from C. Russel et. al. (1989). 


\section{Corrosion Rate (melt line) vs. Chromium Content}

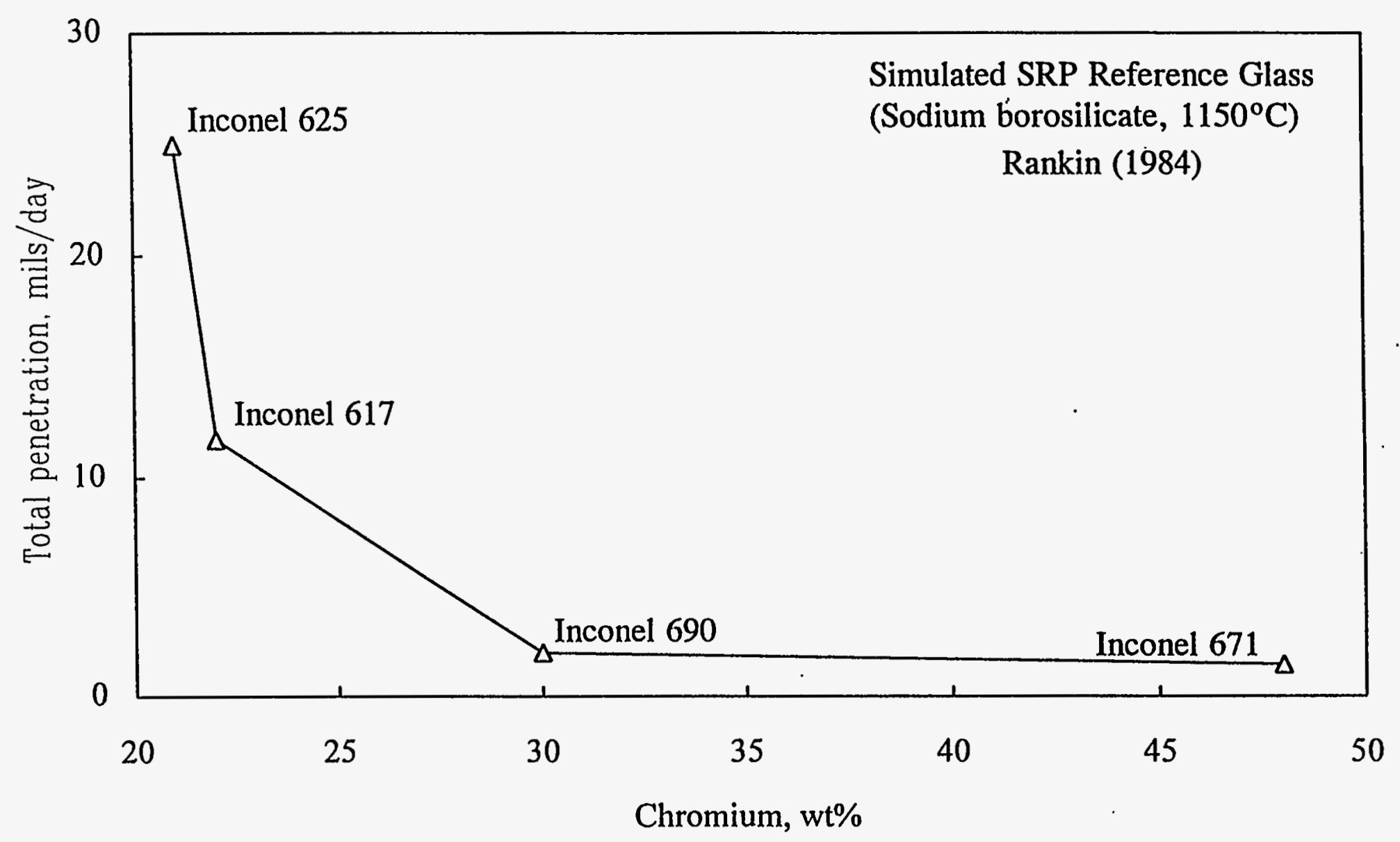

- Inconel 671 is slightly more corrosion resistant than Inconel 690 (melting range, 1343$\left.1377^{\circ} \mathrm{C}\right)$, but has lower melting range $\left(1307-1409^{\circ} \mathrm{C}\right)$ and is scarce. 


\section{Corrosion Mechanism of Inconel 690}

- $\quad$ Rankin, SRL (1981)

Selective penetration of elements of the molten glass such as $\mathrm{Ti}, \mathrm{Al}$, and $\mathrm{C}$ along the grain boundaries of Inconel 690 .

- $\quad$ Barnes et.al, PNL (1982)

Innermost chromium-depleted Inconel 690.

Intermediate layer of mixed spinels, $(\mathrm{Mn}, \mathrm{Ni})(\mathrm{Cr}, \mathrm{Fe}) 2 \mathrm{O}_{4}$.

Outermost layer of $(\mathrm{Fe}, \mathrm{Ni}) \mathrm{Cr}_{2} \mathrm{O}_{4}$ and $\mathrm{Cr}_{2} \mathrm{O}_{3}$.

$\mathrm{Al}, \mathrm{C}, \mathrm{Cr}$, and $\mathrm{Ti}$ phases at the grain boundaries.

Noncontinuous voids to depths of 1-3 microns due to faster chromium diffusion to the reaction zone than the alloy could fill the voids.

Vacancies coalesce at crystal imperfections.

Subsurface void formation (Kirkendall effect ). 


\section{Corrosion of Inconel 690 in Mixed Molten Salts \\ "Catastrophic Sulfidation of Inconel 690 in PAMELA Melter",}

Bickford et.al (1986)

- 46 coupons partially submerged in various mixtures of sodium/sulfur salts, redox agents, and reagents simulating deposits found in melters. 3 levels of testing.

Variables: Oxidation state of $\mathrm{Na}_{2} \mathrm{SO}_{4}$, Halide content, Oxidation state of molybdenum, Saturation of nickel oxide, and alkali fluxing.

Weight loss of Inconel $690=1-04-100 \%$ (in various mixed molten salts)

Alloys containing $30 \%$ or more chromium (Inconel 690 and 671) survived the tests. All others failed by rapid oxidation, sulfidation, or breakaway corrosion.

- To prevent sulfidation-

Avoid accumulation of molten salts

Keep alloys below the critical temperature $\left(\sim 650^{\circ} \mathrm{C}\right.$ for nickel-based alloys)

Marra et.al (1994)

- Extensive degradation in the metal alloys by a combination of attack by the chloride and sulfate. The chloride breaks down the protective oxide film on the alloy allowing subsequent sufidation of the exposed metal.

-Inconel MA-758 (mechanically alloyed)? 
(Pt counter electrode, Pt reference electrode, $1400 \circ \mathrm{C} 0.5 \mathrm{mV} / \mathrm{sec}$ )

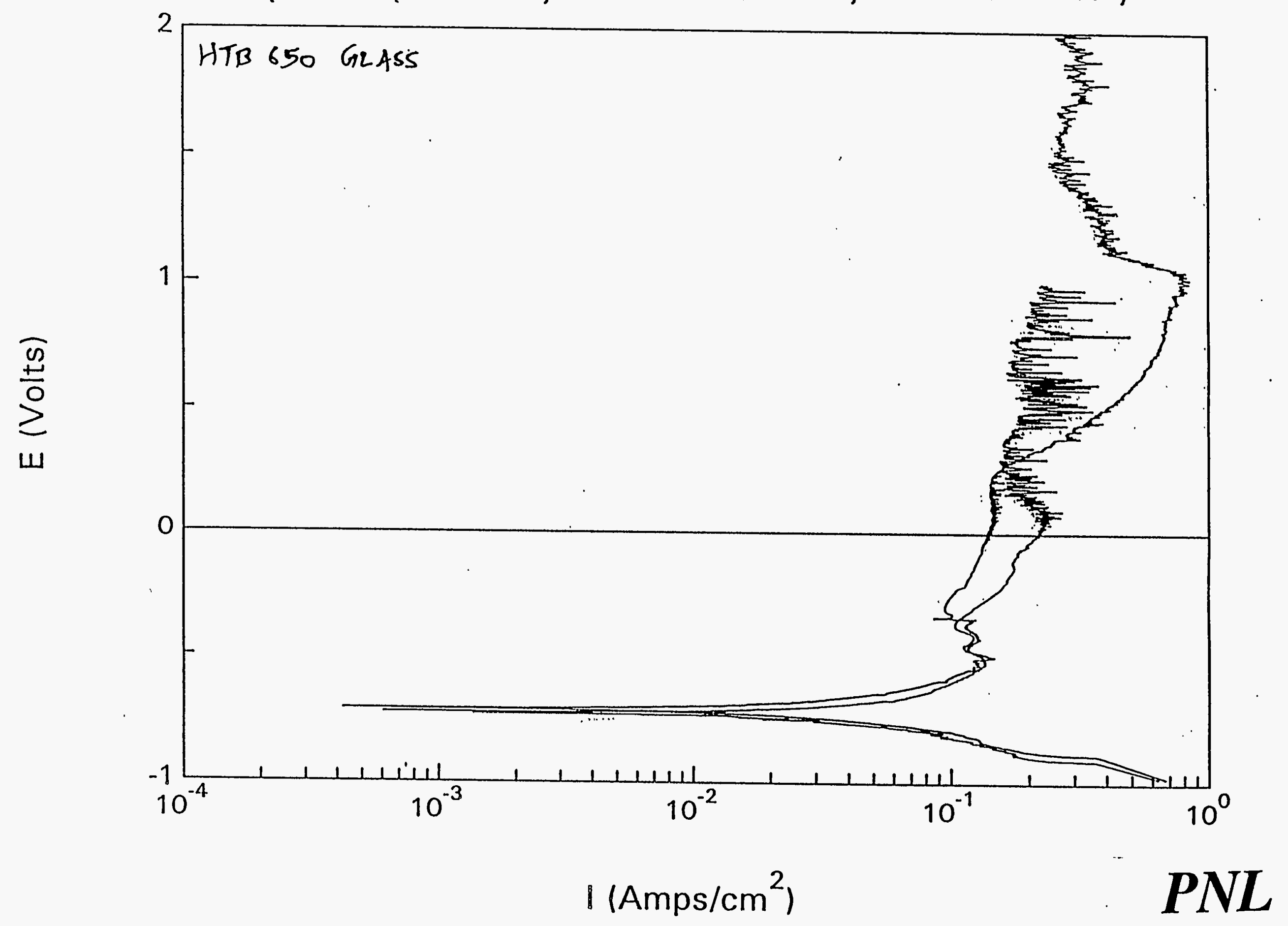




\section{Molybd}

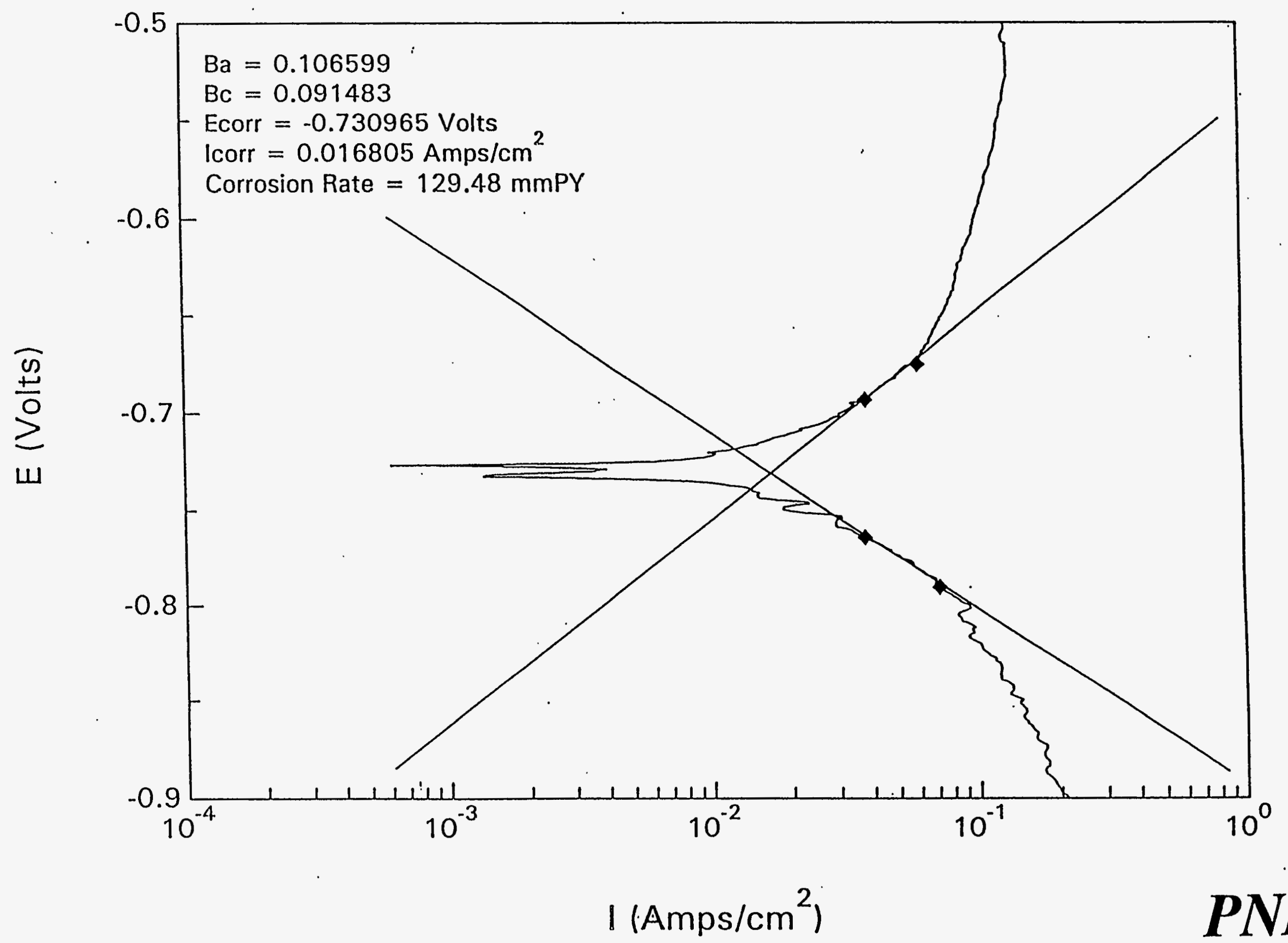




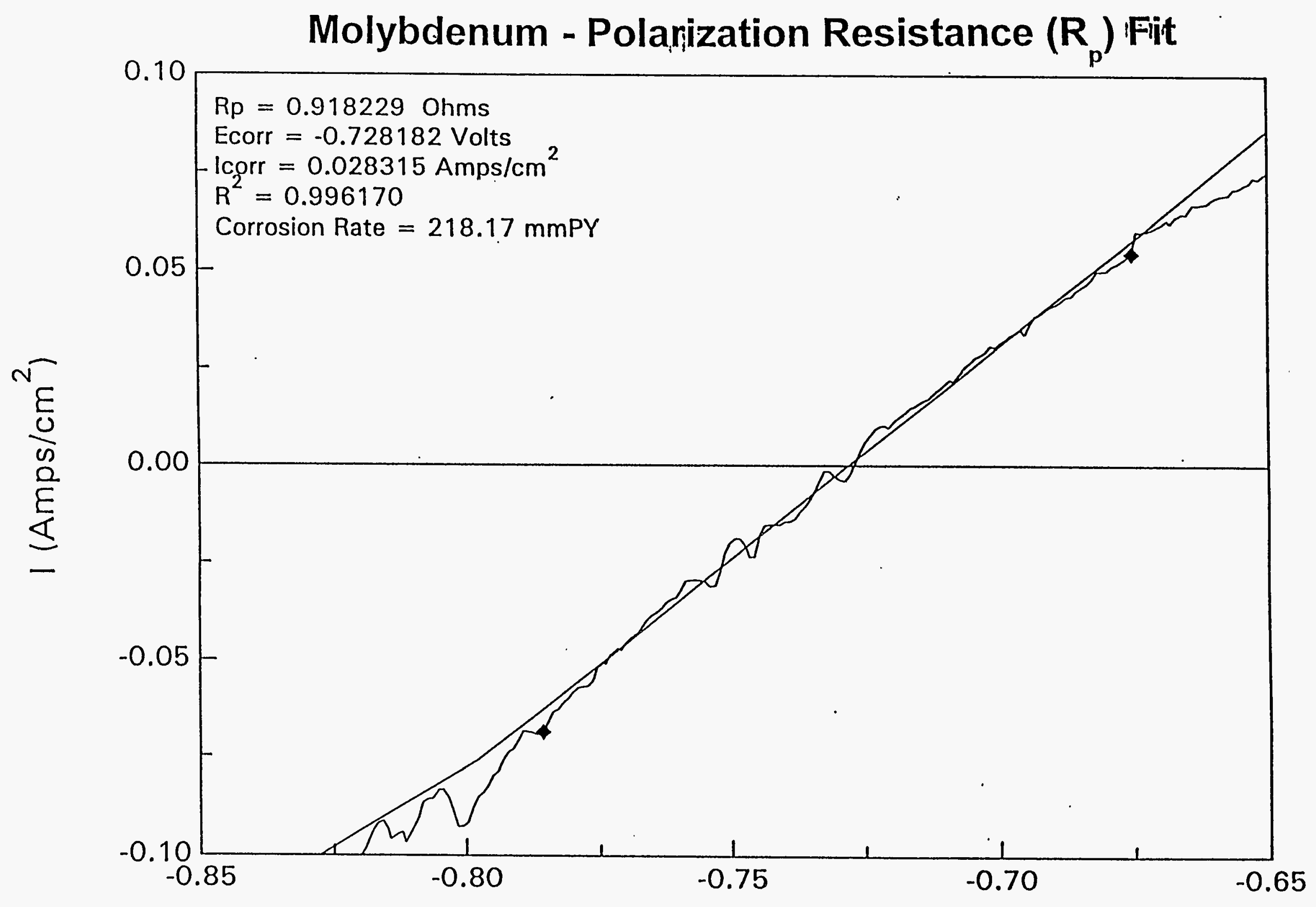

E (Volts) 


\section{Molybdenum - Nyquist Plot}

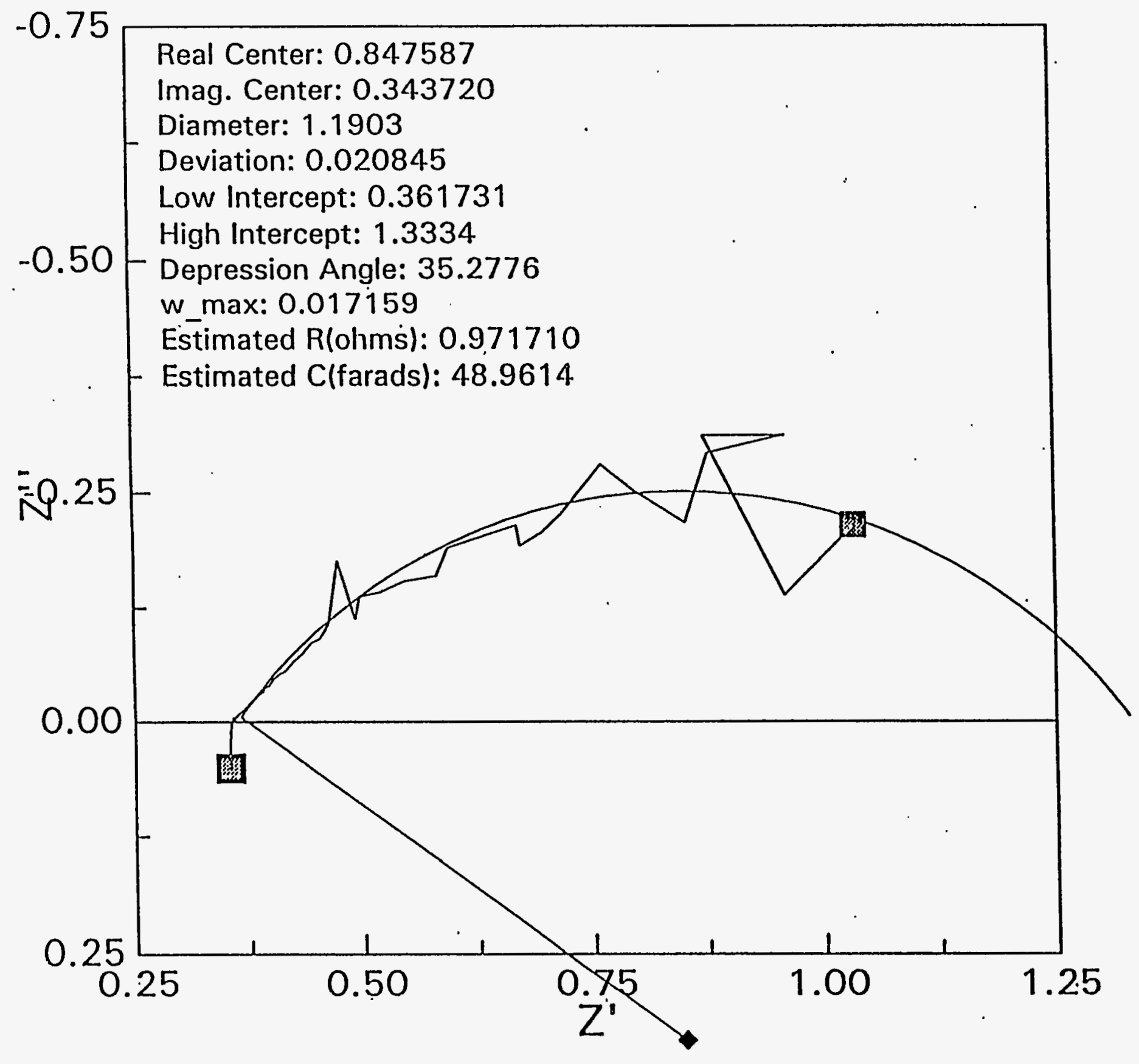




\section{Tantalum - Po. ntiodynamic Scans}

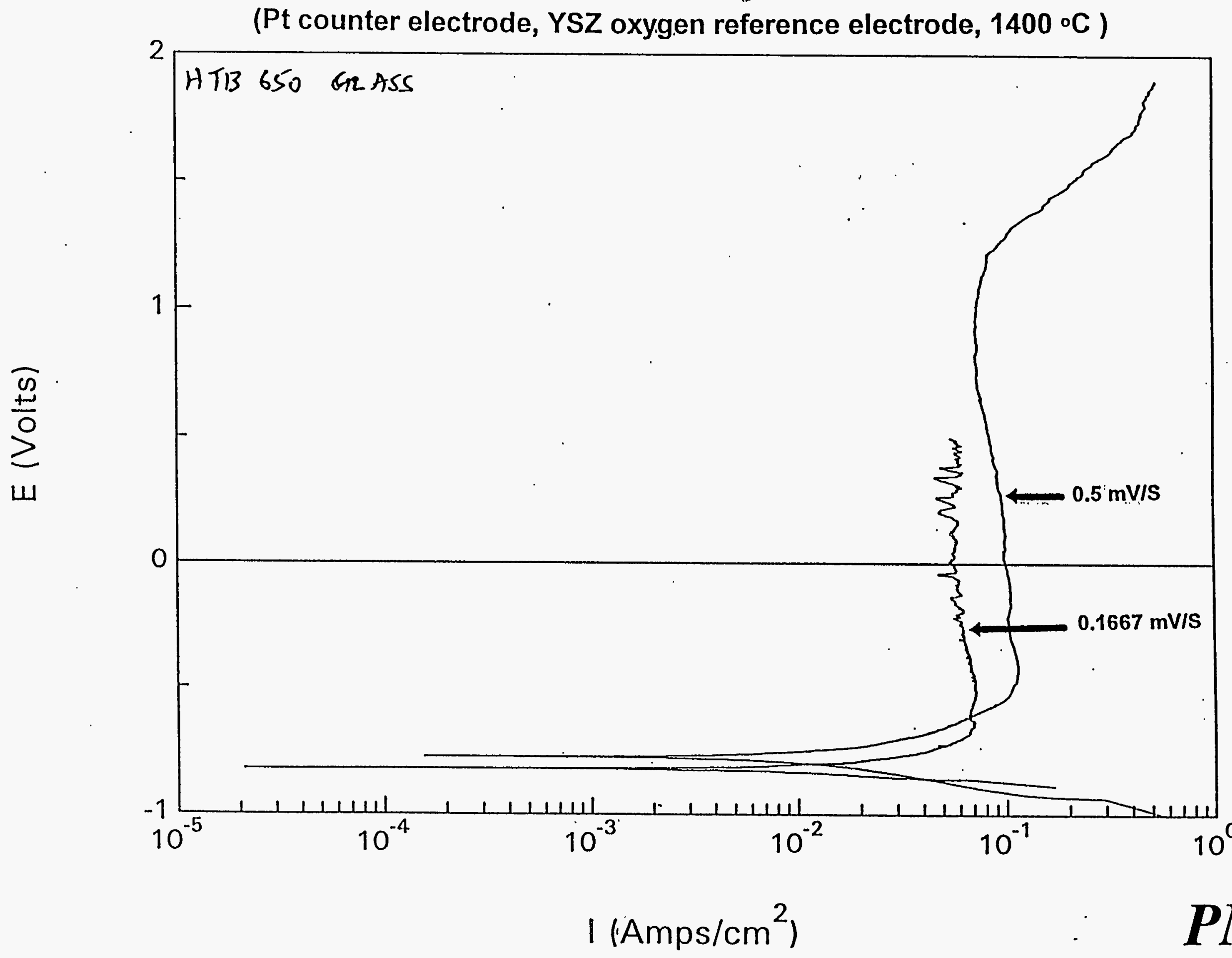




\section{Tantalum - N $N_{n}$ yujist Plot}

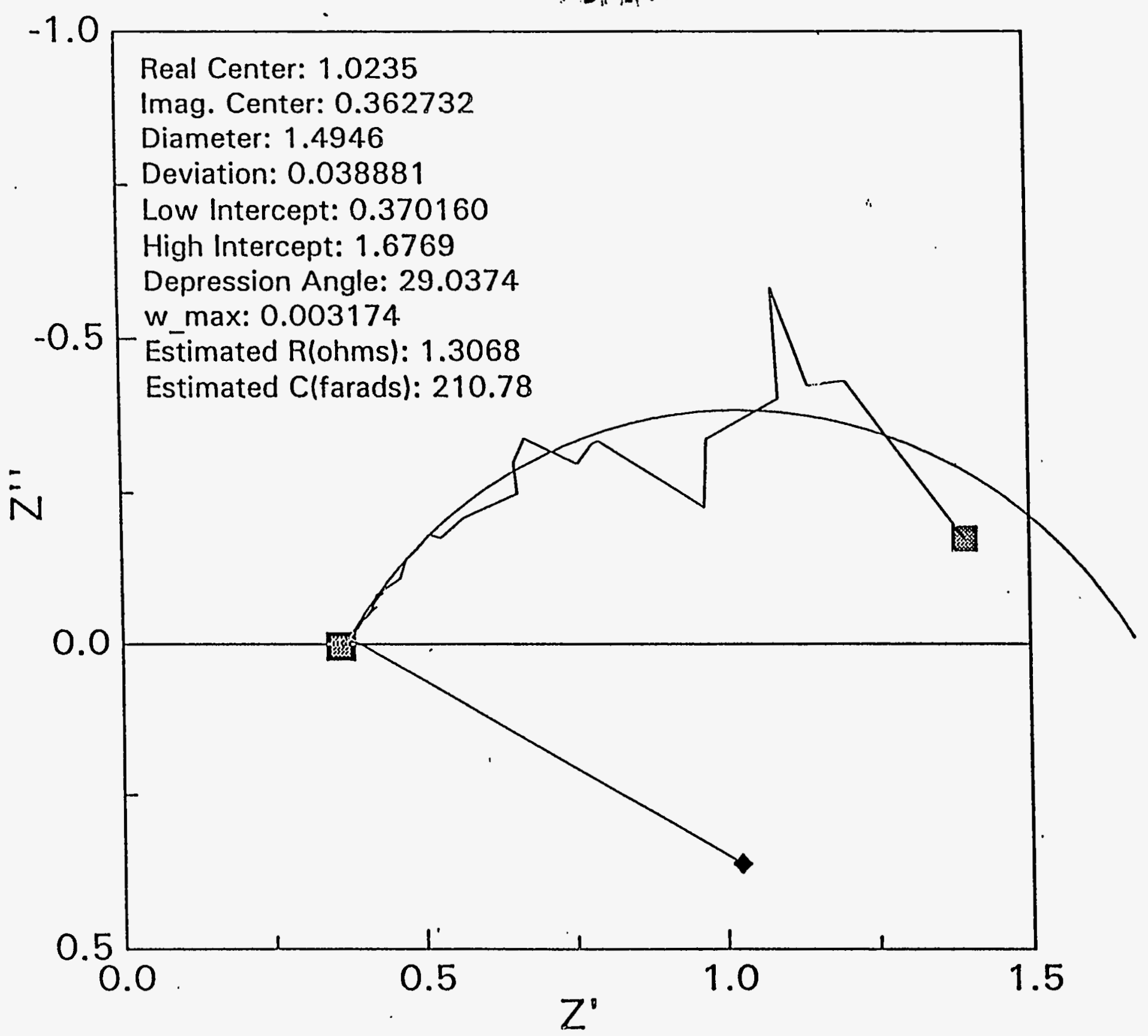




\section{Electrochemical Corrosion Rates (HTB 650,1400' C)}

Corrosion Rate (mils/year)

\begin{tabular}{ccc}
\hline \multicolumn{2}{c}{ Tantalum } & \multicolumn{2}{c}{ Molybdenum } \\
Data $\quad$ Corrected $*$ & Data ${ }^{*}$ Corrected
\end{tabular}

Tafel Fit

$1149 \quad 1049$

$5098 \quad 3700$

$\mathbf{R}_{\mathrm{p}}$ Fit

$5061 \quad 3061$

$8589 \quad 4495$

(Stern-Geary

Approximation)

$* \mathrm{R}_{\mathrm{p}}$ from impedance data. 


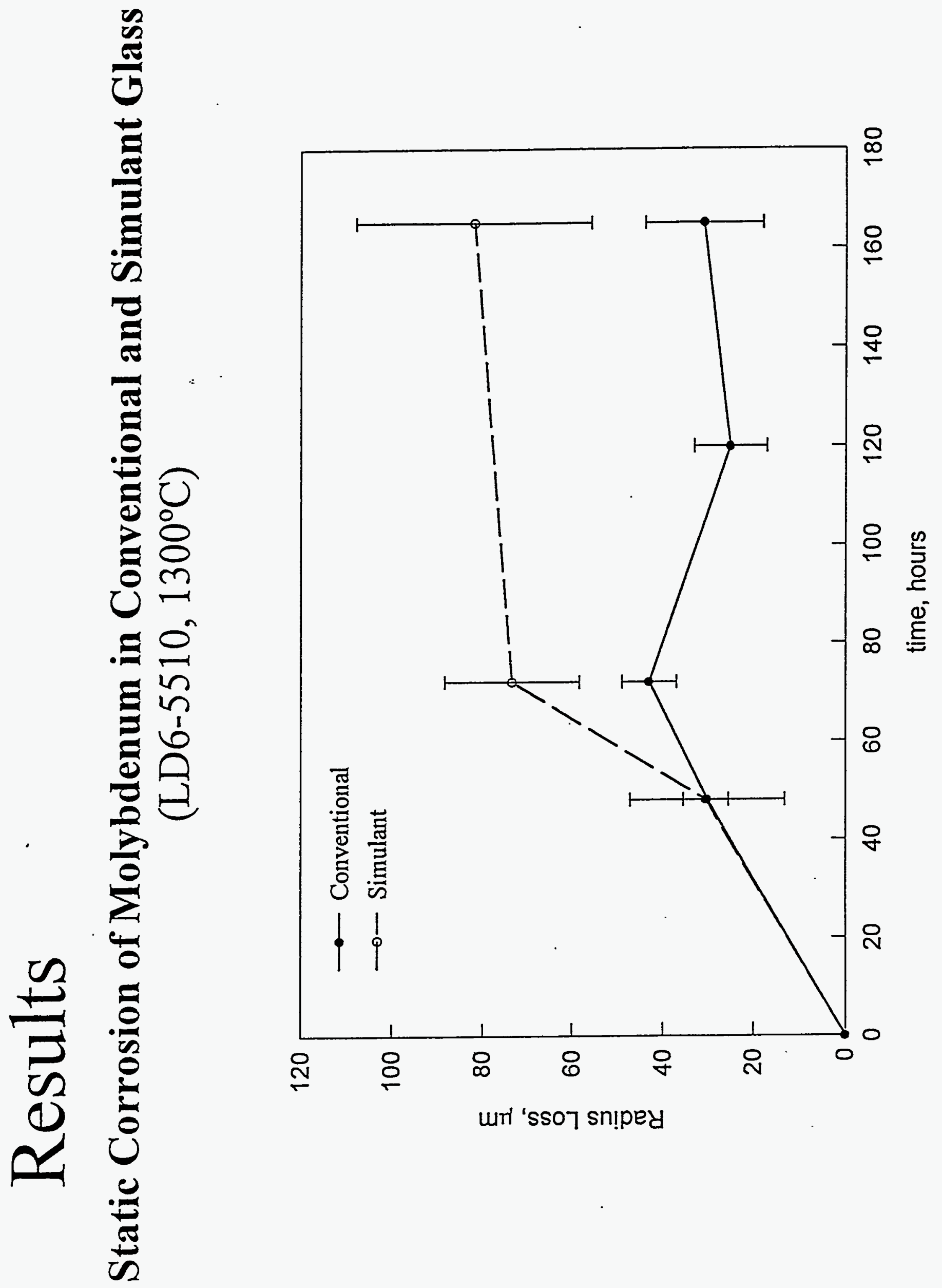




\section{Summary}

- Electrode corrosion rate is dependent on the following parameters:

- Temperature

- Viscosity (Lower the viscosity, higher the corrosion)

- Current density

- Reducible ions present in the melt (redox equilibrium).

- Molten salts present in the plenum/melt

- High chromium content of Inconel alloys :

- Higher corrosion resistance

- resistant to basic fluxing

- low solubility in waste glasses

- Higher Melting temperature

- Lower workability and higher brittleness ( $>50 \mathrm{wt} \%)$

Inconel 690 is the most used electrode materials $\left(<1200^{\circ} \mathrm{C}\right)$

- High salt levels increase corrosion rates.

- Sulfates: S

- Molybdates: $\mathrm{Na}, \mathrm{NH}_{4}$

- Oxides: $\mathrm{Na}, \mathrm{Ni}$

- Halides: Cl, F 


\section{Summary (contd.)}

- Corrosion mechanisms of Inconel 690:

- Selective penetration of Ti, Al, and C (from the melt) along grain boundaries

- Vacancy coalescence and subsurface void formation (Kirkendall effect)

- Catastrophic sulfidation of Inconel 690:

- Oxidation state of $\mathrm{Na}_{2} \mathrm{SO}_{4}$

- Halide content

- Avoid accumulation of molten salts

- In HTB 650 glass melt at $1400^{\circ} \mathrm{C}$ :

- Molybdenum corrodes more than tantalum.

- Tantalum passivating electrode - Protection

- Molybdenum non-passivating electrode

- In LD6-5510 glass melt at $1300^{\circ} \mathrm{C}$ :

- Molybdenum corrodes up to 72 hours and then the corrosion rate tends to "flatten"

- Maximum corrosion is $\sim 50 \mu \mathrm{m}$ in conventional melt

- and $\sim 100 \mu \mathrm{m}$, in simulant melt. 


\section{Glass-Contact Reiractory Corrosion Test Methods}

Static Isothermal

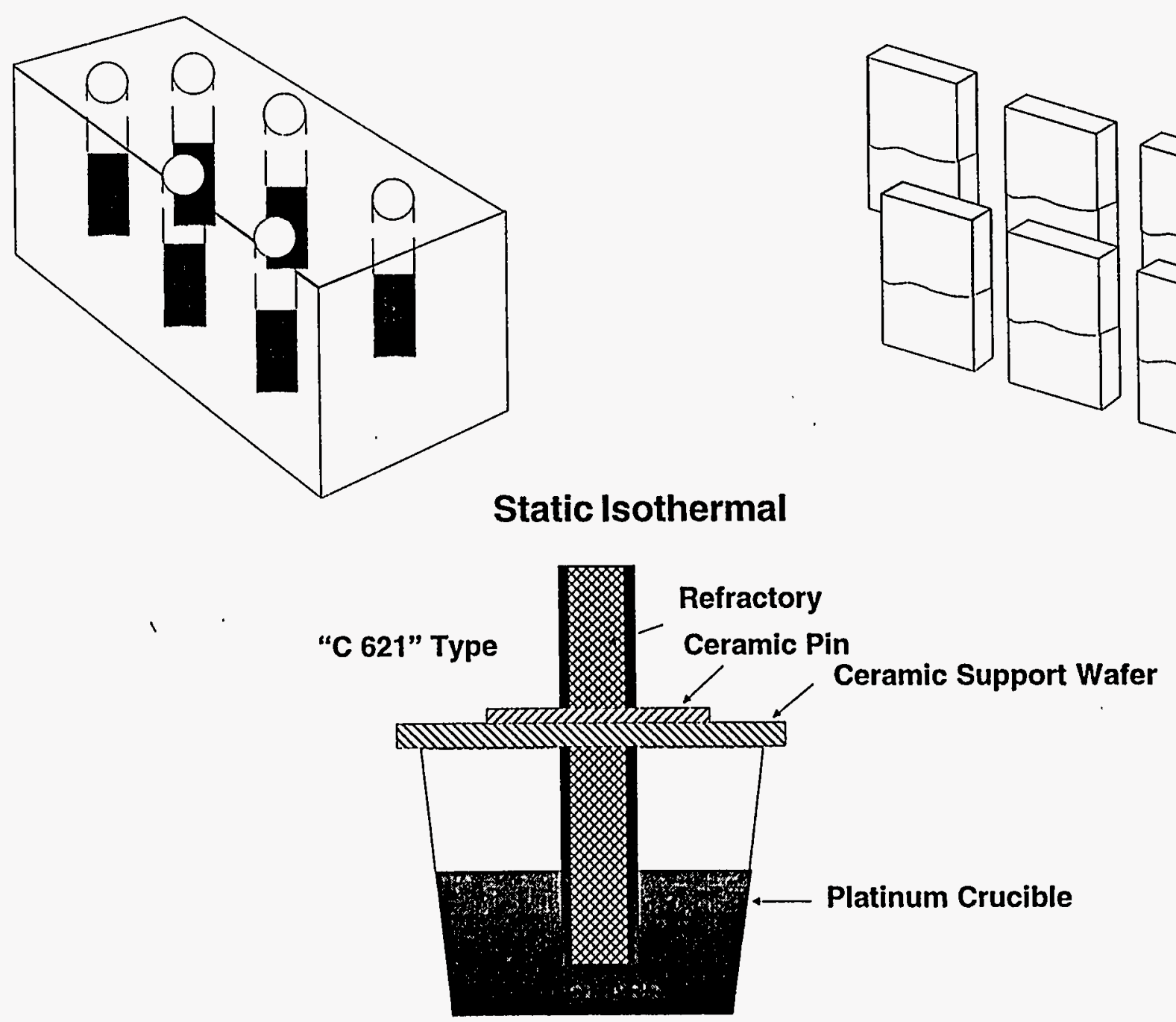

Sample Coupon/Service Test

Service Test

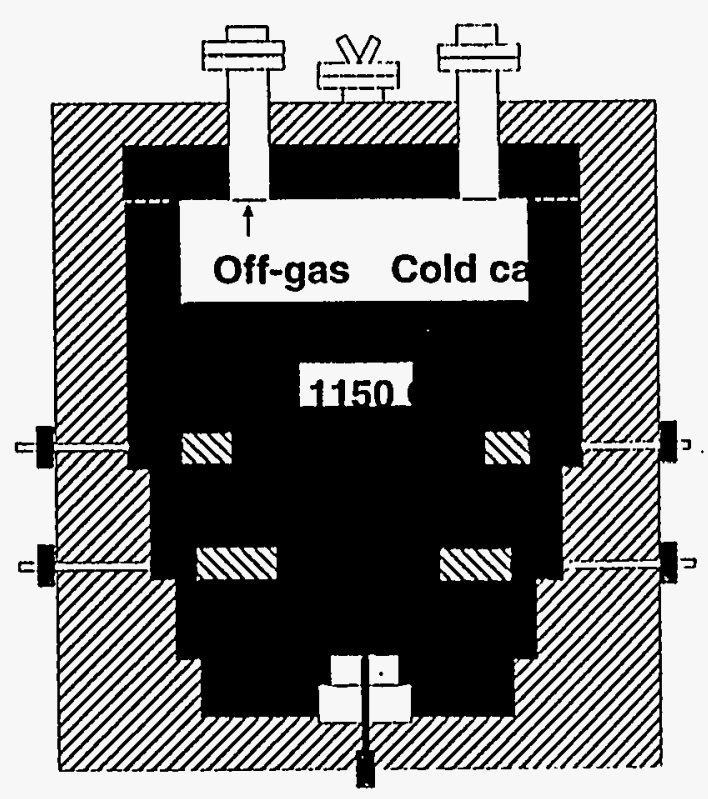

PNL 


\section{Theoretical Background}

\section{Primary mechanism:}

Dissolution of refractory components (DIFFUSION)

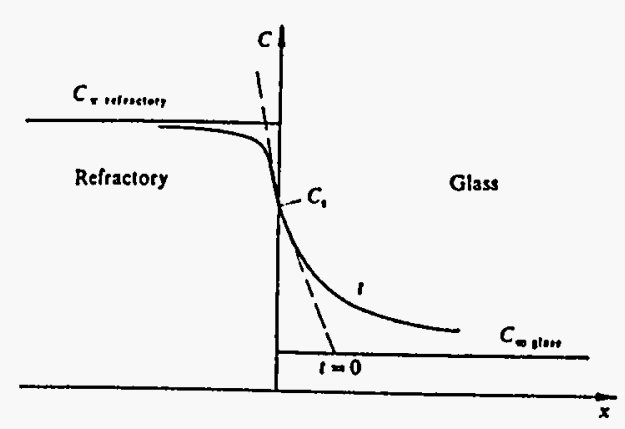

- the phase-boundary reaction rate

- materials transfer

Schematic Concentration Profile

Concentration gradient -

$$
\begin{aligned}
& \left(\frac{\partial c}{\partial x}\right)_{x=0}=-\frac{c, \infty}{\sqrt{\pi D C}}= \\
& \text { Diffusicn coefficieat h Fime }
\end{aligned}
$$

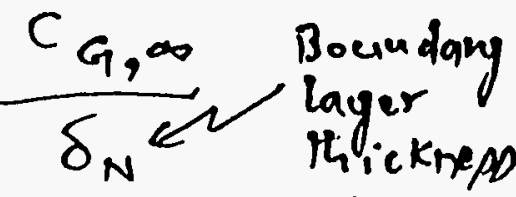

- molecular diffusion

- natural convection

- forced convection

\section{(cs at phase boundary set d)} How to reduce corrosion?
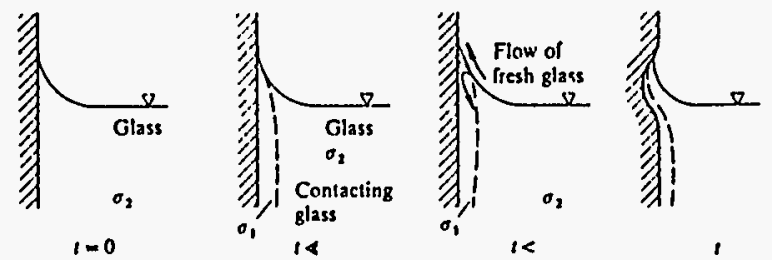

Progrepp of Flux Line Corropion
- reduce $\sigma$ (surface tension)

- reduce densily difference belween glass and dissotured refruactory material

- increase viscosily of the clissolved phase

- reduce $c_{s}$, suturation concentration

- increase $c_{\infty}$, concentralion of effective $P N L$ comporgent is qlaps. 


\section{Ranked Glass-Contact Refractories from Corrosion Testing Studies}

\begin{tabular}{|c|c|c|c|c|c|c|c|c|c|}
\hline \multirow[b]{2}{*}{ Refractory } & \multicolumn{9}{|c|}{ wt\% Oxides } \\
\hline & $\mathrm{Al}_{2} \mathrm{Q}_{3}-$ & $\mathrm{ZrO}_{2-}$ & $\mathrm{SiO}_{2-}$ & $\mathrm{Cr}_{2} \mathrm{O}_{3-}$ & $\mathrm{Fe}_{2} \mathrm{Q}_{3-}$ & $\mathrm{TiO}_{2-}$ & $\mathrm{P}_{2} \mathrm{O}_{5-}$ & $\mathrm{MgO}$ & $\mathrm{Na}_{2} \mathrm{O}+\mathrm{K}_{2} \mathrm{O}$ \\
\hline Dyko CR95WA & & & & 96 & & 4 & & & \\
\hline Ci215 & Trace & & Trace & 92.7 & 0.4 & 3.8 & & Trace & Trace \\
\hline 1780 & & & & 93 & 0.4 & 3.8 & & Trace & Trace \\
\hline Monofrax & 4 & & 1.6 . & 77.7 & 7.9 & & & 8.7 & 0.1 \\
\hline Monofrax K3 & 60.4 & & 1.77 & 27.26 & 4.21 & & & 6.05 & 0.31 \\
\hline XAU-30 & $(26.8)$ & $(27.5)$ & $(15)$ & $(27)$ & $(1.65)$ & & & & $(1.15)$ \\
\hline SEPR2161 & 31.5 & 26 & 13 & 26 & & & & & \\
\hline SEPRS2161 & 31 & 28 & 13 & 16 & & & & & \\
\hline Stannex & \multicolumn{9}{|c|}{ No data available: expected to be close to pure $\mathrm{SnO}$} \\
\hline SEPR1711 & 45.9 & 40.3 & 12.3 & & $0.08^{2}$ & 0.02 & & & 0.8 \\
\hline Bakor-33 & (45.5) & $(41)$ & (12.2) & & & & & & $(1.0)$ \\
\hline Serv-M & 89.7 & & 0.5 & 9.8 & 0.5 & & 1 & & 0.4 \\
\hline Ruby & 89.5 & & 0.1 & 9.5 & 0.1 & & & 0.5 & \\
\hline Chamotte & $(50.6)$ & $(32.5)$ & $(15.6)$ & & & & & & (1.1) \\
\hline Iso-Z-265 & \multicolumn{9}{|c|}{ No data available: expected to be close to pure $\mathrm{ZrSiO}_{4}$} \\
\hline $\mathrm{X} 13181$ & 59 & 26 & 14.5 & & & & & & 0.5 . \\
\hline Iso-alumina & \multicolumn{9}{|c|}{ No data available: expected to be close to pure $\mathrm{Al}_{2} \mathrm{O}_{3}$} \\
\hline SERPJurgal M & \multirow{2}{*}{\multicolumn{9}{|c|}{ No data available: expected to be close to pure $\mathrm{Al}_{6} \mathrm{Si}_{2} \mathrm{O}_{13}$}} \\
\hline Iso-mullite & & & & & & & & & \\
\hline
\end{tabular}




\section{Glass Compositions Used for Refractory Corrosion Testing}

wt\% Oxides

\begin{tabular}{|c|c|c|c|c|c|c|}
\hline Compound & BSG & IEB & TSG & ASG. & SLSG & AshG \\
\hline $\mathrm{SiO}_{2}$ & $25-58$ & $35-57$ & 47 & 53 & 70.5 & $29-41$ \\
\hline $\mathrm{Al}_{2} \mathrm{O}_{3}$ & $0-10$ & $8-17$ & 9 & 21 & & $1-2$ \\
\hline $\mathrm{B}_{2} \mathrm{O}_{3}$ & $9-22$ & & & & & $7-10$ \\
\hline $\mathrm{Fe}_{2} \mathrm{O}_{3}, \mathrm{Cr}_{2} \mathrm{O}_{3}, \mathrm{MnO}$ & $0-20$ & $10-35$ & & & $0.02,(1.28$ & \\
\hline $\mathrm{CaO}, \mathrm{MgO}, \mathrm{ZnO}$ & $0-6$ & $0-18$ & 14 & 12 & $11.6,-,-$ & $16-26$ \\
\hline $\mathrm{Na}_{2} \mathrm{O}, \mathrm{K}_{2} \mathrm{O}, \mathrm{Li}_{2} \mathrm{O}$ & $8-23$ & $0-7$ & 6 & 9 & $8.7,7.7,-$ & $11-17$ \\
\hline $\mathrm{SO}_{3}$ & $0-1$ & & & & 0.2 & \\
\hline $\mathrm{TiO}_{2}$ & $0-1$ & & 18 & & & $13-22$ \\
\hline $\mathrm{ZrO}_{2}$ & $0-3$ & $0-14$ & 1 & & & \\
\hline Waste Component & $0-30$ & $0-20+$ & 5 & 5 & 0 & $30-50$ \\
\hline Temp. 2-10 $\mathrm{Pa} \mathrm{s}\left({ }^{\circ} \mathrm{C}\right)$ & $\begin{array}{l}1400- \\
1000\end{array}$ & $(1500)$ & $\begin{array}{l}1437- \\
1254\end{array}$ & $\begin{array}{l}1817- \\
1572\end{array}$ & $\begin{array}{l}1713- \\
1434\end{array}$ & (1200) \\
\hline \multicolumn{7}{|c|}{$\mathrm{BSG}=$ Borosilicate Glasses } \\
\hline \multicolumn{7}{|c|}{ IEB = Iron Enriched Basalts } \\
\hline \multicolumn{7}{|c|}{$\mathrm{TSG}=$ Titanosilicate Glass } \\
\hline \multicolumn{7}{|c|}{ ASG = Aluminosilicate Glass } \\
\hline \multicolumn{7}{|c|}{ SLSG $=$ Soda-Lime-Silica Glass, container glass composition, SRM 710 from NIS } \\
\hline \multicolumn{7}{|c|}{$\begin{array}{l}\text { Ash } \mathrm{G}=\text { Alpha Waste Incinerator Ash Glass } \\
\left(\mathrm{R}_{2} \mathrm{O}_{3}\right)\end{array}$} \\
\hline
\end{tabular}




\section{Corrosion of Glàss-Contact Refractories in Various Glasses}

Static "C 621" Type Isothermal Testing

(Corrosion* in mils/day)

Refractory

$\begin{array}{llll}\text { BSG } & \text { TSG } & \text { SLSG } & \text { ASG } \\ 1400{ }^{\circ} \mathrm{C} & 1400^{\circ} \mathrm{C} & 1400^{\circ} \mathrm{C} & 1525^{\circ} \mathrm{C} \\ \mathrm{Pa} \cdot \mathrm{s}=2 & \mathrm{~Pa} . \mathrm{s}=2.6 & \mathrm{~Pa} . \mathrm{s}=12.9 & \mathrm{~Pa} . \mathrm{s}=15.7\end{array}$

Deering, Dyko CR95WA

3.1

3.5

3.5

Carborundum Monofrax E

3.9

Carborundum Monofrax K3

8.3

SEPR 2161

4.7

Dyson, Stannex

6.3

SEPR 1711

A.P. Green, Iso-Z-265

9.8

Didier, X13181

19.7

23.2

Dyson, Iso-alumina

37.8

4.3

7.5

5.5

15.0

15.4

10.2

53.5

Failed

Failed

Failed

Failed

SEPR Jurgal-M

Failed

Failed

Failed

5.9

$13.0 \quad 5.5$

8.7

$9.4 \quad 5.1$

$8.3 \quad 18.5$

$18.1 \quad 10.2$

18.5

Failed

26.8

$44.1 \quad 44.9$

Dyson, Iso-mullite

* Data from: Hayward, P.J., I.M. George, M.P. Woods, and T.S. Busby (1987). 


\section{Corrosion of Glass-Contact Refractories in Borosilicate Glass}

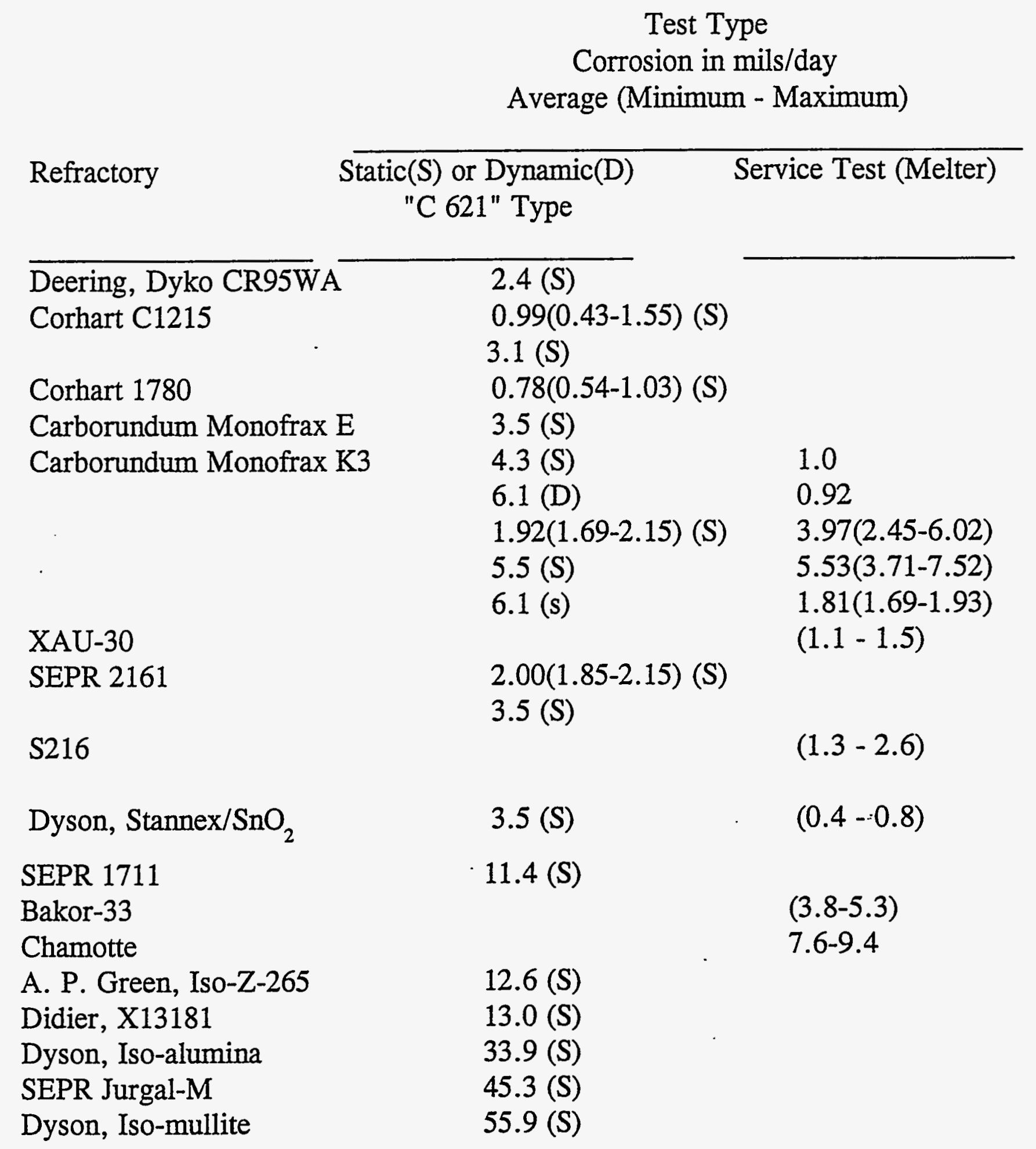


?esults

Static Corrosion of Refractories in Conventional Glass $\left(\mathrm{LD} 6-5510,1300^{\circ} \mathrm{C}\right)$

Glass Line

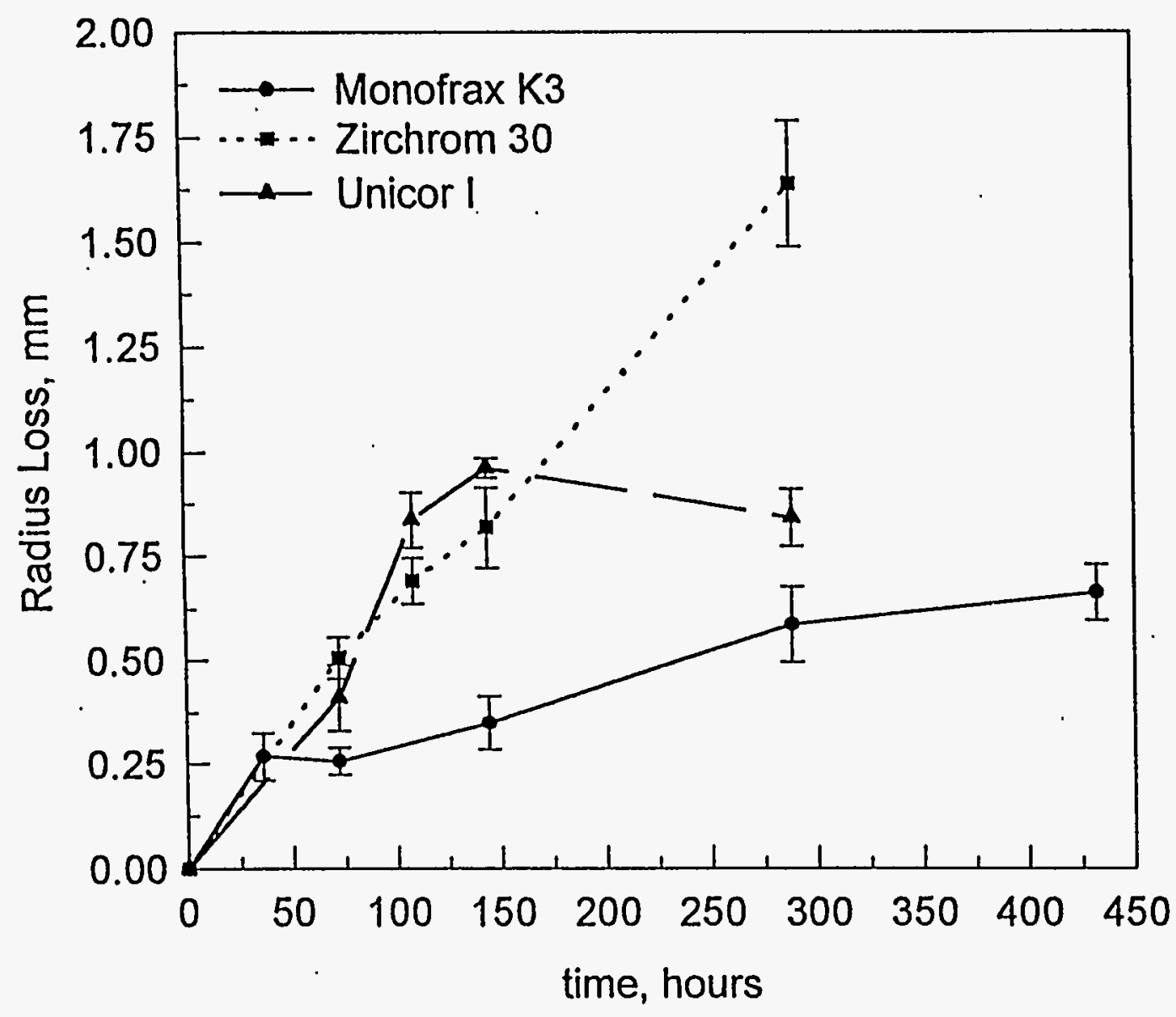

Half-Down

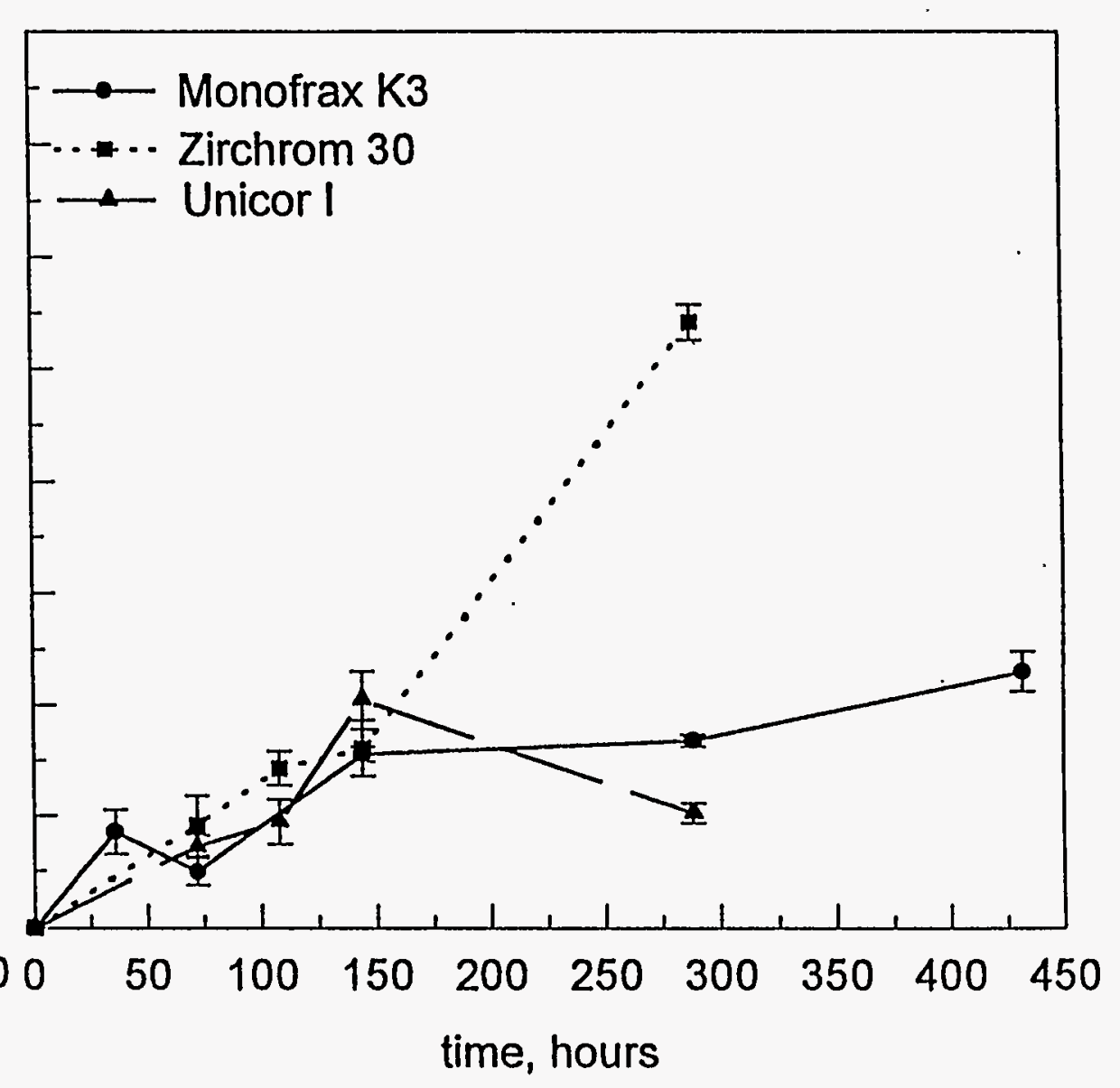




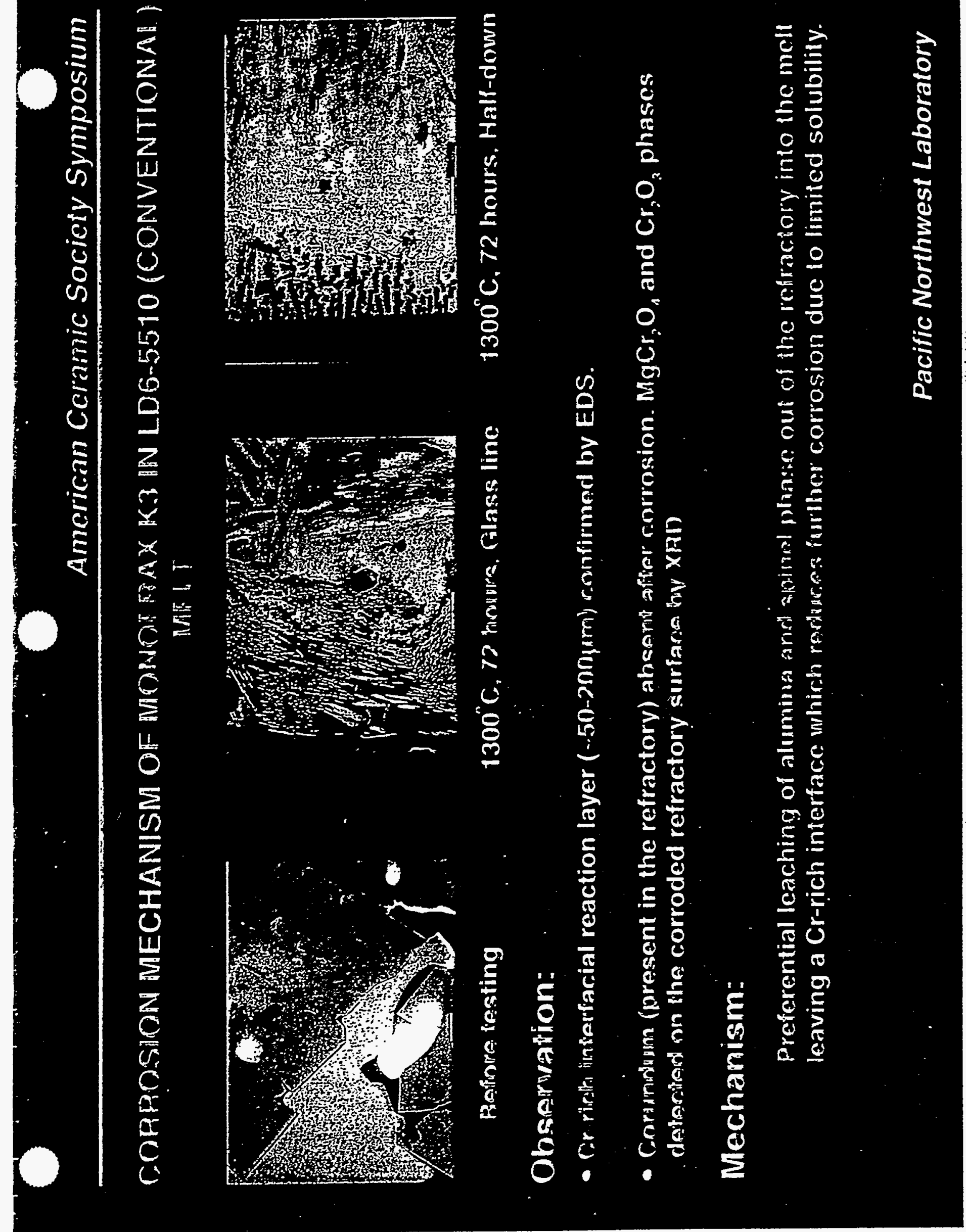




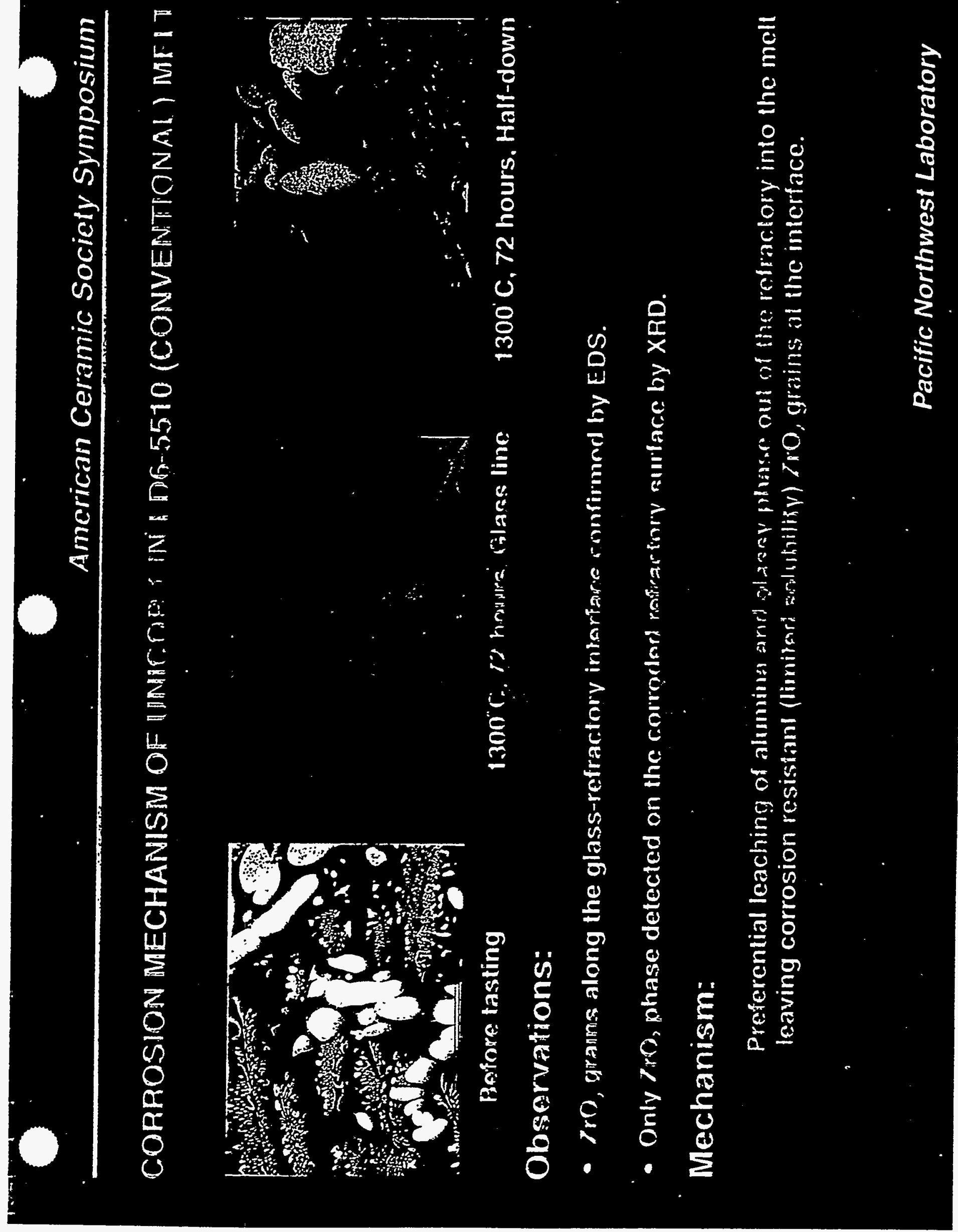




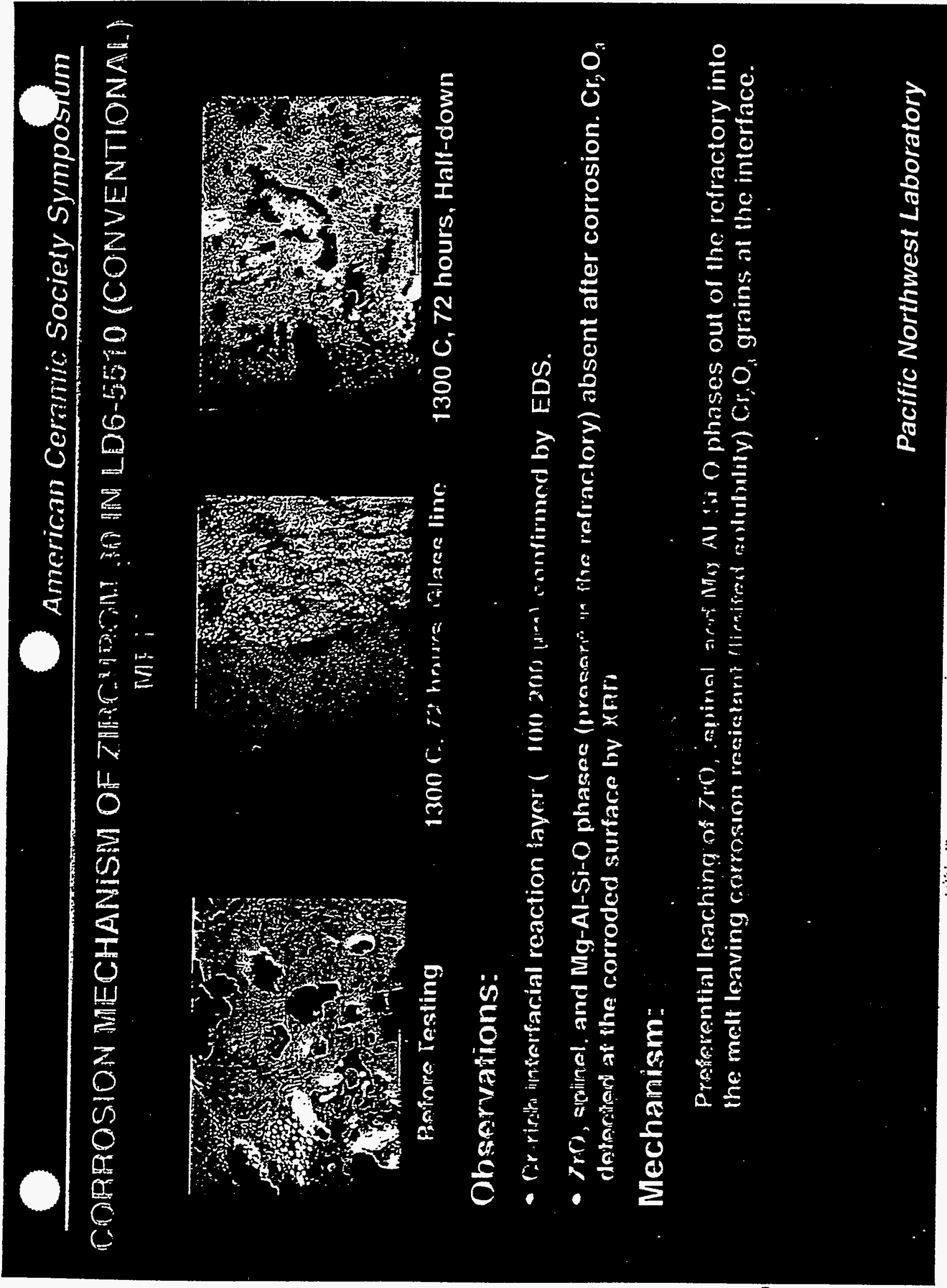




\section{Summary}

- Corrosion rate is dependent on diffusion at the glass-refractory interface, both refractory and glass.

- Interfacial temperature

- Flow rate at interface

- Surface tension, density gradients

- Corrosion rate proportional to glass fluidity

- Porosity of the refractory

- High chromia content refractories

- Higher corrosion resistance

- resistant to basic fluxing

- low solubility in waste glasses

- Lower thermal shock resistance

- Lower electrical resistivity

- High salt levels increase corrosion rates.

- Sulfates: S, P, As, Se, T

- Chromates: V, Nb, W, Mo

- Halides: Cl, F 


\section{Summary (contd.)}

- Monofrax K3 most used glass-contact refractory for Jouleheated waste melters

- Low refractory corrosion rate

- High electrical resistivity $\left(1100-1200^{\circ} \mathrm{C}\right)$

- Good thermal shock resistance

- Corrosion mechanisms of glass-contact refractories

- Alkaline fluxing

- Iron and nickel oxides content of melt

- Spinel formation

- Poor understanding/documentation

- Predicted design life of 2 years for current HLW Jouleheated melters

- Monofrax K3 corrosion, 0.98-5.53 mils/day

- Inconel 690 corrosion, 0.07-14.6 mils/day 


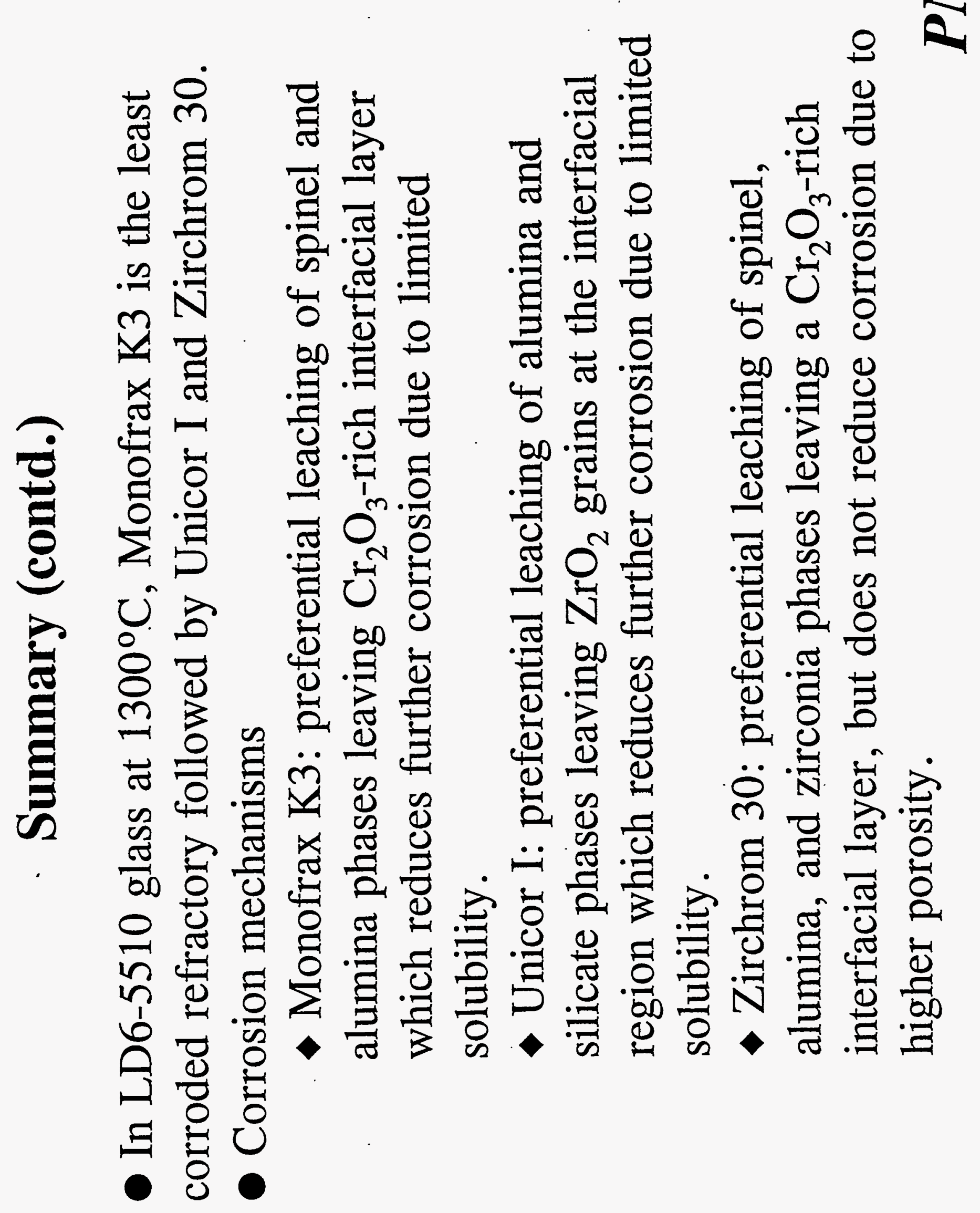




\section{Future Trend}

- Inconel 690 will continue to be the choice of electrode material for melters operating at temperatures below $1200^{\circ} \mathrm{C}$. New refractory metals and oxides are being researched for high temperature melters. Molybdenum, tin oxide, and $\mathrm{Cr}-\mathrm{Al}_{2} \mathrm{O}_{3}$ cermet are promising candidate materials.

- Electrochemical corrosion and protection potential of Inconel 690 and other candidate materials in waste glass melts have to be identified.

- Monofrax K3 will be the choice of refractory for melters operating at below $1200^{\circ} \mathrm{C}$ and is a potential choice of refractory for high-level waste high temperature $\left(1500^{\circ} \mathrm{C}\right)$ melters. High chromia containing refractories with improved corrosion resistance and thermal shock resistance and lower electrical conductivity at the temperature of operation are being researched. C1215Z and AZS are promising candidate materials.

- Mechanism of corrosion of Monofrax K3 needs to be established.

- Mechanisms of mixed salt corrosion of the electrodes and refractories need to be established to avoid any catastrophic failure .

- Study of the effects of glass composition, redox, and process parameters on corrosion of electrodes and refractories is crucial in the development of high temperature melting technology. 


\section{Suggested Reading}

TEXTS:

Wolfgang Trier, “'Glass Furnaces: Design, Construction, and Operation", Society of Glass Technology, Sheffield, UK, (1987).

Herbert H. Uhlig and R. W. Revie, “Corrosion and Corrosion Control”, Third Edition, John Wiley \& Sons, NY, USA, (1985).

\section{REFERENCES:}

Fay V. Tooley, The Handbook of Glass Manufacture", Volumes I \& II, Third Edition, Ashlee Publishing Co., Inc., NY, USA, (1984). Metals Handbook, Volume 13, “Corrosion"', Ninth Edition, ASM International, Metals Park, OH, USA, (1987).

\section{PAPERS:}

\section{Refractory Corrosion:}

1. A. R. Cooper, “Kinetics of Refractory Corrosion”, Ceram. Eng. \& Sci. Proc., 2(11-12), 1063-1089, (1981).

2. P. Hrma, "Effects of Surface Forces in Glass Technology (a review)", Glass Tech., 23(3), 151-155, (1982).

3. T. S. Busby, ' Progress in Refractory Usage in the Glass Industry", Glass Tech., 28(1), 30-37, (1987).

4. F. E. Woolley, 'Predictions of Refractory Corrosion Rate form Glass Viscosity and Composition”, UNITCR'89 Proceedings, Editor:

L. J. Trostel, Jr., American Ceramic Society, OH, 768-779, (1989).

\section{Electrode Corrosion:}

1. G. A. Pecoraro, H. Franz, and J. D. Mackenzie, "Corrosion of Refractory Metals by Molten Oxides", The Glass Ind., 51(10), 454-458, (1970).

2. G. B. Balazs and C. R. Russel, “Electrochemical Studies of the Corrosion of Molybdenum Electrodes in Soda-Lime Glass Melts",

J. Non-Cryst. Sol., 105, 1-6, (1988).

3. J. K. Higgins, "Studies of Platinum and Molybdenum Electrodes in Molten Silicates, Borates, and Phosphates", J. Electrochem. Soc., 140(12), 3436-3448, (1993).

4. S. K. Sundaram, J-Y. Hsu, and R. F. Speyer, “Molten Glass Corrosion Resistance of Immersed Combustion-Heating Tube Materials in Soda-Lime-Silicate Glass", J. Am. Ceram. Soc., 77(6), 1613-23, (1994). 